Europa I M M i t T E L a L T E R B A N D 1

Michael Borgolte (Hg.)

\title{
Das europäische Mittelalter im Spannungsbogen des Vergleichs
}

Zwanzig internationale Beiträge

zu Praxis, Problemen und Perspektiven

der historischen Komparatistik

Akademie Verlag

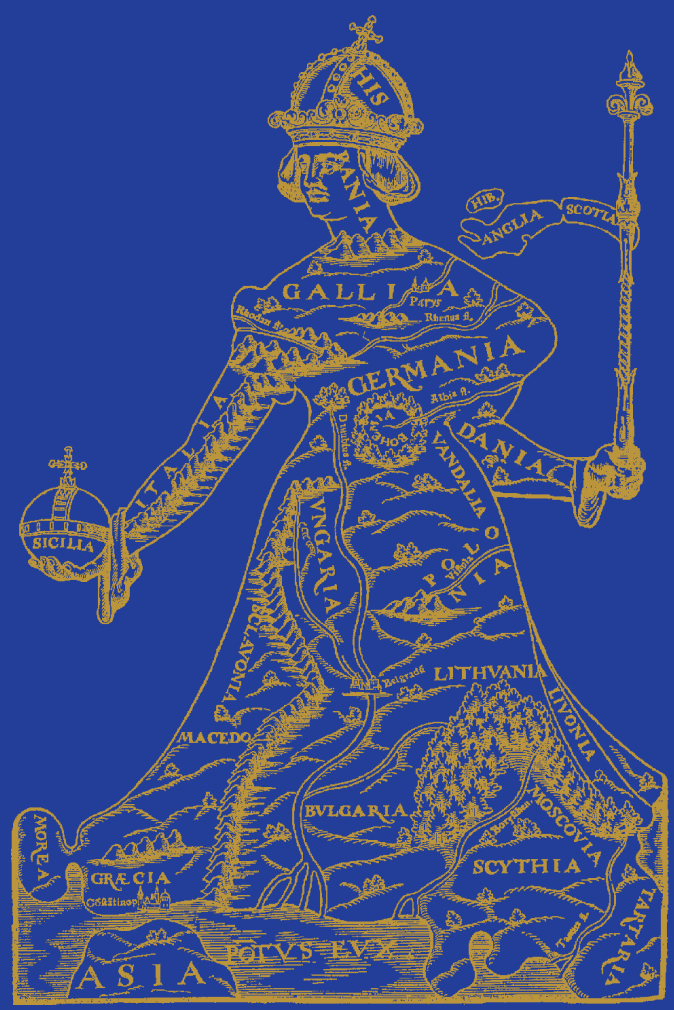


Michael Borgolte (Hg.)

Das europäische Mittelalter im Spannungsbogen des Vergleichs 
Europa im MitTelalter

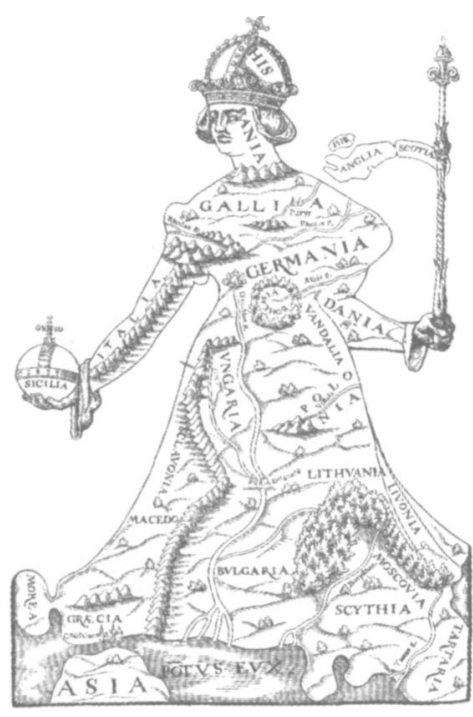

Herausgegeben von

Michael Borgolte
BAND 1

Abhandlungen und

Beiträge zur historischen

Komparatistik 
Michael Borgolte (Hg.)

\section{Das europäische Mittelalter im Spannungsbogen des Vergleichs}

Zwanzig internationale Beiträge zu Praxis, Problemen und Perspektiven der historischen Komparatistik

Redaktion: Ralf Lusiardi

Akademie Verlag 


\section{Gedruckt mit Unterstützung der Fritz Thyssen Stiftung}

Die Deutsche Bibliothek - CIP-Einheitsaufnahme

Ein Titeldatensatz für diese Publikation ist bei Der Deutschen Bibliothek erhältlich.

ISBN 3-05-003663-X

ISSN $1615-7885$

(C) Akademie Verlag GmbH, Berlin 2001

Das eingesetzte Papier ist alterungsbeständig nach DIN/ISO 9706.

Alle Rechte, insbesondere die der Übersetzung in andere Sprachen, vorbehalten.

Kein Teil dieses Buches darf ohne schriftliche Genehmigung des Verlages in irgendeiner Form - durch Photokopie, Mikroverfilmung oder irgendein anderes Verfahren - reproduziert oder in eine von Maschinen, insbesondere von Datenverarbeitungsmaschinen, verwendbare Sprache übertragen oder übersetzt werden.

Einbandgestaltung: Jochen Baltzer Druck und Bindung: Hubert \& Co, Göttingen

Printed in the Federal Republic of Germany 


\section{Inhalt}

Vorwort.

\section{Perspektiven, Geschichte und Theorie des Vergleichs}

Perspektiven europäischer Mittelalterhistorie an der Schwelle zum 21. Jahrhundert.

Von Michael Borgolte (Berlin)

Vergleichende Geschichte und sozialwissenschaftliche Theorie.

Von Patrick J. Geary (Los Angeles) 29

Stände und Gruppen. Über das Europäische in der europäischen Geschichte.

Von Otto Gerhard Oexle (Göttingen) 39

Probleme einer vergleichenden Betrachtung mittelalterlicher Eliten in Ostmitteleuropa.

Von János M. Bak (Budapest) 49

Frühmittelalterliche Grundherrschaften und ihre Erforschung im europäischen Vergleich. Von Hans-Werner Goetz (Hamburg) 65

Quelques possibilités de comparaison dans l'histoire rurale des $\mathrm{XII}^{\mathrm{e}}-\mathrm{XIII}{ }^{e}$ siècles, à partir d'exemples lombards. Von François Menant (Paris) 89 
Die Probleme des Lehnswesens und des Feudalismus aus polnischer Sicht.

Von Stawomir Gawlas (Warschau)

Die „Königsfreien“ und die mittelalterliche Kolonisation.

Von Jan M. Piskorski (Szczecin - Poznań)

125

Partikularsynoden und Synodalstatuten des späteren Mittelalters im europäischen

Vergleich. Vorüberlegungen zu einem möglichen Projekt.

Von Johannes Helmrath (Berlin) 135

Mediävistische Venedig-Forschung 1850-1950. Ein erster Überblick zu Themen und Problemen. Von Daniela Rando (Trient) 171

\section{Transkulturelle und diachrone Vergleiche}

Hofkulturen im Vergleich. ,Liebe‘ bei den frühen Abbasiden.

Von Gadi Algazi (Tel Aviv) 187

Frühes und spätes Mittelalter in Skandinavien - ein möglicher Vergleich?

Von Tore Nyberg (Odense) 197

Comparative History of the Medieval Church's Marriage System.

Von David L. d'Avray (London) 209

Medieval Societies and Historiography. Von Sverre Bagge (Bergen) 223

Familienkonflikt und Brudermord in der Wenzel-Hagiographie. Zwei Modelle des Martyriums. Von Marina Paramonova (Moskau) 
Les idoles musulmanes. Images et réalités. Von Svetlana Luchitskaja (Moskau) 283

\section{Bilaterale Vergleiche}

Divisions of Territory in the early Middle Ages. England and Scotland compared.

Von Geoffrey W. S. Barrow (Edinburgh) 301

Außenblicke für das eigene Herz. Vergleichende Wahmehmung politischer

Ordnung im hochmittelalterlichen Deutschland und Frankreich.

Von Bernd Schneidmüller (Bamberg)

Höfische Feste im Europa des 15. Jahrhunderts. Von Karl-Heinz Spieß (Greifswald) .. 339

Auf der Suche nach der nationalen Identität im Mittelalter. Der Fall Polen.

Von Jerzy Strzelczyk (Posen) 359

Der Vergleich in der Erforschung des europäischen Mittelalters

Versuch eines Resümees. Von Frank Rexroth (Göttingen) 371

Abstracts

$\mathrm{Zu}$ den Autorinnen und Autoren 393

Abkürzungs- und Siglenverzeichnis 401

Indices. Von Ralf Lusiardi (Berlin) 405 



\section{Vorwort}

Fast 75 Jahre sind vergangen, seitdem Marc Bloch auf dem Internationalen Historikertag in Oslo für eine vergleichende Geschichte des europäischen Mittelalters plädiert hat. Seither ist seine Forderung zwar gelegentlich aufgegriffen, aber niemals nachhaltig umgesetzt worden. Schon in der von ihm begrïndeten Schule der Annales empfindet man heute das Defizit. Im Deutschland nach der „Wende“ ist Ernst Pitz leidenschaftlich dafür eingetreten, die Traditionen der vergleichenden Verfassungsgeschichte, die in Europa so alt sei wie das profane Philosophieren, wiederzuleben. „Geschichtliche Erforschung und vergleichende Betrachtung der europäischen Verfassungen“ bleiben, so Pitz, „eine notwendige und dringende Aufgabe der Geschichtswissenschaft, insbesondere der gegenwartsfernen Mediävistik“; denn nur sie können darüber belehren, wie mühsam der europäische Weg zur rechtsstaatlichen Ordnung gewesen und wie hoch das erworbene Gut daher einzuschätzen sei. Hier wie auch sonst zeigt sich, daß vergleichende Mittelalterhistorie Europas, sei sie gesellschafts- oder kulturhistorisch, sei sie rechts- oder verfassungsgeschichtlich betrieben, von Wertfragen ihre wichtigsten Impulse erhält; auch wenn der Vergleich ein rein analytisches Instrument der Erkenntnis darstellt, setzt er Wertentscheidungen ebenso voraus, wie seine Ergebnisse zur Stellungnahme zwingen, aber diese Erfahrung teilt die historische Komparatistik mit allen anderen, wirklich wichtigen Frageansätzen der Geschichtswissenschaft.

Indessen gibt es noch keinen Überblick, in welchem Maße, über welche Themen, mit welchen Methoden und auf welchen theoretischen Grundlagen in der Mediävistik überhaupt vergleichend gearbeitet wird. Deshalb hat das neue „Institut für vergleichende Geschichte Europas im Mittelalter" an der Humboldt-Universität zu Berlin vom 23. bis 25. September 1999 eine internationale Arbeitstagung zum Thema „Europa im Mittelalter. Theorie, Methoden und Praxis des Vergleichs in den europäischen Geschichtswissenschaften vom Mittelalter" veranstaltet. Die anregenden Vorträge und lebhaften Diskussionen haben, obwohl bewußt auf einen kleinen Kreis von Mitwirkenden beschränkt, bis in die Tagespresse hinein Aufmerksamkeit gefunden. In ergänzter Schrifffassung können fast alle Referate nun auch in diesem Band publiziert werden. Erst nach der Tagung wurde in Berlin bekannt, daß Aaron J. Gurjewitsch an der Akademie der Wissenschaften Rußlands einen Arbeitskreis zur vergleichenden Geschichte des westlichen und des (ost-)slawischen Europa gebildet hat. Anläßlich eines Vortrags in Moskau im Mai 2000 konnte der Herausgeber zwei Schülerinnen von A. J. Gurjewitsch für ergänzende Beiträge zu diesem Band gewinnen. Wir schätzen uns auch glücklich, daß Sławomir Gawlas (Warschau) nachträglich ein Manuskript zur Verfügung gestellt hat.

Allen Autorinnen und Autoren gilt unser herzlicher Dank für ihre engagierte Mitarbeit. Viele von ihnen haben es sich nicht nehmen lassen, ihre Vorträge in deutscher Sprache zur 
Publikation zu bringen. Englische Abstracts aller Beiträge am Ende des Bandes sollen aber den internationalen Gedankenaustausch über die Thematik des Bandes weiter fordern.

Die Fritz Thyssen Stiftung in Köln hat das Kolloquium und die Publikation durch großzügige Finanzhilfen ermöglicht, das Präsidium der Humboldt-Universität ließ es sich nicht nehmen, die Gäste aus allen Richtungen Europas, den USA und Israel zu einem Empfang zu bitten, und das Institut für Geschichtswissenschaften unterstützte das Unternehmen administrativ sowie durch einen Zuschuß zu den Übersetzungskosten. Ihnen allen sagen wir herzlichen Dank. Der Herausgeber weiß sich auch allen seinen Mitarbeitern am IVGEM und am Lehrstuhl für Mittelalterliche Geschichte I verbunden, ohne deren fröhliche Begeisterung vieles nicht hätte gelingen können. Besonderer Dank gebührt Frau Gisela Grabo für die Übersetzung der Abstracts, Dr. Ralf Lusiardi für die Redaktion des Bandes und Tim Geelhaar für vielfache bibliographische Nachprüfungen.

Zum Schluß sei noch darauf hingewiesen, daß die rein mediävistische Tagung von Berlin inzwischen durch eine transdisziplinäre Veranstaltung ähnlicher Art ergänzt wurde. Auf dem Aachener Historikertag wurde im September 2000 eine Sektion zum Thema „Unaufhebbare Pluralität der Kulturen? Zur Dekonstruktion und Konstruktion des mittelalterlichen Europa“ veranstaltet, an der neben zwei Mediävisten je ein Byzantinist, Arabist, Osteuropahistoriker und Spezialist furr das mittelalterliche Judentum teilgenommen haben. Ein Sammelband mit den Referaten befindet sich ebenfalls im Druck (erscheint als Beiheft der „Historischen Zeitschrift"). 


\section{Perspektiven, Geschichte und Theorie des Vergleichs}





\title{
Perspektiven europäischer Mittelalterhistorie an der Schwelle zum 21. Jahrhundert ${ }^{*}$
}

\author{
Von \\ Michael Borgolte
}

Bei der Tagung „Europa im Mittelalter“ handelt es sich um das erste wissenschaftliche Symposium des seit dem letzten Jahr bestehenden „Instituts für vergleichende Geschichte Europas im Mittelalter". Der allgemeine Titel verdeutlicht schon, daß wir ganz am Beginn unserer Arbeit stehen, während sein Zusatz „Theorie, Methoden und Praxis des Vergleichs in den europäischen Geschichtswissenschaften vom Mittelalter" die Fragestellung und den Anspruch des heutigen Unternehmens markiert. Das Thema hat bei fast allen, die mit ihm konfrontiert wurden, großes Interesse gefunden, offenbar aber auch eine gewisse Ratlosigkeit ausgelöst. Wie es scheint, haben die meisten, die um einen Beitrag gebeten wurden, das Vorhaben für so wichtig gehalten, daß sie spontan dabei sein wollten, doch waren sie sich nicht ganz sicher, wie das gestellte Problem aus ihrer Sicht anzunehmen wäre. Die Vortragstitel gingen jedenfalls schleppender ein als die generellen Zusagen. Mit Tagungsroutine hat unser Unternehmen wohl wenig zu tun, und mit anders komponierten Versatzstücken älterer Beiträge wäre es kaum getan. So könnte hier und heute wirklich etwas Neues versucht werden.

Erfreulicherweise ist es gelungen ist, Referenten aus allen Richtungen Europas um diesen Tisch zu versammeln; dazu kommen zwei Kollegen aus Übersee, aus der transmarinen Zone des Mittelalters, aus Israel nämlich, und aus der Neuen Welt, den Vereinigten Staaten. Der Kreis der Teilnehmer am Kolloquium ist weitgehend auf die Referenten beschränkt worden, wie es dem Charakter einer Arbeitstagung entspricht. Bewußt verzichtet wurde diesmal auch auf Einladungen an Kollegen der Nachbarfächer; es erschien sinnvoll, zunächst unter Historikern den Stand, die Chancen und die Wege eines vergleichenden Studiums des europäischen Mittelalters beim Überschreiten des nationalen Rahmens auszuloten. ${ }^{1}$ Später sollen,

Im folgenden wird das Einleitungsreferat des Kolloquiums vom 23.9.1999 wiedergegeben, bewußt kaum verändert im Wortlaut. Nur in den Anmerkungen werden spätere Publikationen berücksichtigt.

1 Inzwischen hat der Autor auf dem 43. Deutschen Historikertag in Aachen am 27.9.2000 eine Sektion zur Frage einer transkulturellen Mittelalterforschung durchgeführt, an der sich u. a. ein Byzantinist (RalphJohannes Lilie, Berlin), ein Arabist (Tilman Nagel, Göttingen), ein Osteuropahistoriker (Frank Kämpfer, 
wenn alles gut geht, Kolloquien zu historischen Spezialfragen folgen, die immer wieder Mediävisten verschiedener Disziplinen und Länder zusammenführen mögen. Damit ist schon die erste Aufgabe angesprochen, die dem Institut zugedacht ist: zum Gedankenaustausch und womöglich zu gemeinsamen oder koordinierten Forschungen über Probleme anzuregen, die sich in verschiedenen Regionen des mittelalterlichen Europa stellen.

Auch der Titel dieses Eröffnungsvortrages klingt unbestimmt und verheißungsvoll zugleich; er könnte sogar mit Recht als anmaßend gelten, wären es nicht die praktischen Aufgaben des neuen Instituts, die zur grundsätzlichen Reflexion uber die „Perspektiven europäischer Mittelalterhistorie an der Schwelle zum 21. Jahrhundert" geradezu zwingen. Der Titel zielt auf Zukünttiges ab, denn eine europäische Mittelalterhistorie gibt es offenkundig noch nicht ${ }^{2}$; was es gibt, sind nationale Geschichtswissenschaften, denen Europa noch kaum zum Thema geworden ist. ${ }^{3}$ Was also kann oder muß mit den Subjekten der Betrachtung geschehen, wenn das mittelalterliche Europa im ganzen zum Forschungsobjekt werden soll, wie es für das neue Institut geplant ist? Und welche Wirkungen könnten durch diese und ähnliche Bemühungen an anderen Orten auf die Verfassung der zahlreichen Geschichtswissenschaften selbst ausgehen?

Man nähert sich Antworten auf diese Fragen am besten dadurch an, daß man den Gegenstand selbst als Problem erkennt: Welches Europa soll gemeint sein in einer europäischen Geschichtswissenschaft vom Mittelalter? Ein Rekurs auf die mittelalterliche Überlieferung verschafft keine Entlastung bei der Entscheidung, die hier getroffen werden muß; dazu sind die Zeugnisse selbst zu dürftig und widersprüchlich, vor allem aber kann man den Wertfragen und politischen Implikationen nicht ausweichen, die den Fragenkreis ebenso belasten wie ihm Prominenz verschaffen vor banaleren Aufgaben.

Münster) und ein Mediävist mit der jüdischen Geschichte als Forschungsschwerpunkt (Michael Toch, Jerusalem) beteiligten. Die Sektionsbeiträge erscheinen im Druck.

2 Diese Feststellung gilt auch, wenn man die neuerdings zahlreichen Versuche zu Gesamtdarstellungen der europäischen Geschichte berücksichtigt. Vgl. die „Siedler Geschichte Europas“: Hagen Schulze, Phoenix Europa. Die Moderne. Von 1740 bis heute. Berlin 1998; Heinz Schilling, Die neue Zeit. Vom Christenheitseuropa zum Europa der Staaten. 1250 bis 1750. Berlin 1999; zwei weitere Bănde sind angekündigt. - Peter Rietbergen, Europe. A Cultural History. London/New York 1998; Wim Blockmans, Geschichte der Macht in Europa. Völker, Staaten, Märkte. FrankfurtNew York 1998; Michael Salewski, Geschichte Europas. Staaten und Nationen von der Antike bis zur Gegenwart. München 2000; Wolfgang Schmale, Geschichte Europas. Wien/Köln/Weimar 2000. Zur Monographie von Norman Davies s. unten bei Anm. 45. - Vgl. des weiteren Michael Borgolte, Europäische Geschichten. Modelle und Aufgaben vergleichender Historiographie, in: Die „Blüte“ der Staaten des östlichen Europa im 14. Jahrhundert. Hrsg. v. Marc Löwener (im Druck).

3 Vgl. jetzt Michael Borgolte, Vor dem Ende der Nationalgeschichten? Chancen und Hindernisse für eine Geschichte Europas im Mittelalter, in: HZ (im Druck).

4 Vgl. Bernd Schneidmüller, Die mittelalterlichen Konstruktionen Europas. Konvergenz und Differenzierung, in: „Europäische Geschichte“ als historiographisches Problem. Hrsg. v. Heinz Duchhardt/Andreas Kunz. Mainz 1997, 5-24; Basileios Karageorgos, Der Begriff Europa im Hoch- und Spätmittelalter, in: DA 48, 1992, 137-164; Karl Leyser, Concepts of Europe in the Early and High Middle Ages, in: P \& P 137, 1992, 25-47; Rudolf Hiestand, „Europa“ im Mittelalter - vom geographischen Begriff zur politischen Idee, in: Europa - Begriff und Idee. Historische Streiflichter. Hrsg. v. Hans Hecker. Bonn 1991, 33-48; Borgolte, Vor dem Ende der Nationalgeschichten? (wie Anm. 3), bei Anm. 19 ff. 
Um die erste Feststellung zu belegen, genügen einige Bemerkungen. Denn es ist gut bekannt, daß Europa in der Historiographie, in Geographie und Kartographie des Mittelalters kein eigenes Thema gewesen ist. Zwar gab es Geschichtsschreibung der Klöster und Bischofssitze, der Adelshäuser und der Städte, und neben den Weltchroniken unterscheidet die Forschung Stammesgeschichtsschreibung, nationale Geschichtswerke und Reichschronistik. ${ }^{5}$ Aber ,Europa' als Begriff und Vorstellung wird nur beiläufig in Historiographie anderer Thematik angesprochen. So waren es bezeichnenderweise Bischofsgesten, in denen der Magister Adam im 11. Jahrhundert Europa erwăhnt hat. Adam zählt das Slawenland östlich der Elbe zur Provinz Germanien und nennt dabei den Handelsplatz Jumne - also Vineta/Wollin an der Küste Hinterpommerns - die größte Stadt Europas. Diese sei, wie er erläutert, der Treffpunkt verschiedener Kulturen: „Es ist wirklich die größte von allen Städten, die Europa birgt; in ihr wohnen Slawen und andere Stämme, Griechen und Barbaren. Auch die Fremden aus Sachsen haben gleiches Niederlassungsrecht erhalten, wenn sie auch während ihres Aufenthalts ihr Christentum dort nicht öffentlich bekennen dürfen". ${ }^{6}$ Für Adam gehören zum Slawenland auch Böhmen und Polen, und er kennt die Segelroute von Jumne aus nach Novgorod in Rußland. Vom Reich der Rus' aber weiß er zu berichten: „Dessen Hauptstadt ist Kiev, das mit der Kaiserstadt Konstantinopel wetteifert, eine herrliche Zierde Griechenlands.“ Auch außerhalb der Geschichtsschreibung wird ,Europa“ nur nebenher erwähnt; häufig sind dabei Byzanz und sogar Zypern eingeschlossen - wie bei Dante. ${ }^{7}$ Selten begegnen Name und Begriff so druckstark wie um 800, als Karl der Große von einem Dichter seines Hofes als pater Europae bezeichnet wurde ${ }^{8}$, oder gar affektiv so hochbesetzt wie am anderen Ende des Mittelalters bei Enea Silvio. ${ }^{9}$ Der Piccolomini, der anscheinend Rußland nicht zum Kontinent rechnete, bezeichnet Konstantinopel nach der Eroberung durch die Türken als „das zweite Auge Europas“ und wirbt auf dem Frankfurter Reichstag von 1454 mit dramatischen Worten furr ein gemeinsames Vorgehen der christlichen Mächte gegen die Osmanen: „Gewiß sind wir in zurlickliegenden Zeiten in Asien und Afrika, also in fremden Erdteilen, besiegt worden; jetzt aber ist es Europa, das heißt in unserem Vaterland, in unserem eigenen Haus, in unserer Heimat, wo man uns geschlagen und zu

5 Hans-Werner Goetz, Proseminar Geschichte: Mittelalter. 2. Aufl. Stuttgart 2000, 124 ff.; ders., Theologischer Sinn und politisches Gegenwartsinteresse. Tendenzen, Formen und Funktionen der mittelalterlichen Geschichtsschreibung, in: Geschichte. Ein Grundkurs. Hrsg. v. Hans-Jürgen Goertz. Reinbek bei Hamburg 1998, 233-244, bes. 236-240.

6 Adam von Bremen, Bischofsgeschichte der Hamburger Kirche. Neu übertragen von Werner Trillmich, in: Quellen des 9. und 11. Jahrhunderts zur Geschichte der hamburgischen Kirche und des Reiches. Bearb. v. Werner Trillmich/Rudolf Buchner. (FSGA, Bd. 11.) Darmstadt 1973, 135-499, hier 253 c. II.22. Das folgende Zitat nach ebd. 255.

7 Karageorgos, Der Begriff Europa (wie Anm. 4), 144 f.; vgl. Werner Fritzemeyer, Christenheit und Europa. Zur Geschichte des europäischen Gemeinschaftsgefulhls von Dante bis Leibniz. (HZ, Beih. 23.) München/Berlin 1931.

8 Schneidmüller, Die mittelalterlichen Konstruktionen Europas (wie Anm. 4), 10; Hiestand, „Europa“ im Mittelalter (wie Anm. 4), 37 f.; Jürgen Fischer, Oriens - Occidens - Europa. Begriff und Gedanke „Europa" in der spăten Antike und im frühen Mittelalter. Wiesbaden 1957.

9 Hiestand, „Europa“ im Mittelalter (wie Anm. 4), 44 ff. 
Boden geworfen hat “ ${ }^{10}$ Bescheidener noch als die gelegentlichen Erwähnungen Europas in der Historiographie und im übrigen lateinischen und griechischen Schriftum stellt sich der Befund in der Kartographie dar. Die berühmten T-Karten, schematische Darstellungen der Erde nach antikem Vorbild, zeigen Europa zwar neben den beiden anderen Kontinenten Asien und Afrika. Aber wenn uns die Spezialisten richtig unterrichten, gab es im lateinischen Mittelalter nur eine Separatkarte Europas; Lambert von Saint-Omer hat sie um 1112 dem Autograph seines Liber Floridus beigegeben. ${ }^{11}$ Europa erscheint bei Lambert allerdings ähnlich umfassend wie bei Adam von Bremen: Zwar sind Frankreich, Deutschland und Italien graphisch vereint hervorgehoben, doch werden neben der Iberischen Halbinsel der gesamte byzantinische Raum einschließlich des Balkans sowie die slawischen Länder und Skandinavien dem Erdteil zugerechnet. Die Karte blieb allerdings so vereinzelt, daß sie anscheinend nicht einmal in Kopien ubernommen wurde; aus Byzanz stammt dann eine Europakarte aus der Mitte des 14. Jahrhunderts. ${ }^{12}$ Läßt man die Mittelmeerzeichnung des Opicino de Canistris beiseite, dann hat erst Johannes Putsch Europa wieder furr sich dargestellt, und zwar, wie Opicino, als menschliche Gestalt. Die gekrönte Frauenfigur mit Szepter und Reichsapfel von 1537, die später auch in Sebastian Münsters „Kosmographie“ erschien ${ }^{13}$, Europa Regina also, haben wir als Signet fur die Publikationen unseres Instituts gewählt.

Wenn der mittelalterlichen Überlieferung überhaupt etwas entnommen werden kann, dann dies, daß die Vorstellung von Europa stets schwankend blieb; ,Europa' war kein Begriff, um den sich zu streiten gelohnt hätte. Aus heutiger Sicht lassen sich allenfalls zwei Hauptbedeutungen unterscheiden: die vom Karlsreich hergeleitete Gleichsetzung von ,Europa' mit der westlichen Christenheit, die das ganze Mittelalter durchzieht, und die Identifikation mit einem größeren Raum, der im Osten weite Teile der Sclavinia sowie Byzanz eingeschlossen hat. Da die Fläche eine variable Größe der Geschichte war - und zwar über das Mittelalter hinaus -, hat Geoffrey Barraclough bereits 1963 vorgeschlagen, ,Europa' weniger als Raum

10 Hagen Schulze/Ina Ulrike Paul (Hrsg), Europäische Geschichte. Quellen und Materialien. München 1994, 324 f.; Borgolte, Vor dem Ende der Nationalgeschichten? (wie Anm. 3), bei Anm. 26; Hiestand, „Europa“ im Mittelalter (wie Anm. 4), 44; Karageorgos, Der Begriff Europa (wie Anm. 4), 149.

11 Anna-Dorothee von den Brincken, Europa in der Kartographie des Mittelalters, in: AKG 55, 1973, 289-304, hier 296 ff.; dies., Finis Terrae. Die Enden der Erde und der vierte Kontinent auf mittelalterlichen Weltkarten. (MGH Schr., Bd. 36.) Hannover 1992, XIX, 73.

12 Von den Brincken, Europa (wie Anm. 11), 296.

13 Vgl. Hartmut Kugler, Symbolische Weltkarten - der Kosmos im Menschen. Symbolstrukturen in der Universalkartographie bis Kolumbus, in: Gutenberg und die Neue Welt. Hrsg. v. Horst Wenzel in Zusammenarbeit mit Friedrich Kittler und Manfred Schneider. München 1994, 33-58, hier 56 f.; Sebastian Münster, Cosmographey. Oder beschreibung Aller Länder herrschafftens und fümemesten Stetten des gantzen Erdbodens...Erstlich durch Herm Sebastian Münster...verfasset...Jetzt aber mit allerley Gedechtnuswirdigen Sachen bis in das M.D.LXXXVIII gemehret ...Gedruckt in Basel. (Basel 1588), xli. In den früheren Ausgaben von Münsters (gest. 1552) Werk (seit 1544) fehlt die Figur hingegen, s. Sebastian Münster en zijn Cosmographei, oder Beschreibung aller Länder, Bazel 1550, door R. Oehme. Houten 1987, 3 ff. Für die aufwendigen Recherchen zur Werkgeschichte Münsters danke ich meinem Mitarbeiter Tim Geelhaar. 
denn als historische Idee zu bestimmen, die zu verschiedenen Zeiten verschiedene Inhalte habe. ${ }^{14}$ Barraclough wandte sich auch schon gegen die herrschende Tendenz westlicher Historiker, Europa mit dem Abendland und die europäische mit der okzidentalen Zivilisation gleichzusetzen; dies sei eine bloße Vorentscheidung oder eine „unrichtige Gleichung““ ${ }^{15}$ So treffend diese Ideologiekritik war, hätte er freilich hinzufügen sollen, daß ein wertneutraler Europabegriff gar nicht möglich wäre.

Damit sind wir beim zweiten vorhin angesprochenen Fragenkreis zu unserem Forschungsgegenstand. Die Tragweite der Problematik verdeutlicht exemplarisch eine jüngere Äußerung von Jacques Le Goff. In einem Essay von 1994 uber Das alte Europa und die Welt der Moderne setzt Le Goff trotz der Ursprünge in der griechischen Mythologie die eigentliche Entstehung Europas erst in der Zeit nach dem Römerreich an; das Imperium Romanum selbst sei ein Irrweg Europas gewesen und habe eher der Geschichte des Mittelmeerraums angehört. ${ }^{16}$ Das Erbe der Römer für Europa sei aber schon die Spaltung in einen lateinischen Westen und einen griechischen Osten gewesen. Die größte religiöse und kulturelle Neuheit des Westens seit dem 4. Jahrhundert, das Christentum, habe diese Trennung noch verschärft. Die frühmittelalterliche Ausbildung eines römischen und eines griechischen Christentums habe dann eine kulturelle Grenze der longue durée geschaffen, die durch die politischen Grenzen noch verhärtet worden sei. Diese Scheidelinie habe, von Skandinavien bis Kroatien reichend, Balten, Polen, Tschechen, Slowaken, Ungarn und Slowenen eingeschlossen, auf der anderen Seite aber Rußland und Griechenland abgetrennt. Die Grenze, die 1054 durch das morgenländische Schisma bestätigt worden sei, habe dem römischen Papsttum die griechische Kirche endgültig entzogen und die westliche Christenheit von Byzanz und der orthodoxen Welt getrennt. So hätten sich auf der einen Seite das prunkvolle Byzanz, Erbe des antiken Römerreiches, sowie die russische Welt und auf der anderen Seite der Okzident gegenübergestanden, dieser ,geteilt, barbarisiert, nur unzureichend geeint durch zwei Oberhäupter, Papst und Kaiser“, der aber einen außergewöhnlichen wirtschaftlichen, politischen und kulturellen Aufschwung und eine immer stärkere Expansion erlebt hätte. Diese Welt, das lateinische Christentum, sei das mittelalterliche Europa gewesen. Neben der Gemeinschaft des Christentums seien es die Königtümer gewesen, die den ersten Entwurf Europas prägten. So sei das „Europa der Nationen“ als Vielfalt in der Einheit vorweggenommen worden.

Le Goffs Identifikation von Europa mit dem lateinischen Europa, mit dem Bereich der westlichen, der römischen Kirche, dem Okzident und dem Abendland kann sich auf einen Ausschnitt der Überlieferung stützen, beruht aber vor allem auf einer wissenschaftlichen Tradition. Lange vor seiner Datierung der Grundlegung Europas in der Übergangszeit von der Antike zum Mittelalter und bei den germanischen Staatenbildungen auf Reichsboden war

14 Geoffrey Barraclough, European Unity in Thought and Action. Oxford 1963; dt:: Die Einheit Europas als Gedanke und Tat. Göttingen 1964, 7.

15 Ebd. 8. „Unrichtige Gleichung“ nach Heinz Gollwitzer, Europabild und Europagedanke. Beiträge zur deutschen Geistesgeschichte des 18. u. 19. Jahrhunderts. München 1951.

16 Jacques Le Goff, Das alte Europa und die Welt der Moderne. München 1994, 9. Das Folgende ebd. 9-13. 
schon dem Volk der Franken die „Geburt Europas“ zugeschrieben worden ${ }^{17}$; und erst vor kurzem hat eine große Ausstellung in Mannheim, Paris und Berlin diese Lehre erneuert. ${ }^{18}$ Etwas weiter heraufsteigend hat Christopher Dawson in seinem berühmten Buch The Making of Europe von 1932 die Errichtung des Karolingerreiches als Zäsur hervorgehoben, als „Grundlage und Ausgangspunkt der ganzen Entwicklung der mittelalterlich-christlichen Kultur “'19; zugleich habe dieses Reich eine fortschrittliche Bewegung ausgelöst, die fast ohne Unterbrechung bis zur Neuzeit anhalten sollte. Eine andere Variante der Europa= Abendland-These stellt das neue Werk von Robert Bartlett dar, das in der englischen Originalversion den Titel von Dawson übernommen hat. Nach Bartlett war es aber die „Expansion der lateinischen Christenheit" zwischen 950 und 1350 durch Kolonisation, Kreuzzüge und Mission, die Europa geschaffen hat. ${ }^{20}$

Osteuropahistoriker und Byzantinisten haben gegen diese Sicht der Dinge immer wieder Einspruch erhoben. 1950 versuchte etwa Oskar Halecki zu zeigen, daß die westliche Geschichtsschreibung den Anteil des Ostens an der Geschichte Europas unterschätzt habe, besonders für die Aufbauepoche des europäischen Staatensystems vom 14. bis 16. Jahrhundert. ${ }^{21}$ Es ist bemerkenswert, daß ausgerechnet Dawson dann Halecki bescheinigte, niemand vor ihm habe die Frage nach Europa so umfassend beantwortet. Dawson stimmte Halecki zu, daß auch Osteuropa im Mittelalter eine Gesellschaft von Königreichen gewesen sei, deren politische Struktur der vielstaatlichen Gesellschaft des Westens ähnlich war und mit der sie eine gemeinsame kulturelle und religiöse Tradition teilte. Noch wichtiger ist aber, welche Implikationen dieser Ausweitung des historischen Europabildes zugeschrieben werden. Denn die herrschende Beschränkung auf Westeuropa sei Resultat einer Auffassung von der Geschichte Europas als Universalgeschichte des menschlichen Fortschritts, die auf Gibbon und Condorcet zurückgehe. Die Geschichte Osteuropas könne demgegenüber „eine heilsame Korrektur für das naive Vertrauen in den materiellen Fortschritt“ liefern, „das für die westliche Kultur in Europa und Amerika während der letzten Generationen so bezeichnend war“. ${ }^{22}$ Ganz ähnlich wie im Falle Osteuropas wird auch für Byzanz die Zugehörigkeit zu Europa reklamiert und der Fortschrittsparameter relativiert. Während Gibbon noch vom tausendjährigen „Zerfall und Untergang des Römischen Reiches“ sprach, erkennt die neuere

17 C. Delisle Burns, The First Europe. London 1947. Zit. nach Barraclough, Die Einheit Europas (wie Anm. 14), 12.

18 Die Franken - Wegbereiter Europas. Vor 1500 Jahren: König Chlodwig und seine Erben. 2 Bde. Mainz 1996.

19 Christopher Dawson, The Making of Europe. An Introduction to the History of European Unity. London 1932; dt.: Gestaltung des Abendlandes. Köln 1950, 276 ff.

20 Robert Bartlett, The Making of Europe. Conquest, Colonization and Cultural Change. 950-1350. London 1993; dt.: Die Geburt Europas aus dem Geist der Gewalt. Eroberung, Kolonisierung und kultureller Wandel von 950 bis 1350 . München 1996.

21 Oskar Halecki, The Limits and Divisions of European History. London/New York 1950; dt.: Europa. Grenzen und Gliederung seiner Geschichte. Darmstadt 1957.

22 Christopher Dawson, Vorwort, in: Halecki, Europa (wie Anm. 21), X. 
Forschung in der „Fähigkeit zu überleben“ eine historische Errungenschaft. ${ }^{23}$ Bedeutsamer, als den Ursachen des Niedergangs von Byzanz nachzugehen, erscheine die Frage „nach den Bedingungen und Kräften, die angesichts ständiger Bedrohung von außen und innen Leistung, Dauer und Überleben möglich machten“.

Die Frage, welches Europa in einer europäischen Geschichtswissenschaft vom Mittelalter gemeint sein soll, entscheidet sich allerdings nicht nur beim Verhältnis von Abendland und Orient; man muß sie auch im Hinblick auf die nichtchristlichen Kulturen des Judentums und des Islam beantworten, deren Anteil an der ganzen europäischen Geschichte unbestritten ist, deren Integration in ein europäisches Geschichtsbild aber trotzdem Schwierigkeiten bereitet. Machen wir uns nichts vor. Wer eine wirklich europäische Geschichtswissenschaft will, muß die wissenschaftlichen und ideologischen Grundlagen unseres Faches und das System jener Kulturwissenschaften überprüfen, denen es angehört. Mediävistik, die wir betreiben, ist ja die Wissenschaft vom lateinischen Europa. ${ }^{24}$ Bezogen auf die Geschichte des gesamten Kontinents wird sie ergänzt durch die Byzantinistik und die Slawistik für den Raum Ost- und Südosteuropas, durch die Islamwissenschaft für die muslimischen Herrschaften in Spanien und Italien, schließlich auch durch die Judaistik für die wechselnden Siedlungen der Juden im mittelalterlichen Europa. Wissenschaftsgeschichtlich gesehen war die Ausbildung dieser Disziplinen zweifellos so gut begründet wie die Entstehung nationaler Geschichtswissenschaften im Zuge der modernen Staatenbildung. Aber kann dem Ensemble von Fächern oder Disziplinen die Zukunft gehören? Genügt interdisziplinäre Kooperation dieser Geschichtsund Kulturwissenschaften, wo man doch weiß, daß die Forderung nach Interdisziplinarităt allzu oft zur Entlastung von eigener Verantwortung durch Verweis auf den Fachmann dient? Ist nicht Transdisziplinarität gefordert, also das Denken und Forschen über das traditionelle eigene Terrain hinaus, ist nicht Entdisziplinarisierung nötig, die freilich bald schon zu neuen Fächern überleiten müßte, die die besten Errungenschaften der alten bewahren sollten?

Der herkömmlichen Mediävistik würde in einem solchen Prozeß nicht weniger entzogen als ihre Kernaussage. Außerhalb des Abendlandes ist ja der Begriff ,Mittelalter' selbst problematisch. Wo es keine Antike gegeben hat, kann es streng genommen auch kein Mittelalter geben; und wo die Tradition der lateinischen Sprache und römischen Kultur verschüttet bzw. später nicht adaptiert wurde, gab es keine der für Mittelalter und Neuzeit so bezeichnenden Renaissancen. ${ }^{25}$ Beides gälte, wenn auch in je verschiedener Weise, furr Ostslawen und Byzantiner, für Juden und Muslime. Über Mittelalter kann man eigentlich nur im Hinblick auf die lateinische Welt sprechen. Wenn diese Beschränkung nicht mehr gelten sollte, würde die Mediävistik auch ihre raison d'être verlieren, die darin besteht, das historische Selbst-

23 Franz Georg Maier, Einleitung: Byzanz als historisches Problem, in: Byzanz. Hrsg. v. dems. (Fischer Weltgeschichte, Bd. 13.) Frankfurt a. M. 1973, 21 (hier auch das folgende Zitat).

24 Vgl. jetzt: Hans-Werner Goetz, Moderne Mediävistik. Stand und Perspektiven der Mittelalterforschung. Darmstadt 1999; Otto Gerhard Oexle (Hrsg.), Stand und Perspektiven der Mittelalterforschung am Ende des 20. Jahrhunderts. Mit Beiträgen von Amold Esch, Johannes Fried und Patrick J. Geary. (Göttinger Gespräche zur Geschichtswissenschaft, Bd. 2.) Göttingen 1996.

25 Vgl. Ernst Pitz, Art. Mittelalter, in: LMA. Bd. 6. München/Zürich 1993, Sp. 684-687, hier bes. Sp. 685. 
verständnis der Abendländer zu stabilisieren. Aber ist diese Entwicklung wirklich unvermeidlich? Können wir sie noch verhindern, müssen wir sie erleiden, sollen wir sie gar fördern und gestalten?

Was die Zukunft bringt, läßt sich bekanntlich nicht vorhersagen und nur mäßig beeinflussen; sicher aber ist, daß wir als Historiker Verantwortung für unsere Gegenwart tragen. Zwar wohnt der Historie, wie jeder elaborierten Wissenschaft, die Tendenz zur Autonomie inne, und die kritische Methode, die sie entwickelt hat, ist ein Schatz, den wir - komme, was wolle - verteidigen müssen. Aber genauso gewiß ist auch, daß der unaufhörliche Prozeß historischer Veränderung auch von uns Anpassungen verlangt; dies ist kein Defekt, der zu beklagen wäre, sondern geradezu die Existenzbedingung von Forschung. Denn seitdem wir durch Kant oder Weber wissen, daß Wissenschaft zwar viel weiß, aber nichts als Wahrheit weiß, seitdem also Forschung als unabschließbarer Prozeß des Suchens und Findens definiert ist, seit dieser Zeit ist es nur das Leben, das der Wissenschaft die Fragen stellt. ${ }^{26}$ Auch die Mittelalterhistorie ist ebenso zeitgebunden wie auf ihre Unabhängigkeit bedacht; deshalb wird auch sie durch grundlegende Änderungen der geschehenden Geschichte herausgefordert.

$\mathrm{Da} ß$ wir solche Umbrüche erleben, duldet aber keinen Zweifel. Der Prozeß der europäischen Einigung hat sich in den letzten Jahren und vor allem seit den Ereignissen von 1989/90 dramatisch beschleunigt. Ging es lange nur um den relativ ruhigen Abbau nationalstaatlicher Kompetenzen zugunsten eines einheitlichen Wirtschaftsraumes, dessen Leistungskraft immer mehr westliche Länder anzog, so stellt sich nun die Frage, welche ostmittel- oder gar osteuropäischen Staaten künftig der Europäischen Union einbezogen werden sollen. Strittig ist die Zuordnung der Länder jenseits der baltischen Staaten bzw. Polens, Tschechiens, der Slowakei und Ungarns, vor allem also diejenige Rußlands, des Balkans und der Türkei; andererseits ist die alte kulturelle Scheidelinie durch den Beitritt Griechenlands längst durchbrochen. Auch wenn die Integration der Ostslawen und der muslimischen Randzonen noch offen bleibt, markiert die schon jetzt erreichte oder eingeleitete europäische Einigung für alle überschaubare Geschichte ein Novum.

Wie lange die Grenzen nach Osten durchlässig bleiben, ist im Augenblick ungewiß; die europäische Bewegung mit ihrer vor wenigen Jahren noch unvorstellbaren Mobilisierung der Menschen hat aber bereits zu einer beispiellosen Dichte kulturellen Austauschs gefuhrt. Es ist schwer vorstellbar, daß diese Entwicklung zurückgenommen werden könnte. Schon in der Gegenwart, und nicht erst bei einer realen Einigung Europas, müssen wir uns im täglichen Leben mit einer vorher unbekannten Intensität kultureller Begegnungen und Konflikte auf dem Boden des Kontinents auseinandersetzen. Türken muslimischen Glaubens leben nach Millionen zählend in Deutschland, Schweden und Dänen arbeiten in Portugal, polnische Studenten beziehen die Viadrina in Frankfurt an der Oder und schon bald könnten sogar Ukrainer das Recht der Freizügigkeit nach Verträgen mit der EU beanspruchen. Wir können

26 Otto Gerhard Oexle, Geschichtswissenschaft im Zeichen des Historismus. Studien zu Problemgeschichten der Moderne. (Kritische Studien zur Geschichtswissenschaft, Bd. 116.) Göttingen 1996; Andrea Germer, Wissenschaft und Leben. Max Webers Antwort auf eine Frage Friedrich Nietzsches. (Kritische Studien zur Geschichtswissenschaft, Bd. 105.) Göttingen 1994. 
das Fremde nicht mehr als das Exotische genießen, sondern müssen mit ihm im täglichen Leben fertigwerden.

Die Geschichtswissenschaft muß auf diese Entwicklungen reagieren, und das gilt auch für die Mediävistik. Wer es wie ich vor kurzem in einem Seminar über Karl den Großen erlebt hat, daß ein in Deutschland geborener Türke sich nur einmal zu Wort meldete, dann aber mit glühenden Augen und reißender Rede - als es nämlich darum ging, die historische Wirkung Mohammeds darzulegen -, der weiß, daß die alten Konzepte der Mittelalterforschung und -lehre auf dem Prüfstand stehen. Ob es künftig genügt, sich im interdisziplinären Gespräch auszutauschen und schriftlich dann doch nur Buchbindersynthesen zustandezubringen? Ebensowenig wie wir im praktischen Leben die Auseinandersetzung mit dem Fremden in die Zuständigkeit anderer verweisen können, werden wir uns als Historiker wohl auf Dauer auf die begrenzte Kompetenz des Fachmannes herausreden können. Wer Geschichte für diese Zeit betreiben will, muß selbst zusammendenken, was in der Wirklichkeit noch schwer zueinander findet.

Als Historie, die den Verlauf der Geschichte zwischen Antike und Neuzeit zu betrachten hatte, hat die Mediävistik die Geschichte Europas schon zu lange einseitig unter den Aspekten des Fortschritts und der kommenden Moderne betrachtet. Zum Beleg sei nur daran erinnert, welche Resonanz die These vom hochmittelalterlichen Aufbruch, von der gregorianischen und vielen anderen Revolutionen des 11. und 12. Jahrhunderts in der internationalen Geschichtswissenschaft der letzten Jahrzehnte gefunden hat. ${ }^{27}$ Die Annahme einer einheitlichen und quasigesetzlichen Entwicklungstendenz war nur möglich durch Ausklammerung der griechisch-orthodoxen, aber auch der jüdischen und der muslimischen Welt aus dem Bild des historischen Europa. Denn zweifellos ließe sich etwa die Geschichte von Byzanz nicht als Prozeß des Fortschritts begreifen, dem die aufklärerische Trias Antike - Mittelalter - Neuzeit entspräche. Schon in frühchristlicher Zeit entwickelten die Oströmer zur Überlieferung eine Haltung, die unveränderlich war und jede Entwicklung ausschloß; Renaissancen, Aufklärung und Industrielle Revolution hatten deshalb hier keinen Boden. Selbst Reformen wurden, anders als im Westen, kaum konzipiert, wenn es auch Vorgänge dieser Art tatsächlich gegeben hat. ${ }^{28}$

Die weitgehende Eliminierung des Ostens, der Juden und Muslime aus der europäischen Geschichte des Mittelalters ließ auch das Abendland selbst homogener erscheinen, als es je war. Ohne große Mühe läßt sich an der Literatur über den Westen verifizieren, wie mit generalisierenden Aussagen die Differenzen und unterschiedlichen Entwicklungsgeschwindigkeiten von Land zu Land, ja von Region zu Region, eingeebnet und ausgeglichen werden. Man muß den Blick nur weit genug spannen, um festzustellen, wie vorschnell harmonisiert wird. Was hätte aber beispielsweise der skandinavische Norden gemein mit der Iberischen Halbinsel? Während Dänemark und mehr noch Norwegen und Schweden um 1050 von der

27 Vgl. Michael Borgolte, Einheit, Reform, Revolution. Das Hochmittelalter im Urteil der Modernen, in: GGA 248, 1996, 225-258.

28 Vgl. Evelyne Patlagean, Das byzantinische Kaiserreich von 1054 bis 1122, in: Die Geschichte des Christentums. Bd. 5: Machtfulle des Papsttums (1054-1274). Hrsg. v. André Vauchez. Freiburg/Basel/Wien 1994, 3-32, hier 22-27. 
Vorgeschichte direkt zum Mittelalter übergingen, indem sie sich durch Kirchenorganisation und Königtum den fränkischen Nachfolgestaaten assimilierten ${ }^{29}$, folgten die altchristlichen Bewohner Spaniens, von Europa abgewandt, einem Traum vom Reich der Goten, das sie im zăhen Kampf mit den Muslimen wiederaufzurichten hofften. ${ }^{30}$ Selbst in den Kernländern des Abendlandes lassen sich disparate Entwicklungen in zentralen Lebensbereichen mühelos erkennen. So hat das Reformpapsttum in Deutschland die Entsakralisierung des Königtums in einer Zeit versucht, in der sich im benachbarten Frankreich die Amtsheiligkeit der Herrscher erst verdichtete. ${ }^{31}$

Gegenüber starken Tendenzen zur Vereinheitlichung des europäischen Geschichtsprozesses in der jüngeren Mediävistik begünstigt die gegenwärtige Expansion Europas weit nach Osten eine bessere Wahmehmung und Würdigung der europäischen Vielfalt. Eine erneuerte Geschichtswissenschaft vom Mittelalter könnte mehr Verständnis wecken für das Ungleichzeitige, Gegenläufige, ja Widerständige in der europäischen Geschichte der Vormoderne. Es sind aber nicht nur Gegenwartserfahrungen, die zur Revision historischer Konzepte zwingen, sondern dazu veranlassen die Einsichten der jüngeren Geschichtswissenschaft selbst. Schon vor Jahrzehnten hat der deutsche Sozialhistoriker Otto Brunner gezeigt, daß ganzheitliche Entwicklungsgeschichte nur um den Preis bestimmter ideologischer Vorannahmen möglich wird. Brunner ließ die Denkform ,Entwicklung' zurecht nur noch für Wirklichkeitssegmente zu, während er die Geschichte im ganzen als Prozeß unaufhörlichen Wandels begriff, was etwas grundsätzlich anderes ist. ${ }^{32}$ In Frankreich haben Fernand Braudel und seine Schule gezeigt, daß die Geschichte stets verschiedenen Zeitgeschwindigkeiten folgt, je nachdem, welchen Bereich des Lebens man betrachtet. ${ }^{33}$ Schließlich hat der Neuhistoriker Reinhart

29 Vgl. Göran Dahlbäck, Art. Schweden, in: LMA. Bd. 7. München 1995, Sp. 1626-1637, hier Sp. 1627; Ulla Lund-Hansen/Else Roesdahl/Inge Skovgaard-Petersen, Art. Dänemark. B. Archäologie/C. Allgemeine und politische Geschichte Dänemarks im Früh- und Hochmittelalter, in: LMA. Bd. 3. München/Zürich 1986, Sp. 497-507. - Die Periodisierung ist allerdings nicht einheitlich. Im Katalog der Europaratsausstellung von 1992/93 (Paris, Berlin, Kopenhagen) wurde die Zeit von 800 bis 1200 zusammenfassend als Zeit der Wikinger und des frühen Mittelalters behandelt, ohne daß die Perioden klar voneinander geschieden wären (Wikinger, Waräger, Normannen. Die Skandinavier und Europa 800-1200. Berlin 1992, bes. 24), ähnlich bei Birgit Sawyer/Peter Sawyer, Medieval Scandinavia. From Conversion to Reformation, circa 800-1500. Minneapolis/London 1993, IX.

30 Vgl. Ludwig Vones, Geschichte der Iberischen Halbinsel im Mittelalter (711-1480). Reiche, Kronen, Regionen. Sigmaringen 1993, 35 ff., 78 ff.

31 Vgl. Gerd Tellenbach, Die westliche Kirche vom 10. bis zum frühen 12. Jahrhundert. Göttingen 1988, 177 f., 188 f., 194 f.; Joachim Ehlers, Die Kapetinger. Stuttgart/Berlin/Köln 2000, 78 ff.; ders., Geschichte Frankreichs im Mittelalter. Stuttgart/Berlin/Köln/Mainz 1987, 62 f., 79 f. Jetzt ders., Der wundertätige König in der monarchischen Theorie des Früh- und Hochmittelalters, in: Reich, Regionen und Europa in Mittelalter und Neuzeit. Fschr. Peter Moraw. Hrsg. v. Paul-Joachim Heinig u. a. (Hist. Forsch., Bd. 67.) Berlin 2000, 3-20. - Daß sich die Entsakralisierung des christlichen Herrschertums nie durchgesetzt hat, hat Tellenbach wiederholt betont (z. B.: Die westliche Kirche, 269 f.).

32 Vgl. Michael Borgolte, Das soziale Ganze als Thema deutscher Mittelalterforschung vor und nach der Wende, in: Francia 22, 1995, 155-171, bes. $168 \mathrm{ff}$.

33 Fernand Braudel, Histoire et Sciences sociales, La longue durée, in: Annales 13, 1958, 725-753; dt. in: Marc Bloch/Fernand Braudel/Lucien Febvre u. a., Schrift und Materie der Geschichte. 
Koselleck nachgewiesen, daß der Kollektivsingular ,Geschichte' selbst ein Phänomen der Moderne ist, die Vormoderne demnach aus vielen besonderen Geschichten bestanden hat. ${ }^{34}$ Aus diesen Einsichten Folgerungen zu ziehen bedeutet, das Mittelalter als multiversale Welt zu verstehen, statt der einen Geschichte Europas viele Geschichten europäischen Lebens zu erzählen.

Freilich wird und sollte diese Forderung sofort einen Einwand provozieren: Wer viele einzelne historische Welten behandeln und darstellen will, wird in die Gefahr geraten, nichts mehr erklären, über Vergangenheit nicht mehr aufklären zu können. In der Tat muß man die Sorge ernstnehmen, daß eine Überwindung des abendlandzentrierten Einheitsdenkens die Auslieferung an die europäische Vielfalt bedeuten könnte. Deshalb muß sich eine europäische Mittelalterhistorie, die Anspruch auf Zukunft erheben will, gerade hier bewähren - im Spannungsfeld der Prinzipien Einheit und Vielfalt. Gelingen wird ihr das nur, wenn sie mit beiden Händen arbeitet und ihr bewährtes Instrumentarium bedient, nämlich die Geschichtsforschung ebenso wie die Geschichtsschreibung.

Europäische Mittelalterforschung darf sich nie ans Einzelne verlieren, wenn ihr Name überhaupt etwas bedeuten soll. Die methodischen Gegenmittel, die sie vor einem Rückfall in den Objektivismus bewahren, sind die Analyse von Beziehungen und der Vergleich. ${ }^{35}$ Beide Verfahren können freilich, bezogen auf den ganzen Kontinent und auf den ganzen Reichtum der historischen Sachverhalte, nicht zur Erkenntnis einer einzigen Einheit führen, sondern nur zu Einheiten, in denen die Vielfalt des Einzelnen aufgehoben wird. ${ }^{36}$ Vergleich und Beziehungsanalyse dienen nicht der Erkenntnis einer einzigen, zentralen Entwicklungstendenz, sondern sie evozieren ein System von Verdichtungen, die sich überlagern und durchdringen. Schon die verschiedenen Beziehungsnetze ergeben bei allen Wechselbeziehungen untereinander eigene europäischen Größen. Ich nenne hier nur einige der betreffenden Arbeitsfelder, wenn ich erinnere an die Erforschung des Straßennnetzes und des Verkehrs, der Gesandtschaften, der Königstreffen und der politischen Versammlungen, des Handels, der Pilgerströme und der Synoden, der Schüleritinerare, der Adels- und der Handwerkerreisen, vor allem aber der Austauschprozesse zwischen den verschiedenen Kulturen usw. Ganz andere Zusammenhänge ergeben sich bei den Operationen des europäischen Vergleichs, vor allem dann, wenn man diesen nicht, wie üblich, auf Nachbarländer beschränkt. Die historische Komparatistik entfaltet ja erst dann ihr innovatives Potential, wenn sie unter häufigem Wechsel der Gesichtspunkte in wirklich europäischer Perspektive angelegt ist, die

Vorschläge zur systematischen Aneignung historischer Prozesse. Hrsg. v. Claudia Honegger. Frankfurt a. M. 1977, 47-85; vgl. Peter Burke, Offiene Geschichte. Die Schule der Annales. Berlin 1991, 37 ff.

34 Reinhart Koselleck, Die Herausbildung des modernen Geschichtsbegriffs, in: Geschichtliche Grundbegriffie. Historisches Lexikon zur politisch-sozialen Sprache in Deutschland. Hrsg. v. Otto Brunner/Werner Conze/Reinhart Koselleck. Bd. 2. Stuttgart 1975, 647-691.

35 Zur Methode und Praxis des historischen Vergleichs jetzt Hartmut Kaelble, Der historische Vergleich. Eine Einfuhrung zum 19. und 20. Jahrhundert. Frankfurt/New York 1999; vgl. Michael Borgolte, Die Erfindung der europäischen Gesellschaft. Marc Bloch und die deutsche Verfassungsgeschichte seiner Zeit, in: Marc Bloch. Historiker und Widerstandskämpfer. Hrsg. v. Peter Schöttler. Frankfurt/New York 1999, 171-194; ders., Otto Hintzes Lehre vom Feudalismus in kritischen Perspektiven des 20. Jahrhunderts (im Druck).

36 Vgl. jetzt Borgolte, Vor dem Ende der Nationalgeschichten? (wie Anm. 3), bei Anm. 94 ff. 
von der Kiever Rus' nach Island, vom vorgeschichtlichen Finnland zum gleichzeitigen, aber hochkultivierten Normannenreich in Sizilien und Apulien reicht. ${ }^{37}$ Das Glück des Wiedererkennens historischer Erscheinungen am unerwarteten Ort und ebenso das Staunen über die Differenzen der Geschichte, diese beiden emotionalen Urerlebnisse des Vergleichs schärfen nicht nur die Wertschätzung des Anderen in der Geschichte, sie wirken vor allem auf die Erkenntnis des längst Bekannten zurück, das plötzlich in neuem Licht erscheint. Weil das so ist, muß eine vergleichende europäische Mittelalterhistorie auch nicht sogleich die Aufhebung der Nationalgeschichten und der Spezialdisziplinen bedeuten. ${ }^{38}$ Vielmehr bleibt die komparative Geschichte des Mittelalters, die möglichst alle Teile Europas berücksichtigen sollte, wohl noch auf lange Sicht auf die Zusammenarbeit mit den nationalen Geschichtswissenschaften und den betroffenen Einzelfächern angewiesen; nur wo diese durch ihre Detailstudien Ergebnisse zutage gefördert haben, zu denen sich in anderen Regionen Analogien oder abweichende Befunde ermitteln lassen, kann sie mit ihrer Arbeit beginnen. Der Vergleich sollte dann symmetrisch angelegt sein, $d$. h. kein Einzelphänomen von vormherein abwerten und Generalisierungen ebenso erlauben wie die Würdigung von Differenzen. Weil der Vergleich das geistes- und sozialwissenschaftliche Äquivalent des naturwissenschaftlichen Experiments ist ${ }^{39}$, erlaubt er, in schöpferischer Weise Fragestellungen vom einen aufs andere Gebiet zu übertragen; die komparative Arbeit kann so die Detailforschung der Einzelfächer selbst wieder anregen. Europäische Mittelalterforschung wird also, das ist meine Erwartung und meine Hoffnung, neben die herkömmliche Geschichtswissenschaft treten; mit ihren Fragen lebt sie von den Ergebnissen der partikularen Historiographien, die sie aber in ihren weiteren Horizont integriert und so zum Bezugspunkt auch für andere Mediävistiken werden läßt. Anders und praktischer gesagt: Der europäisch ausgerichtete Mittelalterforscher bearbeitet sein Thema in mindestens zwei Ländern oder Regionen Europas; oder aber er fuhrt die Spezialisten verschiedener Herkunft zusammen und betätigt sich als Manager komparativer Forschung. Beide Aufgaben sollte, wie ich meine, auch das neue Institut fördern und erfullen.

Vergleichende europäische Mittelalterhistorie könnte zum Positivismus zurlucklenken, der die unendlich variierenden Erscheinungen der Geschichte auf Gesetze reduzieren wollte ${ }^{40}$; dieser Weg wäre indessen philosophisch und wissenschaftstheoretisch eine Regression, die vermieden werden muß. Andererseits stellt die Zusammenfassung eines weitgreifenden Vergleichs eine überaus schwierige Aufgabe dar, fur die uns die Erfahrungen noch weitgehend fehlen. Man braucht sich nur im Lexikon des Mittelalters die Dachartikel zu so zentralen Stichwörtern wie ,Bauer' oder ,Stadt' anzusehen, um festzustellen, wie schwer es ist, den Besonderheiten einer Erscheinung ebenso Gerechtigkeit widerfahren zu lassen wie den histo-

37 Ein Versuch: Michael Borgolte, „Europa ein christliches Land“. Religion als Weltstifterin im Mittelalter?, in: ZfG 48, 2000, 1061-1077.

38 Dazu Borgolte, Vor dem Ende der Nationalgeschichten? (wie Anm. 3), passim.

39 Emile Durkheim, Die Regeln der soziologischen Methode. Hrsg. und übers. v. René König. Neuwied 1961, 205.

40 Hartmut Przybylski, Art. Positivismus, in: Historisches Wörterbuch der Philosophie. Bd. 7. Darmstadt 1989, Sp. 1118-1122, hier Sp. 1119 (nach A. Comte). 
rischen Analogien und nach beiden Richtungen leichtsinnige Pauschalurteile zu vermeiden. ${ }^{41}$ Natürlich ist die Erfassung des ganzen mittelalterlichen Europa für kein Gebiet der Geschichte mit all seinen Varianten möglich; aber diese Einsicht ist seit Durkheims Positivismus-Kritik banal. ${ }^{42}$ Was wir anstreben können, wäre hingegen, in der unendlichen Menge historischer Phänomene Ordnungen mittlerer Ansprüche zu etablieren. Eine komparativ verfahrende Geschichtswissenschaft, die die Grenzen historischer Erkenntnischancen anerkennt und sich damit begnügt, Einzelheiten zu Fragmenten, nicht aber zu Ganzheiten zusammenzufügen, könnte dafür jene Vorstellung menschlicher Handlungsräume vermitteln, die wir selbst brauchen, um unsere eigene Zeit zu bestehen. Durch Forschung allein kann die Historie freilich ihren künftigen Aufgaben nicht gerecht werden. Um zur Anschauung zu bringen, was das multipolare Europa ausgezeichnet und wohl auch zusammengehalten hat, braucht man die Geschichtsschreibung. Nur sie kann das heikle Verhältnis von Einheiten und Differenzen in der mittelalterlichen Geschichte zur Evidenz bringen.

Aber ist eine Historiographie Europas im Mittelalter derzeitig überhaupt möglich? Bedarf Geschichtsschreibung nicht eines längst etablierten Gegenstandes, den die Leser kennen und als Geschehniszusammenhang mit ihrer eigenen Erfahrungswelt verknüpfen können? ${ }^{43}$ Offenkundig erfullt das neue, multikulturell vernetzte Europa - wie gesagt ein Novum in der Geschichte - diese Anforderungen noch kaum; wohl ließe sich heute die Geschichte Europas als Abendland furr West- und Mitteleuropäer schreiben, aber gälte das auch für ein sich vereinendes oder mindestens die kulturellen Grenzen öffnendes Europa, wie wir es in unserer Gegenwart erleben?

Das schwierige, wohl das zentrale Problem europäischer Geschichtswissenschaft in unserer Zeit hat meines Wissens bisher vor allem der englische Osteuropahistoriker Norman Davies angepackt und einer akzeptablen Lösung zugeführt. ${ }^{44}$ Davies hatte den Mut, 1996 eine Gesamtgeschichte Europas auf 1300 eng bedruckten Seiten vorzulegen und dabei Grundsatzfragen europäischer Historiographie zu erörtern. Die Idee von ,Europa', so Davies, sei verhältnismäßig jung, sie datiere erst aus den Jahrzehnten um 1700 und sei eine Frucht der Aufklärung. ${ }^{45}$ Das Konzept von Europa habe sich aber erst langsam konsolidieren müssen, bevor europäische Geschichte geschrieben werden konnte. Davies nannte den französischen Autor und Staatsmann François Guizot mit seiner Histoire de la civilisation en Europe (1828/30); diese Pioniertat der europäischen Geschichtsschreibung habe auf Vorlesungen an der Sorbonne beruht. ${ }^{46}$ Trotzdem hielt Davies nicht einmal in der Gegenwart die

41 Werner Rösener, Art. Bauer, Bauerntum, in: LMA. Bd. 1. München/Zürich 1980, Sp. 1563-1571; Ernst Pitz, Art. Stadt, A . Allgemein, in: LMA. Bd 7. München 1995, Sp. 2169-2174.

42 Vgl. Borgolte, Die Erfindung (wie Anm. 35), 184.

43 Vgl. Franz-Josef Schmale, Die Reichenauer Weltchronistik, in: Die Abtei Reichenau. Neue Beiträge zur Geschichte und Kultur des Inselklosters. Hrsg. v. Helmut Maurer. Sigmaringen 1974, 125-158, hier 125 f.; Schulze, Phoenix Europa (wie Anm. 2), 9, dazu Borgolte, Vor dem Ende der Nationalgeschichten? (wie Anm. 3), bei Anm. 79.

44 Andere Titel, die zum größeren Teil nach dem Vortrag vom September 1999 erschienen sind, sind oben Anm. 2 genannt.

45 Norman Davies, Europe. A History. Oxford/New York 1996, 7.

46 Ebd. 15. 
Zeit für gekommen, eine befriedigende europäische Gesamtdarstellung zu geben; die nationalstaatliche und nationalgeschichtliche Perspektive sei noch immer zu stark; er folgerte daraus, "that the reformulating of European history must inch forward alongside the gradual construction of a wider European community", und fugte illusionslos die Erwartung an: „Neither will be built in a day“. ${ }^{47}$ Was jetzt getan werden könnte - und was Davies selbst in eindrucksvoller Meisterschaft vorfuhrte - sei eine pointillistische Darstellung. ${ }^{48}$ Diese entspreche der Differenz-Erfahrung der Europäer. Da Europa niemals politisch geeint gewesen sei, sei Verschiedenheit (diversity) eines seiner stabilsten Kennzeichen. Verschieden seien in den Teilen Europas die Reaktionen auf die gleichen Erfahrungen, verschieden die Nationalstaaten und Kulturen innerhalb der europäischen Zivilisation im ganzen, verschieden die Rhythmen von Machtentfaltung und Niedergang. ${ }^{49}$ Der Pionier Guizot sei nicht der einzige gewesen, der in der Verschiedenheit das hervorstechende Charakteristikum Europas überhaupt gesehen habe. Seit Beginn der neunziger Jahre, so Davies weiter, könne die europäische Einheit nicht mehr auf das westliche Europa beschränkt gedacht werden. Osteuropa könne auch nicht deshalb zurückgewiesen und ausgeklammert werden, weil es ,anders' sei. Demgegenüber betont Norman Davies: „All European countries are different. All West European countries are different" ${ }^{50}$ Andererseits gebe es wichtige Ähnlichkeiten, die das Trennende verknüpten. Ein Land wie Polen möge zwar verschieden von Deutschland oder England sein, doch habe die polnische Erfahrungswelt größere Affinitäten zu derjenigen Irlands oder Spaniens als diejenige vieler westeuropäischer Staaten untereinander. Dieser Lage Europas sei es nach Davies angemessen, einen pluralistischen Blick auf die Geschichte zu wagen und bestehende Grenzen zu überschreiten. Zwar sei es natürlich, in der Geschichte eigene Wurzeln zu suchen, aber es sei bisher noch kaum gelungen, in der Vergangenheit die Antriebe zur europäischen Einheit der Zukunft freizulegen. Seit der Teilung Europas durch Renaissance und Reformation, so der Neuhistoriker Davies, fehlte dem Kontinent ein Ideal der Einheit. Ähnlich wie beim Schmelztiegel der Vereinigten Staaten von Amerika erscheine das Mosaik von Europa deshalb Stein für Stein gleichwichtig. ${ }^{51}$ Zwar sei es notwendig, historische Fehldeutungen und Mißverständnisse zu überwinden, wie sie in jeder Nation vorkämen; aber es sei doch auch schwer, zu einem Konsens über die europäische Geschichte zu kommen. Die Historiker könnten allerdings zur Entwicklung eines Gemeinschaftsgefühls beitragen, indem sie vorerst jenen Millionen Europäern ein geistiges Zuhause schüfen, die durch Integration verschiedener Identitäten die bestehenden Grenzen schon jetzt überschritten. ${ }^{52}$ Am Ende des Prozesses müsse eine neue Vision von Europa stehen, ein Mythos, der auf einem neuen Bild der europäischen Vergangenheit beruhe und der die neuen Hoffnungen für die Zukunft Europas begleiten könnte. ${ }^{53}$

47 Ebd. 36.

48 Ebd. ix.

49 Ebd. 16.

50 Ebd. 28.

51 Ebd. 35.

52 Ebd. 45.

53 Vgl. Michael Borgolte, Historie und Mythos, in: Krönungen. Könige in Aachen - Geschichte und Mythos. Katalog der Ausstellung. Hrsg. v. Mario Kramp. Bd. 2. Mainz 2000, 839-846. 
Davies hat dann eine Geschichte Europas vorgelegt, die mir in der Tat die äußerste Grenze dessen zu erreichen scheint, was europäische Geschichtsschreibung im Augenblick vermag: Nicht die geschlossene Geschichte eines einheitlichen Gegenstandes, sondern die Abbildung vielfältiger Sonderungen und Zusammenhänge in einer scheinbar willkürlichen, tatsächlich aber höchst treffenden Auswahl von Sachverhalten und Aspekten dieses Objektes. Davies hat sein Werk auch wissenschaftspolitisch richtig plaziert: In der Tat ist es nämlich die vornehmste Aufgabe europäischer Historiker, dem realen Prozeß europäischer Einigung und Friedenswahrung Stabilităt zu verleihen.

Das neugegründete „Institut für vergleichende Geschichte Europas im Mittelalter" soll sich im Sinne meiner Darlegungen nicht auf die Koordination und Anregungen von Forschungsaufgaben oder auf den interdisziplinären und internationalen Meinungsaustausch beschränken; es soll vor allem eine Ruhezone schaffen, in der Monographien zur Geschichte des mittelalterlichen Europa entstehen können. Wir müssen vor allem europäische Geschichte denken lernen, und dazu braucht es Selbstbesinnung jenseits des hektischen Betriebs der etablierten Wissenschaft. Unser Publikum, unsere Leser und Studenten werden uns künftig zurecht immer mehr nach den historischen Gründen fragen, weshalb eine europäische Kooperation der praktischen Politik scheitert oder weshalb man Hoffnungen auf eine Konfliktbewältigung hegen darf. Auf Antworten müssen wir in absehbarer Zeit besser vorbereitet sein, als es bisher möglich war. Gewiß sollten wir unsere Aufgabe in der künftigen Geschichte Europas nicht überschätzen, wir haben aber auch keinen Grund, unseren möglichen Beitrag selbst abzuwerten.

Es ist mein besonderer Wunsch, daß vor allem ausländische und auswärtige Mediävisten auf Zeit hier in Berlin an einem Buch zur Geschichte Europas im Mitteomnenlalter arbeiten können. Vergleichende Geschichte betriebe ja schon, wer seine oder ihre Spezialkenntnisse dabei auf einen anderen, vorher so nicht behandelten europäischen Fall anzuwenden bereit wäre. Wenn es dem neuen Institut gelänge, in dichtem Wechsel europäische Mediävisten anzuziehen und zu derartigen komparativen Studien zu bewegen, könnte diese personelle und sachliche Verschränkung einen Beitrag leisten zu einer europäischen Mittelalterhistorie der Zukunft.

Ich freue mich, heute feststellen zu können, daß das Institut in diesem Sinne seine Arbeit bereits aufgenommen hat. Seit dem letzten Herbst haben zwei Kollegen aus dem Osten und Süden Europas bei uns hospitiert. Aus Litauen war Herr Kollege Stanislovas Pamernecki zu Gast, aus Italien kommend hat sich Frau Kollegin Daniela Rando gar ein volles Jahr Zeit gegeben, um in Berlin über europäisches Mittelalter zu forschen. Sie wird uns über ihre Ergebnisse auf diesem Kolloquium selbst vortragen. Ich lade Sie, liebe Kolleginnen und Kollegen, und alle, denen Sie es weitersagen wollen, ein, ebenfalls nach Berlin zu kommen, um hier auf Zeit zu arbeiten. Wo sich ein wissenschaftliches Interesse dieses Anspruchs äußert, werden sich auch die sachlichen und finanziellen Mittel finden, es zu befriedigen. 



\section{Vergleichende Geschichte und sozialwissenschaftliche Theorie*}

Von

Patrick J. Geary

Meine erste Erfahrung mit vergleichender Geschichte war eine gewisse Enttäuschung. Als sehr unerfahrener Assistant-Professor an der Princeton University vor etwa funfundzwanzig Jahren begann ich, von den Beziehungen zwischen lateinischer, griechischer und slawischer Hagiographie im 12. Jahrhundert fasziniert zu sein. In meiner Dissertation hatte ich die rasche Verbreitung der Erzăhlungen über die Translation des heiligen Nikolaus von Myra nach Bari am Ende des 11. Jahrhunderts untersucht, und ich dachte, es könnte nützlich sein, ein kleines Kolloquium zu organisieren furr Forscher, die in diesen verschiedenen kulturellen Sphären arbeiten, um Anliegen vergleichender Hagiographie zu diskutieren. ${ }^{1}$ Ich präsentierte diese Idee dem damaligen Executive Secretary der Medieval Academy of America. Seine Antwort war knapp und abweisend: „Ich stelle fest, daß einige Leute vergleichende Geschichte schätzen. Ich nicht.“

In den siebziger Jahren spielte vergleichende Geschichte eine große Rolle in der Geschichte, obwohl traditionelle Historiker wie unser Executive Secretary sie ablehnten. ${ }^{2}$ Die Arten von vergleichender Geschichte beruhten, so wie sie von Historikern angewandt wurden, explizit oder implizit auf gewissen Annahmen über den Nutzen von Geschichte, die Natur der untersuchten Phänomene und die theoretischen Parameter des Vergleichens selbst. Die Betonung der Einzigartigkeit von historischen Phänomenen, insbesondere der Verantwortlichkeit von großen Darstellern auf der historischen Bühne, ist traditionellerweise asso-

- Aus dem Amerikanischen übersetzt von Brigitte Pohl-Resl. Für Rat und Tat ist der Verfasser Herm Dr. Caspar Ehlers sehr dankbar.

1 Jetzt Patrick J. Geary, Furta Sacra. Thefts of Relics in the Central Middle Ages. 2. Aufl. Princeton 1990, 94-103.

2 Vgl. z. B. die Debatte über Sozialstruktur und Wirtschaftsentwicklung, die ausgelöst wurde durch einen Aufsatz von Robert Brenner, Agrarian class structure and economic development in pre-industrial europe, in: P \& P 70, 1976, 30-75, und später ihre Fortsetzung in einem Sammelband fand: Trevor $H$. Aston/Charles H. E. Philpin (Ed.), The Brenner Debate. Agrarian Class Structure and Economic Development in Pre-Industrial Europe. Cambridge 1985. Eine kurze Einführung in die vergleichende Geschichte des mittelalterlichen Europa bietet James Given, State and Society in Medieval Europe. Gwynedd and Languedoc under Outside Rule. Ithaca/New York 1990, 11-14. 
ziiert mit einer nationalen, konservativen Auffassung von Geschichte. Vergleichende Studien hingegen werden üblicherweise mit liberalen, oppositionellen Historikern in Zusammenhang gebracht, die mehr daran interessiert sind, Geschichte als Teil einer stärker theoretisch orientierten Kultur- und Sozialgeschichte zu betreiben.

Heute steht die vergleichende Geschichte indessen unter Verdacht. In den letzten Jahrzehnten änderte sich die traditionelle Polarität zwischen Konservativen und Liberalen. $\mathrm{Zu}$ dem Vorwurf der Verallgemeinerung hat sich jedoch eine viel ernstere Anschuldigung gegen vergleichende Geschichte gesellt, nämlich daß sie schädlich sei. Kann es sein, daß der Vergleich die Einmaligkeit des Vergangenen relativiert und potentiell trivialisiert? Ist der Vergleich ein Weg, um die Übel der Vergangenheit zu entschuldigen, indem er nahelegt, daß die Verbrechen und Schrecken alle mehr oder weniger gleich sind? Das war, wie Reinhold Bichler argumentiert hat, der Kern des Historikerstreits: „Gegen die Intention, die Massenvernichtung der NS-Ära zu anderen Massenvernichtungen gerade dieses Jahrhunderts in Beziehung zu setzen und solcherart zu historisieren, wurde die Singularität der NS-Verbrechen gegen die Menschlichkeit geltend gemacht." ${ }^{33}$

Hat der Versuch, das nationalsozialistische Programm der Massenvernichtung von Juden, Roma, Homosexuellen und anderen zu vergleichen, eine implizite Relativierung und somit Verteidigung des Holocaust geschaffen? Aus dieser Sichtweise ist vergleichende Geschichte nicht nur trivial, sondern schädlich, gefährlich gar. Vergleichende Geschichte könnte als eine unmoralische Vorgehensweise gesehen werden, als ein Weg, die Einzigartigkeit und Verantwortlichkeit von Personen und Gesellschaften zu leugnen.

Die Debatte um die Angemessenheit und Möglichkeit des Vergleichs des Holocaust mit anderen zeitgenössischen oder früheren Massakern hat, wie Bichler gezeigt hat, nicht nur mit der unmittelbaren Frage des Holocaust selbst viel zu tun, sondern auch mit der Entwicklung von historischen Traditionen innerhalb der deutschen intellektuellen Strömungen der vergangenen beiden Jahrhunderte. ${ }^{4}$ Nur beim Historikerstreit war das gerade umgekehrt. Daher droht die Idee von vergleichender Geschichte, historische Arbeit von Beginn an zu politisieren.

Heute steht vergleichende Geschichte deshalb teilweise unter Verdacht, nicht nur von Konservativen, sondern auch von Liberalen, die nicht nur das Allgemeine erforschen wollen, sondern auch das Besondere innerhalb bestimmter Gesellschaften. Obwohl die Tradition von vergleichender Geschichte so sein mag, wie Bichler es beschrieben hat, so kann man dennoch argumentieren, daß vergleichende Geschichte nicht immer das Allgemeine gegenüber dem Besonderen hervorheben muß, das Theoretische gegenüber dem Experimentellen. Als einer, der an einigen sehr unterschiedlichen Projekten vergleichender Geschichte teilgenommen hat, würde ich heute gerne mit Thnen über einige Probleme und Herausforderun-

3 Reinhold Bichler, Das Diktum von der historischen Singularităt und der Anspruch des historischen Vergleichs. Bemerkungen zum Thema Individuelles versus Allgemeines und zur langen Geschichte deutschen Historikerstreits, in: Teil und Ganzes, Zum Verhältnis von Einzel- und Gesamtanalyse in Geschichts- und Sozialwissenschaften. Hrsg. v. Karl Acham/Winfried Schulze. (Theorie der Geschichte. Beitrăge zur Historik, Bd. 6.) München 1990, 169-192, hier 170.

4 Ebd. $170 \mathrm{f}$. 
gen für vergleichende Geschichte des Mittelalters nachdenken, die sich aus diesen Erfahrungen fur die Annahmen über die vergleichende Methode, so wie sie in den Sozialwissenschaften anerkannt wird, ergeben.

Entsprechend dem Vorschlag von Adam Przeworski und Henry Teune in einem ,klassischen' - vor dreißig Jahren geäußerten - Statement sozialwissenschaftlicher Methodologie ist der Vergleich kein essentieller Bestandteil sozialer Phänomene, sondern hängt vielmehr vollkommen von der Untersuchungsperspektive ab. ${ }^{5}$ Die Frage ist selbstverständlich nicht, ob man Phänomene vergleichen kann oder nicht, sondern vielmehr, welche Fragen man stellen möchte und was daher im Vergleich erreicht werden soll.

Soziologen und Anthropologen haben eine fertige Antwort auf diese Frage. Vergleichende Untersuchungen wurden lange Zeit zusammen mit Versuchen und statistischen Methoden als eine von drei fundamentalen Formen sozialwissenschaftlicher Methodik betrachtet. In den Worten von Przeworski und Teune sollte und kann sozialwissenschaftliche Forschung, inklusive vergleichender Untersuchungen, zu allgemeinen Aussagen über soziale Phänomene führen. ${ }^{6}$ Diese Annahme impliziert, daß menschliches oder soziales Verhalten mit allgemeinen Gesetzen erklärt werden kann, die durch Beobachtung aufgestellt wurden. Zudem ist der typische Sozialwissenschaftler mehr daran interessiert ist, Phänomene zu erklären, wann und wo auch immer sie auftreten, anstatt so genau wie möglich ihre historischen Umstände zu beschreiben. Daher opfert der sozialwissenschaftliche Vergleich bewußt Genauigkeit zugunsten von Allgemeinheit. Solche vergleichende Studien versuchen nicht das Besondere zu erleuchten, sondern das Allgemeine. Ihre Absicht ist es nicht, irgendeine spezielle Gesellschaft besser zu verstehen, sondern ausgefeilte Theorien menschlichen Verhaltens aufzustellen, theoretische Modelle, die universell und - in gewissem Sinne - voraussagbar sind wie in den Naturwissenschaften. Um wieder Przeworski und Teune zu zitieren: Solche Sozialwissenschaftler beurteilen den relativen Wert von Theorien erstens nach ihrer Angemessenheit, zweitens nach der Allgemeingültigkeit, mit der sie auf ein breites Spektrum menschlicher Gesellschaften angewandt werden können, drittens nach ihrer Einfachheit oder Schlichtheit, also danach, wie gering die Anzahl von Faktoren ist, die eine Erklärung ermöglichen, und viertens nach ihrer Kausalităt, das heißt danach, ob keine zwei Variablen inner-

5 Adam Przeworski/Henry Teune, The Logic of Comparative Social Inquiry. New York 1970, 10: „Social phenomena do not have a property of ,being comparable' or ,not comparable'. ,Comparability' depends upon the level of generality of the language that is applied to express observations." Überlegungen zur vergleichende Methode in den Sozialwissenschaften seit Max Weber bei André F. Köbben, Comparativists and Non-Comparativists Anthropology, in: A Handbook of Method in Cultural Anthropology. Ed. Raoul Naroll/Ronald Cohen. New York 1968, 581-596; Raoul Naroll, Some Thoughts on Comparative Method Cultural Anthropology, in: Methodology in Social Research. Ed. Hubert M. Blalock Jr./Ann B. Blalock. New York 1968, 236-277; Maurice Godelier, The Object and Method of Economic Anthropology, in: Relations of Production. Marxist Approaches to Economic Anthropology. Ed. David Seddon. London 1978, 49-126; Ernest Gellner, The Stakes in Anthropology, in: American Scholar 57, 1988, 17-30.

6 Przeworski/Teune, The Logic (wie Anm. 5), 10: „The pivotal assumption of this analysis is that social science research, including comparative inquiry, should and can lead to a general statements about social phenomena.“ 
halb des Systems denselben Anteil an Variationen erklären und ob das Erklärungsmuster auch dann konstant bleibt, wenn neue Variablen hinzugefugt werden. Von diesen vier Kriterien interessieren den Sozialwissenschaftler Angemessenheit am wenigsten und Allgemeingültigkeit am meisten. ${ }^{7}$

Der Vergleich operiert auf zwei Ebenen. Auf einer vorbereitenden Stufe werden verschiedene Gesellschaften miteinander verglichen oder zumindest für einen Vergleich vorgestellt. Tatsächlich wird der grundlegende Vergleich zwischen einem sorgfältig ausgefuhrten Modell menschlicher Natur oder normativer Reaktion auf die Umwelt durchgefuhrt. Individuelle Fälle werden eher mit diesem Modell verglichen denn untereinander. Letztlich wird ein Modell ausgearbeitet, das furr alle Elemente des Vergleichs passen soll, auch wenn es nur wenige Informationen über die einzelnen Elemente selbst beinhalten mag. Theda Skocpol etwa zieht in ihrem vieldiskutierten Werk über den Vergleich von Revolutionen in Frankreich, Rußland und China drei Variablen in Betracht, um erklärungsmächtige Faktoren in den Gesellschaften zu isolieren, in denen Revolutionen stattfanden (oder nicht): internationalen Druck, die Stellung der Monarchie oder herrschenden Klasse und die Agrarwirtschaft. ${ }^{8}$

Es gibt bestimmt keinen Mangel an derartigen vergleichenden Projekten in der Mittelalterforschung. Am bekanntesten sind wohl die einst populären Versuche, den japanischen und den europäischen Feudalismus zu vergleichen. ${ }^{9}$ In dem Maße, in dem der Verallgemeinerungsgrad stieg, mit dem das japanische und das europäische System der Vergabe von Land an eine Kriegerklasse im Gegenzug furr Kriegsdienste beschrieben werden sollten, sank das Präzisionsniveau, bis schließlich weder Japan noch Europa eindeutig erkennbar waren. Andere kulturübergreifende Studien waren ebenso beliebt, so etwa vergleichende Untersuchungen des Bauernstands oder von religiösen Phänomenen wie dem Pilgertum oder dem Mönchtum. ${ }^{10}$

Vergleichende Ansätze dieser Art sind auf beträchtlichen Widerspruch gestoßen, sowohl bei Historikern als auch unter Soziologen und Anthropologen. Historiker halten dem entgegen, daß Abstraktionen - wie ,Feudalismus' - vielleicht nie existiert haben, und sehen

7 Ebd. 20-23.

8 Theda Skocpol, States and Social Revolutions. A Comparative Analysis of France, Russia, and China. Cambridge 1979. S. dazu Rebecca J. Emigh, The Power of Negative Thinking. The Uses of Negative Case Methodology in the Development of Sociological Theory, in: Theory and Society 26, 1997, 649-684, bes. $652 \mathrm{f}$.

9 Siehe z. B. Archibald R. Lewis, Knights and samurai. Feudalism in northern France and Japan. London 1974; Peter Duus, Feudalism in Japan. New York 1976; Reinhard Zöllner, Die Ludowinger und die Takeda. Feudale Herrschaft in Thüringen und Kai no kuni. Bonn 1995.

10 Siehe etwa Austin B. Creel/Vasudha R. Narayanan (Ed.), Monasticism in the Christian and Hindu Traditions. A Comparative Study. New York 1990. Sehr kluge Überlegungen zu den Schwierigkeiten transkultureller Vergleiche von Phänomenen wie der Pilgerfahrt bei Susan Naquin/Chün-fang Yü, Pilgrims and Sacred Sites in China. Berkeley 1992, 1-9. 
daher wenig Wert darin, ein modernes, anachronistisches Konzept mit einem anderen zu vergleichen. ${ }^{11}$

Ein zweiter Kritikpunkt basiert auf neuen Richtungen in den Sozialwissenschaften, insbesondere in der Anthropologie. Anstatt Verallgemeinerungen zu suchen, beschäftigen sich kulturelle und linguistische Anthropologie lieber mit dem inneren Zusammenhalt von Gesellschaften; eine Art dichter Beschreibung, die Kulturen als einzigartiges Set von voneinander abhängigen Elementen versteht. Die Abstraktion eines dieser Elemente von seinem Kontext bedeutet, sie grundsätzlich unverständlich zu machen. ${ }^{12}$

Als Historiker denke ich nicht daran zu diskutieren, ob dies der ,richtige' Weg ist (oder nicht), um vergleichende Geschichte zu betreiben. Solche Vergleiche gehörten einer Tradition der vergleichenden Geschichte an, die Theda Skocpol und Margaret Somers entweder als „Vergleichende Geschichte als Parallelbeweis einer Theorie“ oder als „Vergleichende Geschichte als makrokausale Analyse" bezeichnen. ${ }^{13}$ Ihre Rolle in der Soziologie und in der Theorie sozialen Handelns ist von großer Bedeutung; ihr Wert furr die Geschichte ist eher umstritten.

Es gibt jedoch andere Strategien und Ziele vergleichender Geschichte, von denen ich glaube, daß sie zu Recht historische Methoden sein können, und zwar den Vergleich von eng miteinander verwandten Phänomenen und Vergleichsarten, die die sozialwissenschaftliche Technik des Vergleichs von nichtverwandten Dingen teilen. Diese Vergleiche, die Theda Skocpol und Margaret Somers als „Vergleichende Geschichte als Kontrastierung von Kontexten" bezeichnen ${ }^{14}$, möchte ich mit einigen kurzen Bemerkungen zu einem Gemeinschaftsprojekt über mittelalterliche höfische Kulturen illustrieren, in das ich in den letzten Jahren involviert war.

Traditionell wird von den beiden Typen vergleichender Untersuchung - entweder von zwei oder mehr sehr ähnlichen Phänomenen oder aber von höchst unterschiedlichen Phänomenen - der erstere als höchst nützlich für Historiker angesehen. Durch den Vergleich von ähnlichen Dingen, die erkennbare gemeinsame Ursprünge haben können, und durch Hervorheben der subtilen Unterschiede gelangt man zu einem feineren Verständnis nicht nur der Differenzen und Ähnlichkeiten, sondern auch der historischen Umstände, die dafür verantwortlich sind. Das war die Art von vergleichender Geschichte, furr die Marc Bloch eingetre-

11 Auch wenn man die Auffassungen von Susan Reynolds nicht völlig teilt, die Feudalismus für eine reine Erfindung der Neuzeit hält: Susan Reynolds, Fiefs and Vassals. The Medieval Evidence Reinterpreted. Oxford 1994.

12 S. dazu Given, State and Society (wie Anm. 2), 13. Eine solche Kritik stützt sich vor allem auf die Kulturanthropologie und insbesondere auf Clifford Geertz; s. Clifford Geertz, The Interpretation of Cultures. New York 1973.

13 Theda Skocpol/Margaret Somers, Uses of Comparative History in Macrosocial Inquiry, in: Comparative Studies in Society and History 22, 1980, 174-197, hier 176: „Comparative history as the parallel demonstration of theory“, und 181: „Comparative history as macro-causal analysis“.

14 Ebd. 178: „Comparative history as the contrast of contexts“. 
ten ist. ${ }^{15}$ Aufbauend auf dem Modell der vergleichenden Sprachwissenschaft argumentierte er, daß man Gesellschaften vergleichen sollte, „die sowohl benachbart und gleichzeitig waren, einander beständig gegenseitig beeinflußten, während ihrer gesamten Entwicklung den Auswirkungen derselben übergreifenden Faktoren ausgesetzt waren, schlicht dadurch, daß sie nahe und gleichzeitig waren, und die ihre Existenz teilweise einem gemeinsamen Ursprung verdankten. ${ }^{16}$ Wertvolle vergleichende Untersuchungen dieser Art gibt es zahlreiche, und sie reichen vom Allgemeinen zum sehr Spezifischen. Da sich die europäische Gesellschaft aus gemeinsamen römischen Traditionen entwickelte, wird die Legitimität vergleichender Geschichte von nachrömischen Gesellschaften allgemein anerkannt. Michael McCormicks Werk Eternal Victory, das Triumphrituale von der Antike bis zum Frühmittelalter sowohl im lateinischen Westen wie im griechischen Osten untersucht, ist eine hervorragende Studie, die zugleich vergleichend ist, indem sie Rituale in den Nachfolgestaaten miteinander und mit römischen Modellen vergleicht, und analytisch, indem sie diese Rituale innerhalb ihres spezifischen Kontexts der verschiedenen Erben der römischen Welt erklärt. ${ }^{17}$

Auf einer noch spezifischeren Ebene befinden sich Untersuchungen über Westeuropa als nachkarolingische Gesellschaft. Von der Elbe bis zum Atlantik, von Spanien bis zum Baltikum waren Institutionen, soziale Ordnung und religiöse Kultur Europas stark beeinflußt von der karolingischen Synthese. Nach dem Zusammenbruch des karolingischen Gemeinwesens blieb diese kulturelle Einheit bestehen - genau genommen besteht sie noch heute - und wurde immer wieder Gegenstand wichtiger Studien. Das ehrgeizigste jüngste Beispiel ist Robert Bartletts Die Geburt Europas aus dem Geist der Gewalt, Eroberung, Kolonisierung und kultureller Wandel 950 bis $1350 .{ }^{18}$ Bartlett untersucht die Errichtung von Staaten, die durch die Eroberung und Besiedlung der keltischen, slawischen und islamischen Gebiete an der Peripherie der einstigen karolingischen Welt geschaffen wurden. Er konstatiert eine große Übereinstimmung darin, wie lateinische christliche Gesellschaften diese Regionen in Besitz nahmen und kolonisierten, Ähnlichkeiten, die nicht nur diese Randgebiete veränderten, sondern auch zu einer wachsenden Vereinheitlichung des Zentrums beitrugen. Andererseits deckt seine Studie auch wichtige Unterschiede auf, insbesondere darin, wie islamische und osteuropäische heidnische Gesellschaften in religiöser und kultureller Hinsicht behandelt wurden.

Weniger ehrgeizig, aber vielleicht präziser justiert sind vergleichende Untersuchungen des nachkarolingischen Europa, die den Umgang verschiedener Regionen im 10. und 11. Jahrhundert mit ihrer Vergangenheit analysieren. Heinrich Fichtenaus Lebensordnungen des 10. Jahrhunderts ist ein Beispiel furr solche Studien, die untersuchen, wie Formen und

15 Marc Bloch, A contribution towards a Comparative History of European Societies, in: Land and Work in Medieval Europe. Selected Papers. New York 1966, 44-81 (zuerst in: Revue de Synthèse Historique, Dec. 1928).

16 Ebd. 47.

17 Michael McCormick, Eternal Victory. Triumphal Rulership in Late Antiquity, Byzantium and the Early Medieval West. Cambridge 1986.

18 Robert Bartlett, The Making of Europe. Conquest, Colonization and Cultural Change 950-1350. Princeton 1993. 
Systeme, die im 8. und 9. Jahrhundert entstanden sind, sich in den folgenden Jahrhunderten in Italien, Frankreich und Deutschland verschieden weiterentwickelten. ${ }^{19}$ Ich selbst habe versucht, Bayern, Neustrien und das Rhône-Tal dahingehend zu vergleichen, wie sich diese drei Regionen mit der Erinnerung an ihre karolingische Vergangenheit zurechtfanden ${ }^{20}$ Man kann sowohl gemeinsame Mechanismen von historischem und liturgischem Gedächtnis als auch die besonderen Eigenschaften dieser Gegenden feststellen, die zu steigendem Partikularismus und regionaler Innovation fuhrten.

Noch geeigneter als Gegenstände vergleichender Studien sind Phänomene, die sich nicht nur aus ähnlichen Ursprüngen herleiten, sondern bewußt diese Traditionen fortführen, auch während sie miteinander in Kontakt sind. Ein erstrangiges Beispiel furr ein derartiges Forschungsgebiet sind die karolingischen Königreiche von Karl dem Kahlen, Lothar I. und Ludwig dem Deutschen im 9. Jahrhundert, insbesondere ihre Höfe. Hier liegt höchstmögliche Ähnlichkeit vor: Alle drei knüpfen bewußt und absichtlich an den Hof ihres Großvaters, Karls des Großen, und ihres Vaters, Ludwigs des Frommen, an. Alle drei erben Personal ebenso wie dieselben administrativen und jurisdiktionellen Strukturen und Traditionen, aber auch Formen der Liturgik und der Selbstrepräsentation. Sie übernehmen bewußt die diplomatischen Gewohnheiten ihres Vaters und Großvaters und gründen ihre Legitimität auf dieses Erbe. ${ }^{21} \mathrm{Da}$ sie ständig miteinander in Kontakt stehen und häufig miteinander konkurrieren, sind sie außerdem sehr aufmerksam darauf, wie sie jeweils mit dem gemeinsamen Erbe umgehen. Und dennoch zeigen sich an den Höfen der Erben Ludwigs des Frommen auffällige Unterschiede, Unterschiede, die uns helfen, nicht einige allgemeine, ahistorische Theorien sozialer Organisation und Änderungen zu verstehen, sondern vielmehr die Besonderheiten der einzelnen Herrscher, die Differenzen in ihrem jeweiligen Erbe, und die unterschiedlichen sozialen und kulturellen Regionen, die sie beherrschen. Hier vollbringt vergleichende Geschichte das Gegenteil von dem, was Sozialwissenschaftler fordern: Anstatt das Besondere zugunsten des Allgemeinen zu opfern, erklärt sie das Besondere durch die Gegenüberstellung mit anderen extrem ähnlichen Phänomenen.

Ohne einen derart detaillierten Vergleich zu versuchen, kann man bestimmte Bereiche skizzieren, in denen der Vergleich zwischen karolingischen Höfen uns helfen kann, die Individualität der einzelnen Höfe richtig einzuschätzen, eine Individualität, die andernfalls leicht übersehen werden könnte. Ein Bereich, der sich offensichtlich zum Vergleichen anbietet, sind die Zentren königlicher Residenz: Ludwig wăhlte Regensburg und dann Frankfurt im Osten; Aachen verschaffte der imperialen Tradition in Lothars Reich neuerliche Geltung; bei Karl hingegen fehlte ein derartiges Zentrum im Westfrankenreich, und er zog es vor,

19 Heinrich Fichtenau, Lebensordnungen des 10. Jahrhunderts. Studien über Denkart und Existenz im einstigen Karolingerreich. 2 Bde. (Monographien zur Gesch. des Mittelalters, Bd. 30.) Stuttgart 1984.

20 Patrick J. Geary, Phantoms of Remembrance. Memory and Oblivion at the End of the First Millennium. Princeton 1994.

21 Allgemein zum karolingischen Hof Josef Fleckenstein, Die Hofkapelle der deutschen Könige. 1. Teil: Grundlegung. Die karolingische Hofkapelle. (MGH Schr., Bd. 16/1.) Stuttgart 1959; ders., Karl der Große und sein Hof, in: Karl der Große. Lebenswerk und Nachleben. Bd. 1: Persönlichkeit und Geschichte. Hrsg. v. Helmut Beumann. Düsseldorf 1965, 24-50. 
zwischen seinen Pfalzen in Pîtres, Servais, Attigny und der Gegend von Paris umherzureisen, bis schließlich gegen Ende seiner Herrschaft Compiègne zu seinem Carlopolis wurde. ${ }^{22}$ Zweitens kann man diplomatische Gepflogenheiten beobachten, die eng verbunden waren, da alle Söhne Personal verwendeten, das aus der Kanzlei Ludwigs des Frommen stammte, aber signifikante Unterschiede in den Legitimationsformeln entwickelte: Lothar behielt die kaiserliche Formel seines Vaters bei - divina ordinante providentia; Karl der Kahle übernahm die von Pippin von Aquitanien - gratia Dei; und Ludwig der Deutsche verwendete die Formel divina largiente gratia bis 833 weiter. Dann ersetzte sie seine Kanzlei mit divina favente clementia. ${ }^{23}$ Kulturelle Produktion, mittels derer der königliche Hof sich selbst darstellte, dient ebenso als wichtiges Vergleichsgebiet. Solche Aktivitäten waren unter Karl dem Kahlen weit verbreitet und betonten die Kontinuität der lateinischen Kultur und des christlichen intellektuellen Werks seines Großvaters ${ }^{24}$, während die Kreise um Ludwig den Deutschen, wenn auch weniger umfassend als im Falle Karls, ausdrücklich die volkssprachlichen, fränkischen Traditionen beanspruchten. ${ }^{25}$ Ein anderes Gebiet der Unterscheidung lag im Ritual des Königtums selbst. Lothar betonte sein kaiserliches Erbe; Karl, der vom Vater die regalia geerbt hatte, machte ausfuhrlich von den symbolischen Attributen des Königtums Gebrauch, während Ludwig angesichts des Fehlens solcher regalia Rituale entwickelte, die eher mit Heerkönigtum assoziiert werden. ${ }^{26}$

Was solche Vergleiche erkennen lassen, wenn sie vollständig ausgearbeitet sind, ist nicht bloß die Universalität einiger sozialwissenschaftlicher Modelle von Königtum, sondern vielmehr genau das, was Sozialwissenschaftler zu vermeiden versuchen, nämlich die Besonderheit der drei regna. Der Vergleich selbst erklärt natürlich nicht die Unterschiede: Sind sie das Ergebnis von verschiedenen Auffassungen über die Rolle der drei Könige oder ihrer Berater? Resultieren sie aus der divergenten Quellenlage zu ihrem Königtum? Oder reflektieren sie die zunehmend unterschiedliche Natur der Gesellschaften in ihren Königreichen?

22 Eugen Ewig, Résidence et capitale pendant le haut moyen âge, in: ders., Spătantikes und frănkisches Gallien. Bd. 1 (Francia, Beih. 3/1.) München 1976, 362-408; Thomas Zotz, Le palais et les élites dans le royaume de Germanie, in: La royauté et les élites dans l'Europe carolingienne (du début du IX ${ }^{e}$ aux environs du 920). Ed. Régine Le Jan. Lille 1998, 233-247; Elsbet Orth, Frankfurt, in: Die deutschen Königspfalzen. Bd. 1: Hessen. Hrsg. v. Thomas Zotz. Göttingen 1986, 131-211; Margaret T. Gibson/Janet L. Nelson (Ed.), Charles the Bald. Court and Kingdom. 2. Aufl. Aldershot 1990; Janet L. Nelson, Charles the Bald. London 1992, 36, 247-248.

23 Herwig Wolfram, Die Legitimationsformel von Ludwig dem Frommen bis zum Ende des 10. Jahrhunderts, in: Intitulatio. Bd. 2: Lateinische Herrscher- und Fürstentitel im neunten und zehnten Jahrhundert. Hrsg. v. dems. (MIÖG, Ergänzungsbd. 24.) Wien 1973, 59-77.

24 Gibson/Nelson, Charles the Bald (wie Anm. 22); Paul E. Dutton/Herbert L. Kessler, The Poetry and Paintings of the First Bible of Charles the Bald. Ann Arbor 1997.

25 Dieter Geuenich, Die volkssprachige Überlieferung der Karolingerzeit aus der Sicht des Historikers, in: DA 39, 1983, 104-130.

26 Eric J. Goldberg, „More Devoted to the Equipment of Battle than the Splendor of Banquets“. Frontier Kingship, Martial Ritual, and Early Knighthood at the Court of Louis the German, in: Viator 30, 1999, 41-78. 
Nur eine spezifische Untersuchung kann solche Fragen beantworten, die Fragen selbst werden aber erst durch den Vergleich geschaffen.

Die ergiebigsten Felder für historische Vergleiche mögen jene sein, die organisch verwandt und relativ homogen sind und somit eine genauere Betrachtung erlauben. In der historischen Forschung ist aber auch Raum für die Art von übergreifender kulturvergleichender Studie, die unzusammenhängende historische Phänomene einander gegenüberstellt. Die Ziele und Methoden eines solchen Vergleichs sind jedoch sehr verschieden vom Bloch'schen Vergleich von ähnlichen, verwandten Phänomenen oder der Suche der Sozialwissenschaftler nach einer „wissenschaftlichen Methodologie“. Ich möchte einige allgemeine Grundzüge skizzieren anhand des Beispiels eines internationalen Projekts, an dem ich beteiligt war, das höfische Kulturen in Japan, China und Westeuropa im Mittelalter vergleicht. ${ }^{27}$

Dieses Projekt ist derzeit in seinem dritten Jahr und bringt Historiker, Philologen und Kunsthistoriker zusammen, um gemeinsame Perspektiven auf die kulturelle Produktion zu entwickeln, die im Umkreis von Zentren politischer Macht in vormodernen Gesellschaften entstanden ist. ${ }^{28}$ Die Vergleichskategorien sind allgemein und beinhalten: erstens Spektakel, das heißt Prunk, Ritual, Spiele, Bekleidung, Hinrichtungen und Jagd; zweitens Geschmack und Empfindungsvermögen, repräsentiert in Umgangsformen, Kennertum, ästhetischen Werten, Mode und Sammlertum; drittens Konstruktionen von Gender und Identität, konkretisiert in Themen wie Frauen, Weiblichkeit und Männlichkeit, Eunuchen, Mönchen, Religion, ritterlichen Kodes; viertens Erzeugung von Tradition, Geschichte und Texten, darunter Bibliotheken, Texte, bibliographische Einteilungen, Anthologien und Maßstäben. Die letzte Kategorie ist die Herausbildung von Wissen in Disziplinen und Professionen wie Medizin, Recht, Kartographie, Naturwissenschaft und Ingenieurswesen.

Die Teilnehmer am Projekt bereiten zu der jeweiligen höfischen Kultur, über die sie arbeiten, Präsentationen der vier Bereiche von kultureller Produktion vor. Ihre Arbeiten versuchen nicht, Vergleichspunkte oder allgemeine Modelle zu erstellen, innerhalb derer solche Vergleiche angestellt werden sollten. Die Intention ist weder, erklärungsmächtige Modelle zu schaffen, anhand derer Unterschiede oder Ähnlichkeiten berechnet werden könnten, noch vom Spektrum der Einzelfälle zu abstrahieren, also verallgemeinernde Vorstellungen über die Beziehung zwischen Machtzentren und kultureller Produktion anzubieten. Statt dessen ist die Absicht des Projekts eine zweifache: Erstens macht das Projekt durch die Präsentation der sehr großen Unterschiede in der Konstruktion und Darstellung von Macht den Teilnehmern mehr denn je die Zufälligkeit der Natur von kultureller Produktion

27 Die Teilnehmer wechseln, sind aber - unter anderen - für China: Pauline $Y u$ (Voices of the song lyric in China. [Studies on China, vol. 18.] Berkeley 1994; The poetry of Wang Wei. New translations and commentary. Bloomington 1980); Stephen H. West (ders./Wilt L. Idema [Ed.], The moon and the zither. The story of the wing. [Hsin k'an ch'i miao ch'üan hsiang chu shih Hsihsiang chi.] Wang Shifu. Berkeley 1991); David R. Knechtges (The Han rhapsody. A study of the fu of Yang Hsiung. 53 B. C. A. D. 18. Cambridge 1976); furr Japan: Robert Borgen (Sugawara no Michizane and the early Heian court. Cambridge, Mass. 1986); Stephen D. Carter (Regent redux. A life of the statesman-scholar Ichijo Kaneyoshi. [Michigan monograph series in Japanese studies, vol. 16.] Ann Arbor 1996). 
innerhalb ihres spezifischen kulturellen Systems bewußt. Untersuchungen über die Ursprünge von chinesischen Beamtenprüfungen unter der Herrschaft des Tang-Kaisers Xuanzong zum Beispiel informieren uns nicht über irgendwelche allgemeinen Regeln der Ausbildung zum Dienst am Hof, aber sie machen einem westlichen Historiker mit Sicherheit die Alternativen zum karolingischen Bildungsprogramm bewußt.

Die Prämissen und die Zugangsweise dieses vergleichenden Projekts unterscheiden sich signifikant sowohl von den vergleichenden Untersuchungen der nahe verwandten karolingischen Hofkulturen, die ich beschrieben habe, als auch von traditionellen sozialwissenschaftlichen Vergleichsstudien. Die Unterschiede zu den ersteren sind offensichtlich: Die Teilnehmer untersuchen Kulturen, die keine geographische Nähe aufweisen und die sich in vollkommener Unabhängigkeit voneinander entwickeln. Die Divergenzen zwischen den Höfen sind enorm: Während karolingische Höfe nur lose organisiert waren und allenfalls wenige hundert, überwiegend umherziehende Höflinge zählten, waren Tang-Höfe höchst organisierte Bürokratien mit Tausenden von Angehörigen, die mittels eines komplexen Systems der Rekrutierung und Ausbildung an eine bestimmte kaiserliche Hauptstadt herangezogen wurden.

Anders als der Vergleich, auf den sich Sozialwissenschaftler stützten, die universelle Gesetze entdecken wollten, wie auch Marc Blochs Vergleich, der Unterschiede zwischen nahe verwandten Phänomenen zu verstehen sucht, zielt diese Art des Vergleichs darauf, Unterschiede sichtbar zu machen, die die Gelehrten zu einer Neubewertung ihrer grundsätzlichen Prämissen über die Natur der menschlichen Kulturen bewegen könnten. Ein solcher Vergleich erweitert den Sinn der Gelehrten für das Mögliche; er zwingt uns, die historische Zufälligkeit der Phänomene, die wir untersuchen, zu erkennen. Der Wert eines derartigen vergleichenden Projekts liegt weniger in den erzielten Ergebnissen als in der Dynamik der Diskussion, in der gründlichen Untersuchung (und Nachfragen) über kulturelle Grenzen hinweg. Sein Zweck ist heuristischer, nicht beweisender oder instrumenteller Art. Unsere Hoffnung ist, daß die Teilnehmer zu ihren eigenen Studiengebieten - den karolingischen Höfen, den adeligen Höfen der Champagne, den bischöflichen Höfen des Rheinlandes oder den Höfen in China und Japan - zurückkehren werden mit einer Reihe von subtileren und scharfsinnigeren Fragen, die sie an ihre eigene Arbeit stellen werden.

Beide Vergleiche, der von sehr ähnlichen Phänomenen und der von sehr unterschiedlichen, haben ihren Stellenwert in historischen Untersuchungen. Sie können zu einem Rhythmus innerhalb der Forschung verhelfen, der durch systematische Interaktion mit dem Gleichen und mit dem Verschiedenen Gelehrte nicht die ewigen Wahrheiten der menschlichen Existenz besser verstehen läßt, dafür aber deren jeweilige Besonderheiten, die der Kern von Geschichte sind. 


\title{
Stände und Gruppen
}

\section{Über das Europäische in der europäischen Geschichte}

von

\author{
Otto Gerhard Oexle
}

Die Frage, was das Europäische in der europäischen Geschichte sei, ist schon sehr oft gestellt worden. In letzter Zeit geschieht es mit noch zunehmender Häufigkeit, was nicht überrascht. Für eine wissenschaftliche Erörterung des Themas auf der ,Zweiten Ebene ${ }^{\text {"1 }}$ wären allerdings erst einmal Inventare und Topologien der vielen bereits vorliegenden Antworten nützlich. ${ }^{2}$ Erst recht fehlen vergleichende Analysen, die aufschlußreich sein könnten, wenn es um die Ermittlung der Horizonte nationaler Wissenschafts-Kulturen geht, von denen her Historiker diese Frage stellen und beantworten. ${ }^{3}$

Viele der immer wieder aufs Neue gegebenen Antworten sind seit langem bekannt, zum Beispiel der Hinweis auf die Bedeutung des nationalen Staates ${ }^{4}$ und der Staatenkonkurrenz, oder auf die Singularität einer Institution wie der des Papsttums in der okzidentalen Kirche und die Bedeutung der Polarität des Gegensatzes von Papsttum und weltlicher Herrschaft im Okzident. Besonderer Beliebtheit erfreuen sich die monokausalen Erklärungsmuster. ${ }^{5} \mathrm{Da}$ wird zum Beispiel das Profil schon des mittelalterlichen Europa aus dem ökonomischen Wachstum erklärt, oder aus den naturräumlichen, also physisch-geographischen und klimati-

1 Wolfgang Schmale, Europäische Geschichte als historische Disziplin. Überlegungen zu einer „Europăistik", in: ZfG 46, 1998, 398-405.

$2 \mathrm{Karl} W$. Deutsch, On Nationalism, World Regions and the Nature of the West, in: Mobilization, CenterPeriphery Structures and Nation-Building. Ed. Per Torsvik. Bergen/Oslo/Tromsö 1981, 51-93; Otto Gerhard Oexle, Mittelalterliche Grundlagen des modernen Europa, in: Was ist der Europäer Geschichte? Beiträge zu einer historischen Orientierung im Prozeß der europăischen Einigung. Hrsg. v. Jörg Calließ. (Loccumer Protokolle, Bd. 67.) Rehburg-Loccum 1991, 17-60; Michael Mitterauer, Die Entwicklung Europas - ein Sonderweg? Legitimationsideologien und die Diskussion der Wissenschaft. Wien 1999; Michael Borgolte, „Europa ein christliches Land“. Religion als Weltstifterin im Mittelalter?, in: ZfG 48, 2000, 1061-1077.

3 Dazu die Beitrăge des Bandes: Natalie Fryde/Pierre Monnet/Otto Gerhard Oexle (Hrsg.), Die Gegenwart des Feudalismus (im Druck).

4 Jacques Le Goff, Das Alte Europa und die Welt der Moderne. München 1994.

5 Mitterauer, Die Entwicklung Europas (wie Anm. 2), $30 \mathrm{ff}$. 
schen Bedingungen; oder es werden agrartechnische Innovationen wie die Dreifelderwirtschaft und die Formen der Haustierhaltung oder die technische Entwicklung von Rad, Pflug und Wassermühle, von Kummet und Hufeisen und des Steigbügels, des Schießpulvers, des Kompasses und des Buchdrucks in den Vordergrund gerückt. Zu diesen monokausalen und materialistisch-reduktionistischen Thesen gehört auch die seinerzeit vielerörterte These des englischen Anthropologen Jack Goody in seinem Buch über Die Entwicklung von Ehe und Familie in Europa (1983): daß nämlich die Römische Kirche zwecks Vermehrung ihres Besitzes im Frühmittelalter Verwandtenheiraten immer mehr eingeschränkt habe, wodurch die Weiterentwicklung von Ehe und Familie in Europa in einer entscheidenden und ganz spezifischen Weise beeinflußt worden sei.

Gegenüber solchen monokausalen Erklärungsmodellen sind die multikausalen entschieden vorzuziehen, vor allem dann, wenn sie eine Vielzahl von unterschiedlichen Faktoren in ihrer wechselseiten Vernetzung berücksichtigen. Im Hinblick auf solche Ansätze wäre noch immer vor allem an das Spätwerk des Historikers Otto Hintze um 1930 zu erinnern, zum Beispiel an seine große Abhandlung über Weltgeschichtliche Bedingungen der Repräsentativverfassung von 1931, und an das Euvre eines Max Weber, das auch unter solchen Fragestellungen noch immer zu wenig Beachtung gefunden hat oder nur unter partiellen Aspekten rezipiert wurde, zum Beispiel nur im Hinblick auf die vielzitierte Protestantismus-Kapitalismus-These oder nur im Hinblick auf Webers angebliches Theorem von der ,Rationalisierung' als einem durchgehenden Moment der europäischen Geschichte. Am weitreichendsten und umfassendsten erscheinen mir jene Analysen und Erklärungen, in denen ,Religion' als Faktor der Geschichte in die Überlegungen einbezogen wird; ist doch ,Religion' jener Bereich, in dem das Denken und Handeln von Individuen und Gruppen am tiefsten bestimmt wird und von dem deshalb besonders weitreichende und spezifischen Wirkungen ausgegangen sind, fundamentale Werte in Bindung, Emanzipation und Freiheit, in Individualismus, Universalismus und Verantwortung. ${ }^{6}$

Einen wichtigen Beitrag anderer Art hat zu diesem Thema der französische Historiker und Soziologe Edgar Morin in seinem Buch Penser l'Europe von 1987 beigesteuert. ${ }^{7}$ Morin macht deutlich, wie schwierig es ist, „Europa von Europa selbst aus zu erfassen“. „Der Europäer ist sich nicht bewußt, wie schwierig es ist, sich selber zu begreifen und zu relativieren, und genau dies führte zu einem Pseudo-Bewußtsein, demzufolge Europa der sonnengleiche Mittelpunkt der universalen Vernunft ist. Diese Sichtweise täuschte uns über jene dunklen und unbewußten Seiten hinweg, die unser Einsichtsvermögen und unser Gefühl für das Universale beeinträchtigen". Morin wendet sich deshalb gegen alle Formen der Idealisierung, Abstrahierung oder Reduzierung Europas, die einer „Verstümmelung“ gleichkämen. Er spricht sich gegen die „geschlossenen Konzepte“ und alle „mechanistischen, linearen und streng deterministischen“ Erklärungsmuster und ,jene verengten Konzeptionen“ aus, „die das Ganze in den einzelnen Bestandteilen oder die einzelnen Teile in dem sie umfassenden

6 Arnold Angenendt, Geschichte der Religiosităt im Mittelalter. Darmstadt 1997, 756 ff.

7 Edgar Morin, Penser l'Europe, Paris 1987; dt.: Europa denken. Frankfurt a. M. 1991. Die folgenden Zitate hier $17 \mathrm{ff}$. 
Ganzen ersticken“. „Europa“ sei vielmehr ein „Komplex“, der „die größten Unterschiede in sich vereinigt, ohne sie zu vermengen, und Gegensätze untrennbar miteinander verbindet". Und immer wenn man versuche, eine klar definierte Vorstellung von Europa zu gewinnen, beginne alles $\mathrm{zu}$ verschwimmen. Sobald man Europa als Einheit zu erkennen glaube, beginne es zu zerfallen. Denn: „Eine Einheit repräsentiert Europa nur in und durch seine Vielgestaltigkeit.“ Man müsse also die Idee von einem einheitlichen, klar abgegrenzten Europa aufgeben, „die Vorstellung einer europäischen Uressenz oder -substanz widerlegen“. Im Gegenteil: Gerade die „Uneinigkeit“, die Widersprüchlichkeit mache Europa aus. Europa könne eigentlich nur als eine „Identităt in der Nicht-Identität“ gedacht werden. Dies sei möglich, wenn man als Prinzip der Intelligibilităt das „Prinzip der Dialogik“ wăhle. Das bedeute, daß zwei oder mehr verschiedene Arten von ,Logik' in komplexer Weise (komplementär, konkurrierend oder antagonistisch) in einer Einheit miteinander verbunden sind, ohne daß sich die Dualităt in der Einheit verliere. Ja, die Besonderheit der europäischen Kultur liege sogar „vor allem in der Kontinuität und Intensităt ihrer ,Dialogiken“, bei denen niemals eines der konstituierenden Elemente die anderen erdrückt oder vernichtet noch für längere Zeit eine erstickende Hegimonialherrschaft ausübt" ${ }^{8}{ }^{8}$ Das Wichtige an der europäischen Kultur seien deshalb nicht nur ihre Schlüsselideen, sondern vielmehr die Tatsache, „daß alle diese Ideen auch Gegensätze haben“. Das eigentlich Europäische liege deshalb nicht nur in der Vielfalt und im Wandel, sondern ,im Dialog innerhalb dieser Vielfalt, der letztlich den Wandel bewirkt“. Es gehe um die Erkenntnis des „befruchtenden Aufeinandertreffens von Unterschieden, Antagonismen, Konkurrenzen und Komplementaritäten“. Nicht dieser oder jener Bestandteil oder Augenblick der europäischen Geschichte sei das konstitutiv Europäische, - es sei vielmehr die jeweilige „Dialogik', die das „entscheidende Charakteristikum der kulturellen Identität Europas" darstellt.

Ich denke, daß die Überlegungen Edgar Morins auch für komparatistische Fragestellungen relevant sind, gleichgültig, ob diese sich auf eine europa-interne Komparatistik beziehen oder auf den Vergleich der europäischen Kultur mit anderen Kulturen. ${ }^{9}$ Dazu im folgenden einige Überlegungen im Blick auf Stände und soziale Gruppen.

\section{Stände}

Der Begriff des ,Standes' (ordo, status) in den Gesellschaften des alten Europa hat metaphysischen Rang. ${ }^{10}$ Dies war schon in der Antike so und es gilt auch noch für die frühe Neuzeit.

8 Ebd. $127 \mathrm{f}$.

9 Dazu in dem hier vorliegenden Band die Beiträge von Michael Borgolte und Patrick Geary.

10 Zum folgenden Otto Gerhard Oexle, Deutungsschemata der sozialen Wirklichkeit im frühen und hohen Mittelalter. Ein Beitrag zur Geschichte des Wissens, in: Mentalitäten im Mittelalter. Methodische und inhaltliche Probleme. Hrsg. v. Frantisek Graus. (VuF, Bd. 35.) Sigmaringen 1987, 65-117. Vgl. ders., Perceiving Social Reality in the Early und High Middle Ages. A Contribution to a History of Social Knowledge, in: Ordering Medieval Society. Perspectives on Intellectual and Practical Modes of Shaping Social Relations. Ed. Bernhard Jussen. Philadelphia 2001, 92-143. Außerdem: ders., Art. 
Grundlegend ist dabei der Gedanke, daß ,Stände' Teile eines geordneten, von Gott geschaffenen Kosmos sind, dessen Schönheit und Ordnung (ordo) eben darin besteht und sichtbar wird, daß die einzelnen Teile untereinander sehr verschieden sind und daß jeder Teil an der Stelle steht, die für ihn vorgesehen ist. Die berühmte Reflexion des Augustinus im 19. Buch von De civitate Dei über pax und tranquillitas ordinis, über Frieden als das ,geordnete Zusammenstimmen der Teile" in Eintracht (concordia) (De civitate Dei, XIX, 13), bringt dies unübertroffen, repräsentativ auch für alle folgenden Jahrhunderte und mit stets neuen großen Wirkungen zum Ausdruck. Reflexion über Stände bedeutet somit Reflexion über Harmonie in der Ungleichheit. Dem Denken der Moderne seit dem 18. Jahrhundert ist dies in fundamentaler Weise fremd, - ebenso wie die aus dieser Ständereflexion sich ergebende Ethik fur jeden Stand und jeden einzelnen Menschen, insofern er ,seinem' Stand angehört. Denn deren Grundmaxime lautet: Jeder tue „das Seine“, nämlich das, „wozu er sich seiner Natur nach am geschicktesten eignet". In diesem Falle stammt die exemplarische Formulierung von Plato (Politeia, 433a). Ganz in diesem Sinne hat noch im 17. Jahrhundert der lutherische Pastor Johann Heermann (1585-1647) die auch heute noch gesungene Strophe seines Liedes gedichtet (man ,hört' es in der musikalischen Fassung von Johann Sebastian Bach): „Gib, daß ich tu mit Fleiß, / was mir zu tun gebühret, / wozu mich dein Befehl / in meinem Stande fuhret".

Stände und Ständeordnungen sind ,gedachte' Wirklichkeiten und gerade darin beruht ihre konstitutive Wirkung: in der Begründung von Formen der Lebensführung, in der Begründung einer jeweils spezifischen ,Kultur' mit den ihr eigenen spezifischen Denkformen, Maximen des Handelns und Institutionen, mit Privilegien, sozialer Schätzung („Ehre“), mit Erziehungsweisen und besonderem Abstammungs- oder Berufsprestige. Die Geschichte des Okzident zeigt auf vielfältige Weise, wie Stände entstehen und wie sie wirken, am eindrucksvollsten vielleicht am Beispiel der Entstehung eines Kleriker-Standes seit dem ersten Jahrhundert: ${ }^{11}$ von dem Gedanken der Unterscheidung eines ,Klerus' von den ,Laien' über die Entwicklung spezifischer Formen der Lebensführung und der rechtlichen Privilegierung bis hin zur Formulierung einer eigenen Standes-Moral, nämlich der des Zölibats, die den Lebensformen des Mönchtums entlehnt wurde. Treffend ist gesagt worden, daß dieser Klerus zum „Vorbild aller privilegierten Stände“ in Europa wurde (Otto Hintze), auch bei der Entstehung eines Bauern- und eines Ritter-Standes. ${ }^{12}$ Die außerordentliche Komplexität von Ständebildungen als einem sozial- und mentalitätsgeschichtlichen Prozeß hat Bernhard Jussen jüngst am Beispiel der ,Witwe' gezeigt. ${ }^{13}$ Die Gesamtheit einer ständischen Ordnung in der Vielheit einzelner Stände wurde immer wieder aufs neue in Sozialmetaphern (zum Beispiel der des Körpers) und in Deutungsschemata der sozialen Wirklichkeit beschrieben. Von diesen ist das Deutungsschema der sogenannten ,funktionalen Dreiteilung' wohl das

Stand, Klasse (Antike und Mittelalter), in: Geschichtliche Grundbegriffe. Hrsg. v. Otto Brunner/Werner Conze/Reinhard Koselleck. Bd. 6. Stuttgart 1990, 156-200.

11 Oexle, Deutungsschemata (wie Anm. 10), 86 ff.

12 Ebd. $89 \mathrm{ff}$.

13 Bernhard Jussen, Der Name der Witwe. Erkundungen zur Semantik der mittelalterlichen Bußkultur. (VMPIG, Bd. 158.) Göttingen 2000. 
bedeutendste ${ }^{14}$, einerseits durch die ,lange Dauer', die es vom Fruhmittelalter bis zum Ende des Ancien Régime beanspruchte; andererseits durch die von ihm ausgehende Kraft der Institutionenbildung; und schließlich durch die diesem Konzept eigene Form, wonach ständische Ordnung nicht nur eine absolute, ,ontische‘ Gegenüberstellung, sondern auch ein funktionales Moment wechselseitiger ,Dienste‘ implizieren kann.

Für komparatistische Studien erweist sich dabei die Phasenverschiebung in der Durchsetzung eines Schemas als bedeutsam, wie sie sich zum Beispiel im Blick auf die funktionale Dreiteilung zwischen Frankreich und Deutschland beobachten läßt ${ }^{15}$; auch ist nach funktionalen Äquivalenten zu fragen, wie sie offenbar der ,Dritte Stand' in Frankreich und der ,Gemeine Mann ${ }^{616}$ in Deutschland darstellen. Vergleiche zwischen der okzidentalen Kultur und ihren Nachbarkulturen sind auf diesem Gebiet noch kaum systematisch in Angriff genommen worden. ${ }^{17}$ Welche Vorstellungen von Ständen und Ständeordnungen begegnen in den islamischen Gesellschaften oder in Byzanz, und worin wird darin ein gemeinsames antikes Erbe, worin werden jeweils Unterschiede sichtbar?

Für diese Frage dürfte die Differenz zwischen Antike und Mittelalter, dürften die unterschiedlichen Formen der Rezeption der Antike in den verschiedenen Kulturen von Bedeutung sein. Für die okzidentale Kultur war entscheidend, in welchem Maß die (für einen Plato, einen Aristoteles, einen Cicero undenkbare) positive Bewertung der körperlichen Arbeit und der Armut, die das Christentum vom Judentum geerbt hatte, seit der Spätantike in der Universalisierung des Christentums allmählich mit durchgesetzt wurde. ,Arbeit ${ }^{\star}$, ,Armut ${ }^{6}$ und ,Stand' treten damit in ein spannungsreiches Verhältnis zueinander. ${ }^{18}$ Die Entstehung eines ,Bauern'-Standes, eines ,Bürger'-Standes, eines ,Dritten' Standes - allesamt durch körperliche Arbeit definiert - ist ohne diese fundamentale Umwertung der Werte undenkbar. Und: wesentliche Momente der okzidentalen ,Dialogiken' über gesellschaftliche ,Ordnung

14 Oexle, Deutungsschemata (wie Anm. 10), 89 ff. Zuletzt Roberto Delle Donne, Introduzione, in: Otto Gerhard Oexle, Paradigmi del sociale. Adalberone di Laon e la società tripartita del Medioevo. Introduzione e traduzione italiana di Roberto Delle Donne, Salerno 2000, 9-34. - Über den Zusammenhang von Deutungsschema der sozialen Wirklichkeit und Institutionenbildung: Otto Gerhard Oexle, Die Entstehung politischer Stände im Spätmittelalter - Wirklichkeit und Wissen, in: Institutionen und Ereignis. Über historische Praktiken und Vorstellungen gesellschaftlichen Ordnens. Hrsg. v. Reinhard Blänkner/Bernhard Jussen. (VMPIG, Bd. 128.) Göttingen 1998, 137-162.

15 Vgl. Otto Gerhard Oexle, Die funktionale Dreiteilung als Deutungsschema der sozialen Wirklichkeit in der ständischen Gesellschaft des Mittelalters, in: Stăndische Gesellschaft und soziale Mobilităt. Hrsg. v. Winfried Schulze. (Schriften des Hist. Kollegs, Kolloquien, Bd. 12.) München 1988, 19-51.

16 Zum Begriff des ,Gemeinen Mannes' zuletzt Peter Blickle, Kommunalismus. Skizzen einer gesellschaftlichen Organisationsform. 2 Bde. München 2000, passim.

17 Vgl. dazu die Überlegungen von Antony Black, Islamic und European political thought. A comparative overview, 700-1650, in: Political Thought and the Realities of Power in the Middle Ages / Politisches Denken und die Wirklichkeit der Macht im Mittelalter. Hrsg. v. Joseph Canning/Otto Gerhard Oexle. (VMPIG, Bd. 147.) Göttingen 1998, 269-276.

18 Otto Gerhard Oexle, Arbeit, Armut, ,Stand' im Mittelalter, in: Geschichte und Zukunft der Arbeit. Hrsg. v. Jürgen Kocka/Claus Offe. Frankfurt a. M/New York 2000, 67-79. 
sind davon bestimmt. Wie aber steht es mit der ständebildenden Dynamik der Wahrnehmung körperlicher Arbeit in anderen Kulturen als der des Okzidents?

Dazu kommt ein zweites Moment, das furr die Begründung unterschiedlicher ,Dialogiken innerhalb des Okzidents von nicht geringer Bedeutung war. Es ist darin begründet, daß das Christentum sowohl die von der Antike bekannten Formen des ständischen Denkens propagierte als auch diese zugleich immer wieder aufgehoben hat. ${ }^{19}$ Es gibt im Christentum eine fundamentale Dynamik der Konstituierung von Ständen und ihrer Aufhebung zugleich. Man kann dies exemplarisch zeigen an den in den folgenden Jahrhunderten so unendlich oft zitierten und kommentierten Aussagen über Stände im ersten Brief des Paulus an die Gemeinde in Korinth. Jeder bleibe in seinem Stande, so heißt es hier (1. Kor. 7,24; vgl. 7,17 u. 7,20), und jeder wird ,in seinem Stande“ (in suo ordine) auferstehen (ebd. 15,23). Diese Bedeutung des Standes für die innere Ordnung der Gemeinde wird im zwölften Kapitel des Briefes mit Hilfe der antiken Körpermetapher dargelegt, wonach auch die christliche Gemeinde ein Körper ist, dessen Glieder ungleiche Aufgaben haben und gerade in dieser Ungleichheit einträchtig zusammenwirken sollen, da Gott jedem seine spezifische Aufgabe gegeben hat (ebd. 12,18; 12,25). Zugleich aber wird die dem entgegengesetzte Maxime, wird die Umkehrung dieser ständischen Gliederung formuliert. Denn, wie der Apostel erläutert, haben gerade jene Glieder, welche die schwächeren und niedrigeren Dienste verrichten, den höheren Rang und die größere Bedeutung für das Ganze. Die infirmiora (nämlich: membra corporis) sind die necessariora, und den ignobiliora membra, ja sogar den inhonesta gebührt der honor abundantior (12,22 ff.). Dies fuhrt der Apostel noch weiter aus mit dem Gedanken, daß Gott seine Berufung nicht an die Hochweisen, Hochmächtigen und Hochedlen ergehen ließ, sondern daß er das Törichte erwählte, das Schwache, das Ehrlose, das Verachtete und das Niedrige (ebd. 1,26-29). Und schließlich wird jede ständische Ordnung überhaupt aufgehoben. Denn die Berufung des Menschen zu seinem Heil werde nicht durch ständische Unterschiede definiert, wie Paulus anhand der Unterscheidung von Herren und Sklaven, von Sklaven und Freien darlegt (ebd. 7,22). Freilich bedarf es keiner formlichen Aufhebung dieser Ständeunterschiede mehr. Denn: die Gestalt dieser Welt vergeht (ebd. 7,31 ), - so daß es also dabei bleibt, daß jeder in seinem Stande verbleibe. Und so schließt sich der Kreis der Überlegungen des Apostels: Es sind Überlegungen und Reflexionen über eine polare Spannung, eben die Konstituierung von Ständen und deren Aufhebung zugleich - oder umgekehrt.

Die Wirkungen solcher Gegensätze lassen sich im okzidentalen Mittelalter als konkrete soziale ,Dialogiken' an vielen dramatischen Beispielen gut beobachten. ${ }^{20}$

19 Darüber Otto Gerhard Oexle, „Die Statik ist ein Grundzug des mittelalterlichen Bewußtseins“. Die Wahrnehmung sozialen Wandels im Denken des Mittelalters und das Problem ihrer Deutung, in: Sozialer Wandel im Mittelalter. Wahrnehmungsformen, Erklärungsmuster, Regelungsmechanismen. Hrsg. v. Jürgen Miethke/Klaus Schreiner. Sigmaringen 1994, 45-70, hier $66 \mathrm{ff}$.

Ebd. $68 \mathrm{ff}$. 


\section{Soziale Gruppen}

Jeder Stand repräsentiert eine spezifische Kultur und Wert-Welt, und alle Stände-Ordnungen stellen Ordnungen solcher jeweils verschiedener Wert-Welten dar. Diese Vielzahl der WertWelten in der mittelalterlichen Gesellschaft vermehrt sich, sobald wir nicht nur Stände, sondern auch soziale Gruppen in unsere Überlegungen einbeziehen. ${ }^{21}$ Die Analyse der mittelalterlichen Gesellschaft als einer Gruppen-Gesellschaft ist, gegenüber dem Aspekt der Stände-Gesellschaft, noch zu wenig entfaltet.

Auch soziale Gruppen repräsentieren eine jeweils spezifische ,Kultur', sie repräsentieren spezifische Wertvorstellungen, Formen des sozialen Handeln und der Institutionenbildung, sie erzeugen spezifische Repräsentationen. ${ }^{22}$ Am Beispiel des ,Hauses' (oikos, domus) hat dies Ulrich Meyer für die Zeit von der Spätantike und des frühen und hohen Mittelalters bis zum 12. Jahrhundert, also noch vor der Rezeption der antiken Lehren vom ,Haus ${ }^{6}$ gezeigt $^{23}$ und dabei die Debatten über die Welt als ,Haus' und die Heilsökonomie, über Eigentum und Herrschaft, oder über die Gemeinde als ,Haus` und über ,Gesellschaft‘ und ,Stände` erstmals umfassend dargelegt. Ganz andere Formen von Weltbildern, Praxis, Institutionen und der Repräsentation eignen Verwandtengruppen, also zum Beispiel den ,Geschlechtern' des Adels, ${ }^{24}$ oder aber solchen Gruppen, die auf Konsens und Vertrag der Individuen beruhen, zu denen die ,Conjuratio', die ,Vita apostolica' und die Vasallität gehören. ${ }^{25}$

Die Wirkungen sozialer Gruppen vom Typus der Gruppenbildung durch Konsens und Vertrag liegen vor allem darin beschlossen, daß es die soziale Praxis, das Alltagshandeln und Alltagsleben selbst sind, die die Individuen zum Zusammenschluß und damit zur Hervorbringung von entsprechenden Wert-Systemen und spezifischen Institutionen bewegen. ${ }^{26}$ Für unsere Frage nach dem spezifischen Profil der okzidentalen Kultur und ihren ,Dialogiken' ist dabei wichtig, daß diese verschiedenen Gruppen-Kulturen sich untereinan-

21 Otto Gerhard Oexle, Soziale Gruppen in der Ständegesellschaft: Lebensformen des Mittelalters und ihre historischen Wirkungen, in: Die Repräsentation der Gruppen. Texte - Bilder - Objekte. Hrsg. v. Otto Gerhard Oexle/Andrea von Hülsen-Esch. (VMPIG, Bd. 141.) Göttingen 1998, 9-44.

22 Dazu der in Anm. 21 genannte Band: Die Repräsentation der Gruppen.

23 Ulrich Meyer, Soziales Handeln im Zeichen des ,Hauses'. Zur Ökonomik in der Spätantike und im früheren Mittelalter. (VMPIG, Bd. 140.) Göttingen 1998.

24 Otto Gerhard Oexle, Welfische Memoria. Zugleich ein Beitrag über adlige Hausüberlieferung und die Kriterien ihre Erforschung, in: Die Welfen und ihr Braunschweiger Hof im hohen Mittelalter. Hrsg. v. Bernd Schneidmüller. (Wolfenbütteler Mittelalter-Studien, Bd. 7.) Wiesbaden 1995, 61-94; ders., Kulturelles Gedächtnis in der Renaissance. Die Fugger-Kapelle bei St. Anna in Augsburg. Vierte Sigurd Greven-Vorlesung, gehalten am 11. Mai 2000 im Schnütgen-Museum Köln. Köln 2000; Tanja Michalsky, Memoria und Repräsentation. Die Grabmäler des Königshauses Anjou in Italien. (VMPIG, Bd. 157.) Göttingen 2000.

25 Dazu Oexle, Soziale Gruppen in der Ständegesellschaft (wie Anm. 21), 25 ff.

26 Otto Gerhard Oexle, Friede durch Verschwörung, in: Träger und Instrumentarien des Friedens im hohen und späten Mittelalter. Hrsg. v. Johannes Fried. (VuF, Bd. 43.) Sigmaringen 1996, 115-150. Vgl. ders., Peace Through Conspiracy, in: Ordering Medieval Society (wie Anm. 10), 285-322; Christoph Anz, Gilden im mittelalterlichen Skandinavien. (VMPIG, Bd. 139.) Göttingen 1998. 
der in einer Konkurrenz befinden, daß also verschiedene Wert-Welten in Konkurrenz das Alltagsleben bestimmt haben. Auf die Gefahr des Eurozentrismus hin sei festgestellt, daß im Okzident offensichtlich Konsens- und Vertragsgruppen eine besondere Bedeutung hatten ${ }^{27}$. Dies ist am Beispiel der ,Conjuratio' in ihren Erscheinungsformen der ,Assoziation" (,Gilde') und der ,Gemeinde' (,Kommune') deutlich erkennbar. ${ }^{28}$ In Byzanz gibt es Hochschulen, aber keine Universitäten; Handwerkervereinigungen, aber keine Zünfte; Städte, aber keine Stadtgemeinden. ${ }^{29}$ Schließlich ist auch darauf aufmerksam zu machen, daß die okzidentale Stadt als eine Kommune und das heißt auch: als eine ,Gruppe von Gruppen' eine Form der ,Vergesellschaftung' bildet, in der ,Gesellschaft' im modernen Sinn zum ersten Mal historisch in Erscheinung getreten ist. ${ }^{30}$

Der Rechtshistoriker Gerhard Dilcher hat in seiner 1999 veröffentlichten, großen Rechtsgeschichte der Stadt auf die „revolutionäre Bedeutung der Bildung kommunal verfaßßter Städte in Europa seit dem 12. Jahrhundert für den Begriff einer Gesellschaft" hingewiesen, und ebenso darauf, daß angesichts des ,häufig wahllosen Gebrauchs des Gesellschaftsbegriffs für das Mittelalter" dieser Sachverhalt bisher ,selten thematisiert" wurde. Es ist aber die mittelalterliche kommunale Stadt, in der eine wirkliche „Vergesellschaftung" stattfand: „über nahes Zusammenwohnen, Bürgerversammlungen, politische und rechtliche Willensbildung, Markt und andere Wirtschaftsbeziehungen“. ${ }^{31}$ Dies liegt einerseits daran, daß die mittelalterliche Stadt „,elbst eine Genossenschaft“ ist, andererseits daran, daß sich ,in ihrem Rahmen (...) als innere Struktur ein reiches internes genossenschaftliches Leben“ ausformte. ${ }^{32}$

Die Stadt als ,Gemeinde' bildet eine Struktur, in der sich eine Vielfalt ,gemeindlich' verfaßter Gruppen - Gilden, Zünfte, Bruderschaften - in Konkurrenz bewegen, aber auch andere Gruppen: Familien, ,Geschlechter', Verwandtengruppen, monastische und klerikale

27 Vgl. Deutsch, On Nationalism (wie Anm. 2), 77, über ,the rise and persistence of diverse autonomous groups not based on blood relationship or marriage“: „Nowhere, however, do these reach the strength, ubiquity and century-long persistence as they do in the West". Vgl. als Gegensatz dazu die überragende Bedeutung der Familien-Bindung in der chinesischen Kultur: Shaoping Gan, Die chinesische Philosophie. Die wichtigsten Philosophen, Werke, Schulen und Begriffe. Darmstadt 1997, $47 \mathrm{ff}$.

28 Otto Gerhard Oexle, Gilde und Kommune. Über die Entstehung von ,Einung' und ,Gemeinde' als Grundformen des Zusammenlebens in Europa, in: Theorien kommunaler Ordnung in Europa. Hrsg. v. Peter Blickle. (Schriften des Hist. Kollegs. Kolloquien, Bd. 36.) München 1996, 75-97.

29 Oexle, Soziale Gruppen in der Ständegesellschaft (wie Anm. 21), 34 f. Zu diesem Thema auch: Manfred Hildermeier, Max Weber und die russische Stadt, in: Max Weber und die Stadt im Kulturvergleich. Hrsg. v. Hinnerk Bruhns/Wilfried Nippel. (Kritische Studien zur Geschichtswissenschaft, Bd. 140.) Göttingen 2000, 144-165, bes. 159 ff.

30 Gerhard Dilcher, Die Rechtsgeschichte der Stadt, in: Deutsche Rechtsgeschichte. Land und Stadt Bürger und Bauer im Alten Europa. Hrsg. v. Karl S. Bader/Gerhard Dilcher. Berlin/Heidelberg/New York 1999, 249-827, hier $481 \mathrm{ff}$.

31 Ebd. 482 f. Zum Thema zuletzt Barbara Frenz, Gleichheitsdenken in deutschen Städten des 12. bis 15. Jahrhunderts. Geistesgeschichte, Quellensprache, Gesellschaftsfunktion. (Städteforschung, Rh. A: Darstellungen, Bd. 52.) Köln/Weimar/Wien 2000.

32 Dilcher, Die Rechtsgeschichte der Stadt (wie Anm. 30), 485. 
Gruppen, die ganz unterschiedlichen Wertvorstellungen und Formen des sozialen Handelns folgen. ${ }^{33}$ Auch Pfarreien sind, so wissen wir neuerdings, nicht nur als die untersten Einheiten des kirchlichen Sprengelsystems zu sehen, sondern auch als Rahmen für ,freies ${ }^{6}$ gesellschaftliches Handeln von Laien. ${ }^{34}$

Für die Vielheit von ,Dialogiken' in der Kultur des Mittelalters ist dabei von Bedeutung, daß die Differenz zwischen ,Gesellschaft' im modernen Sinne - so wie die mittelalterliche Stadt sie erstmals darstellt - und ,ständischer Gesellschaft' im Sinne der ,Ganzheit' einer in sich vollständigen und geordneten Struktur einzelner Stände bereits im Mittelalter erörtert wurde. Es sind die einzelnen Schwureinungen, es ist vor allem die Stadt selbst als ,Conjuratio', die in Frage gestellt wird in der Auseinandersetzung über die Werte einer ,ständischen' Ordnung, deren Einhaltung vor allem vom Klerus gefordert wurde. Dabei wurde der Kontrast zu den durch Konsens und Vertrag konstituierten Gruppen und ihren Werten herausgestellt. Es ging um die einander widersprechenden Auffassungen von gesellschaftlichen Grundwerten wie ,Brüderlichkeit', ,Freiheit', ,Recht', ,Gleichheit', deren Widersprüchlichkeit in dem Gegensatz von Universalität und Partikularität begründet war. Dabei ging es zum Beispiel um die Frage der Verbindlichkeit und Rechtlichkeit von gruppenspezifischem Sonderrecht (consuetudo) gegenüber allgemeinem Recht (lex), um die Legitimität von gruppenspezifischer Brüderlichkeit gegenüber der Pflicht zu universaler fraternitas, und es ging vor allem um den Konflikt zwischen gruppenspezifischer Gleichheit (Parität) und der in der Stände-Ordnung geforderten ,Harmonie in der Ungleichheit', vor der die gruppenspezifische Gleichheit der Conjurationes nur als eine Rebellion gegen die gute Ordnung der Welt erscheinen konnten. ${ }^{35}$

Die Gesellschaften der Antike kennen die ,Conjuratio ${ }^{36}$, aber nicht solche Formen der ,Dialogik' über gesellschaftliche Grundwerte. Es ist deshalb zu fragen, was diesen kulturellen Unterschied zwischen Antike und Mittelalter konstituiert hat.

Man wird die Gründe einerseits in dem sehr spezifischen Verlauf des Übergangs von der Antike zum Mittelalter im Westen des Römischen Reiches erkennen können, wo den Gruppen eine bisher nicht dagewesene Bedeutung in den politischen und sozialen Prozessen zukam. $^{37}$ Dahinter steht aber die große Bedeutung, die das Christentum als eine ,gruppenfreundliche ${ }^{\natural}$ Religion auf diesem Feld hatte. Diese ,Gruppenfreundlichkeit ${ }^{t}$ des Christentums und die daraus resultierende Bedeutung örtlicher Gemeinden waren ein histo-

33 Darüber Otto Gerhard Oexle, Wie entstanden Werte in der Gesellschaft des Mittelalters?, in: Das Individuum und die Seinen. Hrsg. v. Michael Bojcov/Otto Gerhard Oexle. Bd. 2 (im Druck).

34 Martial Staub, Memoria im Dienst von Gemeinwohl und Öffentlichkeit. Stiftungspraxis und kultureller Wandel in Nürnberg um 1500, in: Memoria als Kultur. Hrsg. v. Otto Gerhard Oexle. (VMPIG, Bd. 121.) Göttingen 1995, 285-334.

35 Dazu Oexle, Friede durch Verschwörung (wie Anm. 26), 144 ff.

36 Otto Gerhard Oexle, Conjuratio und Gilde im frühen Mittelalter. Ein Beitrag zum Problem der sozialgeschichtlichen Kontinuität zwischen Antike und Mittelalter, in: Gilden und Zünfte. Kaufmännische und gewerbliche Genossenschaften im frühen und hohen Mittelalter. Hrsg. v. Berent Schwineköper. (VuF, Bd. 29.) Sigmaringen 1985, 151-214.

37 Dazu Oexle, Soziale Gruppen in der Ständegesellschaft (wie Anm. 21), 36 ff. 
risch differenzierender und konstitutiver Faktor von größter Bedeutung. ${ }^{38}$ Im Islam fehlt die örtliche Gemeinde völlig: Hier gibt es nur die umma als die Gesamtheit aller Gläubigen. Das Christentum aber hat allein schon im ersten Jahrhundert seines Bestehens nicht weniger als drei und außerdem drei sehr verschiedene Formen von Gemeinde hervorgebracht. ${ }^{39}$

Die Bedeutung der Gemeinde im Christentum und damit die Bedeutung von Konsensund Vertragsverhältnissen in der Geschichte des Okzidents ist allerdings auch eine Folge der Wirkungen jener Religion, in der die Form des ,Bundes' und Vertrags, nämlich des Vertrags von Menschen mit Gott, eine so fundamentale Rolle gespielt hat: des Judentums. ${ }^{40}$

38 Ebd. 36.

39 Ebd.

40 Darüber Oexle, Wie entstanden Werte? (wie Anm. 33). 


\title{
Probleme einer vergleichenden Betrachtung mittelalterlicher Eliten in Ostmitteleuropa
}

\author{
Von
}

\author{
János M. Bak
}

Bevor ich mich meinem engeren Thema zuwende, möchte ich einiges, wenn auch nur skizzenhaft, über die Funktion vergleichender Geschichtsbetrachtung in der ungarischen Historiographie voraussenden. ${ }^{1}$ Diese Überlegungen dürften unter Umständen nicht nur für Ungarn relevant sein, so daß sie vielleicht dem allgemeinen Thema dieser Tagung etwas beizusteuern vermögen. Ich könnte mir gut denken, daß historische ,Vergleiche' - und echte Vergleiche - mutatis mutandis auch in anderen Ländern (vor allem bei ,kleinen Nationen') ähnliche Funktionen hatten und haben. ${ }^{2}$

Vergleichender Zugang zur Geschichte ist zwar - so glaube ich - fast so alt wie Geschichtsschreibung selbst, doch diesmal sollen wir nur das letzte Jahrhundert, und das auch nur (schon wegen des Profils unserer Tagung und meiner begrenzten Kompetenz) in bezug auf die mittelalterliche Geschichte, überblicken. ${ }^{3}$ Es wäre, freilich, einer gesonderten

I Da bloß als Vorspann gemeint, kann ich freilich keine Vollständigkeit anstreben und werde mich auch nur auf Ungarn begrenzen, obwohl das Thema mindestens für Ostmitteleuropa im Zusammenhang behandelt werden sollte; s. hierzu den eleganten Überblick, mit Bibliographie, von Jerzy Kloczowski, L'Europe du centre-est dans l'historiographie des pays de la région. Lublin 1995. Die Anmerkungen wurden auch knapp gehalten, vor allem was Titel in ungarischer Sprache betrifft.

2 Es ist interessant, daß in Westeuropa (England, Frankreich, Spanien, das Reich) eben die Vernachlässigung des Vergleichs den gleichen Zweck erfullt zu haben scheint: Neulich las ich bei einem englischen Historiker einen sehr treffenden Satz darüber: „The common interests and problems of thirteenth-century rulers have tended to be ignored because medieval political history has often been written with a nationalist bias. (...) Consequently, instead of examining the similarities between medieval rulers, historians of each nation picked out individual traits in their own kings which they thought revealed incipient national character." Michael Clanchy, England and its Rulers 1066-1272. London 1983, 214. Er zitiert auch Historiker unserer Zeit, die wie Frederick M. Powicke (The Thirteenth Century 1216-1307. [The Oxford History of England, vol. 4.] London 1953, 130) solche rhetorische Fragen stellen wie: „How was it that in England alone, among the monarchies of the west, the right of the king to select his own advisers became a subject of such bitter controversy?" - Als ob das gleiche Problem nicht in fast allen Ländern Europas zum zentralen Problem jener Zeit geworden wäre!

3 Ich stecke den Rahmen recht begrenzt ab und lasse im weiteren sowohl die quellenkritischen Studien als auch die mittelalterliche Archäologie und die Kunst- und Literaturgeschichte aus dem Blickfeld, obwohl 
Diskussion wert, ob man den Begriff ,Vergleich' so weit fassen will, daß man mittelalterliche Chronisten, die etwa die Nationalgeschichte mit den biblischen oder anderen mythischklassischen Erzählungen ,vergleichen' - im Falle Ungarns der Anonymus P. oder Simon von $\mathrm{Kéza}^{4}$ mit ihren biblischen, skythischen und hunnischen Parallelen zur origo gentis -, miteinbeziehen sollte.

Im späten 19. und frühen 20. Jahrhundert bemühten sich ungarische Historiker, vor allem die der Verfassung, die staatlich-rechtlichen Grundlagen des eigenen Staates mit denen der anderen Völker Europas und vor allem mit denjenigen des für seine altehrwürdige parlamentarische Verfassung berühmten England zu vergleichen. Historiker, wie Ákos Timon ${ }^{5}$ und seine Zeitgenossen, lieferten das Legitimationsmaterial zu solchen Aussagen von Politikern, wie Graf Albert Apponyi, der 1904 in St. Louis den Parlamentariern der Welt bekanntgab, daß „die ungarische Verfassung mit dem magyarischen Volk gleichaltrig ist, und (...) erwies sich als besser denn alle anderen in der Stärkung der Monarchie, ohne die Freiheit zu opfern." ${ }^{\text {"6 }} 1884$ schrieb Graf Julius Andrássy Jr. in einer Familienzeitschrift schlicht und einfach: „Die ungarische Verfassung ist die älteste unter allen Völkern des Kontinents.“7

Freilich gingen solche Positionen auf den nicht unbegründeten Nationalstolz der in der Türkenzeit leidgeprüften Ungarn zurück, der bereits im 17. Jahrhundert, vom Poeten, Politiker und General Nicholas Zrínyi (Zrinski) in dem geflügelten Wort ausgesprochen wurde: „Wir sind keiner anderen Nation an Wert unterlegen! ${ }^{8} \mathbf{~ N u r}$ galten solche Aussagen um die Jahrhundertwende vor allem zur Begründung der Sonderstellung Ungarns im Habsburgischen Vielvölkerstaat (gegen mögliche Ausgleiche mit Tschechen oder Kroaten), und der Vorherrschaft der Magyaren innerhalb der ungarischen Reichshälfte (in der sie knapp die Hälfte der Einwohner zählten).

Ernsthafte Versuche wurden unternommen, die Goldene Bulle Andreas' II. (1222) mit der englischen Magna Charta ${ }^{9}$ oder die vermeintliche Verantwortlichkeit königlicher Räte in Aragón mit der Position ungarischer Hofamtsträger ${ }^{10} \mathrm{zu}$ vergleichen. Manche dieser Studien,

gerade in diesen Gebieten vergleichende Methoden seit eh und je - und mehr oder weniger sine ira et studio - angewendet worden waren.

4 Z. B. Gabriel Silagi, Die "Gesta Hungarorum“ des anonymen Notars. Die ălteste Darstellung der ungarischen Geschichte. Sigmaringen 1991; Simon of Kéza, The Deeds of the Hungarians. Ed. László Veszprémy/Frank Schaer. Budapest 1999, bes. 17-27.

5 Akos Timon, Ungarische Verfassungs- und Rechtsgeschichte mit Bezug auf die Rechtsentwicklung der westlichen Staaten. Berlin 1904, stellt die beste Synthese dieser Ansichten dar. Der im Titel genannte „Bezug" ist allerdings mehr rhetorisch als echt komparativ.

6 Dt. in: Forum (Wien), Juni-Juli 1901 (engl. Originalfassung in: Jogállam 7, 1908, 561-88).

7 Vasárnapi Újság [Sonntagsblatt], 15. 6. 1884, zit. in: János M. Bak/Anna Gara-Bak, The Ideology of a ,Millennial Constitution' in Hungary, in: East European Quarterly 15, 1981, 307-336, hier 307.

8 ,(...) egy nemzetnél sem vagyunk alábbvalóak!“, in: Ne bánts a magyart. A török áfium ellen való orvosság (...) [Hände weg von den Ungarn. Arznei gegen das Türkische Opium oder Gegengift zum Unfrieden des Türken gegen die Ungarn], in: Zrinyi Miklós hadtudományi munkái [Kriegswissenschaftliche Schriften des Nicholas Zrínyi]. Budapest 1957, 384.

9 Z. B. Elemér Hantos, The Magna Charta of the English and of the Hungarian Constitution. A comparative View of the Law and Institutions of the Early Middle Ages. London 1904.

10 Gyula Schvarcz, A király tanácsosainak felelössége Aragóniában és Magyarországon [Verantwortlichkeit der kőniglichen Răte in Aragón und Ungam]. Budapest 1889. 
ja fast alle, die von Berufshistorikern verfaßt wurden, enthalten interessante Gedanken und keineswegs unnütze Hinweise auf die historische Entwicklung, sind allerdings selten fähig, den ihnen von der politischen Elite gestellten Erwartungen gerecht zu werden. Erst im 20. Jahrhundert haben Historiker - in Ungarm etwas weniger als anderswo - darauf hingewiesen, $\mathrm{da} ß$ vergleichbare oder gar übereinstimmende Ideen und Institutionen teilweise auf die ,gesamt-europäische' Schulung der Kleriker und sonstiger gelehrter Autoren, teilweise auf die ,Europäisierung' des Adels in der Zeit der Kreuzzüge zurückgehen dürften. Sie beweisen das Zusammenleben der Völker in der abendländischen Christenheit, aber taugen kaum dazu, die Priorität der einen oder anderen Nation in bezug auf Staatlichkeit oder ,Zivilisation' nachzuweisen. ${ }^{11}$

In den Jahrzehnten der sich verschärfenden nationalen Gegensätze innerhalb der Doppelmonarchie und noch mehr nach dem Untergang des historischen Königreichs in dem Pariser Friedenswerk 1920 wandte sich der,Vergleich' gegen die Nachbarm und jene Völker, die die landnehmenden Ungam im Karpatenbecken vorfanden. Es sollte nachgewiesen werden, daß Slawen und Rumänen (Walachen), seit eh und je weniger ,staatsbildend' und ,zivilisiert' waren als die Magyaren. Zwar waren eher Dichter von historischen Romanen (wie Maurus Jókai und andere mehr) die Wortfuhrer einer solchen Geschichtsauffassung, doch sie fanden immer auch Fachhistoriker, die ihre Ansichten unterstützten. ${ }^{12}$ Es ist bemerkenswert, daß gleichzeitig Vergleiche mit Polen das Verhältnis der beiden Länder eher von der positiven Seite auffaßten und die historische Verbundenheit Ungarns und Polens (die ja tatsächlich mehrfach in der mittelalterlichen Geschichte Realität war und durch Sympathien mit polnischen Aufständen auch in der Moderne relevant gewesen ist) zu unterstreichen trachteten. ${ }^{13}$ Aus der politischen Realität ist dieser Unterschied unschwer zu erklären. Einerseits hatte man Polen gegenüber keine Nationalitätenprobleme (und auch nach dem Frieden von Trianon keine Gebietsansprüche), andererseits konnte die Teilung Polens durch jene Mächte, die

11 Allerdings bemühten sich Historiker auch später noch, die Einzigartigkeit ungarischer Entwicklung durch ,Vergleiche' herauszustellen, vor allem polemisch gegen ausländische Forscher. So verwarf z. B. der hochgelehrte Rechtshistoriker György Bónis, Szent István törvényeinek önállósága [Die Unabhängigkeit der Gesetzgebung St. Stephans], in: Századok 82, 1938, 433-487 - vor allem gegen die Behauptungen von Jakob v. Sawicki, Zur Textkritik und Entstehungsgeschichte der Gesetze König Stefans des Heiligen, in: Ungarische Jbb. 9, 1929, 395-425 - in vielen Punkten grundlos die ,internationalen' Entlehnungen im Gesetzeswerk des ersten Königs, anstatt eben die europäische Eingebundenheit des neuen Königreichs zu unterstreichen.

12 Siehe hierzu Bak/Gara-Bak, The Ideology (wie Anm. 7), insbesondere über die ,wissenschaftliche Untermauerung des sog. Feszty-Panoramas von der Landnahme der Ungarn, in der die Urbewohner (d. h. Slawen u. a.) arg verunglimpft wurden (... und weiterhin werden, da man das Objekt als ,historisches Denkmal' in einem Nationalpark in Ungarn, furr teueres Geld restauriert, auch heute sehen kann). S. auch meine Skizze: Die Mediävisierung der Politik im Ungarn des 19. und 20. Jahrhunderts, in: Umkämpfte Vergangenheit. Geschichtsbilder, Erinnerung und Vergangenheitspolitik im internationalen Vergleich. Hrsg. v. Petra Bock/Edgar Wolfrum. Göttingen 1999, 103-113.

13 Gelegentlich gar weit ausgreifend, wie z. B. Adorján Divéky, La constitution du Royaume de Jérusalem et les institutions hongroises et polonaises, in: Résumés des communications présentées au congrès. Varsovie 1933, 436-442 (dann ausführlicher auf ungarisch, 1942). 
die traditionelle ungarische Staatlichkeit auch bedrohten, als dem eigenen in mancher Hinsicht ähnliches Schicksal aufgefaßt werden. ${ }^{14}$

Hier sei vermerkt, daß die oppositionellen, bürgerlich-radikalen oder sozialistischen Historiker die vergleichende Methode bereits in jener Zeit genau gegen die gängigen politischen Implikationen angewandt hatten, allerdings, soweit ich sehe, meist in bezug auf die Moderne, wo ja die geistige Auseinandersetzung am schärfsten war. Sie waren vor allem durch die Rezeption der ,neuen' Wissenschaft der Soziologie beeinflußt und versuchten die Methoden von Spengler, Durkheim und Max Weber in ihren historischen Arbeiten zu verwerten. ${ }^{15}$

In der Zwischenkriegszeit scheint die vergleichende Betrachtung durch die Vorherrschaft der sogenannten geistesgeschichtlichen Schule, die nur in einem recht allgemeinen Sinne Vergleiche anzustellen gewillt war, etwas in den Hintergrund gedrängt worden zu sein. Trotzdem lag den Historikern jener Zeit weiterhin daran, die eigene Geschichte als „dem Westen“ ebenbürtige darzustellen, ja auch weiterhin „Prioritäten“ aufzuweisen. Dies läßt sich an der Behandlung der Regierungszeit des Königs Matthias I. Corvinus, der nunmehr als Renaissancefürst par excellence dargestellt wurde, beispielhaft ablesen. ${ }^{16}$ Die „ungarische Großmacht" des Spätmittelalters einerseits und die (gewiß aufgrund vergleichender Betrachtung so genannte) Barockzeit Habsburg-Ungams andererseits standen im Mittelpunkt des Interesses, und, natürlich, nach dem Frieden von Trianon, jene Art von ,Volksgeschichte', die die ungerecht gezogenen Grenzen historisch in Frage stellen konnte oder wollte. ${ }^{17}$

14 Es ist auffallend, daß die meisten historischen Vergleiche, bis auf unsere Tage, zwischen Ungarn und Polen unternommen wurden - von Adorján Divéky, Az Aranybulla hatása a lengyel jogra [Einfluss der Goldenen Bulle (von 1222) auf das polnische Recht]. Budapest 1942, bis György Székely, Gemeinsame Züge der ungarischen und polnischen Kirchengeschichte im XI. Jahrhundert, in: Annales Universitatis Scientiarum Budapestinensis de Rolando Eoetvoes Nominatae, Sectio historica 4, 1962, 55-80, usw. Zu nennen ist auch der auf eine Konferenz zurückgehende Sammelband: György Székely/Erik Fügedi (Ed.), La renaissance et la réformation en Pologne et en Hongrie. Budapest 1963, und, unlängst erschienen: Lajos Hopp/Jan Ślaski, A magyar-lengyel múltszemlélet elözményei: politikai es kulturalis kagyomanyok Bathory Istvanig [Vorgeschichte der polnisch-ungarischen Vergangenheitsbetrachtung: politische und kulturelle Traditionen bis zur Zeit Stephan Bathorys]. Budapest 1992. Auch unser vergleichendes Projekt der Adelsgesellschaften (s. unten) erwies sich - gewiß aus vielen Gründen, aber ungewollt! - als ein vornehmlich ungarisch-polnisches Unternehmen.

15 Ich denke hier an solche Arbeiten wie Oskar Jászi, A nemzeti államok kialakulása és a nemzeti kérdés. Budapest 1912. S. zum allgemeinen Kontext Zoltán Horváth, Die Jahrhundertwende in Ungarn. Geschichte der zweiten Reformgeneration 1896-1914. Neuwied 1966.

16 Vgl. etwa Gyula Szekfú in: Bálint Hóman/Gyula Szekfü, Magyar történet [Ungarische Geschichte]. Bd. 2. Budapest 1936, $330 \mathrm{ff} .1940$ wurde der 500. Jahrestag seiner Geburt gefeiert, was zu Festschriften usw. führte; es ist lehrreich, jene Schriften, mit wenigen Ausnahmen Panegyriken - wenn auch recht gelehrte Stücke des Genres - mit den viel zurückhaltenderen und kritischeren Beiträgen ein halbes Jahrhundert später, zum 500. Todestag 1990 (z. B. die Aufsătze von Bak, Marosi, Macek, Kubinyi und Russocki in: Bohemia 31, 1990, 312-359), zu vergleichen!

17 Der Titel einer Zeitschrift, 1943-1949 von der ungarischen Regierung unterstutzt, aber zeitweilig in Zusammenarbeit mit den Presses Universitaires de France in Paris herausgegeben, „Revue d'histoire 
Historiker, die nicht dieser vorherrschenden Richtung angehörten, wandten sich der vergleichenden Forschung mit dem Anliegen zu, die Probleme der ungarischen Entwicklung (einschließlich ihrer ,Rückständigkeit') historisch zu erklären. Ein gutes Beispiel hierfür sind die Werke von István Hajnal, bestens bekannt für sein Buch über mittelalterlichen Schriftunterricht ${ }^{18}$, der in den dreißiger Jahren des 20. Jahrhunderts eine Arbeitsgemeinschaft der Historiker der „kleinen Nationen“ anregte ${ }^{19}$, und zwar mit dem methodischen Argument, daß in ihrer Geschichte manches, was bei den "Großen“ weniger sichtbar sei, besser erforscht werden könne. Daß die Spitze eines solchen Vergleichs eindeutig gegen die aufkommende und drohende Großmacht des Dritten Reiches (oder jedenfalls weitgehend gegen diese) gerichtet war, scheint mir eindeutig. Hajnal bemühte sich auch, die Sozialgeschichte Ungarns durch Vergleiche (vor allem mit Frankreich) zu erhellen; hierin benutzte er, der sich auch ausfuhrlich mit Technikgeschichte befaßt hatte, gerne den Begriff der „Betrieblichkeit“ (üzemszernűség) - womit er etwas Professionelles, Fachmännisches, Pragmatisches meinen wollte - im Gegensatz zu der, seiner Meinung nach in Ungarm vorherrschenden, Amtsausübung aufigrund von Geburtsprivileg (ohne Rücksicht auf Kompetenz). ${ }^{20}$

Vergleichende Betrachtung ist vielleicht ein allzu wohlwollender Ausdruck fur jene Bemühungen, die die Geschichte Ungarns, der nach 1948 vorherrschenden Ideologie entsprechend, partout in das im wesentlichen aus westeuropäischen Verhältnissen abgeleitete Schema des Marxismus-Leninismus einzupferchen trachteten. Wenn es in England eine ursprüngliche Kapitalakkumulation durch enclosure gegeben hatte, wenn ,auf dem preußischen Weg“ eine „zweite Leibeigenschaft“ anzutreffen war, so mußten diese auch in der ungarischen Geschichte nachgewiesen werden. Ähnlich verhielt es sich mit den sowjetmarxistischen Kategorien von ,barbarischem Feudalismus', ,Zentralisation der Monarchie', usw. ${ }^{21}$ Allerdings bewirkte das - anfangs wohl eher aufgezwungene - besondere Interesse an den slawischen Völkern im alten Ungarn oder an den Verbindungen des Königreichs mit seinen „sozialistischen Nachbar" (einschließlich Rußlands) eine relevante Korrektur des

comparée“, ist bezeichnend: Vergleichende Geschichte erschien offenbar als die beste „Fahne“ für ein Organ, das vornehmlich (doch keineswegs ausschließlich) Artikel herausbrachte, die eine Revision des Friedensvertrags von 1920 historisch unterstützen sollten. Allerdings wandten sich die Verfasser auch stark gegen die expansionistischen Absichten des Dritten Reichs und - in der neuen Serie der Nachkriegsjahre (gegründet und herausgegeben von Domokos Kosáry) - besonders gegen die ,Historiker des Nazi-Regimes. Eine Art vergleichender Artikelsammlung, weniger auf Gegensătze als auf möglichen Ausgleich ausgerichtet, war herausgegeben worden von József Deér/László Gáldi, Magyarok és románok [Ungarm und Rumänen]. Budapest 1943.

18 Sein bahnbrechendes Werk, István Hajnal, L'enseignement de l'écriture aux universités médiévales. Budapest 1954, fußt weitgehend auf vergleichenden Studien des Unterrichts im Schreiben.

19 István Hajnal, A kis nemzetek történetírásának munkaközösségéröl [Über die Arbeitsgemeinschaft der Geschichtsschreibung kleiner Nationen], in: Századok 76, 1942, 1-42, 133-65. Ähnliche Anregungen kamen auch von seiten der polnischen Historiker Marceli Handelsman und Oskar Halecki und vom Ungarn Emerich [Imre] Lukinich; siehe Kłoczowski, L'Europe du centre-est (wie Anm. 1), 9-18.

20 Ein kleines Beispiel seiner Analysen ist auch übersetzt worden: István Hajnal, From Estates to Classes, in: History and Society 2, 1994, 163-83; sonst ist, leider, alles andere, was er schrieb, nur auf ungarisch erschienen.

21 Es ist vielleicht besser, auf einzelne Beispiele hier zu verzichten, da diese ,Werke' am besten der Vergessenheit anheimgegeben werden sollten. 
früheren, einseitig westlich orientierten Geschichtbildes. Nur waren diese Korrekturen oft so auffallend Pflichtubungen, daß sie, auf recht dünner Quellenbasis beruhend, den ,östlichen ‘ Anteil unbegründet hoch bewerteten und somit viel von ihrer Glaubwürdigkeit einbüßten. ${ }^{22}$ Ebenso fraglich erscheint mir, ob man jenen Historikern, die im Sinne der kodifizierten ,fortschrittlichen Traditionen' in jeder geistigen oder sozialen Bewegung des 15. Jahrhunderts, ob schön, ob Regen, „Hussitisches“ erkennen wollten ${ }^{23}$, den Titel eines vergleichenden Geschichtsforschers verleihen sollte. Aber wiederum: trotz alledem wurde Licht auf historische Details geworfen, die dann, nachdem (bereits in den späten sechziger Jahren) die primitiven ideologischen Zwänge nachgelassen hatten, mit entsprechend wissenschaftlichem Apparat untersucht werden konnten und wichtige Einsichten etwa in den Hintergrund der Bauernaufstände lieferten.

Letzten Endes hing es auch mit dem von Marx (aber auch vielen anderen Historikern seiner Zeit und danach) postulierten „Sieg des Kapitalismus“ im Westen Europas zusammen, daß Vergleiche in dieser Zeit die unterschiedliche Entwicklung Ostmitteleuropas (oder Ungarns) gegenüber jenem vermeintlich geradlinigen Modell des ,Fortschritts' unterstrichen. Obwohl dafurr bereits ältere Beispiele (etwa in den Schriften der Radikalen der Jahrhundertwende, aber auch, wie erwähnt, bei Hajnal und anderen) vorhanden waren, war dies vor allem durch die Bemühung bestimmt, den Platz der ostmitteleuropäischen Region im großen Schema der Weltgeschichte (die ja als bekannt vorausgesetzt wurde) zu finden. Daher kamen Begriffe wie ,Abweichung' und ,Variante' sehr in Mode. In bezug auf das Spätmittelalter wies Zsigmond Pál Pach diese Abweichung in der Landwirtschaft ${ }^{24}$, Jenő Szücs im Städtewesen ${ }^{25}$ nach, während László Makkai die Unterschiede zwischen „einheimischen“ und importierten Elementen des osteuropäischen Frühmittelalters ${ }^{26}$ zu umreißen trachtete. Daß diese meist ein künstlich entworfenes Modell der ,Entwicklung' mit der Realität der Region verglichen, vermindert ihre Verdienste nur in geringem Maße. Gleichzeitig litten viele solcher Versuche daran, daß sie ,den Westen' (volens nolens, vielleicht gar als Reflex zur allgemeinen Unzufriedenheit mit dem ,real-existierenden ${ }^{6}$ Osten) idealisierten und die ,Unvollkommenheiten' der eigenen Geschichte zwar wegzuinterpretieren trachteten, doch diese oft überschätzten. Die ganze Breite der ideologischen Implikationen dieses Zuganges -

22 Doch keineswegs unnütz sind Sammelwerke wie Endre Kovács, Magyar-cseh történelemi kapcsolatok [Ungarisch-tschechische historisch Kontakte]. Budapest 1952, oder ders., Magyarok és lengyelek a történelem sodrában [Ungarn und Polen im Strom der Geschichte]. Budapest 1973. Diese sind aber meist den ,Kontakten' (und überwiegend den positiven) gewidmet und nicht einem Vergleich der Entwicklung in den Nachbarländern, vielleicht mit Ausnahme Polens; s. oben Anm. 13.

23 Z. B. György Székely, A husszitizmus és a magyar nép [Hussitismus und das ungarische Volk], in: Századok 88, 1956, 331-67.

24 Zsigmond Pál Pach, Die ungarische Agrarentwicklung im 16.-17. Jahrhundert. Abbiegung vom westeuropäischen Entwicklungsgang. (Studia Historica Acad. Sc. Hung., Bd. 54.) Budapest 1964, und viele andere Beiträge.

25 Kurz in: Jenó Szũcs, Das Städtewesen Ungarns im 15.-17. Jahrhundert, in: La Renaissance et la Réformation en Pologne et en Hongrie. Ed. György Székely. Budapest 1963, 97-164.

26 László Makkai, Les charactères originaux de l'histoire économique et sociale de l'Europe oriental pendant le Moyen Âge, in: Acta Historica Acad. Sc. Hung. 16, 1970, 261-87. 
der, so glaube ich, für den gesamten Bereich der marxistisch-leninistisch dominierten Sozialwissenschaften gilt - wäre einmal einer eigenen Untersuchung wert. ${ }^{27}$

Eine völlig neue Dimension der vergleichenden Geschichtsforschung und -betrachtung wurde mit der weitbekannten und politisch ebenso wie fachlich bedeutenden ,Skizze über die drei Regionen Europas von Jenő Szücs ${ }^{28}$, ursprünglich für eine oppositionelle SamizdatVeröffentlichung geplant, eröffnet. Das Büchlein stellt einen Höhepunkt in der auf wissenschaftlich begründetem Vergleich fußenden historisch-politischen Argumentation dar. ${ }^{29}$ In einer gewissen Weise ist die These von der Sonderstellung einer, weder zum ,feudalen Westen noch zum byzantinisch-autokratischen Osten gehörenden dritten, mittleren Region eine Weiterentwicklung früherer Studien über Ungams Stellung im christlichen Europa des Mittelalters und der frühen Neuzeit, nur wird diesmal das Argument einerseits viel differenzierter untermauert, andererseits wendet es sich nicht gegen die Nationalitäten oder die Nachbarn des Landes, sondern gegen die Hegemonialmacht des Sowjetsystems. Grob gesagt, was Milan Kundera im Pariser Exil in die Worte „Warum mag ich die Russen nicht?،30 gießen konnte, wurde von dem Mediävisten Szücs in einem breiten historischen Panorama argumentativ ausgefuhrt. Noch wichtiger: Die These von den drei Regionen wies auf die unvollkommene, ,unorganische' und daher für die moderne Entwicklung mit schweren Hypotheken belastete mittelalterliche Entwicklung des eigenen Landes (ja der gesamten Region zwischen Elbe und, sagen wir, Dnjepr) hin und enthielt - wie auch zahlreiche andere Studien des Verfassers ${ }^{31}$ - eine scharfe Kritik jeglicher Überbewertung ,nationaler Einzigartigkeit' und Sonderstellung.

Soweit ich sehe, wurde dieses zweifache Anliegen furr die vergleichenden Studien „nach der Wende" (und bereits einige Zeit davor) charakteristisch: die kritische und differenzierte Einordnung des mittelalterlichen Königreichs Ungarn in die gesamteuropäische (im wesentlichen abendländische) Entwicklung, aber ohne die Phasenverschiebungen und Unterschiede (die Ungam mehrfach mit seinen Nachbam gemeinsam hatte) zu übersehen oder gar $\mathrm{zu}$

27 Und dann auch die ,postkommunistische' Reaktion, die nun in vielen Gebieten (wenn auch eher am Rande der Wissenschaft) zu der Verherrlichung der eigenen (oder als solche angesehenen) Vergangenheit fuhrt, wie derjenigen der Zarenzeit in Rußland oder der Urmagyaren in Ungarn.

28 Jenõ Szúcs, Die drei historischen Regionen Europas. Frankfurt a. M. 1990.

29 Die Anregung zu dieser Schrift - für die von der Zensur verbotene Gedenkschrift fưr István Bibó (1911-1979) verfaßt - kam von den historischen Analysen eben dieses Verfassers, der zwar kein Historiker, sondern Jurist und Politologe war, aber die Probleme der Region - oder, wie er sie in einer wichtigen Studie nannte: Die Misere der mitteleuropäischen Kleinstaaterei. Frankfurt a. M. 1992 - aufgrund eingehender vergleichender Studien der neuzeitlichen Entwicklung Ostmitteleuropas untersucht hatte; s. auch andere Aufsätze in: István Bibó, Democracy, Revolution, Self-determination. Selected Writings, Ed. Károly Nagy/András Boros-Kazai. New York 1991. S. zu seiner Würdigung auch Kłoczowski, L'Europe du centre-est (wie Anm. 1), 27 f.

30 Leider habe ich vergessen, wo und wann dieser Artikel des tschechischen Dichters erschien.

31 Die meisten von ihnen sind auch in deutscher Sprache zugänglich in dem Sammelband: Jenö Szücs, Nation und Geschichte. Budapest 1981, und in dem postum erschienenen Aufsatz: ders., Zwei Fragmente, in: East central Europe/L'Europe du centre-est, 20/23, 1993/96, 2, 55-90. 
verheimlichen. ${ }^{32}$ Bereits 1990 erschien der erste Band einer Serie Ungarn in Europa mit dem charakteristischen Titel: Eingliederung in Europa von den Anfängen bis 1440. Als Warmung vor der (durch die früheren ,Vergleiche' meist nur unterstrichenen) Überbewertung der eigenen Vergangenheit wies Pál Engel in seinem Vorwort darauf hin, daß man vorsichtig mit der Benutzung der ersten Person Mehrzahl für die Magyaren des 11. bis 15. Jahrhunderts umgehen solle, denn, so schrieb er, „die Heere des mittelalterlichen Ungams sind nicht ganz einer heutigen Fußballmannschaft, deren Fans sich über ihre Siege freuen, vergleichbar.“33 Sein Hinweis auf die Distanz ehemaliger Einwohner des Ungamlandes, die mit den heutigen Bürgern der Republik höchstens soviel gemeinsam haben, daß auch sie Magyarisch sprachen, erntete lauten Protest und die Anklage des geistigen Hochverrats gegen den Verfasser in Leserbriefen und Zeitungsartikeln. Die im 19. Jahrhundert begründete Vorstellung von der ,unvergleichbaren Einmaligkeit' der eigenen Geschichte (und ihrer Priorităt vor allen anderen, die dann auch für die heutige Politik zu gelten hat) stirbt langsam - wenn überhaupt.

Vergleichende Forschung fand in den letzten Jahrzehnten vor allem in dem Sinne Eingang in die ungarische Geschichtsforschung, als man sich bemühte, das Eigene in den Kontext der weltweiten Diskussionen der Historiker einzubauen. Wenn auch wenig systematischer Vergleich unternommen wurde, bemühte man sich jedenfalls aus dem begrenzten heimischen Rahmen auszubrechen und ,mitzusprechen'. (Über dieses Anliegen des ,Mitredens' mehr weiter unten.) Erik Fügedi war vielleicht der erste, der in den siebziger Jahren die Ergebnisse ungarischer Forschung in die im Westen laufenden Diskussionen einzuschalten vermochte, wie etwa mit seinem Beitrag zur französischen Annales-Enquete über Mendikantentum und Städteentwicklung oder zur Tagung über die deutsche Ostbewegung im Kontext des europäischen Siedlungsprozesses. ${ }^{34}$ György Györffy versuchte die ungarische Geschichte des 9. bis 11. Jahrhunderts weitgehend durch den Vergleich mit anderen ,Randstaaten' der Christenheit, vom angelsächsischen England bis zu den ostmitteleuropäischen Nachbarn, aber auch mit den Strukturen eurasischer Nomadenvölker und -reiche zu

32 Im Ausland lebende ungarische Historiker zeigten bereits früher den Wert echter Vergleiche. Zum Beispiel vermochte József Deér (1905-1972, seit 1948 in Deutschland bzw. in der Schweiz) wichtige Aspekte der Ansprüche ungarischer Herrscher auf apostolische Legation durch den Vergleich mit ähnlichen Gedanken im normannischen Sizilien zu erklären oder den ideellen Hintergrund der alten ungarischen Königsstadt Alba Regia durch einen Vergleich mit Aachen aufzzuhellen. Zwar eine Zeit lang ,nicht zitierbar' zu Hause, waren solche Hinweise von großem Wert für seine ungarische Kollegen.

33 Pál Engel, Beilleszkedés Európába, a kezdetektől 1440-ig. (Magyarok Európában [Die Ungarn in Europa]. Hrsg. v. Ferenc Glatz. Bd. 1.) Budapest 1990, 11 f. In demselben Vorwort zitiert Engel einen Satz seines damaligen Freundes Szücs: „(...) von Geschichtsschreibung kann man nur dann sprechen, wenn man mit solchen Kategorien arbeitet, die in Budapest, Bukarest und Prag das gleiche bedeuten" (ebd. $12 \mathrm{f}$.). Wie schwierig das zu verwirklichen ist, soll weiter unten angedeutet werden.

34 Erik Fügedi, La formation des villes et les ordres mendiants en Hongrie, in: Annales 25, 1970, 966 987; ders., Das mittelalterliche Königreich Ungarn als Gastland, in: Die deutsche Ostsiedlung des Mittelalters als Problem der europäischen Geschichte. Hrsg. v. Walter Schlesinger. Sigmaringen 1975, 471-507. 
erhellen. ${ }^{35}$ András Kubinyi war bahnbrechend in der vergleichenden Untersuchung etwa der Urbanisierung Ungarns und der Stadtpolitik seiner Herrscher, die er im ost- und westmitteleuropäischen Kontext untersuchte und darstellte. ${ }^{36}$ Die vergleichenden Studien von József Gerics zu Fragen der Staats- und Rechtsentwicklung im späten 13. Jahrhundert vermochten theoretische und institutionelle Parallelen etwa aus Aquileia zur Erklärung der ,vorzeitigen ständischen Episode unter dem letzten Árpáden (Andreas III., dem Venezianer) aufzuzeigen. ${ }^{37}$ Emil Niederhauser, einer der wenigen ungarischen Historiker, der viele Sprachen Osteuropas beherrscht (womit ich auf die Borniertheit unserer Schulung hinweisen möchte!), schrieb meist über die Neuzeit, aber seine Exkurse ins Spätmittelalter zeichneten sich durch Vergleiche mit dem Balkan und Osteuropa aus. ${ }^{38}$ Unter den jüngeren Historikern möchte ich meinen Kollegen Gábor Klaniczay hervorheben, der eine breite Palette dynastischer Heiligkeit entwarf, um in diesem gesamteuropäischen Zusammenhang die Besonderheiten Ostmitteleuropas und Ungarns einzuordnen. Es wurde ihm (und seinem Vater, dem Literaturhistoriker Tibor Klaniczay) klar, daß hagiographische Traditionen, die in Ungarn entstanden waren, im Laufe der Transmission, etwa nach Italien, seltsame Metamorphosen durchmachten, die dann wiederum auf die Heiligenverehrung in Mitteleuropa zurückwirkten. Klaniczays Studien dürfen auch in dem Sinne als Beispiel der heutigen Bemühungen gelten, daß sie sich unmittelbar an die von Historikern wie František Graus, Robert Folz oder André Vauchez aufgeworfenen Fragen anschließen und diese kritisch rezipierend, mit dem ostmitteleuropäischen Material ergänzen bzw. revidieren. ${ }^{39}$ In all diesen vergleichenden Arbeiten ist zudem wichtig, daß sie sich nicht mehr ausschließlich ,nach Westen' orientieren, sondern immer mehr dessen gewahr werden, daß Ungarns Entwicklung im Rahmen eben jenes „drit-

35 Diese Aspekte kommen auch in seinem Hauptwerk: György Györffy, István király és müve [König Stephan und sein Werk]. Budapest 1977 (dt.: Wirtschaft und Gesellschaft der Ungarn um die Jahrtausendwende. Budapest 1983; engl.: Saint Stephen the King. Boulder 1986) zum Tragen; s. ferner z. B. ders., $\mathrm{Zu}$ den Anfängen der ungarischen Kirchenorganisation auf Grund neuer quellenkritischer Ergebnisse, in: ArchHPont 7, 1969, 79-113; ders., Die Anfänge der ungarisch-slawischen Beziehungen, in: Studia Slavica Acad. Sc. Hung. 36, 1990, 159-186.

36 S. jetzt die beiden Sammelbände: András Kubinyi, König und Volk im spätmittelalterlichen Ungarn. Stădteentwicklung, Alltagsleben und Regierung im mittelalterlichen Ungarn. (Studien zur Geschichte Ungarns, Bd. 1.) Herne 1998; ders., Matthias Corvinus. Die Regierung eines Königreichs in Ostmitteleuropa, 1458-1490. (Studien zur Geschichte Ungarns, Bd. 2.) Herne 1999.

37 Z. B. József Gerics, Quellenanalyse zur Geschichte des Ständewesens in Ungarn am Ende des 13. Jahrhunderts, in: Herrschaftsverträge, Wahlkapitulationen, Fundamentalgesetze. Hrsg. v. Rudolf Vierhaus. (VMPIG, Bd. 56.) Göttingen 1977, 131-139; ders., Über eine ungarländische Anwendung des Terminus ,Status' in der Bedeutung ,Versammlung, Congregatio' im Gesetz von 1298, in: Annales Universitatis Scientiarum Budapestinensis de Rolando Eoetvoes Nominatae, Sectio linguistica 7, 1976, 109-117.

38 Z. B. Emil Niederhauser, Unity and Variety in Eastern European Development, in: Danubian Historical Studies 2, 1988, 3-21.

39 Gábor Klaniczay, The Cinderella-Effect. Late Medieval Female Sainthood in Central Europe and Italy, in: East central Europe/L'Europe du centre-est 20/23, 1993/96, 1, 51-68; und jetzt. ders., Az uralkodók szentsége a középkorban [Herrscherheiligkeit im Mittelalter]. Budapest 2000 (engl. Übersetzung in Vorbereitung). 
ten Europas" zu verstehen und analysieren sei, das Szücs so treffend charakterisiert hatte. Während Byzanz schon immer mit im Blickfeld gewesen ist ${ }^{40}$, wird heute, besonders fur die Frühzeit und manch andere Fragen (wie zum Beispiel Volksglauben), auch die eurasische Dimension herangezogen. ${ }^{41}$

Nach der Öffnung der Grenzen gen Westen kam ein neuer Anstoß zur vergleichenden Methode hinzu: es wurde immer mehr Mediävisten klar, daß sie die eigene Geschichte erst dann ins Gesamtbild der internationalen Forschung einbauen und bekanntmachen können, wenn sie sich jenen Fragestellungen zuwenden, die ,im Westen' diskutiert werden, auch wenn diese gelegentlich als bloße Modeerscheinungen erkennbar sind. Unsere Vorhaben in bezug auf den Adel Ostmitteleuropas entstammten vor allem diesem Bedürfnis. Wir mußten feststellen, daß es zwar wichtige Studien auf diesem Gebiet gab (und zwar nicht erst aus den letzten Jahren), doch sind diese - nur teilweise aus sprachlichen Gründen - von den Historikern mittelalterlicher Eliten unbeachtet geblieben. Daran war auch die Tatsache schuld, daß - gewiß auch wegen der mangelnden Kontakte und der Schwierigkeiten, die neueste Literatur zu beschaffen - jenen Fragen und Methoden, mit denen etwa ein Georges Duby oder Léopold Genicot oder Lawrence Stone in diesem Gebiet den Ton angegeben hatten, in Ostmitteleuropa nicht, oder jedenfalls nicht in vergleichbarer Form, nachgegangen wurde. Es war auch auffallend, daß einige Studien aus der Region, die mehr oder weniger dem gängigen Diskurs entsprachen, mit größtem Interesse aufgenommen, aber, mangels ausreichender Parallele, oft als für die gesamte Region und für größere Zeiträume gültig erschienen. ${ }^{42}$ Die Losung lautete daher: ohne in den laufenden Diskussionen mitsprechen zu können, bleiben wir ungehört, auch wenn die eine oder andere Studie in eine westliche Sprache übersetzt wird. ${ }^{43}$

In Anbetracht dessen begannen wir gleich nach der Wende eine Serie von Sammelbänden (ursprünglich als Zeitschrift geplant, doch mangels Geld und Organisation zu „zeitweiliger Veröffentlichung" umgetauft) unter dem Titel History \& Society in Central Europe herauszubringen. Band 2 dieser Serie (in Zusammenarbeit mit Medium Aevum Quotidianum, als dessen Band 29) war dem mittelalterlichen und frühneuzeitlichen Adel gewidmet. Die Verfasser wurden gebeten, sich zu Fragen, die in der westlichen Eliteforschung diskutiert

40 Man denke nur an die Arbeiten von Gyula Moravcsik, zusammengefaßt etwa in: Byzantium and the Magyars. Budapest/Amsterdam 1970.

41 S. z. B. András Róna-Tas, Hungarians and Europe in the Early Middle Ages. An Introduction to Early Hungarian History. Budapest 1999.

42 Ein auffallendes Beispiel ist das wichtige Buch von Witold Kula über den ,Feudalismus' in Polen (Théorie économique du système féodal. Pour un modèle de l'économie polonaise $\mathrm{XVI}^{\mathrm{e}}-\mathrm{XVIII}{ }^{\mathrm{e}}$ siècle. [Civilisations et sociétés, vol. 15.] Paris 1970), das im,Westen' bald bekannt und als die Charakterisierung ostmitteleuropäischer Entwicklung schlechthin - die es weder anstrebte noch darstellte - verstanden wurde.

43 Es ist z. B. auffallend, wie wenig Kenntnis von den Veröffentlichungen in den fremdsprachigen Zeitschriften (den verschiedenen Acta Historica und dergleichen mehr) und Sammelbändern aus der Region (z. B. denen, die zu den Welthistorikertagen erschienen) in der internationalen Forschung genommen wurde, obwohl sie schon immer viele wertvolle und der vergleichenden Forschung nützliche Beiträge enthielten. 
werden (Besitzverhältnisse, Familienstruktur, Differenzierung usw.) aus ihrer lokalen oder regionalen Sicht zu äußern. Einiges haben wir aus dem Ungarischen, aus früher erschienenen Arbeiten (etwa von Hajnal ${ }^{44}$ ) eigens für den Band übersetzt. Schon hier zeigte sich, daß den ostmitteleuropäischen Kollegen die Erfahrung, historische Themen gleichsam historischanthropologisch oder strukturell zu erfassen und in einen breiteren Zusammenhang einzuordnen, so sehr fehlt, daß am Ende, trotz redlichen Bemühens allerseits, nur eine Sammlung entstand, in der jeder sein einstudiertes Liedchen sang. Trotzdem, oder eben deshalb, kündigten wir ein anspruchsvolles Forschungsvorhaben an - von der Central European University, Budapest, kulant unterstützt - über den ostmitteleuropäischen Adel, genauer gesagt: über den mittleren und Kleinadel (denn die Aristokratie ist verhältnismäßig gut untersucht). Wir waren darin durch eine sehr gut gelungene Vortragssitzung auf dem Mediävistenkongreß in Leeds, 1994 ermutigt worden, wo Karl-Heinz Spieß auf Grund genau umrissener Fragen (über die Lage der Frauen und Witwen in Adelsfamilien) drei Historiker bewegen konnte, ziemlich klar zur Sache zu sprechen und deutsches, tschechisches und burgundisches Material vergleichend vorzutragen. Wir planten also einen ähnlichen, präzisen ,Fragenkatalog' auszuarbeiten, der auf jene Probleme orientiert werden sollte, die in Frankreich, England, Italien und Deutschland in diesem Problemkreis diskutiert werden. Bereits in diesem Stadium erwies sich - bei der ersten Arbeitstagung mit ungarischen, polnischen und kroatischen Kollegen -, daß man ungern bereit ist, sich auf so Spezifisches festzulegen. Es wurden so viele Fragen vorgeschlagen, daß damit de facto nur das gleiche erreicht werden konnte, was bislang immer geschehen war: Jeder sprach über dasjenige, was er oder sie seit eh und je betrieben hatte, womit dann ein relevanter und kritischer Vergleich doch wieder unmöglich wurde. Erst anderthalb Jahre später, nach einigen Arbeitstagungen, stimmten die Teilnehmer des Projekts einer begrenzten Fragestellung zu. Als Schlußdiskussion - und daraus folgend in einem Sammelband als Abschluß - sollten Beiträge über zwei (so schien uns) in der Region unbearbeitete, aber international relevante Fragen in Angegriff genommen werden: Heiratsstrategien und verwandte Phänomene einerseits und Abhängigkeitsverhältnisse innerhalb der Adelsgesellschaft (,Klientelismus', ,Vasallităt' und ähnliches mehr) andererseits. Das Endergebnis blieb heterogen: Aus den anderthalb Dutzend eingereichten Studien hielten sich nur ein oder zwei Kollegen streng an die Vorgabe, die meisten anderen sprachen zwar manche Aspekte des gestellten Rahmens an, aber selten in der Art und Weise, wie wir es uns vorgestellt hatten. Vor allem waren wenige bereit, den herkömmlichen Begriffsapparat kritisch unter die Lupe zu nehmen und zu versuchen, aus den Ergebnissen der Eliteforschung außerhalb der Region (ja des eigenen Landes) Lehren zu ziehen.

Doch es wäre falsch, sich einfach über die Unerfahrenheit ostmitteleuropäischer Historiker in der Teamarbeit zu beklagen. Die Probleme liegen tiefer, und das war die wichtigste Erkenntnis, die aus dem Projekt hervorging. Erstens kann keine sinnvolle vergleichende Geschichtsforschung betrieben werden, ohne die Begriffe - die mittelalterlichen sowohl wie die modernen - eingehend zu prüfen und eine ,Sprachregelung' zu treffen. Zweitens sollen Fragen nicht einfach aus der ,allgemeinen' (lies: westeuropäischen) Diskussion importiert 
werden, denn für diese Ansätze ist nicht nur die Quellenlage hoffnungslos ungünstig, sondern die historische Entwicklung selbst scheint so abweichend zu sein, daß keine sinnvollen Antworten gegeben werden können.

Das Problem der Terminologie ${ }^{45}$ ist keineswegs begrenzt auf die Sprachgewohnheiten der vergangenen Jahrzehnte, mit ihrem, für die ostmitteleuropäische Geschichte gewiß irrelevanten (aber heute ja auch für den Rest Europas in Frage gestellten) Begriff von ,Feudalismus' oder gar ,zweiter Leibeigenschaft'. Bis auf ,deutsche' lehnrechtliche Elemente in Böhmen und im Südwesten (Krain usw.) gab es keine, nach welcher Definition auch immer beschreibbaren feudalen Abhängigkeiten in diesem Raum. Und Leibeigenschaft entwickelte sich zum ersten Mal im 16. Jahrhundert, und dies auch nur in begrenzten Gebieten, denn in den früheren Jahrhunderten war der Großteil des Bauerntums (teilweise dem Beispiel westlicher Siedler angeglichen) im wesentlichen persönlich (also ,im Leib') frei, wenn auch von den Landbesitzern abhängig. Doch diese Korrekturen lassen sich verhältnismäßig einfach durchfuhren. Worum es vielmehr geht, sind die zahlreichen sozialen und juristischen Kategorien und Institutionen, die bislang fast ausschließlich innerhalb der Landesgeschichte beschrieben und analysiert wurden, gelegentlich mit (meist unbegründeten) Vergleichen zu vermeintlichen Parallelen in ganz anderen Kontexten West- oder Westmitteleuropas.

Ein Beispiel zum Begriffsapparat. Es ist wohl bekannt, daß mittelalterliche Adelsgesellschaften - zumindest in der Frühzeit - in verschiedene, auf echte oder fiktive Blutsverwandtschaft gegründete Gruppen aufgeteilt waren: Sippen, Geschlechter, Clans usw. Soweit ersichtlich, blieben solche Gruppierungen, oft durch gemeinsamen Besitz eng zusammengefuggt, in Ostmitteleuropa auch für das Hoch- und Spätmittelalter bestimmend. Sie sind in den Quellen meist als genus oder generatio(nes) genannt ${ }^{46}$, und zwar in fast allen Ländern der Region, über mehrere Jahrhunderte hinaus. Somit wäre, prima facie, der Vergleich zwischen ihnen unproblematisch. Bei näherer Betrachtung stellt es sich aber heraus, daß das lateinische Wort in Zeit und Raum recht verschiedene Personengruppen beschrieb. In seiner Monographie über ein mittleres Adelsgeschlecht aus Oberungam (Slowakei) entwarf Erik Fügedi eine Folge von modellhaften Definitionen für ungarische generationes. Es scheint, daß im 9.-11. Jahrhundert diese Sippen ${ }^{47}$ wahrscheinlich blutsverwandt waren, die Bestand-

45 Ich lasse die recht komplizierte Grundfrage, nämlich inwieweit der zentrale Begriff ,Adel f für diesen Raum des „pays de la noblesse nombreuse“" (wie der Titel einer guten Übersicht von László Maksay, Budapest 1980, lautet) angebracht ist, beiseite. Es ist wohl bekannt, daß die breite Schicht von freien Leuten mit mehr oder weniger ,Freiheiten' und Privilegien, allgemein als Adel oder auch Gemeinadel (szlachta, köznemesség) bezeichnet, keineswegs mit der noblesse Frankreichs oder dem Adel im Reich gleichzusetzen ist. In vieler Hinsicht ähneln z B. abhängige, aber persönlich privilegierte Kleinadelige in Ungarn oder Polen manchen Ministerialen Deutschlands oder Österreichs. Doch da sich der Begriff in der Literatur eingebürgert hat, müssen wir damit leben und von Fall zu Fall glossieren, über welche Schicht (im juristischen, ökonomischen oder sozialen Sinne) wir gerade reden.

46 Soweit ersichtlich wurden diese beiden Wörter synonym benutzt, aber dies müßte noch näher nachgeprüft werden.

47 Und hier soll gleich darauf hingewiesen werden, daß die ganze deutsche Diskussion über ,Sippe' und ,Geschlecht' zwar in Ostmitteleuropa rezipiert, doch nie kritisch mit den dortigen Verhältnissen verglichen wurde. Man benutzte magyarische (oder polnische, tschechische usw.) Wörter, meist nur aus 
teile der landnehmenden Stämme (auch ein problembelastetes Wort!) darstellten, und militärische, wohl auch kultische Bedeutung hatten. Im 12.-13. Jahrhundert wurde es unter dem Adel (aber auch unter Gemeinfreien und gelegentlich gar Minderfreien) üblich, Personen als Mitglieder einer generatio zu bezeichnen mit dem Prädikat de genere soundso. Diese genera, von denen manche von den ,Ursippen' abgestammt haben konnten (was sich kaum nachweisen läßt), betrachteten sich als Nachfolger eines berühmten Spitzenahn, besaßen gemeinsamen Besitz und oft auch eine eigene Kultstätte (etwa eine Nekropolis im „Sippenkloster $\left.{ }^{648}\right)$. Im 14. Jahrhundert scheint der Charakter dieser generationes sich zu ändern, was zum Beispiel daraus hervorgeht, daß Mitglieder seltener als fratres generationales und öfter als fratres condivisionales bezeichnet wurden: die Bedeutung der (zumindest postulierten) Blutsverwandtschaft wurde also von der des gemeinsamen (aufgeteilten oder nicht geteilten, aber durch gegenseitigen Erbanspruch zusammengehörenden) Besitzes abgelöst. Die Wichtigkeit dieser Art von generationes ist auch daran abzulesen, daß viele Adelige im 14. Jahrhundert neue Landschenkungen ${ }^{49}$ beantragten, in denen das Erbrecht der Seitenlinien beseitigt wurde und nur dem Beschenkten und seinen direkten Nachkommen zukam. Am Ende des 15. Jahrhunderts scheinen diese genera sich weiter zu ändern und - obwohl das Erbrecht aller männlichen Nachkommen weiterhin die Regel blieb - sich allmăhlich in Familien in modernem Sinne zu zerspalten. Diese drei oder vier verschiedenen Bedeutungen des lateinischen Fachausdruckes versuchte Fügedi mit neuen ungarischen Übersetzungen auseinanderzuhalten, wobei er sich einer solchen künstlichen Konstruktion bedienen mußte, daß er für die generationes des 13.-15. Jahrhunderts den Ausdruck „klán“ (also das englisch-schottische Wort clan in magyarischer Rechtschreibung!) einfuhrte. ${ }^{50}$ Ob nun diese verhältnismäßig klare Scheidung die tatsächlichen Verhältnisse des Mittelalters widerspie-

späteren Jahrhunderten bekannt, und das Problem ihrer Anwendbarkeit kommt erst bei der Übersetzung in eine Fremdsprache auf. Dann wăhlt der eine Übersetzer das eine, ein anderer das andere Wort, ohne zu prüfen, ob damit der ausländische Leser, dem die Unterschiede wohl bewußt sind, auch richtig informiert wird. Darauf komme ich noch zurück.

48 Klöster, von einem bedeutenden Mitglied des genus gegründet, wurden in der Forschung als „Sippenklöster" (nemzetségi monostorok) bezeichnet, doch dieser Begriff ist heute unter Beschuß, denn es scheint, daß sie meist von einem mächtigen Mitglied der Sippe (für sich und seine Familie) gestiftet wurden und erst spăter, und auch nicht immer, zum sakralen Zentrum der generatio wurden. Zu dieser Diskussion s. Erik Fügedi, Sepulierunt corpus eius in proprio monasterio. A nemzetségi monostor [Das Sippenkloster], in: Századok 125, 1991, 35-67; Beatrix Romhányi, Monasteriologia Hungarica Nova. Diss. phil. D. Budapest 1996, 13-18.

$49 \mathrm{Da}$ es sich um eine bedeutende Wandlung um die Mitte des 14. Jh. - die vielleicht mit der Knappheit der verschenkbaren Königsgüter zusammenhängt - handelt, wurde neuerdings angedeutet von Pál Engel, Nagy Lajos ismeretlen adományreformja [Ein unbekannte Donationsreform Ludwigs des Großen], in: Történelmi Szemle 39, 1997, 137-157; ders., Erbteilung und Familienbildung, in: ... The Man of Many Devices, Who Wandered Full Many Ways ... Fschr. János M. Bak. Ed. Balázs Nagy/Marcell Sebök. Budapest 1999, 411-421.

50 In der englischen Übersetzung seines Buches entschlossen wir uns, diese als „kindred“ zu bezeichnen, ein Ausdruck, der auch sonst von der historischen Anthropologie angewandt wird. Aber ob es immer das gleiche bedeutet? 
gelt, ist keineswegs so eindeutig, wie das Fügedi meinte. ${ }^{51}$ Doch vorerst darf sie als Arbeitshypothese gelten. Und damit haben wir nur die Entwicklung in einem Land, wenn auch über mehrere Jahrhunderte, skizziert.

Wie vergleichbar sind aber jene wohlbekannten ,Adelsnester' Polens mit diesen Sippen oder Geschlechtern? Generatio ist auch für sie das meist benutzte lateinische Wort, doch scheint dieser Begriff nicht nur zeitlich, sondern auch räumlich (innerhalb der Gebiete des Königreichs, etwa zwischen Schlesien und Pommern oder Masowien) ganz anderen Sinn gehabt zu haben. Während die Existenz eines Personenverbandes mit dem gleichen heraldischen Zeichen (herb) und Schlachtruf (polnisch: proklama) seit dem 12. Jahrhundert bezeugt ist, entwickelten sich ,Sippennamen' erst viel später, im 14. Jahrhundert. ${ }^{52} \mathrm{Da}$ im 14.-15. Jahrhundert nicht einmal die Fiktion echter oder legendärer Blutsverwandtschaft aufrechterhalten wurde, ist durch die Adoption vieler (katholischer) Adelssippen Litauens eindeutig. Während in Polen, so scheint mir, viel mehr an zuverlässiger genealogischer Forschung betrieben wurde als in Ungarn, hat man jene strukturellen Fragen, die etwa Fügedi aufgegriffen hatte, noch sehr wenig untersucht. Demgemäß bleibt die polnische generatio weiterhin ein Begriff, den man, aufgrund der vorhandenen Kenntnisse, schwer mit den ungarischen aber welchen der drei oder vier Typen ungarischer Geschlechter? - vergleichen kann. Sippe (Geschlecht, genus, generatio) ist aber nur einer von mehreren Schlüsselbegriffen in der Adelsforschung. Hof, Rittertum, Ehestrategien, Erbrecht, Klientel (in Ungarn familiaritas genannt) usw. werfen mehr Fragen auf, als man kurzerhand klären und vergleichen könnte.

Die Quellenlage ist auch kein einfaches Problem. Es geht nämlich nicht nur darum, daß in den zahlreichen Kriegen und Besatzungen die Urkunden und Register verschollen oder verbrannt sind, daher noch weniger aus dem Mittelalter übrig blieb als in Ländern mit weniger turbulenter Geschichte. ${ }^{53}$ Erik Fügedi hat nachgewiesen, daß der ungarische Adel in einer ,mündlichen Kultur' lebte, und zumindest bis zum Anfang des 16. Jahrhunderts Recht und Besitz, ja Genealogie und Stand vornehmlich (oder gar ausschließlich) aufigrund mündlicher Überlieferung und (einzelner oder kollektiver) Zeugenaussagen bestimmt worden war. ${ }^{54}$

51 In der Diskussion um die Doktorarbeit meines jungen Kollegen Damir Karbić (über die aristokratische Sippe Subić in Kroatien) im Januar 2000 wurde uns klar, daß die Selbstverständlichkeit, mit der der Begriff generatio in der Region für diese Familienstruktur über die Jahrhunderte hindurch - und dann von der modernen Forschung - benutzt wurde, keineswegs begründet ist und näherer Nachprüfung bedarf. So benutzten z. B. die Subići die Formel de genere erst im Spätmittelalter, als sie anderswo bereits ,außer Mode' war, während sie die Sippschaft seit dem 13. Jh. in recht weitem Kreise gepflegt hatten.

52 S. Jan Pakulski, The Development of Clan Names in Medieval Poland, in: History and Society 2, 1994, 85-96.

53 Michael Clanchy, From Memory to Written Record. Oxford 1993, 58, schätzte, da $\beta$ von Englands mittelalterlichen Dokumenten etwa 1-2\% auf uns gekommen sind. Wenn das für das nie von Krieg überzogene Inselland richtig ist, welche Bruchteile eines Prozents soll man für dann Ostmitteleuropa schätzen?

54 Erik Fügedi, „Verba volant...“. Oral Culture an Literacy among the Medieval Hungarian Nobility, in: ders., Kings, Bishops, Nobles and Burghers in Medieval Hungary. Ed. János M. Bak. (Variorum Collected Studies Series, vol. 229.) London 1986, IV. 
D. h., daß Schriftzeugnisse nicht nur verlorengegangen sind, sondern in vielen Lebensbereichen überhaupt nie geschrieben wurden. So fehlen zum Beispiel jegliche Inventare oder Urbare fur anderen als kirchlich-monastischen Besitz bis in die frühe Neuzeit. Wir haben kaum Zeugnisse über die Größe von Ländereien, bestenfalls werden Dörfer genannt, aber wie viele Hufen (oder andere Flächeneinheiten) in diesen dem einen oder dem anderen Besitzer gehörten, bleibt im dunkeln. In Familienangelegenheiten ist die Lage nicht besser: aus etwa achtzig Ehen, die er über einen Zeitraum von über zweihundert Jahren untersuchte, war Fügedi imstande, den Namen der Frauen in dreißig und ihre Herkunft (genus) in bloß elf Fällen festzustellen. Soweit ich weiß, ist die Situation in Polen (bis auf, wie gesagt, gute genealogische Studien) nicht viel besser, während in Böhmen, durch die Registrierung von Besitz und Stand an der Landtafel, die Schriftquellen reicher fließen. Die Quellenarmut ist aber keineswegs nur eine allgemeine Erscheinung: sie ist differenzierter. In manchen Bereichen, für die etwa im Mâconnais für Duby oder im Namurois für Genicot reiches Urkundenmaterial vorlag, gibt es kaum etwas in Ostmitteleuropa, während in anderen Gebieten, zum Beispiel für die politische Tătigkeit des mittleren und kleinen Adels in den Komitaten Ungarns oder den regionalen Landtagen (sejmiki) Polens viel mehr bekannt ist, und dies war für die Politik der Königreiche recht bedeutsam, viel mehr als etwa ,county politics' für England. Wegen der neuzeitlichen Kriege ist die Quellenlage innerhalb der Region auch recht verschieden. Im Königreich Ungam vernichteten zum Beispiel die Türkenkriege fast alle Schriftzeugnisse für Slawonien, das mittlere Donaubecken und Südungarn, daher läuft man Gefahr, eine lokale Erscheinung (etwa im Norden) als furr das ganze Land ,typisch anzusehen, mangels ausreichenden Vergleichsmaterials.

Last not least wird all dies auch dadurch erschwert, daß man sich auf eine moderne Sprache furr Kommunikation und Darstellung einigen muß, da unser (und unserer Leser) Latein nicht mehr so gut ist, wie es sein sollte. Es wäre mehr oder weniger egal, ob diese Sprache deutsch, französisch, spanisch oder englisch ist, denn das Grundproblem ist immer das gleiche. Jede Sprache hat Worte und Begriffe, die aus der historischen Erfahrung des gegebenen Landes hervorgehen. Wo es keine proklama der Geschlechter gab, gibt es kein Wort dafur; wo die Töchter nicht durch ein Viertel des väterlichen Besitzes ausgesteuert werden, hat die ungarische gewohnheitsrechtliche Institution der quarta filialis (oft nur kurz quarta) keine Entsprechung. Gewiß, manche Parallelen oder Übereinstimmungen lassen sich finden, aber um diese auszuwählen, bedarf es eingehender Vergleiche. Wir einigten uns, der Realität in der heutigen Welt entsprechend, auf das Englische. Damit ergab sich die Schwierigkeit, Worte, die aus der angelsächsischen historischen Praxis entstanden sind, auf die Erscheinungen in Ostmitteleuropa zu übertragen bzw. für,Sachen', die es im mittelalterlichen England (Schottland, Wales) nicht gab, sinnvolle englische Ausdrücke zu finden. Während es so aussieht, daß die Einführung eines neuen Herren in seinen Besitz, in den Urkunden statutio oder introductio genannt, mit dem, was in England „[de]livery of seisin“ hieß, fast genau identisch ist, läßt sich der comes (ungarisch: ispán) an der Spitze eines königlichen Komitats (oder Forsts usw.) kaum mit dem sheriff einer shire gleichsetzen. Aber Stellung und Amtsbereich des comes palatinus von Ungarn sind schon mit dem Palatin Polens keineswegs identisch: Sollen aber beide als count palatine oder einfach palatine übersetzt werden? Und so weiter und so fort.

Nun soll all dies keineswegs eine Rechtfertigung zur Absage an vergleichende Studien sein. Nur müssen einige Lehren aus ihnen gezogen werden. Solche etwa, daß man zuerst, oder zumindest parallel mit anderen vergleichenden Versuchen, an einem Glossar fur das 
Thema arbeiten muß, welches zeitliche und räumliche Unterschiede gleichzeitig berücksichtigt und auch die möglichen Übersetzungen in anderen Sprachen beinhaltet. Noch tiefer gehend: Es muß ernsthaft überlegt werden, ob das Projekt, die gleichen Fragen, die in der ,westlichen' Forschung gestellt werden, und zwar mit den gleichen Methoden aufzugreifen, unbedingt so sinnvoll ist, wie wir uns das vorgestellt hatten. Die implizite Bemühung, partout nachweisen zu wollen, daß die „Länder des zahlreichen Adels ${ }^{\text {“55 }}$ zu Europa gehören und ihre Adelsgesellschaften mit denen Frankreichs oder Kastiliens vergleichbar seien, ist gewiß ein Erbe der vergleichenden Ansichten vergangener Jahrzehnte. Wăhrend das erstere heute kaum mehr fraglich sein kann, folgt letzteres nicht mit zwingender Logik daraus. Es ist gut möglich, daß weitere vergleichende Studien, mit präzisen Fragestellungen und einem klar herausgearbeiteten Begriffisapparat dazu führen werden, daß man ein eigenständiges Modell (oder gar mehrere Modelle) für die Adelsgesellschaften Ostmitteleuropas entwirft ${ }^{56}$ und ebenbürtig neben jene, die für Westeuropa ausgearbeitet worden sind, stellt. Daß ein solches Ergebnis unter Umständen auch neue Gedanken über den ,Westen' zeitigen könnte, wäre sehr wohl im Sinne von István Hajnal, und keineswegs unmöglich.

55 S. Maksay, Le pays de la noblesse nombreuse (wie Anm. 45); allerdings ist auch diese Generalisierung zu hinterfragen: Sind denn diese Gesellschaften tatsăchlich so ăhnlich, wie das oft, sowohl inner- als auch außerhalb der Region - auch in unserem Forschungsvorhaben! - angenommen wurde?

56 In der Schlußdiskussion unseres Forschungsprojektes wies vor allem Patrick J. Geary darauf hin, daß wir uns hüten sollen, fremde Hypothesen und Methoden, nur um der Konformität und der Kommunikation willen, unbedingt auf unser Gebiet anwenden zu wollen. 


\title{
Frühmittelalterliche Grundherrschaften und ihre Erforschung im europäischen Vergleich
}

\author{
Von
}

Hans-Werner Goetz

Die abendländische Grundherrschaft ist, wenngleich entwicklungs- und phasenmäßig differenziert, nicht nur ein zentrales, nach verbreiteten Lehrmeinungen (nicht zuletzt der marxistischen) sogar ein konstituierendes Kennzeichen der mittelalterlichen Geschichte, sondern darüber hinaus, unbeschadet regionaler Differenzierungen, eine gesamteuropäische Erscheinung. ${ }^{1}$ Das Thema sollte sich von daher gut für einen Vergleich eignen, wie ihn Michael Borgolte mit der in diesem Band dokumentierten Tagung angestrebt hat, auch wenn die fur die Grundherrschaft typischen Quellen, die großen karolingischen Urbare, wie Robert Fossier feststellt, lediglich aus einem Achtel des Okzidents, nämlich einem ,Dreieck ${ }^{`}$ zwischen Seine, Rhein und Bayern, stammen. ${ }^{2}$ Einem solchen Vergleich sind allerdings Grenzen gesetzt. Wenngleich Forschungen zur mittelalterlichen Grundherrschaft seit der zweiten Hälfte des 19. Jahrhunderts intensiv betrieben worden sind und man sich in den letzten beiden Jahrzehnten in Belgien, Frankreich, Italien und Deutschland, aber auch in Amerika wieder intensiv gerade mit der frühmittelalterlichen Grundherrschaft befaßt hat ${ }^{3}$, so stand diese dennoch nie im Zentrum des geschichtswissenschaftlichen Interesses, das sich zudem höchst unterschiedlich auf die einzelnen Regionen verteilt.

1 Vgl. Jan A. van Houtte, Europäische Wirtschaft und Gesellschaft von den großen Wanderungen bis zum Schwarzen Tod, in: Handbuch der europăischen Wirtschafts- und Sozialgeschichte, Bd. 2: Europäische Wirtschafts- und Sozialgeschichte im Mittelalter. Hrsg. v. dems. Stuttgart 1980, $110 \mathrm{ff}$.

2 Robert Fossier, Polyptyques et censiers. (Typologie des sources du moyen âge occidental, vol. 28.) Tumhout 1978, 33.

3 Als wichtige jüngere Studien seien exemplarisch genannt: Adriaan Verhulst (Ed.), Le grand domaine aux époques mérovingienne et carolingienne. Die Grundherrschaft im frühen Mittelalter. (Centre belge d'histoire rurale, vol. 81.) Gent 1985; Werner Rösener (Hrsg.), Strukturen der Grundherrschaft im frühen Mittelalter. (VMPIG, Bd. 92.) Göttingen 1989; ders. (Hrsg.), Grundherrschaft und băuerliche Gesellschaft im Hochmittelalter. (VMPIG, Bd. 115.) Göttingen 1995; Adriaan Verhulst, Rural and Urban Aspects of Early Medieval Northwest Europe. (Variorum Collected Studies Series, vol. 385.) Aldershot 1992; Jean-Pierre Devroey, Études sur le grand domaine carolingien. (Variorum Collected Studies Series, vol. 391.) Aldershot 1993. 
In diesem Band sollen nach dem Wunsch des Herausgebers sowohl die mittelalterlichen Phänomene (wie die Grundherrschaft) der einzelnen Länder als auch die moderne, internationale Geschichtsforschung miteinander verglichen werden. Beides ist in meinem Fall das sei gleich vorweg eingestanden - wegen der inhärenten Probleme und des ungleichen Forschungsstandes jedoch nahezu unmöglich. ${ }^{4}$ Solange zentrale Fragen der Grundherrschaft in den einzelnen Regionen offen oder strittig sind, lassen sich diese Grundherrschaften schlechterdings nicht untereinander vergleichen. Die frühmittelalterliche Grundherrschaft, auf die ich mich hier beschränke, befand sich nach verbreiteter Ansicht in vielen Gegenden noch in der Entwicklung (nach manchen sogar erst in der Entwicklung zur Grundherrschaft) und weist beträchtliche Differenzierungen auf. Ich werde mich in einem ersten Teil bei einem kurzen regionalen Vergleich der Grundherrschaft(en) daher auf die inhärenten Probleme konzentrieren und im zweiten Teil ansatzweise einen Vergleich der Forschungen versuchen. Der Schwerpunkt wird dabei auf der deutschen und der französisch-belgischen Forschung liegen, mit Seitenblicken auf Italien, England und Amerika. Der Japaner Yoshiki Morimoto, der sich seit Jahrzehnten mit diesen Problemen auseinandersetzt, hat zwei nützliche Forschungsberichte über die Jahre 1981-1992 vorgelegt - er listet für diese Zeit 261 Titel auf ${ }^{5}$-, und Ludolf Kuchenbuch zog 1988 und 1997 „Bilanzen“ zur geistlichen und zur hochmittelalterlichen Grundherrschaft. ${ }^{6}$ Diese Arbeiten können hier als willkommene Grundlage dienen.

\section{Problematik eines Vergleichs der Grundherrschaften}

Als Adriaan Verhulst 1987 auf einem von Werner Rösener organisierten Göttinger Kolloquium die Aufgabe übernahm, ost- und westfränkische Grundherrschaft des frühen Mittelalters zu vergleichen, mußte er leidvoll feststellen, daß die jüngere deutsche Grundherrschaftsforschung zwar einige wichtige Spezialstudien hervorgebracht hat, die allgemeinen Darstellungen jedoch durchweg auf dem westfränkischen Material der urbarial dokumen-

$4 \mathrm{Zu}$ den Schwierigkeiten eines sozialgeschichtlichen Vergleichs überhaupt vgl. Chris Wickham, Problems of comparing rural societies in early medieval western Europe, in: ders., Land and Power. Studies in Italian and European Social History, 400-1200. London 1994, 201-226 (zuerst in: Transactions of the Royal Historical Society 6/2, 1992, 221-246), der das Fehlen einer vergleichenden Sozialgeschichte des Frühmittelalters beklagt.

5 Yoshiki Morimoto, État et perspectives des recherches sur les polyptyques carolingiens, in: Annales de l'Est 40/1, 1988, 99-150; ders., Autour du grand domaine carolingien: aperçu critique des recherches récentes sur l'histoire rurale du haut Moyen Ầge (1987-1992), in: Économie rurale et Économie urbaine au Moyen Âge. Landwirtschaft und Stadtwirtschaft im Mittelalter. Ed. ders./Adriaan Verhulst. (Centre belge d'histoire rurale, vol. 108.) Gent/Fukuoka 1994, 25-79.

6 Ludolf Kuchenbuch, Die Klostergrundherrschaft im Frühmittelalter. Eine Zwischenbilanz, in: Herrschaft und Kirche. Beiträge zur Entstehung und Wirkungsweise episkopaler und monastischer Organisationsformen. Hrsg. v. Friedrich Prinz. (Monographien zur Gesch. des Mittelalters, Bd. 33.) Stuttgart 1988, 297-343; ders., Potestas und Utilitas. Ein Versuch über Stand und Perspektiven der Forschung zur Grundherrschaft im 9.-13. Jahrhundert, in: HZ 265, 1997, 117-146. 
tierten Klostergrundherrschaften beruhten und vergleichende Studien fehlten. ${ }^{7}$ Diese Reminiszenz mag bereits eine zentrale Schwierigkeit meines Themas veranschaulichen: Einen systematischen Vergleich der Grundherrschaften im europäischen Rahmen gibt es bislang nicht $^{8}$ (und er kann naturlich auch hier nicht geleistet werden), wăhrend die verallgemeinernden Charakterisierungen - durchweg - auf relativ schmaler und einseitiger Quellengrundlage beruhen.

Vergleicht man - als Ausgangspunkt - die gut erforschten west- und ostrheinischen Grundherrschaften, von denen ausfuhrlichere Urbare erhalten sind, zum Beispiel die klösterlichen Grundherrschaften Saint-Germain-des-Prés in der Île-de-France ${ }^{9}$, Prüm in der Eifel ${ }^{10}$, das mittelrheinische Königsgut im Lorscher Urbar ${ }^{11}$ oder das Gut Staffelsee ${ }^{12}$, so gewinnt man, trotz unterschiedlicher Überlieferung, zumindest den Eindruck, daß in allen diesen Beispielen ein voll entwickeltes Villikationssystem, also die ,klassische', nämlich zweigeteilte Grundherrschaft (mit Salland- und Hufenbetrieb und bäuerlichen Frondiensten) vorherrschte, die sich - nach einer weithin rezipierten, 1966 in Spoleto geäußerten These Adriaan Verhulsts ${ }^{13}$ - im späten 6. oder frühen 7. Jahrhundert auf den königlichen Domänen

7 Adriaan Verhulst, Die Grundherrschaftsentwicklung im ostfränkischen Raum vom 8. bis 10. Jh. Grundzüge und Fragen aus westfränkischer Sicht, in: Strukturen der Grundherrschaft (wie Anm. 3), 29-46; vgl. auch ders., Étude comparative de régime domanial classique à l'est et à l'ouest du Rhin à l'époque carolingienne, in: La croissance agricole du haut Moyen Âge. Chronologie, modalités, géographie. (Flaran, vol. 10.) Auch 1990, 87-101 (auch in: ders., Rural and Urban Aspects [wie Anm. 3], IV).

8 Werner Rösener, Grundherrschaft im Wandel. Untersuchungen zur Entwicklung geistlicher Grundherrschaften im südwestdeutschen Raum vom 9. bis 14. Jahrhundert. (VMPIG, Bd. 102.) Göttingen 1991, $111 \mathrm{ff}$., liefert immerhin einen Vergleich zwischen Weißenburg, Saint-Bertin, Prüm und Staffelsee, beschränkt sich dabei aber auf den Aspekt der Größe und Organisation der Fronhöfe. In diesen Hinsichten stellt er keine gravierenden Unterschiede fest. Aufsătze zur geistlichen Grundherrschaft des 10. und 11. Jahrhunderts in Norditalien, Frankreich und Deutschland finden sich in dem Sammelband: Chiesa e mondo feudale nei secoli X-XII. Atti della XII settimana internazionale di studio, Mendola, 24-28 agosto 1992. (Miscellanea del Centro di studi medioevali, vol. 14.) Milano 1995: Giancarlo Andenna, La signoria ecclesiastica nell'Italia settentrionale, 111-147; Olivier Guyotjeannin, La seigneurie épiscopale dans le royaume de France ( $\mathrm{X}^{e}-\mathrm{XIII}^{e}$ siècles), 151-188; Werner Rösener, Die kirchliche Grundherrschaft im deutschen Reich des frühen Hochmittelalters, 193-222.

9 Vgl. dazu Konrad Elmshäuser/Andreas Hedwig, Studien zum Polyptychon von Saint-Germain-desPrés. Köln/Weimar/Wien 1993.

10 Vgl. Ludolf Kuchenbuch, Bäuerliche Gesellschaft und Klosterherrschaft im 9. Jahrhundert. Studien zur Sozialstruktur der Familia der Abtei Prüm. (VSWG, Beih. 66.) Wiesbaden 1978, der bereits einen Vergleich vor allem mit Saint-Germain-des-Prés vorgenommen hat.

11 Vgl. Michael Gockel, Karolingische Königshöfe am Mittelrhein. (VMPIG, Bd. 31.) Göttingen 1970.

12 Vgl. dazu Konrad Elmshäuser, Untersuchungen zum Staffelseer Urbar, in: Strukturen der Grundherrschaft (wie Anm. 3), 335-369.

13 Adriaan Verhulst, La genèse du régime domanial classique en France au haut moyen âge, in: Agricoltura e mondo rurale in occidente nell'alto medioevo. (SSCI, vol. 13.) Spoleto 1966, 135-160 (auch in: ders., Rural and Urban Aspects [wie Anm. 3], I). Zur Rezeption der Theorie vgl. ders., Étude (wie Anm. 7), 89 ff. 
im merowingischen Kernraum Nordfrankreichs entwickelt ${ }^{14}$, sich von dort aus in den fränkischen Kernlanden in Neustrien bis zur Loire ${ }^{15}$ sowie in Lothringen ausgebreitet - in den Urbaren des 9. Jahrhunderts ist sie hier überall bezeugt - und sich im 9. Jahrhundert auch im Ostfrankenreich und in Norditalien ${ }^{16}$ durchgesetzt hatte. ${ }^{17}$ Ihre Existenz in Alamannien und Bayern ist bereits ein Jahrhundert früher in den berühmten Paragraphen der beiden entsprechenden Volksrechte über die „Kirchenhörigen“ bezeugt (dabei wurde allerdings noch streng zwischen coloni und servi unterschieden) ${ }^{18}$; die frühesten Schenkungen an das Kloster St. Gallen aus der Mitte des 8. Jahrhunderts belegen sogar eine ausgebildete, zweigeteilte Grundherrschaft (neben der Rentengrundherrschaft) bereits der Vorbesitzer. ${ }^{19}$ Die Ausbreitung der Villikationsverfassung, die gern auf die Ausstrahlung des karolingischen Königtums zurückgeführt wird ${ }^{20}$, ging daher nicht zwangsläufig erst auf die königlichen (oder geistlichen) Träger zurück, und sie erfolgte jedenfalls, wie Ludolf Kuchenbuch betont, weder linear noch kontinuierlich noch konzentrisch. ${ }^{21} \mathrm{Ob}$ die sogenannte klassische Grundherr-

$14 \mathrm{Da} ß$ auch Formeln und Volksrechte bereits in der Merowingerzeit die Existenz einer zweigeteilten Grundherrschaft voraussetzen, zeigt Dieter Hägermann, Einige Aspekte der Grundherrschaft in den fränkischen formulae und in den leges des Frühmittelalters, in: Le grand domaine (wie Anm. 3), 51-77.

15 Unter Karl dem Großen reichte das System bis zur Seine, unter Karl dem Kahlen bis zur Loire; südlich davon setzte es sich hingegen vor der Jahrtausendwende nicht durch. Vgl. Michel Rouche, Géographie rurale du royaume de Charles le Chauve, in: Charles the Bald. Court and Kingdom. Papers based on a Colloquium held in London in April 1979. Ed. Margaret Gibson/Janet Nelson. Oxford 1981, 193-211.

16 Hier breitete sich das „sistema curtense“ in der Karolingerzeit aus. Vgl. Bruno Andreolli/Massimo Montanari, L'azienda curtense in Italia. Proprietà della terra e lavoro contadino nei secoli VIII-XI. Bologna 1983, 57 ff., die es (15 ff.) ebenfalls als charakteristischste Form der Wirtschaftsorganisation bezeichnen.

17 Ob tatsächlich erst von Nordfrankreich aus phasenweise eine gezielte Ausbreitung erfolgte, ist allerdings kaum endgültig geklärt; letztlich stammen von dort nur die ältesten Zeugnisse. In einem Aufsatz über die „Verschiedenheit des domanialen Systems“ hat Verhulst selbst später eher die Diskontinuität des Systems betont: Adriaan Verhulst, La diversité du régime domanial entre Loire et Rhin à l'époque carolingienne, in: Villa - curtis - grangia. Landwirtschaft zwischen Loire und Rhein von der Römerzeit zum Hochmittelalter. Hrsg. v. Walter Janssen/Dietrich Lohrmann. (Francia, Beih. 11.) München/Zürich 1983, 133-148 (auch in: ders., Rural and Urban Aspects [wie Anm. 3], III).

18 Vgl. Theodore-John Rivers, The manorial system in the light of „Lex Baiuvariorum“ I, 13, in: FMSt 25, 1991, 89-95, der auf den Widerspruch zwischen den (starren) Gesetzen und der weit größeren Variation in der Praxis im Spiegel der Urkunden und Urbare hinweist; Wolfgang Metz, Die hofrechtlichen Bestimmungen der Lex Baiuuariorum I, 13 und die fränkische Reichsgutsverwaltung, in: DA 12, 1956, 187-196.

19 Vgl. Hans-Werner Goetz, Beobachtungen zur Grundherrschaftsentwicklung der Abtei St. Gallen vom 8. zum 10. Jh., in: Strukturen der Grundherrschaft (wie Anm. 3), 197-246. Entsprechend viele Hinweise auf ein Villikationssystem gibt es auch in Bayern. Vgl. Wilhelm Störmer, Frühmittelalterliche Grundherrschaft bayerischer Kirchen (8.-10. Jahrhundert), in: ebd. 370-410. Vgl. auch Werner Rösener, Strukturfiormen der adeligen Grundherrschaft in der Karolingerzeit, in: ebd. 126-180.

20 Vgl. etwa Rösener, Strukturformen (wie Anm. 19), 154 f. Die Karolingerzeit hat vor allem Karl Theodor von Inama-Sternegg, Deutsche Wirtschaftsgeschichte. Bd. 1. Wien 1891, als wegweisende Epoche der Ausbildung der Villikationsverfassung betrachtet.

21 Kuchenbuch, Die Klostergrundherrschaft (wie Anm. 6), 320 f. 
schaft sich von West nach Ost ausgebreitet hat (Verhulst), ob regionale Besonderheiten vorherrschten (Kuchenbuchs These der „Rentenlandschaften“22) oder ob jeweils andere Wirtschaftsstrukturen entscheidend waren (Rösener) ${ }^{23}$, bleibt folglich umstritten. Bei der Frage des Ursprungs der Grundherrschaft wäre zudem zu differenzieren zwischen der Entstehung a) des Großgrundbesitzes, b) der Wirtschaftsformen, c) der Herrschaftsrechte, d) der Administration (Organisation) und e) der einschlägigen Schriftzeugnisse.

Immerhin könnte man (grob) eine Großregion der (verbreiteten) Villikationsverfassung nördlich und östlich der Loire von dem Raum südlich der Loire, wo jene nahezu unbekannt war, und, ganz ähnlich, zwischen dem langobardischen Norden und dem Süden Italiens unterscheiden, wo das Domanialsystem ebenfalls keinen Einzug hielt ${ }^{24}$, muß dann aber erstens anerkennen, daß wir immer nur punktuelle Belege besitzen, wobei die - insgesamt wenigen - großen Urbare unser Bild bestimmen. Und zweitens gab es auch nach Ausweis dieser Urbare neben den Villikationen andere Betriebssysteme, nämlich vor allem die Gutswirtschaft (mit ausschließlichem Sallandbetrieb) und die Abgabengrundherrschaft (ohne Sallandbetrieb), so daß vor einer Überschätzung der Verbreitung der Villikationsverfassung zu Recht gewarnt wird. ${ }^{25}$ Die umfangreiche, aber weitgestreute Grundherrschaft des Klosters Werden an der Ruhr war beispielsweise weithin, doch keineswegs ausschließlich, auf Hebestellen ausgerichtet, ohne daß eine solche Beobachtung nun Rückschlüsse auf eine trägeroder regionenspezifische Ausrichtung zuließe. Werner Rösener konnte vielmehr nachweisen, daß das Betriebssystem innerhalb einer Grundherrschaft variierte und von der Besitzkonzentration und anderen Faktoren abhängig war, man hingegen nicht einfach zwischen einer „fränkischen“ und einer „sächsischen“ Grundherrschaft unterscheiden darf. ${ }^{26}$ Die idealtypische Unterscheidung nach Regionen, wie sie vor allem Friedrich Lütge zugrundelegte ${ }^{27}$, wird dadurch fragwürdig, und auch die Unterschiede zwischen königlicher, geistlicher und priva-

22 Ludolf Kuchenbuch, Probleme der Rentenentwicklung in den klösterlichen Grundherrschaften des frühen Mittelalters, in: Benedictine Culture 750-1050. Ed. Willem Lourdaux/Daniel Verhelst. Leuven 1983, 132-172; zur Kritik Verhulst, La diversité (wie Anm. 17), 136 ff.; Morimoto, État et perspectives (wie Anm. 5), 104.

23 Vgl. unten Anm. 26.

24 Vgl. etwa Massimo Montanari, Contadini e città fra Langobardia e Romania. Florenz 1988; Andreolli/Montanari, L'azienda curtense (wie Anm. 16), 161 ff.; Chris Wickham, Early Medieval Italy. Central Power and Local Society 400-1000. London/Basingstoke 1981, 101; Morimoto, Autour du grand domaine (wie Anm. 5), 33. Umstritten ist in der italienischen Forschung auch, ob die Frondienste ein Relikt der Antike (Montanari) oder ein Ergebnis der Hufenwirtschaft sind (Andreolli); vgl. Morimoto, Autour du grand domaine (wie Anm. 5), $53 \mathrm{ff}$.

25 Vgl. Rösener, Grundherrschaft im Wandel (wie Anm. 8), 40.

26 Werner Rösener, Strukturformen der ălteren Agrarverfassung im săchsischen Raum, in: NdsJb 52, 1980, 107-143, gegen Georg Droege, Fränkische Siedlung in Westfalen, in: FMSt 4, 1970, 271-288. Vgl. auch Werner Rösener, Zur Struktur und Entwicklung der Grundherrschaft in Sachsen in karolingischer und ottonischer Zeit, in: Le grand domaine (wie Anm. 3), 173-207.

27 Friedrich Lütge, Die mitteldeutsche Grundherrschaft. Untersuchungen über die băuerlichen Verhăltnisse (Agrarverfassung) Mitteldeutschlands im 16.-18. Jahrhundert. Jena 1934. 2., stark erw. Aufl.: Die mitteldeutsche Grundherrschaft und ihre Auflösung. Stuttgart 1957. 
ter Grundherrschaft ${ }^{28}$ wird man letztlich nicht überbetonen dürfen. ${ }^{29}$ In Wirklichkeit sind die verschiedenen Betriebssysteme Idealtypen, die in der Praxis vermischt auftraten. Wenn Ulrich Weidinger als Hauptergebnis seiner Untersuchungen zur Grundherrschaft des Klosters Fulda einen „Mischcharakter der Klosterökonomie“ aus Villikationsverfassung, Gutswirtschaft und Hebeamtsverfassung feststellt ${ }^{30}$, so scheint mir das zumindest in den ostrheinischen Gebieten die Regel gewesen zu sein. ${ }^{31}$ Es ist aber auch im Westen nicht unbekannt, wie sich an der Grundherrschaft von Montier-en-Der zeigen läß $\mathrm{t}^{32}$, und anscheinend auch für Italien typisch. ${ }^{33}$

Nicht minder problematisch ist ein Vergleich der ost- und westrheinischen Grundherrschaften im einzelnen. Als besondere Kennzeichen der ostrheinischen Grundherrschaft gelten nach herrschender Ansicht ${ }^{34}$ kleinere Höfe mit weniger Salland ${ }^{35}$ und einer geringen Zahl der zugehörigen Hufen, aber einer hohen Zahl von mancipia, die jedoch zunehmend auf Bauernhufen gesetzt wurden (dieser Prozeß war nach Verhulst Mitte des 9. Jahrhunderts abgeschlossen), ein entsprechend hoher Anteil der Unfreien und der Unfreienhufen ${ }^{36}$ gegen-

28 Für eine Differenzierung nach den Trägern plädiert Alfred Haverkamp, „Herrschaft und Bauer“ - das „Sozialgebilde Grundherrschaft“ [Zusammenfassung Teil I - Südliches Deutschland], in: Die Grundherrschaft im späten Mittelalter. Bd. 2. Hrsg. v. Hans Patze. (VuF, Bd. 27.) Sigmaringen 1983, 315-347, hier $346 \mathrm{f}$., in bezug auf das späte Mittelalter.

29 Vgl. Goetz, Beobachtungen (wie Anm. 19), 230: Private Schenkungen an das Kloster St. Gallen belegen immer wieder ähnliche Strukturen der privaten Grundherrschaft, die zunächst sogar unverändert in der klösterlichen Grundherrschaft aufgingen, so daß wohl nicht erst König oder Klöster als ,Begründer der Grundherrschaft angesehen werden können. Vgl. auch Ulrich Weidinger, Untersuchungen zur Wirtschaftsgeschichte des Klosters Fulda in der Karolingerzeit. (Monographien zur Gesch. des Mittelalters, Bd. 36.) Stuttgart 1991, 274 ff., zu Fulda. Nach Rösener, Strukturformen (wie Anm. 19), 175 f., waren die Höfe der privaten Grundherrschaft kleiner als in der geistlichen, lagen jedoch ebenfalls in Streulage.

30 Weidinger, Untersuchungen (wie Anm. 29), 278. Man wird meines Erachtens nicht von einem „Auseinanderfallen der Klosterökonomie in unterschiedliche Formen der Wirtschaftsverfassung" sprechen dürfen (vgl. ebd. 244), sondern deren Zusammenwirken betonen müssen. Weidinger selbst stellt folgerichtig die Überschneidungen und Überlagerungen der Systeme heraus.

31 Vgl. auch Karl-Heinz Spieß, Zur Wirtschafts- und Sozialstruktur der frühmittelalterlichen Grundherrschaft östlich des Rheines, in: HessJbLG 41, 1991, 265-276, hier 271.

32 Vgl. Claus-Dieter Droste, Das Polyptichon von Montierender. Kritische Edition und Analyse. (Trierer Hist. Forsch., Bd. 14.) Trier 1988, 143 f.

33 Vgl. die Typologie bei Pierre Toubert, L'Italie rurale aux $\mathrm{VIII}^{\mathrm{e}}-\mathrm{IX} \mathrm{X}^{\mathrm{e}}$ siècles. Essai de typologie domaniale, in: I problemi dell'Occidente nel secolo VIII. (SSCI, vol. 20/1.) Spoleto 1973, 95-132, bes. $99 \mathrm{ff}$. zur ,structure domaniale italienne“.

34 Vgl. Verhulst, Étude (wie Anm. 7), 36 ff.; ders., Grundherrschaftsentwicklung (wie Anm. 7), 40 ff.

35 Vgl. dagegen aber Thomas Zotz, Beobachtungen zur königlichen Grundherrschaft entlang und östlich des Rheins vornehmlich im 9. Jh., in: Strukturen der Grundherrschaft (wie Anm. 3), 74-125: hoher Sallandanteil in der königlichen Grundherrschaft.

36 Philippe Dollinger, L'évolution des classes rurales en Bavière depuis la fin de l'époque carolingienne jusqu'au milieu du XIII' ${ }^{\mathrm{e}}$ siècle. (Publications de la faculté des lettres de l'université de Strasbourg, Fasc. 112.) Paris 1949 (dt.: Der bayerische Bauernstand vom 9. bis zum 13. Jahrhundert. München 1982), wollte in Bayern sogar ein Anwachsen der Zahl der Unfreien beobachten. 
über einem geringen Anteil der Freien unter den Hufenbauern, ferner die Übereinstimmung von Hufentyp und Rechtsstand der Hufenhalter sowie die Drei-Tage-Fron der Unfreienhufen und die Wochendienste der Freienhufen (meist zwei Wochen im Jahr). ${ }^{37}$ Verhulst erblickt gemäß seiner Evolutionstheorie in der ostrheinischen Grundherrschaft ein ,primitives Stadium “638, eine Situation wie vor der Einfulhrung der Villikationsverfassung ${ }^{39}$, und auch Ulrich Weidinger bezeichnet die Fuldaer Grundherrschaft mit ihren verstreuten Herrengutkomplexen, dem zahlreichen Gesinde und dem hohen Anteil an Viehwirtschaft als „rückständig“ und ,archaisch“. ${ }^{40}$ Ein Wandel zeichnet sich gerade in der Karolingerzeit ab. ${ }^{41}$

Man wird solche Unterschiede jedoch nicht ausschließlich als Entwicklungsstufen werten dürfen, sondern darüber hinaus die Vielfalt verschiedener Wirtschaftsformen anerkennen müssen. Tatsächlich lassen sich - und dieser Aspekt bewirkt eine weitere Komplikation des Vergleichs - fur alle angeführten (angeblichen) Merkmale mühelos Gegenbeispiele beibringen: In Staffelsee war beispielsweise der Sallandanteil, im gesamten Bistum Augsburg der Anteil der Freienhufen recht hoch ${ }^{42}$, in Weißenburg waren gerade die rechtsrheinischen Fronhöfe größer, eine Verkleinerung der Höfe und der ihnen angeschlossenen Hufen war hier ein Kennzeichen erst des 10 . Jahrhunderts ${ }^{43}$, was letztlich auf eine ,gegenläufige‘ Entwicklung weisen würde. In Werden war die Drei-Tage-Fron äußerst selten, auf den elsässischen Gütern des Klosters Weißenburg hingegen üblich ${ }^{44}$ (und das ließe sich mühelos fort-

37 Hingegen warnt Yoshiki Morimoto, „In ebdomada operatur, quicquit precipitur ei“ (Le polyptyque de Prüm, X). Service arbitraire ou service hebdomadaire? Une contribution à l'étude de la corvée au haut Moyen Âge, in: Peasants and Townsmen in Medieval Europe. Studia in honorem Adriaan Verhulst. Ed. Jean-Marie Duvosquel/Erik Thoen. Gent 1995, 347-362, davor, zwischen willkürlichen Diensten und bemessenen Wochendiensten zu unterscheiden; beide seien in der Praxis nicht so unterschiedlich gewesen.

38 Verhulst, Étude (wie Anm. 7), 42; ders., Grundherrschaftsentwicklung (wie Anm. 7), 46. Einen „archaischen" Zustand der ostrheinischen Gebiete konstatierte bereits Charles-Edmond Perrin, La Seigneurie rurale en France et en Allemagne du début du $\mathrm{IX}^{\mathrm{e}}$ à la fin du $\mathrm{XII}^{\mathrm{e}}$ siècle. Vol. 1: Les antécédents du régime domanial. La villa de l'époque carolingienne. Paris 1953, $125 \mathrm{ff}$.

39 Verhulst, Étude (wie Anm. 7), 40.

40 Weidinger, Untersuchungen (wie Anm. 29), 250 ff.; Eckhard Müller-Mertens, Die Genesis der Feudalgesellschaft im Lichte schriftlicher Quellen. Fragen des Historikers an den Archäologen, in: ZfG 12/2, 1964, 1384-1402, wollte in den ostrheinischen Zuständen des frühen Mittelalters überhaupt noch keine „Grundherrschaft“, sondern ein Nachwirken der Leib- und Sklavenherrschaft erblicken, doch war die Frage auch innerhalb der DDR-Geschichtswissenschaft höchst strittig. Vgl. den Sammelband: Eckhard Müller-Mertens (Hrsg.), Feudalismus. Entstehung und Wesen. (Studienbibliothek DDR-Geschichtswissenschaft, Bd. 4.) Berlin 1985.

41 Das hatte schon Georg von Below gegen Alfons Dopsch betont; vgl. Rösener, Strukturformen (wie Anm. 19), 180. In Bayern läßt sich vom 8. bis 10. Jh. die Schaffung und Intensivierung von Bauernhufen beobachten; so Störmer, Frühmittelalterliche Grundherrschaft (wie Anm. 19), $388 \mathrm{ff}$. Einen wichtigen Wandel in der Organisation der Weißenburger Grundherrschaft stellt Rösener, Grundherrschaft im Wandel (wie Anm. 8), 117-122, hingegen im 10. Jahrhundert fest: Neue Höfe waren (erst) jetzt erheblich kleiner, und ihnen waren weit weniger Hufen zugeordnet als zuvor.

42 Vgl. Elmshäuser, Untersuchungen (wie Anm. 12), 349 f., 355.

43 Vgl. Rösener, Grundherrschaft im Wandel (wie Anm. 8), 104. Vgl. oben Anm. 41.

44 Vgl. ebd. $106 \mathrm{f}$. 
setzen). Für Weißenburg konnte Rösener in bezug auf die Fronhofsorganisation keine gravierenden Unterschiede zwischen den links- und rechtsrheinischen Gütern der Abtei feststellen. $^{45}$ Man wird angesichts der vielfachen Abweichungen von der (angenommenen) Norm daher nirgends von einheitlichen Grundherrschaftsstrukturen ausgehen dürfen. Kennzeichnend ist vielmehr überall eine Vielfalt praktischer Ausprägungen bereits innerhalb einer Grundherrschaft. ${ }^{46}$ In Saint-Germain ${ }^{47}$ variierte bei relativ nahe beieinander gelegenen Höfen beispielsweise

- die Größe der Villikation zwischen 154 und 4114 bunuaria Ackerland,

- das Verhältnis von Salland und Hufenland (bei dem Ackerland) in den einzelnen fisci zwischen $1: 1,14$ und 1:7,75,

- die einem Fronhof zugeordnete Hufenzahl zwischen 6,5 und 225,

- die Hufengröße zwischen 3,28 und 16,23 bunuaria,

- der Anteil der Freienhufen zwischen 44,6\% und 100\%,

- der Anteil der coloni unter den Hufenbauern zwischen 17,6\% und 92,5\%,

- der servi zwischen $0,9 \%$ und $44,1 \%$,

- die Hufenbelegung zwischen einem und fünf (in einem Fall sogar zwölf!) Haltern bzw. Familien oder (insgesamt)

- zwischen einer und (als Maximum in einem Fall) 23 Personen usw.,

und auch die Dienste und Abgaben waren keineswegs durchweg ,standardisiert', auch wenn hier innerhalb eines Hofes eine Art ,Norm‘ vorherrschte. ${ }^{48}$ Ähnliche Differenzen lassen sich im Osten beobachten. In den Höfen des Lorscher Reichsurbars schwankten die Größe des Sallandes und die Zahl der Hufen enorm, ohne daß eine aufeinander bezogene Relation erkennbar wäre ${ }^{49}$, und auch in Fulda gab es erhebliche Unterschiede zwischen den Höfen einer Grundherrschaft; das Verhältnis zwischen Hufen- und Herrenland schwankte hier

45 Ebd. $103 \mathrm{ff}$.

46 Die Verschiedenheit (Typen) schon innerhalb der „azienda curtense“, des Villikationssystems, betonen Andreolli/Montanari, L'azienda curtense (wie Anm. 16), 147 ff.

47 Dieter Hägermann (Hrsg., unter Mitarbeit v. Konrad Elmshäuser und Andreas Hedwig), Polyptychon von Saint-Germain-des-Prés. Köln/Weimar/Wien 1993. Vgl. dazu grundlegend Elmshäuser/Hedwig, Studien (wie Anm. 9). Die hier präsentierten Zahlen beruhen auf eigenen Berechnungen.

$48 \mathrm{Zu}$ Gemeinsamkeiten und Unterschieden vgl. Hans-Werner Goetz, Băuerliche Arbeit und regionale Gewohnheit im Pariser Raum im fruhen 9. Jahrhundert. Beobachtungen zur Grundherrschaft von SaintGermain-des-Prés, in: La Neustrie. Les pays au nord de la Loire de 650 à 850.2 Bde. Hrsg. v. Hartmut Atsma. (Francia, Beih. 16.) Sigmaringen 1989, 505-522.

49 Lorscher Reichsurbar: Karl Glöckner (Hrsg.), Codex Laureshamensis. Bd. 3. Darmstadt 1925-1936, 173-176, Nr. 3671-3675.

Gernsheim: $\quad 264$ iorn. Salland - 53 Hufen,

Dreieich: 1627 iom. Salland - 112 Hufen,

Kaiserslautern: 91 iorn. Salland - 24,5 Hufen,

Florstadt: $\quad 1000$ iom. Salland - 60,5 Hufen. 
zwischen den Werten 2:1 und 15:1, die Hufenzahl zwischen $31 / 2$ und $43 \frac{1 / 2 .}{50}$ Für Bayern hatte schon Dollinger eine Vielfalt und Komplexität der Herrschafts-, Freiheits- und Hörigkeitsverhältnisse, eine Differenzierung des Unfreienstandes und eine große Mobilität festgestellt $^{51}$, auch wenn immer wieder „dörfliche Einheiten“ erkennbar sind. ${ }^{52}$ Nahe beieinander gelegene Höfe ein- und derselben Grundherrschaft waren demnach keineswegs einheitlich organisiert.

Bei einer solchen Ausgangslage - enorme Unterschiede ebenso zwischen den fisci einer Grundherrschaft wie zwischen verschiedenen Grundherrschaften und Răumen - wäre es beim gegenwärtigen Forschungsstand vermessen, die Grundherrschaften etwa in den einzelnen Regionen oder Teilreichen des ehemaligen Frankenreichs (Westfranken, Burgund, Ostfranken, Italien) insgesamt zu vergleichen. Grundlegende Fragen, wie sie Werner Rösener auf seinem Göttinger Kolloquium von 1987 in der Einleitung gestellt hat ${ }^{53}$, etwa nach der Verbreitung der drei Hauptformen (Villikationen, Abgabengrundherrschaft und Gutswirtschaft), der Mansustypen und Leistungsstrukturen sind nicht einmal in einzelnen Räumen, geschweige denn vergleichend klar zu beantworten. Grundherrschaftliche Verhältnisse im weiteren Sinn, nämlich die Existenz von adligen und kirchlichen Grundherren auf der einen und von abhängigen Hörigen und Haltern von Bauernstellen („tenants", „tenanciers") mit ihren Leistungen (Diensten und/oder Abgaben) auf der anderen Seite sind zwar vielfach nachweisbar $^{54}$ : in der Bretagne ${ }^{55}$ ebenso wie in Südfrankreich ${ }^{56}$, in England ebenso wie in Italien. ${ }^{57}$ Doch nicht überall lassen sich auch Strukturen und Organisationsformen dieser „Grundherrschaften“ erkennen: in der Bretagne ebensowenig wie in England, wo aus der vornormannischen Zeit kaum entsprechende Quellen vorliegen ${ }^{58}$, wăhrend schon die Gesetze Ines (um 700) „tenants“ mit Land und Diensten bezeugen. Das „manor system“ gilt daher

50 Weidinger, Untersuchungen (wie Anm. 29), 285 (Tabelle 4). Zu den Unterschieden in Weißenburg im Elsaß vgl. Rösener, Grundherrschaft im Wandel (wie Anm. 8), 102 (Tabelle A1).

51 Dollinger, L'évolution (wie Anm. 36), zusammenfiassend 483 (in der deutschen Fassung: 430 f.).

52 Vgl. Martin Heinzelmann, Beobachtungen zur Bevölkerungsstruktur einiger grundherrschaftlicher Siedlungen im karolingischen Bayern, in: FMSt 11, 1977, 202-217, zu Lauterbach.

53 Werner Rösener, Einleitung, in: Strukturen der Grundherrschaft (wie Anm. 3), $23 \mathrm{ff}$.

54 Vgl. dazu Adriaan Verhulst, Economic organisation, in: New Cambridge Medieval History. Vol. 2: 700-900. Ed. Rosamond McKitterick. Cambridge 1995, 481-509, hier 488 ff.; zur Grundherrschaft als System Hans-Werner Goetz, Social and military institutions, in: ebd. 451-480, hier $473 \mathrm{ff}$.

55 Vgl. Wendy Davies, Small Worlds. The village community in early medieval Brittany. London 1988, $86 \mathrm{ff} ., 188 \mathrm{ff}$.

56 Vgl. Elisabeth Magnou-Nortier, La terre, la rente et le pouvoir dans les pays de Languedoc pendant le haut moyen âge, T. 1: La villa: une nouvelle problématique, in: Francia 9, 1981, 79-115; T. 2: La question du manse et de la fiscalité foncière en Languedoc pendant le haut moyen âge, in: Francia 10, 1982, 21-66; T. 3: Le pouvoir et les pouvoirs dans la société aristocratique languedocienne pendant le haut moyen âge, in: Francia 12, 1984, 53-118; dies., A propos de la villa et du manse dans les sources méridionales du haut moyen âge, in: Annales du Midi 96, 1984, 85-91.

57 Vgl. dazu die grundlegende Studie von Pierre Toubert, Les structures du Latium médiéval. Le Latium méridional et la Sabine du $\mathrm{LX}^{e}$ à la fin du $\mathrm{XI}^{\mathrm{e}}$ siècle. 2 vol. (Bibliothèque des écoles françaises d'Athènes et de Rome, vol. 221.) Rom 1973.

$58 \mathrm{Vgl}$. Henry R. Loyn, Anglo-Saxon England and the Norman Conquest. London 1962, $163 \mathrm{ff}$. 
schon seit langem als angelsächsischen Ursprungs und nicht als eine Folge der normannischen Eroberung. ${ }^{59}$

Wenn die Forschung - wahrscheinlich zu Recht - von einer Ausbreitung der „Grundherrschaft" an sich, nämlich (mit Friedrich Lütge) von einem Prozeß der „Vergrundholdung“ freier Bauern (durch Zwang oder freiwillige Eingliederung) und der "Verbäuerlichung“ (oder „Casatierung") der Hofhörigen auf Kosten des Sallandes ausgeht ${ }^{60}$, so bleiben Ausmaß und regionale Differenzierungen dieses Prozesses schon im Ostfränkischen Reich, geschweige denn im europäischen Vergleich doch weithin unbekannt, so daß ein weiträumiger Vergleich sich verbietet. Ein freies Bauerntum hat ebenso weiterexistiert wie der Sallandbetrieb mit Hofhörigen. Die Theorie einer Verschmelzung von servi und ingenui zu „Hörigen“61 verstellt zudem - aus der Lektüre jedes größeren Urbars leicht belegbar - den Blick auf die individuell sehr unterschiedliche Stellung und Belastung der Hörigen in der Grundherrschaft des frühen Mittelalters. Außerdem ist mit Phasenverschiebungen zu rechnen: Im christlichen Norden Spaniens ist eine Abhängigkeit der Freien anscheinend erst seit dem 9. Jahrhundert nachweisbar ${ }^{62}$; in Südfrankreich und in Katalanien herrschten kleine allodiale Bauemhöfe vor, während das Salland eher gering war. ${ }^{63}$ Ein Umbruch wird hier erst um die Jahrtausendwende angenommen. ${ }^{64}$ Die Forschungen haben aber zumindest die Dynamik der grundherrschaftlichen Entwicklung aufzeigen können.

Die sich durchaus abzeichnenden Unterschiede aber beruhen auf punktuellen, von der Quellenlage diktierten Einblicken und geben allenfalls - relative - Tendenzen wieder, die über die überall anzutreffende Mannigfaltigkeit nicht hinwegtäuschen dürfen. Zudem wäre es einseitig, die „Grundherrschaft", wie weithin üblich, nur an den großen Urbaren zu

59 Vgl. Trevor H. Aston, The English Manor, in: P \& P 16, 1956, 6-14; ders., The origin of the Manor in England, in: Social Relations and Ideas. Essays in Honour of R. H. Hilton. Ed. Trevor H. Aston/Peter R. Coss/Christopher Dyer/Joan Thirsk. Cambridge 1983, 1-43; zusammenfassend Christopher Dyer, Lords, Peasants, and the Development of the Manor: England 900-1280, in: England and Germany in the High Middle Ages. In Honour of Karl J. Leyser. Ed. Alfred Haverkamp/Hanna Vollrath. Oxford 1996, 301-315. Die angelsăchsischen Bauern waren rechtlich frei, aber unter strikter Kontrolle des Grundherren (so Dyer, ebd. 302 ff.). Das Interesse am Gegenstand hat in England seit den sechziger Jahren jedoch gänzlich nachgelassen (so ebd. $314 \mathrm{f}$.).

60 Vgl. Kuchenbuch, Die Klostergrundherrschaft (wie Anm. 6), 321, 333 f.. Für Italien: Toubert, L'Italie rurale (wie Anm. 33), $114 \mathrm{ff}$. (Verringerung der servi) und $118 \mathrm{ff}$.. (Entstehen eines neuen „Kolonats“ der servi residentes im 8./9. Jahrhundert); vgl. Andreolli/Montanari, L'azienda curtense (wie Anm. 16), 85 ff., zur Krise der Freien im 9. Jh.

61 Vgl. Kuchenbuch, Die Klostergrundherrschaft (wie Anm. 6), 340.

62 Vgl. Charles-Emmanuel Doufourcq/Jean Gautier-Dalché, Histoire économique et sociale de l'Espagne chrétienne au Moyen Âge. Paris 1976, 24 ff.

63 Vgl. Verhulst, Organisation (wie Anm. 54), $488 \mathrm{ff}$.; zu den Unterschieden auch Georges Duby, La société aux XI ${ }^{e}$ et XII' siècles dans la région mâconnaise. Paris 1953, 79, der im Süden von einer „Bauerngesellschaft" spricht (ebd. 85). Zu Südfrankreich und Katalanien vgl. vor allem Pierre Bonnassie, $\mathrm{La}$ Catalogne du milieu du $\mathrm{X}^{\mathrm{e}}$ à la fin du $\mathrm{XI}^{\mathrm{e}}$ siècle. Croissance et mutations d'une société. (Publications de l'Université de Toulouse-Le Mirail, vol. A 23.) Toulouse 1975, ND Paris 1990; ders., From Slavery to Feudalism in South-Western Europe. Cambridge/New York/Paris 1991.

64 Vgl. unten Anm. 122. 
messen. Wo diese fehlen - wie eben durchweg in Südfrankreich -, hinterläßt die vor allem auf Traditionsurkunden beruhende Forschung einen gänzlich anderen Eindruck. ${ }^{65}$ Die Forschungsansichten zur Verbreitung der Grundherrschaft zeigen sich folglich abhängig von der Quellenlage. Unter solcher Perspektive relativieren sich aber Ansichten, daß die „Grundherrschaft" nicht in allen Regionen Europas vorherrschend war. Wenn man grundherrschaftliche Strukturen in unserem Zeitraum für Südfrankreich und Spanien abgestritten hat, dann ließe sich - als Ergebnis dieses Überblicks - doch fragen, ob hier nicht nur andere Formen von „Grundherrschaft“ (oder „Seigneurie“) vorherrschten.

\section{Die Grundherrschaftsforschungen im Vergleich}

Betrachten wir vor diesem Hintergrund nun die Grundherrschaftsforschungen im europäischen Kontext, so ergibt sich sogleich ein ăhnlicher Eindruck: Auch ein Forschungsvergleich enthullt in diesem Fall - im Gegensatz zu manchen anderen Themen - keineswegs klare ,nationale' Unterschiede, obwohl die Forschung, etwa in Deutschland und Frankreich, zweifellos auf unterschiedlichen Traditionen fußt. Die jüngere deutsche Forschung mußte sich zunächst einmal aus ihren rechtsgeschichtlichen Traditionen à la Brunner und Lütge lösen (was noch keineswegs ganz gelungen ist), nach denen die Ursprünge der Grundherrschaft (Maurer: Hofverfassung ${ }^{66}$, Seeliger: Grundeigentum ${ }^{67}$, Dopsch: Adelsherrschaft $^{68}$, mit jeweils konträren Theorien), die Herrschaftsstrukturen (Otto Brunner: Hausherrschaft und Herrschaftsrechte) ${ }^{69}$ bzw. die Agrarverfassung (Friedrich Lütge) ${ }^{70}$ im Zentrum des Interesses standen. ${ }^{71}$ Die „Grundherrschaft“ war aber nicht nur ein „bipolares Herrschaftsverhältnis“,

65 Vgl. auch meinen Versuch, die St. Galler Grundherrschaft aus den Traditionsurkunden zu erschließen; Goetz, Beobachtungen (wie Anm. 19).

66 Georg Ludwig von Maurer, Einleitung zur Geschichte der Mark-, Hof-, Dorf- und Stadtverfassung und der öffentlichen Gewalt. München 1854, bes. $226 \mathrm{ff}$.

67 Gerhard Seeliger, Die soziale und politische Bedeutung der Grundherrschaft im früheren Mittelalter. Leipzig 1903; ders., Forschungen zur Geschichte der Grundherrschaft im früheren Mittelalter, in: HJb 8, 1905, 305-361; 10, 1907, 305-354; ders., Staat und Grundherrschaft in der allteren deutschen Geschichte. Leipzig 1909.

68 Alfons Dopsch, Die Wirtschaftsentwicklung der Karolingerzeit vornehmlich in Deutschland, 2 Bde. Weimar 1912/13.

69 Otto Brunner, Land und Herrschaft. Grundfragen der territorialen Verfassungsgeschichte Österreichs im Mittelalter. 4., veränd. Aufl. Wien/Wiesbaden 1959, bes. 240 ff. Zur Kritik an Brunners Herrschaftstheorie vgl. Gadi Algazi, Herrengewalt und Gewalt der Herren im späten Mittelalter. Herrschaft, Gegenseitigkeit und Sprachgebrauch. (Hist. Studien, Bd. 17.) Frankfurt a. M./New York 1996.

70 Friedrich Lütge, Die Agrarverfassung des frühen Mittelalters im mitteldeutschen Raum vornehmlich in der Karolingerzeit. (Quellen und Forsch. zur Agrarwirtschaft, Bd. 17.) Jena 1937, ND Stuttgart 1966; ders., Geschichte der deutschen Agrarverfassung vom frühen Mittelalter bis zum 19. Jahrhundert. (Deutsche Agrargeschichte, Bd. 3.) 2. Aufl. Stuttgart 1967.

71 Zum Forschungsgang vgl. Rösener, Grundherrschaft im Wandel (wie Anm. 8), 14-55. Zur Kritik an dieser Tradition vgl. Dieter Scheler, Grundherrschaft. Zur Geschichte eines Forschungskonzepts, in: Vom Elend der Handarbeit. Probleme historischer Unterschichtenforschung. Hrsg. v. Hans Mommsen/ 
das den Spielraum im Verhältnis zwischen Herren und Hörigen regelte, sondern auch ein komplexes Sozialgefüge der in sich differenzierten familia, der Hörigen eines Herren, mit jeweils unterschiedlichem Rechts- und Funktionsstand und sozialem Status, nicht nur Gutsverwaltung, sondern auch Wirtschaftsform. Solche Erkenntnisse haben in der jüngeren Forschung zu wichtigen Differenzierungen geführt. Die marxistische Forschung wiederum hat neben der Entstehung feudaler Strukturen vor allem die Frage der Reaktion der Hörigen auf die feudale Grundherrschaft beschäftigt, ob es nämlich einen bäuerlichen Widerstand gegeben habe ${ }^{72}$, eine Frage, die, soweit ich sehe, inzwischen wieder aus der Diskussion geraten ist.

In der französischen Grundherrschaftsforschung hingegen spielt der verfassungsrechtliche Herrschaftsaspekt zwar durchaus eine Rolle (etwa bei Elisabeth Magnou-Nortier) ${ }^{73}$, doch ging es hier, wie auch in Italien, traditionell zum einen mehr um die Erfassung der „seigneurie" als Ganzes $^{74}$, zum anderen, im Gefolge Marc Blochs und vor allem Georges Dubys, um eine gesamtgesellschaftliche Einordnung in sozioökonomische und anthropologische Aspekte der ländlichen Gesellschaft und des Landlebens. ${ }^{75}$ Die "Grundherrschaft" im engeren Sinn, die „seigneurie foncière“, spielte in Frankreich eine integrierte, letztlich aber untergeordnete Rolle, während die italienische „signoria rurale" meist als eine Art Entwicklungsstufe zur hochmittelalterlichen „signoria territoriale“ verstanden wurde. Dabei wird man allerdings auch beachten müssen, daß die franzősische „seigneurie“ begrifflich ebensowenig wie die italienische „signoria rurale“ dasselbe ist wie die herrschaftlich eher komplexe, begrifflich aber an den Boden gebundene deutsche "Grundherrschaft“ ${ }^{76}$ Cinzio Violante warnte zwar zu Recht davor, das „regime curtense“ und das „regime feudale“ gleich-

Winfried Schulze. (Geschichte und Gesellschaft. Bochumer Hist. Studien, Bd. 24.) Stuttgart 1981, 142-157.

72 Vgl. vor allem Siegfried Epperlein (Hrsg.), Herrschaft und Volk im karolingischen Imperium. Studien über soziale Konflikte und dogmatisch-politische Kontroversen im frankischen Reich. (Forsch. zur mittelalterlichen Geschichte, Bd. 14.) Berlin 1969. In der DDR-Forschung stritt man außerdem darum, ob es sich überhaupt bereits um Hörigenaufstănde oder erst um Erhebungen freier Bauern gegen die Einführung der Feudalordnung handelte. Vgl. den Band: Feudalismus (wie Anm. 40).

73 Vgl. Elisabeth Magnou-Nortier, Le grand domaine: des maitres, des doctrines, des questions, in: Francia 15, 1987, 659-700; dies., La terre (wie Anm. 56).

74 Vgl. zuletzt etwa, vor allem zum Hoch- und Spătmittelalter: Seigneurs et Seigneuries au Moyen Âge. Actes du $117^{\mathrm{e}}$ Congrès national des Sociétés Savantes. Paris 1995; Dominique Barthélemy (Ed.), L'ordre seigneurial. Xle ${ }^{e}-\mathrm{XII}^{e}$ siècle. (Nouvelle histoire de la France médiévale, vol. 3.) Paris 1990.

75 Der wirtschaftliche Aspekt war allerdings auch der deutschen Tradition nicht ganz fremd; man denke nur an Alfons Dopsch oder Wilhelm Abel.

76 Vgl. dazu Monika Pelz, Signoria rurale - Grundherrschaft. Storiografia italiana - storiografia tedesca: una messa a confronto, in: Società e storia 69, 1995, 583-598, in ihrer ausführlichen Besprechung der Trienter Tagung "Strutture e trasformazioni della signoria rurale in Italia e Germania durante il Medioevo (secc. X-XIII)“; inzwischen erschienen unter dem Titel: Gerhard Dilcher/Cinzio Violante (Ed.), Strutture e trasformazioni della signoria rurale nei secoli X-XIII. Atti della XXXVII settimana di studio, 12-16 settembre 1994. (Annali dell'Istituto storico italo-germanico, Quademo 44.) Bologna 1996 (dt.: Strukturen und Wandlungen der ländlichen Herrschaftsformen vom 10. zum 13. Jahrhundert. Deutschland und Italien im Vergleich. [Schriften des Italienisch-Deutschen Historischen Instituts in Trient, Bd. 14.] Berlin 2000). 
zusetzen ${ }^{77}$, und unterschied zwischen der „signoria fondiaria“, der „signoria immunitaria“ und der „signoria territoriale“, betrachtete diese Formen zugleich aber als einen Entwicklungsprozeß der Signoria. ${ }^{78}$ In der amerikanischen Forschung (um Walter Goffart ${ }^{79}$ oder John Percival ${ }^{80}$ ) schließlich wurde weniger um die Wurzeln der Grundherrschaft (wie in Deutschland) als vielmehr um deren zeitliche Ursprünge (spätantik oder germanischfrühmittelalterlich) und, mehr noch, diejenigen ihrer wichtigsten Quellen, der Urbare, gestritten.

In der neueren Forschung haben in Frankreich fast überall regionale Schwerpunkte, in Deutschland die Aufarbeitung einzelner Grundherrschaften die älteren globalen Einschätzungen abgelöst. Als Initiatoren können Charles-Edmond Perrin zu Lothringen ${ }^{81}$, Georges Duby zu Burgund ${ }^{82}$, Pierre Toubert zu Latium ${ }^{83}$, Robert Fossier zur Pikardie ${ }^{84}$ oder François Menant zur Lombardei ${ }^{85}$, in Deutschland (etwas später) Ludolf Kuchenbuch mit seiner umfassenden Untersuchung der Klostergundherrschaft Prüm $^{86}$ gelten. Seither sind viele Einzelstudien gefolgt. ${ }^{87}$ Werner Rösener geht mit seiner Untersuchung zu Schwaben - allerdings vor dem Hintergrund der traditionellen Frage nach der Auflösung der Villikationsverfassung seit dem hohen Mittelalter - erstmals wieder einer langfristigen Entwicklung in diesem Raum nach. ${ }^{88}$ In diesen (und anderen) Forschungen ist nicht nur eine methodische und inhaltliche Angleichung, sondern auch eine Internationalisienung zu beobachten: Der ,Hägermann-Kreis' befaßte sich mit nordfranzösischen Klostergrundherrschaften, der

77 Cinzio Violante, La signoria rurale nel secolo X. Proposte tipologiche, in: Il secolo di ferro. Mito et realtà del secolo X. (SSCI, vol. 38.) Spoleto 1991, 329-385, bes. 333 ff.; stärker diffierenzierend jetzt ders., La signoria rurale nel contesto storico dei secoli X-XII, in: Strutture e trasformazioni (wie Anm. 76), 7-48.

78 Ebd. $347 \mathrm{ff}$. Vgl. auch Andreolli/Montanari, L'azienda curtense (wie Anm. 16), $177 \mathrm{ff}$., und Toubert, L'Italie rurale (wie Anm. 33), 128-132, der den Wandel im 8. und 9. Jh. als eine Entwicklung zum „incastellamento“ des 10 . Jh. betrachtet.

79 Walter Goffart, Old and New in Merovingian Taxation, in: P \& P 96, 1982, 3-21; ders., From Roman Taxation to Mediaeval Seigneurie: Three Notes, in: Speculum 47, 1972, 165-187, 373-394; ders., Merovingian Polyptychs. Reflections on two recent publications, in: Francia 9, 1981, 57-77.

80 John Percival, Ninth-century Polyptyques and the Villa-system: a Reply, in: Latomus 25, 1966, 134-138.

81 Charles-Edmond Perrin, Recherches sur la seigneurie rurale en Lorraine d'après les plus anciens censiers $\left(\mathrm{IX}^{\mathrm{e}}-\mathrm{XII}{ }^{\mathfrak{e}}\right.$ siècle). Paris 1935; ders., Les classes paysannes et le régime seigneurial en France du début du $\mathrm{LX}^{e}$ siècle à la fin du XII ${ }^{e}$ siècle. Paris 1953; ders., La Seigneurie rurale (wie Anm. 38).

$82 \mathrm{Vgl}$. Duby, La société (wie Anm. 63), $65 \mathrm{ff}$. (zum Ende des 10. Jh.); vor allem ders., L'économie rurale et la vie des campagnes dans l'occident médiéval. (France, Angleterre, Empire, IX'-XV' siècles). Essai de synthèse et perspectives de recherches. 2 vol. Paris 1961.

83 Wie Anm. 57.

84 Robert Fossier, La terre et les hommes en Picardie jusqu'à la fin du XII' ${ }^{e}$ siècle. Paris/Louvain 1968.

85 François Menant, Campagnes lombardes du Moyen Âge. L'économie et la société rurales dans la région de Bergame, de Crémone et de Brescia du X $X^{e}-\mathrm{XIII}^{\mathrm{e}}$ siècles. Rom 1993.

86 Kuchenbuch, Bäuerliche Gesellschaft (wie Anm. 10).

87 Vgl. oben Anm. 8-12.

88 Rösener, Grundherrschaft im Wandel (wie Anm. 8). 
Belgier Jean-Pierre Devroey arbeitete auch zu Prüm, die Franzosen Pierre Toubert und François Menant über Mittel- bzw. Norditalien, Pierre Bonnassie über Katalanien, amerikanische Forscher (wie Thomas Bisson oder Stephen Weinberger) befaßten sich vorwiegend mit Südfrankreich, und der Japaner Yoshiki Morimoto wurde gar zu einem der größten Spezialisten der nordfranzösisch-lothringischen Grundherrschaft (um nur einige Beispiele zu nennen). Entsprechend resultieren die derzeitigen Forschungsdiskussionen meinem Eindruck nach oft weniger aus den unterschiedlichen nationalen Traditionen als vielmehr aus dem gewählten Gegenstand, also unterschiedlichen regionalen Verhältnissen, wie auch aus der Tendenz, diese zu verallgemeinern.

In seiner „Zwischenbilanz“ von 1988 registrierte Ludolf Kuchenbuch noch vier große Forschungsbereiche: die Entstehung der bipartiten Grundherrschaft, die Grundherrschaft als bipolares Beziehungsgefuge, als Sozialstruktur und als Einkunftsquelle. ${ }^{89}$ Inzwischen hat sich das Bild schon wieder gewandelt. Die neueren Grundherrschaftsforschungen sind durch eine Abwendung von rechtsgeschichtlichen Betrachtungsweisen und abstrakten Theorieansätzen hin zu konkreten Beschreibungen und ,Rundumanalysen', von den Herrschaftsstrukturen zu wirtschaftlichen Aspekten und praktischen Lebensverhältnissen und nicht zuletzt durch eine zunehmende Problematisierung der Quellengrundlagen und der Erklärungsansätze, eine immer intensivere Betrachtung der Texte, ihrer Überlieferung und ihrer Begrifflichkeit und eine Integration der verschiedenen Aspektbereiche gekennzeichnet. Früher zentrale Fragen nach der Herrschaft (wie die Kontroverse zwischen Hanna Vollrath, die die Herrschaftsrechte der Grundherren durch die Gewohnheiten beschränkt sieht, und mir) ${ }^{90}$ sind nurmehr Randerscheinungen. Die neueren Interessen sollen im folgenden an zwei Aspekten, der Urbarforschung und der grundherrschaftlichen Wirtschaft, verdeutlicht werden.

Die (von Charles-Edmond Perrin initiierten) Urbarstudien bilden zweifellos einen Schwerpunkt der (internationalen) Grundherrschaftsforschung. ${ }^{91}$ Dabei rückte man von einer strikten „Typologie“ der Urbarformen à la Wolfgang Metz $\mathrm{ab}^{92}$, um zum einen die Individualităt jeder einzelnen Quelle nach Gestalt und Funktionen zu betonen (wie es eindringlich

89 Kuchenbuch, Die Klostergrundherrschaft (wie Anm. 6).

90 Vgl. Hanna Vollrath, Herrschaft und Genossenschaft im Kontext frühmittelalterlicher Rechtsbeziehungen, in: HJb 102, 1982, 33-71. Zur Auswirkung des Gewohnheitsrechts auf die Grundherrschaft, nämlich der Folgerung, daß die Hörigen mehr durch die lokale Gemeinschaft als durch die Grundherrschaft geprägt waren, dies., Il ruolo della signoria fondiaria nella formazione consociativa del diritto, in: Strutture e trasformazioni (wie Anm. 76), 557-594. Kritisch zu manchen Überspitzungen: HansWerner Goetz, Herrschaft und Recht in der frühmittelalterlichen Grundherrschaft, in: HJb 104, 1984, 392-410. Vgl. aber auch Kuchenbuch, Rentenentwicklung (wie Anm. 22). Bei der rechtlichen (auch der ,gewohnheitsrechtlichen') Perspektive darf man natürlich nicht übersehen, daß die Praxis stets in hohem Maße durch Abweichungen von der Norm geprägt ist. Die Kontroverse zwischen Vollrath und Goetz zeige, so meint Morimoto, État et perspectives (wie Anm. 5), 104, 136, wie unterschiedlich die Ansichten über die Realităt der grundherrschaftlichen Macht sind.

91 Vgl. dazu Morimoto, État et perspectives (wie Anm. 5), $113 \mathrm{ff}$.

92 Vgl. Wolfgang Metz, Zur Geschichte und Kritik der frühmittelalterlichen Güterverzeichnisse Deutschlands, in: AfD 4, 1958, 183-206. 
Dieter Hägermann im Hinblick auf die ostrheinischen Quellen vorgeführt hat). ${ }^{93}$ Die ältere Lehre eines „Mustenurbars“ aus der Reichskanzlei als Vorlage fur die erhaltenen Aufzeichnungen darf heute als erledigt gelten. Zum anderen geht es in der modernen Urbarforschung um Fragen des Realitätsgehalts (Urbare als ,Momentaufnahmen') ${ }^{94}$, damit aber auch der ,Aufnahmetechnik' (Befragung der Betroffenen, vor Ort' $)^{95}$ und der anschließenden Verarbeitung, um die quellenkritische Erschließung der in der erhaltenen Form oft erst später zusammengestellten ,Teil'-Urbare. Das macht quellenkritische Untersuchungen zu Formular, Schreibern und Überlieferungsschichten ebenso unerläßlich wie Begriffsuntersuchungen zu den Schlüsseltermini der Grundherrschaft wie mansus oder curtis, servus und mancipium ${ }^{96}$ und erklärt im übrigen noch einmal, weshalb ein Vergleich der Grundherrschaften so schwierig ist. Musterbeispiele sind die Untersuchungen von Jean-Pierre Devroey zu Saint-Remi bei Reims ${ }^{97}$ und zu Saint-Germain-des-Prés ${ }^{98}$, Franz Staab zum Codex Laureshamensis ${ }^{99}$ oder auch, wenngleich umstritten, von Christoph Dette zum Kloster Weißenburg im Elsaß (Liber Edilini). ${ }^{100}$ Die Anerkennung eines „dynamischen Charakters“ der Urbare, verschiedener

93 Dieter Hägermann, Quellenkritische Bemerkungen zu den karolingerzeitlichen Urbaren und Güterverzeichnissen, in: Strukturen der Grundherrschaft (wie Anm. 3), 47-73.

94 Anders noch Fossier, Polyptyques et censiers (wie Anm. 2), 29, 33: Urbare als theoretisches Bild.

95 Vgl. Ingo Schwab (Hrsg.), Das Prümer Urbar. (Publikationen der Gesellschaft fur Rheinische Geschichtskunde, Bd. 20; Rheinische Urbare, Bd. 5.) Dusseldorf 1983; ders., Probleme der Anfertigung von frühmittelalterlichen Güterverzeichnissen am Beispiel des Prümer Urbars, in: Le grand domaine (wie Anm. 3), 152-170. Kritisch dazu: Yoshiki Morimoto, Le polyptyque de Prüm n'a-t-il pas été interpolé? A propos de sa nouvelle édition, in: MA 92, 1986, 265-276, der die Mőglichkeit spăterer Fixierungen nachweist.

96 Vgl. Elisabeth Magnou-Nortier, Trois approches de la question du manse, in: Aux sources de la gestion publique. T. 1: Enquête lexicographique sur fundus, villa, domus, mansus. (Travaux et recherches, Presses universitaire de Lille. Collection UL 3.) Ed. dies. Lille 1993. Vgl. bereits dies. (Ed.), La société laïque et l'église dans la province ecclésiastique de Narbonne (zone cispyrénéenne) de la fin du VIII à la fin du XI ${ }^{\mathrm{e}}$ siècle. (Publications de l'Université de Toulouse-Le Mirail, Série A, t. 20.) Toulouse 1974, 129-196; zuletzt Étienne Renard, Lectures et relectures d'un polyptyque carolingien (Saint-Bertin, 844-859), in: Revue d'histoire ecclésiastique 94, 1999, 373-435; ders., Les mancipia carolingiens étaient-ils des esclaves? Les données du polyptyque de Moutier-en-Der dans le contexte documentaire du $\mathrm{LX}^{\mathrm{e}}$ siècle, in: Les moines du Der 673-1790. Actes du colloque international d'histoire Joinville-Moutier-en-Der, $1^{\text {er }}-3$ octobre 1998. Ed. Patrick Corbet avec le concours de Jackie Lusse et Georges Viard. Langres 2000, 179-209.

97 Jean-Pierre Devroey, Les polyptyques et les listes de cens de l'abbaye de Saint-Remi de Reims (LX' $\mathrm{XI}^{\mathrm{e}}$ siècles). Reims 1984; ders., Les premiers polyptyques rémois, $\mathrm{VII}^{\mathrm{e}}-\mathrm{LX}^{\mathrm{e}}$ siècles, in: Le grand domaine (wie Anm. 3), 78-97; ăhnlich: Britta Lützow, Studien zum Reimser Polyptychum sancti Remigii, in: Francia 7, 1979, 19-99.

98 Jean-Pierre Devroey, Problèmes de critique autour du polyptyque de l'abbaye de Saint-Germain-desPrés, in: La Neustrie. Vol. 1 (wie Anm. 48), 441-465.

99 Franz Staab, Aspekte der Grundherrschaftsentwicklung von Lorsch vornehmlich aufgrund der Urbare des Codex Laureshamensis, in: Strukturen der Grundherrschaft (wie Anm. 3), 285-334.

100 Christoph Dette, Liber Possessionum Wizenburgensis. (Quellen und Abh. zur mittelrheinischen Kirchengeschichte, Bd. 59.) Mainz 1987; ders., Einige Bemerkungen zum ältesten Weißenburger Urbar, in: Le grand domaine (wie Anm. 3), 112-124. Vgl. dazu allerdings die scharfe Kritik von 
Zeitstufen, Ergänzungen und Wandlungen ${ }^{101}$, hat weitreichende Folgen für die Auswertung. Elmshäuser und Hedwig behandeln als Konsequenz in ihrer Studie zu Saint-Germain-desPrés ${ }^{102}$ deshalb jeden Fiskus (Fronhof) bzw. jedes „Breve“ (als entsprechenden Urbarabschnitt) getrennt, um auch die lokalen Strukturen der Grundherrschaft aufdecken zu können. Am weitesten in der Urbarauswertung ging Ludolf Kuchenbuch, indem er die Urbare nicht nur quellenkritisch, sondern kulturwissenschaftlich unter die Lupe nahm und als Zeugnisse eines Organisationstalents und einer pragmatischen Schriftlichkeit erwies ${ }^{103}$, die sogar mit der Entwicklung der ,Wissenschaft', der artes liberales, Schritt hielt. ${ }^{104}$

Während die herrschaftlichen Aspekte der Grundherrschaft heute eher zurückgetreten sind, wird - in der deutschen wie der internationalen Forschung - den wirtschaftlichen Aspekten seit einiger Zeit erhöhte Aufmerksamkeit geschenkt. Die Anregungen dazu kamen ebenfalls aus Frankreich: mit wegweisenden Aufsätzen von Jean Durliat und Jean-Pierre Devroey über den Weinhandel bzw. dem Nachweis, welch wichtige Rolle dem Handel überhaupt einzuräumen ist ${ }^{105}$; Devroeys Studie zwang nicht nur dazu, die bäuerlichen Transportdienste anders zu bewerten und in einen größeren Zusammenhang zu stellen, sondern konnte mit ihren Ergebnissen auch die ältere Meinung widerlegen, daß die Grundherrschaften wirtschaftlich autarke Gebilde gewesen seien. ${ }^{106}$ Hier sind aber auch die Arbeiten der DDRHistorikerin Waltraut Bleiber über die neuen grundherrschaftlichen (Lokal-)Märkte im nordfranzösischen Raum und ihre Bedeutung für die Wirtschaft zu nennen. ${ }^{107}$ Märkte wiederum

Michael Gockel, Kritische Bemerkungen zu einer Neuausgabe des Liber possessionum Wizenburgensis, in: HessJbLG 39, 1989, 353-380; Rösener, Grundherrschaft im Wandel (wie Anm. 8), 92 ff.; Enno Bünz, Probleme der hochmittelalterlichen Urbarüberlieferung, in: Grundherrschaft und băuerliche Gesellschaft (wie Anm. 3), 31-75, bes. $46 \mathrm{f}$.

101 Vgl. Morimoto, Autour du grand domaine (wie Anm. 5), 37-43.

102 Wie Anm. 9.

103 Ludolf Kuchenbuch, Teilen, Aufzăhlen, Summieren. Zum Verfahren in ausgewăhlten Güter- und Einkünfteverzeichnissen des 9. Jahrhunderts, in: Schriftlichkeit im frühen Mittelalter. Hrsg. v. Ursula Schaefer. (ScriptOralia, Bd. 53.) Tübingen 1993, 181-206.

104 So Ludolf Kuchenbuch, Ordnungsverhalten im grundherrlichen Schriftgut vom 9. zum 12. Jahrhundert, in: Dialektik und Rhetorik im früheren und hohen Mittelalter. Hrsg. v. Johannes Fried. (Schriftenreihe des Hist. Kollegs. Kolloquien, Bd. 27.) München 1997, 175-268.

105 Jean Durliat, Le vigne et le vin dans la région parisienne au début du $\mathrm{IX}^{\mathrm{e}}$ siècle d'après le polyptyque d'Irminon, in: MA 74, 1968, 387-419; Jean-Pierre Devroey, Un monastère dans l'économie d'échanges: les services de transport à l'abbaye Saint-Germain-des-Prés au IX siècle, in: Annales 39, 1984, 570-589. Zum Handwerk: Fred Schwind, Zu karolingerzeitlichen Klöstern als Wirtschaftsorganismen und Stătten handwerklicher Tătigkeit, in: Institutionen, Kultur und Gesellschaft im Mittelalter. Fschr. Josef Fleckenstein. Hrsg. v. Lutz Fenske/Werner Rösener/Thomas Zotz. Sigmaringen 1984, 101-123.

106 Vgl. Jean-Pierre Devroey, Réflexions sur l'économie des premiers temps carolingiens (768-877). Grands domaines et action politique entre Seine et Rhin, in: Francia 13, 1985, 475-488. Hingegen spricht Rösener, Grundherrschaft im Wandel (wie Anm. 8), 45, immer noch von eigenversorgender Hauswirtschaft als grundherrschaftlichem Kennzeichen.

107 Waltraut Bleiber, Grundherrschaft, Handwerk und Markt im Gebiet von Paris in der Mitte des 9. Jh., in: Siedlung, Burg und Stadt. Studien zu ihren Anfängen. Hrsg. v. Karl-Heinz Otto/Joachim Herrmann. (Dt. Akad. der Wiss. Berlin. Schriften der Sektion für Vor- und Frühgesch., Bd. 25.) Berlin 1969, 140-152; dies., Naturalwirtschaft und Ware-Geld-Beziehungen zwischen Somme und Loire 
förderten die Geldwirtschaft, und so sind auch die bäuerlichen Geldzinse, auf deren wachsende Bedeutung schon Kuchenbuch hingewiesen hat, im frühen Mittelalter, das früher als ,klassisches' Zeitalter der Naturalwirtschaft galt, immer stärker als Indikator einer bereits existierenden Geldwirtschaft gedeutet worden. ${ }^{108}$ Selbst der Zusammenhang von Grundherrschaft und Stadt ist zuletzt mehrfach thematisiert, die alte Lehre vom „Dualismus“ zwischen Stadt und Land im frühen Mittelalter dadurch aufgelockert worden. ${ }^{109}$ Gemäß solchen Ansätzen sucht man die spezifische Ausgestaltung der Grundherrschaft heute vielfach in diesen ökonomischen Bedingungen, und es scheint mir in dieser Hinsicht kennzeichnend, daß die jüngste Gesamtauswertung einer Grundherrschaft, die Studie von Elmshäuser und Hedwig über das Kloster Saint-Germain-des-Prés, sich neben der Urbaruntersuchung nahezu ausschließlich der Kloster- und Hufenwirtschaft (Getreidebau, Weinbau, Herrenhöfen und Mühlen) widmet und soziale Aspekte nur noch beiläufig im letzten, statistischen Teil anspricht. Andere, über die Grundherrschaftsforschung im engeren Sinn hinausgehende, aber an den Urbaren untersuchte Fragen gelten einer Neubewertung der bäuerlichen Leistungen, der bäuerlichen Lebensgrundlage und der bäuerlichen Familienstrukturen (mit der Hufe als „Familienverband“). ${ }^{110}$ Sämtliche Forschungen konzentrieren sich auf die königlichen und vor allem die geistlichen Grundherrschaften. Eklatante Defizite der intensiven neueren Grundherrschaftsforschung liegen hingegen im weiten Bereich der privaten Grundherrschaft, zu dem - trotz der in Deutschland lange Zeit so intensiv betriebenen Adelsforschung - nur wenige und noch keine systematischen Studien vorliegen. ${ }^{111}$

Neben solchen - international vergleichbaren - Themen und Perspektiven der neueren Grundherrschaftsforschung wird man aber auch Unterschiede in Ansätzen und Heran-

während des 7. Jahrhunderts. (Forsch. zur mittelalterlichen Geschichte, Bd. 27.) Berlin 1981; dies., Grundherrschaft und Markt zwischen Loire und Rhein wăhrend des 9. Jahrhunderts. Untersuchungen zu ihrem wechselseitigen Verhältnis, in: JbWG 1982, H. 3, 105-135.

108 Vgl. Klaus Petry, Die Geldzinse im Prümer Urbar von 893. Bemerkungen zum spătkarolingischen Geldumlauf des Rhein-Maas- und Moselraumes im 9. Jh., in: RhVjbll 52, 1988, 16-42; Kuchenbuch, Gesellschaft (wie Anm. 10), 156-160. Zur Zunahme der Geldzinse in den St. Galler Traditionsurkunden vgl. auch Goetz, Beobachtungen (wie Anm. 19), $226 \mathrm{ff}$.

109 Vgl. Georges Despy, Villes et campagnes aux $\mathrm{IX}^{\mathrm{e}}-\mathrm{X}^{\mathrm{e}}$ siècles: L'exemple du pays mosan, in: Revue du Nord 50, 1968, 145-168; Jean-Marie Duvosquel/Alain Dierkens (Ed.), Villes et campagnes au Moyen Âge. Mélanges Georges Despy. Liège 1991; Klaus Flink/Wilhelm Janssen (Hrsg.), Grundherrschaft und Stadtentstehung am Niederrhein. Referate der 6. Niederrhein-Tagung des Arbeitskreises niederrheinischer Kommunalarchivare für Regionalgeschichte (24.-25. Februar 1989 in Kleve). (Klever Archiv, Bd. 9.) Kleve 1989; Économie rurale (wie Anm. 5).

110 Vgl. Youri Bessmertny, Les structures de la famille paysanne dans les villages de la Francia au IX siècle. Analyse anthroponymique du polyptyque de l'abbaye de Saint-Germain-des-Prés, in: MA 90, 1984, 165-193. Vgl. bereits Kuchenbuch, Gesellschaft (wie Anm. 10), 76-94. Vgl. auch Stephen Weinberger, Peasant Households in Provence: ca. 800-1100, in: Speculum 48, 1973, 247-257.

111 Vgl. zuletzt (mit Forschungsstand) Rösener, Strukturformen (wie Anm. 19). Zu einem Einzelfall, der Grundherrschaft des burgundischen Grafen Heccard: Brigitte Kasten, Erbrechtliche Verfügungen des 8. und 9. Jahrhunderts. Zugleich ein Beitrag zur Organisation und zur Schriftlichkeit bei der Verwaltung adeliger Grundherrschaften am Beispiel des Grafen Heccard aus Burgund, in: ZRG GA 107, 1990, 236-338, hier 304 ff. Ein Projekt zur Erforschung der privaten Grundherrschaft ist an der Universität Hamburg geplant. 
gehensweisen zwischen der deutschen und der französischsprachigen Forschung feststellen können. Die deutsche Forschung (um Dieter Hägermann und Werner Rösener) scheint stärker durch den (ans Positivistische grenzenden) Versuch einer minutiösen Bestandsaufnahme unter Berücksichtigung aller in Frage kommenden Faktoren gekennzeichnet. In einer Art Strukturplan hat Dieter Hägermann die zu betrachtenden Aspekte zusammengestellt und dabei nicht zuletzt auch die äußeren Rahmenbedingungen (Topographie, Bodenqualität, Klima, Infrastruktur) einbezogen. ${ }^{112}$ Individualisierung der Befunde und Fragen nach der Grundherrschaftspraxis haben hier allerdings eine gewisse Scheu vor übergreifenden theoretischen Erklärungsmodellen zur Folge, so daß zwar Gestalt und Funktionieren einzelner Grundherrschaften bekannt sind, während deren Hintergründe, Herkunft und Entwicklung kaum mehr reflektiert werden (eine Ausnahme bildet hier Ludolf Kuchenbuch). Umgekehrt sind theoretische Erklärungsansätze (wie die These einer zunehmenden Casatierung) nirgends hinreichend praktisch untermauert worden.

Hingegen ist in Frankreich die Tendenz, die „Grundherrschaft“ in die seigneurialen Herrschaftsstrukturen, das bäuerliche Leben und die Wirtschaftsentwicklung einzuordnen, nach wie vor weit größer. Konsequenterweise stehen daher breitere (durchweg Streit-)Fragen im Vordergrund: nicht nur nach Herkunft und Ausbreitung der (zweigeteilten) „Grundherrschaft", sondern nach Wachstum oder Stagnation der Wirtschaft ${ }^{113}$ (seit Robert Fossier ein Wirtschaftswachstum in der Karolingerzeit bezweifelt und die Seigneurie als ein ineffizientes System betrachtet hat ${ }^{114}$, damit aber auf breite Ablehnung gestoßen ist) ${ }^{115}$, oder die Frage, ob ein Wachstum der Initiative der Grundherren (wie Adriaan Verhulst glaubt) ${ }^{116}$ oder der

112 Dieter Hägermann, Anmerkungen zum Stand und zu den Aufgaben frühmittelalterlicher Urbarforschung, in: RhVjbll 50, 1986, 32-58.

113 Vgl. dazu Morimoto, Autour du grand domaine (wie Anm. 5), $26 \mathrm{ff}$.

114 Vgl. Robert Fossier, Les tendances de l'économie: stagnation ou croissance?, in: Nascità dell'Europa ed Europa carolingia. Un'equazione da verificare. (SSCI, vol. 27.) Spoleto 1981, 261-274 (auch in: ders., Hommes et villages d'occident au Moyen Âge. Paris 1992, 341-350).

115 Vgl. dagegen vor allem Pierre Toubert, Il sistema curtense: la produzione e lo scambio interno in Italia nel secoli VIII, IX e X, in: Storia d'Italia. Annali 6: Economia naturale, economia monetaria, Torino 1983, 3-63; Devroey, Réflexions (wie Anm. 106); La croissance agricole (wie Anm. 7); JeanPierre Devroey/Chantal Zoller, Villes, campagnes, croissance agraire dans le pays mosan avant l'an mil: vingt ans après ..., in: Villes et campagnes au Moyen Âge (wie Anm. 109), 223-260. Immerhin lassen sich in manchen Klöstern des ostfränkischen Reichs (wie St. Gallen) im Verlauf des 9. Jh. ein Nachlassen der Neuerwerbungen (Schenkungen) und eine Tendenz zur Abrundung des Besitzes erkennen; vgl. Goetz, Beobachtungen (wie Anm. 19), Tabelle 2, 236 f. Vgl. auch Störmer, Frühmittelalterliche Grundherrschaft (wie Anm. 19), 375 f. (seit Mitte des 9. Jh. gab es in Bayern kaum mehr Schenkungs-, sondern vornehmlich Tauschurkunden). Auch infolge der vielen Prekarieschenkungen blieb die freie Verfügung der Klöster über ihre Güter beschränkt. Um so wichtiger wurde allerdings eine effektivere Organisation der Grundherrschaft, und ich verstehe die Urbare durchaus als einen ersten Ausgangspunkt der Grundherren, sich einen Überblick über ihren verstreuten Besitz und ihre Rechte zu verschaffien.

116 Vgl. etwa Verhulst, Étude (wie Anm. 7), 99. Die Ausdehnung der (zweigeteilten) Grundherrschaft ging nach Verhulst im Westen - mangels servi - auf Kosten der Freien, im Osten auf Kosten der Unfreien. 
Bauem zu verdanken ist (wie, im Gefolge Dubys, Pierre Bonnassie betont) ${ }^{117}$, die in dieser Alternative aber wohl falsch gestellt ist (weshalb nicht ein Zusammenwirken bei gemeinsamen Interessen?). ${ }^{118}$ Die Interpretationen sind dabei immer subtiler geworden. So gelten die mansi absi, die verlassenen Hufen, heute nicht mehr als ,unbesetzt ${ }^{\text {s }}$ und folglich auch nicht als Indiz eines allgemeinen Niedergangs ${ }^{119}$, ist selbst die Mehrfachbelegung der Hufen mit mehreren Familien kürzlich ebenfalls als ein Element der entwickelten „Grundherrschaft" und nicht als Zeichen der Dekadenz gewertet worden. ${ }^{120}$ Hinsichtlich der Ursprünge der "Grundherrschaft“ und ihrer Quellen hat die Kontinuitătstheorie in Jean Durliat einen vehementen Verteidiger gefunden, der, in dieser Form zweifellos überspitzt, in der Grundherrschaft ein Moment der „fiscalite“, des Weiterwirkens des antiken Steuersystems, und in den Hufen Steuer- und Heerfolgeeinheiten erblickt. ${ }^{121}$

Auch wenn solche Diskussionen immer wieder über Frankreich hinausgreifen, bleibt es doch bezeichnend, daß es sich hier zunächst um Kontroversen innerhalb der französischsprachigen Forschung handelt. Dazu werden wieder Grunddebatten geführt, bis hin zu der Frage, was „Grundherrschaft“ bzw. „seigneurie“ überhaupt ist bzw. seit wann es „feudale“ Strukturen gibt. Den Höhepunkt bildet in dieser Hinsicht zweifellos der große, bis heute andauernde Streit um die „feudale Revolution" um die Jahrtausendwende, der zumindest kurz erwähnt werden soll, obwohl er über meinen Berichtszeitraum hinausgeht (doch zumindest darauf zurückwirkt). Diese Diskussion, die mittlerweile in der französischen, belgischen, englischen und amerikanischen Geschichtswissenschaft geführt wird ${ }^{122}$, ist in

117 Vor einer Überschätzung der grundherrschaftlichen Initiative warnen auch Zotz, Beobachtungen (wie Anm. 35), 122 f., und Goetz, Beobachtungen (wie Anm. 19), 230 f.

118 Jean-Pierre Devroey, „Ad utilitatem monasterii“. Mobiles et préoccupations de gestion dans l'économie monastique du monde franc, in: Revue Bénédictine 103, 1993, 224-240, hălt es zu Recht für überzogen, den geistlichen Grundherren einen wirtschaftichen Unternehmergeist zu unterstellen, doch sie waren sehr wohl an der Rentabilităt und der „bonne gestion de la maisonnée“ interessiert (ebd. 233 f.). Vgl. auch Dieter Hägermann, Der Abt als Grundherr. Kloster und Wirtschaft im frühen Mittelalter, in: Herrschaft und Kirche (wie Anm. 6), 345-385.

119 Jean-Pierre Devroey, Mansi absi: Indices de crise ou de croissance de l'économie rurale du haut moyen âge?, in: MA 82, 1976, 421-451.

120 So Yoshiki Morimoto, Sur les manses surpeuplés ou fractionnaires dans le polyptyque de Prüm: phénomènes marginaux ou signes de décadence?, in: Campagnes médiévales. L'homme et son espace. Études offertes à Robert Fossier. Paris 1995, 409-423.

121 Jean Durliat, Les finances publiques de Dioclétien aux Carolingiens (284-889). (Francia, Beih. 21.) Sigmaringen 1990. Durliat wertet die Urbare als Beweis eines Weiterlebens des spätromischen Steuerwesens und erklärt sie aus einem fiskalischen Interesse des Königs. Vgl. auch ders., Du caput antique au manse médiévale, in: Pallas 29, 1982, 67-77; ders., Le polyptyque d'Irminon et l'impot pour l'armée, in: BECh 141, 1984, 183-208. Kritisch dazu: Jean-Pierre Devroey, Polyptyques et fiscalité à l'époque carolingienne: une nouvelle approche?, in: RBPH 63, 1985, 783-794. Zur Hufie als Fiskaleinheit vgl. schon Elisabeth Magnou-Nortier, A propos (wie Anm. 56), 85-91; dies., Le grand domaine (wie Anm. 73): Der mansus war keine „tenure“, sondern eine „unité de couple“; dies., Trois approches (wie Anm. 96).

122 Vgl. Jean-Pierre Poly/Eric Bournazel, La mutation féodale. $\mathrm{X}^{\mathrm{e}}-\mathrm{X} \mathrm{Il}^{\mathrm{e}}$ siècle. (Nouvelle Clio, vol. 16.) 2. Aufl. Paris 1991; Gry Bois, La Mutation de l'An Mil. Lournand, village mâconnais de l'Antiquité 
Deutschland bislang überhaupt noch nicht aufgegriffen worden. Auslöser waren Arbeiten von Georges Duby ${ }^{123}$, der den Übergang von der Sklaverei zur Hörigkeit als „, feudale Revolution" begriff, und Pierre Bonnassie, der diesen Übergang am Ende des 10. Jahrhunderts veranschlagte ${ }^{124}$, Jean-Pierre Poly und Eric Bournazel, die eine strikte Trennung zwischen der „offentlichen Ordnung“ vor 1000 und dem „Feudalzeitalter" vorschlugen ${ }^{125}$, bedingt auch das große Hugo-Capet-Kolloquium „L'An Mil“ des Jahres 1987, und zuletzt vor allem die vieldiskutierte Lokalstudie von Guy Bois, der aus der Untersuchung des südburgundischen Dorfes Loumand im Mâconnais weitreichende Folgerungen über den Beginn des Feudalismus zog und ein Andauern der antiken Sklaverei und der Sklavenhaltergesellschaft („société esclavagiste") bis in diese Zeit annahm. ${ }^{126}$ Diese Thesen sind auf vehementen Widerspruch gestoßen. Der Streit hat hier - erneut - eine hochtheoretische Ebene erreicht. $\mathrm{Ob}$ man nun einen Umbruch (,mutation“) oder, mit Dominique Barthélemy, eher einen allmăhlichen Wandel bzw. sukzessive Anpassungen („ajustements successifs") annehmen möchte: letztlich - und das bleibt bezeichnend - werden in diesen Diskussionen Unter-

au féodalisme. Paris 1989 (dt.: Umbruch im Jahr 1000. Lournand bei Cluny - ein Dorf in Frankreich zwischen Spätantike und Feudalherrschaft. Stuttgart 1993); Bonnassie, Slavery (wie Anm. 63). Kritisch: Monique Bourin, L'an mil: Rhythmes et acteurs d'une croissance, in: Médiévales 21, 1991 (mit Beiträgen von Chris Wickham, Pierre Bonnassie, Yoshiki Morimoto, Robert Fossier, Barbara Rosenwein, Monique Bourin); Alain Guerreau, Lournand au $X^{\mathrm{e}}$ siècle: histoire et fiction, in: MA 96, 1990, 519-537; Adriaan Verhulst, The Decline of Slavery and the Economic Expansion of the Early Middle Ages, in: P \& P 133, 1991, 195-203; Dominique Barthélemy, La mutation féodale a-t-elle eu lieu?, in: Annales 47, 1992, 767-777; Adriaan Verhulst, Die Jahrtausendwende in der neueren französischen Historiographie: theoretische Konstruktion und historische Wirklichkeit, in: Économie rurale (wie Anm. 5), 81-87; Thomas N. Bisson, The „Feudal Revolution“, in: P \& P 142, 1994, 6-42; Dominique Barthélemy, Debate: The „Feudal Revolution“: Comment 1, in: P \& P 152, 1996, 196-205. Stephen D. White, Debate: The „Feudal Revolution“: Comment 2, ebd. 205-223; Timothy Reuter/Chris Wickham/Thomas N. Bisson, Debate: The „Feudal Revolution“, in: P \& P 155, 1997, 177-225; Dominique Barthélemy, L'an mil et la paix de Dieu. La France chrétienne et féodale, 980-1060. Paris 1999.

123 Georges Duby, L'An mil. Paris 1981.

124 Vgl. Pierre Bonnassie, The Survival and extinction of the slave system in the early medieval West (fourth to eleventh centuries), in: ders., Slavery (wie Anm. 63), 1-59 (zuerst: ders., Survie et extinction du régime esclavagiste dans l'Occident du haut moyen âge, $\mathrm{IV}^{\mathrm{e}}-\mathrm{XI}^{\mathrm{e}}$ s., in: $\mathrm{CCM} 28,1985$, 307-343). Bonnassie folgert das aus der Verwendung des servus-Begriffis, ohne einen Bedeutungswandel in Rechnung zu stellen. Zur Problematik der Begrifflichkeit vgl. Hans-Werner Goetz, Serfdom and the beginnings of a ,seigneurial system ' in the Carolingian period: a survey of the evidence, in: Early Medieval Europe 2/1, 1993, 29-51; Elisabeth Magnou-Nortier, Servus Servitium: une enquête à poursuivre, in: Media in Francia ... Recueil de mélanges offert à Karl Ferdinand Werner. Paris 1989, 269-284.

125 Poly/Bournazel, La mutation féodale (wie Anm. 122); vgl. auch Jean-Pierre Poly, Régime domanial et rapports de production „féodalistes“ dans le Midi de la France (VIII ${ }^{\mathrm{e}}-\mathrm{X}^{\mathrm{e}}$ siècles), in: Structures féodales et féodalisme dans l'Occident méditerranéen $\left(\mathrm{X}^{\mathrm{e}}-\mathrm{XIII}{ }^{\mathrm{e}}\right.$ siècles). Bilan et perspectives de recherches. Paris 1980, 57-84.

126 Ein allmähliches Verschwinden der frühmittelalterlichen Sklaverei erst zwischen der Mitte des 11. und den ersten Jahrzehnten des 12. Jh. nimmt für Italien an: Francesco Panero, Servi e rustici. Ricerche per una storia della servitù, del servaggio e della libera dipendenza rurale nell'Italia medievale. Vercelli 1990. 
schiede zwischen dem romanischen Süden Frankreichs und Nordspaniens und dem von der bipartiten Grundherrschaft charakterisierten Norden verallgemeinert. ${ }^{127}$ Die daraus gezogenen Folgerungen lassen sich jedoch nicht einfach übertragen, zumal die Theorien einer feudalen Revolution, soweit ich sehe, allesamt auf einer schwachen empirischen Grundlage beruhen: Die Zeit vor dem Ende des 10. Jahrhunderts wird nämlich überall recht pauschal abgehandelt. ${ }^{128}$ Beide Seiten gehen zudem - wie ich meine: fälschlicherweise - von einer einheitlichen, ,fortschrittlichen' Entwicklung aus und vernachlässigen die Möglichkeit, daß diese nicht nur vielschichtig und phasenverschoben verlief, sondern daß die frühmittelalterliche Gesellschaft und Wirtschaft tatsächlich durch verschiedene, nebeneinander verlaufende Tendenzen geprägt war bzw. die „Grundherrschaft“ ebenso wie die „seigneurie“ vielgestaltige Formen annehmen konnte. ${ }^{129}$ Ein Gesellschaftswandel um das Jahr 1000 (wie er zumindest in Südrankreich zu beobachten ist) wäre aus solcher Sicht mit dem Übergang von der Sklaverei zum Feudalismus (nicht nur wegen der marxistischen Terminologie) unzureichend charakterisiert.

\section{Fazit}

Versuchen wir, aus diesen noch sehr vorläufigen Beobachtungen ein kurzes Fazit zu ziehen. Die heutige Grundherrschaftsforschung, die sich in einer internationalen Diskussion befindet, erscheint ambivalent: Einerseits ist sie hoch spezialisiert und auf minutiöse Erfassung aller Einzelheiten aus den - kritisch betrachteten - Quellen bedacht, wobei immer mehr Aspekte, aber auch deren Verflechtung in den Blick geraten sind; andererseits diskutiert man auf einer hochtheoretischen Ebene Wesen, Bedeutung und Wandel der „Grundherrschaft" bzw. der Seigneurie. Beide Richtungen argumentieren (noch) aneinander vorbei, obwohl sie einander bedürfen: Da sich viele Streitfragen aus den Quellen nicht unmittelbar beantworten lassen, wird die moderne Grundherrschaftsforschung ohne Theorien weder bestehen noch etwas erklären können; umgekehrt bedürfen die Theorien allerdings der empirischen Überprüfung.

Ansätze, Lehrmeinungen und Streitfragen orientieren sich in der Regel nicht an den nationalen Grenzen, doch ist eine Befangenheit in den Traditionen, gerade auch in der deutschen Forschung, ebensowenig zu verkennen wie ein enormer Nachholbedarf. Wenn man bedenkt, daß die Landwirtschaft die entscheidende frühmittelalterliche Wirtschaftsform war,

127 So auch Morimoto, État et perspectives (wie Anm. 5), $110 \mathrm{f}$.

128 Das gilt für Bonnassie, Catalogne (wie Anm. 63), ebenso wie für Duby, Société (wie Anm. 63). Andere, unbestritten wichtige Untersuchungen wie die Touberts über Latium (wie Anm. 57) oder Magnou-Nortiers über die Narbonnensis (wie Anm. 96) differenzieren, im Blick auf die späteren Wandlungen, in der Darstellung der ländlichen Verhältnisse in dieser Hinsicht zu wenig zeitlich, um die hier betrachteten Verhältnisse des 9 . Jh. klar abgrenzen zu können.

129 Vgl. ganz in diesem Sinn auch Morimoto, Autour du grand domaine (wie Anm. 5), $66 \mathrm{f}$., und Ludolf Kuchenbuch, Grundherrschaft im früheren Mittelalter. (Hist. Seminar NF., Bd. 1.) Idstein 1991, 44: Der Alltag der Grundherrschaft wurde bestimmt durch „schwer abgrenzbare, sich überlappende, in okkasioneller Bewegung befindliche Verhältnisse“. 
daß die ländliche (und städtische) Ordnung in wirtschaftlicher, sozialer und herrschaftlicher Hinsicht weithin durch grundherrschaftlich-seigneuriale Verhältnisse geprägt war und daß diese unbestritten als ein signifikantes Merkmal der „Feudalgesellschaft“ gelten, daß deren Gestalt, Durchsetzung und Wandlung aber höchst umstritten sind, dann kommt man an der (traurigen) Feststellung nicht vorbei, daß der Grundherrschaftsforschung in Deutschland, gemessen an seinen großen Ressourcen - anders als in Frankreich -, trotz langer Tradition und intensiver, jüngerer Einzelstudien um Dieter Hägermann, Ludolf Kuchenbuch und Werner Rösener und einer Reihe einschlägiger Arbeiten, weiterhin eine ihrer Bedeutung diametral entgegenstehende Außenseiterposition beschieden ist (auch wenn es Werner Rösener immerhin gelingt, sich in seinem langen Forschungsüberblick fast ganz auf die deutsche Forschung zu beschränken und der französischen gerade anderthalb Seiten zu widmen). ${ }^{130}$ Hier bleibt noch viel zu tun, um zu einer besseren Verständigung zu kommen.

Mir scheint - und das betrifft nun die gesamte, internationale Forschung - aber auch ein offenerer Blick auf die spezifisch frühmittelalterlichen Verhältnisse nötig. Obwohl es inzwischen längst bekannt ist, daß nicht nur in einzelnen Regionen, sondern auch innerhalb einer Grundherrschaft gleichzeitig unterschiedliche Wirtschafts- und Organisationsformen nebeneinander existierten, drehen sich die Einschätzung der Forschung - gerade auch auf seiten der Gegner einer ,feudalen Revolution“ - und auch die Forschungsstreitigkeiten noch weithin um die „Grundherrschaft“ (oder den „Feudalismus“) als (einheitlich verstandene) Wirtschafts- und Sozialform. Das geht an der Realität vorbei. ${ }^{131}$ Der Streit resultiert mit anderen Worten - neben Unterschieden der Produktionsverhältnisse nördlich und südlich der Loire -

130 Rösener, Grundherrschaft im Wandel (wie Anm. 8), 11-54; zur französisch-belgischen Forschung ebd. $38 \mathrm{f}$. Ordnet man die in den Forschungsüberblicken Morimotos (wie Anm. 5) zitierten Arbeiten und Forscher nach Ländern (vgl. die folgende Tabelle), so läßt sich immerhin erkennen, daß das Interesse hier, wie auch in Italien, in der zweiten Untersuchungsperiode (1987-92) merklich zugenommen hat. Dieser Trend hat sich seither allerdings nicht fortgesetzt.

\begin{tabular}{lrrrrrr} 
& Arbeiten & \multicolumn{5}{c}{ Wissenschaftler } \\
\cline { 2 - 6 } & $1980 / 86$ & $1987 / 92$ & Summe & $1980 / 86$ & $1987 / 92$ & Summe \\
Frankreich/ & & & & & & \\
Belgien & 56 & 59 & 115 & 25 & 28 & 53 \\
Deutschland & 24 & 63 & 85 & 15 & 27 & 42 \\
Italien & 2 & 24 & 26 & 2 & 9 & 11 \\
England & 1 & 5 & 6 & 1 & 2 & 3 \\
Amerika & 3 & 4 & 7 & 2 & 2 & 4 \\
andere & 10 & 12 & 22 & 8 & 6 & 14.
\end{tabular}

131 Auch eine ,klassische‘ Definition wie die von Friedrich Lütge, die Grundherrschaft sei durch die Trennung von Eigentum und Nutzung gekennzeichnet (Lütge, Geschichte [wie Anm. 70], 51), betrifft nur einen Teil, nämlich das Leiheland. Im Unterhalt des Herren hatte $D u b y$, L'économie rurale (wie Anm. 82), 98, den Sinn der Grundherrschaft gesehen. Ähnlich funktional, aber allgemeiner definiert Kuchenbuch, Potestas und Utilitas (wie Anm. 6), jetzt, in Anlehnung an Thomas Zotz, Zur Grundherrschaft des Königs im deutschen Reich vom 10. bis zum frühen 13. Jahrhundert, in: Grundherrschaft und bäuerliche Gesellschaft (wie Anm. 3), 76-115, hier 76, wieder die Grundherrschaft durch Herrschaft (potestas) und Nutzen (utilitas). Vgl. auch Devroey, „Ad utilitatem monasterii“ (wie Anm. 118). 
zum einen aus einem zielgerichteten Entwicklungsdenken, zum anderen aus einem vorgeprägten Grundherrschaftsbegriff, der in dieser Form ,unmittelalterlich“ ist. „Grundherrschaft", ohnehin ein moderner Ordnungsbegriff ${ }^{132}$, ist, wie wir heute wissen, weder eine besondere Form der personalen Herrschaft (so Friedrich Lütge), noch ist sie Ausfluß der Hausherrschaft (so Otto Brunner), sie ist aber ebensowenig - moderner argumentiert - nur die zweigeteilte Grundherrschaft oder das Gegenstück zur Latifundien- und Sallandwirtschaft. Fronhofsverfassung und Hebeamtsverfassung sind weder zwei unterschiedliche (oder auch unterschiedlich alte) (so Rudolf Kötzschke) noch auf die Regionen verteilte Typen der Grundherrschaft (so Friedrich Lütge), „Sklavenwirtschaft“ und Hufenbauernwirtschaft nicht zwei gegensätzliche Wirtschaftssysteme (worum die französische Forschung streitet), sondern den Umständen angepaßte Organisationsformen einer durch Vielfalt gekennzeichneten frühmittelalterlichen „Grundherrschaft“ bzw. „seigneurie foncière“. Man wird, auch um den Streit um die „feudale Revolution“ lösen zu können, meines Erachtens daher nicht nur eine Dynamik anerkennen ${ }^{133}$, sondern auch einen offeneren Grundherrschaftsbegriff aufgreifen und Differenzierungen innerhalb der „Grundherrschaft“ ebenso wie der „seigneurie“ beach$\operatorname{ten}^{134}$, aber auch zwischen der Grundherrschaft als Herrschaftsverhältnis, als Organisationsform und als Wirtschaftsweise unterscheiden müssen. Erst dann wird ein europaweiter Vergleich sinnvoll sein und sich von - bislang vorherrschenden - Pauschalgegensätzen befreien können. Die Vielfalt (gewissermaßen auch als Summe der Forschungen) zu beachten, entspräche nur unseren heutigen Forschungsinteressen und -grundlagen, unbeschadet nationaler Unterschiede. Es sollte uns zudem - und hier sehe ich ein weiteres, allgemeines Defizit - zu denken geben und wäre in Zukunft, auch als Prüfstein für unsere eigenen Interessen, stärker zur Kenntnis zu nehmen, daß die mittelalterlichen Menschen selbst ganz andere Probleme bewegten als die Unterscheidung zwischen „Sklaven“ und „Hörigen“ oder der Zeitpunkt einer „feudalen Revolution“.

132 Vgl. Klaus Schreiner, „Grundherrschaft“. Entstehung und Bedeutungswandel eines geschichtswissenschaftlichen Ordnungs- und Erklărungsbegriffis, in: Die Grundherrschaft im spăten Mittelalter (wie Anm. 28), Bd. 1, 11-74.

133 Der Streit ist allerdings nicht dadurch zu lösen, daß man mit Kuchenbuch, Potestas und Utilitas (wie Anm. 6), 144, eine Phase der domanialen Offiensive von Königtum und Kirche im 8./9. Jh. und eine Phase der seigneurialen Offensive des Adels im 10./11. Jh. unterscheidet.

134 In der Tagungsdiskussion zu meinem Vortrag forderten mehrere Teilnehmer/innen als Konsequenz meiner Beobachtungen einen Verzicht auf den Grundherrschaftsbegriff. Wo aber läge die Alternative? Mein Vorwurf eines (zu engen) Vorverständnisses richtete sich nicht minder gegen die franzősische und italienische Forschung, denen der Grundherrschaftsbegriff fremd ist; auch dort werden „seigneurie" und (mehr noch) „féodalisme" ähnlich eng verstanden und mit den nordfranzősischen Verhältnissen bzw. dem „sistema curtense“ identifiziert. Wichtiger ist es vielmehr, sich die eigenen Traditionen und deren Vorverständnisse bewußter zu machen und die grundherrschaftlichen Verhăltnisse (und nicht nur die Begriffe) zu vergleichen. 



\title{
Quelques possibilités de comparaison dans l'histoire rurale des $\mathrm{XII}^{\mathrm{e}}-\mathrm{XIII}{ }^{\mathrm{e}}$ siècles, à partir d'exemples lombards
}

\author{
Von \\ François Menant
}

Dans un colloque sur "Théorie, méthodes et pratique de la comparaison dans l'historiographie du Moyen Âge européen", je me situe résolument du côté de la pratique, en proposant quelques situations que j'ai eu l'occasion d'étudier dans les sources lombardes, et en me demandant en quoi elles peuvent être singulières, ou au contraire exemplaires, par rapport à d'autres situations contemporaines, dans d'autres régions de l'Italie ou de l'Occident. Je souhaite donc à la fois présenter rapidement des résultats de recherche, et me demander si la problématique qui se dégage de l'histoire lombarde correspond à des questions effectives dans d'autres régions. En d'autres mots, je vais présenter quelques résultats de recherche comme objets de comparaison.

Mais je veux d'abord préciser dans quelles conditions cette démarche comparative peut être valide: Il s'agit, dans mon esprit, de partir d'une situation historique dont la recherche a montré la relative homogénéité - en l'occurrence, les situations sociales et économiques de l'Italie des communes, ou plus étroitement de la Lombardie - et de se demander dans quelle mesure les caractères de cet objet historique se retrouvent ailleurs dans un cadre plus large (la Méditerranée occidentale chrétienne, ou l'Occident chrétien). La comparaison n'est à mon avis vraiment efficace que lorsqu'elle porte sur des situations qui présentent des analogies suffisantes, et c'est l'expérience de la comparaison elle-même qui peut seule confirmer, empiriquement, dans quelle mesure ces analogies existent.

Par exemple, pour réaliser une enquête comparative sur les phénomènes de crédit et d'endettement aux derniers siècles du Moyen Âge, on a choisi le cadre de la Méditerranée occidentale chrétienne, du royaume de Valence à la Toscane ${ }^{1}$ : les situations économiques et

1 Lors des rencontres „Les sources notariales pour l'histoire du crédit dans l'Occident méditerranéen médiéval“ (Nice-Bordighera, octobre 1996, et Lyon, décembre 1997), „Crédit et justice dans l'Occident méditerranéen médiéval“ (Asti, février 1999), et „Crédit et fiscalité dans l'Occident méditerranéen médiéval" (Lyon, décembre 1998, et Paris, décembre 1999), organisées par Jean-Louis Gaulin, Antoni Furió, Renato Bordone, Monique Zerner et moi-même; les actes sont en cours de publication. 
documentaires de cet ensemble de pays présentent a priori suffisamment d'analogies pour permettre la comparaison. On a ainsi pu comparer la pratique des notaires en matière de contrats de prêt, la présence des dettes dans les documents fiscaux, et la procédure judiciaire envers les mauvais payeurs, d'un bout à l'autre de cet ensemble géographique. La présence, dans les différentes régions étudiées, de documents de même type - registres de notaires, relevés fiscaux ou actes judiciaires ${ }^{2}$ - et les analogies de structures économiques et sociales (notamment le fort développement urbain et le rôle central tenu par ces régions dans les échanges européens) ont permis de mettre en évidence les similitudes, mais aussi les profondes différences qu'offrent les phénomènes de crédit d'une région à l'autre: par exemple, l'endettement aboutit pour les paysans italiens à la saisie de leur terre, mais en Espagne il débouche sur l'établissement d'une rente constituée.

Pour prendre un autre exemple, tout à fait différent et extérieur au thème de cette contribution, il me paraît très possible de comparer l'évolution de la pratique administrative autour de 1200 - à l'époque où elle subit d'importants changements - dans les communes italiennes et dans la France de Philippe Auguste, et aussi dans l'Angleterre des Plantagenêt; les travaux récents sur le développement à cette époque de la documentation administrative dans ces différents pays ${ }^{3}$ suggèrent la possibilité d'une enquête comparative sur les méthodes d'écriture, de comptabilité et d'archivage, ou sur la prosopographie des employés gouvernementaux.

J'en arrive maintenant aux situations concrètes dont je veux parler ici. Je prendrai deux séries d'exemples, choisis dans deux des domaines les plus classiques de l'historiographie du Moyen Âge: la société rurale et la préminence de la ville sur la campagne.

La première question que j'évoquerai concerne l'encadrement social et ses rapports avec l'économie rurale. La société rurale lombarde de l'époque communale est très fortement encadrée, à tous les niveaux: l'aristocratie constitue de puissants réseaux féodaux centrés sur les évêchés et les grands monastères, tandis que l'immense majorité de la paysannerie est

2 En ce qui concerne les documents judiciaires, voir l'étude de cas détaillée qui sert de point de départ à l'enquête: Jean-Louis Gaulin (Dir.), Le bannissement pour dettes à Bologne au XIII ${ }^{\mathrm{e}}$ s., dans: Mélanges de l'École française de Rome. Moyen Âge 109, 1997, 477-567.

3 Parmi les plus significatifs: Jean-Claude Maire Vigueur (Dir.), Le personnel politique itinérant dans l'Italie communale (sous presse); Hagen Keller/Jörg W. Busch (Hrsg.), Statutencodices des 13. Jahrhunderts als Zeugen pragmatischer Schriftlichkeit. Die Handschriften von Como, Lodi, Novara, Pavia und Voghera. München 1991; Hagen Keller/Thomas Behrmann (Hrsg.), Kommunales Schriftgut in Oberitalien. Formen, Funktionen, Überlieferung. München 1995; Thomas Scharff/Thomas Behrmann (Hrsg.), Bene vivere in communitate. Beiträge zum italienischen und deutschen Mittelalter. Hagen Keller zum 60. Geburtstag überreicht von seinen Schülerinnen und Schülern. Münster 1997; Paolo Cammarosano, Italia medievale. Struttura e geografia delle fonti scritte. Rome 1991, et le compte-rendu de Jean-Claude Maire Vigueur, Révolution documentaire et révolution scripturaire dans l'Italie médiévale, dans: BECh 151, 1993, 177-185; John W. Baldwin, The Government of Philip Augustus. Foundations of French Royal Power in the Middle Ages. Berkeley/Los Angeles/Oxford 1986 (éd. française: Philippe Auguste et son gouvernement. Les fondations du pouvoir royal en France au Moyen Âge. Paris 1991); Michael T. Clanchy, From Memory to Written Record. England 1066-1307. Oxford/Cambridge/Harvard 1979. 
libre, mais soumise à des seigneuries rurales solides. ${ }^{4}$ On a là un type de société rurale bien caractérisé, qui comporte à la fois, d'une part de fortes institutions seigneuriales et une puissante aristocratie féodale, et d'autre part une paysannerie de petits propriétaires (ou concessionnaires perpétuels), sujets de la seigneurie. Or la comparaison avec d'autres régions de l'Italie communale révèle des situations très différentes: les récentes études de Chris Wickham sur la Toscane, par exemple, montrent un monde peu féodalisé, et dans lequel des régions entières échappent à la seigneurie rurale. ${ }^{5}$ Ces différences de structures sociales ont des conséquences dans toutes sortes de domaines, parfois inattendues; elles sont par exemple sans doute la cause que les nobles toscans et lombards adoptent des systèmes anthroponymiques différents: les nobles lombards prennent précocement le nom de leur château, tenu en fief et centre d'une seigneurie rurale, alors que l'aristocratie toscane reste très tard fidèle à un système de référence aux ancêtres dont le nom personnel se répète de génération en génération. Le nom de famille se fixe ainsi chez les élites lombardes un siècle au moins avant qu'il ne se généralise chez celles de Toscane. ${ }^{6}$

Remarquons d'autre part que la forte présence seigneuriale en Lombardie n'empêche pas le développement des communautés rurales et leur précoce autonomie: la plupart des villages lombards sont organisés en communes avant la fin du XII siècle, et ces communes rachètent les droits seigneuriaux qu'elles gèrent ensuite elles-mêmes, souvent en association avec le seigneur. Cette évolution vers la libération des contraintes seigneuriales n'est pas non plus générale dans toute l'Italie: les travaux de Sandro Carocci montrent ainsi qu'en

4 Hagen Keller, Adelsherrschaft und städtische Gesellschaft in Oberitalien (9.-12. Jahrhundert). Tübingen 1979 (éd. ital.: Signori e vassalli nell'Italia delle città. Turin 1995); François Menant, Campagnes lombardes du Moyen Âge. L'économie et la société rurales dans la région de Bergame, de Crémone et de Brescia du Xe au XIII' siècle. Rome 1993.

5 Chris Wickham, La signoria rurale in Toscana, dans: Strutture e trasformazioni della signoria rurale nei secoli X-XIII. Dir. Gerhard Dilcher/Cinzio Violante. (Annali dell'Istituto Storico Italo-germanico, Quaderno 44.) Bologne 1996, 343-409; id., Property Ownership and Signorial Power in Twelfth-Century Tuscany, dans: Property and Power in the Early Middle Ages. Ed. Wendy Davies/Paul Fouracre. Cambridge 1995, 221-244; id., Comunità e clientele in Toscana nel XII secolo. Le origini del comune rurale nella Piana di Lucca. Rome 1995 (éd. anglaise: Community and clientele in twelfth-century Tuscany. The origins of the rural commune in the plain of Lucca. Oxford 1998); voir aussi $i d$., Land and Power. Studies in Italian and European Social History, 400-1200. London 1994. Le contraste est fort avec d'autres parties de la Toscane, où l'encadrement seigneurial est solide: Piero Brancoli Busdraghi, Masnada e boni homines come strumento di dominio delle signorie rurali in Toscana (sec. XI-XIII), dans: Strutture e trasformazioni (voir note 5), 287-342; voir aussi Odile Redon, Seigneurs et communautés rurales dans le contado de Sienne au XIII ${ }^{\mathrm{e}}$ siècle, dans: Mélanges de l'École française de Rome. Moyen Âge 91, 1979, 149-196, 619-657; autres exemples de seigneuries rurales toscanes dans la bibliographie de Wickham, La signoria rurale (voir note 5).

6 François Menant, Ancêtres et patrimoine. Les systèmes de désignation dans l'aristocratie lombarde des $\mathrm{XI}^{\mathrm{e}}-\mathrm{XII}^{\mathrm{e}}$ siècles, dans: Nomen et gens. Zur historischen Aussagekraft frühmittelalterlichen Personennamen. Hrsg. v. Dieter Geuenich. Berlin 1997, 176-189.

7 Sandro Carocci, Baroni di Roma. Dominazioni signorili e lignaggi aristocratici nel Duecento e nel primo Trecento. Rome 1993; id., La signoria rurale nel Lazio, dans: La signoria rurale nel medioevo italiano. Dir. Amleto Spicciani/Cinzio Violante. Vol 1. Pise 1997, 167-198; id., Ricerche e fonti sui poteri signo- 
Latium, c'est au XIII ${ }^{\mathrm{e}}$ siècle que la seigneurie se renforce, et atteint un degré de puissance inconnu en Lombardie à l'époque même où, ici, la plupart des seigneuries perdent leurs moyens d'action. ${ }^{8}$

Un autre aspect qui me paraît propre à susciter la confrontation est l'importance et la nature des groupes sociaux intermédiaires dans la société rurale. Par cette expression, que j'utilise faute de mieux - on pourrait parler aussi d'élites rurales mineures -, je désigne différents groupes de paysans aisés, caractérisés par un statut social particulier: il s'agit de vassaux de rang inférieur (ceux qu'on appelle vassaux conditionnels) ou de serfs, les hommes de masnada. ${ }^{9}$ Ces personnages peuvent être nombreux dans les villages, et ils y tiennent une place très particulière et importante: ils occupent les fonctions de ministériaux dans les seigneuries, encadrent et commandent donc les autres paysans, et beaucoup d'entre eux portent les armes et assurent un service militaire à cheval. Certains sont riches, et détiennent de grosses exploitations; ils ont une place particulière par rapport à la commune rurale, dont ils peuvent être exclus parce qu'ils sont trop étroitement liés au seigneur, mais ils la dominent aussi parfois. Ces petits vassaux et masnadieri constituent en somme un élément à part dans la société rurale, et leur importance amène à nuancer la dichotomie simpliste entre seigneurs et paysans. On n'assiste cependant pas en Italie à des ascensions sociales aussi spectaculaires que celles des ministériaux allemands; la raison en est sans doute que les maîtres des ministériaux italiens ne détiennent pas le gouvernement au plus haut niveau comme les princes territoriaux allemands: les plus grosses masnades et équipes de vassaux conditionnels doivent appartenir à des évêques et des abbés, dont l'autorité politique est battue en brèche dès le XII ${ }^{\mathrm{e}}$ siècle. Ce type de catégorie sociale se retrouve dans d'autres

rili nel Lazio meridionale nella prima metà del XIII secolo: Villamagna e Civitella, dans: Il Sud del Patrimonium Sancti Petri al confine del Regnum nei primi trent'anni del Duecento. Due realtà a confronto. Atti delle giornate di studio (Ferentino, Centro di Studi „Giuseppe Ermini“, 28-29-30 ottobre 1994). Rome 1997, 111-144. Le panorama des pouvoirs seigneuriaux dans l'Italie communale s'est beaucoup enrichi ces dernières années, grâce aux rencontres organisées par Cinzio Violante; outre: Strutture e trasformazioni (voir note 5), et: La signoria rurale nel medioevo italiano (voir note 7), on trouvera des études monographiques et des réflexions thématiques dans les recueils: La signoria rurale in Italia nel Medioevo. II Convegno di studi, Pisa, 6-7 novembre 1998 (en cours de publication); Chiesa e mondo feudale (sec. X-XII). Atti della XII settimana internazionale di studio, Mendola, 24-28 agosto 1992. (Miscellanea del Centro di studi medioevali, vol. 14.) Milan 1995.

8 Pour une comparaison du phénomène à l'échelle européenne, on verra les actes du colloque „Pour une anthropologie du prélèvement seigneurial" (Medina del Campo $1^{\text {er }}-3$ juin 2000), en cours de publication.

9 Brancoli Busdraghi, Masnada e boni homines (voir note 5); Gina Fasoli, Prestazioni in natura nell'ordinamento economico feudale: feudi ministeriali nell'Italia nord orientale, dans: Economia naturale, economia monetaria. Dir. Ruggiero Romano. (Storia d'Italia. Annali, vol. 6.) Turin 1983, 65-89; François Menant, Les écuyers (scutiferi), vassaux paysans d'Italie du Nord au XII ${ }^{\mathrm{e}}$ siècle, dans: Structures féodales et féodalisme dans l'Occident méditerranéen $\left(\mathrm{X}^{\mathrm{e}}-\mathrm{XIII}{ }^{\mathrm{e}} \mathrm{s}\right.$.). Colloque international organisé par le Centre national de la recherche scientifique et l'École française de Rome, Rome 10-13 octobre 1978. Rome 1980, 285-297 (trad. ital. dans: id., Lombardia feudale. Studi sull'aristocrazia padana nei secoli X-XIII. Milan 1992, 277-293); id., Campagnes lombardes (voir note 4), 691-705; Alessandro Barbero, Vassalli, nobili e cavalieri fra città e campagna. Un processo nella diocesi di Ivrea all'inizio del Duecento, dans: Studi Medievali, $3^{\mathrm{e}}$ sér. 33, 1992, 619-644. Voir aussi Francesco Panero, Schiavi servi e villani nell'Italia medievale. Turin 1999. 
régions de l'Occident, dans une configuration sociale et juridique plus ou moins proche: Marc Bloch en avait esquissé l'étude comparée, et avait tracé un portrait collectif d'un groupe de ce type, les sergents d'île-de-France. ${ }^{10}$

Ajoutons, pour nuancer encore un peu plus le tableau de la société rurale, que les campagnes lombardes fourmillent aussi de très petits milites, souvent très proches des vassaux conditionnels. Dans beaucoup de villages, il y a à la fin du XII ${ }^{\mathrm{e}}$ siècle deux communes juxtaposées: commune rusticorum et commune militum ou vassallorum. La société rurale est donc très articulée, pleine de nuances. Le statut personnel d'un individu ou d'un groupe ne correspond pas forcément à sa richesse, ni à son rôle politique dans la communauté, ni à l'image que se forment de lui ses voisins. L'influence des citadins, que je vais analyser ensuite, complique encore les situations. Cette complexité des sociétés rurales, sous l'apparente division binaire entre seigneurs et paysans, est certainement une des données les plus mouvantes, d'un lieu à l'autre, d'un pays à l'autre, à travers l'Occident médiéval, de par la combinaison toujours diffiérente de ses variables.

La deuxième grande question que je voudrais évoquer concerne la place de la ville dans le développement des campagnes: la ville et ses habitants dominent l'histoire des campagnes lombardes, et cette constatation n'a certes rien d'original; dans toute la Méditerranée occidentale chrétienne, la prééminence urbaine est une donnée centrale du développement médiéval. Et en Italie même, les thèmes dominants de l'histoire rurale ont toujours été la „conquête du contado" par les communes, „l'inurbamento“ (émigration des ruraux vers la ville), et la domination économique des citadins sur la campagne. Ces thèmes ont paru tellement usés et désuets que certains historiens ont cherché en réaction, entre les années 70 et 80, à mettre en valeur l'importance des campagnes; ils ont voulu souligner la place que tenaient les élites rurales dans le gouvernement des villes, et l'influence qu'elles exerçaient sur les bourgeoisies urbaines: les travaux de Hagen Keller et de Philip Jones ${ }^{11}$, pour citer ceux qui ont donné lieu aux débats les plus vifs, participent de cet essai de rééquilibrage. Même si l'on tient tout le compte voulu de l'acquis de ces travaux, la prééminence des citadins reste malgré tout un trait caractéristique de l'Italie communale, qu'on ne retrouve probablement pas ailleurs - même dans d'autres pays méditerranéens- avec une égale intensité.

Prenons un premier exemple de la prééminence citadine, qui est d'ordre à la fois social et culturel: il s'agit de la façon de se nommer. Le système de désignation des aristocraties

10 Voir surtout Marc Bloch, Un problème d'histoire comparée. La ministérialité en France et en Allemagne, dans: id., Mélanges historiques. Paris 1963, 503-528.

11 Keller, Adelsherrschaft (voir note 4); Philip Jones, Economia e società nell'Italia medievale. La leggenda della borghesia, dans: Dal feudalesimo al capitalismo. Dir. Ruggiero Romano/Corrado Vivanti. (Storia d'Italia. Annali, vol. 1.) Turin 1978, 183-372; rééd. sous le titre: Economia e società nell'Italia medievale. Il mito della borghesia, dans: Philip Jones, Economia e società nell'Italia medievale. Turin 1980, 3-189. Sur ces tendances historiographiques, voir - parmi beaucoup d'autres réactions - Renato Bordone, Tema cittadino e ritorno alla terra nella storiografia comunale recente, dans: Quademi Storici 52, 1983, 255-277; id., Nascità delle autonomie cittadine, dans: La storia. I grandi problemi dal medioevo all'età contemporanea. Dir. Nicola Tranfaglia. Vol. 2: Il medioevo; 2. Popoli e strutture politiche. Turin 1986, 449-457; et la revue historiographique placée par Keller luimême en introduction à l'édition italienne de son livre: Signori e vassalli (voir note 4). 
urbaines (une chaîne de noms personnels suivie d'un nom de famille collectif, à l'ablatif pluriel: Albertus Benvenuti Ariprandi de Rossis ${ }^{12}$ ) se répand dans la société rurale à partir du $\mathrm{XIII}^{\mathrm{e}}$ siècle, d'abord dans les élites paysannes puis chez les plus pauvres. Considérée du point de vue anthroponymique, la société rurale semble particulièrement dépendante de la ville, non seulement par le système de désignation, mais aussi par le choix des noms personnels. ${ }^{13}$

Il y aurait beaucoup à dire de cette acculturation, mais je préfere développer d'autres exemples de l'influence citadine, en les prenant dans le domaine économique: il s'agit du crédit et du marché foncier. À partir de la fin du $\mathrm{XI}^{\mathrm{e}}$ siècle, la documentation des grandes villes italiennes est dominée par la concentration continue de la terre dans les mains des citadins riches. Le phénomène est particulièrement bien connu à ses débuts autour de Milan et en Lombardie, et à partir du XIII ${ }^{\mathrm{e}}$ siècle autour de Florence et en Toscane. Le moyen principal utilisé par les citadins pour acquérir la terre des propriétaires ruraux est le prêt à intérêt, développé par l'appauvrissement croissant de beaucoup de propriétaires paysans ${ }^{14}$ : l'essor démographique réduit sans cesse les surfaces de terre dont ils disposent, et l'accroissement de la productivité ne suffit apparemment pas à compenser ce rétrécissement des exploitations. Leurs difficultés financières sont aggravées par la généralisation de l'impôt public à partir de la fin du XII ${ }^{\mathrm{e}}$ siècle. Les besoins d'argent sont encore accrus par le rachat des droits seigneuriaux et par les investissements nécessaires pour s'adapter au progrès agricole: l'irrigation par exemple coûte très cher. Les paysans riches partent d'ailleurs s'installer en ville pour y faire fructifier leur capital, comme l'a autrefois illustré Johann Plesner ${ }^{15}$; restent les pauvres, qui sont de plus en plus pauvres. Chaque fois qu'un emprunt ne peut pas être remboursé, le créancier saisit un champ ou une exploitation agricole entière. Au bout de deux siècles et demi de ce procédé, les campagnes toscanes ou lombardes appartiennent presque entièrement aux citadins. La paysannerie est prolétarisée, et réduite à exploiter pour le compte des propriétaires de la ville les terres que possédaient ses ancêtres.

12 Qui succède à la référence au château mentionnée ci-dessus, ou complète le nom formé sur un ancêtre éponyme.

13 François Menant, L'anthroponymie du monde rural, dans: L'anthroponymie, document de l'histoire sociale des mondes médiévaux méditerranéens. Rome 1996, 349-363 (version allemande: Die Namen der Landbevölkerung im Mittelalter [Oberitalien und Südfrankreich], dans: Personennamen und Identităt. Hrsg. v. Reinhard Härtel. Graz 1997, 423-440).

14 Jean-Louis Gaulin/François Menant, Crédit rural et endettement paysan dans l'Italie communale, dans: Endettement paysan et crédit rural dans l'Europe médiévale et moderne. Actes des XVI ${ }^{\text {es }}$ Journées internationales d'histoire de l'abbaye de Flaran (septembre 1995). Toulouse 1998, 35-68, où l'on trouvera aussi la bibliographie. L'historiographie du marché de la terre dans l'Italie communale reste peu abondante; le recueil d'articles: Il mercato della terra. Dir. Gérard Delille/Giovanni Levi, dans: Quaderni Storici 65, 1987, 351-614, ne comportait qu'un article sur le Moyen Âge italien, de Chris Wickham; on attendra la publication des actes de la rencontre „Le marché de la terre. De nouvelles voies pour l'histoire économique du Moyen Âge occidental: entre économie, économétrie et anthropologie économique?“ (Fondation des Treilles, Tourtour 19-25 juin 1999).

15 Johan Plesner, L'émigration de la campagne à la ville libre de Florence au XIII ${ }^{e}$ siècle. Copenhague 1934. 
On sait qu'en Toscane ce transfert de propriété s'accompagne d'un remodèlement des exploitations et des paysages agraires, avec la généralisation du métayage (mezzadria) et la constitution d'exploitations compactes (appoderamento). Dans la plaine du Pô se constituent les très grandes exploitations irriguées (corti) cultivées par des dizaines d'ouvriers. Ailleurs les propriétaires citadins peuvent se contenter de prélever un loyer sur les terres qu'ils ont acquises, sans modifier les conditions d'exploitation. Les communautés rurales elles-mêmes sont victimes de l'endettement, et beaucoup d'entre elles perdent leurs biens communaux, en particulier les terrains incultes qui permettaient aux paysans pauvres de survivre.

Cette immense dépossession de la paysannerie, individuelle et collective, me semble être un phénomène particulièrement intense en Italie: ailleurs aussi l'endettement paysan se développe après le $\mathrm{XI}^{\mathrm{e}}$ siècle, mais il aboutit à des solutions différentes, comme la constitution de rentes perpétuelles sur les propriétés. ${ }^{16} \mathrm{La}$ différence de ressources doit aussi être particulièrement forte en Italie entre les paysans et les citadins des grandes villes marchandes, qui concentrent entre leurs mains les profits du grand commerce international. L'exemple de la Toscane est sur ce point particulièrement remarquable, richement documenté, et a été souvent commenté. ${ }^{17}$

Il faudrait aussi introduire des distinctions selon les milieux naturels: la ruine des paysans et des communautés rurales est particulièrement intense autour des grandes villes et dans les secteurs les plus productifs, comme la plaine du Pô. ${ }^{18} \mathrm{Au}$ contraire les citadins ne risquent pas leurs capitaux à la périphérie des territoires de leurs villes, ni dans les milieux naturels peu productifs ou difficiles d'accès, comme les vallées alpines ou les marécages de la Maremma toscane. Le prêt à intérêt à grande échelle semble peu répandu dans ces régions déshéritées. ${ }^{19}$

Cette question du crédit et du marché de la terre se prête ainsi à une comparaison entre l'Italie communale et d'autres pays d'Occident, où la prééminence économique des villes n'a pas forcément induit la même dépossession de la paysannerie; mais le crédit et le marché foncier appellent aussi des comparaisons internes à l'Italie communale, entre des ensembles

16 Voir les différentes contributions à: Endettement paysan (voir note 14).

17 Je me borne à citer trois études particulièrement suggestives: Paolo Cammarosano, Città e campagna: rapporti politici ed economici, dans: Società e istituzioni dell'Italia comunale. L'esempio di Perugia (secoli XII-XIV). Congresso Storico Internazionale, Perugia, 6-9 novembre 1985. Vol. 1. Pérouse 1988, 302-349; Giuliano Pinto, Note sull'indebitamento contadino e lo sviluppo della proprietà fondiaria cittadina nella Toscana tardomedievale, dans: Ricerche storiche 10, 1980, 3-19, rééd. sous le titre: Aspetti dell'indebitamento e della crisi della proprietà contadina, dans: id., La Toscana nel tardo medioevo. Florence 1982, 207-223; id., Ordinamento colturale e proprietà fondiaria cittadina nella Toscana del tardo Medioevo, dans: Contadini e proprietari nella Toscana moderna. Atti del convegno di studi in onore di Giorgio Giorgetti. Vol. 1: Dal medioevo all'età moderna. Florence 1979, 222-277.

18 Ou les environs des villes toscanes, cf. la Tavola delle possessioni siennoise du début du XIV ${ }^{\mathrm{e}} \mathrm{s}$. analysée sous la direction de Giovanni Cherubini, La proprietà fondiaria in alcune zone del territorio senese all'inizio del Trecento, dans: Rivista di Storia dell'Agricoltura 14, 1974, 5-176.

19 Francesca Bocchi, I debiti dei contadini (1235). Note sulla piccola proprietà terriera bolognese nella crisi del feudalesimo, dans: Studi in memoria di Luigi Dal Pane. Bologne 1982, 161-209. 
régionaux où les méthodes et l'issue des opérations des citadins ne sont pas exactement les mêmes.

Le dernier aspect de la prééminence citadine que je voudrais présenter est d'ordre social et politique: les citadins ne se contentent pas d'acquérir des terres, mais ils prennent aussi, bien souvent, la place des anciens seigneurs. Ils rachètent les domaines de l'ancienne aristocratie féodale, ou les reçoivent en fief des évêchés et des monastères. Aux instruments de domination dont disposait l'ancienne aristocratie, c'est-à-dire le pouvoir banal et la propriété de la terre, ces nouveaux seigneurs ajoutent des moyens que leur fournit leur appartenance à l'élite citadine: les lois imposées par les communes protègent la propriété des citadins et leurs intérêts (en les aidant par exemple à récupérer leurs créances, et à exécuter des saisies de biens sur leurs débiteurs paysans). Les grandes familles citadines imposent leur domination aux communautés rurales en rachetant les anciens droits seigneuriaux, mais aussi en prêtant aux communautés l'argent nécessaire pour payer l'impôt exigé par la commune urbaine, et en occupant dans les communes rurales les fonctions de podestà (gouverneurs, généralement nommés sous l'influence des communes urbaines). ${ }^{20}$ La conquête du pouvoir dans les villes par les grandes familles, qui va être le trait dominant de la vie politique italienne à partir du $\mathrm{XIV}^{\mathrm{e}}$ siècle, commence ainsi bien souvent par la construction de zones de pouvoir dans les campagnes: ces puissantes familles citadines disposent, dans les villages qu'elles dominent, à la fois de terres, du pouvoir seigneurial, de fonctions politiques, éventuellement de charges ecclésiastiques dans l'église paroissiale. Elles y ajoutent souvent des réseaux de fidélité et de service militaire chez les paysans. Il faudrait évidemment nuancer ces affirmations très rapides: par exemple les régimes de Popolo, au pouvoir dans beaucoup de villes dans la seconde moitié du XIII ${ }^{\mathrm{e}}$ siècle, cherchent à démanteler les réseaux de fidélité et le pouvoir seigneurial en général; mais leur politique fiscale peut accélérer par ailleurs la prolétarisation des paysans, et donc la mainmise citadine sur les terres.

Je n'ai voulu, à travers ces quelques exemples tirés de situations sur lesquelles j'ai pu rassembler une information directe, que proposer des objets possibles de comparaison. Il me semble que les spécificités dégagées, à l'échelle d'une région - la Lombardie - ou d'un ensemble politique plus vaste - l'Italie des communes - appellent la confrontation. Le cadre géographique qui s'offre d'emblée à ces rapprochements est la Méditerranée occidentale chrétienne, qui présente a priori les indispensables analogies de structures sociales, économiques, documentaires. Mais la comparaison peut concerner aussi d'autres régions de l'Occident: les entreprises collectives en cours sur le prélèvement seigneurial, le marché de la terre ou le crédit fournissent quelques exemples de cette démarche.

20 Massimo Giansante, Patrimonio familiare e potere nel periodo tardo-comunale. Il progetto signorile di Romeo Pepoli banchiere bolognese (1250 c. - 1322). Bologne 1991. 


\title{
Die Probleme des Lehnswesens und des Feudalismus aus polnischer Sicht
}

\author{
Von \\ Stawomir Gawlas
}

Feudalismus ist ein Terminus, der zur begrifflichen Grundausstattung der Historiker des Mittelalters und der Neuzeit gehört, allerdings wird er auf sehr unterschiedliche Weise benutzt und verstanden. Die stets aufs Neue unternommenen Versuche, den Bereich seiner Anwendung enger zu fassen, spiegeln gleichzeitig die Verschiedenheit genereller Annahmen und Einstellungen der Forscher wider. Hieraus ist also keine einheitliche Auffassung zu gewinnen. Zugleich zeigen sie die Hauptschwierigkeit vergleichender sozialgeschichtlicher Forschungen unter den Bedingungen der Isolation der nationalen Historiographien und ihrer Flucht in eigene Problemfelder und eine eigene Terminologie. Wăhrend der Begriff in der französischen und angelsächsischen Forschung lebhaft diskutiert wird, wird er in Deutschland seit längerem gemieden und statt dessen durch Bezeichnungen mit engerer Bedeutung ersetzt, ,Lehnswesen' etwa oder auch ,Grundherrschaft ${ }^{1}{ }^{1}$ Ein besonderes Problem bilden das Erbe und der Umgang mit der in den Ländern des ehemals real existierenden Sozialismus entworfenen marxistischen Theorie von der Abfolge sozialökonomischer Gesellschaftsformationen. In der DDR wurde sie äußerst streng und unflexibel benutzt; die deutschen Historiker bemühen sich heute um die Prüfung ihres Wahrheitsgehaltes. ${ }^{2}$ Polnische Historiker fühlen deren Notwendigkeit aus verschiedenen Gründen weit weniger. Bereits Ende der fünfiger Jahre verringerten sich die staatlichen Bedrückungen gegen die mediävistische Forschung. Forscher, die den Feudalismus-Begriff bewußt nicht benutzen wollten, konnten ihn vermeiden. Die Mehrheit hat ihn zunehmend mit Gleichgültigkeit behandelt bzw. für ihre Zwecke, etwa für sozialökonomische Forschungen, nutzbar gemacht. Der Sturz des Kommu-

1 Heide Wunder, Art. Feudalismus, in: LMA. Bd. 4. München 1987, Sp. 411-414; vgl. Werner Rösener, Art. Grundherrschaft, in: ebd. Sp. 1739 ff.; ders., Grundherrschaft im Wandel. Untersuchungen zur Entwicklung geistlicher Grundherrschaften im südwestdeutschen Raum vom 9. bis 14. Jahrhundert. Göttingen 1991; Hans-Werner Goetz, Moderne Mediävistik. Stand und Perspektiven der Mittelalterforschung. Darmstadt 1999, $251 \mathrm{ff}$.

2 Michael Borgolte, Sozialgeschichte des Mittelalters. Eine Forschungsbilanz nach der deutschen Einheit. (HZ, Beih. 22.) München 1996, bes. 93 ff.; ders., Feudalismus. Die marxistische Lehre vom Mittelalter und die westliche Geschichtswissenschaft, in: ZHF 25, 1998, 245-260. 
nismus führte hier nicht zu schwerwiegenden Abbrüchen in den wissenschaftlichen Strukturen, allein es wurden die theoretischen und terminologischen Diskussionen ihrer ideologischen Schärfe beraubt. ${ }^{3}$

Die in der wissenschaftlichen Literatur vorkommenden gewaltigen Unterschiede bei der Verwendung des Feudalismus-Begriffs lassen sich meines Erachtens auf drei Anwendungsbereiche zurückführen, nämlich 1. auf das System von Gewohnheiten und Normen des Lehnrechts in engerem Sinne, 2. auf den Typ und die wichtigsten Merkmale der Gesellschaft als ganzer, in der dieses Recht entstanden ist und in der es funktionierte, sowie 3. in weitestem Sinne auf die nicht nur marxistische Auffassung vom agrarischen, durch Großgrundeigentum dominierten sozialökonomische System, welches dem Kapitalismus vorausging und diesem entgegengestellt wird.

In letzterem Fall fällt es schwer, die gewählte Terminologie nicht als sehr unglücklich zu bezeichnen, denn sie trifft vor allem auf die frühneuzeitliche Ständegesellschaft zu, welche sich bedeutend später entwickelte als die Feudalgesellschaft im zweiten, engeren Sinne. Das Problem läßt sich begriffsgeschichtlich erklären. ${ }^{4}$ Die lehnrechtlichen Normen blieben auch in der Neuzeit ein beständiges Element der sozialen Ordnung und wurden zum Objekt juristischer Analysen. Im 18. Jahrhundert, insbesondere während der französischen Aufklärung, fulhrten die Vertreter des Fortschrittes und der Ratio die Bezeichnung régime féodal zur Bestimmung der bekämpften Herrschaftsform ein. Man stützte sich dabei auf das herrschende Bild vom Mittelalter als einer durch Gesetzlosigkeit und Machtverfall bestimmten Epoche. Den Privilegien des Großeigentums - den adligen und geistlichen seigneuries stellte man das Prinzip der Gleichberechtigung freier Bürger gegenüber. In der ersten Phase der Revolution, in der Nacht vom 4. auf den 5. August 1789, wurden jene durch die Nationalversammlung liquidiert. Zwar modifizierte die Romantik bald darauf die negative Einstellung zum Mittelalter, doch hielt sich jene breite Definition des Feudalismus im 19. Jahrhundert und wurde zur populären Bezeichnung der alten Ordnung sowie zum Element publizistischer Diskussionen. Somit ist verständlich, daß die frühen Sozialisten wie SaintSimon und später Karl Marx an die gängige Bezeichnung anknüpften. Letzterer empfand für

3 Vgl. die Materialien einer Konferenz polnischer und italienischer Historiker vom 30./31. Mai 1997 in Warschau: Halina Manikowska/Jacek Kochanowicz (Hrsg.), Feudalizm w Europie średniowiecznej i nowożytnej, in: Roczniki Dziejów Społecznych i Gospodarczych 58, 1998.

4 Claude Mazauric, Zum Gebrauch von „régime féodal“ und „féodalité" wăhrend der französischen Revolution, in: Feudalismus - Materialien zur Theorie und Geschichte. Hrsg. v. Ludolf Kuchenbuch/Bernd Michael. Frankfurt a. M./Berlin/Wien 1977, 78-96 (vgl. auch andere in diesem Band gedruckte Artikel); Otto Brunner, „Feudalismus“ - Ein Beitrag zur Begriffsgeschichte, in: ders., Neue Wege der Verfassungs- und Sozialgeschichte. 2. Aufl. Göttingen 1968, 128-159; ders., Art. Feudalismus, feudal, in: Geschichtliche Grundbegriffie. Historisches Lexikon zur politisch-sozialen Sprache in Deutschland. Hrsg. v. dems./Werner Conze/Reinhart Koselleck. Bd. 2. Stuttgart 1975, 337-350; vgl. auch Elisabeth Magnou-Nortier, Les „Lois féodales“ et la Société d'après Montesquieu et Marc Bloch au la Seigneurie banale reconsidérée, in: RH 289, 1993, 321 ff.; Dominique Barthélemy, Qu'est-ce que la chevalerie en France aux X $X^{e}$ et XI ${ }^{e}$ siècles?, in: RH 290, 1994, 18 ff.; die Tätigkeit und Rolle der neuzeitlichen Juristen wird m. E. zu stark betont von Susan Reynolds, Fiefs and Vassals. The Medieval Evidence Reinterpreted. Oxford 1994, 2 ff. 
den Feudalismus stets nur Abneigung, wobei er mit dessen Problemen kaum vertraut war und auch nicht beabsichtigte, diese zu untersuchen. Er diente ihm allein als Hintergrund zur Analyse der kapitalistischen Gesellschaft. ${ }^{5}$ Ohne auf Einzelheiten einzugehen, läßt sich feststellen, daß diese Denkrichtung - trotz des sehr ungünstigen ideologischen und politischen Umfeldes, in welchem die Analyse nicht selten durch vom Staat aufgezwungene Schemata erschwert wurde - unter günstigeren Umständen wesentliche erkenntnistheoretische Ergebnisse hätte erbringen können. Dies betrifft vor allem die Forschungen zur Wirtschaftsgeschichte der Neuzeit. Im Polen der Zwischenkriegszeit hat sich Jan Rutkowski (der übrigens vom Marxismus weit entfernt war) in seinen Forschungen über die Verteilung des gesellschaftlichen Einkommens des Feudalismus-Begriffs bedient. ${ }^{6} \mathrm{Zu}$ den größten und dauerhaftesten Leistungen der wissenschaftlichen Forschung zählen alsdann die Untersuchungen Witold Kulas über die Ökonomie des Großgrundbesitzes. ${ }^{7}$ Das breite Verständnis des Begriffs als Agrarfeudalismus beruhrt eine eigene, wichtige Problematik, die sich seit langem unabhängig von der marxistischen Formationstheorie entwickelte. ${ }^{8}$ Sie behandelt vom Mittelalter entfernte Fragen, enthält aber gleichwohl für dessen Erforschung anregende Beobachtungen, insbesondere für das Funktionieren des Marktes.

Die Untersuchungen zum Mittelalter haben, besonders seit der Mitte des 19. Jahrhunderts, eine Vertiefung unseres Wissens über die Entstehung und Entwicklung des Lehnrechts erbracht. Dies mußte eine Veränderung der Semantik des Feudalismus-Begriffs in der Forschung nach sich ziehen, die jedoch im Zeitalter des Triumphes nationaler Geschichtsschreibung nicht einheitlich verlaufen konnte. Die vergleichsweise geringsten Probleme bereitete die Erforschung des Lehnrechtes selbst, deren Erträge seit langem in Standardwerken, etwa von Heinrich Mitteis ${ }^{9}$ oder François Ganshof ${ }^{10}$, zusammengefaßt sind; die Institutionen des Lehnrechts sind Gegenstand immer eingehenderer Analysen. ${ }^{11}$

5 Andrzej Malkiewicz, Karol Marks o przedkapitalistycznych stosunkach produkcji. Wrocław 1989.

6 Vgl. Jan Rutkowski, Wokół teorii ustroju feudalnego. Prace historyczne. Hrsg. v. Jerzy Topolski. Warszawa 1982; ders., Wieś europejska późnego feudalizmu (XVI-XVIII w.). Hrsg. v. Jerzy Topolski. Warszawa 1986. Man kann hinzufügen, daß der Gelehrte den Untersuchungen u. a. Max Webers mit Sympathie begegnete.

7 Witold Kula, Teoria ekonomiczna ustroju feudalnego. 2. Aufl. Warszawa 1983. Außerhalb Polens erlangten seine Untersuchungen besonderen Ruhm in Italien (ital.: Teoria economica del sistema feudale. Proposta di un modello. Torino 1970) und Frankreich (frz.: Théorie économique du système féodal. Pour un modèle de l'économie polonaise $16^{\mathrm{e}}-18^{\mathrm{e}}$ siècles. Préface de Fernand Braudel. Paris 1970). Die Analogie zwischen den Funktionsmechanismen der ostmitteleuropäischen Gutsherrschaft der Neuzeit und dem sowjetischen Kolchossystem war für den Autor und seine Kreise eindeutig, nur konnten sie aus verständlichen Gründen nicht zum Gegenstand öffientlicher Diskussion gemacht werden.

8 Adam Czarnota/Andrzej Zybertowicz (Hrsg.), Interdyscyplinarne studia nad genezą kapitalizmu. 2 Bde. Toruń 1989/93; vgl. zuletzt die scharfsinnigen Bemerkungen von Jacek Kochanowicz, Czy w Polsce nowożytnej był feudalizm?, in: Feudalizm (wie Anm. 3), 187-202.

9 Heinrich Mitteis, Lehnrecht und Staatsgewalt. Untersuchungen zur mittelalterlichen Verfassungsgeschichte. Weimar 1933, ND Darmstadt 1974; vgl. Peter Landau/Hermann Nehlsen/Dietmar Willoweit (Hrsg.), Heinrich Mitteis nach Hundert Jahren (1889-1989). Symposion anläßlich des hundertsten Geburtstages in München am 2. und 3. November 1989. München 1991; vgl. auch Walther Kienast, Die 
Jüngst wurde fast deren gesamter Ertrag durch Susan Reynolds in Frage gestellt. ${ }^{12}$ Sie trat mit der These hervor, daß der klassische Feudalismus, also das auf Vasallităt beruhende Lehnssystem mit seinen typischen Eigentumsrechten, wie es sich die Historiker vorstellen, eine Erfindung sei, die mehr aus den Werken neuzeitlicher Juristen als aus mittelalterlichen Quellen geschöpft sei. Die offensichtlich mit persönlichem Engagement und sehr umfangreich dokumentierte Analyse fuhrt zu der weniger radikalen Feststellung, daß dieses System von den akademisch geschulten Juristen des 12. Jahrhunderts geschaffen wurde, um den wachsenden Anforderungen der damals entstehenden bürokratischen Herrschaft zu entsprechen. Sowohl die generellen Konklusionen als auch etliche Einzelheiten finden nicht die Akzeptanz der Spezialisten, mithin gab die Untersuchung den Anstoß zur abermaligen Hinwendung der Forschung zu diesen Problemen. ${ }^{13}$ In der Tat, die Anhänger der traditionellen Rechtsgeschichte bedienen sich hăufig der im 19. Jahrhundert entstandenen Terminologie, womit eine deutliche Tendenz zur anachronistischen Betrachtung der Eigentums- und Sozialverhältnisse des Mittelalters verbunden ist, jedoch wurde diese durch Detailuntersuchungen teilweise überholt. Daß das 12. Jahrhundert eine Zäsur in der Rechtsgeschichte ausmachte, gehört zum Handbuchwissen. ${ }^{14}$ Das Studium des römischen Rechts an den Universităten, die Entstehung des kanonischen Rechts, die Territorialisierung des Gewohnheits-

fränkische Vasallităt von den Hausmeiern bis zu Ludwig dem Kind und Karl dem Einfältigen. (Frankfurter wiss. Beiträge, Kulturwiss. Rh., Bd. 18.) Frankfurt a. M. 1990.

10 François Louis Ganshof, Qu'est-ce que la féodalité? Bruxelles 1957 (dt.: Was ist das Lehnswesen? 4. rev. Aufl. Darmstadt 1975).

11 Elisabeth Magnou-Nortier, Foi et fidélité. Recherches sur l'évolution des liens personnels chez les francs du VII ${ }^{e}$ au IX ${ }^{e}$ siècle. (Publications de l'Université de Toulouse-le Mirail, Série A, vol. 28.) Toulouse 1976; Gérard Giordanengo, Le droit féodal dans les pays de droit écrit. L'exemple de la Provence et du Dauphine XII ${ }^{e}$-début XIV ${ }^{e}$ siècle. (Bibliothèque des écoles françaises d'Athènes et de Rome, vol. 266.) Rom 1988; Rodolfo del Grata, Feudum a fidelitate. Esperienze feudali e scienza giuridica dal medioevo all'età moderna. (Pubblicazioni del Seminario per le Scienze Giuridiche e Politiche dell'Università di Pisa, vol. 29.) Pisa 1994; vgl. auch: Structures féodales et féodalisme dans l'Occident méditerranéen $\left(\mathrm{X}^{e}-\mathrm{XIII}{ }^{e}\right.$ siècles). Bilan et perspectives de recherches. (Collection de l'école française de Rome, vol. 44.) Rom 1980; Eric Bournazel/Jean-Pierre Poly (Ed.), Les féodalités. Paris 1998, 17 ff.; die Diskussionen der italienischen Forschung faßt zusammen Giovanni Tobacco, Fief et seigneurie dans l'Italie conmunale. L'évolution d'un thème historiographique, in: MA 75, 1969, 5-37, 203-218.

12 Reynolds, Fiefs (wie Anm. 4).

13 Am umfiangreichsten Elisabeth Magnou-Nortier, La féodalité en crise. Propos sur „Fiefs and Vassals“ de Susan Reynolds, in: RH 296, 1995, 253-348; vgl. die kritische Rezension von Karl-Friedrich Krieger, in: HZ 264, 1997, 174-179; sehr freundlich wegen der Übereinstimmung mit eigenen Anschauungen Dominique Barthélemy, La théorie féodale à l'épreuve de l'anthropologie (note critique), in: Annales 52, 1997, 321-341.

14 Hans Hattenhauer, Europäische Rechtsgeschichte. 2. Aufl. Heidelberg 1994, 248 ff.; Harold J. Berman, Law and Revolution. The Formation of the Western Legal Tradition. Cambridge/Mass. 1983; Helmut Coing (Hrsg.), Handbuch der Quellen und Literatur der neueren europäischen Privatrechtsgeschichte. Bd. 1: Mittelalter (1100-1500). Die gelehrten Rechte und die Gesetzgebung. München 1973. 
rechts ${ }^{15}$ und die beginnende Verschriftlichung des Rechts bedeuten durchaus nicht den Zusammenbruch alter Institutionen, darunter des Lehnswesens. ${ }^{16}$

Die Ausführungen Susan Reynolds entsprechen älteren Tendenzen, welche hier extrem zugespitzt formuliert sind. Dem außenstehenden Beobachter scheinen die eine lange Tradition besitzenden Diskussionen über die Bedeutung des Jahres 1066 für die englische Geschichte und über die Transformation neuer Erscheinungen durch die normannische Eroberung nicht ohne nationalen Unterton geführt. ${ }^{17} \mathrm{Da}$ die Nützlichkeit des FeudalismusBegriffs von der angelsächsischen Forschung in Frage gestellt wird, scheint mit einem gewissen Überdruß an einer schematischen, didaktischen Zwecken dienenden Herangehensweise in Zusammenhang zu stehen, die sich bei seiner Verwendung zur Charakterisierung der Monarchie offenbart. ${ }^{18}$ In einem 1974 publizierten Artikel sprach sich Elisabeth Brown gegen die „Tyranny“ des Begriffs aus ${ }^{19}$; in einer kritischen Umschau verschiedener Untersuchungen erfreute sie der Umstand, daß sich einige Historiker des Begriffes nur zurückhaltend, andere sogar gar nicht bedienten und ihn durch andere Termini ersetzten. ${ }^{20}$ Die an sich richtige Forderung nach einer präziseren Terminologie ${ }^{21}$ und einem möglichst analytischen Begriffsapparat kann die Verwendbarkeit und Gültigkeit allgemeinerer Begriffe jedoch nicht grundsätzlich erschüttern. Dem entspricht ja auch die feststellbare Tendenz des Rückzugs der Rechts- und Verfassungsgeschichte, was in hohem Maße auf die Aussonderung dieses Forschungsfeldes aus der Sozialgeschichte zurückzufuhren ist. ${ }^{22}$ Dies erfordert die Verifizierung des alten, mit romantischen und nationalistischen Geschichtsbildern belasteten Erbes und die Entwicklung eines neuen Begriffsapparates einschließlich seiner Objektivierung und Erweiterung, um die Verschiedenheit sozialer Erscheinungen in ihrer ganzen Breite erfassen zu können. Vor dem Hintergrund gegenwärtiger struktureller und verfassungsrechtlicher Transformationsprozesse in den postkommunistischen Ländern ist es wiederum schwierig, die Existenz gewisser Grundlagen sozialer Ordnungen zu leugnen und auf integrative Beobachtungsfelder aus der Verfassungsgeschichte zu verzichten.

15 Karl Kroeschell, Recht und Rechtsbegriff im 12. Jahrhundert, in: Probleme des 12. Jahrhunderts. Hrsg. v. Theodor Mayer. (VuF, Bd. 12.) Stuttgart 1968, 309-338.

16 Vgl. die Zusammenfiassung bei Magnou-Nortier, La féodalité (wie Anm.13), 347-348, die unterstreicht, daß das Lehnswesen eine lebendige, Veränderungen ausgesetzte Institution war, die aber eine strukturelle Kontinuităt bewahrte.

17 Vgl. Heiner Haan/Karl-Friedrich Krieger/Gottfried Niedhart, Einfürung in die englische Geschichte. München 1982, 15 f., 18 ff.; vgl. C. Warren Hollister, The Norman Conquest and the Genesis of English Feudalism, in: AHR 66, 1961, 641-663; Reynolds, Fiefs (wie Anm. 4), 342 ff.., 393-395.

18 Carl Stephenson, Mediaeval Feudalism. New York 1956; Sidney Painter, The Rise of the Feudal Monarchies. 12. Aufl. New York 1968; David Herlihy, The History of Feudalism. London 1970.

19 Elizabeth A. R. Brown, The Tyranny of a Construct: Feudalism and Historians of Medieval Europe, in: AHR 79, 1974, 1064-1088.

20 Ebd. 1080 f.; als ein positives Beispiel diente ihr u. a. Richard William Southern, The Making of the Middle Ages. New Haven 1953.

21 Eine Auflistung der Termini bei Brown, The Tyranny (wie Anm. 19), 1087.

22 Für die deutsche Historiographie vgl. František Graus, Verfassungsgeschichte des Mittelalters, in: HZ 243, 1986, 529-589; jüngst Goetz, Moderne Mediävistik (wie Anm. 1), 225 ff. 
Die Entwicklung der Geschichtswissenschaften hat (insbesondere seit dem Ende des 19. Jahrhunderts) das Verständnis für die gegenseitige Abhängigkeit verschiedener historischer Erscheinungen wachsen lassen, so daß neben die Auffassung vom Feudalismus, der auf lehnrechtlichen Abhängigkeiten basierte, Versuche traten, seine umfassendere Bedingtheit genauer zu erklären. In Deutschland eröffneten die historisch-soziologischen Forschungen Otto Hintzes den Zugang zu breiter angelegten vergleichenden Studien. ${ }^{23}$ Gleichzeitig wuchs die Einsicht in das Erfordernis einer ganzheitlichen Untersuchung der Gesellschaften, in denen die lehnrechtlichen Abhängigkeiten entstanden waren und funktionierten. Die wichtigste Etappe dieser Forschungsrichtung markiert das Buch von Marc Bloch La société féodale. ${ }^{24}$ Indem Bloch die spezifischen Eigenarten persönlicher vasallitischer Abhängigkeit, die Verfassung der großen Landgüter (,seigneuries“) in der Naturalwirtschaft, das Ethos der privilegierten Schichten und das Funktionieren von Herrschaft betrachtete, schuf er ein Untersuchungsschema, das nach wie vor Gültigkeit besitzt.

In Polen, wo es in der Vergangenheit keine bedeutsamen Erscheinungen des Lehnswesens gegeben hat, entwickelte sich der entsprechende wissenschaftliche Begriffisapparat in Anlehnung an die deutsche Historiographie. ${ }^{25}$ Der Terminus ,Feudalismus ' verbreitete sich hier um die Jahrhundertwende, als bekanntlich auch die französischen Forschungen zum Mittelalter an Bedeutung gewannen. ${ }^{26}$ In der Zwischenkriegszeit gelangte die Forschung zwar zu unterschiedlichen Ansichten, allgemein anerkannt war allerdings die Tatsache, daß es wegen der fehlenden Rezeption vasallitisch-lehnrechtlicher Beziehungen in Polen keinen Feudalismus gegeben habe. Tadeusz Manteuffel hat anfangs sogar Quellenstudien über das Lehnrecht unternommen $^{27}$, nach 1950 hierauf aber verzichtet, da er sich nicht der oktroyierten stalini-

23 Otto Hintze, Wesen und Verbreitung des Feudalismus, in: ders., Staat und Verfassung. Gesammelte Abhandlungen zur allgemeinen Verfassungsgeschichte. Hrsg. v. Gerhard Oestreich. 3. Aufl. Göttingen 1970, 84-119.

24 Marc Bloch, La société féodale. 2 vol. Paris 1939/40 (poln.: Społeczeństwo feudalne. Warszawa 1981; dt.: Die Feudalgesellschaft. Frankfurt a. M./Berlin 1982); ders., Art. European Feudalism, in: Encyclopaedia of Social Sciences. Vol. 4. New York 1931, 203 f.; Wiederabdruck in: ders., Mélanges Historiques. Vol. 1. Paris 1961, 177-188 (dt.: Europäischer Feudalismus, in: Feudalismus - Materialien [wie Anm. 4], 576-594); vgl. Michael Borgolte, Die Erfindung der europäischen Gesellschaft. Marc Bloch und die deutsche Verfassungsgeschichte seiner Zeit, in: Marc Bloch. Historiker und Widerstandskämpfer. Hrsg. v. Peter Schöttler. Frankfurt a. M./New York 1999, 171-194; Stanislaw Russocki, Od „feudalizmu“ do „feudalizmu“ (Refleksje nad polskim przekładem „Społeczeństwa feudalnego“ Marka Blocha), in: Przegląd Humanistyczny 26, 1982, 115-122.

25 Die Diskussion zwischen Georg Waitz und Paul Roth skizzierte Stanisław Smolka, Początki feudalizmu. Studium historyczne. Lwów 1874.

26 Vgl. Henryk Lowmiański, Trzy koncepcje feudalizmu w historiografii polskiej do 1939, in: Zapiski Historyczne 41, 1976, 9-23; zuletzt scharfsinnig Stanistaw Trawkowski, Spory o feudalizm w polskiej historiografii, in: Feudalizm (wie Anm. 3), 91-100; eine breite Umschau der polnischen Forschungen bei Jerzy Strzelczyk, Die Elemente des Lehnswesens im mittelalterlichen Polen, in: Patronage und Klientel. Ergebnisse einer polnisch-deutschen Konferenz. Hrsg. v. Hans-Heinrich Nolte. (AKG, Beih. 29.) Köln/Wien 1989, 35-50.

27 Tadeusz Manteuffel, Teoria ustroju feudalnego według Consuetudines Feudorum XII-XIII w. Warszawa 1930; vgl. ders., On Polish feudalism, in: Medievalia et Humanistica 16, 1964, 94-104; 
stischen Terminologie bedienen wollte. Eine ideologische Auflockerung brachte die Anerkennung der Lehnsstruktur als einer besonderen Form des Feudalsystems ${ }^{28}$, was die Suche nach wesentlichen Gemeinsamkeiten der unterschiedlichen Feudalismus-Begriffe ermöglichte. In der neueren polnischen Literatur hat Stanisław Russocki die interessantesten Vorschläge hierzu vorgestellt. So legte er besonderen Wert auf den Charakter der Abhängigkeit vom Herrscher und auf den Status des Grundeigentums privilegierter Schichten (etwa bedingter Verleihungen). ${ }^{29}$ Russocki unterschied zwei Formen von Feudalismus, den älteren, der zusammen mit dem allgemeinen erscheint, weniger formalisiert ist und der als benefiziär - auch in der Klientelbeziehung - bezeichnet werden kann, sowie den Feudalismus, der sich nur in wenigen Staaten entwickelt hat und stärker formalisiert war - als Teil eines Systems vasallitisch-lehnrechtlicher Beziehungen. ${ }^{30}$

Gegenwärtig haben alle drei genannten Feudalismusbegriffe - zur Bezeichnung rein rechtlicher, verfassungs- und sozialhistorischer bzw. wirtschafts- und sozialhistorischer Phänomene - ihre Grundlagen sowohl in den Detailforschungen als auch in den theoretischen Reflexionen. Unabhängig von diesbezüglichen Unterschieden zwischen den einzelnen nationalen Historiographien, welche sich nur bedingt mit Eigenarten auf lokaler Ebene erklären lassen, gibt es doch eine Reihe sehr brauchbarer Ansätze zu vergleichenden Untersuchungen, und zwar sowohl komplexerer Art als auch solche, die nur einzelne Merkmale in den Vordergrund rücken wollen. Als besonders fruchtbar scheint sich der Weg zu erweisen, den Feudalismus in erster Linie als ein System von Herrschaft zu betrachten, das auf die Zersplitterung politischer Macht hinauslief. ${ }^{31}$ Für das Mittelalter verspricht die zweite Herangehensweise größeren Erfolg, nämlich zu ergründen, welche die wichtigsten Merkmale der durch Lehnsbindungen organisierten Gesellschaften waren. In dieser Hinsicht verdienen die Untersuchungen französischer Historiker besondere Beachtung. Auf regionale Studien

weitere Arbeiten gedruckt in: ders., Historyk wobec historii. Hrsg. v. Stanisław Trawkowski. Warszawa 1976.

28 Unter der wissenschaftlichen Handbuchliteratur bes. deutlich Michat Sczaniecki, Powszechna Historia państwa i prawa. 9. Aufl. Hrsg. v. Katarzyna Sójka-Zielińska. Warszawa 1997, 75-82 (zuerst 1968); vgl. auch noch ders., Essai sur les fiefs-rentes. (Publications de la Société d'Histoire du Droit, vol. 6.) Paris 1946, eine Arbeit, die von der internationalen Kritik gut aufgenommen wurde; sodann ders., Problem przymusu lennego w dawnej Rzeszy Niemieckiej, in: Czasopismo Prawno-Historyczne 17, 1965, 247-259.

29 Stanisław Russocki, Z badań nad czeskim systemem beneficjalnym, in: Czasopismo Prawno-Historyczne 23, 1971, 33-45; ders., Spory o istotę i genezę feudalizmu europejskiego, in: Kwartalnik Historyczny 77, 1971, 404-412; ders., Rola „fidelitas i beneficjum“ w ustroju państw słowiańskich, in: Z polskich studiów slawistycznych. Ser. 4: Prace na VII Miedzynarodowy kongres slawistów w Warszawie 1973. Bd. 3: Historia. Warszawa 1972, 67-82; ders., Oblicza zachodnioeuropejskiego feudalizmu, in: Kwartalnik Historyczny 90, 1983, 859-869; ders., Instytucje - wpływy - kultura: wanunkowe nadania ziemi w procesie centralizacji feudalnych monarchii środkowo-wschodniej Europy późnego średniowiecza, in: Przegląd Humanistyczny 28, 1984, 1, 3-13; ders., Art. Lehenswesen, Lehnrecht. VII. Polen und Böhmen, in: LMA. Bd. 5. München 1991, Sp. 1821 f.

30 Russocki, Instytucje (wie Anm. 29), 4.

31 Rushton Coulborn (Ed.), Feudalism in History. Princeton/New York 1956; in der polnischen Literatur knüpft an diese Auffiassung an Manteuffel, On Polish feudalism (wie Anm. 27). 
gestützt ${ }^{32}$ haben sie das Vorhandensein der von Marc Bloch eruierten ersten feudalen Epoche hinterfragt und bewiesen, daß sie keinen derartigen Charakter besessen hat. Vielmehr begannen vasallitisch-lehnrechtliche Beziehungen das gesellschaftliche und politische Leben erst ab dem 11./12. Jahrhundert zu dominieren. ${ }^{33}$

In der jüngsten Diskussionen wird die Zäsur um 1000 (980-1030) gesetzt. Beruhrt ist damit das grundsätzliche Problem gesellschaftlicher Transformation in Europa und der Genese eines kumulativen Modells, das sich über Jahrhunderte zum Weltsystem entwickelte. Die sehr breite Diskussion kreist vor allem um die Erwägungen französischer ${ }^{34}$ und angelsächsischer ${ }^{35}$ Historiker. Die Konzeption der „mutation féodale“ bzw. „feudal revolution“ verbindet unterschiedliche Aspekte sozialer, wirtschaftlicher und politischer Erscheinungen und bündelt sie zu der These von der beinahe gleichzeitigen radikalen Umwandlung aller Lebensbereiche. Benannt ist damit im Kern der Zusammenbruch der karolingischen sozialen Ordnung und der auf das Grafschaftssystem gestützten öffentlichen Gewalt. Ersetzt wurden sie durch neue Strukturen der Grund- und Landesherrschaft, welche auf der Beherrschung von Burgen, dem Rittertum als Berufsgruppe und deren vasallitischer Abhängigkeit basierten. Die Leistungen der Untertanen und der Gerichtsbarkeit des Herm unterstehenden Bauern bildeten die ökonomische Grundlage dieses Systems. Für die französische Forschung maßgeblich sind das Buch von Jean-Pierre Poly und Éric Bournazel La mutation féodale. $X^{e}$ $X I I^{e}$ siècle sowie die unter ihrer Redaktion herausgegebene vergleichende Synthese Les

32 Erstrangigkeit zuerkannt wird dem Buch von Georges Duby, La société aux $\mathrm{XI}^{\mathrm{e}}$ et $\mathrm{XII}^{\mathrm{e}}$ siècles dans la région mâconnaise. Paris 1953.

33 Jean-Pierre Poly/Éric Bournazel, La mutation féodale. $\mathrm{X}^{\mathfrak{e}}-\mathrm{XI}{ }^{\mathfrak{e}}$ siècle. (Nouvelle Clio, vol. 16.) Paris 1980; Robert Fossier, Enfance de l'Europe. $\mathrm{X}^{\mathrm{e}}-\mathrm{XII}^{\mathrm{e}}$ siècle. Aspects économiques et sociaux. Vol. 1: L'homme et son espace. Paris 1982, 435 ff.; vol. 2: Structures et problèmes. Paris 1982, 951 ff.; am Rande sei erwähnt Guy Bois, La mutation de l'an mil. Loumand, village mâconnais, de l'Antiquité au féodalisme. Paris 1989 (dt.: Umbruch im Jahr 1000. Lournand bei Cluny - ein Dorf in Frankreich zwischen Spätantike und Feudalherrschaft. Stuttgart 1993) - der Autor entwickelt anhand eines burgundischen Dorfes eine nur ungenügend dokumentierte Konstruktionen für ganz Europa; vgl. Alain Guerreau, Lournand au X $X^{e}$ siècle: histoire et fiction, in: MA 96, 1990, 519-537, hier 533: „cette superbe ignorance de la bibliographie récente n'empêche nullement G. B. de manifester une légère désinvolture à l'égard des collègues qu'il cite."

34 Wohl kaum vollkommen zustimmen wird man Timothy Reuter, in: Debate: „The Feudal Revolution“: Comment 3, P \& P 155, 1997, 194: „The mutation féodale is a by-product of very specific French historiographical tradition, that of the regional monograph"; richtig ist indes wohl, daß es semantische Unterschiede in der französischen und deutschen Terminologie und folglich auch Schwierigkeiten mit ihrer Übersetzbarkeit bei den Forschungen über dieselbe Region gibt.

35 Eine Orientierung leistet Thomas N. Bisson, The „Feudal Revolution“, in: P \& P 142, 1994, 6-42; durch diesen Artikel ist eine Diskussion ausgelöst worden: Debate: „The Feudal Revolution“: Comment 1: by Dominique Barthélemy; Comment 2: by Stephen D. White, in: ebd. 152, 1996, 196-223; Comment 3: by Timothy Reuter; Comment 4: by Chris Wickham; Reply: by Thomas N. Bisson, in: ebd. 155, 1997, 177-225. 
féodalités. ${ }^{36}$ In der erstgenannten Publikation analysierten sie die Verhältnisse zwischen Rhein und Pyrenäen, die zweite, breiter angelegte Veröffentlichung berücksichtigt auch die Probleme des antiken Nahen Ostens und Phänomene des Fernen Ostens, unter anderem in China und Japan, wohingegen Ostmittel- und Osteuropa völlig vernachlässigt werden. Es fällt hier eine traditionelle und wenig tiefgründige Behandlung der in Deutschland ablaufenden Prozesse auf ${ }^{37}$, obgleich doch die eingehend erforschte Herausbildung der Landesherrschaft zu den wichtigsten Elementen dieser „feudalen Mutation“ gehörte. ${ }^{38}$ Dies zeugt sehr deutlich von den Schwierigkeiten, auf die die vergleichenden Untersuchungen in Zusammenhang mit der unterschiedlichen wissenschaftlichen Terminologie treffen. In diesem Kontext ist auf die zuerst von Karl Schmid beobachteten Veränderungen in den verwandtschaftlichen Bindungen durch die Formierung fester agnatischer Adelsgeschlechter hinzuweisen, die unter anderem von der Konzentration des Grundbesitzes um eine Burg begleitet wurde. ${ }^{39}$ In der englischsprachigen Literatur ist Thomas N. Bisson der Hauptvertreter der These von der feudalen Revolution; er legt besonderen Nachdruck auf die in ihrer Begleitung erscheinenden Formen der Gewalt („violence“). ${ }^{40}$ In der Argumentation für eine weitgehende Gleichzeitigkeit der betreffenden Erscheinungen wird für Polen auf die Anfang des 12. Jahrhunderts entstandene Chronik des sogenannten Gallus Anonymus verwiesen. ${ }^{41}$ Ich halte dies jedoch für ein großes Mißverständnis. ${ }^{42}$ Der Chronist bediente sich bei der

36 Bournazel/Poly, La mutation (wie Anm. 33); dies. (Ed.), Les féodalités (wie Anm. 11); die Konzeption des Buches folgt Robert Boutruche, Seigneurie et féodalité. Vol. 1: Le premier âge des liens d'homme à homme; vol. 2: L'apogèe (XI'-XIII' siècle). Paris 1968/70.

37 Franz Pellaton, Féodalité et Empire romain germanique, in: Les féodalités (wie Anm. 11), 263-311; der Autor konzentriert sich auf die politische Geschichte und die Probleme des Lehnrechts.

38 Ernst Schubert, Art. Landesherrschaft und -hoheit, in: LMA. Bd. 5. München 1991, Sp. 1653-1656; Hagen Keller, Zwischen regionaler Begrenzung und universalem Horizont. Deutschland im Imperium der Salier und Staufer 1024 bis 1250. (Propyläen Geschichte Deutschlands, Bd. 2.) Berlin 1986, 26 ff., $186 \mathrm{ff}$., $342 \mathrm{ff}$.; der Stand der Forschung bis zum Ende der achtziger Jahre ist von mir besprochen: Sławomir Gawlas, 0 kształt zjednoczonego Królestwa. Niemieckie władztwo terytorialne a geneza społecznoustrojowej odrębności Polski. Warszawa 1996, Kapitel 2-10.

39 Karl Schmid, Zur Problematik von Familie, Sippe und Geschlecht, Haus und Dynastie beim mittelalterlichen Adel. Vorfragen zum Thema „Adel und Herrschaft im Mittelalter“ (1957), in: ders., Gebetsdenken und adliges Selbstverständnis im Mittelalter. Ausgewăhlte Beitrăge. Festgabe zu seinem sechzigsten Geburtstag. Sigmaringen 1983, 183-244; vgl. auch andere Artikel in diesem Band.

40 Bisson, The „Feudal Revolution“ (wie Anm. 35); ders., Reply (wie Anm. 35); ders., The Problem of Feudal Monarchy: Aragon, Catalonia and France, in: Speculum 53, 1978, 460-478; ders., Medieval Lordship, in: Speculum 70, 1995, 743-759; ders., Feudalism in Twelfth-Century Catalonia, in: Structures féodales (wie Anm. 11), 173-192; vgl Pierre Bonnassie, in: ders., From Slavery to Feudalism in South-Western Europe. Cambridge 1991, 149-169.

41 Bisson, Reply (wie Anm. 35), 220 f.; ders., On not Eating Polish Bread in Vain: Resonance and Conjuncture in the Deeds of the Princes of Poland (1109-1113), in: Viator 29, 1998, 275-289 (auf diese Artikel hat mich freundlicherweise Grzegorz Myśliwski aufmerksam gemacht). Die betreffende Chronikstelle in: Galli Anonymi Chronica et gesta ducum sive principum Polonorum. Hrsg. v. Karol Maleczyński. (MPH NF., Bd. 2.) Kraków 1952, Kap. I/19, 42 f.

42 Bisson, On not Eating (wie Anm. 41), 283 ff.; der Autor will hier eine enge Analogie zu Katalonien erkennen. 
Beschreibung der heidnischen Reaktion in Polen 1038 eines ihm zeitgenössischen Vokabulars. Zudem hatten die Vorgänge, die zum Zusammenbruch des Staates führten, welcher von der großen Kriegergefolgschaft der ersten Piastenfursten gebildet wurde, einen anderen Charakter als die feudale Revolution und waren durch die Unterbrechung der Expansion des Staates verursacht. ${ }^{43}$

Die Konzeption einer feudalen Revolution („mutation“) um 1000 hat viele Gegner, zu ihren größten gehört sicherlich Dominique Barthelémy. ${ }^{44}$ Insbesondere bezweifelt er die Quellengrundlagen, und vor einem breiten historiographischen Hintergrund beweist er die Unbrauchbarkeit dieser Zäsur für die Forschung; vielmehr akzentuiert er die Krise zwischen 860 und 890 sowie die Wandlungen um 1100.

Es ist aus polnischer Perspektive schwierig, eine begründete Position zu den einzelnen analytischen Erörterungen der Anhänger wie der Gegner der Konzeption abzugeben. Einleuchtend scheint, daß die Konzeption des Zusammenbruchs der öffentlichen Gewalt anachronistische Assoziationen nach sich zieht. Andererseits sind die zunehmende Gewalt und die Entstehung der Gottesfriedensbewegung Symptome eines Zusammenbruchs der damaligen sozialen Ordnung. Unschwer ist die große Ungenauigkeit in der Bestimmung des zeitlichen Rahmens zu erkennen, nur teilweise kann sie durch regionale Untersuchungen beseitigt werden. Auch die industrielle Revolution des 18./19. Jahrhunderts verlief bei ungleich besseren Kommunikationsmöglichkeiten über viele Generationen hinweg, und in ihren Zentren koexistierten sogar über längere Zeiträume hinweg schwach entwickelte Regionen; folglich besteht kein Grund zu vermuten, daß es im 10./11. Jahrhundert anders gewesen sein sollte.

An dieser Stelle muß jedoch entschieden die These von der feudalen Revolution im strukturellen Sinn ${ }^{45}$ verteidigt werden - unabhängig davon, wie sie zu bezeichnen sein wird.

43 Vgl. Zafia Kurnatowska, Frühstädtische Entwicklung an den Zentren der Piasten in Großpolen, in: Burg - Burgstadt - Stadt. Zur Genese mittelalterlicher nichtagrarischer Zentren in Ostmitteleuropa. Hrsg. v. Hansjürgen Brachmann. (Forsch. zur Geschichte und Kultur des östlichen Mitteleuropa, Bd. 2.) Berlin 1995, 133-148; dies., The Organisation of the Polish State - Possible Interpretations of Archaeological Sources, in: Quaestiones Medii Aevi Novae 1, 1996, 5-24; Stawomir Gawlas, Die mittelalterliche Nationenbildung am Beispiel Polens, in: Mittelalterliche nationes - neuzeitliche Nationen. Probleme der Nationenbildung in Europa. Hrsg. v. Almut Bues/Rex Rexheuser. (Deutsches Historisches Institut Warschau. Quellen und Studien, Bd. 2.) Wiesbaden 1995, 121-143, hier 125-127.

44 Dominique Barthélemy, La mutation féodale a-t-elle eu lieu? (note critique), in: Annales 47, 1992, 767-777; ders., Qu'est-ce que (wie Anm. 4); ders., La mutation de l'an mil a-t-elle eu lieu? Servage et chevalerie dans la France des $\mathrm{X}^{\mathrm{e}}$ et XI $\mathrm{XI}^{\mathfrak{e}}$ siècles. Paris 1997; ders., Comment 2 (wie Anm. 35), 196-205; ders., Encore le débat sur l'an mil, in: Revue Historique de Droit Français et Etranger 73, 1995, 349-360; vgl. Jean-Pierre Poly/Éric Bournazel, Post scriptum, in: ebd. 361 f.; Dominique Barthélemy, Que faut-il préférer au ,mutationisme'? ou le problème du changement social, in: ebd. 72, 1994, $401-412$.

45 S. die sehr aufschlußreiche Überschau der Argumente der Anhänger und Gegner der Revolutionstheorie aus der quellenmäßig besser belegten italienischen Perspektive bei Sandro Carocci, Zwierzchność senioralna, społeczeństwo wiejskie i ,przełom feudalny“, in: Feudalizm (wie Anm. 3), 53-89; hier auch die Artikel von Stefano Gasparri, Stosunki klientalne, zwierzchność senioralna i zależność chłopów w Italii longobardzej frankijskiej, in: ebd. 39-52 (frz.: Les relations de fidélité dans le 
Die auf Burgen gestützte Territorialherrschaft des Adels, das Rittertum als eine soziale und Berufsgruppe sowie die Ausnutzung der lehnrechtlicher Abhängigkeitsverhältnisse zur Ordnung des politischen Systems waren im 11. Jahrhundert reale Erscheinungen und Grundlage des im Bewußtsein der Zeitgenossen existierenden Staatsmodells. Die traditionelle Ansicht, dieses sei in Nordfrankreich entstanden, erscheint kaum widerlegbar. Dessen Diffusion ist das wichtigste Argument der Anhänger der Revolutionstheorie. Die Existenz der der Epoche entsprechenden Herrschaftsmodelle respektive Standards politischen und sozialen Lebens ist oft weniger aus der Perspektive des Zentrums, wo sie entstanden waren, als vielmehr von den Peripherien aus zu erkennen, wo sie wegen ihrer verspäteten Rezeption in schärferem Kontrast zu den örtlichen Verhältnissen auftraten. ${ }^{46}$ Die Aufklärung des Modells der Lehnsgesellschaft und ihrer lokalen Varianten erfordert, über die Analyse der spezifischen Konfigurationen ihrer Elemente hinauszugehen und die zum selben Umkreis des lateinischen Europa gehörenden Gesellschaften, die sich freilich in mancher Hinsicht unterschieden, mitzuberücksichtigen.

Die ganzheitliche Betrachtung der sich gegenseitig bedingenden Erscheinungen, unternommen mit dem Ziel, den Feudalismus als Gesellschaftsform zu erkennen, die uber Lehnsbindungen funktionierte, erlaubt es, ein ganzes Paket von Problemen anzupacken (mithin wird die Diskussion hierdurch oft verwirrend und also angreifbar). In dieser Hinsicht scheint es nützlich, sich auf das Lehnswesen im engeren Sinne zu beschränken und nach den Mechanismen der Verbreitung seiner Prinzipien zu fragen. Im Falle Polens verbirgt sich dahinter die Frage nach den Gründen für das Fehlen einer größeren Rezeption des Lehnrechts. Die erfolgte Klärung gestattet es, die hier geführten terminologischen Diskussionen in ihrer Mehrheit beiseite zu schieben, sie ermöglicht gleichzeitig die Untersuchung sozialer und verfassungsrechtlicher Erscheinungen, die die Diffusion des Lehnrechts bedingten.

Die hierfür spezifischen Prinzipien der Abhängigkeit, die die feierliche Kommendation und den Treueid mit der Verleihung des Benefiziums verbanden, entstanden in einem Moment der Geschichte, nämlich in Folge des Zusammenstoßes und der langjährigen Koexistenz der Provinzinstitutionen der römischen Zivilisation mit den Prinzipien des Gefolgschaftswesens der germanischen Eroberer eben im nördlichen Teil des fränkischen Reiches. Dieser Prozeß, dessen Mechanismen - wie oben erwähnt - einer steten Verifizierung unterliegen, ist in seiner Grundstruktur seit langem bekannt. ${ }^{47}$ Die allmähliche Anerkennung

royaume d'Italie [VII'-IX ${ }^{e}$ siècle], in: La royauté et les élites dans l'Europe carolingienne (débout IX siècle aux environs du 920). Ed. Régine Le Jan. Villeneuve d'Ascq 1998), und Giorgio Chitolini, W sprawie geografii i historii systemu feudalnego we Włoszech u schyłku średniowiecza i w początkach ery nowożytnej, in: Feudalizm (wie Anm. 3), 157-176.

46 Über die Verwendbarkeit des Begriffs ,gesellschaftliche Standards“ für die Untersuchung von Diffusion und Modernisierung s. Slawomir Gawlas, Polska Kazimierza Wielkiego a inne monarchie Europy Środkowej - możliwości i granice modernizacji władzy, in: Modernizacja struktur władzy w warunkach opóźnienia. Europa Środkowa i Wschodnia na przełomie średniowiecza i czasów nowożytnych. Hrsg. v. Marian Dygo/Sławomir Gawlas/Hieronim Grala. Warszawa 1999, $11 \mathrm{ff}$.

47 Vgl. oben Anm. 9-13. Außerdem Theodor Mayer (Hrsg.), Studien zum mittelalterlichen Lehnswesen. (VuF, Bd. 5.) Lindau/Konstanz 1956; Hans K. Schulze, Grundstrukturen der Verfassung im Mittelalter. Bd. 1: Stammesverband, Gefolgschaft, Lehnswesen, Grundherrschaft. 3. Aufl. Stuttgart 1995, 54 ff.; Boutruche, Seigneurie (wie Anm 36), vol. 1, 147 f.; vol. 2, 152 ff.; Elisabeth Magnou-Nortier, Fidélité 
derartiger Verbindungen durch Karl den Großen und seine Nachfolger sollte der Stärkung der Macht des Monarchen dienen. Die weitere Entwicklung des Lehnsvertrages fiel jedoch in eine Epoche, in der die Zentralgewalt den normannischen Überfällen und dem ab der zweiten Hälfte des 10. Jahrhunderts zügig voranschreitenden Burgenbau des Adels ohnmächtig gegenüberstand. ${ }^{48}$ Sehr wichtig war hierbei die Entstehung des Ritterturns als einer gesonderten Berufs- und sozialen Schicht mit eigener Kultur. ${ }^{49}$ Damit verbunden war die Verbreitung einer neuen Technik des Reiterkampfes (endgültig durchgesetzt nach 1000), die auf dem schwerbewaffneten Reiter beruhte. Dies erforderte eine entsprechende Vorbereitung hinsichtlich der Erziehung der künftigen Ritter; das höfische Leben wurde fortan durch feste Prinzipien des Benehmens bestimmt. Eine bedeutende Rolle bei der Christianisierung sowohl des ritterlichen Ethos wie auch beim Zeremoniell des Vasalleneids spielte die Kirche. ${ }^{50}$

Über die Kraft und Bedeutung der vorgenannten Erscheinungen entschied ihre militärische Wirksamkeit. In dieser Phase wurden die Lehnsbindungen, insbesondere in der sich

et féodalité méridionales d'après les serments de fidélité ( $\mathrm{X}^{\mathrm{e}}$-début $\mathrm{XI}^{\mathrm{e}}$ siècle), in: Les structures sociales de l'Aquitaine, du Languedoc et de l'Espagne au premier âge féodal. Toulouse, 28-32 mars 1968. Paris 1969, 115-142.

48 Bournazel/ Poly, La mutation (wie Anm 33), 81 ff.; Bisson, The „Feudal Revolution“ (wie Anm 35); ders., The Problem (wie Anm. 40); Bernard S. Bachrach, The Angevin Strategy of Castle Building in the Reign of Fulk Nerra 987-1040, in: AHR 88, 1983, 533-560; ders., Enforcement of the Forma Fidelitatis: the Techniques used by Fulk Nerra, Count of the Angevins (987-1040), in: Speculum 59, 1984, 796-819; Sidney Painter, Castellans of the Plain of Poitou in the Eleventh and Twelfth Centuries, in: Speculum 31, 1956, 243-257; Barbara English, Towns, Mottes and Ring-works of the Conquest, in: The Medieval military revolution. State, Society, and Military Change in Medieval and Early Modern Europe. Ed. Andrew Ayton/J. L. Price. London/New York 1995, 45-61.

49 Maurice Keen, Chivalry. New Haven/London 1984 (dt.: Das Rittertum. München/Zürich 1987); Jean Flori, L'essor de la chevalerie XI'-XII' siècles. Genève 1986; ders., Chevaliers et chevalerie au Moyen Âge. Paris 1999; Lorenz Bonninger, Die Ritterwürde in Mittelitalien zwischen Mittelalter und früher Neuzeit, mit einem Quellenanhang: päpstliche Ritterernennungen 1417-1464. Berlin 1995; Arno Borst (Hrsg.), Das Rittertum im Mittelalter. (Wege der Forschung, Bd. 349.) Darmstadt 1976; Josef Fleckenstein, Ordnungen und formende Kräfte des Mittelalters. Ausgewăhlte Beiträge. Göttingen 1989; Hagen Keller, Adel, Rittertum und Ritterstand nach italienischen Zeugnissen des 11.-14. Jahrhunderts, in: Institutionen, Kultur und Gesellschaft. Festschrift für Josef Fleckenstein zu seinem 65. Geburtstag. Hrsg. v. Lutz Fenske/Werner Rösener/Thomas Zotz. Sigmaringen 1984, 581-608; John Gillingham, 1066 and the Introduction of Chivalry into England, in: Law and Government in Medieval England and Normandy. Essays in Honour of Sir James Holt. Hrsg. v. George Garnett/John Hudson. Cambridge 1994, 31-55; Barthélemy, Qu'est-ce (wie Anm. 4), 15-74.

50 Michel Parisse, Le tournoi en France, des origines à la fin du XIII siècle, in: Das ritterliche Turmier im Mittelalter. Beiträge zu einer vergleichenden Formen- und Verhaltensgeschichte des Rittertums. Hrsg. v. Josef Fleckenstein. Göttingen 1985, 175-211, und andere Artikel in diesem Band; Keen, Das Rittertum (wie Anm. 49), 71 ff.., 129 ff., 191 ff.; Erich Köhler, Die Rolle des niederen Rittertums bei der Entstehung der Trobadorlyrik, in: Das Rittertum im Mittelalter (wie Anm. 49), 293-314 (zuerst 1966); Joachim Bumke, Höfische Kultur. Literatur und Gesellschaft im Hohen Mittelalter. 2 Bde. München 1986 (bes. Bd. 1, 83 ff.); Thomas Woodcook/John Martin Robinson, The Oxford Guide to Heraldry. Oxford 1988, 1-13; Adrian Ailes, The Knight, Heraldry and Armour. The Role of Recognition and the Origins of Heraldry, in: Medieval Knighthood IV. Papers from the Fifth Strawberry Hill Conference. Ed. Christopher Harper-Bill/Ruth Harvey. Suffolk 1992, 1-21. 
damals ausbreitenden intensiveren Form der Ligesse, die eine Treuebindung nur gegenüber einem Herm gestattete, von den Eliten des 11. Jahrhunderts als effektivste Art der Herrschaftsausübung erkannt. Dies förderte die Diffusion des Lehnrechts von oben ${ }^{51}$ : in England nach 1066, in Südfrankreich, Aragonien und Katalonien, in den normannischen Staaten Süditaliens, im Königreich Jerusalem sowie den anderen Kreuzfahrerstaaten. Das Lehnrecht hatte in dieser Zeit weiterhin einen gewohnheitsmäßigen Charakter, seine grundlegenden Institutionen beeinträchtigten nicht die verschiedenen lokalen Sitten, vielmehr vergrößerten sie die Plastizität des Lehnrechts durch seine Anpassung an die lokalen Erfordernisse. ${ }^{52}$ Dessen Niederschrift erfolgte bekanntlich erst im 12. Jahrhundert, am frühesten in Norditalien, wo eine - mehrfach durch römischrechtlich gebildete Juristen redigierte - Kompilation lombardischer Sitten und Normen entstand, die sogenannten Consuetudines oder Libri Feudorum. Sie sollte in der Zukunft, insbesondere in der Neuzeit, noch eine bedeutende Rolle spielen. $^{53}$

Aus mitteleuropäischer Sicht hatten die Entwicklungen im deutschen Reich fundamentale Bedeutung. Die Rezeption von Mustern und Standards verlief im Mittelalter zumeist auf eine indirekte Art, dem Reich kam folglich - schon wegen seiner geographischen Lage - die Rolle des Hauptvermittlers zu. Unter den Ottonen und Saliern bewahrten die karolingischen Prinzipien der Staatsverfassung eine beachtliche Lebendigkeit, die Lehnsverbindungen wurden daher nicht zum grundlegenden Element gesellschaftlicher Bindungen ${ }^{54}$ Im 12. Jahrhundert änderte sich die Situation. Die deutschen Könige bemühten sich um eine eindeutig lehnrechtliche Interpretation des Wormser Konkordats von $1122^{55}$ und forcierten den auf entsprechenden Prinzipien beruhenden Umbau der innerstaatlichen Verhältnisse, so schon Lothar III. und nach ihm die ersten Vertreter der Stauferdynastie. Friedrich I. Barbarossa verstärkte, indem er die Zahl der Fürsten vergrößerte, deren Abhängigkeit und berief sich

51 Bournazel/Poly, La mutation (wie Anm 33); Fossier, Enfiance (wie Anm. 33), 453 ff.; Boutruche, Seigneurie (wie Anm. 36), vol. 2, 312 ff.; Kurt Kluxen, Englische Verfassungsgeschichte. Darmstadt 1987, 15 ff.; R. Allen Brown, Origins of English Feudalism. London/New York 1973, 83 ff.; Ludwig Buisson, in: Studien (wie Anm 47), 95-184; Structures féodales (wie Anm. 11); Les structures sociales (wie Anm. 47); Giordanengo, Le droit féodal (wie Anm. 11); vgl. auch oben Anm. 35 und 40.

52 Vgl. Giordanengo, Le droit féodal (wie Anm. 11), 228: „comme toute structure juridique le droit féodal est extrêmement plastique"; ăhnlich Magnou-Nortier, La féodalité (wie Anm 13), 348.

53 Gerhard Dilcher, Art. Libri Feudorum, in: HRG. Bd. 2, Sp. 1995-2001; Giordanengo, Le droit féodal (wie Anm. 11), 112 ff., 122 ff; Reynolds, Fiefs (wie Anm. 4), 483 ff.; Manteuffel, Teoria (wie Anm. 27); Gérard Giordanengo, État et droit féodal en France (XII'-XIV siècles), in: L'État moderne. Le droit, l'espace et les formes de l'État. Actes du colloque tenu à la Baume Les Aix 11-12 octobre 1984. Ed. Noël Coulet/Jean-Philippe Genet. Paris 1990, 61-83.

54 Vgl. Eduard Hlawitschka, Vom Frankenreich zur Formierung der europăischen Staaten- und Völkergemeinschaft 840-1046. Darmstadt 1980, 201 ff.; Egon Boshof, Königtum und Königsherrschaft im 10. und 11. Jahrhundert. (EdG, Bd. 27.) München 1993.

55 Peter Classen, Das Wormser Konkordat in der deutschen Verfassungsgeschichte, in: Investiturstreit und Reichsverfassung. Hrsg. v. Josef Fleckenstein. (VuF, Bd. 17.) Sigmaringen 1973, 411-460 (bes. 422 ff.). 
hierbei seit 1184 auf das Lehnrecht in Form der Ligesse. ${ }^{56}$ Eine noch breitere Anwendung fand es schließlich im Zuge der Konsolidierung der Landesherrschaften. ${ }^{57}$ Zuvor hatten die Ministerialen im 11. Jahrhundert eine funktional der Ligesse ähnliche Rolle gespielt. ${ }^{58} \mathrm{Ihr}$ im allgemeinen unfreier Status sowie ihre Zugehörigkeit zur Familia des Herm garantierten ihre engere Unterordnung. Daher wurden sie gern zur Erfullung von Funktionen bei Hofe, zur Güterverwaltung und für den Heeresdienst herangezogen. Noch während dieses Jahrhunderts kam es zu einer beachtlichen Vereinheitlichung ihres Status, was zu Anfang des folgenden Jahrhunderts Ausdruck fand in der Verbreitung einer gemeinsamen Bezeichnung: ministeriales (vorher zumeist servientes). ${ }^{59}$ Die Ministerialen werden für eine für die deutsche Geschichte spezifische Gesellschaftsschicht gehalten. Die Formen ihrer Abhängigkeit, die durch Geburt und nicht durch Anknüpfung vasallitischer Beziehungen bestimmt war, unterlagen frühzeitig lehnrechtlichen Einflüssen und bereits im 12. Jahrhundert einer weitgehenden Anpassung, wenngleich ihr ursprunglicher sozialer Status zunächst nicht in Frage gestellt wurde. Grundlage dieses Prozesses war vor allem die kulturelle Gemeinschaft der Ritter. Das Wissen über die niedere soziale Herkunft der Ministerialen war noch im 13. Jahrhundert verbreitet.

Die lehnrechtliche Strukturierung der politischen Verhältnisse im deutschen Reich fuhrte gegen Ende des 12. Jahrhunderts zur Präzisierung des Grundsatzes, daß ein Reichsfürst nur

56 Zuletzt Sigrid Hauser, Staufische Lehnspolitik am Ende des 12. Jahrhunderts. 1180-1197. (Europäische Hochschulschriften, Rh. 3: Geschichte und ihre Hilfswissenschaften, Bd. 770.) Frankfurt a. M. 1998; vgl. Franz Josef Schmale, Lothar III. und Friedrich I. als Könige und Kaiser, in: Probleme des 12. Jahrhunderts (wie Anm. 15), 46 ff.; Hans Patze, Friedrich Barbarossa und die deutschen Fürsten, in: Die Zeit der Staufer. Geschichte - Kunst - Kultur. Hrsg. v. Reiner Haussherr/Christian Văterlein. Bd. 5: Supplement: Vorttäge und Forsch. Stuttgart 1979, 35-73, bes. 48 ff.; Karl Friedrich Krieger, Die königliche Lehnsgerichtsbarkeit im Zeitalter der Staufer, in: DA 26, 1970, 400-433.

57 Volker Henn, Das ligische Lehnswesen im Westen und Nordwesten des mittelalterlichen Deutschen Reichs. München 1970, 17 ff., 81 ff., 102 ff.

58 Auf die funktionale Gleichartigkeit von Ligesse und Ministerialităt machte aufmerksam Mitteis, Lehnrecht (wie Anm. 9), 568; vgl. auch Karl Bosl, Das ius ministerialium. Dienstrecht und Lehnrecht im deutschen Mittelalter, in: Studien (wie Anm 47), 51-94 (bes. 89 ff.); ders., Die Reichsministerialităt der Salier und Staufer. Ein Beitrag zur Geschichte des hochmittelalterlichen deutschen Volkes, Staates und Reiches. 2 Bde. Stuttgart 1950.

59 Thomas Zotz, Die Formierung der Ministerialităt, in: Die Salier und das Reich. Hrsg. v. Stefan Weinfurter. Bd. 3: Gesellschaftlicher und ideengeschichtlicher Wandel im Reich der Salier. Sigmaringen 1991; 3-50; vgl. Karl Brunner, Ius quod veri ministeriales habent, in: MIÖG 100, 1992, 175-180; aus der sehr umfangreichen, den späteren Weg der Ministerialităt betreffenden Literatur vgl. bes. Friedrich Ludwig Wagner (Hrsg.), Ministerialităt im Pfälzer Raum. Referate und Aussprachen der Arbeitstagung vom 12. bis 14. Oktober 1972 in Kaiserslautern. Speyer 1975; Josef Fleckenstein (Hrsg.), Herrschaft und Stand. Untersuchungen zur Sozialgeschichte im 13. Jahrhundert. (VMPIG, Bd. 51.) Göttingen 1977; Benjamin Arnold, German Knighthood 1050-1300. Oxford 1985, bes. 53 ff.; Ulrich Ritzerfeld, Das Kölner Erzstift im 12. Jahrhundert. Verwaltungsorganisation und wirtschaftliche Grundlage. (Rheinisches Archiv, Bd. 132.) Köln 1994, 40 ff., 58 ff., 209 ff.; František Kubů, Die staufische Ministerialităt im Egerland. Ein Beitrag zur Siedlungs- und Verwaltungsgeschichte. Bamberg 1995; Winfried $H$. Witzel, Die fuldischen Ministerialen des 12. und 13. Jahrhunderts. Ein Beitrag zur mittelalterlichen Geschichte der Reichsabtei Fulda. (Veröff. des Fuldaer Geschichtsvereins, Bd. 62.) Fulda 1998. 
direkter Lehnsmann des Kaisers sein kann. Zwar war die Feudalisierung der politischen Strukturen noch nicht vollkommen, doch fuhrte sie im Rechtsleben zur Rationalisierung der deutschen Form der Lehnspyramide (sechs- oder siebenstufig), zur sogenannten Heerschildordnung. ${ }^{60}$ Diese Wandlungen wurden vom fortschreitenden Zerfall des Staates in Landesherrschaften unterschiedlicher Größe und Qualităt begleitet. Es war dies ein sehr komplexer Prozeß, eng verbunden mit der Herausbildung des Feudalismus in seiner weiteren (zweiten) Bedeutung; furr die Konsolidierung der entstehenden Herrschaften besaß der Landesausbau entscheidende Bedeutung. ${ }^{61}$ Hieraus ergaben sich besonders günstige Möglichkeiten für die flächenmäßige und kompakte Entwicklung der Landesherrschaften an der östlichen Reichsgrenze, insbesondere in den eroberten und dann kolonisierten slawischen Gebieten.

Anfangs spielten auch in diesem Raum die Ministerialen eine große Rolle. Überall, von Holstein über Mecklenburg, Brandenburg bis nach Österreich und in die Steiermark, bildeten sie das Hauptinstrument zur Herrschaftsausübung, oft haben sie die Verdrängung bzw. Ausschaltung des alten Hochadels ermöglicht. ${ }^{62}$ Vereinheitlichung und Senkung des Status der Untertanen gehörten zu den Mitteln, mit welchen Verselbständigung und Herrschaftsbildung auf niederer Stufe verhindert wurden. Gleichzeitig wurden hierdurch die Territorialisierung sowie die frühständische Bewußtseinsbildung ritterlicher Schichten beschleunigt. Zwar erleichterten die im Zuge der Rodung gewachsenen Möglichkeiten einzelnen Familien die Festigung ihrer Stellung bzw. ihren Aufstieg als „neue Eliten“ - durch Burgenbau und Ansiedlung eigener Leute -, doch wurden in einigen Territorien ihre Wirkungsmöglichkeiten

60 Karl Heinemeyer, König und Reichsfürsten in der späten Salier- und frühen Stauferzeit, in: BlldtLG 122, 1986, 1-66; Karl Friedrich Krieger, Die Lehnshoheit der deutschen Könige im Spătmittelalter (ca. 1200-1437). Aalen 1979.

61 Dieses Problem ist von mir unter Verwendung der umfangreichen Fachliteratur besprochen worden in: Gowlas, O kształt (wie Anm. 38), die weiteren Erwägungen stützen sich in großem Maße auf die dort vorgestellten Beobachtungen und ihre Dokumentation. Vgl. allgemein Hans Patze (Hrsg.), Der deutsche Territorialstaat im 14. Jahrhundert. 2 Bde. (VuF, Bd. 14.) Sigmaringen 1971; unlängst Ernst Schubert, Einführung in die Grundprobleme der deutschen Geschichte im Spätmittelalter. Darmstadt 1992, 196 ff.; ders., Fürstliche Herrschaft und Territorium im spăten Mittelalter. (EdG, Bd. 35.) München 1996.

62 Gawlas, O ksztalt (wie Anm. 38), 38 ff., hier weitere Literatur; Peter Feldbauer, Herren und Ritter. (Herrschaftsstruktur und Stăndebildung. Beiträge zur Typologie der österreichischen Länder aus ihren mittelalterlichen Grundlagen, Bd. 1.) München 1973, 20 ff., 37 ff., 96 ff., 154 ff., 236 ff.; Heinz Dopsch, Probleme ständischer Wandlung beim Adel Österreichs, der Steiermark und Salzburgs vornehmlich im 13. Jahrhundert, in: Herrschaft und Stand (wie Anm. 59), 207-253; Hans K. Schulze, Territorienbildung und soziale Strukturen in der Mark Brandenburg im hohen Mittelalter, in: ebd. 254-275; ders., Die Besiedlung der Mark Brandenburg im Hohen und Späten Mittelalter, in: Jahrbuch für Geschichte Mittel- und Ostdeutschlands 28, 1979, 42-178; Dieter Rübsamen, Kleine Herrschaftsträger im Pleissenland. Studien zur Geschichte des mitteldeutschen Adels im 13. Jahrhundert. (Mitteldeutsche Forsch., Bd. 95.) Köln 1987, 264 ff.; Kubü, Die staufische Ministerialităt (wie Anm. 59); Herwig Weigl, Materialien zur Geschichte des rittermäßigen Adels im südwestlichen Österreich unter der Enns im 13. und 14. Jahrhundert. Wien 1991, 227 ff. 
durch bewußte herrscherliche Politik sowie die frühständische Stärkung der Position des Rittertums begrenzt. ${ }^{63}$

Der gesellschaftliche Aufstieg der Ministerialen und die Vereinheitlichung ihres Status gemäß lehnrechtlicher Normen führten dazu, daß sich in den meisten Territorien nur ausnahmsweise anderes als Lehnseigentum erhalten hat. Lehnrechtlichen Charakter erhielt im 13. Jahrhundert auch die Funktion des Schulzen, der an der Spitze des neulozierten bzw. reorganisierten Dorfes stand und gleichfalls zum Militärdienst mit Pferd verpflichtet war. ${ }^{64}$ Der auf das Lehnrecht gestützte Umbau der Eigentumsverhältnisse ritterlicher Schichten war (neben der komplexen Erschließung ganzer Gebiete, der „Stadt-Land-Kolonisation“) eingebettet in die Umorganisierung der inneren Verhältnisse, welche die deutsche Ostkolonisation begleitete. Beinahe ausschließlich Lehnscharakter hatten unter anderem die Rittergüter in Brandenburg, und die Existenz konkreter Vorbilder ist ausgesprochen deutlich erkennbar am Beispiel Pommerns. Nachdem die Fürsten Wartisław III. von Demmin (1219-1264) und Barnim I. von Stettin (1220-1278) 1236 vom Brandenburger Markgrafen besiegt und zum Lehnseid verpflichtet worden waren, haben sie im Laufe weniger Jahre die bisherige slawische Elite durch fremde deutsche Ritter ministerialischer Herkunft ersetzt; deren neue Besitztümer hatten ausschließlich Lehnscharakter. Diese Wandlungen gingen einher mit der radikalen und vollkommenen Modernisierung der Grundlagen fürstlicher Herrschaft im Zuge der Kolonisation zu deutschem Recht, der Städtelokation und der Reorganisation der territorialen Verwaltung. ${ }^{65}$

Die Interessen der Territorialherren deckten sich in dieser Phase in hohem Maße mit den Bestrebungen des hauptsächlich aus Ministerialen rekrutierten Rittertums, das nach Osten zog: aus der Altmark ins Havelland, in den Barnim, den Teltow und in die Neumark, aus Thüringen und Meißen in die Lausitzen, nach Schlesien, ins südliche Großpolen und später

63 Diese Beobachtungen betreffen vor allem Österreich und die Steiermark, die Herrschaft der Erzbischöfe von Salzburg und den Staat des Deutschen Ordens in Preußen; vgl. Gawlas, O kształt (wie Anm. 38), 22 ff., 41 ff., 47 ff.; Folker Reichert, Landesherrschaft, Adel und Vogtei. Zur Vorgeschichte des spätmittelalterlichen Ständestaates im Herzogtum Österreich. (AKG, Beih. 23.) Köln/Wien 1985, 120 ff., 340 ff.; Max Weltin, Das österreichische Landrecht des 13. Jahrhunderts im Spiegel der Verfassungsentwicklung, in: Recht und Schrift im Mittelalter. Hrsg. v. Peter Classen. (VuF, Bd. 23.) Sigmaringen 1977, 381-424.

64 Volker Rödel, Art. Lehnsschulze, in: HRG. Bd. 2. Berlin 1978, Sp. 1702-1704; Hans K. Schulze, Art. Erbschulze, in: HRG. Bd. 1. Berlin 1971, Sp. 978-980; Gawlas, O kształt (wie Anm. 38), 148, Anm. 447; Jan M. Piskorski, Kolonizacja wiejska Pomorza Zachodniego w XIII i w początkach XIV wieku na tle procesów osadniczych w średniowiecznej Europie. (Poznańskie Towarzystwo Przyjaciół Nauk, Prace Komisji Historycznej, Bd. 41.) Poznań 1990, 80, 172 ff.

65 Gawlas, O kształt (wie Anm. 38), 40, 52; Schulze, Territorienbildung (wie Anm 62), 260 ff.; Benedykt Zientara, Możni słowiańscy na dworze Ottona I szczecińskiego, in: Wieki średnie - Medium Aevum. Prace ofiarowane Tadeuszowi Manteufflowi w 60 rocznicę urodzin. Hrsg. v. Aleksander Gieysztor/Marian H. Serejski/Stanisław Trawkowski. Warszawa 1962, 201-212; Piskorski, Kolonizacja (wie Anm. 64), 132 ff., 239-240; Rudolf Benl, Die Gestaltung der Bodenrechtsverhältnisse in Pommern vom 12. bis zum 14. Jahrhundert. (Mitteldeutsche Forsch., Bd. 93.) Köln/Wien 1986, 426 ff. 
nach Rotreußen, aus Sachsen und Brandenburg nach Pommern. ${ }^{66}$ Viel seltener stammten sie aus entfernteren Gebieten, etwa im Fall der Kreise des Bischofs von Olmütz, Brunos von Schauenburg, der Ministerialen aus Holstein und den Nachbargebieten nach Nordmähren führte. ${ }^{67}$ Die Ankömmlinge, die im Osten gesellschaftlichen Aufstieg suchten, brachten hierher die Werte der ritterlichen Kultur und die Standards des deutschen Lehnrechtes.

An dieser Stelle ist jedoch nochmals darauf hinzuweisen, daß der Status ritterlichen Eigentums ein ausgesprochen komplexes Forschungsproblem darstellt. Trotz des Fehlens zusammenfassender Studien ist allein die Tatsache unumstritten, daß seine einzigartige Vielfalt aus der sozialen Stratifikation und den regionalen Besonderheiten resultierte. Die in der wissenschaftlichen Literatur gezogenen Schlußfolgerungen sind schon wegen der schmalen Quellenbasis fragwürdig, Mißtrauen erweckt auch das weit verbreitete Verfahren retrogressiver Analyse. Die mit den Besitztümern der Ministerialen verbundene Kategorie des „Inwärtseigen“, das die Forderung nach Zustimmung des Herm bei jedweder Alienation eines Gutes außerhalb seiner Familia beinhaltete, erscheint nach der Mitte des 13. Jahrhunderts in den Quellen. Es scheint, daß dies eher ein Ergebnis herrschaftlicher Bestrebungen ist, die sich hierzu auf das Regalien- und Hoheitsrecht beriefen, als daß es auf tradierte Reste des ursprünglichen Status der Familia zurückginge. ${ }^{68}$ Man könnte meinen, daß die Erblichkeit des Besitzes den Ministerialen schon früh den relativ freien Umgang hiermit ermöglicht hätte. Das Eigentumsrecht war im Mittelalter ein sehr empfindlicher Bereich und Gegenstand dauerhafter Auseinandersetzungen zwischen den Herren und ihren Untertanen, da jene immer wieder versuchten, ihren Einfluß darauf auszudehnen. Der Vorteil der Lehnsbindung beruhte furr den Lehnsherm eben in der Begrenzung des Kreises der Erbberechtigten. Dieses

66 Vgl. zuletzt Tomasz Jurek, Obce rycerstwo na Śląsku do połowy XIV wieku. (Poznańskie Towarzystwo Przyjaciół Nauk, Prace Komisji Historycznej, Bd. 54.) Poznań 1996; ders., Fremde Ritter im mittelalterlichen Polen, in: Quaestiones Medii Aevi Novae 3, 1998, 19-49; von den älteren Arbeiten vgl. besonders Eberhard Sauer, Der Adel während der Besiedlung Ostpommerns (der Länder Kolberg, Belgard, Schlawe, Stolp) 1250-1350. Stettin 1939; Harald Schieckel, Herrschaftsbereich und Ministerialität der Markgrafen von Meissen im 12. und 13. Jahrhundert. Untersuchungen über Stand und Stammort der Zeugen markgräflicher Urkunden. (Mitteldeutsche Forsch., Bd. 7.) Köln/Graz 1956; Hans K. Schulze, Adelsherrschaft und Landesherrschaft. Studien zur Verfassungs- und Besitzgeschichte der Altmark, des ostsächsischen Raumes und des hannoverschen Wendlandes im hohen Mittelalter. (Mitteldeutsche Forsch., Bd. 29.) Köln/Graz 1963.

67 Heinz Stoob, Bruno von Olmütz, das mährische Städtenetz und die europäische Politik von 1245 bis 1281, in: Die mittelalterliche Städtebildung im südöstlichen Europa. Hrsg. v. dems. (Städteforschung, Rh. A: Darstellungen, Bd. 4.) Köln 1977, 90-133; Olga Laszczyńska, Ród Herburtów w wiekach średnich. (Poznańskie Towarzystwo Przyjaciół Nauk, Prace Komisji Historycznej, Bd. 14, H. 4.) Poznań 1948.

68 Paul Puntschart, Das „Inwärts-Eigen“ im österreichischen Dienstrecht des Mittelalters. Ein Beitrag zur Eigentums-Theorie, in: ZRG GA 43, 1922, 66-102; Ch. Hafke, Inwärtseigen, in: HRG. Bd. 2. Berlin 1978, Sp. 412 f.; Herwig Ebner, Das Freie Eigen. Ein Beitrag zur Verfassungsgeschichte des Mittelalters. Klagenfurt 1969, bes. 70 ff.; Arnold, German Knighthood (wie Anm. 59), 140 ff.; vgl. auch die treffienden Bemerkungen von Max Weltin, Die Gedichte des sogenannten „Seifried Helbling“ als Quelle für die Ständebildung in Österreich, in: Jahrbuch für Landeskunde von Niederösterreich, NF. 50/51, 1984/1985, 338-416, bes. 392 ff., 397 ff. 
Problem steht im Zusammenhang mit generellen Veränderungen in der gesellschaftlichen Wirksamkeit rechtlicher Normen wie etwa einem langsamen Abrücken von primitiven Rechtsgrundsätzen. ${ }^{69}$ Es scheint, daß die Verteidigung des Lehnseigentums vor Allodifikation dank der seit dem 13. Jahrhundert zunehmenden Schriftlichkeit leichter war als die des Diensteigentums.

Man kann annehmen, daß in der ersten Phase der deutschen Ostkolonisation der Status des Rittertums vor allem durch Normen des Dienst- und Siedlungsrechtes bestimmt wurde. Auf den entsprechenden Charakter des Kulmer Rechts, das in der Kulmer Handfeste von 1232 festgelegt und im Deutschordensstaat Preußen angewendet wurde, hat kürzlich Marian Dygo in einer scharfsinnigen Analyse hingewiesen. ${ }^{70}$ Hier ist auch das beständige Festhalten an lokalen Gewohnheiten durch die Ministerialen im Gebiet des Erzbischofs von Magdeburg anzufuhren. ${ }^{71}$ In den weltlichen Herrschaften unterlag das Rittertum einer schnelleren Evolution, es wurde hier eher einer Aufschichtung unterworfen, wobei die Lehnsmänner in Brandenburg und den Nachbargebieten die niedrigste Schicht bildeten. ${ }^{72}$

Wenn die deutschen Verhältnisse hier auch nur in ihren wichtigsten Problemen behandelt sind, ist insgesamt doch die Lebendigkeit des Lehnrechts im Spätmittelalter zu betonen. Die vor allem seit den sechziger Jahren unternommenen Forschungen zeigen, daß es von den Territorialherren gewinnbringend instrumentalisiert wurde und ihnen die Konsolidierung und Abrundung ihrer Territorien ermöglichte. ${ }^{73}$ Das betrifft insbesondere auch solche Institutio-

69 Hattenhauer, Europäische Rechtsgeschichte (wie Anm. 14), 2-48, 207 ff., $269 \mathrm{ff}$.

70 Marian Dygo, Studia nad początkami władztwa Zakonu Niemieckiego w Prusach (1226-1259). Warszawa 1992, 87 ff., 100 ff., 105 ff.; vgl. auch Reinhard Wenskus, Das Ordensland Preußen als Territorialstaat des 14. Jahrhunderts, in: Der deutsche Territorialstaat (wie Anm. 61), Bd. 1, 347-382, hier 377; zur Datierung der Handfeste Marc Löwener, Die Einrichtung von Verwaltungsstrukturen in Preußen durch den Deutschen Orden bis zur Mitte des 13. Jahrhunderts. (Deutsches Historisches Institut Warschau, Quellen und Studien, Bd. 7.) Wiesbaden 1998, $47 \mathrm{ff} ., 67 \mathrm{ff}$.

71 In einer Unterweisung für Breslau (lateinische Fassung von 1369) bemerkten die Magdeburger Ratsherren: sunt aput nos uiri speciales, ministeriales scilicet, qui in uulgari nostro nominantur „dynstlute" duplici generis. Primi sunt, qui sub suo omagio tenent et habent milites et clientes. (...) Alii sunt simplices milites, clientes, famuli, uillani ceterique tales persone seculares: Friedrich Ebel (Hrsg.), Magdeburger Recht. Bd. 2: Die Rechtsmitteilungen und Rechtssprüche für Breslau. T. 1: Die Quellen von 1261 bis 1452. (Mitteldeutsche Forsch., Bd. 89.) Köln/Graz 1989, 33; vgl. Dietrich Claude, Geschichte des Erzbistums Magdeburg bis in das 12. Jahrhundert. Bd. 2. (Mitteldeutsche Forsch., Bd. 67/2.) Köln 1975, 252 ff., 271 ff.; Karl Heinz Lampe, Die băuerlichen Ministerialen des 14. bis 16 Jahrhunderts im Erzbistum Magdeburg, in: Geschichts-Blătter für Stadt und Land Magdeburg 46, 1911, 11-58, 234-261.

72 Georg Winter, Die Ministerialităt in Brandenburg. Untersuchungen zur Geschichte der Ministerialităt und zum Sachsenspiegel. München/Berlin 1922; Stefan Chmielewski, Manowie w ziemi wałeckiej w XVI w. Przyczynek do kwestii manów wielkopolskich, in: Studia i Materiały do Dziejów Wielkopolski i Pomorza 6, 1960, 209-255; Eberhard Schmidt, Die Mark Brandenburg unter den Askaniern (11341320). (Mitteldeutsche Forsch., Bd. 71.) Köln/Wien 1973, 75 ff.

73 Gerhard Theuerkauf, Land und Lehnswesen vom 14. bis zum 16. Jahrhundert. Ein Beitrag zur Verfassung des Hochstifts Münster und zum nordwestdeutschen Lehnrecht. (Neue Münsterische Beiträge zur Geschichtsforschung, Bd. 7.) Köln 1961; Bernhard Diestelkamp, Das Lehnrecht der Grafschaft Katzenelnbogen (13. Jahrhundert bis 1479). Ein Beitrag zur Geschichte des spătmittelalterlichen deut- 
nen wie das Heimfallrecht oder das Öffnungsrecht. $\mathrm{Zu}$ einer Stabilisierung des rechtlichen Status der Lehnsmänner fuhrten die Ende des 12. Jahrhunderts einsetzende Anlage von Lehnbüchern $^{74}$ sowie die im Spätmittelalter zunehmende Bedeutung geschriebenen Rechts für die richterliche Praxis. Besondere Bedeutung gewannen die Vorschriften des Sachsenspiegels. ${ }^{75}$ Diese zwischen 1220 und 1235 entstandene Bearbeitung des sächsischen Gewohnheitsrechts aus der Feder des Eike von Repchow enthält sowohl das Land- wie auch das Lehnrecht. Schnell gewann er an Popularität und Autorität, unterlag der Bearbeitung, Übersetzung und Glossierung. Im Kolonisationsgebiet fand er bereits in der zweiten Hälfte des 13. Jahrhunderts schnelle und weitreichende Rezeption. Der Lehnsbesitz, der damals einer allgemeinen Umwandlung unterlag - unter anderem in Form der schon erwähnten, die Freiheit seiner Verfügung vergrößernden Allodifikation sowie der Versachlichung und Territorialisierung der Lehnsbindungen -, blieb im Reich aber dennoch ein unentbehrlicher Grund der politischen Verfassung.

Gestützt auf die vorstehenden Beobachtungen kann man schon jetzt eine bedeutende zeitliche Verspätung in der Adaptation des Lehnrechts in Polen annehmen. Auch auf der ,internationalen' Ebene ist zur mehrfach erneuerten Abhängigkeit Polens vom Reich festzuhalten, daß diese im allgemeinen tributären Charakter, nicht jedoch Lehnscharakter (wie im Fall Böhmens) trug. Eine Ausnahme bildeten die kaiserlichen Oberhoheitsansprüche auf Schlesien. ${ }^{76}$ Die vergleichende Betrachtung erweist die große Zweckmäßigkeit der Ministe-

schen Lehnrechts, insbesondere zu seiner Auseinandersetzung mit oberitalienischen Rechtsvorstellungen. (Untersuchungen zur deutschen Staats- und Rechtsgeschichte NF., Bd. 11.) Aalen 1969; ders., Lehnrecht und spätmittelalterliche Territorien, in: Der deutsche Territorialstaat (wie Anm. 61), Bd. 1, 65-96; Herrschaft und Stand (wie Anm. 59); Karl-Heinz Spieß, Lehnrecht, Lehnspolitik und Lehnsverwaltung der Pfalzgrafen bei Rhein im Spätmittelalter. (Geschichtliche Landeskunde, Bd. 18.) Wiesbaden 1978; Wolf-Rüdiger Berns, Personelles Element und Herrschaft im 14. Jahrhundert. Beobachtungen zur Lehnspolitik des Erzbischofs Balduin von Trier (1307-1354), in: Politik, Gesellschaft, Geschichtsschreibung. Festgabe für František Graus zum 60. Geburtstag. Hrsg. v. Herbert Ludat/Rainer Christoph Schwinges. (AKG, Beih. 18.) Köln 1982, 183-223.

74 Im 14. Jh. waren sie sehr verbreitet; Grundlage der Forschung bildet nach wie vor Woldemar Lippert, Die deutschen Lehnbücher. Beitrag zum Registerwesen, Leipzig 1903 (mit einem Verzeichnis der Lehnbücher); vgl. zuletzt Lutz Fenske/Ulrich Schwarz, Das Lehnsverzeichnis Graf Heinrichs I. von Regenstein 1212-1227. (VMPIG, Bd. 94.) Göttingen 1990, 11 ff.

75 Karl Kroeschell, Von der Gewohnheit zum Recht. Der Sachsenspiegel im späten Mittelalter, in: Recht und Verfassung im Übergang vom Mittelalter zur Neuzeit. Bd. 1: Bericht über Kolloquien der Kommission zur Erforschung der Kultur des Spätmittelalters 1994 bis 1995. Hrsg. v. Hartmut Boockmann. (Abh. der Akad. der Wiss. in Göttingen, Phil.-Hist. Kl., 3. Folge, Bd. 228.) Göttingen 1998, 68-92 (mit Literatur); vgl. auch ders., Rechtsaufzeichnung und Rechtswirklichkeit. Das Beispiel des Sachsenspiegels, in: Recht und Schrift (wie Anm. 63), 349-380; Rolf Liebewirth, Eike von Repchow und der Sachsenspiegel. (Sitzungsberichte der Sächsischen Akad. der Wiss. zu Leipzig, Phil.-Hist. Kl. Bd. 122/4.) Berlin 1982; für Polen Zygfryd Rymaszewski, Lacińskie teksty Landrechtu Zwierciadła Saskiego w Polsce: versio vratislaviensis, versio sandomiriensis, Laski. Wrocław/Warszawa/Kraków/Gdańsk 1975.

76 Gernot von Grawert-May, Das staatsrechtliche Verhältnis Schlesiens zu Polen, Böhmen und dem Reich während des Mittelalters (Anfang des 10. Jahrhunderts bis 1526). Aalen 1971; Gerard Labuda, O stosunkach prawnopublicznych między Polską a Niemcami w połowie XII wieku, in: Czasopismo Prawno-Historyczne 25, 1973, 25-58; ders., Stosunki prawno-polityczne Polski i Niemiec w średniowieczu. Program Badań, in: Niemcy - Polska w średniowieczu. Materialy z konferencji naukowej 
rialität. Die Heranziehung von Menschen niederer oder unfreier Herkunft scheint eine so selbstverständliche Erscheinung aller paternalistischen Gesellschaftsordnungen zu sein, daß es keines speziellen Beweises bedarf. Jedoch scheint die Entstehung der Ministerialität in Deutschland als einer eigenen sozialen Schicht ein derart attraktives Modell gewesen zu sein, daß zumindest Elemente hiervon nach Ostmitteleuropa gedrungen sind. Soweit mir bekannt, ist dieses Problem bisher jedoch noch nicht - geschweige denn vergleichend analysiert worden. ${ }^{77}$ Schon in der ältesten polnischen Chronik des sogenannten Gallus Anonymus (1113-1119) finden sich Informationen über die Heranziehung von Menschen niederer Herkunft durch Palatin Sieciech (ignobiles vero nobilibus preponebat) ${ }^{78}$ Mangel und Mehrdeutigkeit der Quellen bewirken, daß sich die Analyse vorwiegend auf mittelbare Hinweise stützen muß. Die Forschungsprobleme sind wegen der Dürftigkeit der Quellen zu verworren, als daß sie hier näher analysiert werden könnten; ich beschränke mich daher auf eigene Arbeitsergebnisse: Danach spielte das Vorbild der Ministerialität eine bedeutende Rolle in den Wandlungsprozessen des polnischen Rittertums. ${ }^{79}$ Auch die Rezeption der ritterlichen Kultur deutet darauf hin, daß etliche Rechtsgewohnheiten ähnlicher Herkunft waren. ${ }^{80}$ Die Verspätung der gesellschaftlichen Entwicklung fuhrte dazu, daß trotz der

zorganizowanej przez Instytut Historii UAM, w dniach 14-16 XI 1983 roku. Hrsg. v. Jerzy Strzelczyk. (Uniwersytet im. Adama Mickiewicza w Poznaniu, Ser. Hist., Bd. 126.) Poznań 1986, 121-135; Jerzy Hauziński, Polska a Królestwo Niemieckie w II połowie XII wieku, in: ebd. 138-155; ders., Śląsk wobec cesarstwa Sztaufów w świetle listu Fryderyka II Hohenstaufa do Bolesława II Łysego, in: Sobótka 40, 1985, 203-223; Edward Rymar, Prawnopolityczny stosunek Kazimierza Odnowiciela do Niemiec oraz termin odzyskania przez niego Sląska (1041 r.), in Sobótka 52, 1987, 137-169.

77 Besondere Möglichkeiten bieten hierfür die Verhältnisse in Ungarn, insbesondere die dortige Schicht der servientes regis; vgl. zuletzt Erik Fügedi, The Elefánthy. The Hungarian Nobleman and His Kindred. Ed. Damir Karbić. Budapest 1998, 35 ff.; József Gerics, Von den Universi Servientes Regis bis zu der Universitas Nobilium Regni Hungariae, in: Album Elemér Mályusz. (Études présentées à la Commission internationale pour L'histoire des assemblées d'états, vol. 56.) Bruxelles 1976, 99-108; Gyula Kristó, Die Arpadendynastie. Die Geschichte Ungarns von 895 bis 1301. [Budapest] 1993, $164 \mathrm{ff} ., 184 \mathrm{ff}$.

78 Galli Anonymi Chronica (wie Anm. 41), cap. II/4, 68; ebd. cap. I/16, 79: Palatin Sieciech in castellis (...) aut sui generis aut inferioris (...) comites vel pristaldos preponebat.

79 Gawlas, 0 kształt (wie Anm. 38), 86 ff.; den Verlauf der Untersuchungen und der Diskussion schildert Gerard Labuda, Przeobrażenia w organizacji sił zbrojnych w XI wieku, in: Pax et Bellum. Hrsg. v. Karol Olejnik. (Uniwersytet im. Adama Mickiewicza w Poznaniu, Ser. Hist., Bd. 175.) Poznań 1993, 87-110; das Quellenmaterial hat am umfangreichsten analysiert Zygmunt Wojciechowski, Prawo rycerskie w Polsce przed statutami Kazimierza W. Poznań 1928 (dt.: Das Ritterrecht in Polen vor den Statuten Kasimirs des Großen. Breslau 1930; frz.: La condition des nobles et le problème de la féodalité en Pologne au Moyen Age. Paris 1937); eine andere Konzeption und einige Quellenkorrekturen bietet Karol Buczek, Prawo rycerskie i powstanie stanu szlacheckiego w Polsce, in: Przegląd Historyczny 69, 1978, 23-44; ders., The Knight Law and the Emergence of the Nobility Estate in Poland, in: The Polish Nobility in the Middle Ages. Anthologies. Ed. Antoni Gasiorowski. (Polish Historical Library, vol. 5.) Wrocław 1984, 87-122; vgl. auch Antoni Gqsiorowski, Research into Medieval Polish Nobility. Introduction, in: ebd. 7-20.

80 Vgl. Jurek, Fremde Ritter (wie Anm. 66); Ambroży Bogucki, Rycerz i panosza w źródłach polskich XIV i XV wieku, in: Społeczeństwo Polski średniowiecznej. Zbiór studiów. Hrsg. v. Stefan Krzysztof 
Kenntnis der ritterlichen Sitten am $\mathrm{Hofe}^{81}$ in den Beziehungen $\mathrm{zu}$ den Untergebenen ,archaische', dienstbarere Formen der Abhängigkeit Verwendung fanden. In Anbetracht all dessen wäre zu erwarten, daß die weitere Entwicklung des Lehnrechts dessen stärkere Diffusion hätte nach sich ziehen müssen, so daß es zum gesellschaftlichen Strukturelement und Instrument der Territorialherrschaft geworden wäre. Warum es hierzu nicht gekommen ist, habe ich an anderer Stelle zu zeigen versucht und dabei auch in vergleichender Sicht die Hauptelemente der Wandlungsprozesse der polnischen Gesellschaft und des polnischen Staates im 12. und 13. Jahrhundert analysiert. ${ }^{82}$

Die in den Quellen faßbaren Ambitionen und Befugnisse der polnischen Großen des 12. Jahrhunderts und die organisatorische Aktivität des Großgrundbesitzes ${ }^{83}$ waren zentrifugal gerichtete Momente, die eine direkte Bedrohung der Herrschaft der regierenden Piastendynastie darstellten. Aus dieser Schicht, in den Quellen zumeist principes terre genannt, stammten wohl auch die obersten Verwalter der einzelnen Provinzen. Die - einige Jahrzehnte früher schon einmal vorgesehene - Einführung der Senioratsverfassung im Jahre 1138 durch das sogenannte Statut Bolesławs des Schiefmündigen fuhrte zu ihrer faktischen Ersetzung durch die jüngeren Vertreter der herrschenden Dynastie. Die um den höchsten Thron rivalisierenden Fürsten nutzten die erhebliche Verspätung der gesellschaftlichen Entwicklung und rezipierten Prinzipien der damaligen territorialherrschaftlichen Organisation, auf diese Weise der endogenen Entwicklung zuvorkommend. Ihre Vervollkommnung ging einher mit tiefgreifenden Wandlungen im Verständnis oberhoheitlicher Macht während des 12. Jahrhunderts. Besondere Bedeutung hatte die durch den Investiturstreit und die Erneuerung der Kenntnisse des römischen Rechts beeinflußte Formulierung des Regalienrechts als allein dem Herrscher vorbehaltene Gerechtsame, insbesondere des finanz-wirtschaftlichen Monopols. Über die Kontakte zum kaiserlichen Hof und den deutschen Fürsten drangen konkrete Vorbilder und Standards nach Polen. Deren Adaption durch die duces Polonorum, intensiviert vor allem seit dem letzten Viertel der 12. Jahrhunderts, ermöglichte unter anderem die Stabilisierung der Teilfürstentümer, die Herausbildung der Idee der „fürstenrechtlichen Verfassung" (ius ducale) und die Ablehnung hochadliger Ansprüche auf die aus dem Landesausbau gezogenen Gewinne. ${ }^{84}$ Die so konsequent gefuhrte furrstliche Politik ist mei-

Kuczyński. Bd. 7. Warszawa 1996, 165-200 (hier auch die ălteren Arbeiten des Autors); Dariusz Piwowarczyk, Obyczaj rycerski w Polsce późnośredniowiecznej (XIV-XV wiek). Warszawa 1998.

81 Vgl. Zbigniew Dalewski, Knighting of Polish Dukes in Early Middle Ages. Ideological and Political Significance, in: Acta Poloniae Historica 80, 1999, 15-43.

82 Gawlas, $\mathrm{O}$ kształt (wie Anm. 38), 72 ff.; ein Teil der Erwăgungen auch in ders., Die Territorialisierung des Deutschen Reichs und die teilfurstliche Zersplitterung Polens zur Zeit des hohen Mittelalters, in: Quaestiones Medii Aevi Novae 1, 1996, 25-43.

83 In Form einer Serie von Artikeln analysierte diese Themen am umfangreichsten Janusz Bieniak, Polska elita polityczna XII w., T. I-III, in: Społeczeństwo (wie Anm. 80). Bd. 2. Warszawa 1982, 11-61; Bd. 3. Warszawa 1985, 13-74; Bd. 4. Warszawa 1990, 13-107; Bd. 7. Warszawa 1996, 11-44; Bd. 8. Warszawa 1999, 9-66; vgl. hierzu die polemischen Bemerkungen von Jarosław Wenta, O stróżach „Testamentu“ Bolesława Krzywoustego, in: ebd., 67-112.

84 Das eindrucksvollste Zeugnis ist die Beschreibung der Politik Fürst Mieszkos III. des Alten, Senioratsfürst von Krakau, 1173-1176, in: Magistri Vincentii dicti Kadkubek Chronica Polonorum. Hrsg. v. Marian Plezia. (MPH NF., Bd. 11.) Kraków 1994, cap. IV/2, 130 f.; vgl. die Interpretation bei Gawlas, 
nes Erachtens die Hauptursache fur die Zurücksetzung der hochadligen Eliten im 13. Jahrhundert. Bestătigt wird dies durch das böhmische Beispiel, wo die Teilnahme des Hochadels am Landesausbau und die Erweiterung seiner Herrschaft auf die um die Burgen auf seinem Grundbesitz siedelnden Menschen eben damals seinen Aufstieg ermöglichten. ${ }^{85}$

In Polen war die Situation in den einzelnen Teilfurstentümern durchaus unterschiedlich. Eine starke Position behielt die einheimische Oligarchie in Kleinpolen, da hier die Kämpfe um den Senioratsstuhl ausgetragen wurden. Auch kam es hier nicht zur Gründung selbständiger Landesherrschaften, obgleich es nicht an entsprechenden Versuchen, insbesondere durch die Krakauer Bischöfe, gefehlt hat. Auch in den anderen Teilen Polens lassen sich derartige Bestrebungen beobachten, doch allein die Bemühungen der Breslauer Bischöfe waren schließlich Anfang des 14. Jahrhunderts von Erfolg gekrönt. ${ }^{86}$ Insgesamt gelang es den Piastenfürsten jedoch, die Ritterschaft in unmittelbarer Abhängigkeit zu halten und den Aufstieg bzw. die Umgestaltung der hochadligen Klientel in Lehnsvasallen zu verhindern. Es fehlten somit Bedingungen zur Rezeption des Lehnrechtes von unten. Dies hatte gravierende gesellschaftliche Folgen. Die Lehnsabhängigkeit, ursprünglich als Antipode gegen verwandtschaftliche Bindungen geschaffen, begrenzte im 13. Jahrhundert weiterhin die Rechte der Seitenverwandten. Von daher ist verständlich, daß in den Gebieten, wo das Lehnrecht keine Wurzeln schlug, die Familien- und Geschlechterbande die Grundform sozialer Bindungen blieben bzw. sich als solche neu konstituierten. Es gibt nicht wenige Beispiele hierfü: von den schottischen Clans und den baskischen Geschlechtern bis hin zu den selbstverwaltenden Bauerngemeinschaften mit den bekannten Geschlechtern in Ditmarschen. ${ }^{87}$

0 kształt (wie Anm. 38), 79 ff.; ders., Die Territorialisierung (wie Anm. 82), 37 ff.; ders., Polityka wewnętrzna Przemysła II a mechanizmy społecznych dążeń i konfliktów w Wielkopolsce jego czasów, in: Przemysł II. Odnowienie Królestwa Polskiego. Hrsg. v. Jadwiga Krzyżaniakowa. Poznań 1997, $66 \mathrm{ff}$. Zur (von mir entschieden angezweifelten) „fürstenrechtlichen Verfassung“ vor allem Karol Modzelewski, The System of the Ius Ducale and the Idea of Feudalism. Comments on the Earliest Class Society in Medieval Poland, in: Quaestiones Medii Aevi 1, 1977, 71-99; ders., Das mittelalterliche Polen von Oskar Kossmann. Polemische Bemerkungen, in: Acta Poloniae Historica 65, 1992, 171-210; ders., Europa romana, Europa feudale, Europa barbara, in: Bulletino dell'Istituto Storico per il Medio Evo e Archivio Muratoriano 100, 1995/96, 377-409, bes. 398 ff.; vgl. Stanisław Russocki, Figuré ou réel: Le „féodalisme centralisé“ dans le centre-est de l'Europe, in: Acta Poloniae Historica 66, 1992, 31-37.

85 Josef Žemlicka, Ke zrodu vrcholně feudální „pozemkové“ šlechty ve státě Přemyslovcủ, in: Časopis Matice Moravské 109, 1990, 17 ff.; ders., Die Anfänge des „grundherrschaftlichen“ Adels im Staat der Přemysliden, in: Historica 31, 1994, 37-57; das Problem wird eingehend analysiert in der im Druck befindlichen Arbeit von Marcin Pauk, Działalność fundacyjna możnowładztwa czeskiego i jej uwarunkowania społeczne (XI-XIII wiek).

86 Vgl. Sławomir Gawlas, Człowiek uwikłany w wielkie procesy - przykład Muskaty, in: Człowiek w społeczeństwie średniowiecznym. Hrsg. v. Roman Michałowski u. a. Warszawa 1997, 391-401; vgl. ders., 0 ksztalt (wie Anm. 38), 85 f.; zum Bistum Breslau demnăchst Thomas Wünsch, Die Entwicklung der Landesherrschaft der Breslauer Bischöfe vom 12. bis zum beginnenden 16. Jahrhundert. Ein Überblick, im Druck.

87 Vgl. z. B. Heinz Stoob, Geschichte Dithmarschens im Regentenzeitalter. Heide i. Holst. 1959, 233 ff.; ders., Die dithmarsischen Geschlechterverbănde. Grundfragen der Siedlungs- und Rechtsgeschichte in 
Es scheint, daß das Fehlen lehnrechtlicher Beziehungen und die Konfrontation mit dem "furstlichen Recht" (ius ducale) in Zusammenhang mit der Rezeption von Wappen und anderen Elementen ritterlicher Kultur günstige Bedingungen boten für die Entstehung polnischer Wappengeschlechter (letztendlich im 14. Jahrhundert) als einem Faktor bei der Formierung des Adelsstandes, wodurch schließlich die Lehnspyramide ersetzt werden sollte. ${ }^{88}$ Der nivellierende Druck auf die Untertanen verhinderte die Zersplitterung der Fürstentümer in kleine Landesherrschaften und trug zur Vereinheitlichung der Verhältnisse in den vergleichsweise großen Gebieten sowie zur verhältnismäßig frühen Organisierung der Ritterschaft unter Führung der Mächtigen zur Verteidigung ihrer Rechte gegenüber dem Herm bei. Es ist schwierig, den genauen Zeitpunkt zu bestimmen, seit dem nicht mehr der Wille des Fürsten, sondern das Geburtsrecht über die Zugehörigkeit zur Ritterschaft entschied. Die Anfänge dieser Wandels liegen jedenfalls in der zweiten Hälfte des 13. Jahrhunderts.

Ganz eigenartig verlief die Entwicklung in Schlesien. Dort wurde der mit der Adaption der Regalienkonzeption verbundene innere Umbau vom Zufluß fremder Ankömmlinge begleitet. ${ }^{89}$ Der am Anfang des 13. Jahrhunderts vom Herzog monopolisierte und auf komplexe Weise unternommene Landesausbau wurde zu einem äußerst wirksamen Instrument herrscherlicher Machtstärkung. Allein in Schlesien bestanden günstige Bedingungen für die Zuwanderung deutscher Ritter - in großem Ausmaß seit Mitte des 13. Jahrhunderts - und die rasche Umwandlung dienstlicher in lehnrechtliche Verbindungen ${ }^{90}$ sowie - in weiterer Perspektive - für die Angleichung der gesellschaftlichen und politischen Verfassung insbesondere der niederschlesischen Fürstentümer an die Standards des deutschen Reiches. In den anderen polnischen Gebieten, wo die Einfuhrung der auf dem Fürstenrecht beruhenden Verfassung nicht durch den Zustrom fremder Ansiedler begleitet wurde, bestanden später zu deren Anwerbung schon keine Möglichkeiten mehr und also auch nicht zur Verwendung fremder Ritter für die Stärkung fürstlicher Macht. Derartige Versuche provozierten der Widerstand der Untertanen, wie zum Beispiel 1268-1278 in Kujawien: Die Fürst Siemomysł damals abgerungene Entfernung der fremden Ritter aus seinem Herzogtum beugte eventuellen Versuchen vor, den Rechtsstatus der einheimischen Grundbesitzer zu verschlechtern. ${ }^{91}$ Hier ist anzumerken, daß eine neue Fürstengeneration in den achtziger Jahren des 13. Jahr-

den Nordseemarschen. Heide i. Holst. 1951; Jacques Heers, Le clan familial au Moyen Âge. Étude sur les structures politiques et sociales des milieux urbaines. Paris 1974.

88 Janusz Bieniak, Knight Clans in Medieval Poland, in: The Polish Nobility (wie Anm. 79); ders., Heraldyka polska przed Długoszem. Uwagi Problemowe, in: Sztuka i ideologia XV wieku. Hrsg. v. Piotr Skubiszewski. Warszawa 1978, 165-210.

89 Benedykt Zientara, Henryk Brodaty i jego czasy. Warszawa 1975; Gawlas, 0 kształt (wie Anm. 38), $82 \mathrm{f}$.

90 Tomasz Jurek, U początków niemieckiej migracji rycerskiej na Śląsk: świadkowie układu Bolesława Rogatki z arcybiskupem magdeburskim Wilbrandem z 1249 r., in: Społeczeństwo (wie Anm. 80), Bd. 7. Warszawa 1996, 107-127; vgl. oben Anm. 66; Mateusz Goliński, Służba rycerska a potencjał militarny księstw śląskich w późnym średniowieczu. T. 1: księstwo nysko-otmuchowskie, in: Sobótka 53, 1998, 33-67; T. 2: księstwo wrocławskie na tle innych ziem dziedzicznych Korony czeskiej, in: ebd., 519-545; T. 3: Uwagi ogólne, in: Sobótka 54, 1999, 1-17.

91 Kodeks Dyplomatyczny Wielkopolski. Hrsg. v. Ignacy Zakrzewski. Bd. 1. Poznań 1877, Nr. 482, 422; vgl. Gawlas, O kształt (wie Anm. 38), 87 f., 198, Anm. 1112. 
hunderts damit begann, ihre wechselseitigen Beziehungen auf eine lehnrechtliche Grundlage zu stellen. ${ }^{92}$ Folglich ist kaum zu bezweifeln, daß sie sich dessen auch zur Ordnung der inneren Verhältnisse bedient hätten, wenn denn die Voraussetzungen und Möglichkeiten hierzu bestanden hätten.

Seit Mitte des 13. Jahrhunderts können wir in allen polnischen Fürstentümern wachsende Bestrebungen zur Ausnutzung der Möglichkeiten beobachten, welche die Kolonisation zu deutschem Recht bot; in Schlesien fand dagegen deren Intensivierung statt. ${ }^{93}$ Lokationen zu deutschem Recht umfaßten auch alte städtische Zentren. Mit dem deutschen Bürgertum erschien ein neues soziales Element in der Gesellschaft - mit eigenen politischen Ambitionen, frei von einheimischen Traditionen, auch nicht auf die Interessen des ansässigen Rittertums und zusehends weniger auf die der Fürsten verpflichtet. Besondere Aktivităt zeigten in dieser Hinsicht die Hauptstädte der einzelnen Landschaften mit einem kaufmännischen Patriziat, das über große Mengen Geldes verfugte und seine eigenen Interessen verfolgte, z. B. die Ausdehnung der Gerichtsbarkeit zu deutschem Recht über die Stadtmauern hinaus (gerade in Schuldangelegenheiten). Durch die wachsende innere Krise und die Kämpfe der Thronprätendenten gegen Ende des 13. Jahrhunderts verschärfte sich der in ganz Mitteleuropa zu beobachtende Konflikt zwischen den Städten mit ihren Bestrebungen nach mehr Selbständigkeit, den örtlichen Eliten und dem Rittertum.

Die weiteren Unternehmungen zur Vereinigung des Staates hatten unmittelbaren Einfluß auf dessen Verfassung; die Erneuerung des Königreiches Polen wurde von einer inneren gesellschaftlichen Krise begleitet. Deren Kulminationspunkt war der sogenannte Aufstand des Vogtes Albert 1311/12. Dieser trug den Charakter eines Städtebundes, dem Krakau, Sandomir und Wieliczka angehörten und mit dem unter anderem einige von deutschen Mönchen dominierte Klöster Kleinpolens sympathisierten. ${ }^{94}$ Dessen Niederlage und die folgenden Repressionen, die vor allem das im Bund dominierende Krakau trafen, haben die politischen Aspirationen der Städte dauerhaft gebrochen. Strukturell ähnliche Ereignisse sind ein Jahr später in Großpolen zu beobachten. Hier wie dort konnte das Rittertum seine dominierende Position im Staat verteidigen. Dies förderte seine innere Konsolidierung, seine ständische Vereinheitlichung sowie seine Ausstattung mit vollem Grundbesitzrecht, was für viele Ritter eine Verbesserung ihrer sozialen Stellung bedeutete. Unter diesen Bedingungen konnte also keine Rede davon sein, daß dem Adel die Fesseln des Lehnrechts auferlegt wor-

92 Auf diese berief man sich wohl im Vertrag von Kępno 1282 über die Sukzession des Fürsten von Großpolen in Pommerellen; Janusz Bieniak, Postanowienia układu kępińskiego (15 lutego 1282) in: Przegląd Historyczny 82, 1991, 205-232; Tomasz Jurek, Henryk Probus i Henryk Głogowski: Stosunki wzajemne w latach 1273-1290, in: Sobótka 42, 1987, 556 ff.; ders., Dziedzic Królestwa Polskiego ksiazżę głogowski Henryk (1274-1309). (Poznańskie Towarzystwo Przyjaciół Nauk, Prace Komisji Historycznej, Bd. 45.) Poznań 1993, 10 ff.

93 Gawlas, O kształt (wie Anm. 38), 88 f.; ders., Polityka (wie Anm. 84), 71 ff.

94 Gawlas, O kształt (wie Anm. 38), 93 f.; ders., Nova civitas in Okol. Fragment z dziejów Krakowa, in: Społeczeństwo (wie Anm. 80). Bd. 6. Warszawa 1994, 107 ff.; Edmund Dlugopolski, Bunt wójta Alberta, in: Rocznik Krakowski 7, 1905, 135-186, bes. 159 ff. 
den wăren. Die Rezeption des territorialstaatlichen Herrschaftsmodells, das für die deutsche Ostkolonisation charakteristisch war, erfolgte in Polen eben deshalb nur selektiv.

Die weitere, intensivere Modernisierung, die Kasimir der Große (1333-1370) unter Zuhilfenahme der zu seiner Zeit üblichen Machtmittel ${ }^{95}$ realisierte, fuhrte lediglich zur Verbreitung des Lehnsschulzenamtes. ${ }^{96}$ Der König konnte sich, obgleich ein persönlicher Regierungsstil bei ihm erkennbar ist, des Lehnrechts nicht in größerem Maße bedienen, wie dies zur selben Zeit Karl IV. in Böhmen möglich war. Kasimir mußte nämlich auf die schon formierten gesellschaftlichen Kräfte Rücksicht nehmen, weshalb es auch nicht zu ernsthaften Konflikten mit den Untertanen kam. Eine Ausnahme bildete die Lage in Großpolen, wo seit der zweiten Hălfte des 13. Jahrhunderts eine wachsende Selbstăndigkeit der einheimischen Mächtigen und die Übernahme sozialer Standards aus den benachbarten deutschen Gebieten durch diese erkennbar ist. In den kolonisierten Grenzgebieten zu Schlesien und Brandenburg konnte die Befestigung adliger Territorialherrschaften mit Hilfe einer eigenen ritterlichen Klientel nur durch die Stabilisierung des polnischen Staates nach 1314 und das militărische Eingreifen der Könige verhindert werden. ${ }^{97}$ Dagegen hat sich im 1343 wiedergewonnenen Fraustädter Land bis 1422 der Lehnsstatus des Grundbesitzes erhalten. Noch dauerhafter erwiesen sich die gesellschaftlichen Veränderungen im Norden des Königreiches, im Deutsch Kroner Land, das 1368 wiedergewonnenen wurde und wo sich auf den großen Landgütern der abhängige niedere Lehnsadel, die Lehnsmannen, bis zum Ende des 16. Jahrhunderts hielt. ${ }^{98}$ Unabhängig davon befand sich Großpolen zwar im Rahmen der polnischen Sozialverfassung, doch haben die strukturellen Züge seiner politischen Elite im 14. Jahrhundert die Anarchie im Innern und den Widerstand gegen die königliche Politik gefördert.

Die fehlende Rezeption des Lehnrechts war einerseits mit der erfolgreichen Verteidigung der unmittelbaren teilfurstlichen Hoheit uber das ganze Rittertum spätestens seit Ende des

95 Sławomir Gawlas, Monarchia Kazimierza Wielkiego a społeczeństwo, in: Genealogia. Władza i społeczeństwo w Polsce średniowiecznej. Hrsg. v. Andrzej Radzimiński/Jan Wroniszewski. Toruń 1999, 197-236; ders., Polska Kazimierza Wielkiego (wie Anm. 46), 15 ff.

96 Ludwik Lysiak, Własność sołtysia (wójtowska) w Małopolsce do końca XVI wieku. Kraków 1964; ders., U podstaw formowania się polskiego stanu sołtysiego, in: Czasopismo Prawno-Historyczne 16, 1964, 231-250; ders., Ius supremum Maydeburgense castri Cracoviensis 1356-1794. Organisation, Tătigkeit und Stellung des Krakauer Oberhofs in der Rechtsprechung Altpolens. Frankfurt a. M. 1990, 79 ff.; Stanistaw Marian Zajączkowski, O wojskowych powinnościach sołtysów w Polsce w okresie monarchii stanowej, in: Studia i Materiały z Historii Wojskowości 19, 1973, 1, 23-59; ders., Obowiązki wojskowe wójtów w państwie polskim w okresie monarchii stanowej, in: Studia i Materiały z Historii Wojskowości 21, 1978, 3-44.

97 Gawlas, Polityka (wie Anm. 84), 74 f.; Tomasz Jurek, Omagialitas alias manowstwo. Przyczynek do dziejów recepcji prawa lennego w średniowiecznej Wielkopolsce, in: Kościół, kultura, społeczeństwo. Studia $\mathrm{z}$ dziejów średniowiecza i czasów nowożytnych. Hrsg. v. Stanisław Bylina u. a. Warszawa 2000, 259-271.

98 Tomasz Jurek, Starostwo wschowskie w latach 1343-1422, in: Homines et societas. Czasy Piastów i Jagiellonów. Studia historyczne ofiarowane Antoniemu Gąsiorowskiemu w sześćdziesiatą piąta rocznicę urodzin. Hrsg. v. Tomasz Jasiński/Tomasz Jurek/Jan M. Piskorski. (Poznańskie Towarzystwo Przyjaciół Nauk, Prace Komisji Historycznej, Bd. 55.) Poznań 1997, 241-253; Chmielewski, Manowie (wie Anm. 72). 
12. Jahrhunderts verbunden. Daran knüpfte offenbar Siemowit IV. von Masowien-Płock 1390 mit dem Statut an, das unter anderem all denen das Ritterrecht aberkannte, die unter die Hoheit eines anderen Ritters getreten und hierzu an dessen Hof gezogen waren. ${ }^{99}$ In Masowien, dessen Fürsten aus der Piastendynastie König Kasimir 1351/52 gehuldigt hatten, behielten jene mit Rücksicht auf die herrschaftliche Kontinuität eine stärkere Position gegenüber ihren Untertanen, wie überhaupt die gesellschaftliche Entwicklung hier weniger fortgeschritten war. Daher haben sie bei den zahlreichen Landverleihungen im 15. Jahrhundert vielfach die Klausel ad servitia communia verwandt, der damit verbundene Status wurde damals als bona feodalia interpretiert. ${ }^{100}$ Im eigentlichen Königreich Polen war die Gestaltung und Abgrenzung des Rittertums als eines Standes weiter fortgeschritten, es bildete sozusagen - nach den Bemühungen der Herrscher, territoriale hochadlige oder kirchliche Herrschaften nicht entstehen zu lassen - den zweiten wichtigen Faktor, der die breitere Rezeption des Lehnrechts in Polen verhinderte. Im politischen Leben haben die Lücke, die sich aus dem Fehlen einer Lehnspyramide ergab, die erwähnten Wappengeschlechter ausgefullt. Sie blieben bis zum ersten Viertel des 15. Jahrhunderts von Bedeutung. Dies wiederum verursachte eine Verspätung bei der Herausbildung adliger Korporationen und ihrer Vertretungen in Form von Provinzlandtagen (sejmiki).

Der skizzierte Komplex von Faktoren, der die Rezeption des Lehnrechts in Polen verhinderte, betraf nicht das seit 1340 eroberte Halic-Volhynien. Hier gelang es einigen kleinpolnischen Magnaten, halbsouveräne Herrschaften mit eigener Verwaltung und niederem abhängigen Adel, den (Lehns-),Mannen“, zu errichten. ${ }^{101}$ Derartiger Verleihungen haben sich auch die Herrscher bedient: Władysław von Oppeln 1372-1378, und später König Władysław Jagiełło. ${ }^{102}$ Hier sind auch die im allgemeinen weniger bedeutenden Verleihungen zu

99 Item si aliqui milites sederent in aliqua villa sub aliquo milite et non esset sibi concessum de speciali amicicia seu fraternitate, et non haberent aliquam sculteciam datam vel emptam tunc milites ibidem inhabitantes non habent ius militale, sed cmetonum, quia iam cmetones appellantur tamdiu, donec ab illo non recedant. Sed cum ad sua patrimonia recesserint, tunc ius militale viceversa habebunt, sicut ante habuerunt: Iura Masoviae Terrestria. Pomniki dawnego prawa mazowieckiego ziemskiego. Hrsg. v. Jakub Sawicki. Bd. 1: 1228-1471. Warszawa 1972, Nr. 38, 56 f.

100 Stanisław Russocki, Nadania ziemi ,ad servitia communia“ a obowiązek shuzby wojskowej na Mazowszu w XV wieku, in: Miscellanea Juridica złożone w darze Karolowi Koranyiemu w czterdziestolecie pracy naukowej. Warszawa 1961, 111-119; ders., Formy władania ziemią w prawie ziemskim Mazowsza (koniec XV - połowa XVI wieku). Warszawa 1961, bes. $66 \mathrm{ff.}$. Dieser Typ von Gütern erwies sich nach der Inkorporation Masowiens 1526 als nicht beständig.

101 Janusz Kurtyka, Problem klienteli możnowładczej w Polsce późnośredniowiecznej, in: Genealogia (wie Anm. 95), 103 ff.; Włodzimierz Dworzaczek, Leliwici Tamowscy: z dziejów możnowładztwa małopolskiego: wiek XIV-XV. Warszawa 1971; Maria Stankowa, Dawny powiat szczebrzeski XIVXVIII w. Warszawa 1975; Józef Kus, Manowie jarosławscy. Z zagadnień stosunków lennych na Rusi Czerwonej (XIV-XVI w.), in: Przemyskie Zapiski Historyczne 3, 1985, 19-35.

102 Antoni Prochaska, Lenna i maństwa na Rusi i na Podolu. (Rozprawy Akademii Umiejętności, Wydzial Historyczno-Filozoficzny, Bd. 42.) Kraków 1902; Aleksy Gilewicz, Stanowisko i działalność gospodarcza Władysława Opolczyka na Rusi w latach 1372-1378, in: Prace historyczne wydane ku uczczeniu 50-lecia Akad. Koła Historyków UJK we Lwowie. Lwów 1929 (auch als Sonderdruck); 
Lehnrecht durch die polnische Kirche zu erwähnen. ${ }^{103}$ Das Lehnrecht war also im Spätmittelalter nach wie vor ein attraktives Verfassungsmuster, insbesondere fur den Großgrundbesitz ${ }^{104}$, wo es jedoch nicht genutzt werden konnte und man daher nach Ersatzlösungen gesucht hat. ${ }^{105}$ Die Betrachtung der langwierigen Konsequenzen, die die ausbleibende Rezeption des Lehnrechts in Polen nach sich zog, würde eine separate vergleichende Analyse seiner Entwicklung im Spätmittelalter erfordern. ${ }^{106}$ Sicher waren die Folgen größer, als aus den bislang vorliegenden Forschungsarbeiten hervorgeht. Die Herrscher waren verschiedener Instrumente der Herrschaftsausübung beraubt, die die spätmittelalterliche und neuzeitliche Interpretation dieses Rechtes und seine Anwendung geboten hătten.

Das Beispiel Polen zeigt, daß das Lehnswesen eine Erscheinung war, die großen Einfluß auf die Entwicklung gesellschaftlicher und staatlicher Strukturen in Europa hatte. Die Rezeption des Lehnrechts hat die Entwicklung der Landesherrschaft begleitet. Einerseits gab sie den Herrschern Machtmittel in die Hand, andererseits unterstützte sie die Verselbständigung des Großgrundbesitzes. Das so definierte Wechselspiel zwischen Herrscher und Gesellschaft erschwerte es beiden Seiten, ein Übergewicht zu gewinnen. Daß die polnischen Fürsten ihre Untertanen mit Erfolg an der Ausbildung von Landesherrschaften hinderten, unterband seinerseits die Rezeption des Lehnrechts, eine Entwicklung, die sich aufgrund der Mechanismen der adligen Ständegesellschaft schließlich gegen die Könige wenden sollte.

Laszczyńska, Ród Herburtów (wie Anm. 67), 38 ff.; vgl. auch Strzelczyk, Die Elemente (wie Anm. 26), $43 \mathrm{ff}$.

103 Fakten und Literatur finden sich zusammengestellt bei Stefan Cackowski, Wsie szlachty wasalnej w dobrach biskupstwa i kapituły chełmińskiej w XVI-XVII w., in: Zapiski Historyczne 47, 1982, $153 \mathrm{ff}$.

104 Noch in der Neuzeit waren sie von Bedeutung; vgl. Ignacy Tadeusz Baranowski, Nadania iure feudi w nowożytnej Polsce, in: Themis Polska, 2. Ser., 2, 1913, 26-46. Im 16. Jh. kämpfte der abhängige Adel auf den Gütern der Radziwiłł in Podlesien noch lange für die Verbesserung seines Status; vgl. ders., Z dziejów feudalizmu na Podlasiu. Rajgrodzko-goniądzkie „państwo“ Radziwiłłów w pierwszej połowie XVI wieku, in: Przegląd Historyczny 4, 1907, 62-74, 158-169; ders., Sprawa szlachty poddańczej w starostwie tykocińskim, in: Przegląd Historyczny 13, 1911, 248-254; Antoni Maczak, Feudalizm w pierwszej Rzeczypospolitej: wieloznaczność terminu i ewolucja zjawiska, in: Feudalizm (wie Anm. 3), 177-185; Józef Maroszek, Pogranicze Litwy i Korony w planach króla Zygmunta Augusta. Z historii dziejów realizacji myśli monarszej między Niemnem a Narwią. Białystok 2000, $63 \mathrm{ff}$.

105 Manteuffel, On Polish feudalism (wie Anm. 27); Kurtyka, Problem (wie Anm. 101), 47-140.

106 Die Bedeutung des spätmittelalterlichen Lehnrechts für die Modernisierung der Herrschaftsgrundlagen des Deutschen Ordens in Preußen und die Manipulation der Strukturen des Adels und seiner Eigentumsrechte am Boden hat aufgezeigt Marian Dygo, Feudalizm w Prusach XIII-XVI wieku, in: Feudalizm (wie Anm. 3), 143-153. 



\title{
Die „Königsfreien“ und die mittelalterliche Kolonisation
}

Von

\author{
Jan M. Piskorski
}

Der französische Historiker Marc Ferro, der 1994 die bekannte, in viele Sprachen übersetzte Histoire des colonisations veröffentlichte, stellte dort fest, daß das Phänomen der Kolonisation im alten Griechenland entstanden sei. Unter ,Kolonisation" verstand er nämlich die Besetzung fremder Territorien sowie ihre spätere Besiedlung und Beackerung. Eine solche Form von Kolonisation sollten dann die Römer fortsetzen, die die Veteranen in den eroberten Provinzen ansiedelten. Zwischen der römischen Periode und dem Zeitalter der großen geographischen Entdeckungen des 15. und 16. Jahrhunderts habe es nach Ferros Ansicht keine Kolonisationsvorgänge gegeben, und Bezeichnungen wie „Kolonisation“, ,Kolonie“ und ,Kolonist ${ }^{6}$ seien spurlos aus den historischen Quellen und den entsprechenden historischen Darstellungen verschwunden. ${ }^{1}$

Eine solche - durchaus gängige - Sichtweise kann ein Mediävist, auch ein französischer, schwerlich teilen. Aufwendige Forschungen über das Mittelalter haben nämlich gezeigt, daß auch die lange Periode zwischen dem Untergang des römischen Imperiums und der Renaissance sowohl den Landesausbau (melioratio terrae) als auch die Kolonisation kannte. ${ }^{2}$ Auch die von Ferro genannten Termini verschwanden keineswegs aus den Quellen. Es mag genügen, an die berühmte Formulierung Helmolds von Bosau aus der Mitte des 12. Jahrhunderts von der Umwandlung Westmecklenburgs (Slavorum regionis) in unam Saxonum coloniam zu erinnern. ${ }^{3}$ Von den Kolonisten und den Kolonien sprechen aber nicht nur die Quellen zur sogenannten deutschen Ostsiedlung, sondern auch - und keineswegs selten - die anderen Zeugnisse des europäischen Mittelalters. Aelfric of Eynsham hat in seinem Glossarium schon gegen Ende des 10. Jahrhunderts colonia als peregrinorum cultura erklärt, was in diesem Zusammenhang nur ,Ansiedlung von Fremden' bedeuten kann. Giraldus Cambrensis

1 Marc Ferro, Histoire des colonisations. Des conquêtes aux indépendances. $\mathrm{XIII}^{e}-\mathrm{XX}^{\complement}$ siècle. Paris 1994; ich benutze die polnische Fassung: Historia kolonizacji. Übers. v. Michał Czajka. Warszawa 1997, 11.

2 Sehr wichtig in diesem Zusammenhang: Robert Bartlett/Angus MacKay (Ed.), Medieval Frontier Societies. Korr. Aufl. Oxford 1992.

3 Helmold von Bosau, Slawenchronik. Hrsg. v. Heinz Stoob. (FSGA, Bd. 19.) 2., verb. Aufl. Darmstadt 1973, lib. II, c. 110, 382. 
machte sich an der Wende vom 12. zum 13. Jahrhundert Gedanken darüber, wie der englische Herrscher das eroberte Wales regieren könne: Nach der Vertreibung der alten Bevölkerung (veteri coloni) solle er Wales in eine Kolonie (coloniam) umwandeln. ${ }^{4}$ Ein noch schöneres Beispiel mittelalterlicher Kolonisation bildet die englische Eroberung und Besiedlung Irlands in der zweiten Hälfte des 12. Jahrhunderts, zudem ein Fall überseeischer Kolonisation. ${ }^{5} \mathrm{Zu}$ denken ist auch an die sogenannte reconquista und repoblación, also die ,Wiedergewinnung' und ,Wiederbesiedlung ${ }^{6}$ im mittelalterlichen Spanien. ${ }^{6}$ Viele charakteristische Züge von kolonialer Eroberung und Besiedlung findet man auch im Falle Livlands, wohin im 12. Jahrhundert eine kleine Zahl von deutschen Geistlichen, Rittern und Bürgern auf dem Seewege gelangte, deren Nachfahren sich unter der Masse von einheimischen Kuren, Liven, Letten und Esten bis ins 20. Jahrhundert behaupteten. ${ }^{7}$

Anders als Marc Ferro es wollte, müßte man also in die Betrachtung der Frage nach der Entstehung der Kolonien und nach der Kolonisation ganz allgemein auch das europäische

4 Giraldus, Itinerarium Kambriae et descriptio Kambriae. Ed. James F. Dimock. (Giraldi Cambrensis opera, vol. 6.) London 1868, lib. II, c. 9, 225 und Anm. 4. Für die britischen Hinweise möchte ich Herm Prof. John Gillingham danken. Zur Historiographie der englischen Kolonisation in Wales, Schottland und Irland s. demnächst den wichtigen Aufsatz von John Gillingham, The Second Tidal Wave? The Historiography of English Colonization of Ireland, Scotland and Wales in the Twelfth and Thirteenth Centuries, in: The So-Called East Colonization in the Historiography. Ed. Jan M. Piskorski. Boulder 2001 (im Druck). S. auch Rees Davies, Frontier Arrangements in Fragmented Societies: Ireland and Wales, in: Medieval Frontier Societies (wie Anm. 2), 77-100.

$5 \mathrm{Vgl}$. John A. Watt, Approaches to the history of fourteenth-century Ireland, in: A New History of Ireland. Vol. 2: Medieval Ireland. 1169-1534. Ed. Art Cosgrove. Oxford 1993, 303-313, hier 313: „Ireland became a country to which Englishmen of all levels of society, save the very highest, emigrated and settled in large numbers, expropriating the lands and towns of the indigenous population, building a new society in the image of the one they had left. It was also a society which the home government retained and maintained as a dependency, exercising firm control over the policies and personnel of the oversea administration it had established and continued to develop. Thus medieval Ireland fulfils the strictest criteria semantics can impose on the word ,colony' (...).“ S. auch Robert Bartlett, Colonial Aristocracies of the High Middle Ages, in: Medieval Frontier Societies (wie Anm. 2), 23-47; Katharine Simms, Bards and Barons: The Anglo-Irish Aristocracy and the Native Culture, in: ebd. 177-197.

6 Dietrich Claude, Die Anfänge der Wiederbesiedlung Innerspaniens, in: Die deutsche Ostsiedlung des Mittelalters als Problem der europäischen Geschichte. Hrsg. v. Walter Schlesinger. (VuF, Bd. 18.) Sigmaringen 1975, 607-656; Manuel González Jiménez, Frontier and Settlement in the Kingdom of Castile (1085-1350), in: Medieval Frontier Societies (wie Anm. 2), 49-74. Zur Historiographie der genannten Problematik demnächst John V. Tolan, Using the Middle Ages to Construct Spanish Identity: Nineteenth and Twentieth-Century Spanish Historiography of Reconquest, in: The So-Called East Colonization (wie Anm. 4).

7 Vgl. dazu Manfred Hellmann, Das Lettenland im Mittelalter. Studien zur ostbaltischen Frühzeit und lettischen Stammesgeschichte, insbesondere Lettgallens. Münster 1954; Jan M. Piskorski, Die deutsche Ostsiedlung des Mittelalters in der Entwicklung des östlichen Europa. Zum Stand der Forschung aus polnischer Sicht, in: JbGMOD 40, 1991, 27-84, hier 33 f.; Robert Bartlett, The Making of Europe. Conquest, Colonization and Cultural Change. 950-1350. Princeton 1994, 31 ff., $111 \mathrm{ff} . ;$ dt.: Die Geburt Europas aus dem Geist der Gewalt. Eroberung, Kolonisierung und kultureller Wandel von 950 bis 1350. München 1996, 46 ff., 138 ff. 
(und wohl ebenfalls das asiatische ${ }^{8}$ ) Mittelalter einbeziehen. Ich finde übrigens, daß man Ähnlichkeiten und Differenzen zwischen den alten (antiken und mittelalterlichen) und den neuzeitlichen und modernen Kolonisationsphänomenen von neuem erforschen sollte. Die zumeist vertretene Auffassung von einer großen Kluft zwischen ihnen erscheint mir nämlich etwas zu künstlich. ${ }^{9}$

Die mediävistische Forschung unterscheidet in der mittelalterlichen Geschichte unseres Kontinents zwei Besiedlungswellen. ${ }^{10}$ Die erste erfaßte im 8. und 9. Jahrhundert das karolingische Europa. Die zweite setzte im 11. Jahrhundert ein, gewann in den folgenden zwei bis drei Jahrhunderten immer mehr an Dynamik und ergriff fast den gesamten Kontinent. Es ist daher nicht verwunderlich, daß Mediävisten schon seit jeher die Wurzeln der Siedlungsrechte des Hochmittelalters in der frulhmittelalterlichen Kolonisation zu finden suchten. Dabei behielt man zwar die unterschiedlichen Ausgangspunkte beider Prozesse im Auge: Die erste hatte vor allem, wenn auch nicht ausschließlich, militårischen Charakter, sie diente der Sicherung der Außengrenzen des Staates und der Besetzung unterworfener Gebiete; die zweite wurde stärker durch wirtschaftliche Motive gespeist. Dennoch änderte dies nichts an der Ausrichtung der Forschungen, und insbesondere in der deutschen Mediävistik setzte sich die Ansicht durch, daß das sogenannte deutsche Recht des Hochmittelalters im karolingischen und damit mittelbar im römisch-byzantinischen Siedlungsrecht verwurzelt sei.

Ohne hier auf die Einzelheiten näher einzugehen, stellen wir fest, daß das spätrömische Reich aufigrund der immer schneller voranschreitenden Feudalisierung und des daraus resultierenden Verschwindens der freien Bauernschaft gegen einen empfindlichen Mangel an Soldaten zu kämpfen hatte. Um diesen Mangel zu beheben, setzte der Staat eine enorme Siedlungsaktion in Gang. Hierfür griff man auf das städtische Proletariat, das verarmte Bauerntum und die freiwillig oder als Kriegsgefangene zuströmenden „Barbaren“, vor allem Germanen, zurück. Die Kolonisten - laeti und gentiles - bewohnten getrennte Siedlungen auf staatlich zugeteiltem Boden. Ihre Hauptverpflichtung war der Militärdienst. Diese römische Politik wurde in Byzanz fortgefuhrt. Man vermutet sogar, daß Byzanz just durch den Ausbau des Militărsiedlungssystems in bislang unerreichte Dimensionen bis ins 15. Jahrhundert fortbestehen konnte. Parallel zur Ansiedlung von Soldaten und Kriegsgefangenen vollzog sich in Byzanz mit Hilfe der örtlichen Bauernschaft eine Binnenkolonisation. Das zeigt

8 Vgl. z. B. Felipe Fernández-Armesto, Millennium. A History of the Last Thousand Years. New York 1996, 36 f. und passim nach dem Register. Von der Post-Kolonisation Chinas im Mittelalter schrieb interessant Marco Polo in seinem Werk Le divisament dou Monde; ich zitiere nach der polnischen Übersetzung: Marko Polo, Opisanie świata. Übers. v. Anna Ludwika Czerny. Warszawa 1954, c. 99, 270.

9 Dazu sehr interessant, aber zugleich traditionell Jan Kieniewicz, Od ekspansji do dominacji. Próba teorii kolonializmu. Warszawa 1986, bes. 15.

10 Der zweite Teil des Aufsatzes ist eine Art von Zusammenfassung der Ergebnisse eines der Abschnitte meines Buchs: Die ländliche Kolonisation Pommerns im 13. und in den Anfängen des 14. Jahrhunderts vor dem Hintergrund der Siedlungsvorgănge im mittelalterlichen Europa; zuerst poln.: Kolonizacja wiejska Pomorza Zachodniego w XIII i w początkach XIV wieku na tle procesów osadniczych w średniowiecznej Europie. Poznañ 1990. Weil das Buch in Kürze auf Deutsch erscheint, verzichte ich hier auf ausführliche Nachweise und gebe nur die wichtigsten Titel an. 
sich im sogenannten Agrarrecht, dem nomos georgikos, einer Gesetzessammlung, die vermutlich zwischen dem 7. und 9. Jahrhundert verfiaßt wurde. In ihr ist sowohl von Rodungen als auch von der Beackerung von Brachland die Rede.

Die Traditionen der römischen Kolonisation sollen nicht nur in Byzanz, sondern auch in den germanisch-römischen Königreichen der Langobarden und Franken eine Fortsetzung gefunden haben. Dabei sind die Vorbilder angeblich aus Byzanz übernommen worden, doch sei dies in einigen Gebieten, vor allem entlang der Südalpen und in Gallien, auch ohne diese Mittlerschaft geschehen. ${ }^{11}$

Berichte über die sogenannte Militärsiedlung im Reich der Karolinger stammen von der fränkisch-arabischen Grenzregion. Zur Grenzfestigung nahmen die Karolinger westgotische Flüchtlinge auf und siedelten sie in den durch die Kriege zerstörten Grenzwüstungen an. Die Neuankömmlinge, die sogenannten aprisionarii, erhielten vom König Land zugeteilt, das sie nur innerhalb ihrer Gruppe veräußern durften. Sie bezahlten keinerlei Zins, konnten ihr Grundstück verlassen und waren zum Militärdienst, zur Bewachung der Grenze, zur Bereitstellung von Postpferden und zur Gastfreundschaft gegenüber königlichen Gesandten verpflichtet. Ihre Verpflichtungen ähnelten also denen der gesamten freien Bevölkerung.

Einen ăhnlichen Status wie die aprisionarii sollen die Arimannen im italienischen Königreich der Langobarden gehabt haben. Die ältere italienische und bald darauf die deutsche

11 S. vor allem Heinrich Dannenbauer, Adel, Burg und Herrschaft bei den Germanen. Grundlagen der deutschen Verfassungsentwicklung, in: HJb 61, 1941, 1-50; ders., Hundertschaft, Centena und Huntari, in: HJb 62-69, 1942-49, 155-219, bes. 215; ders., Die Freien im karolingischen Herr, in: Aus Verfiassungs- und Landesgeschichte. Fschr. zum 70. Geburtstag von Theodor Mayer. Bd. 1: Zur allgemeinen und Verfiassungsgeschichte. Lindau/Konstanz 1954, 49-64, hier 60; ders., Bevölkerung und Besiedlung Alemanniens in der fränkischen Zeit, in: ZWLG 13, 1954, 12-37, hier 25 ff.; Theodor Mayer, Königtum und Gemeinfreiheit im frühen Mittelalter (zuerst 1943), in: ders., Mittelalterliche Studien. Gesammelte Aufsătze. Sigmaringen 1959, 139-163, hier 153; ders., Staat und Hundertschaft in fränkischer Zeit (zuerst 1952), in: ebd. 98-138, hier 107 ff.; ders., Bemerkungen und Nachtrăge zum Problem der freien Bauern, in: ZWLG 13, 1954, 46-70, hier 50 ff., 60 ff.; ders., Vom Werden und Wesen der Landgemeinde, in: Die Anfänge der Landgemeinde und ihr Wesen. Bd. 2. (VuF, Bd. 8.) Konstanz/Stuttgart 1964, 465-495; Karl Bosl, Freiheit und Unfreiheit. Zur Entwicklung der Unterschichten in Deutschland und Frankreich wăhrend des Mittelalters (zuerst 1957), in: ders., Frühformen der Gesellschaft im mittelalterlichen Europa. Ausgewăhlte Beitrăge zu einer Strukturanalyse der mittelalterlichen Welt. München/Wien 1964, 180-203, hier 187; ders., Die alte deutsche Freiheit. Geschichtliche Grundlagen des modernen deutschen Staates (zuerst 1955), in: ebd. 204-219, hier 213; Eckhard Müller-Mertens, Karl der Große, Ludwig der Fromme und die Freien. Wer waren die Liberi homines der karolingischen Kapitularien (742/743-832)? Ein Beitrag zur Sozialgeschichte und Sozialpolitik des Frankenreiches. (Forsch. zur mittelalterlichen Geschichte, Bd. 10.) Berlin 1963, 65; Josef Joachim Menzel, Die schlesischen Lokationsurkunden des 13. Jahrhunderts. Studien zum Urkundenwesen, zur Siedlungs-, Rechts- und Wirtschaftsgeschichte einer ostdeutschen Landschaft im Mittelalter. (Quellen und Darstellungen zur schlesischen Geschichte, Bd. 19.) Würzburg 1977, 5, 20. Diese Möglichkeit wurde auch erwogen von Benedykt Zientara, Źródła i geneza „prawa niemieckiego" (ius Teutonicum) na tle ruchu osadniczego w Europie zachodniej i środkowej w XI-XII w., in: Przegląd Historyczny 69, 1978, 47-72, hier 59 mit Anm. 50; ders., Z zagadnień prawa prawa niemieckiego na Śląsku (w związku z ksiązką J. J. Menzla), in: Przegląd Historyczny 70, 1979, 331-340, hier 332. 
Forschung erkannten sie als „Produkt' der langobardischen Siedlungstätigkeit, die die römisch-byzantinische nahtlos und ohne große Veränderungen fortgesetzt habe. Die Mitglieder der langobardischen centenae hätten Parzellen auf Königsland erhalten und seien dafur zu Militärdienst und zu anderen öffentlichen Aufgaben verpflichtet gewesen. Gemäß der Theorie waren die arimannischen Grundstücke nicht allodial, sondern lediglich zum Erbgebrauch übertragen. Einige Forscher behaupten sogar, die arimannische Siedlung zeige eine besondere und angeblich der germanischen Welt eigene „freiheitliche genossenschaftliche Organisation", wie sie charakteristisch fur die Ostsiedlung sei. Dabei zögert man nicht einmal, den langobardischen sculdahis mit dem Schultheißen des Hochmittelalters zu vergleichen. Beide hätten - nach der Auffassung von Josef Joachim Menzel - ähnliche Funktionen im Rahmen der eigenen Gemeinde erfullt. ${ }^{12}$ In einigen Gebieten hätten sich diese angeblichen königlichen Militärkolonisten - vor allem dank der staufischen Begünstigung bis zum Ende des Mittelalters gehalten. Sie seien somit als „Transmissionsriemen“ zwischen den Besiedlungsrechten des antiken Rom und den Rechten der Kolonisten im 11. bis 13. Jahrhundert anzusehen. $^{13}$

Diese Theorie machte trotz ihrer Unzulänglichkeiten europäische Karriere - schufen doch die spanischen aprisionarii und die italienischen Arimannen die Grundlage für das Konzept der „Königsfreien“. Mit diesem Terminus, der zum ersten Mal wohl von Theodor Mayer gebraucht wurde, begann man nun, Militärkolonisten zu bezeichnen, die fränkische und langobardische Herrscher angeblich auf Königs-(also Staats-)land zu Erbrecht ansiedelten, wofür diese sich zu bestimmten erblichen Militärdiensten verpflichtet hätten. Die „Königsfreien" seien mithin ,Produkt" einer bewußten Politik der Herrscher gewesen, die eine nur von ihnen abhängige und zu ihren Diensten stehende Bevölkerungsschicht geschaffen hätten. Die Freiheit dieser neuen Bevölkerungsgruppe habe vor allem aus ihrer unmittelbaren Abhängigkeit vom König resultiert. Aus der Tatsache, daß die königlichen Militărkolonisten unbestelltes Land bekommen hätten, sei dann das bekannte Prinzip „Rodungsarbeit macht frei" entstanden. Diese Annahmen mündeten schließlich in die These, daß die Rodungsfreiheit, die eine derart tragende Rolle in der Entwicklung des mittelalterlichen Europas spielte, auf die „Freiheit der Heermänner“ zurückzuführen sei. ${ }^{14}$

Die Theorie der „Königsfreien“ wurde auf das ganze Gebiet des merowingisch-karolingischen Staates und damit auch auf das deutsche Altsiedelgebiet ausgedehnt. Die durch Quellen nicht zu belegende Hypothese der fränkischen Kolonisation mit Hilfe von „Königsfreien" wurde zur communis opinio eruditiorum teutonicorum, und zwar bis in die siebziger Jahre hinein. Diskutiert wurden allenfalls die quantitativen Ausmaße des Phänomens.

Fragen wir nun, ob man wirklich die Kolonisation des Hochmittelalters aus der sogenannten Militärsiedlung im römischen Imperium und in den Staaten der Franken und Langobarden abzuleiten hat. Heinrich Dannenbauer und seine Schüler zweifelten nicht daran, daß

12 Menzel, Die schlesischen Lokationsurkunden (wie Anm. 11), 17, 19 f.

13 Karl Bosl, Die Markengründungen Kaiser Heinrichs III. auf bayerisch-österreichischem Boden, in: ZBLG 14, 1943/44, 177-247, hier 199 f.; Mayer, Bemerkungen und Nachträge (wie Anm. 11), 60.

14 Mayer, Bemerkungen und Nachträge (wie Anm. 11), 55; ders., Königtum und Gemeinfreiheit (wie Anm. 11), 161. 
sich die alten fränkischen Siedler in Deutschland bis ins 12. Jahrhundert hielten und daß gerade sie jene freien Bauern waren, die ein neues Kapitel in der Geschichte Europas aufschlugen. Unmittelbar aus dem Siedlungsrecht der fränkischen Centenen und durch ihre Vermittlung aus römischen Soldaten-Gemeinden leiteten sie auch Freiheiten der Bauern und Bürger des Hochmittelalters ab. Etwas anders sah es Theodor Mayer, der auf die unterschiedlichen Ausgangspunkte der Kolonisation im Früh- und Hochmittelalter hingewiesen hat, obwohl auch er nicht daran zweifelte, daß die Geschichte der europäischen Gemeinde in den Siedlungen der römischen limitanei und der germanischen „Königsfreien“ ihren Anfang nahm. Ähnliche Ansichten vertritt auch Josef Joachim Menzel, der trotz verschiedener Vorbehalte behauptet, daß die Freiheiten und Siedlungsformen des Hochmittelalters eine Weiterentwicklung jener Prinzipien darstellen, die in der wehrhaften Grenzsiedlung auf unbewirtschaftetem Staatsland in der Frankenzeit angewandt wurden. Immerhin weist Menzel aber darauf hin, daß gewisse Parallelen zwischen früh- und hochmittelalterlichen Siedlungsrechten nicht zwingend auf unmittelbare oder mittelbare Traditionen zurückzufuhren sind, weil sie ebensogut unabhängig voneinander aufgrund ähnlicher Bedingungen entstanden sein können. ${ }^{15}$

Für die Frage nach dem möglichen Fortbestand frühmittelalterlicher Siedlungsrechte und -formen stammen die interessantesten Anmerkungen zweifelsohne von Walter Schlesinger, wenngleich er aus seinen wertvollen Beobachtungen nicht die glücklichsten Schlußfolgerungen gezogen hat. Schlesinger stellte als erster fest, daß die Dorfstruktur des 12. und 13. Jahrhunderts in den sogenannten Kolonialgebieten tatsächlich spezifisch kolonial gewesen ist, allerdings in dem Sinne, daß die den Siedlern verliehenen Rechte und Privilegien in den Herkunftsregionen der Kolonisten gänzlich unbekannt gewesen sein könnten. ${ }^{16}$ Die zuvor allgemein anerkannte Behauptung, das deutsche Siedlerrecht im Elberaum habe sich im Altsiedelgebiet herausgebildet und sei in den Osten übertragen worden ${ }^{17}$, mußte also nicht stimmen. Aus dieser Feststellung zog Schlesinger den Schluß, daß an der Entstehung der Siedlungsrechte in allen neubesiedelten Gebieten des 11. bis 13. Jahrhundert, also in den Niederlanden, in Deutschland, Frankreich und im Elbegebiet neben den Gewohnheitsrechten der Herkunftsregionen ein weiteres Recht Anteil gehabt habe. Seine Herkunft sei ungewiß,

15 Dannenbauer, Hundertschaft, Centena und Huntari (wie Anm. 11), 179 ff.; ders., Freigrafschaften und Freigerichte, in: Das Problem der Freiheit in der deutschen und schweizerischen Geschichte. Mainauvortrăge 1953. (VuF, Bd. 2.) Lindau/Konstanz 1955, 57-76, hier 61 ff.; ders., Die Freien (wie Anm. 11), 64; ders., Bevölkerung und Besiedlung Alemanniens (wie Anm. 11), 26 ff.; Edeltraud Gallmeister, Königszins und westfălisches Freigericht, in: Nassauische Annalen 65, 1954, 251-253; Mayer, Vom Werden (wie Anm. 11), 476, 479, 493; Menzel, Die schlesischen Lokationsurkunden (wie Anm. 11), 5, 15, 20. Ähnlich eigentlich auch Zientara, Źródła (wie Anm. 11), 59 f., und - etwas vorsichtiger - ders., Z zagadnieñ prawa (wie Anm. 11), 332.

16 Walter Schlesinger, Bauuerliche Gemeindebildung in den mittelelbischen Landen im Zeitalter der deutschen Ostbewegung, in: ders., Mitteldeutsche Beiträge zur deutschen Verfassungsgeschichte des Mittelalters. Göttingen 1961, 212-274, hier 270.

17 So sah es etwa Theodor Mayer, Adel und Bauern im Staat des deutschen Mittelalters, in: Adel und Bauern im deutschen Staat des Mittelalters. Hrsg. v. dems. Leipzig 1943, 1-21, hier 12. 
und $m$ an könne es am besten als Kolonistenrecht definieren. ${ }^{18}$ Anscheinend lasse es sich aber aus einem „allgemeinen Siedelrecht“ im fränkischen Reich ableiten, worauf die Privilegienung von Militärkolonisten auf Königsland hinweisen könnte. ${ }^{19}$

Die Erkenntnis, daß es so etwas wie ein ,allgemeines Kolonisationsrecht" gegeben hat, scheint das große Verdienst Schlesingers zu sein. Doch besteht wirklich die Notwendigkeit, es aus der fränkischen Epoche oder gar - wie andere meinen - aus römisch-byzantinischer Zeit abzuleiten? Ohne das Thema weiter auszufuhren, hat Heinrich Dannenbauer einmal festgestellt, daß fur die Organisation der Siedlung im Neusiedelland den Kolonisten überall und immer Versprechen gegeben werden mußten, was ihren besonderen Rechtsstatus, ihre Privilegien, erklärt. ${ }^{20}$ Henri Pirenne wiederum hat darauf hingewiesen, daß eine ähnliche Situation wie im europäischen Hochmittelalter auch im Nordamerika des 19. Jahrhunderts herrschte, als amerikanische Kolonialunternehmer entlang der Eisenbahnlinien im ,Wilden Westen' planmäßig towns gründeten und den Siedlern für deren Umsiedlung bessere Lebensbedingungen anboten. Die Geschichte der Kolonisation Amerikas bietet übrigens eine Vielzahl an Institutionen und Handlungsweisen, die denen im mittelalterlichen Europa täuschend ăhneln. ${ }^{21}$

Diese Beispiele - und man könnte sie noch mehren, und wohl nicht nur aus dem europäischen Kulturkreis, wenn auch die Forschung hier erst am Anfang steht - erlauben es, das „allgemeine Kolonisationsrecht" etwas anders zu definieren. Es besteht nämlich eine gewisse allgemeine Tendenz, eben jene zu privilegieren, an denen zu einem bestimmten Zeitpunkt ein besonderer Bedarf besteht. Siedlungstätigkeit kann in Anlehnung an die unterschiedlichsten Rechtsformen durchgefuhrt werden, etwa das deutsche Recht im Osten, das französische Recht in Spanien, das flämische und holländische Recht in Nord- und Mitteldeutschland oder auch das walachische Recht in den Karpaten. Immer aber bedarf sie eines freien Wirkungsraums, einer wirtschaftlichen und sozialen Nische, die gleichsam nach Besetzung verlangt.

Im Lichte dieser Ausfuhnungen besteht keine Notwendigkeit, die hochmittelalterliche Kolonisation auf die fränkisch-langobardische oder gar die römische zurückzuführen. Die fränkischen Siedler des 7. bis 9. Jahrhunderts wanderten nicht auf der Suche nach einem

18 Schlesinger, Băuerliche Gemeindebildung (wie Anm. 16), 261.

19 Ebd. 270; Walter Schlesinger, Die geschichtliche Stellung der mittelalterlichen deutschen Ostbewegung, in: HZ 183, 1957, 517-542, hier 521; ders., Kirchengeschichte Sachsens im Mittelalter.

Bd. 2: Das Zeitalter der deutschen Ostsiedlung. 1100-1300. (Mitteldeutsche Forschungen, Bd. 27.) Köln 1962, 3.

20 Dannenbauer, Freigrafschaften und Freigerichte (wie Anm. 15), 72.

21 Henri Pirenne, Histoire économique et sociale du moyen âge. Éd. revue et mise à jour. Paris 1963, 59. Vergleichsmaterial bietet insbesondere: Eberhard Schmitt (Hrsg.), Dokumente zur Geschichte der europäischen Expansion. Bd. 3: Der Aufbau der Kolonialreiche. Hrsg. v. Matthias Meyn. München 1987, bes. 268-455. Vgl. auch Howard Lamar/Leonard Thompson (Ed.), The Frontier in History. North America and Southern Africa Compared. New Haven 1981; Pieter C. Emmer/Magnus Mörner (Ed.), European Expansion and Migration. Essays on the Intercontinental Migration from Africa, Asia, and Europe. New York/Oxford 1992; Clyde A. Milner/Carlo O'Connor (Ed.), The Oxford History of the American West. New York/Oxford 1994. 
besseren Recht in Deutschland und Italien ein, sondern als Eroberer. Ihre Aufgabe war es, die unterworfenen Stämme unter Kontrolle zu halten. Die Lehen wurden vom König vergeben und betrafen kein bestimmtes Territorium, sondern konkrete einzelne Personen. Wenn diese das verliehene Land verließen, fiel es an den König zurück. Es handelte sich also um das durch ethnische Herkunft begründete Recht einer bestimmten Person.

Anders war die Situation während der hochmittelalterlichen Kolonisation, als das Recht ein bestimmtes Territorium umfaßte und grundsätzlich Gruppen, nicht einzelnen Siedlern verliehen wurde. Die Siedler wechselten, das Recht blieb bestehen. Das Recht wirkte damit im Gegensatz zur frühmittelalterlichen Zeit ethnisch und gesellschaftlich nivellierend. ${ }^{22}$ Von dessen Vorteilen versuchte man lediglich - und auch das nur anfänglich - die eigenen Untertanen auszuschließen.

Zwar sind auch aus der hochmittelalterlichen Kolonisation Lokationsverträge zwischen dem Grundherm und jedem einzelnen Siedler bekannt, was also nicht der charakteristischen Gründerleihe entspricht. Besonders häufig sind sie in den romanisch besiedelten Südalpen. Es besteht aber ein prinzipieller Unterschied zwischen diesen Privilegien und der fränkischen Militärsiedlung. Die aprisionarii konnten ihr Land ausschließlich innerhalb ihrer eigenen, ethnisch definierten Gruppe veräußern. Die Grundherren in den Südalpen dagegen interessierten sich nicht im geringsten furr die ethnische Herkunft ihrer Siedler. ${ }^{23}$

Den oben beschriebenen Unterschieden zwischen früh- und hochmittelalterlicher Kolonisation entspricht die Ansicht Karl Siegfried Baders, der eine Zurückfuhrung der freien Gemeindestruktur des 12. bis 14. Jahrhunderts auf die germanische Centene verwarf. ${ }^{24}$ Heute weiß man übrigens, daß das Gesamtkonzept der „königsfreien“ Arimannen, auf dem alle weiteren Ausfuhrungen fußen, eine Legende ist. Im Lichte der neueren italienischen Forschungen, besonders von Giovanni Tabacco, ist die langobardische Centene nicht mehr als eine der germanischen Welt eigene freiheitlich-gesellschaftliche Organisation zu verstehen, denn die damalige ,Demokratie‘ war ein Überbleibsel einer vergehenden Epoche und nicht eine entwicklungsträchtige Neuschöpfung. ${ }^{25}$

22 Vgl. u. a. die Urkunde Bischof Wichmanns von 1152 für Flemmingen: Herbert Helbig/Lorenz Weinrich (Hrsg.), Urkunden und erzăhlende Quellen zur deutschen Ostsiedlung im Mittelalter. T. 1: Mittel- und Norddeutschland. Ostseeküste. (FSGA, Bd. 26a.) 2., verb. Aufl. Darmstadt 1975, Nr. 5.

23 Vgl. u. a. die Urkunde des Trienter Bischofs für die Kolonisten von Costa Cartuta von 1216: Hermann Wopfner (Hrsg.), Urkunden zur deutschen Agrargeschichte. (Ausgewăhlte Urkunden zur deutschen Verfassungs- und Wirtschaftsgeschichte, Bd. 3.) Stuttgart 1928, Nr. 118.

24 Karl Siegfried Bader, Studien zur Rechtsgeschichte des mittelalterlichen Dorfes. Bd. 2: Dorfigenossenschaft und Dorfigemeinde. Köln/Graz 1962, 92.

25 S. vor allem Giovanni Tabacco, Sulla protezione politica della libertà nell'alto medioevo, in: Studi Medievali, ser. 3, 5, 1964, 723-739; ders., I liberi del re nell'Italia carolingia e postcarolingia. (Biblioteca degli Studi medievali, vol. 2.) Spoleto 1966; ders., Dai possessori dell'età carolingia agli esercitali dell'età longobarda, in: Studi Medievali, ser. 3, 10, 1969, 221-268; zusammenfassend ders., Egemoni sociali e strutture del potere nel medioevo Italiano. Torino 1974, $15 \mathrm{ff}$.; ders., La storia politica e sociale, in: Storia d'Italia. Vol. 2: Dalla caduta dell'Impero romano al secolo XVIII. T. 1. Torino 1974, 5-274, bes. 56-72. Ebenso kritisch: Jörg Jarnut, Beobachtungen zu den langobardischen arimanni und exercitales, in: ZRG GA 88, 1971, 1-28, hier 21 ff.; Hans Kurt Schulze, Rodungsfreiheit 
Es ist an der Zeit, den Einfluß der Königsfreientheorie, deren Entstehung zweifelsohne in die Zeit der wachsenden Staatsmacht in der dreißiger Jahre des 20. Jahrhunderts zurückreicht, auf die gegenwärtige deutsche Mediävistik zu erforschen. Dies könnte dazu beitragen, manche ihrer Merkwürdigkeiten von deren Genese her zu verstehen.

und Königsfreiheit. $\mathrm{Zu}$ Genesis und Kritik neuer verfassungsgeschichtlicher Theorien, in: HZ 219, 1974, 529-550, hier 538; Karol Modzelewski, La transizione dall'antichità al feudalesimo, in: Storia d'Italia. Annali I: Dal feudalesimo al capitalismo. Torino 1978 (= Giulio Einaudi), 3-109, hier 30-64; ders., Społeczeñstwo i gospodarka, in: Italia. Prace zbiorowa. Hrsg. v. Eleonora Tabaczyñska. (Kultura Europy wczesnośredniowiecznej, Bd. 10.) Wrocław 1980, 149-257, passim. Zu den Historikern, die kritisch gegenüber der Konigsfreientheorie waren, sind u. a. der Schweizer Fritz Wernli, der Franzose Georges Duby und der Belgier François Louis Ganshof zu zăhlen. 



\title{
Partikularsynoden und Synodalstatuten des späteren Mittelalters im europäischen Vergleich
}

\author{
Vorüberlegungen zu einem möglichen Projekt
}

Von

\author{
Johannes Helmrath
}

Die Christianisierung bildet geistig wie institutionell einen der dominant einheitsstiftenden Faktoren der europäischen Geschichte. ${ }^{1}$ Der Missionierungs- und Akkulturationsprozeß zog sich von der Spätantike bis ins 14. (Litauen) und 15. Jahrhundert (Granada) hin. Diese Phasenverschiebung hatte erhebliche Entwicklungsunterschiede zur Folge, insbesondere ein Nachziehen Nord- und Osteuropas sowie von großen Teilen des in der Reconquista rechristianisierten Spaniens. Die expansive Römerin Ecclesia wirkte als Organisatorin und Gleichmacherin. Denn mit der Christianisierung einher ging das räumliche ,Encadrement ${ }^{2}$ Europas durch das Netz von Provinzen, die oft noch antiken Circumscriptionen folgten, von Diözesen und Pfarreien. Insofern entstand in der Differenzierung zugleich etwas elementar Gemeinsames zwischen Schweden und Spanien, Schottland und Ungarn.

Die kirchliche Raumordnung war eine neben anderen Raumordnungen, etwa den politisch-nationalen. Aber sie erwies sich als eine dauerhafte, sozusagen als eine Ordnung der longue durée. Trotz mancher Veränderungen ihrer Sprengel war sie auf lange Sicht stabiler als die Grenzen vieler, sich agonal verändernder, weltlicher Herrschaften. ${ }^{3}$ Politische und

Abkürzungen: DS = Diözesansynode(n); PS = Provinzialsynode(n).

1 Zuletzt Richard Fletcher, The Conversion of Europe. From Paganism to Christianity. 371-1386 AD. London 1997.

2 Zu Begriff und Sache - hier aber mehr im spirituellen Sinn: Vgl. L'encadrement religieux des fidèles au Moyen Âge et jusq'au Concile de Trente. (Actes du $109^{\complement}$ Congrès national des Sociétés Savantes Dijon 1984. Section d'histoire médiévale et de philologie, vol. 1.) Paris 1985.

3 Erst kürzlich wurde einmal gewagt, dieses Probemfeld systematisch und zusammenfassend anzugehen. Insofern öffnet neue Perspektiven Hans-Joachim Schmidt, Kirche - Staat - Nation. Raumgliederung der Kirche im mittelalterlichen Europa. (Forsch. zur mittelalterlichen Geschichte, Bd. 37.) Weimar 1999; zur Veränderung der Diözesansprengel ebd. 176-228, zur Bedeutung des IV. Lateranum für die kirchliche 
kirchliche Raumgliederungen verliefen nur fallweise kongruent, wenngleich es im Mittelalter an Versuchen nicht fehlte, die kirchliche Einteilung dem politischen Herrschaftsgebiet anzupassen, ein Faktor, der auch fur die Geschichte der Synoden nicht zu unterschătzen ist. In vieler Hinsicht analoge Phänomene bildeten die großen Orden aus. Auch hier finden sich die konsequente Raumerfassung der Provinzen und die abgestuften Einzugsbereiche der zentralen Generalkapitel und der regionalen Provinzialkapitel. ${ }^{4} \mathrm{Da}$ unser Thema notgedrungen erfordert, den engeren Europabegriff, des lateinisch-papstchristlichen Europas, zu verwenden, sei vorweg ausdrücklich festgestellt. ${ }^{5}$

Seit dem 3. Jahrhundert kennen die Bischöfe den Versammlungstyp Synode als kollegiales Element der kirchlichen Verfassung. Seit dem Nikaenum 325 war ihre regelmäßige Abhaltung kirchenrechtlich vorgeschrieben. Die Gesamtzahl aller Synoden ist unbekannt, auch die Anzahl der quellenmäßig belegbaren nur partiell geklärt. ${ }^{6}$ Die synodale Schriftproduktion, kirchliches Partikularrecht in Gestalt von Statuten, wird als Quelle furr vergleichende Studien noch unterschätzt. Für das zu skizzierende Forschungsprojekt stellen die Statuten daher die Basisquellen dar. Sinn des folgenden Beitrags kann nur sein, das Vorfeld für ein praktikables Konzept zu sondieren, indem er Sachverhalte klärt, Probleme aufweist und - auch ungeschützt - Fragen stellt.

Die Hypothese: Eines der Ziele vergleichender Geschichtsbetrachtung könnte sein, ein Profil der europäischen Kirche(n) des Spätmittelalters zu erstellen, ihrer Einheitlichkeit wie ihrer regionalen und nationalen Unterschiede. ${ }^{7}$ Der gewaltige Fundus der Synodalstatuten

Raumordnung 104-130, zu den Synoden 89-99, 114-116, 130-164 (PS), 261-264. Unter der päpstlichen ,Zentralperspektive', d. h. auf der quantitativen Basis der schriftlichen Kurienkontakte der einzelnen europäischen Länder und Diözesen im späteren 15. und fruhen 16. Jh., künftig grundlegend die Habilitationsschrift von Götz Rüdiger Tewes, Die römische Kurie und die europäischen Länder am Vorabend der Reformation. (Bibliothek des DHI in Rom, Bd. 95.) Tübingen 2001. Vgl. auch Erich Meuthen, Reiche, Kirchen und Kurie im spăteren Mittelalter, in: HZ 265, 1997, 597-637.

4 In der Erörterung der politischen Verschiebung kirchlicher Răume sehe ich eine besondere Bedeutung des Buchs von Schmidt, Kirche - Staat - Nation (wie Anm. 3), bes. 120-228, für unser Thema. Zu den Orden vgl. ebd. 333-439.

5 Einem Vergleich von Synoden etwa der orthodoxen und der katholischen Kirche stünde prinzipiell natürlich nichts im Wege.

6 Die einzige Gesamtübersicht bringt Pietro Palazzini (Ed.), Dizionario dei concili. 6 vol. Rom 1963-68, bes. vol. 6, 336-377 (Index). Das Werk ist aber äußerst unvollständig, terminologisch unscharf und schöpft nur aus ausgewăhltem gedruckten Material. Eine Neubearbeitung wird von Walter Brandmüller und Johannes Grohe vorbereitet. Zur Auswertung des Index s. unten bei Anm. 47. - Hilfreich auch Repertorium Fontium Historiae Medii Aevi [RepFont]. Vol. 3. Rom 1970, 557-603.

7 Ansätze in Gestalt nebeneinandergestellter Länderartikel finden sich in den Handbüchern durchaus, etwa in: Histoire de l'Église des origines jusqu'à nos jours. Fondée par Augustin Fliche et Victor Martin. Vol. 14, 2: Etienne Delaruelle/Edmond-Rene Labande/Paul Ourliac (Ed.), L'Église au temps du Grand Schisme et de la crise conciliaire (1378-1449). Paris 1962, 315-447 („L'Église en Angleterre“, „L'Église en Allemagne“ etc.), und in: Histoire du christianisme des origines à nos jours. Vol. 6: Un temps d'épreuves (1274-1449). Ed. Michel Mollat du Jourdin/André Vauchez. Paris 1990 (dt.: Die Geschichte des Christentums. Religion - Politik - Kultur, Bd. 6: Die Zeit der Zerreissproben [12741449]. Freiburg/Basel/Wien 1991, 567-811); vol. 7: De la réforme à la Réformation (1450-1530). Ed. Marc Vernard. Paris 1994 (dt.: Von der Reform zur Reformation [1450-1530]. Freiburg/Basel/Wien 
bietet für den historischen Vergleich ein ausgezeichnetes Material! Es ist aber in diesem Sinne bisher zu wenig genutzt worden. Die folgenden Überlegungen enthalten viel Selbstverständliches; doch erscheint es uns innerhalb dieses Bandes im Sinne der angestrebten komparatistischen Methodenreflexion gerechtfertigt, sie wenigstens $\mathrm{zu}$ formulieren. Synodalstatuten und deren Sammlungen im späteren Mittelalter bilden ein europaweit in mehr oder weniger großer Dichte anzutreffendes Materialsubstrat, dem hinreichend große inhaltliche und formale Homogenităt unterstellt werden kann. Wie bei jedem vergleichenden Ansatz bedingt auch hier die Materialbasis Art und Methode des Vergleichs. Da diese hier aus wesentlich homologen, nicht analogen oder bloß konvergenten Elementen besteht, bietet sie auf der einen Seite dem Vergleich beste Voraussetzungen, bis hin ins Statistische. Auf der anderen Seite erfordert gerade diese Homogenität vorbereitende Überlegungen und Maßnahmen, um das Material für den Vergleich überhaupt handhabbar zu machen; denn man kann bekanntlich nichts mit sich selbst vergleichen. Es ist also Profilierung, Strukturierung in Entitäten gefordert, damit es überhaupt zur Separation von zu Vergleichendem aus dem Ensemble der Statuten kommt. Dies bildet wiederum die Voraussetzung dafur, daß jeweils das unverzichtbare Tertium comparationis relational angelegt werden kann. Die Vorstellung einer zunächst amorphen, profillosen Masse von Statuten, die gleichsam aus der Vogelschau betrachtet werden, ist selbstverständlich Fiktion, aber eine methodisch legitime. ${ }^{8}$

Zunächst sollte zwischen einem quantitativen Zugang, einer bloßen vergleichenden Frequenzstatistik der Partikularsynoden, und einem qualitativen, der die Materien der Statuten untersucht, unterschieden werden. Für den vergleichenden Zugang bieten sich folgende Profilienungen des Statutenmaterials an: a) von räumlichen Untereinheiten, entweder nach den statuteneigenen, also dem internen kirchlichen Encadrement selbst (Diözesen, Metropolitanverbände etc.), oder nach primär nichtkirchlichen Einheiten: Staaten, Länder, Regionen. Der traditionelle Ländervergleich dürfte auch hier das meiste Interesse finden; b) zeitliche Profilierung in synchronen Längsschnitten, etwa nach Art: Synoden europaweit um 1100, Synoden um 1400 bzw. Materien um 1200, Materien um 1500; c) folgerichtig eine Kombination von räumlicher und zeitlicher Profilierung: Synoden in Spanien 1300-1350, 14001450, oder Synoden in der Kirchenprovinz Reims $1200-1500$ etc. Für den Historiker am weitaus fruchtbarsten wird die Analyse der diachronen Entwicklung einzelner Statutenmaterien wie zum Beispiel Heiligenfeste, Exkommunikation, Klerusbildung oder Beginenwesen, gesamteuropäisch und im Ländervergleich sein. Um das Besondere zu gewichten, muß man das Ganze kennen. Am Anfang müßte eine Gesamterfassung aller Synodalstatuten ,zwischen Linköping und Lissabon' per Computer stehen, zunächst auf der Basis der Drucke, beginnend mit Mansi. ${ }^{9}$ Dies ist derzeit noch eine hybride Vorstellung, allein schon angesichts der Quantitäten. Ehe an eine statistische Erfassung der Einzelkanones gedacht werden kann, sind verschiedene Sachverhalte und Probleme ins Auge zu fassen, die

1994, 305-438); dies war noch nicht, zumindest nicht für das Mittelalter, in dem klassischen, von Hubert Jedin herausgegebenen „Handbuch der Kirchengeschichte“ (1962 ff.) der Fall.

8 Zur Problematik s. unten bei Anm. 47.

9 Die technisch-methodischen Modalităten (Synodenstatistik, Problem von Art und Umfang der Statutentexterfassung etc.) bedürfen einer eigenen Untersuchung. 
das eigentümliche Feld der Synodalstatuten und ihrer langen Forschungsgeschichte betreffen:

Forschungen uber Partikularsynoden in Europa existieren im Bereich der Kanonistik in nicht geringer, im Bereich der lokalen Kirchenhistorie sogar in großer Zahl. Die ,Bibliographia synodorum particularium' von Jakub Sawicki enthielt schon 1967 rund 3400 Titel. $^{10}$ Gemeinsam ist aber fast allen Einzelstudien, daß sie gerade nicht vergleichend vorgingen! Den weitesten Überblick und zugleich erstes Zahlenmaterial gewinnt man nach wie vor mit Hilfe der drei Monumentalwerke von Hinschius, Hefele-Leclercq und - fur Deutschland Hauck. ${ }^{11}$ Ihnen tritt eine beachtliche Reihe mehr systematischer Arbeiten ${ }^{12}$ und wichtiger

10 Jakub Th. Sawicki, Bibliographia synodorum particularium. (Monumenta Iuris canonici [MIC], Ser. C: Subsidia, vol. 2.) Città del Vaticano 1967. - Nachtrăge in: Traditio 24, 1968, 508-511; 25, 1970, 470-478; Bulletin of Medieval Canon Law N. S. 2, 1972, 91-100; 4, 1974, 87-92; 6, 1976, 95-100. Lauf ende Bibliographien im Annuarium Historiae Conciliorum [AHC], 1969 ff. - Den unzureichenden Forschungsstand betont Michael Borgolte, Die mittelalterliche Kirche. (EdG, Bd. 17.) München 1992, 94.

11 Paul Hinschius, Das Kirchenrecht der Katholiken und Protestanten in Deutschland. System des katholischen Kirchenrechts mit besonderer Rücksicht auf Deutschland. Bd. 3. Berlin 1883, ND Graz 1959, 473-508, 582-603; s. auch Hans Erich Feine, Kirchliche Rechtsgeschichte. Die katholische Kirche. 5. Aufl. Köln/Wien 1972, 119 f., 365 (PS), 375 f. (DS); Charles J. Hefele, Histoire des conciles d'après les documents originaux. Nouvelle traduction française fondée sur la $2^{\text {tne }}$ édition allemande, corrigée et augmentée par Dom H. Leclercq. Vol. 5-8. Paris 1912-1921, ND 1973; Albert Hauck, Kirchengeschichte Deutschlands. 5 Bde. Leipzig 1897-1920, ND 8. Aufl. Berlin/Leipzig 1954; Bd. 3, 215-218, 244-248, 732-735; Bd. 4, 6-10 mit Anm. 7; Bd. 5, 132-150 (PS), 166-181 (DS), mit unverzichtbaren Listen.

12 Silvio C. Bonicelli, I concili particolari da Graziano al concilio di Trento. (Pubblicazioni del Pontificio Seminario Lombardo in Roma. Ricerche di Scienze Teologiche, vol. 8.) Brescia 1971; Jean Gaudemet, Le gouvernement de l'Église à l'époque classique. II ${ }^{e}$ partie: Le gouvernement local. (Histoire du Droit et des Institutions de l'Église en Occident, vol. 8, 2.) Paris 1979, 27 f.. (PS), 173-180, 176 f. Literatur (DS), 205-215 (PS); Bernard Guillemain, L'exercise du pouvoir épiscopal à la fin du moyen âge, in: Colloque de Strasbourg 1983 sur l'institution et les pouvoirs dans les églises de l'antiquité à nos jours. Ed. Bernard Vogler. (Miscellanea Historiae Ecclesiasticae, vol. 8.) Brüssel/Löwen 1987, 101-132, hier 102-105; Hermann Josef Sieben, Die Partikularsynode. Studien zur Geschichte der Konzilsidee. Frankfurt a. M. 1990, bes. 80-83; Ernesto Capellini/Gian Giacomo Sarzi Sarpody, Il sinodo diocesano. Storia, normativa, esperienza. Cinisello Balzamo 1994; Schmidt, Kirche - Staat - Nation (wie Anm. 3), 120-164 (wichtig). - Über den Titel hinaus auch zum Synodalwesen instruktiv: Göran Inger, Das kirchliche Visitationsinstitut im mittelalterlichen Schweden. (Bibliotheca Theologiae Practicae, vol. 11.) Lund 1961, 100-105, 355-375 (PS), 131-133, 487-495 (DS). Ferner: James A. Coriden, The diocesan synod, an instrument of renewal for the local church, in: The Jurist 34, 1974, 68-93; Raymonde Foreville, Royaumes, métroplitains et conciles provinciaux. France, Grande-Bretagne, Péninsule ibérique, in: Le istituzioni ecclesiastiche della ,Societas christiana' dei secoli XI-XII. Papato, cardinalato ed episcopato. Atti della V settimana internazionale di studio, Mendola 1971. (Miscellanea del Centro di Studi medioevali, vol. 7.) Mailand 1974, 272-313, bes. 274-277; Josef Leinweber, Provinzialsynode und Reform im Spätmittelalter, in: Reformatio Ecclesiae. Festgabe Erwin Iserloh. Hrsg. v. Remigius Bäumer. Paderborn 1980, 113-128; Peter Johanek, Vescovo, clero e laici in Germania prima della Riforma, in: Strutture ecclesiastiche in Italia e in Germania prima della Riforma. Ed. Paolo Prodi/Peter Johanek. (Annali dell'Istituto storico italo-germanico, Quaderno 16.) Bologna 
Regionalstudien ${ }^{13}$ an die Seite, wobei von letzteren diejenigen von Binz ${ }^{14}$ und Wiegand ${ }^{15}$ modellhaft zu nennen sind.

Ein erstes Problem stellt sich schon bei der Klassifikation. Synode ist nicht gleich Synode. In vorgratianischer Zeit, in den Germanenreichen und ihren Nachfolgestaaten, ist Pluralismus, auch Unschärfe der Synodentypen zu konstatieren, was ihren Einzugsbereich und die Überschneidung mit weltlichen Versammlungen betrifft. ${ }^{16}$ Erinnert sei an Synodal-

1984, 87-134, hier 111-117; Joseph Avril, L'évolution du synode diocésain, principalement dans la France du Nord, du $\mathrm{X}^{\mathrm{e}}$ au XIIIr siècle, in: Proceedings of the Seventh International Congress of Medieval Canon Law, Cambridge 1984. (MIC, Ser. C: Subsidia, vol. 8.) Città del Vaticano 1988, 305-325; dasselbe ausführlicher in: ders., Naissance et évolution des législations synodales dans les diocèses du Nord et de l'Ouest de la France (1200-1250), in: ZRG KA 72, 1986, 152-249; Antonio García y Garcia, Asambleas episcopales, in: Proceedings of the Ninth International Congress of Medieval Canon law, Munich 1992. (MIC, Ser. C: Subsidia, vol. 10.) Città del Vaticano 1997, 287-304; Michel Rubellin, Les statuts synodaux, in: Comprendre le XIIIr siècle. Études offiertes à Marie-Thérèse Lorcin. Dir. Pierre Guichard/Danièle Alexandre-Bidon, Lyon 1995, 121-132 (instruktiv), s. vor allem ebd. 129-131 „quelques pistes d'exploitation“. - Hervorzuheben ist die von Walter Brandmüller herausgegebene, auf 75 Bände geplante Reihe „Konziliengeschichte“, von der einige Bănde auch die Partikularsynoden auf nationaler Ebene behandeln, bislang aber fast nur für das Früh- und Hochmittelalter.

13 Otto E. Kehrberger, Provinzial- und Synodalstatuten des Spätmittelalters. Eine quellenkritische Untersuchung der Mainzer Provinzialgesetze des 14. und 15. Jahrhunderts und der Synodalstatuten der Diözesen Bamberg, Eichstătt und Konstanz. Diss. phil. Tübingen. Stuttgart 1938, mit zahlreichen Texten; Josef Leinweber, Die Provinzialsynoden in Frankreich vom Konzil von Vienne bis zum Tridentinum. Habil. Augsburg 1975 (masch.) [vorhanden im Nachlaß Leinweber, Bibliothek des bischöfl. Priesterseminars Fulda]. Leider ungedruckt blieb die Würzburger Habilitationsschrift von Peter Johanek, Synodalia. Untersuchungen zur Statutengesetzgebung in den Kirchenprovinzen Mainz und Salzburg wăhrend des Spătmittelalters. 3 Bde. 1978/79 (masch.). Jüngst für Bayern Franz Machilek, Die bischöfliche Reformtătigkeit, die Diözesansynoden, in: Handbuch der Bayerischen Kirchengeschichte. Bd. 1. Hrsg. v. Walter Brandmüller. St. Ottilien 1999, 466-484. Zu konsultieren sind ferner die einzelnen Diözesangeschichten. Weitere Literatur zu Ländern und Diözesen in Anm. 35-44.

14 Louis Binz, Vie religieuse et réforme ecclésiastique dans le diocèse de Genève pendant le Grand Schisme et de la crise conciliaire (1378-1450). (Mémoires et documents publiés par la Société d'histoire et d'archéologie de Genève, vol. 46.) Genf 1973, zu den Synoden 143-176; ebd. 174-176: Inhalt der Statuten von 1394 und 1431.

15 Peter Wiegand, Diözesansynoden und bischöfliche Statutengesetzgebung im Bistum Kammin. Zur Entwicklung des partikularen Kirchenrechts im spätmittelalterlichen Deutschland. (Veröff. der Hist. Kommission für Pommern, Rh. 5: Forsch. zur pommerschen Gesch., Bd. 32.) Köln/Weimar/Wien 1998, 245-324: Statuten-Edition mit Konkordanztabellen, 325-336: Liste der Synoden und Statuten furr die Diözesen der Provinzen Bremen und Magdeburg; s. dazu unten bei Anm. 65. Vgl. Peter Wiegand, Die synodale Statutengesetzgebung im spätmittelalterlichen Bistum Kammin und ihre ălteste Überlieferung, in: Schriftkultur und Landesgeschichte. Studien zum südlichen Ostseeraum vom 12. bis zum 16. Jahrhundert. Hrsg. v. Matthias Thumser. (Mitteldeutsche Forsch., Bd. 115.) Köln/Weimar 1997, 109-154.

16 Zuletzt Wilfried Hartmann, Die Konzilien in der vorgratianischen Zeit des Kirchenrechts, in: Proceedings of the Ninth International Congress of Medieval Canon law, Munich 1992. (MIC, Ser. C: Subsidia, vol. 10.) Città del Vaticano 1997, 259-286. - García y García, Asambleas episcopales (wie Anm. 12), 289-293, hebt verschiedene Formen bischöflich geleiteter Versammlungen „sin categoria de concilios“ hervor. Zu nennen wăren auch die Domherren-Generalkapitel, die eigene Statuten produzierten. Beispiel Hildesheim: Johannes Maring, Diözesansynoden und Domherm-Generalkapitel des Stifts Hildes- 
formen, deren Teilnehmerprofil über die Erzdiözese hinausging, etwa Reichs(teil)synoden, Nationalkonzile, sowie an die päpstlichen Reformsynoden des 11 . bis 12 . Jahrhunderts. ${ }^{17}$ Es empfiehlt sich daher, den Untersuchungszeitraum des Projekts auf ca. 1200 bis ca. $1550 \mathrm{zu}$ begrenzen, also grob die Zeit zwischen dem IV. Laterankonzil und dem Tridentinum; denn erst fur diesen Zeitraum ist in der Regel eine eindeutige Differenzierung der beiden Grundtypen partikularer Synoden und ihre instanzenähnlich hierarchische Koppelung möglich ${ }^{18}$ : der Provinzialsynoden (PS) und der Diözesansynoden (DS). Zwischen beiden ist prinzipiell zu unterscheiden, auch wenn in der Literatur, gelegentlich auch im folgenden, oft pauschal von ,Synoden' gesprochen wird.

Provinzialsynode (-konzil) ist die Versammlung der Suffraganbischöfe, auch der Äbte, Pröpste und Domkapitel, einer Kirchenprovinz unter Leitung des Metropoliten. Thre Berufung gehörte zu dessen insgesamt geringen Metropolitanrechten. Ihr diözesanübergreifendes Zustandekommen bedurfte nicht zuletzt günstiger politischer Bedingungen und setzte neben der Duldung des Monarchen ein Mindestmaß an kollegialem Einvernehmen unter den weitgehend souveränen Bischöfen voraus. Der kirchenrechtlich vorgeschriebene Turnus schwankte im Laufe der Geschichte. Das Nikaenum etwa hatte eine Synode zweimal im Jahr, das IV. Lateranum einen jährlichen, die Konzilien von Basel und Trient einen mindestens dreijăhrigen Turnus eingeschärft. ${ }^{19}$

Diözesansynode ist die Versammlung des Diözesanklerus (Domkapitel, Kapitel, Äbte, Archidiakon, Dekane, Priester) unter Leitung des Bischofs. Die Entstehung hing eng mit derjenigen des Pfarmetzes auf dem Land zusammen.$^{20} \mathrm{Ihr}$ Charakter war nicht kollegial, sondern es handelte sich neben der Visitation um eines der Kontroll- und Disziplinarinstrumente des Bischofs, die Binz treffend als ,moyens d'action“21 bezeichnet hat. Ihre Funktionen waren vielfältig: kirchlicher Gerichtshof, Informations- und Interrogationsforum des Bischofs, Instrument der Lehr- und Sittenaufsicht über den Diözesanklerus ${ }^{22}$ sowie - bisher unterschätzt - seiner fiskalischen Inanspruchnahme, schließlich Forum lokalkirchlicher

heim bis zum Anfiang des XVII. Jahrhunderts. (Quellen und Darstellungen zur Geschichte Niedersachsens, Bd. 20.) Hannover/Leipzig 1905, 81-124.

17 Johannes Laudage, Ritual und Recht auf päpstlichen Reformkonzilien (1040-1123), in: AHC 29, 1997, 287-334 (Literatur; auch generell zum Zeremoniell von Synoden).

18 Nicht zuletzt unter dem Einfluß des Dekrets Sicut olim (c. 6) des IV. Lateranum; Conciliorum Oecumenicorum Decreta (COD). Cur. Josephus Alberigo u. a. 3. Aufl. Bologna 1973, 236 f.

19 Lateranum IV: Metropolitani singulis annis cum suis suffraganeis provincialia non omittant concilia celebrare; ebd. 236 Z. 26 f. - Basler Konzil: Celebretur quoque in singulis provinciis (...) ad minus semel de triennio in triennium provinciale concilium; ebd. $474 \mathrm{Z}$. 19-21.

20 Ob Auxerre 585 die „erste bekannte Diözesansynode“ war und ihre 45 Kanones mithin die ersten Diözesanstatuten darstellen, ist unsicher; Hermann Josef Sieben, Art. Synodalstatuten, in: LMA. Bd. 8. München/Zürich 1997, Sp. 374 f.

21 Binz, Vie religieuse (wie Anm. 14), 143, 177.

22 Dafür klassisch die arengale Formulierung de corrigendis excessibus et moribus reformandis praesertim in clero, so PS Magdeburg 1313; Ioannes Dominicus Mansi (Ed.), Sacrorum Conciliorum nova et amplissima Collectio. 35 vol. Florenz 1759-1798, ND und Erweiterung bis zum I. Vaticanum. Ed. Ludovicus Petit/Joannes Baptista Martin. 53 vol. Paris/Leipzig 1903-1927 [vol. 48-53: Amhem/Leipzig]; hier vol. 25 (1903), 523. 
Gesetzespromulgation. ${ }^{23}$ Die kanonischen Bestimmungen zum Turmus schwankten hier zwischen einem mindestens jährlichen Turnus, wie ihn das IV. Lateranum und wieder das Basler Konzil festlegten ${ }^{24}$, und dem älteren, in der Praxis durchaus verbreiteten, halbjährlichen.

Mit dem 12. Jahrhundert, deutlich dann seit dem IV. Lateranum, wird ein bedeutsamer Wandel bei den Partikularsynoden konstatiert. Im Zuge einer allgemeinen Klerikalisierung der Kirche trat auch in den Synoden das Laienelement fast ganz zurück, ebenso die alte Funktion des Gerichtshofs, die zum Teil von neuen Behörden wie Offizialat und Generalvikariat übernommen wurde. ${ }^{25}$ Es handelte sich jetzt um mehr oder weniger reine Klerusversammlungen, die sich auf die Verbessenung kirchlicher Mißstände sowie auf Kontrolle und Instruierung des Klerus konzentrierten. Als Hauptaufgabe kristallisierte sich jetzt noch stärker die Gesetzgebung heraus, vornehmlich durch Publikation von zentralem Kirchenrecht, des Decretum Gratiani, päpstlicher Dekretalen und vor allem der 71 wahrhaft europaprägenden Dekrete des IV. Lateranum selbst. ${ }^{26}$ Die Phasen intensiver Implementierung nach

23 Inwieweit das Gesetzgebungsrecht des Bischofs wesentlich an die Institution Synode, zumindest als Publikationsforum, gebunden ist oder ob ,autogene ${ }^{6}$ bischöfliche Statutengesetzgebung auch synodenunabhängig stattfinden konnte, erscheint als eine Frage mit Klärungsbedarf. Würde man die Koppelung von Statutenüberlieferung an die Existenz einer Synode in Frage stellen, hătte dies auch weitreichende Folgen für Erstellung und Bewertung der Synodenlisten.

24 Lateranum IV: In episcopalibus synodis, annuatim per singulas dioeceses celebrandis; COD (wie Anm. 18), 236 Z.38 - 237 Z.1. - Basler Konzil: Praecipit synodum episcopalem in qualibet dioecesi ... ad minus semel in anno, ubi non est consuetudo bis, annuatim celebrari per dioecesanum; ebd. 473 Z. 10-12. Die DS von Auxerre (s. oben Anm. 14) schrieb die jahreszeitliche Zweitaktigkeit der DS vor (wie sie für die frănkischen Heeres- und Gerichtsversammlungen bekannt ist): Ut in medio Maio omnes presbyteri ad synodum in civitatem veniant et Kal. Novembris omnes abbates ad concilium conveniant; MGH LL, Concilia 1, 180 c. 7. Vgl. Hinschius, Das Kirchenrecht (wie Anm. 11), 583 f.. - Bei Vernachlässung der DS konnten auch PS deren regelmäßige Abhaltung einschärfen, so die PS Tarragona 1329: reperimus aliquos episcopos nostrae provinciae negligentes ... precipimus ut singulis annis per se vel per idoneos viros ... dicta concilia synodalia habeant celebrare; Mansi, Sacrorum Conciliorum nova et amplissima Collectio (wie Anm. 22), vol. 25, 869.

25 Avril, L'évolution (wie Anm. 12), 325, sieht als Folge davon an, daß die DS „risquait (...) de se scléroser“, um ganz gegenüber der zusehends zentralisierten bischöflichen Bürokratie zurückzutreten. Möglicherweise ein Grund für sinkende Frequenz im 14. Jh.? S. aber Beispiele für anhaltende Gerichtsfunktion bei Hinschius, Das Kirchenrecht (wie Anm. 11), 592 Anm. 4, und für Schweden im spăten Mittelalter Inger, Das kirchliche Visitationsinstitut (wie Anm. 12), 493-495. Systematische Studien fehlen.

26 C. 6: et quae statuerint (sc. auf der PS), faciant observari, publicantes ea in episcopalibus synodis annuatim (...) celebrandis; COD (wie Anm. 18), 236 Z. 38 - 237 Z. 1. Vgl. aber schon c. 7 des XVI. Toletanums (693): Publikation auf DS sechs Monate nach PS oder Nationalsynode. - Raymonde Foreville, La réception des conciles généraux dans l'Église et la province de Rouen, in: Droit privé et institutions régionales. Études historiques offertes à Jean Yver. Paris 1976, 243-253; Antonio García y García, Primeros reflejos del concilio IV Lateranense en Castilla, in: Studia historico-ecclesiastica. Festgabe für Prof. Luchesius Georg Spătling OFM. Hrsg v. Isaac Vazquez OFM. Rom 1977, 249-282; Paul B. Pixton, Watchmen of the tower. The German episcopacy and the implementation of the decrees of the Fourth Lateran Council 1216-1274, in: Proceedings of the Sixth International Congress of 
dem IV. Lateranum und nach dem Viennense (1311) ebbten jedoch ab; die zentrale Rechtskodifikation endete weitestgehend mit dem Liber Sextus (1298) und den schon recht schlanken Clementinen und Extravaganten. ${ }^{27}$ Die Statuten der Partikularsynoden ${ }^{28}$ ersetzten und ergänzten bzw. ,regionalisierten' in gewisser Hinsicht subsidiär die Zentralgesetzgebung des Corpus juris. Die seit dem 13. Jahrhundert angelegten Sammlungen von Synodalstatuten

Medieval Canon Law, Berkeley 1980. (MIC, Ser. C: Subsidia, vol. 7.) Città del Vaticano 1985, 579-593, 581 f.: Synodenliste. Vgl. Louis Boisset, Les conciles provinciaux français et la réception des décrets du $\Pi^{\mathrm{e}}$ Concile de Lyon (1274), in: Revue d'histoire de l'Église de France 69, 1983, 29-59, mit Untersuchung der rezipierten bzw. nicht rezipierten Materien: 47-57. Die Wirkungen des IV. Lateranum auf die kirchliche Raumordnung untersucht Schmidt, Kirche - Staat - Nation (wie Anm. 3), 102-119.

27 Einen Schub neu formulierter Gesetze brachte erst das Basler Konzil (1431-1449) mit seinen Reformdekreten. Deren regional sehr unterschiedliche, mit Ausnahmen wie etwa Carpentras, vor allem auf Mitteleuropa konzentrierte Rezeption auf PS und DS, die bis in das 16. Jh. zu verfolgen ist, hant systematischer Untersuchung. Vgl. bisher Kehrberger, Provinzial- und Synodalstatuten (wie Anm. 13), passim; Johannes Helmrath, Das Basler Konzil 1431-1449. Forschungsstand und Probleme. (Kölner Hist. Abh., Bd. 32.) Köln 1987, 342-348 (Literatur); ders., Reform als Thema der Konzilien des Spătmittelalters, in: Christian Unity. The Council of Ferrara-Florence 1438/39-1989. Ed. Giuseppe Alberigo. (Bibliotheca Ephemeridum Theologicarum Lovaniensium, vol. 97.) Leuven 1991, 75-152, hier 124-131; zuletzt: Wiegand, Diözesansynoden (wie Anm. 15), 174-184, 187, 190-193, 207-209, 352 s. v. - Systematisch nutzte Nikolaus von Kues $1451 / 52$ auf seiner deutschen Legationsreise PS zur Publikation von Reformstatuten, darunter wichtiger Dekrete des Basler Konzils: Erich Meuthen/Hermann Hallauer (Hrsg.), Acta Cusana. Bd. I/3ab. Hamburg 1996; Bd. I/4. Hamburg 2000 (Gesamtregister); Erich Meuthen, Die deutsche Legationsreise des Nikolaus von Kues 1451/52, in: Lebenslehren und Weltentwïrfe im Übergang vom Mittelalter zur Neuzeit. Hrsg. v. Hartmut Boockmann/Bernd Moeller/Karl Stackmann. (Abh. der Akad. der Wiss. in Göttingen, Phil.-Hist. Kl., 3. Folge, Bd. 179.) Göttingen 1989, 421 -499; ders., Thomas von Aquin auf den Provinzialkonzilien zu Mainz und Köln 1451 und 1452, in: Köln. Stadt und Bistum in Kirche und Reich des Mittelalters. Fschr. für Odilo Engels zum 65. Geburtstag. Hrsg. v. Hanna Vollrath/Stefan Weinfurter. (Kölner Hist. Abh., Bd. 39.) Köln/Weimar/Wien 1993, 641-658. Meuthens Studien zur Legationsreise des Cusanus verstehen sich als Nucleus furr ein Profil der deutschen Kirche vor der Reformation. Siehe auch ders., Nikolaus von Kues und die deutsche Kirche am Vorabend der Reformation, in: Mitteilungen und Forschungsbeiträge der Cusanus-Gesellschaft 21, 1994, 39-85.

28 Neben der in Anm. 5-9 genannten Literatur bes.: Sieben, Art. Synodalstatuten (wie Anm. 20); Odette Pontal, Les statuts synodaux. (Typologie des sources du moyen âge occidental, vol. 11.) Turnhout 1975; dies. (Ed.), Les statuts synodaux français du XIII' ${ }^{e}$ siècle. Vol. 1: Les statuts de Paris et le synodal de l'Ouest (XIII' siècle). (Collection de documents inédits sur l'histoire de France, Série in $\mathbf{8}^{\circ}$, vol. 9.) Paris 1971, LXVIII-LXXVII; Gaudemet, Le gouvernement (wie Anm. 12), 176-180, 211-215; Garcia y Garcia, Asambleas episcopales (wie Anm. 12), 292-301; Borgolte, Die mittelalterliche Kirche (wie Anm. 10), 94 f. Inventarisiert bisher nur für Frankreich: André Artonne/Louis Guizard/Odette Pontal (Ed.), Répertoire des statuts synodaux des diocèses de l'ancienne France du XIII ${ }^{e}$ à la fin du XVIII siècle. (Documents, études et répertoires publ. par l'Institut de recherche et d'histoire des textes, vol. 8.) 2. Aufl. Paris 1969. Zu Grundsatzfragen vgl. Peter Johanek, Methodisches zur Verbreitung und Bekanntmachung von Gesetzen im Spätmittelalter, in: Histoire comparée de l'administration. Actes du $\mathrm{XIV}^{\mathrm{e}}$ Colloque historique franco-allemand. Hrsg. v. Werner Paravicini/Karl Ferdinand Werner (Francia, Beih. 9.) Zürich/München 1980, 89-101, bes. 96-98; Horst Wolter, Erfiahrungen und Probleme bei der Erforschung und Darstellung der Partikularsynoden Deutschlands und Italiens zwischen 916 und 1215, in: AHC 11, 1979, 38-54. Vgl. ferner unten S. 159. 
(Synodalia), regelrechte Gesetzhandbücher, ordneten sich in die Welle der Rechtskodifizierung in Europa ein und setzten sie fort. „Dies gab ihnen für die Effektivität der kirchlichen Rechtsfortbildung und Rechtsanwendung große Bedeutung". ${ }^{29}$ Machte die Kodifizierung dieser systematisch angelegten Gesetzbücher und die durch sie gewährleistete Rechtssicherheit die Synoden überflüssig? Die These ${ }^{30}$ ist unbedingt diskutierenswert. Träfe sie in vollem Umfang zu, hätte dies beträchtliche Folgen für die Bewertung der spätmittelalterlichen Synodenfrequenz. Der nachdruckliche Hinweis auf die multiple Funktion der Partikularsynoden läßt ein ,überflüssig' allenfalls bezüglich ihrer legislativen bzw. promulgativen Teilaufgabe erwägen. Es blieben die anderen praktischen Aufgaben (correctio morum, Instruktion des Klerus etc.), die - vom kanonischen Gebot abgesehen - bischöfliche Synoden weiterhin nötig machten.

Ein kurzer tour d'horizon über die Editionslage: Wie sehr das bloße Vorhandensein von Editionen den Wahrnehmungsraum der Historikerzunft bedingen kann, hat jüngst Erich Meuthen vor Augen gefuhrt. ${ }^{31}$ Für die Synodaltexte gilt dies nicht minder: Die mit der Pariser Ausgabe von Petit in zwei Bänden $1524^{32}$ einsetzenden großen Konziliensammlungen erfaßten zunächst nur die Canones von Generalkonzilien, nahmen aber später auch Statuten von Partikularsynoden auf. Nach dem Kettenprinzip schwollen sie nach und nach über die Ausgaben eines Crabbe, Surius, Hardouin, Coleti und anderer quantitativ, seltener qualitativ, immer mehr an und mündeten vor nunmehr 250 Jahren in das gewaltige Auffangbecken der 35-bändigen ,Collectio amplissima' des Luccheser Bischofs Giovanni Domenico Mansi. Und mit Mansi endete auch die europaweite Sammlung älterer Synodaltexte. Trotz seiner bekannten Unzulänglichkeiten wird man also mit ,Mansi' weiter arbeiten müssen.

In üblicher Zeitverschiebung folgten auf allgemeine auch nationale Editionen. Für Deutschland bleibt man auf das von dem luxemburgischen Abbé Franziskus Schannat begründete, vom Kölner Jesuiten Joseph Hartzheim weitergefuhrte Corpus der ,Concilia

29 Peter Landau, Art. Kirchenverfassungen, in: TRE. Bd. 19. Berlin/New York 1990, 136. Zu den Synodalbüchem Bernando A. Rodriguez/Francisco C. Rodriguez/Antonio Garcia y Garcia, Liber Synodalis. Para la historia de un concepto, in: Studia in Honorem eminentissimi Cardinalis Alphonsi M. Stickler, cur. Rosalio Iosepho Card. Castilli Lara. (Studia et Textus Historiae Iuris Canonici, vol. 7.) Rom 1992, 1-11, und die in Anm. 40 genannte Literatur. Es präfigurierten in gewisser Hinsicht die capitula episcoporum der Karolingerzeit, die Anfang des 10. Jh. versiegten. S. als Beispiel Peter Brommer, Die bischöfliche Gesetzgebung Theodulfs von Orléans, in: ZRG KA 60, 1974, 1-120, zu den DS als Kontrollorganen: 42-106.

30 So Andrea Polonyi, Synodale Gesetzgebung in der Kirchenprovinz Mainz, dargestellt an der Beginenfrage, in: Rottenburger Jahrbuch für Kirchengeschichte 5, 1986, 33-51, hier 46 (gestützt auf Kehrberger, Provinzial- und Synodalstatuten [wie Anm. 13]): „Synoden waren nicht mehr notwendig“.

31 Erich Meuthen, Der Quellenwandel vom Mittelalter zur Neuzeit und seine Folgen für die Kunst der Publikation, in: Quelleneditionen und kein Ende? Hrsg. v. Lothar Gall/Rudolf Schieffer. (HZ, Beih. 28.) München 1999, 17-36.

32 Mansi, Sacrorum Conciliorum nova et amplissima Collectio (wie Anm. 22). Vgl. Johannes Helmrath, Art. Konziliensammlungen, in: LThK. Bd. 6. 3. Aufl. Freiburg u. a. 1997, Sp. 352-355 (Quellen und Literatur); Übersicht über nationale und provinziale gedruckte Statutensammlungen und Drucke einzelner PS-Statuten einzig in RepFont. Vol. 3 (wie Anm. 6), 557-603. 
Germaniae' angewiesen. ${ }^{33}$ Auf der unteren Ebene kann für einzelne Diözesen auf Textsammlungen meist älteren Datums zurlickgegriffen werden.$^{34}$ Kaum mehr übersichtlich ist der Schwarm einzelner Statutendrucke. ${ }^{35}$ Aus jüngster Zeit ist die kritische Edition der Lütticher Statuten durch Joseph Avril ${ }^{36}$ und die methodisch für die ganze Synodalforschung

33 Joannes F. Schannat (Ed.), Concilia Germaniae, ... Josephus Hartzheim continuavit. 11 Bde. Köln 1759-1790. Hartzheim bearbeitete die ersten fünf Bände. Auf der Basis der Concilia Germaniae entstand Anton J. Binterim, Pragmatische Geschichte der deutschen Concilien vom 4. Jahrhundert bis auf das Concilium von Trient. 7 Bde.; Bd. 1: 2. Aufl. Mainz 1851; Bd. 2-6: 1852; Bd. 7: 1848 (unter dem Titel: Pragmatische Geschichte der deutschen National-, Provinzial- und vorzüglichsten Diöcesanconcilien).

34 Auswahl: Florianus Dalham, Concilia Salisburgensia provincialia et dioecesana. Augsburg 1788; Johannes J. Blattau, Statuta synodalia, ordinationes et mandata archidiocesis Trevirensis. Trier 1844; Franz X. Himmelstein, Synodicon Herbipolense. Geschichte und Statuten der im Bisthum Würzburg gehaltenen Concilien und Dioecesansynoden. Würzburg 1855; Gustav Bickell (Ed.), Synodi Brixinenses saeculi XV. Innsbruck (Oeniponte) 1880.

35 Einen Teil der älteren Drucke deutscher Synoden stellte Hauck, Kirchengeschichte (wie Anm. 11), Bd. 5, 146 f. Anm. 1, zusammen. Ausgewählte Einzelstudien, zum Großteil mit Synodaltexten: Max Sdralek, Die Straßburger Diöcesansynoden, in: Strassburger Theologische Studien 2, 1897, 1-168, darin 94-168: Edition von Statuten; Nicolaus Hilling, Die Westfalischen Diözesansynoden bis zur Mitte des 13. Jahrhunderts. Ein Beitrag zur geistlichen Verfassungsgeschichte der Bistümer Münster, Paderborn, Osnabrück und Minden. Bingen 1898; Fritz Vigener, Synodalstatuten des Erzbischofs Gerlach von Mainz usw., in: Archiv für Hessische Geschichte und Altertumskunde. Beiträge zur hessischen Kirchengeschichte II, 1, 1903, 287-332, darin 305-332: Edition der Statuten von 1355; Maring, Diözesansynoden (wie Anm. 16); Karl Hübner, Die Brixener Diözesansynoden bis zur Reformation, in: Deutsche Geschichtsblätter 15, 1914, 85-103; Max Hopfner, Synodale Vorgänge im Bistum Regensburg und in der Kirchenprovinz Salzburg unter besonderer Berücksichtigung der Reformationszeit, in: Beiträge zur Geschichte des Bistums Regensburg 13, 1979, 235-388, bes. 269-276; Councils and Synods of Prague and their statutes, in: Apollinaris 45, 1972, 471-532, $698-470$ (ed. R. Zeleny); ebd. 52, 1979, 200-237, 495-527; 53, 1980, 131-166, 421-457 (ed. J. K. Polc); Georg May, Exekutoren der Provinzialstatuten im Erzbistum Mainz während des hohen und späten Mittelalters, in: De iure canonico Medii Aevi. Fschr. Rudolf Weigand. Hrsg. v. Peter Landau. (Studia Gratiana, Bd. 27.) Rom 1996, 331-373. - Zu Köln: Franz Gescher, Die kölnischen Diözesansynoden am Vorabend der Reformation (1490-1515), in: ZRG KA 21, 1932, 190-288, darin 252-283 Edition von Statuten der Jahre 1490 ff.; Wilhelm Janssen, Unbekannte Synodalstatuten der Kölner Erzbischöfe Heinrich von Virneburg (1306-1332) und Walram von Jülich (1332-1349), in: AHVN 172, 1970, 113-154; Herbert Lepper, Unbekannte Synodalstatuten der Kölner Erzbischöfe Heinrich von Virneburg (1306-1332) und Wilhelm von Gennep (1349-1362), in: AHC 11, 1979, 339-355 (mit fehlerreicher Edition); Horst Wolter, Die Kölner Provinzialsynoden bis zum vierten Laterankonzil im Jahre 1215, in: AHC 21, 1989, 62-102; Monika Storm, Die Metropolitangewalt der Kölner Erzbischöfe im Mittelalter bis zu Dietrich von Moers. (Studien zur Kölner Kirchengesch. 29.) Siegburg 1995, 54-74, 118-135, 192-211.

36 Joseph Avril (Ed.), Les statuts synodaux de Jean de Flandre évêque de Liège (1288). Édition critique précédée d'une étude de leur sources et de leur contenu, in: Bulletin de la Société d'art et d'histoire du diocèse de Liège 61, 1996, 1-229; separat: Liège 1996; vgl. die Rez. in RH 299, 1998, 161-163 (Michel Pacaut) und ZRG KA 85, 1999, 590-595 (Ludwig Falkenstein). 
weiterführende Studie mit Edition über die Diözese Kammin von Peter Wiegand hervorzuheben. ${ }^{37}$

Für England ist noch auf die Sammlung von Wilkins (1737) zu rekurrieren, an modernen Editionen liegt (1313 endend) die von Powicke-Cheney und Whitelock (1964/81) vor, die nicht nur Statuten, sondern auch flankierende Texte bringt. ${ }^{38}$ Die Krönung der vergleichsweise sehr reichen spanischen Synodenforschung bildet das von Antonio García y García herausgegebene ,Synodicon Hispanum' (1982ff.) in bisher sieben Bänden, das derzeit die Statuten von ca. zwanzig Bistümern ediert. ${ }^{39}$ Für Frankreich ${ }^{40}$ erfullt die von Odette Pontal

37 Wiegand, Diözesansynoden (wie Anm. 15), 245-319 (Edition). - Eine nützliche, den Vergleich anregende Aufsatzserie bietet Bd. 5 (1986) des Rottenburger Jahrbuchs für Kirchengeschichte: Gerhard B. Winkler, Die Salzburger Provinzialsynoden (25-32); Andrea Polonyi, Synodale Gesetzgebung in der Kirchenprovinz Mainz, dargestellt an der Beginenfrage (33-51); Konstantin Maier, Die Konstanzer Diözesansynoden im Mittelalter und in der Neuzeit (53-70); Peter Thadidäus Lang, Die Synoden in der Diözese Würzburg (70-84).

38 William Lyndwood, Provinciale seu Constitutiones Angliae. Oxford 1483 (!), (neuere Aufl. 1679); dazu Christopher R. Cheney, in: The Jurist 21, 1961, 414-416; David Wilkins (Ed.), Concilia Magnae Britanniae et Hiberniae. 4 vol. London 1737; Councils and Synods with other Documents relating to the English Church, Part I: 871-1204. Ed. Dorothy Whitelock/Martin Brett/Christopher N. L. Brooke. 2 vol. Oxford 1981; dasselbe, Part II: 1205-1313. Ed. Christopher R. Cheney/Frederik M. Powicke. 2 vol. Oxford 1964. - Christopher R. Cheney, English synodalia of the Thirteenth century. Oxford 1941, 2. Aufl. 1968; ders., The earliest English diocesan statutes, in: EHR 75, 1960, 1-29, wieder in: ders., The English Church and Its Laws, 12th-14th century. (Variorum Collected Studies Series, vol. 160.) London 1982, VII. Ferner Christopher R. Cheney, Statute Making in the English Church in the 13th Century, in: Proceedings of the Second International Congress of Medieval Canon Law, Boston 1963. (MIC, Ser. C: Subsidia, vol. 1.) Città del Vaticano 1965, 399-414; Dorothy M. Owen, Synods in the diocese of Ely in the Later Middle Ages and the sixteenth Century. Leiden 1967. Schottland: J. Robertson (Ed.), Concilia Scotiae. Ecclesiae Scotianae Statuta tam Provincialia quam Synodalia quae supersunt. 2 vol. Edinburgh 1866. - Donald E. R. Watt, The Provincial Council of the Scottish Church 1215-1472, in: Medieval Scotland. Crown, Lordship and Community. Essays presented to Geoffrey W. S. Barrow. Ed. Alexander Grant/Keith J. Stringer. Edinburgh 1993, 140-155.

39 Antonio Garcia y García u. a. (Ed.), Synodicon Hispanum. 7 vol. Madrid 1981-1997. Ältere Sammlungen: José Sáenz de Aguirre (Ed.), Collectio maxima Conciliorum omnium Hispaniae et Novi Orbis ... Editio altera ... novis additionibus aucta cur. J. Catalani. 6 vol. Rom 1753-1755; Juan Tejada y Ramiro (Ed.), Colección de cánones y de todos los concilios de la Iglesia de España y de América. 7 vol. (Bis vol. 5 unter dem Titel: Colección de cánones [y de todos los concilios] de la iglesia española.) Madrid 1849-1862. Für kein anderes Land existieren Übersichten wie die des Diccionário de Historia ecclesiástica de España: ,Concilios nacionales y provinciales', in: ebd. vol. 1. Madrid 1972, 537-577 (die Einzelartikel stammen in der Regel von Gonzalo Martinez); L. Ferrer, Art. Sinodo, in: ebd. vol. 3. Madrid 1974, 2487-2494, mit alphabetischen Synoden-Listen; Gonzalo Martínez Diez, Concilios españoles anteriores a Trento: Repertorio de la Historia de las ciencias Eclesiásticas en España.Vol. 5. Salamanca 1976, 299-350. - Grundlegend: José Sánchez Herrero, Los Concilios provinciales y los Sínodos diocesanos españoles 1215-1550, in: Quaderni Catanesi di studi classici e medievali 3, 1981, 113-181; 4, 1982, 111-197 (Apéndice); vgl. jetzt auch Schmidt, Kirche - Staat Nation (wie Anm. 3), 133-140. Ferner Paul Linehan, Councils and Synods in 13th century Castile and Aragon, in: Councils and Assemblies. Papers read at the Eighth Summer Meeting and the Ninth Winter Meeting of the Ecclesiastical History Society. Ed. Geoffrey J. Cuming/Derek Baker. (Studies in Church 
und Joseph Avril edierte, bisher vierbăndige Reihe von DS ,Les statuts synodaux Français

History, vol. 7.) Cambridge 1971, 1-11; Juan Candido Matias Vicente, La clerecia en los sinodos Astur-Leoneses del siglo XII al XVI, in: Revista Española de derecho canónico 44, 1987, 93-136; Antonio García y García, Concilios y sínodos en el ordenamiento del reino de León, in: El Reino de León en la Alta Edad media. Vol. 1: Cortes, Concilios y Fueros. (Fuentes y estudios de Historia Leonesa, vol. 48.) León 1988, 353-494; ders., Legislación de los concilios y sínodos del Reino Leonés, in: El Reino de León en la Alta Edad media. Vol. 2: Ordenamiento juridico del reino. (Fuentes y estudios de Historia Leonesa, vol. 49.) León 1992, 7-114. - José Sánchez Herrero, La legislación conciliar y sinodal hispana de los siglos XIII a mediados del XVI y su influencia en la enseñanza de la doctrina cristiana. Los tratados de la doctrina cristiana, in: Proceedings of the Seventh International Congress of Medieval Canon law, Cambridge 1984. (MIC, Ser. C: Subsidia, vol. 8.) Città del Vaticano 1988, 349-372. - Einzelstudien: Nicolás López Martinez, Sínodos burgaleses del siglo XV, in: Burgense. Collectanea scientifica 7, 1966, 211-406; Manuel Guallar Pérez, Los concilios celebrados in Lérida (siglos VI-XV). Lérida 1975; Federico Rafael Aznar Gil, Concilios provinciales y sinodos de Zaragoza de 1215 a 1563. (Publicación de la Caja de Ahorros de la Inmaculada, vol. 25.) Zaragoza 1982; Johannes Grohe, Die Synoden im Bereich der Krone Aragón von 1418 bis 1429. (Konziliengeschichte. Rh. A: Darstellungen, Bd. 9.) Paderborn 1991 (modellhaft für die Einbettung der Synoden in die [Kirchen-]Politik); D. Gonzalo Millan, Sinodos diocesanos de Osma (1228-1906), in: Celtiberia 42, 1994, 59-103; Johannes Grohe, Das Provinzialkonzil von Tarragona 1415 unter Erzbischof Pere de Saggariga, in: Tempus Implendi Promissa. Homenaje al Prof. Dr. Domingo RamosLissón. Ed. Elisabeth Reinhardt. (Collección Historia de la Iglesia, vol. 33.) Pamplona 2000, 679-698. - Portugal: Synodicon Hispanum (wie oben Anm. 39), vol. 2. Madrid 1983. - Isaias da Rosa Pereira, Sínodos medievais Portugueses (Séculos XIII-XV), in: Proceedings of the Second Congress of Medieval Canon Law, Boston 1963. (MIC, Ser. C: Subsidia, vol. 1.) Città del Vaticano 1965, 457-466.

40 Les statuts synodaux français du XIII ${ }^{e}$ siècle. (Collection de documents inédits sur l'histoire de France, Série in $8^{\circ}$, vol. 9, 15, 19, 23.) 4 vol. Paris 1971-1995, textkritische Editionen mit frz. Übersetzung und wichtigen Sachregistern, wobei die bisher von Joseph Avril betreuten Bände 3 und 4 vorbildlich genannt werden dürfen; vgl. dazu die Rez. in: ZRG KA 83, 1997, 624-632. Ferner Joseph Avril (Ed.), Les conciles de la province de Tours. Concilia provinciae Turonensis (saec. XIII-XV). (Sources d'Histoire Médiévale, vol. 16.) Paris 1987, mit instruktiver Einleitung. - Ausgewăhlte Einzelstudien: Odette Pontal, Histoire du synode diocésain et des statuts synodaux français du XIII ${ }^{e}$ siècle. Vol. 1. Paris 1971; Leinweber, Die Provinzialsynoden in Frankreich (wie Anm. 13); Odette Pontal, Les conciles de la France capétienne jusqu'en 1215. Paris 1995, ohne hinreichende Rezeption jüngerer Forschung, s. die Rez. von Isolde Schröder, in: DA 52, 1997, 376 f.- Raymonde Foreville, The Synod of Rouen in the 11th and 12th centuries, in: Church and Government in the Middle Ages. Essays presented to Christopher R. Cheney. Ed. Christopher N. L. Brooke u. a. Cambridge 1976, 19-30; Jacques Choux, Le synode diocésain de Toul à la fin du Moyen Âge, in: Revue d'Histoire de l'Église de France 45, 1959, 63-72, wiederabgedruckt in: ders., La Lorraine chrétienne au Moyen Âge. Metz 1981, 137-146; Jean Gaudemet, Aspects de la législation conciliaire française au XIII ${ }^{\mathrm{e}}$ siècle, in: Revue du Droit canonique 9, 1959, 319-340; wiederabgedruckt in: ders., La formation du droit canonique médiéval. (Variorum Collected Studies Series, vol. 111.) London 1980, VI; Louis Boisset, Un concile provincial au $13^{\mathrm{e}}$ siècle, Vienne 1289. Église locale et société. (Théologie historique, vol. 21.) Paris 1973; Joseph Avril, Naissance et évolution (wie Anm. 12); Henri Vidal, Les conciles méridionaux aux $\mathrm{XIII}^{\mathrm{e}}$ et XIV ${ }^{\mathrm{e}}$ siècles, in: L'Église et le Droit dans le Midi. Ed. Jean-Louis Biget. (Cahiers de Fanjeaux, vol. 29.) Toulouse 1994, 147-180; Jean-Louis Biget, La législation synodale: le cas d'Albi aux XII' et XIV ${ }^{e}$ siècles, in: ebd. 181-213. Zuletzt Joseph Avril, Remarques sur le livre de Guillaume de Trie, archevêque de Reims (vers 1330), in: Licet praeter solitum. Ludwig Falkenstein zum 65. Geburtstag. Hrsg. v. Lotte Kéry/Dietrich Lohrmann/Harald Müller. Aachen 1998, 193-20 1, mit weiterer Literatur. 
du XIII' siècle' moderne Standards; als kritische Einzeledition ist die der Provinzialstatuten von Tours durch Avril zu nennen. Am meisten editorisch defizitär erscheint das - vortridentinische - Italien, wo freilich auch das Synodalwesen im späteren Mittelalter am wenigsten ausgeprägt gewesen zu sein scheint. ${ }^{41}$ Unter den Ländern des ,jüngeren Europa' ist Polen durch Sawickis Editionen in den ,Concilia Poloniae ${ }^{62}$ am besten ausgestattet. Für Skandinavien/Schweden ${ }^{43}$ und Ungarn ${ }^{44}$ scheinen jüngere Editionen zu fehlen. Trotz dieser gewaltigen Menge des Gedruckten bleibt die Menge des Unedierten noch groß.

41 Vgl. unten bei Anm. 61. Als übergreifende Edition ist nur Mansi zu nennen. Einzeleditionen: Richard C. Trexler, Synodal Law in Florence and Fiesole 1305-1518. (Studi e testi, vol. 268.) Città del Vaticano 1971, Edition: 179-379; Giuseppe Briacca (Ed.), Gli statuti sinodali Novaresi di Papiniano della Rovere (a. 1298). Milano 1971, Edition: 169-279; ders., I decreti sinodali torinesi di Goffredo di Mantovano (a. 1270-1286). Turin 1985. - Die reiche italienische Diözesen- und Pfarr- und Visitationsforschung trägt den Synoden wenig Rechnung. S. aber Michele Miele, Concili provinciali e rapporti interdiocesani tra ' 400 e ' 500 , in: Vescovi e diocesi in Italia dal XIV alla metà del XVI secolo. Ed. Giuseppina DeSandre Gasparini. Vol. 1. (Italia Sacra, vol. 43.) Rom 1990, 259-294; Richard C. Trexler, Diocesan Synods in Late Medieval Italy, in: ebd. 295-336 (wichtig, hebt Rolle der DS für die Besteuerung des Klerus durch Bischof, Papst und weltliche Instanzen hervor, bes. 298-310; vgl. auch unten Anm. 62); Giovanni Vitolo, Sinodi e visite pastorali in Campania tra XV e XVI secolo, in: ebd. 373-395; Enzo Petrucci, Vescovi e cura d'anime nel Lazio (sec. XIII-XV), in: ebd. 429-547; Guiseppina de Sandre Gasparini, Vescovi e vicari nelle visite pastorali del Tre-Quattrocento veneto, in: ebd. 569-600. Für die synodenintensive Zeit nach dem Tridentinum: Silvino Da Nardo, Sinodi diocesani italiani. Catalogo bibliografico degli atti a stampa (1534-1878). (Studi e testi, vol. 207.) Città del Vaticano 1960; Michele Miele, Die Provinzialkonzilien Süditaliens in der Neuzeit (Konziliengeschichte, Rh. A: Darstellungen, Bd. 15.) Paderborn u. a. 1996.

42 Jakub Th. Sawicki (Ed.), Concilia Poloniae. Źródla i studia krytyczne. 10 Bde. Lublin/Warschau 19451963. Vgl. zum Gesamtprojekt ders., Geschichte und heutiger Stand der Vorarbeiten zur Gesamtausgabe der polnischen Synodalstatuten, in: ZRG KA 46, 1960, 395-429, auch methodisch wichtig. Ulrich Heythmann (Ed.), Statuta synodalia episcoporum Cracoviensium XIV et XV seculi. (Starodawne prawa polskiego pomniki, Bd. 4.) Krakau 1875. Wacław Uruszczak, Ustawodawstwo synodów Kościoła katolickiego w Polsce w XIII i XIV wieku [Die Gesetzgebung der katholischen Kirche in Polen im 13. u. $14 \mathrm{Jh}$.], in: Czasopismo prawno-historyczne 51, 1999, 133-148; mit Literatur und Statistik (138 f.).

43 H. Reuterdahl (Ed.), Statuta synodalia veteris ecclesiae sveogothicae. Lund 1841; Jaakko Gummerus (Ed.), Synodalstatuter och andra kyrkorättsliga aktstycken fran den svenska medeltidskyrkan. (Skrifter utgiven af Kyrkohistoriska förenigen, Bd. II, 2.) Uppsala 1902. - Art. Synode und Synodalstatuter, in: Kulturhistorisk lexikon för nordisk medeltid fran utingatid till medeltid. Bd. 17. Malmö 1972, 630-643, zu Schweden 636-640 (Sigurd Kroon). - Sigurd Kroon, Det svenska prästmötet under medeltiden. (Acta historico-ecclesiastica Suecana, Bd. 18.) Stockholm 1948, frz. Resumée 169-189 mit dem wohl verfehlten Versuch, der skandinavischen Bischofssynode ein höheres, vorlateranisches Alter zu vindizieren; Sten Gagnér, Zur Entstehung der europäischen und der schwedischen Diözesansynode, in: Kyrkohistorisk Årsskrift 98, 1948, 1-31, Kritik an Kroon ebd. 26 f.; Inger, Das kirchliche Visitationsinstitut (wie Anm. 12), 100-105, 355-375 (PS), 131-133, 487-495 (DS). Nach Abschluß des Ms. erschienen: Bertil Nilsson, Medieval Province Councils in Scandinavia. A preliminary survey, in: AHC 32, 2000, 23-43 (42 f.: Synodenliste).

44 Károly Péterffy (Ed.), Sacra Concilia Ecclesiae Romano-Catholicae in Regno Hungariae celebrata ab anno Christi MXVI usque ad annum MDCCXV. 2 Bde. Preßburg 1741-42; Ignac Graf Batthyány (Ed.), Leges ecclesiasticae regni Hungariae et provinciarum adjacentium. 3 Bde. Karlsburg/ 
Nur als Perspektiven seien neben dem Synodenprojekt zwei weitere Möglichkeiten vergleichender Forschung angedeutet. Sie betreffen: 1. Die Visitation. Als zweiter den Metropoliten und Bischöfen regelmäßig vorgeschriebener raumerfassender „moyen d'action“, der zudem mit der Synode funktional korrespondierte ${ }^{45}$, könnte sie anhand spezifischer Schriftproduktion (hier: der Visitationsprotokolle) mit zum Teil ăhnlichen Fragestellungen wie die Partikularsynoden zum Thema eines Projekts der vergleichenden Geschichte Europas gemacht werden. - 2. Die Verbindungen von Konzilien/Synoden und weltlichen (Reichs-) Tagen: Die politischen Funktionen von Partikularsynoden als ,Nationalkonzile‘ etc., ihre Koppelung mit weltlichen Repräsentativversammlungen und die Herausformung eigener politischer Klerusversammlungen wie der englischen Convocations könnten typologisch im Rahmen eines Projekts zur Ständeforschung untersucht werden. ${ }^{46}$ Dort hat der Vergleich Tradition.

Klausenburg 1785-1825. - Alexander Szentirmai, Die ungarische Diözesansynode im Spätmittelalter, in: ZRG KA 78, 1961, 266-292 (Liste von 39 Synoden 1256-1513); Gabriel Andriányi, Die ungarischen Synoden, in: AHC 8, 1976, 541-575, bes. 542-549; Lothar Waldmüller, Die Synoden in Dalmatien, Kroatien und Ungarn, von der Völkerwanderung bis zum Ende der Arpaden (1311). (Konziliengeschichte, Rh. A: Darstellungen, Bd. 4.) Paderborn u. a. 1987; Z. J. Kosztolnyik, Rome and the Church in Hungary in 1279: The Synod of Buda, in: AHC 22, 1990, 68-85; Peter Erdö, Polnische Quellen des großen Synodalbuchs von Esztergom (1382), in: ZRG KA 83, 1997, 377-391.

45 Visitationsprotokolle sind vor dem 16. Jh., als die Kirchenvisitation zentrales Mittel der Reform und Konfessionalisierung wurde, viel seltener und verstreuter erhalten (und wohl auch angefertigt worden) als Synodalstatuten. Ausnahme scheint wie so oft England, dank seiner bischöflichen Records, zu sein. Eine Bestandsaufnahme wäre äußerst wünschenswert. Bisher modellhaft für Frankreich, aber mit relativ wenigen Texten vor 1500: Répertoire des visites pastorales de la France. ${ }^{\text {ìre }}$ série. Anciens diocèses (jusqu'en 1790). 1. Agen-Bourges, 2. Cahors-Lyon, 3. Mâcon-Riez, 4. La Rochelle-Ypres. Paris $1977-$ 1985. Allgemein Noël Coulet, Les visites pastorales. (Typologie des sources du moyen âge occidental, vol. 23.) 2. Aufl. Turnhout 1985; Gaudemet, Le gouvernement (wie Anm. 12), 28-30, 130-134; Ernst W. Zeeden/Peter Th. Lang (Hrsg.), Kirche und Visitation. Beiträge zur Erforschung des frühneuzeitlichen Visitationswesens in Europa. (Spätmittelalter und Frühe Neuzeit, Bd. 14.) Stuttgart 1984; als Regionalstudie wiederum modellhaft Binz, Vie religieuse (wie Anm. 14), 177-221 und passim. - Breit sind, wie bei den Synoden, die Forschungen für Italien in der frühen Neuzeit: Umberto Mazzone/Angelo Turchini (Ed.), Le visite pastorali. Annalisi di una fonte. (Annali dell'Istituto storico italo-germanico. Quaderno 18.) Bologna 1985; Vescovi e diocesi in Italia (wie Anm. 41). Als Modell einer umfassenden Computerisierung: Cecilia Nubola (Ed.), Per una banca dati delle visite pastorali utaliane. Le visite della diocesi di Trento (1537-1940). (Annali dell'Istituto storico italo-germanico. Quaderno 49.) Bologna 1998, mit CD-Rom. - Klärungsbedarf besteht in der Frage des genetischen und funktionalen Zusammenhangs zwischen Visitation und Send - ebenfalls vom Wort synodos abgeleitet. Vgl. Hauck, Kirchengeschichte (wie Anm. 11), Bd. 5, 225-235. Wichtige Regionalstudie: D. Lambrecht, De parochiale synode in het oude bisdom Doomik gesitueerd in de Europese ontwikkeling 11de eeuw - 1559. Brissel 1984.

46 Einige Beispiele bei Schmidt, Kirche - Staat - Nation (wie Anm. 3), 130-164; künftig Johannes Helmrath, „Geistlich und werntlich“. Zur Beziehung von Konzilien und Reichsversammlungen im 15. Jahrhundert, in: Deutscher Königshof, Hoftag und Reichstag im späten Mittelalter. Hrsg. v. Peter Moraw (Der Druck des als Nr. XIVIII der Reihe ,Vorträge und Forschungen' vorgesehenen Bandes ist in Vorbereitung). 


\section{Frequenz von Provinzial- und Diözesansynoden}

Hier zählt zunächst nur das bloße Faktum, daß eine Synode getagt hat, unabhängig von deren Schriftproduktion. Genaue Zahlen über alle europäischen Synoden des Spätmittelalters, immerhin einige Tausend, sind derzeit noch nicht zu gewinnen. Man wird in jedem Fall vor allem bei den DS mit einer hohen Dunkelziffer von ,Routinesynoden` zu rechnen haben, die keine statutarischen, ja überhaupt keine schriftlichen Spuren hinterließen. Eine nur sehr relative und grob unvollständige Annäherung gewinnt man durch den Index von Palazzinis Dizionario dei concili ${ }^{47}$, der aber die einzige globale Übersicht bietet. Der Index wird hier probeweise nach Epochen und nach Ländern ausgezählt. Aufschlußreich sind an der folgenden Tabelle weniger die absoluten Synodenzahlen (hier ohne Differenzierung von PS und DS), sondern nur die statistische Tendenz. Feste Untersuchungszeiträume (hier probeweise Einheiten von fünfzig Jahren) zu fixieren, ist auch für eine künttige Systematik unabdingbar.

$\begin{array}{ll}\text { 1000-1049: } 188 & 1300-1349: 286 \\ \text { 1050-1099: } 336 & 1350-1399: 181 \\ \text { 1100-1149: } 336 & 1400-1449: 233 \\ \text { 1150-1199: } 227 & 1450-1499: 212 \\ \text { 1200-1249: } 280 & 1500-1549: 149 \\ 1250-1299: 307 & \end{array}$

Man erkennt eine relativ hohe Gleichformigkeit. Spitzen der Gesamtkurve sind in der Phase 1050-1150 und wieder 1250-1300 auszumachen. Der Aufschwung des Synodalwesens begann längst vor 1250. Er kam als Fernwirkung des IV. Lateranum und der päpstlichen Politik zustande, durch Aussendung einer Kohorte von Legaten in die Länder Europas Synoden dauerhaft zu initiieren. Eine Tiefphase ist für die Periode 1350-1400 erkennbar, was der verbreiteten Einschätzung entspräche, daß die Synodaltätigkeit in den meisten Regionen Europas nach ca. 1330 stark abnahm. Die nachfolgenden fünfzig Jahre 1400-1450 zeigen wieder einen ,Aufschwung'; es ist die Zeit der großen Konzilien, wo man die Kirchenreform gerade auf dem Wege von General- und Partikularsynoden auf allen Ebenen umsetzen wollte. ${ }^{48}$ Der ungeachtet der beginnenden ,katholischen Reform ' deutliche Rückgang 1500-1550 könnte schon auf den Ausfall der lutherischen bzw. reformierten Gebiete zurückzuführen sein.

47 Palazzini, Dizionario dei concili (wie Anm. 6), vol. 6, 336-377 (Index). Zur Charakterisierung des Werks und seiner Schwăchen siehe Anm. 6.

48 Bonicelli, I concili particolari (wie Anm. 12), 83-132; Helmrath, Reform (wie Anm. 27), 80 f. und passim. 
Sortiert man nach Ländern, steht man vor zwei Schwierigkeiten: a) hinsichtlich der politischen Grenzen, ob man nămlich die heutigen oder die damaligen zugrundelegt; letzteres wird mit Ausnahme Italiens hier versucht; b) hinsichtlich der verzerrenden quantitativen Grundgegebenheiten. Das Tableau der geplanten Gesamtanalyse bilden ja die über 500 mittelalterlichen Bistümer (davon ca. sechzig Erzbistümer). Frankreich mit seinen dreizehn Provinzen und rund hundert Bistumern erlebte so, kaum verwunderlich, auch bei geringer Frequenz mehr Synoden als Schweden mit seinen sechs Bistümern, ohne daß dieses Gesetz absolut zwingend wäre. Die Diözesendichte in Italien (zwanzig Provinzen, 263 Bistümer im 15. Jahrhundert) war ungleich höher als die im Reich mit sechs Provinzen und über vierzig Bistümern, als im zunächst noch wachsenden Spanien mit funf (1492: sieben) Provinzen und 43 Bistümern (Portugal: zwei Provinzen, sieben Bistümer) und als in England mit zwei Provinzen, zwanzig Bistümern (ohne Schottland und Irland). Auch in den Ländern des ,jüngeren Europa', der spät(er) christianisierten Gebiete im Norden und Osten, setzte die Gründung von Bistümern und Metropolen die entscheidenden institutionellen und auch quantitativen Marken: Lund (1103) mit zunächst sechzehn, nach Ausgliederung von Drontheim und Uppsala im 12. Jahrhundert dann mit acht Suffraganen (sieben dänische und Riga), das 997 gegrindete, 1152/53 zum Erzbistum erhobene Drontheim selbst mit schließlich zehn -, Uppsala 1164 mit sechs Suffraganen. Die Millenargründungen in Polen und Ungarn kamen im Fall Gnesens im 15. Jahrhundert auf zehn Suffragane, im Falle von Gran/Esztergom auf alsbald zwölf.

Ordnet man die Synodenzahlen aus dem Index Palazzinis nach Ländern ${ }^{49}$, so sieht man in allen elf Zeitabschnitten bis auf den vorletzten (1450-1499) immer Frankreich vorn, gefolgt von Italien oder vom Reich. Polen und Ungarn kommen überhaupt erst im 12. Jahrhundert dazu. Auffallig sind auch die antizyklisch anschwellenden Frequenzziffern für Spanien im 14. und 15. Jahrhundert, fur England in der zweiten Hälfte des 15. Jahrhundert, wo es mit 45 Synoden erstmals Frankreich übertrifft, auffällig auch der fast völlige Ausfall Italiens in der zweiten Hälfte des 15. Jahrhunderts.

Zuverlässige Zahlen lassen sich nur über systematische Länder- und Regionalstudien gewinnen. Als Beispiel sei Spanien vorgefuhrt, das hierin den breitesten Fundus an Vorarbeiten bietet, insbesondere in der Studie von Sánchez Herrero über Kastilien und Aragón: Die Zahl der Synoden stieg in Kastilien und abgeschwächt auch in Aragón sprunghaft im 14. Jahrhundert an, in deutlicher Gegenläufigkeit zu Mittel- und Westeuropa, insbesondere zu Deutschland. Die Spitzenfrequenz erreichten PS wie DS in Aragón ebenfalls im 14. Jahrhundert. Die Diözese Gerona mit 27 DS, also immerhin jedes vierte Jahr eine, stach dabei besonders heraus. In Kastilien sieht dagegen das 15. Jahrhundert mit 107 die meisten DS, während die Höchstzahl an PS im 14. Jahrhundert (15) liegt, aber im folgenden Jahrhundert

49 Die Zahlen bei Palazzini enthülen dabei ihre Unvollstăndigkeit noch eklatanter; sie könnten durch die Literatur sofort modifiziert werden und sollen hier uberhaupt nur wegen des europaweiten Überblicks genannt werden: I. 1300-1350: 1. Frankreich 97; 2. Italien 39; 3. Deutschland (Reich) 33; 4. Spanien 35; 5. England 31; 6. Skandinavien 11; 7. Ungarn 11; 8. Polen 2. - II. 1450 bis 1499: 1. England 45; 2. Frankreich 30; 3. Deutschland (Reich) 26; 4. Polen 22; 5. Spanien 14; 6. Skandinavien 8; 7. Italien 6; 8. Ungarn 1. 
rapide auf zwei abfällt. Rückschlüsse auf die in Spanien früher als anderswo einsetzende katholische Reform sind denkbar - Spanien um 1500 war eben bereits ,reformiert'. Das Beispiel Spanien zeigt auch, daß die Synodenfrequenz sich nicht gleichmäßig über alle Diözesen verteilte, sondern daß extreme Unterschiede und Verzerrungen bestehen konnten. Mit Abstand die meisten PS aller sieben spanischen Metropolen wies etwa die erst 1090 wiedereroberte aragonische Metropole Tarragona auf, nämlich 62 bis 1536, bei einer auffälligen Unterbrechung von 1476 bis $1517 .{ }^{50}$ Offenbar kam ihm im Königreich Aragón eine Art Patriarchalstellung zu. Für das kastilische Bistum Burgos sind für den Zeitraum vom 13. bis 16. Jahrhundert zwanzig Synoden nachweisbar, achtzehn mit erhaltenen Texten; davon entfallen drei auf das 13., funf auf das 14., neun auf das 15. und drei auf das 16. Jahrhundert. Für Tarragona hingegen ist unter den beiden reformaktiven Bischöfen Gonzalo Vargas und Juan de Villacreces sogar eine lückenlose Jahresfolge von DS für den Zeitraum von 1382 bis 1404 nachweisbar. Ähnliches gilt für Gerona mit lückenloser Jahresfolge für 1245-54, 1267-74 und 1344-48.

Diese Befunde relativieren zumindest die verbreitete Ansicht, daß die regelmäßige Abhaltung von DS im späteren Mittelalter allgemein ungebrăuchlich geworden sei. Das Bistum Gerona veranschaulicht auch ein weiteres Paradoxon: Gerona lag im 13. Jahrhundert hinter Valencia (14 DS) mit zwölf DS an zweiter Stelle in Spanien, und war im 14. (27 DS) und 16. Jahrhundert (19 DS) gar das synodenfreudigste spanische Bistum (insgesamt 61 DS); ab 1368 hingegen und im gesamten 15. Jahrhundert weist es ganze drei DS auf (1487, 1498, 1499). ${ }^{51}$ Derartige ,Paradoxa' in der Synodenfrequenz könnten überall begegnen. Die bloßen statistischen Werte bleiben ohne Analysen der strukturellen und politischen Bedingungen freilich steril. An solchen Analysen und Synthesen fehlt es jedoch. ${ }^{32}$

Gerade die Befunde aus Spanien lenken den Blick entscheidend auf zwei Faktoren, ohne die jede Synodendeutung zu kurz griffe, erstens auf die päpstlichen Initiativen (sie sollen hier nicht năher untersucht werden!), zweitens auf die politischen Verhältnisse der Königreiche mit ihren zum Teil konkurrierenden Raumvorstellungen. In Aragón, auch in Kastilien, Frankreich und England griff das Königtum stark in die Verhältnisse der Kirche ein, mit der Folge, daß auch die Synoden einen „herrschaftlich-politischen Charakter“ erhielten. Der König von Aragón war es, der massiv auf die Abhaltung von PS der einzigen Metropole

50 Sánchez Herrero, Los Concilios provinciales. T. 2 (wie Anm. 39), 123-148; ebd. 187 f.. Liste von 13 DS („sinodos") von Tarragona; Josep Raventos $i$ Giralt, Concilis Provincials Tarraconenses. Revisió dela cronologia, in: 25 anys de servei episcopal. Miscellánea Dr. Ramon Rorella i Cascante. Tarragona 1993, 179-191: 7 PS zwischen 1378 und 1429; Grohe, Das Provinzialkonzil von Tarragona (wie Anm. 39), 679 f.; Schmidt, Kirche - Staat - Nation (wie Anm. 3), 135. Wie des ofteren kommen die früher als Sánchez Herrero verfaßten Artikel ,Concilios nacionales y provinciales' und ,Sinodos ${ }^{6}$ des DHEE (wie Anm. 39) zu anderen Zahlen (84 PS bis 1560; 10 DS bis 1420, dann Lücke der DS bis 1566!). Weitere Literatur oben Anm. 39.

51 Sánchez Herrero, Los Concilios provinciales (wie Anm. 39), T. 1, 179 und 181 (Tabelle 2 und 4); T. 2, 163-166; vgl. aber Ferrer, Art. Sinodos (wie Anm. 39), 2489-2492.

52 Siehe aber jetzt die ausbaufahigen Ansătze bei Schmidt, Kirche - Staat - Nation (wie Anm. 3), 130-164, über PS in Italien, der iberischen Halbinsel, Frankreich, England, Schottland, Deutschland/ Böhmen, Ostmittel- und Nordeuropa. 
seines Reiches, Tarragona, hinwirkte, was die hohe Frequenz zu einem Teil erklärt. ${ }^{53}$ In einem verfassungsgeschichtlich hochinteressanten Vorgang ubernahmen PS unter königlicher Ägide ihre kirchliche Funktion gleichsam reichsweit, mutierten aber zugleich zu jenem besonderen Typus königlicher Klerusversammlungen mit politisch-fiskalischen Kompetenzen, wie man sie nur in Westeuropa kennt. ${ }^{54}$ In Kastilien war die Dominanz des Königtums ähnlich stark. Da aber die Circumskription der kirchlichen Raumordungen (Metropole Toledo etc.) sich hier nicht wie in Aragón mit denen des Reiches deckten, scheint der Monarch das Instrument regulärer kirchlicher PS bewußt nicht benutzt und stattdessen von Fall zu Fall eigene Reichssynoden berufen zu haben. ${ }^{55}$

Für andere Länder muß es hier mit einigen ausgewăhlten Zahlen sein Bewenden haben: Für Frankreich im Spätmittelalter liegen, soweit ich sehe, keine umfassenden Zahlen vor. ${ }^{56}$ Die fur die Provinz Tours zwischen 1201 und dem Ende des 15. Jahrhunderts ermittelten 31 PS - d. h. ca. alle acht Jahre eine Synode - müssen für (Nord-)Frankreich als ,guter Mittelwert' gelten, etwa gegenüber den Provinzen Reims mit 55, Sens mit vierzig einerseits, Rouen mit dreißig, Bordeaux achtzehn, Auch zwölf und Lyon nur neun PS. ${ }^{57}$ Ein Blick auf die zeitlichen Proportionen zeigt, daß das Gros der PS, kaum verwunderlich, in das 13. Jahrhundert fiel. ${ }^{58}$ Die politische Nutzung der PS durch das Königtum begegnet auch in Frankreich, insbesondere was die königsnahe Metropole Sens mit dem Suffraganbistum Paris betrifft. Die Krisen des 14. Jahrhunderts lockerten jedoch die Bindungen an die Krone; möglicherweise mit ein Grund dafür, daß seit der Mitte des Jahrhunderts bis zur hohen Zeit der französischen Schismapolitik um 1400 mit ihren nationalen Klerusversammlungen fast keine PS mehr stattfanden. ${ }^{59}$

Einige gesonderte Zahlen zu den erhaltenen Statuten und Statutensammlungen: Hier ist Frankreich das bisher einzige Land, dessen Statuten systematisch erfaßt sind. Artonne, Guizard und Pontal haben aus den 13 Kirchenprovinzen, inklusive Besançon (mit Basel) und Vienne (mit Genf und Lausanne) vom 13. bis zum 18. Jahrhundert - im folgenden nur bis zum Tridentinum ausgezăhlt -992 Statutensammlungen erfaßt, die an 107 Synodalorten

53 Überzeugend Schmidt, Kirche - Staat - Nation (wie Anm. 3), 133-140, dort die Literatur.

54 Vgl. oben bei Anm. 16.

55 Schmidt, Kirche - Staat - Nation (wie Anm. 3), 137-140. In Toledo konnte wohl aus diesem Grunde zwischen 1355 und 1473 keine PS stattfinden (ebd. 139).

56 Für die Zeit zwischen 888 und 1215 werden 495 Synoden gezăhlt; Pontal, Les conciles de la France capétienne (wie Anm. 40), 461-466 (Liste). Weitere Literatur oben Anm. 40.

57 Avril, Les conciles de la province de Tours (wie Anm. 40), 52 („,bonne moyenne“), ebd. 51-53 diese und weitere Zahlen.

58 Zum Beispiel Bourges 1200- ca. 1500: 26, davon allein zwischen 1227 und 1315: 15 PS, dann bis 1378 nur mehr eine (1336); Gaudemet, Le gouvernement (wie Anm. 12), 27 f. Anm. 114. - Die Reihe der DS in Frankreich scheint, wie fast überall, nach Maßgabe erhaltener Statuten, dichter gewesen zu sein; s. unten bei Anm. 79.

59 Schmidt, Kirche - Staat - Nation (wie Anm. 3), 140-150. 
erlassen wurden. ${ }^{60}$ Auch hier gewahrt man größte Differenzen: Angers (auch als Ort für die PS von Tours) weist 107 Mal Statuten auf, Cambrai 48, Nantes 38, Avignon 33, Tréguier 28 Mal, für andere Diözesen wie Angoulême oder Mende ist nur ein einziges Mal Statutenproduktion erhalten.

In ganz Italien, besonders aber im Süden, sind PS offenbar im gesamten Mittelalter überhaupt sehr selten. Zwischen 1484 und 1517 kann Miele überhaupt keine PS nachweisen ${ }^{61}$, im gesamten 15. Jahrhundert nur sechs, im 16. Jahrhundert nur zwei isolierte in Florenz 1517 und Benevent 1545, ehe dann mit Carlo Borromeo 1565 ff. eine neue Ära anbrach. Hatten Streit und Rivalităt der italienischen Kommunen die für PS nötige Kollegialităt ihrer Bischöfe gelähmt? Anders dürfte das Bild bei den DS ausfallen, eindeutig etwa für Florenz, Bologna, Ferrara; doch hier fehlen bisher übergreifende Kenntnisse. ${ }^{62}$ DS in Italien - das größte Desiderat überhaupt!

In Deutschland war die Zahl von PS relativ gering, welche die sechs deutschen Metropoliten, in ihrer für Europa singulären Stellung als Kur- bzw. als Reichsfürsten, zu veranstalten für nötig hielten. ${ }^{63}$ Für die Provinz Köln sind für die gesamte Zeit von 887 bis 1452 nur sechzehn PS eindeutig nachweisbar; der konsequente Jahresturnus hätte 575 Synoden ergeben! Signifikant erscheint auch die zwischen 1332 und 1423 liegende Unterbrechung von neunzig Jahren ohne PS, der von 1452 bis in die Zeit der Gegenreformation ebenfalls keine Synode mehr folgt. ${ }^{64}$ Für die elf Diözesen der Sprengel Bremen und Magdeburg hat jüngst

60 Artonne/Guizard/Pontal, Répertoire (wie Anm. 28). Zu den Genfer Statuten etwa auch Binz, Vie religieuse (wie Anm. 14), 172 f. Ein deutsches Beispiel: Wiegand, Diözesansynoden (wie Anm. 15), 325-336.

61 Miele, Concili provinciali (wie Anm. 41), 267-277, ebd. 274 f., über gelegentliche PS in Benevent als relativ ,konzilsfreudige‘ süditalienische Ausnahme. Ähnlich ders., Il concilio ,medievale‘ di Benevento del 1545, in: AHC 15, 1983, 322-356, ebd. 322 (,silenzio assoluto“). PS nur Venedig 1455, Mantua 1459 (während des Türkenkongresses Pius' II.!), Sassari 1463, Turin 1465, Benevent 1470, Salerno 1484. Vgl. Schmidt, Kirche - Staat - Nation (wie Anm. 3), 130-132.

62 Vgl. Trexler, Diocesan synods (wie Anm. 41), 297: „synods were more common than previously thought“, ebd. Anm. 6: Bologna DS 1455, 1481, 1482, 1483, 1535, 1549, 1551 usw., ebd. weitere Literatur. Zu Florenz: Trexler, Synodal law (wie Anm. 41). Gemeinsam auf Synodaltătigkeit zu untersuchen wären vor diesem Hintergrund die italienischen ,Reformbischöfe ${ }^{6}$ des 15 . Jh. wie Ludovico Barbo, Abt v. Sta. Giustina und Bf. von Treviso, oder Giovanni Tavelli, Bf. v. Ferrara, Pietro Barozzi, Bf. von Padua, und ganz besonders der berühmte Antonin, Ebf. von Florenz. Vermutlich hatte in Italien die Visitation gegenüber der Synode die höhere Bedeutung; vgl. oben Anm. 41.

63 Vgl. die Versuche einer politischen Deutung bei Schmidt, Kirche - Staat - Nation (wie Anm. 3), 156-162.

64 Storm, Die Metropolitangewalt (wie Anm. 35). - Weitere Beispiele, leider mit stark variierenden Untersuchungszeitrăumen: 1. Genf 1287 bis 1535: 25 DS; Binz, Vie religieuse (wie Anm. 14), 143-172, ebd. 172 f. Liste der 28 überlieferten Genfer Statuten. - 2. Würzburg 984 bis 1548: 34 DS, davon zwischen 1292 und 1548: 11 DS; Lang, Die Synoden (wie Anm. 37), 71 f. - 3. Straßburg 992 bis 1560: 20 DS, davon 4 vor 1201, Bündelungen (3 Synoden in 1 Jahrzehnt) in der Mitte des 13. und des 14. Jh., zwischen 1354 und 1423 eine Lücke von siebzig Jahren, ăhnlich derjenigen bei den Kölner PS; Sdralek, Die Straßburger Diöcesansynoden (wie Anm. 35). 
Wiegand neue exakte Frequenzdaten vorgelegt und dabei prinzipiell die Unsicherheiten der Quellenbelege aufgezeigt ${ }^{65}$ :

$\begin{aligned} \text { Bremen (1148-1517): } & \text { DS } 18+3 \text { (unsichere Synoden); PS } 11+3 \\ \text { Lübeck (1218-1530): } & \text { DS } 25+1 \\ \text { Ratzeburg (1217-1392): } & \text { DS } 7+1 \\ \text { Schwerin (1177-1520): } & \text { DS } 12+2 \\ \text { Magdeburg (1107-1403): } & \text { DS } 2+16 \text { (!); PS 6+9 } \\ \text { Brandenburg (1166-1512): } & \text { DS } 23+1 \\ \text { Havelberg (1288-1511): } & \text { DS } 26 \\ \text { Meißen (1130-1504): } & \text { DS } 8 \\ \text { Naumburg (1125-1507): } & \text { DS } 11 \\ \text { Merseburg (1174-1286): } & \text { DS } 9 \\ \text { Halberstadt (1120-1417): } & \text { DS } 58\end{aligned}$

Auffallend ist die Schwankungsbreite zwischen acht Synoden fur Meißen und immerhin 26 fur das kleine Havelberg. Aber noch weit darlber liegt mit 58 Synoden in 300 Jahren Halberstadt, davon allein 34 im 12. Jahrhundert; dies ist - nur durch die Gunst der Überlieferung? - geradezu rekordverdächtig.

Die äußerst geringe Synodaltätigkeit des Erzbistums Hamburg/Bremen (gegründet 831) ist beispielsweise „viel stärker von den ortsspezifischen Gegebenheiten her geprägt, als (...) andere Kirchenprovinzen", hier schlicht deshalb, weil es längere Zeit gar keine Suffraganbistümer gab. ${ }^{66}$ PS fanden nur unter Erzbischof Adalbert seit 1066 statt. Nach der Ordnung von 1160 (Aufteilung der rechts- und linkselbischen Gebiete auf die Kapitel Hamburg und Bremen) weist Hamburg eine einzige PS (1201) auf, während in Bremen dann sogenannte Generalsynoden ,ziemlich regelmäßig (...) zweimal jährlich“67 stattgefunden haben sollen.

In Schottland erfullte man die Normen des IV. Lateranum mit besonderem Eifer, Synoden tagten in großer Regelmäßigkeit. Den Hintergnund bildete das kirchenräumliche Dilemma, daß das Königreich lange keine eigene Kirchenprovinz besaß, sondern seine Bistümer Suffragane des englischen York waren. So kam es zu dem bemerkenswerten Phänomen, daß die schottischen Bischöfe gleichsam „eine provinziale Hierarchie imitierten“ und damit die Kongruenz von politischen und kirchlichen Grenzen Schottlands fingierten, indem eine

65 Wiegand, Diözesansynoden (wie Anm. 15), 325-336.

66 Horst Wolter, Die Synodaltătigkeit der Erzbischöfe von Hamburg-Bremen bis zum Jahre 1233, in: AHC 22, 1990, 1-30, hier 30.

67 Ebd. 29. 
„Provinzialsynode“ unter wechselndem Vorsitz eines schottischen Diözesanbischofs oft und intensiv tagte. ${ }^{68}$

Für die ,jungeuropäischen' Länder Skandinaviens und Ostmitteleuropas gilt zunächst: Die Einrichtung von Bistümern bedeutete nicht automatisch die Existenz von Synoden! Ob allerdings die „Defizite der kommunikativen Vernetzung, (...) die weniger verdichtete Herrschaftspraxis“ und die große Ausdehnung der Kirchenprovinzen „mehr als andernorts die synodale Aktivität" behinderten oder aber umgekehrt gerade besonders erleichterten bzw. nötig machten, sei vorerst dahingestellt. ${ }^{69}$ Der Aufbau eines Synodalwesens begann in diesen Ländern mit einer gewissen Verzögerung. Zunächst war die archaischere Kopplung mit weltlichen Reichsversammlungen noch die Regel.

Als Beispiele seien Ungarn und Schweden herausgegriffen: Ungarns erste DS ist erst 1096 für Gran nachweisbar. Für den Metropolitanverband Gran lassen sich zwischen 1256 und 1513, bei spärlicher Statutenproduktion, 42 DS belegen (davon eine Propsteisynode 1460 in Zips); zwei entfallen auf das 13. Jahrhundert, siebzehn auf das 14., neunzehn auf das 15., vier auf das 16. Jahrhundert; davon fanden achtzehn im Metropolitanbistum Gran, acht in Erlau, drei in Veszprém, zwei in Agram, die anderen je einmal in den sieben restlichen Bistümern statt. ${ }^{70}$ Die Synodenfrequenz in Polen erscheint, vor allem im 15. Jahrhundert, deutlich höher. ${ }^{71}$

Schwedens Synodalgeschichte läßt man gewöhnlich mit der 1248 in Skänninge unter Vorsitz des päpstlichen Legaten Wilhelm von Santa Sabina tagenden PS beginnen. Das kontinentale Vorbild erhellt unter anderem die Tatsache, daß die ersten erhaltenen Statuten (Bistum Skara 1280) die Pariser Statuten des Odo von Sully übernahmen. Bis 1491 sind für die - einzige - Metropole Uppsala immerhin 28 PS nachweisbar. ${ }^{72}$ Bei DS war angesichts der geringen Pfarrdichte auch die geistliche ,Personaldecke' der Synodenteilnehmer recht dünn. Ingers Studie zum Visitationswesen könnte die These wagen lassen, daß statt häufiger DS das unmittelbarere itinerante Kontrollmittel der Visitation vorherrschte. Gerade die geringe Pfarreidichte ließ die Diözesanvisitation auch leichter und schneller bewältigen als etwa in alteuropäischen Gebieten mit dichtem Pfarmetz.

Das Bild, das die oben aufgefuhrten Zahlen zu erzeugen vermögen, erweist sich als äußerst disparat. Auch innerhalb einzelner Länder schwankt die Frequenz zu verschiedenen

68 So Schmidt, Kirche - Staat - Nation (wie Anm. 3), 154-156; ebd. 150-154 zu England, dessen zwei Provinzen, eine große mit Canterbury, eine kleine mit York, aus ihren PS eigene politische Klerusversammlungen (Convocations) ausbildeten. Dazu demnächst andernorts mehr.

69 Ebd. 162-164 (162: Zitat).

70 Szentirmai, Die ungarische Diözesansynode (wie Anm. 44), 290 f. (Liste); Andriányi, Die ungarischen Synoden (wie Anm. 44), 543-549; weitere Literatur oben Anm. 44.

71 Besonders hohe Frequenz weist Gnesen auf, für die Zeit von 1400 bis 155037 DS, zum Vergleich Posen im selben Zeitraum nur 14 DS; Sawicki, Geschichte (wie Anm. 42), 421, 425; weitere Literatur oben Anm. 42.

72 Inger, Das kirchliche Visitationsinstitut (wie Anm. 12), 356 f., 487 f.., zu den Synoden auch ebd. 355-375, 487-495; Gagnér, Zur Entstehung (wie Anm. 43), 26; Kroon, Det svenska prästmötet (wie Anm. 43), 172 (Sully-Rezeption) und passim; Schmidt, Kirche - Staat - Nation (wie Anm. 3), 162-164; weitere Literatur oben Anm. 43. 
Zeiten, von Diözese zu Diözese - und dies scheinbar ohne eine evidente Logik. Individuelle Faktoren wie die Person der Bischöfe und ihr synodaler Eifer spielten sicherlich eine Rolle, ebenso aber kirchenpolitische Trends (nach dem IV. Lateranum oder dem Basler Konzil) wie das Maß königlicher Eingriffe in die Kirchenverwaltung. Was läßt sich also mit derartigen, noch dazu meist fragmentarischen Zahlen anfangen? Zunächst ist das relativ hohe Maß an Quantifizierbarkeit als erfreuliches Faktum hervorzuheben, schließlich ermöglicht diese die leichteste und schlankeste Form des Vergleichs. Daß Statistiken stets auch Pseudostatistiken sind, ist allzu gut bekannt. Die Forderung ,ponderandi - non numerandi“ macht durchaus auch hier Sinn. Die Statistik ersetzt natürlich nicht die genaue Einzelbewertung des politischen Umfelds, der Einbettung in die lokale Synodaltradition, vor allem aber die qualitative und quantitative Gewichtung der promulgierten Gesetze bzw. ihrer Verschriftlichung und der Anzahl uberlieferter Texte. Ein zureichendes Qualitătskriterium für den ,Erfolg einer Synode lăßt sich aus den Überlieferungszahlen kaum aufstellen, es fehlt zum Beispiel völlig die unmittelbare spirituelle Wirkdimension.

In jedem Fall haben Synoden mit weltlichen Versammlungen gemeinsam, daß allein schon ihr bloßes Zustandekommen, das Tagen und Miteinanderhandeln selbst, einen wichtigen Akt politischer Intensităt darstellte. Insofern bedeutet aber auch höhere Quantităt (Frequenz) von Synoden höhere politische bzw. geistliche Intensităt, und das heißt: Qualităt. Die Frequenzziffern deuten auch deshalb über die bloße Quantität hinaus, weil das Abhalten von Synoden als solches die Erfullung einer kanonischen Norm darstellte. ${ }^{73}$ Die Forschung hat sich fur die Frage, ob die Partikularsynoden regelmäßig stattanden, stets interessiert, quantitativ im Hinblick auf synodale Periodizităt, qualitativ im Sinne der Frage, ob die Bischöfe ihr Amt pflichtbewußt ausübten; und das taten sie - so die moralische Prämisse -, wenn oder indem sie Synoden abhielten. In reformbewegten Zeiten wie der Epoche der ,Reform'konzilien im 15. Jahrhundert erklärte man die kirchlichen ,Mißstände' kausal vor allem damit, daß keine oder zuwenig Synoden stattgefunden hätten. Regelmäßig abgehaltene Synoden auf allen Ebenen werden so zum Beweis von Reformwillen aufgewertet. ${ }^{14} \mathrm{Da}$ es darauf im 15. Jahrhundert tatsächlich zu gesteigerter Synodaltätigkeit in vielen Diözesen kam, wird in der Forschung kaum mehr bezweifelt. ${ }^{75}$

Was die Periodizităt der PS betrifft, so gibt Hinschius' Ansicht wohl immer noch grob den heutigen Urteilsstand wieder, daß nämlich „auch nach Auflösung des karolingischen Reiches von einer regelmässigen Abhaltung (...) keine Rede“ sein kann, sondern PS nur „hin

73 Siehe oben bei Anm. 19 und 24.

74 Helmrath, Reform (wie Anm. 27), 80 f. Zugleich erhöht man für die (Erz-)Bischöfe den Pflichtdruck durch verschärfe Sanktionen; betont bei Schmidt, Kirche - Staat - Nation (wie Anm. 3), 126-129.

75 Erich Meuthen, Das Basler Konzil als Forschungsproblem der europäischen Geschichte. (Rheinisch-Westfalische Akad. der Wiss., Vorträge G: Geisteswissenschaften, Bd. 274.) Opladen 1985, 12 f. mit Anm. 26; ders., Die deutsche Legationsreise (wie Anm. 27), 451 f.; ders., Die Synode im Kirchenverstăndnis des Nikolaus von Kues, in: Staat, Kultur, Politik - Beitrăge zur Geschichte Bayems und des Katholizismus. Fschr. zum 65. Geburtstag von Dieter Albrecht. Kallmünz 1992, 11-25, 12 f. jedes Mal dezidiert gegen Leinweber, Provinzialsynode (wie Anm. 12), 126 f., der ein Nachlassen der Synodaltatigkeit im 15 . Jh. behauptete. 
und wieder" einberufen wurden. ${ }^{76}$ Auf die DS läßt sicch diese Sicht freilich nicht unbesehen übertragen; hier geht die jüngere Forschung eher davon aus, daß sie ,hăufiger istattfanden, ais man früher angenommen hat" ${ }^{* 77}$. Ja man vermutet sogar eine jährliche oder - seltener hallbjährliche Regelmäßigkeit, eine geräuschlos selbstverständliche sozusagen, da oft jeder Beleg fehlt. ${ }^{78}$ Von systematischer Prüfung dieser Annahme kann denn auch bisher keine Rede sein. Allerdings sind schon oben für Spanien (Tarragona, Gerona) vereinzelt grőßere Segmente eines nachweislich lückenlosen 'Turnus aufgetaucht. Weitere Beispiele aus anderen Regionen lassen sich in einer so nennenswerten Zahl ergänzen, daß kaum mehr von seltenen Ausnahmen zu sprechen ist. Die bretonische Diözese Tréguier weist 1435-40 eine Serie auf, die sogar für jedes Jahr Statuten aufweist, für das kleine Bistum Speyer werden zwischen 1464 und 1513 fast jedes Jahr zwei DS angenommen ${ }^{79}$, für Hildesheim sogar eine Frequenz von bis zu vier DS pro Jahr, freilich im 11./12. Jahrhundert, nicht mehr im spăten Mittelalter. ${ }^{80}$

Um sich abschließend die Quantitäten zu verdeutlichen: Unterstellte man in den elf ungarischen Bistümern über die oben angesetzten 260 Jahre einen regulären Jahresturnus, so hätten theoretisch allein in Ungarn nicht weniger als 2860 DS stattgefunden! Nach Mā̄igabe der bisher tatsächlich belegten 42 Synoden fand dort rein rechnerisch aber nur alle 65 Jahre eine Synode statt. ${ }^{81}$

\section{Die Materien europäischer Synodalstatuten}

Kommen wir zum zweiten Schritt, der inhaltlichen Analyse: Die Materien der Statuten umfassen ein breites Spektrum. Sie betreffen zum größeren Teil den Klerus, zum kleineren die Laien, oft geistlich-weltliche Zwischenbereiche. Es geht um Glaubens- und Sakramen-

76 Hinschius, Das Kirchenrecht (wie Anm. 11), 483. Ähnlich später, hier stellvertretend für viele andere, Gaudemet, Le gouvernement (wie Anm. 11), 27: „Toute hypothèse sur leur périodicité est donc vaine“. Von Avril, L'évolution (wie Anm. 12), 324, auch auf die DS bezogen.

77 Erich Meuthen, Das 15. Jahrhundert. (Oldenbourg Grundriß der Geschichte, Bd. 9.) 3. Aufl. Müncheñ 1996, 16.4; abgewogen urteilte bereits Hauck, Kirchengeschichte (wie Anm. 11), Bd. 5, 166 t.

78 Schon Maring, Diözesansynoden (wie Anm.16), 75: „daß in dieser Zeit [sc. i.m Spătmittelalter; J. H.] die Synoden ziemlich regelmaßßig gehalten wurden".

79 Tréguier: Artonne/Guizard/Pontal, Répertoire (wie Anm. 28), 457 f. - Speyer. Frānż Xāuèr Rèmling, Geschichte der Bischöfe zu Speyer. Bd. 2. Mainz 1854, 145-222. - Ähnlich für Köln Janišsēen, Unbekannte Synodalstatuten (wie Anm. 35), 113, nach Gescher, Die kölnischen Diözesansynodeñ (wie Anm. 35), 216-237. Für Genf zu Beginn des 13. Jh. B̈inz, Vie religieuse (wie Anm. 14), 145, über dén Genfer Bischof Aymon de Grandson: „plusieurs témöinss cërtifient qu'Aymoñ a régulièrement convoqué le synode chaque année dans sa cathédrale ou ailleurs".

80 Es wurden „bis zum Anfang des 11. Jh. jăhrlich mehrere, dann in der ersten Hälfte dés 11. Jh. vier, in der folgenden Zeit bis zum Ende des 12. Jh. drei, bis 1260 zwei Synoden gehalten“; Maring, Diöztsansynoden (wie Anm. 16), 10.

81 S. oben bei Anm. 70. 
tenlehre, den Schutz der libertas ecclesiae und der Klerusprivilegien ${ }^{82}$, um Benefizialpraxis, Lebensweise und Moral der Kleriker (de vita et honestate clericorum), Exkommunikation und Interdikt, Richtlinien für die Katechese, aber auch um Matrimonialia und Testamente, Juden und Sekten sowie die Orden (Klausur etc.) ${ }^{83}$; auch die Wirtschaft (Wucherverbot etc.) und Agrarwelt fehlen nicht. ${ }^{84}$

Eine übergreifende typologische Untersuchung der Statuten und Statutensammlungen, die sich etwa mit den Schemata ihres Aufbaus beschäftigte, gibt es, soweit ich sehe, nicht. ${ }^{85}$ Offenbar herrschte hier Pluralismus. Deutlich lag oft grob die Einteilung des Liber Extra bzw. des Liber Sextus zugrunde, was als Indiz für den Angleichungsprozeß der Statutensammlungen an die allgemeinen kirchlichen Gesetzbücher gewertet werden könnte. ${ }^{86}$ Hăufig stehen ausfuhrlich die Glaubens- und Sakramentenlehre (Trinităt, Credo, sieben Sakramente etc.) am Anfang, damit auch inhaltlich Priorităt signalisierend. ${ }^{87}$ In anderen Fällen bilden die bischöflichen casus reservati den ersten Teil, usw. ${ }^{88}$

82 Als Thema vor allem in der reichskirchlichen Statutengesetzgebung dominant; Wiegand, Diözesansynoden (wie Anm. 15), 54 f.

83 Hinschius, Das Kirchenrecht (wie Anm. 11). Bd. 2. Berlin 1878, 492-494, systematisierte die Aufgaben der PS vierfach: legislative Aufgaben, Strafgewalt (u. a. gegen Übergriffe von Laien), kirchenorganisatorische Geschăfte (etwa Auflagen zu Lasten des Klerus, Kreuzzugssubsidien etc.) sowie die Lehre (Glauben, Ketzerei etc.). Einen umfangreichen Katalog möglicher Materien bietet Sánchez Herrero, Los Concilios provinciales (wie Anm. 39), 162-169. Gute Zugănge eröffnen die Sachregister moderner Statuteneditionen: Statuts synodaux français (wie Anm. 40); Avril, Conciles de Tours (wie Anm. 40), 495-501; Wiegand, Diözesansynoden (wie Anm. 15), 351-368.

84 Zum Wucherverbot s. unten Anm. 108. Zum Agrarischen etwa Avignon 1326: Ne laici praetextu alicuius statuti prohibeant clericos extrahere blada de terris ipsorum; Mansi, Sacrorum Conciliorum nova et amplissima Collectio (wie Anm. 22), vol. 25, 762; PS Auch 1326: Quod decima praeferatur angariis; ebd. 787.

85 Siehe aber Avril, Livre de Guillaume de Trie (wie Anm. 40), 200 f.; Kehrberger, Provinzial- und Synodalstatuten (wie Anm. 13); Johanek, Synodalia (wie Anm. 13).

86 Beobachtet bei Kehrberger, Provinzial- und Synodalstatuten (wie Anm. 13), 4. Er nennt die Statuten der PS Mainz 1310 als erstes derartiges Beispiel in Deutschland, das bei der Modellbedeutung dieser Sammlung (s. bei Anm. 92) nachgeahmt wurde, etwa in Magdeburg 1370 oder Salzburg 1420; Schannat/Hartzheim, Concilia Germaniae (wie Anm. 33), Bd. 4, 411 f.; Bd. 5, 171 f. Statt vieler möglicher Beispiele: Bf. Wolfram von Würzburg DS Würzburg 1329: Er habe das Statutenmaterial (quaedam de jure communi, nonnulla vero de provincialibus [...] archiepiscoporum Moguntinarum ac etiam predecessorum nostrorum causa brevitatis excerpta et extracta) in huius libellum sub certis titulis decretalium redigi mandavimus; Polonyi, Synodale Gesetzgebung (wie Anm. 37), 42 Anm. 41 nach Himmelstein, Synodicon Herbipolense (wie Anm. 34), 136 f. 1341 wurde aber nach anderen Kriterien geordnet; Polonyi, Synodale Gesetzgebung (wie Anm. 37), 43 Anm. 49, nach Sdralek, Die Straßburger Diöcesansynoden (wie Anm. 35), 32. Gleiche Ordnung auch außerhalb Deutschlands, etwa in Florenz 1346; Mansi, Sacrorum Conciliorum nova et amplissima Collectio (wie Anm. 22), vol. 26, 23-74.

87 Gerade diese Passagen konnten sich zu handbuchähnlichen Sammlungen auswachsen, wie etwa das in Sudfrankreich verbreitete Synodale von Rodez 1289; Mansi, Sacrorum Conciliorum nova et amplissima Collectio (wie Anm. 22), vol. 24, 963-1056. Vgl. Gaudemet, Le gouvernement (wie Anm. 12), 179; Guillemain, L'exercice (wie Anm. 12), 104 f.

88 In den umfangreichen Statuten von Novara 1298 fullen die Reservatfalle mehr als ein Drittel des Gesamttexts; Briacca, Gli statuti sinodali (wie Anm. 41), 169-213. 
Als Grundlage einer thematischen Auswertung wäre, wie gesagt, die breite Erfassung aller Einzelstatuten nötig. Die Computerisierung verlangt einen standardisierten Themenkatalog, mit dessen Hilfe sich alle einzelnen capitula angemessen subsumieren lassen. Er könnte sich zunächst an den überlieferten Kapitelüberschriften (Tituli), zum Beispiel De excommunicatis, de matrimoniis clandestinis etc., orientieren. Die Tituli sind jedoch oft später hinzugefügt oder fehlen ganz, so daß eigene Ordnungsrubriken kreiert werden müssen.

Anhand dieser Grundlagen läßt sich ein differenziertes Spektrum an Fragen entwickeln: Wie gemeinkirchlich sind diese Gesetze? Gibt es Verordnungen, die flächendeckend mehr oder weniger gleichmäßig überall und in gleicher Intensität präsent auftreten? Immer dasselbe zwischen Burgos und Uppsala? Oder inwiefern unterliegen auch sie der Kontingenz regionaler Bedingungen und spiegeln diese in einer vergleichend profilierbaren Weise wider? Gibt es ferner Statuten, die zu gewissen Zeiten dominanter auftreten, die in anderen Zeiten aber an Zahl und Umfang abflauen oder ganz verschwinden? Den Anfang machen würde die diachronische Analyse der Statutenkonfiguration einer Diözese und ihrer Veränderungen, jeweils in Längsschnitten, zum Beispiel bis 1200 (bis 1400, bis 1500). Dies könnte in einem nächsten Schritt dann auch vergleichend geschehen. Auf dieser Basis könnte der Fragehorizont dann auf Provinzen und vor allem auf Länder ausgedehnt werden. Gibt es etwa in Schweden (in Aragón) bestimmte Materien, die häufiger als in anderen benachbarten oder entfernten Ländern eingeschärft werden oder die sogar singulär sind? Bzw. welche Materien kommen überall vor und sind überall gleich formuliert?

Diese Frage lenkt auf das schwierige, für eine methodenbewußte Synodenforschung zentrale Problem der Rezeption. Auf welche Weise kommen Verordnungen ,von oben' (päpstliche Dekretalen, Dekrete allgemeiner Konzilien) - nach der Bestimmung von Sicut olim (IV. Lateranum) - ,unten', also über die PS bei den DS, an und werden kirchliches Partikularrecht? Mindestens die folgenden Varianten sind möglich: a) direkte vollständige oder partielle Implementierung bzw. Übernahme der Statuten von Generalkonzilien, anderen PS; b) Anpassung/Modifikation von Bestimmungen des allgemeinen Kirchenrechts an lokale Verhältnisse; c) okkasionell auf Regionales reagierende Statuten; d) regionale Eigenmixturen, die regional oder darüber hinausreichend, einzeln oder im Set iteriert werden oder aber nur einmalig auftauchen.

Es scheint an dieser Stelle angemessen, sich die Grundbedingungen statutarischer Überlieferung kurz zu verdeutlichen, mögen sie auch dem Kanonisten gut vertraut sein: Statuten bestehen aus Bausteinen (canones) oder - um einen Fetischbegriff zeitgenössischer Universitătsreform anzuwenden - aus einzelnen ,Modulen'. Diese können variabel kombiniert werden und dann einzeln zirkulieren (bzw. rezipiert werden) oder aber, und dies ist die Regel, in Ensembles. Angelt man im Statutensee und zieht einen Fisch aus dem Wasser, hängt meist gleich ein ganzer Schwarm an der Rute. Der jeweilige Grad der ,Modularisierung' muß erkannt werden, die einzelnen Texte identifiziert, d. h. in der Regel auf ihre Herkunft zurückverfolgt werden.

Das wohl berühmteste Beispiel bilden die Pariser Statuten des Bischofs Odo von Sully aus dem Jahr 1208; sie fanden als eine Art „gemeinsamer Grundstock fur Synodalstatuten“ 
europaweite Verbreitung. ${ }^{89}$ Die Statuten von Nîmes (1252), ein veritables Buch, das wesentlich der gelehrte Jurist Pierre de Sampson im Auftrag des Bischofs erstellt hatte ${ }^{90}$, wurden in Teilen nicht nur in Südfrankreich und Spanien rezipiert, sondern wanderten auch nach Krakau (1320) und von dort nach Gran (1382) sowie noch 1479 nach Breslau. ${ }^{91}$ In der Reichskirche erhielten die Mainzer Provinzialstatuten von 1310, welche die seit 1233 recht intensive Gesetzgebung zusammenfaßten, eine konstitutive Rolle für die folgenden Mainzer Statuten (etwa die des Kardinals Branda 1423) und fur die Gesetzgebung der Mainzer Suffraganbistümer, aber auch für Bamberg, fur die Magdeburger Statuten von 1389, die Salzburger von $1418 .^{92}$

So entstanden Konglomerate, die nur begrenzt ,originell' ${ }^{\star}$ waren, sondern zu einem hohen Prozentsatz - je später, desto mehr - aus einer Schnittmenge älterer Rechtsmaterie bestanden. ${ }^{93}$ Die Statuten von Avignon 1457 beispielsweise bestehen aus älteren ordinaciones in concilio S. Rufi (Kloster St. Ruf bei Marseille) (c. 1 und c. 27), aus ,Modulen' der letzten PS in Arles (c. 2) und des Allgemeinen Konzils von Vienne 1311 (c. 6 uber die congrua portio), schließlich aus dem Basler Konzilsdekret von 1439 über die Immaculata Conceptio Mariens. ${ }^{94}$ Die 1298 unter Bischof Papinianus della Rovere erlassenen Statuten des lombardischen Novara - sie fullen in der Edition nicht weniger als 110 Seiten! - enthalten Material aus Gratian und dem Liber Extra, aus dem Synodalbuch des Guillelmus Durandus von Mende (1291-95), den oben genannten Statuten von Nîmes 1252, einer Kölner Synode,

89 Falkenstein, Rez. Avril, Les statuts synodaux de Jean de Flandre (wie Anm. 36), 594. Sullys Statuten ediert bei Pontal, Les statuts synodaux français. Vol. 1 (wie Anm. 28), 3-101. Statt vieler Einzelbeispiele für ihre Rezeption siehe Peter Johanek, Die Pariser Statuten des Bischofs Odo von Sully und die Anfänge der kirchlichen Statutengesetzgebung in Deutschland, in: Proceedings of the Seventh International Congress of Medieval Canon Law, Cambridge 1984 (MIC, Ser. C: Subsidia, vol. 8.), Città del Vaticano 1988, 327-347; Avril, Statuts synodaux français (wie Anm. 40), vol. 4, 213-256 (Aufweis für die Statuten von Noyon); zuletzt Avril, Livre de Guillaume de Trie (wie Anm. 40), 193, 197 f., zu den Quellen des Reimser Synodalbuchs von ca. 1330, einer „encyclopédie confuse et désordonnée“. Die praktische Funktion bestand vor allem darin, den Priestern als Leitfaden für ihre Befragung durch den Bischof auf der DS zu dienen.

90 Odette Pontal (Ed.), Les statuts synodaux français du XIII' siècle. Vol. 2: Les statuts de 1230 à 1260. (Collection de documents inédits sur l'histoire de France, Série in $8^{\circ}$, vol. 15.) Paris 1983, 237-453.

91 Vgl. Nachweise bei Erdö, Polnische Quellen (wie Anm. 44).

92 Untersucht von Kehrberger, Provinzial- und Synodalstatuten (wie Anm. 13), passim. Vgl. Hauck, Kirchengeschichte (wie Anm. 11), Bd. 5, 138 f., 144 f.; Johanek, Vescovo (wie Anm. 12), 115. Eine PS wurde nach 1310 in Mainz (und Trier) das ganze Jh. über nicht mehr gehalten. Vgl. Polonyi, Synodale Gesetzgebung (wie Anm. 37), 38 f. Die Vorbildfunktion der Statuten von Kleriker-Bruderschaften für Synodalstatuten in Italien wie überhaupt deren Bedeutung für die synodale Korporation ,des Klerus' zeigt Trexler, Diocesan synods (wie Anm. 41), 320 f.. und 310-323.

93 Vgl. Avril, Les conciles de la province de Tours (wie Anm. 40), 53: „Les législations manquent souvent d'originalité".

94 Mansi, Sacrorum Conciliorum nova et amplissima Collectio (wie Anm. 22), vol. 32, 186B. - Gelegentlich werfen die Handschriften selbst in den tituli Identifikationen aus (ex concilio Lateranensi oder ähnlich), meistens jedoch geschieht es nicht. 
gemeinsamen Statuten der Diözesen Cahors, Rodez und Tulle von 1289 sowie älteren Statuten der Diözese Novara selbst von 1257 und 1277 (Corpus statutorum). ${ }^{95}$

Das Statutenprofil einer einzelnen Diözese oder Kirchenprovinz hat also über die Jahrhunderte eine Evolution in Etappen, die dann, wie oben angedeutet, oft in Statutensammlungen (Synodalia) gebündelt wurde. ${ }^{96}$ Es zeigt sich auch, daß die Statutenreihen einander ergänzten, modifizierten, aktualisierten: Die Mainzer Provinzialstatuten von 1225 enthalten vierzehn Kanones, davon funf über Sexualităt, vier über Exkommunikationspraxis, drei über Simonie; in den Statuten von 1259 sind darüber hinaus klandestine Ehen, Sedisvakanz, Beginen, Kapellen, die Tracht von Mönchen und Judenzeichen thematisiert; 1261 kommen ausführliche Kapitel über liturgische Gerăte, den Versehgang, die Spendung der Sakramente, Predigt, Altäre, den Patronat, Verbot der Hehlerei etc. dazu. So lassen sich Sets von ,Mutterstatuten' beobachten, die provinzintern oder ubergreifend immer wieder mehr oder weniger erneuert ${ }^{97}$, ergănzt, manchmal auch ausdrücklich ersetzt wurden. ${ }^{98}$ In Mainz nahmen die genannten Statuten von 1310 (also nicht unbedingt die frühesten), im exemten Bistum Kammin die Statuten von 1352, die 1454 und 1500 zu großen Teilen rezipiert wurden, diese Rolle von Mutterstatuten ein; in Köln waren es die von 1322, in Buda diejenigen von $1279 .^{99}$ $\mathrm{Da}$ Iteration von Gesetzen nur mit großer Vorsicht als Indiz von ,Nichtbefolgung' gedeutet werden kann, dürfte allgemein einleuchten. Es ist vielmehr die Vorstellung angemessen, daß es einen fur unverzichtbar gehaltenen Grundstock von Regeln gab, den man immer wieder glaubte einschärfen zu müssen. Insofern signalisiert das Auftauchen einer Materie, mag es sich auch um eine oft iterierte handeln, natürlich in irgendeiner Form deren Relevanz für den Statutenerlasser. ${ }^{100}$ Auf längere Sicht konnte es zur Bildung und Pflege einer eigenen Rechtstradition kommen. Es entstanden „synodale Kirchenrechtslandschaften“, wie jüngst am Beispiel Kammins und der norddeutschen Nachbardiözesen eindrucksvoll demonstriert

95 Briacca, Gli statuti sinodali (wie Anm. 41), 169-279.

96 Als Modell s. Avril, Remarques (wie Anm. 40), bes. 199. Vgl. oben bei Anm. 86-88.

97 Als Beispiel der găngigen Formeln PS Tours 1282: Item, omnia alia et singula statuta provincialia tam a nobis quam a predecessoribus nostris bone memorie archiepiscopis Turonensibus hactenus edita renovantes presentis auctoritate concilii confirmamus; Avril, Les conciles de la province de Tours (wie Anm. 40), 287 f. c. 13.

98 Das Recht, alte Statuten secundum varietatem temporum zu ăndern, findet sich für PS ausdrücklich formuliert, so PS Rouen 1313; Mansi, Sacrorum Conciliorum nova et amplissima Collectio (wie Anm. 22), vol. 25. Bei Kollision sollten alte Statuten, falls sie neuen faktisch widersprachen, per se als aufgehoben gelten; ebd. 526B.

99 Letztere adaptierten wiederum ältere Statuten aus Avignon 1209, Rouen 1231 und Wien 1267; Andriányi, Die ungarischen Synoden (wie Anm. 44), 546. - Die frühen Statuten einer dănischen PS von 1257 bestehen nur aus vier Paragraphen, die aus Briefen Papst Alexanders IV. genommen waren, betreffend die Bestrafung von Übergriffen auf Bischöfe; Mansi, Sacrorum Conciliorum nova et amplissima Collectio (wie Anm. 22), vol. 23, 945 f.

$100 \mathrm{Da} \beta$ der Umkehrschluß, das, Fehlen' einer Materie in Statuten lasse auch auf die Absenz des inkriminierten Faktums schließen, unzulässig ist, versteht sich von selbst. 
wurde. ${ }^{101}$ Sie formten dann ihrerseits „das Normenbewußtsein von Klerus und Kirchenvolk“. ${ }^{102}$

Für unser Projekt ergibt sich freilich ein schweres Dilemma: Die Einzelstatuten müssen einerseits in ihren Kontexten, Ketten und Sammlungen betrachtet werden, andererseits erfordert eine systematisch vergleichende Analyse bestimmter Materien die Auflösung, gleichsam die Atomisierung der Einzelstatuten. Es ist dies wohl eines der heikelsten Probleme des Projekts. Eine elegante Lösung sehe ich momentan noch nicht.

Die Frage der legislativen Urheberschaft und Rezeption (,Allgemeine Normierung von oben oder lokal gewachsenes Eigenprofil?') ist in der Forschung mit dem wichtigen Problem des ,Realitätsbezugs' vor allem der Diözesanstatuten verknüpft worden, ein Problem, das sich beim Umgang mit normativen Texten grundsätzlich stellt. Bilden die Statuten in den Materien ihrer Gebote und Verbote ,Realităt' ab? Erfolgte die „Selektion der Vorschriften (...) im Hinblick auf die gegebenen Verhältnisse“? ${ }^{103}$ Bzw. wie flexibel ,reagierte' Statutengesetzgebung auf verănderte Situationen? Die Frage provozierte kontroverse Sichtweisen. Otto Kehrberger (1938) hatte die Statutentransmission unter sulddeutschen PS und DS des 15. Jahrhunderts untersucht und zog den extremen Schluß, Synodalstatuten seien „nichts anderes als geschichtlich gewordene allgemeine Gesetzsammlungen über die verschiedensten Gebiete des kirchlichen (...) Lebens, ohne durch den einzeln stehenden Fall veranlaßt zu sein". Sie seien also so gut wie nie Reflex lokaler Zustände und nichts weniger als ein ,Sittengemälde' derselben. ${ }^{104}$ Dieser in der Kanonistik verbreiteten Sicht schloß sich tendenziell, aber abwägender Peter Johanek an und sprach von Anpassung päpstlichen Rechts an die lokalen Gegebenheiten ${ }^{105}$, wogegen etwa Odette Pontal im Anschluß an Gabriel LeBras im gegenteiligen Sinne widersprach, daß nämlich „la plupart des canons conciliaires sont provoquées par les affaires locales ${ }^{\star 106}$. Eine realistische Sicht muß wohl zwischen der

101 Wiegand, Diőzesansynoden (wie Anm. 15), bes. 135-141: „Zur Existenz partikularer Kirchenrechtslandschaften“. Vgl. für Köln Janssen, Unbekannte Synodalstatuten (wie Anm. 35), 114-119.

102 Johanek, Methodisches zur Verbreitung (wie Anm. 28), 98.

103 Borgolte, Die mittelalterliche Kirche (wie Anm. 10), 94. Vgl. auch unten bei Anm. 126.

104 Kehrberger, Provinzial- und Synodalstatuten (wie Anm. 13), 117. „Als Quelle für volkstümliche Sonderheiten oder Gebrăuche kőnnen die Statuten wohl nur in den seltensten Fällen herangezogen werden"; ebd. 109.

105 Johanek, Methodisches zur Verbreitung (wie Anm. 28), 96: „Die auf den Partikularsynoden erlassenen Statuten begrundeten kein neues Kirchenrecht mehr ... Vielmehr erlăuterten, ergănzten und prăzisierten sie das păpstliche Recht, paßten es den lokalen Gegebenheiten an“. Das Gros der Kanonisten, weniger der Historiker, dürfte sich dieser Richtung anschließen.

106 Pontal, Les statuts synodaux (wie Anm. 28), 79. Pontal denkt vor allem an Gerichtsfalle; vgl. dazu oben Anm. 23 und 26. Vgl. Avril, L'évolution (wie Anm. 12), 317, mit dem grundsătzlichen Hinweis auf die „propres coutumes“ jeder Diסzese. In diesem Sinne auch Borgolte, Die mittelalterliche Kirche (wie Anm. 10), 95: „Im einzelnen geben die Diøzesanstatuten ein hochst anschauliches Bild von dem kirchlichen Alltagsleben des Spătmittelalters, auch wenn der ,Realitătsbezug' im einzelnen strittig sein mag." Sehr vorsichtig Rudolf Holbach, Stiftsgeistlichkeit im Spannungsfeld von Kirche und Welt. Studien zur Geschichte des Trierer Domkapitels und Domklerus im Spătmittelalter. (Trierer Hist. Forsch., Bd. 2.), Bd. 1, Trier 1982, 275: „Sie [die Statuten; J. H.] stellten also nicht nur eine spezielle Reaktion auf lokale Mißstănde dar.“ 
Vorstellung eines hierarchisch durchnormierten, von oben nach unten implementierten Rechts und einer regional gewachsenen Partikularrechtslandschaft vermitteln, die auch statutarische ad-hoc-Entscheidungen, etwa auf Grund von Erfahrungen des Bischofs während der Visitation, zuließ. ${ }^{107}$ Die genrebedingte Sprödigkeit der Textsorte ,Synodalstatuten sollte man dabei nicht überfordern.

Bei aller Vorsicht scheint uns doch evident, daß gerade auf der untersten Ebene der Diözesanstatuen nicht selten ein unleugbarer Rest an ,Sondergut' erkennbar bleibt, unmittelbare Anspielungen auf lokale Orte, Institutionen, Praktiken, unverkennbare Reaktion auf Mißstände vor Ort etc., darunter manches kurios Anmutende. Einige der Möglichkeiten, derartige Materien im Rahmen des Projekts zu untersuchen, seien hier, ohne Verifikation durch vergleichende Studien, lediglich zur Diskussion gestellt:

Während kirchenrechtliche Sonderthemen wie etwa die in der allgemeinen Gesetzgebung einschlägig verankerten Bestimmungen zu Juden ${ }^{108}$ und Ketzern besondere Chancen eines flächendeckenden Vergleichs bieten, lenken Semireligiosen und Beginen ${ }^{109}$ in ihren vielfältigen, überhaupt nur mehr lokal regelbaren Ausprägungen den Blick stärker auf das Besondere. Weniger lokale Besonderheiten als vielmehr veränderte Bedürfnisse und Wandlungen des allgemeinen Zeitgeschmacks offenlegen könnte über Jahrhunderte hinweg ein Thema wie die ,Priestermode' (de vestitu clericorum). ${ }^{110}$ Weitere Statutenmaterien, die durchweg in besonderem Maß in lokaler Prägung aufzutauchen scheinen:

1. Lokale Kirchen und Sakralorte, die bisweilen explizit in den Statuten erwähnt sind. ${ }^{111}$

107 Rubellin, Les statuts synodaux (wie Anm. 12), 127: „Le produit de l'experience personelle de chaque évêque leur foumit aussi des éléments pour la rédaction de leur statuts." Mit Beispielen von Bekundung eigener Erfahrung des Bischofs in Statuten nach Avril, Les statuts synodaux français (wie Anm. 40), vol. 3, 110, 112, 116. - Anders gelagert ist etwa das folgende Beispiel: Die Salzburger PS von 1281 ordnet ein Psalmgebet per praesentis anni decursu an; Mansi, Sacrorum Conciliorum nova et amplissima Collectio (wie Anm. 22), vol. 24, $385 \mathrm{f}$. Methodisch blauăugig wăre vollends Goldwăscherei der Art: Man eliminiere alles Ältere und ,von oben' Rezipierte und behalte dann das regionale Sondergut rein und glänzend zurlick.

108 Vgl. Legatensynode Wien 1257, wo von 19 Kapiteln sechs die Juden betreffen; Mansi, Sacrorum Conciliorum nova et amplissima Collectio (wie Anm. 22), vol. 23, 1167-1176. PS Avignon 1457: Juden sollen ein Abzeichen tragen, dürfen keine christlichen Ammen haben, kein Fleisch bei christlichen Metzgern kaufen; ebd. vol. 32, 190 f., c. 24-26. Dazu kommen (c. 27) Gesetze gegen den Wucher, die oft implizit Judengesetze darstellten; etwa PS Lambeth 1331 (für Canterbury): Verbot des Versetzens sakraler Gegenstănde; ebd. vol. 25, 895; besonders umfangreich DS Ferrara 1332; ebd. 923B-925A (De usurariis). Zur umfangreichen Literatur hier nur Michael Toch, Die Juden im mittelalterlichen Reich. (EdG, Bd. 44.) München 1998, bes. $107 \mathrm{f} ., 145 \mathrm{f}$.

109 Die Beginen sind exemplarisch für die Kirchenprovinz Mainz untersucht; Polonyi, Synodale Gesetzgebung (wie Anm. 37), 33, 49, stellt dabei die deutliche Präzedenz der regionalen (Mainz 1233) vor der zentralen päpstlichen Gesetzgebung fest.

110 Vgl. Wiegand, Diözesansynoden (wie Anm. 15), 67. Natürlich stellen die Statuten nur einen Quellenbereich zur Erforschung der genannten Themen dar.

111 Ein marginales Beispiel für viele: Die PS von Arles bestimmt 1234 (c. 18), die Suffragane sollten die kaiserlichen Regalien der Kirche von St. Trophime, welche der Kirche von Arles zugehört, viriliter 
2. Die Normierung des Heiligen- und Festkalenders sowie der Liturgie. In Köln werden mit Gereon und Ursula andere Heilige und Feste herausgehoben als in Würzburg oder Florenz ${ }^{112}$ Dazu gehörte auch die Kehrseite, die Narren- und Gegenfeste, deren Reglementierung bzw. Verbot zwar gemeinkirchlich erscheint, dabei aber gelegentlich regionale Brăuche und Begriffe erkennbar macht; so spricht die PS Bordeaux 1260 de balleatione (!) in festo Inncentiarum ${ }^{113}$. Daran anknüpfend

3. Frömmigkeitspraktiken bzw. deren Mißbrauch: Auf der Reimser PS, gehalten $1344 \mathrm{zu}$ Noyon, erklärt der Erzbischof, er habe gehört, daß in multis civitatibus et villis nostrae Remensis provinciae joculatores sive histriones de novo candelas cereas tanquam res sacras deferunt, et nituntur processionaliter deportare, populum dictas candelas tanquam res sacras adorantem ad idolatriam inducendo. ${ }^{14}$

4. Nur vordergründig als ,Kuriosa' zu bezeichnen wären Phänomene wie die folgenden: In Norwegen wurde die Nottaufe mit - offenbar leicht verfügbarem - Bier erlaubt, was kein Zufall war, gefror doch im hohen Norden öfters das fur die Taufe nötige Wasser. ${ }^{115}$ Ebenso nachvollziehbar ist es, daß gerade in weinbaufernen Gebieten Kleriker beim Kauf von Meßwein, der vorschriftsmäßig von guter Qualität zu sein hatte, Opfer skrupelloser Panscher wurden; die Statuten des pommerschen Kammin von 1500 belegen es. ${ }^{116}$

Weitgehend ausgeklammert blieb die allgemeine, auch methodisch relevante Frage, ob und wie weitgehend die zahllosen Bestimmungen, mit denen die europäische Kirche über Jahrhunderte überschwemmt wurde, denn vor Ort von Klerus und Laien ,befolgt' wurden. Sie läßt sich im Sinne steigender oder abnehmender Moral oder wenigstens Gesetzestreue bekanntlich kaum beantworten. Verengt man die Frage auf den Rechtsbereich, also auf die ,Effektivität' von Gesetzen, wird man mit Johanek ${ }^{117}$ als Kriterien anfuhren: a) den Nachweis der Anwendung in der gerichtlichen Praxis und b) ihren Bekanntheitsgrad, ihre Publi-

verteidigen; Mansi, Sacrorum Conciliorum nova et amplissima Collectio (wie Anm. 22), vol. 23, 341B.

112 Vgl. Wiegand, Diőzesansynoden (wie Anm. 15), $68 \mathrm{f}$. Beipiele auch bei Jürgen Petersohn, Bischof und Heiligenverehrung im Mittelalter, in: RQA 91, 1996, 207-229.

113 C. 2; Mansi, Sacrorum Conciliorum nova et amplissima Collectio (wie Anm. 22), vol. 23, 1033C. Auf oberster konziliarer Ebene erfolgt erst spăt das generelle Verbot, durch das Basler Konzil am 9. Juni 1435; COD (wie Anm. 18), 492 Z. 13-28 (De spectaculis in ecclesia non faciendis). Vgl. aber schon ausfuhrlich das Verbot (de ludis prohibitis) auf der PS der Provinz Tours in Nantes 1431; ed. Avril, Les conciles de la province de Tours (wie Anm. 40), 428 f. c. 16 f.

114 C. 7; Mansi, Sacrorum Conciliorum nova et amplissima Collectio (wie Anm. 22), vol. 26, 9AB. Vgl. in diesem Zusammenhang Falkenstein, Rez. Avril (wie Anm. 36), 595, zum Problem von regionalem „Eigengut". Besonderes Augenmerk verdiente unter diesem Aspekt die lokale Albigensergesetzgebung in Südfrankreich; vgl. Schmidt, Kirche - Staat - Nation (wie Anm. 3), 143 f.

115 Martin Kaufhold, Eine norwegische Biertaufe im 13. Jahrhundert. Probleme liturgischer Normierung im 13. Jahrhundert, in: ZRG KA 83, 1997 362-376, allerdings auf der Grundlage eines păpstlichen Responsums (1241 August 28) auf eine Anfrage des Ebf. von Drontheim. Synodale Texte wären zu prifien.

116 Quod caupones insipida et filancia vina vocant vinum missale, feces diversorum vinorum confundunt ad divina misteria deputando, quod eciam sues gustare abhorrerent(!); c. 10; Wiegand, Diözesansynoden (wie Anm. 15), 296.

117 Johanek, Methodisches zur Verbreitung (wie Anm. 28), 90 f.; ders., Vescovo (wie Anm. 12), 116 f. 
zităt, was im Spätmittelalter in der Regel bedeutet: ihre schriftliche Verbreitung. In besonders günstigen Fällen ergibt sich die Möglichkeit, Synodalbestimmungen mit dem Befund mehrerer aufeinander folgender Visitationsprotokolle aus derselben Diözese zu vergleichen. ${ }^{118}$

Als Beispiel einer Statutenmaterie, die künftig im zeitlichen Längsschnitt vergleichend untersucht werden könnte, sei am Ende kurz skizziert:

\section{Priesterbildung und Laienkatechese als Modell einer vergleichend untersuchten Statutenmaterie}

Das Thema gehört zu zwei großen Materienkomplexen, der Glaubenslehre und der vita et honestas clericorum. Schon für das beginnende 13. Jahrhundert, mit dem prägenden Einfluß des IV. Lateranum, hat man von einer ,révolution pastorale“ (Delaruelle) gesprochen, einer „orientation principale et décisive vers la pastorale sacramentelle et fondement théologique“, die sich verstärkt auch in den Synodalstatuten niederschlug. ${ }^{119}$ Im Vordergrund standen der sakramentale, spirituelle und sittliche (,Konkubinat' etc.) Bereich. Dagegen trat der Aspekt der intellektuell-sprachlichen oder theologischen Bildung bzw. Unbildung des Klerus hier nicht dominant zutage. Dies wurde aber im Laufe des 15. Jahrhunderts - so die vorläufige These - dank der von den Reformkonzilien angestoßenen Belebung der Kirchenreform mit-

118 Ein Beispiel unten Anm. 133.

119 Thematische Statutenauswertung dazu bisher wesentlich in der französischen Forschung: Raymonde Foreville, Les statuts synodaux et le renouveau pastoral du XIII' siècle dans le Midi de la France, in: Le Credo, la morale et l'Inquisition. (Cahiers de Fanjeaux, vol. 6.) Toulouse 1971, 119-150, Zitate ebd. 120 (Delaruelle) und 121; Foreville erkennt einen ,retard du mouvement pastorale“ in dem von der Katharerbekämpfung absorbierten Midi Frankreichs, der erst in der Mitte des 13. Jh. aufgebrochen worden sei (Statuten von Nîmes 1252 und Rodez 1289; ebd. 137-139, 143-148). Siehe auch Odette Pontal, Le rôle du synode diocésain et des statuts synodaux dans la formation du clergé, in: Les évêques, les clercs, et le roi 1250-1300. (Cahiers de Fanjeaux, vol. 7.) Toulouse 1972, 337-359. Versuch einer breiteren thematischen Auswertung dann in der Quellensammlung: Odette Pontal, Clercs et laics au Moyen Âge d'après les statuts synodaux. Paris 1990. Vgl. auch Arnaldo d'Addario, Il problema ,de vita et moribus clericorum" nella diocesi di Firenze. Legislazione canonica e civile, e iniziative spontanee, fra XIV e XVI secolo, in: Chiesa e società dal secolo IV ai nostri giorni. Studi storici in onore del P. Ilarino da Milano. Vol. 2. (Italia Sacra, vol. 31.) Rom 1979, 383-414. Franco Morenzoni, L'encadrement et l'instruction religieuse des fidèles d'après les statuts synodaux des diocèses de Genève et de Sion (XIII' au XV' siècle), in: Zeitschrift für Scheizerische Kirchengeschichte 91, 1997, 7-37. Nach Abschluß des Ms. erschienen: Nicholas Coureas, Latin Provincial Synods of the Thirteenth Century as a means of promoting Ecclesiastical Discipline and Doctrinal Uniformity, in: AHC 32, 2000, 82-105, über zwei zypriotische Synoden ca. 1280 und 1298. Vgl. schon Anm. 114 und Beispiel bei Anm. 127. - Zur Situation der Pfarreien und Pfarrer als Möglichkeit thematischer Statutenforschung: Rubellin, Les statuts synodaux (wie Anm. 12), 130, sowie Joseph Avril, Église, paroisse, encadrement diocésain aux XIII' et $\mathrm{XIV}^{e}$ siècles d'après les conciles et les statuts synodaux, in: La Paroisse en Languedoc aux XIII' et $\mathrm{XIV}^{e}$ siècles. (Cahiers de Fanjeaux, vol. 25.) Toulouse 1990, 23-46; Jean Longère, Le prêtre de paroisse d'après les statuts synodaux de XIII' siècle, in: ebd. 287-326. 
tels Partikularsynoden stärker der Fall. ${ }^{120}$ Künftig ist systematischer der Frage nachzugehen, inwieweit schon die spätmittelalterlichen Statuten lange vor Reformation und Tridentinum durch hăufigere und qualitativ differenzierter werdende Bestimmungen jenen Wandel anzeigen, in dem sich der gesteigerte Bedarf, der höhere Anspruch des Laienpublikums an Bildung und Predigtniveau der Geistlichkeit manifestiert. ${ }^{121}$

Priesterbildung, aber auch Kinderkatechese zeigen sich fruh als Thema von Synodalstatuten besonders in Frankreich, Spanien und tendenziell in England. ${ }^{122}$ Die Legatensynode von Valladolid 1228 bestimmte: 1. Alle künftigen Benefizieninhaber müssen Latein sprechen können, 2. Dispens bei dreijăhriger Sicherung der Pfründe für die, que quisieren estudiar e aprovechar en gramatica; wenn sie es nach drei Jahren noch nicht können, sollen sie ihre Benefizien nicht zurückerhalten, bis sie ihre Schludrigkeit überwunden haben $e$ fablen latin. ${ }^{123}$ Der Kölner Erzbischof forderte 1260 von seinen Klerikern ausdrücklich nicht scientiam eminentem, sondern nur soviel Lesefähigkeit, wie zum Lesen bzw. Singen der

120 Mit vergleichendem Ansatz richtungweisend Erich Meuthen, Zur europäischen Klerusbildung vom 14. bis zum 16. Jahrhundert, in: Mediävistische Komparatistik. Fschr. furr Franz Josef Worstbrock zum 60. Geburtstag. Hrsg. v. Wolfgang Harms/Jan-Dirk Müller. Stuttgart/Leipzig 1995, 263-294, bes. 270-275; Machilek, Die bischöfliche Reformtătigkeit (wie Anm. 13), 482: „Im 15. Jahrhundert mehren sich die auf eine Verbesserung dieses Zustands [sc. der priesterlichen Unbildung; J.H.] abzielenden Synodalbeschlüsse“. Dort auch der wichtige Hinweis, „daß Synodalbeschlüsse dieser Art kaum durchgesetzt wurden“ und gerade die „Institutionalisierung von Kirchenreform als Bildungsreform insgesamt weniger von den offiziellen Reforminstitutionen (...) getragen wurden“, als vielmehr von Einzelpersonen und geistigen Bewegungen wie dem Humanismus.

121 In diesem Sinne Meuthen, Das 15. Jahrhundert (wie Anm. 77), 87, 164; ders., Zur europäischen Klerusbildung (wie Anm. 120), bes. 270-275, wesentlich auf Synodalstatuten gestützt; Sánchez Herrero, La legislación conciliar (wie Anm. 39), passim; Garcia y Garcia, Asambleas episcopales (wie Anm. 12) 301-304; Wiegand, Diőzesansynoden (wie Anm. 15), 54; einschrănkend Heribert Smolinsky, Kirchenreform als Bildungsreform im Spätmittelalter, in: Bildungs- und schulgeschichtliche Studien zu Spătmittelalter, Reformation und konfessionellem Zeitalter. Hrsg. v. Harald Dickerhof. (Wissensliteratur im Mittelalter, Bd. 19.) Wiesbaden 1994, 35-51, zu den Synoden 37-39; Machilek, Die bischöfliche Reformtătigkeit (wie Anm. 13), 481 f. Zum Thema nach wie vor grundlegend Friedrich Wilhelm Oediger, Über die Bildung der Geistlichen im späten Mittelalter. (Studien und Texte zur Geistesgesch. des Mittelalters, Bd. 2.) Leiden/Köln 1953 passim, zum Bildungsstand der Kleriker bes. 131-137.

122 Meuthen, Zur europäischen Klerusbildung (wie Anm. 120), 270-273. Für England Roy M. Haines, Education in English Ecclesiastical Legislation of the later Middle Ages, in: Councils and Assemblies. Papers read at the Eighth Summer Meeting and the Ninth Winter Meeting of the Ecclesiastical History Society. Ed. Geoffrey J. Cuming/Derek Baker. (Studies in Church History, vol. 7.) London 1971, 161-175.

123 C. 3; Garcia y Garcia, La legislación (wie Anm. 39), 107 f. Vgl. für Asturien-Leon Beispiele aus dem 13. bis 16. Jh., freilich ohne jede zeitliche Differenzierung, bei Vicente, La clerecia (wie Anm. 39), 113-118 („ciencia“). Ein oberitalienisches Beispiel, vornehmlich nach Notariatsquellen: Ciamapaolo Cambin, „Ad discendum artem et officium clericatus“. Note sul recrutamento e sulla formazione del clero a Treviso (sc. XIV), in: Preti nel medioevo. (Quaderni di Storia Religiosa, vol. 4.) Verona 1997, 93-124. 
Messe und des Chorgebets nötig war. ${ }^{124} \mathrm{Zu}$ den Paradoxa scheint es zu gehören, daß das Thema Kinderkatechese zwar in spanischen Statuten des 13. Jahrhunderts und früher Platz hat, aber dann völlig aus den Statuten verschwindet, um ca. 1480 wieder regelmäßig darin aufzutauchen. ${ }^{125}$ Man wird aber hier schlicht von Reaktualisierung älteren Rechts sprechen dürfen. Pfarrschulen findet man besonders (fruh) in Statuten Englands, auch Portugals, thematisiert, kaum in Italien. ${ }^{126}$ Diese Beispiele spitzen die Frage erneut $\mathrm{zu}$, inwieweit Synodalstatuten eine Rückkopplung zur gesellschaftlich-kirchlichen ,Realität' unterstellt werden darf, so daß sie zu deren Rekonstruktion dienen können. So wird man kaum annehmen, die Kinderkatechese habe sich exakt für den Zeitraum aus Spanien verabschiedet, in welchem entsprechende Statuten nicht mehr auftauchten. Statuten sind eben zunächst nur Reflex dessen, was der Bischof mit seiner Synode aus oft unbekannten Gründen für regelungsbedürftig hielt. Das Grundschulwesen in Italien wăre allein deshalb nicht regelungsbedürftig gewesen, weil Kirche und Pfarrei diese Aufgabe wegen des dort hochentwickelten kommunalen Schulwesens - tatsächlich! - nicht wahmahmen.

Ein Beispiel für die Katechese: Die PS von York unter Erzbischof George Neville erkennt 1466, daß die Ignorantia sacerdotum plurimum praecipitat in foveam erroris, und ordnet an, jeder Priester solle viermal im Jahr dem Volk in der Volkssprache (vulgariter) und zwar absque cuiuslibet subtilitatis textura fantastica ${ }^{127}$ (d. h. ohne unsichere Grundlage und hochgestochene Form, - die erzeugen zu können ihm immerhin unterstellt wird?) folgende Dinge in der Predigt erklären: die vierzehn Artikel des Glaubensbekenntnisses, die Zehn Gebote, die Gebote der Barmherzigkeit, die - es sind immer sieben - Werke der Barmherzigkeit, Todsünden, Kardinal-Tugenden, Sakramente; es folgt ein Dossier mit Erläuterung anspruchsvollerer Glaubensartikel, sieben davon zur Trinität. Eine Bestimmung wie diese stellt gegenüber der „révolution pastorale“ des 13. Jahrhunderts nichts prinzipiell Neues dar,

124 PS Köln 1260, c. 3: Item de clericis, de inefficientia doctrinae, quae est illiteratura, notatis sicut de omnibus scientiam eminentem non requirimus, sed quin sciant legere et cantare ad Divini officii ministerium competenter; Mansi, Sacrorum Concilionm nova et amplissima Collectio (wie Anm. 22), vol. 23, 1015AB. - Vgl. Lavaur 1368, c. 20: statuimus prohibentes, ne ad sacras promoveantur ordines, nisi personae, quae grammaticam sciant seu latinis verbis loqui valeant competenter; ebd. vol. 26, $498 \mathrm{f}$.

125 Meuthen, Zur europäischen Klerusbildung (wie Anm. 120), 272, nach Sánchez Herrero, La legislación conciliar (wie Anm. 39), 368-372.

126 Meuthen, Zur europăischen Klerusbildung (wie Anm. 120), 271-275, lănderweise Stichproben mit zahlreichen Beispielen. Inwieweit die Universităten aus dem Horizont der Statutengesetzgebung ausgeblendet wurden, bleibt zu untersuchen; vgl. Smolinsky, Kirchenreform (wie Anm. 121), 39; Meuthen, Zur europäischen Klerusbildung (wie Anm. 120), 277-282. Die umfangreiche jüngere Literatur zum spätmittelalterlichen Schulwesen kann hier nicht aufgeführt werden; siehe Literatur bei Jacques Verger, Art. Schule. A. Abendland, in: LMA. Bd. 7. München/Zürich 1995, Sp. 1582-1586; Meuthen, Das 15. Jahrhundert (wie Anm. 77), 103 f., 264-266; ders., Zur europäischen Klerusbildung (wie Anm. 120), 274-276.

127 Mansi, Sacrorum Conciliorum nova et amplissima Collectio (wie Anm. 22), vol. 32, 275C. Die ganze Passage ebd. 275D-278E. Ein fruheres Beispiel bietet die PS von Lavaur 1368 (für die Provinzen Auch, Narbonne und Toulouse); ebd. vol. 26, 484-486. 
es war insofern „eine alte katechetische Tradition“ ${ }^{128}$; neu sind aber Umfang und Niveau der geforderten pastoralen Leistung.

Realiter konnte eine solche „Kirchenreform als Bildungsreform“(Smolinsky) furr den Klerus zum Beispiel erstens häufigere und verschärfte Weiheexamina ${ }^{129}$ bedeuten; zweitens, daß die Pfarrer und Seelsorger - wie schon in der pastoralen Welle im 13. Jahrhundert - sich mehr Bücher anschaffen mußten. Dazu gehörte traditionell auch ein handschriftliches bzw. später ein gedrucktes Exemplar der Synodalstatuten selbst. Es fehlte kontinuierlich nicht an Bestimmungen, daß jeder Pfarrer nach der mündlichen Promulgation auf der Synode sich einen Text zu besorgen und ihn zu kennen hatte. ${ }^{130}$ Zunehmend aber werden spezielle Handbücher für die Pastoralpraxis (Predigt, Beichte etc.) auf Partikularsynoden empfohlen bzw. ihr Besitz eingeschärft, vornan der 1333 verfaßte Manipulus curatorum des Guillaume de Montrocher (Guido de Monte Roterio) oder das im 15. Jahrhundert in Deutschland verbreitete Directorium curatorum des Johannes von Auerbach, unter dem Legaten Nikolaus von Kues 1452 sogar eine Schrift des Thomas von Aquin. ${ }^{131}$

Einige Zahlen aus einem deutschen Beispiel: Für Würzburg zeigt sich bei dem Thema Klerusbildung eine undramatische, aber deutliche Entwicklung, wobei nicht die Prozentzahlen, sondern die Tendenz es ist, die zählt. Betreffe zum niederen Klerus wachsen in den Würzburger Statuten nach 1400 an, Moral- und Bildungsqualifikation für die Zulassung zu Priesteramt und Seelsorge von 7,7\% vor 1400 auf $12,1 \%$ nach 1400, Kenntnis der Statuten durch den Klerus von 1,9 auf $4 \% .{ }^{132}$ Für Kammin hat man anhand einer späten Statutensammlung den gleichen Trend beobachtet: „Spürbar treten mithin in diesem letzten Gesetz-

128 Smolinsky, Kirchenreform (wie Anm. 121), 38; Meuthen, Zur europăischen Klerusbildung (wie Anm. 120), 276; Rubellin, Les statuts synodaux (wie Anm. 12), 130. Vgl. die Bestimmungen des IV. Lateranum zur Bildung und amtsbefăhigenden Idoneităt des Klerus: c. 10-11, 27 und 39; COD (wie Anm. 18), 239 f., 248 f.

129 Eichstătt 1447 c. 1; Schannat/Hartzheim, Concilia Germaniae (wie Anm. 33), Bd. 5, 366: De examine sacerdotum (...) praecipimus sollicitos et diligentes esse circa studium sacrarum litterarum (...) volumus, quod deinceps non solum quando ad sacras ordines admittuntur, sed etiam dum ecclesias suscipiunt regendas de scientia et peritia et aliis videlicet vita et honesta conversatione et moribus diligenter examinentur. Vgl. die Hinweise bei Smolinsky, Kirchenreform (wie Anm. 121), 38; Meuthen, Zur europäischen Klerusbildung (wie Anm. 120), 269, und Machilek, Die bischöfliche Reformtătigkeit (wie Anm. 13), 482: Mainz (PS 1423) und Eichstătt (DS 1435, 1437 und 1447). Zum oft simplen ălteren Weiheexamen Oediger, Über die Bildung (wie Anm. 121), 86-94.

130 Johanek, Methodisches zur Verbreitung (wie Anm. 28), 96; vgl. die Belege bei Avril, Remarques (wie Anm. 40), 196. - Als Beispiel die Statuten von Brandenburg 1417 sowie Havelberg 1435 und 1464: Pfarrer in den Städten müssen Statuten von DS und PS verfügbar haben; Oediger, Über die Bildung (wie Anm. 121), 122 Anm. 3.

131 Oediger, UUber die Bildung (wie Anm. 121), 122-127; García y Garcia, Asambleas episcopales (wie Anm. 12), 301-304; Johanek, Vescovo (wie Anm. 12), 117-123; Meuthen, Zur europăischen Klerusbildung (wie Anm. 120), 273 mit Anm. 43. Zu einzelnen dieser Handbücher siehe Hartmut Boockmann, Aus den Handakten des Kanonisten Johannes Urbach (Auerbach), in: DA 28, 1972, 517-529, und Meuthen, Thomas von Aquin (wie Anm. 27).

132 Lang, Die Synoden (wie Anm. 37), 82 (Tabelle). Auch die Zahl der Betreffe für die Laien und die Juden wuchs an. 
gebungswerk des katholischen Kammin die Anliegen der inneren Reform der Kirche in den Vordergrund." 133

Der Gesamttrend scheint also unverkennbar. Er fuhrt den besonderen Quellenwert der Synodalstatuten und die Möglichkeiten eines europäischen Ländervergleichs wenigstens ansatzweise vor Augen. Die Statuten zeigen aber auch hier ihre oben erörterten, durch Genre und Tradition bedingten Grenzen. So wird man gerade zum Thema Bildung abschließend sagen müssen, daß nicht die bischöfliche Statutengesetzgebung der Motor, ja selbst nur in beschränktem Maße der Spiegel des neuen Bildungsaufschwungs bei Klerus und Laien gewesen ist. Bahnbrechend wirkten vielmehr Einzelpersönlichkeiten und anfangs außerinstitutionelle Bewegungen wie die Frömmigkeitstheologie und vor allem der Humanismus. Dieser wurde aber bald auch institutionell in den Curricula der Schulen und Universitäten integriert und konnte damit langfristig und überkonfessionell das europäische Bildungswesen prägen. ${ }^{134}$

Um zur Ausgangsperspektive zurückzukehren: Ein Profil der spåtmittelalterlichen Kirche(n) zu erarbeiten kann Ziel der vergleichenden Geschichte Europas sein. Der Verfasser hegt die Hoffnung, daß fur das komparatistische ,brainstorming', welches dieser Band pionierhaft zu leisten versucht, auch der synodale Aspekt einige Synapsen anzubieten vermag.

133 Wiegand, Diözesansynoden (wie Anm. 15), 209. Als Beispiel einer ,Gegenprobe' mit der Hilfe von Visitationsprotokollen möge Genf dienen: In der Zeit zwischen der bischöflichen Visitation von 1411 und derjenigen von 1443 stieg die Zahl der Pfarrer, die die gebotene Residenzpflicht mißachteten, von 31 auf $43 \%$ an. Auf Bildung waren die visitierten Kleriker nur 1411 abgefragt worden: $30 \%$ hatten gute, $56 \%$ ausreichende Bildung, $14 \%$ waren debilis sciencie, ignarus oder gar totaliter ignarus. Was die Moral betraf, lebten - laut Protokoll - immerhin $61 \%$ einwandfrei, 29\% waren ,Konkubinarier', nur 10\% Exzessoren anderer einschlägiger Art: Säufer, Kneipengănger (tabernarum frequentatores), Spieler; Binz, Vie religieuse (wie Anm. 14), 496 (Tableau XII).

134 Vgl., bezogen auf die Devotio moderna, Smolinsky, Kirchenreform (wie Anm. 121), 39. Machilek, Die bischőfliche Reformtătigkeit (wie Anm. 13), 482: „daß Synodalbeschlüsse dieser Art kaum durchgesetzt wurden“ und gerade die Institutionalisierung von „Kirchenreform als Bildungsreform (...) insgesamt weniger von den offiziellen Reforminstitutionen (...) getragen“ wurde. 



\title{
Mediävistische Venedig-Forschung $1850-1950$
}

\section{Ein erster Überblick zu Themen und Problemen ${ }^{*}$}

\author{
Von \\ Daniela Rando
}

Die folgenden Überlegungen sind einige vorläufige Forschungsergebnisse, die ich bei einem einjährigen Forschungsaufenthalt am „Institut für Vergleichende Geschichte Europas im Mittelalter" der Humboldt-Universität zu Berlin erzielt habe. Das Gesamtprojekt lautet: „Venedig in der Wahmehmung des Westens. Hundert Jahre mediävistischer Forschung im Vergleich (ca. 1850-1950)“. Das bedeutet einmal ganz konkret die Frage: Wer wann über Venedig im Mittelalter gearbeitet hat und wie dies geschah. Also: Themen und Methoden, Personen und ,Schulen', Forschungsstrukturen wie Institute, Editionen, Projekte und Kongresse. Für eine vergleichende Erforschung der Venedig-Historiographien gilt all das als allgemeine Vorbedingung; die eigentlichen Hauptziele sind jedoch umfassender. nämlich festzustellen, inwiefern Fragenkomplexe, Chronologien und methodologische Ansätze zeit-, orts- und traditionsbedingt gewesen sind und die Aussagen der Venedig-Historiker ,das Gepräge der politischen Lebensinteressen, Sichtweisen und Wertmaßstäbe ihrer jeweiligen nationalen, kulturellen und gesellschaftlichen Herkunft" ${ }^{\text {‘l }}$ transportieren.

Für einen Vergleich erscheint Venedig wie prädestiniert: An der Nahtstelle von Orient und Okzident gelegen, mit einer langen, wechselvollen Geschichte und einem überreichen Quellenreservoir kommt der Stadt als steingewordenes Symbol (so der berühmte Titel von John Ruskin) ${ }^{2}$ der transalpinen Begeisterung für den Süden und der Zufluchtstătte des Ennui

- Die Vortragsform ist beibehalten. Die Studien wurden ermöglicht durch ein Stipendium der Gerda-Henkel-Stiftung in Düsseldorf, für das ich mich bedanke. Ebenso geht mein Dank an Prof. Michael Borgolte für die Gastfreundschaft in Berlin. Geplant ist eine Buchveröffentlichung im Rahmen seiner Reihe „Europa im Mittelalter. Abhandlungen und Beiträge zur historischen Komparatistik“. Durch die anschließende Diskussion des Vortrags ergab sich eine Einladung an das Max-Planck-Institut für Geschichte in Göttingen; mein Dank dafür gilt Prof. Otto Gerhard Oexle.

1 Karl D. Erdmann, Die Ökumene der Historiker. Geschichte der Internationalen Historikerkongresse und des Comité International des Sciences Historiques. Göttingen 1987, 15.

2 John Ruskin, The stones of Venice. 3 vol. London 1851-1853. 
im Fin de siècle ${ }^{3}$ eine besondere Stellung in der Kulturgeschichte des Abendlandes zu. Ausgangspunkt muß die Feststellung sein, daß es bis zum Zweiten Weltkrieg keine institutionalisierte Beschäftigung mit Venedig, keine eigentliche „Venezianistik“, gab. Das überrascht nicht, denn Venedig ist auch ,in der (...) Kunst und Kunsttheorie des 19. Jahrhunderts nur eines von vielen Themen dieses enzyklopädisch sammelnden Säkulums ${ }^{\text {“4 }}$ gewesen.

Die Aufsplitterung ist nicht nur durch die Themen, die Objekte, sondern auch durch die Historiker und ihre Erkenntnisse, die Subjekte, vorgegeben. Es gab keine ,Ökumene der Historiker', keine ,Exegetengemeinde', sondern einzelne Forscher, die sich im Bannkreis ihres je eigenen Vorverständnisses bewegten. Mit Gadamer können wir also von einer „Antizipation von Sinn“ sprechen, die das Verständnis geleitet und den Horizont des Verstehens mitgeprägt hat. ${ }^{5}$ Ein paar Beispiele: Zwei deutsche Rezensenten der Early History of Venice von Francis C. Hodgson ${ }^{6}$, Emil Daniels und Heinrich Kretschmayr, behaupteten, der Verfasser beherrsche die deutsche Literatur nicht ${ }^{7}$; Kretschmayr dazu: „Die Schwächen seiner Arbeit gehen zurück auf seine Unkenntnis der deutschen, zum Teile auch der italienischen Detailliteratur und den Mangel an hilfswissenschaftlicher Schulung (...). Die Arbeit zeigt deutlich die Schwächen der englischen Geschichtsschreibung überhaupt. In dem augenscheinlichen Bestreben, nur ja nicht zopfig zu sein und es den ,trockenen' deutschen Büchern nicht nachzutun, geht über lauter Anspielungen auf die Gegenwart oft genug die wissenschaftlich genaue Erfassung der Vergangenheit verloren (...). Weniger Raisonnement, mehr Forschung!“8 Kritik wird also von Kretschmayr auf zwei verschiedenen Ebenen geübt: einmal recht vordergründig und dann von der Methode her. Aus heutiger Sicht zeigt Hodgson aber keine ausgesprochene Polemik und Distanzierung von der deutschen Geschichtswissenschaft - ein (typisch deutsches?) Vorverständnis des Rezensenten.

Zweites Beispiel: Kretschmayrs eigene Geschichte von Venedig - ein Meilenstein der Venedig-Forschung -, auf die ich noch zurückkomme ${ }^{9}$, provozierte bei ihrem Erscheinen äußerst gegensätzliche Urteile: In den Preußischen Jahrbüchern wurde sie 1906 vom schon

3 Vgl. Jürgen Julier, Venedig in der deutschen künstlerischen Kultur des 19. Jahrhunderts, in: Italienischdeutsche Begegnungen um die Jahrhundertwende. Symposion des Deutschen Studienzentrums in Venedig am 22./23. September 1980. (Centro tedesco di studi veneziani, Quaderno 22, B.) Venedig 1982, 65-89, hier 65 .

4 Ebd.

5 Hans-Georg Gadamer, Wahrheit und Methode. Grundzüge einer philosophischen Hermeneutik. 3., erw. Aufl. Tübingen 1972, 252, 277.

6 Francis Cotterell Hodgson, The Early History of Venice. From the Foundation to the Conquest of Constantinople, A. D. 1204. London 1901.

7 Emil Daniels, Der Staat von Venedig in seiner ălteren Zeit, in: Preußische Jahrbücher 123, 1906/1, 1-48, hier 2; Heinrich Kretschmayr, Rez. Hodgson, The Early History (wie Anm. 6), in: MIÖG 25, 1904, 146-154, hier 154.

8 Kretschmayr, Rez. Hodgson, The Early History (wie Anm. 7), 154.

9 Heinrich Kretschmayr, Geschichte von Venedig. Bd. 1: Bis zum Tode Enrico Dandolos. Gotha 1905; Bd. 2: Die Blüte. Gotha 1920; Bd. 3: Der Niedergang. (Allgemeine Staatengeschichte, Abt. 1: Geschichte der europăischen Staaten, Bd. 35.) Stuttgart 1934, ND Aalen 1964. 
genannten Emil Daniels ganz und gar abgelehnt als Buch aus der Lamprechtschen Schule ${ }^{10}$ (eine geradezu klassische Fehleinschătzung, wie andere Rezensenten bemerkten: Lamprecht war nur der Herausgeber der gesamten Reihe Geschichte der europäischen Staaten). Aber es ging noch um etwas anderes: Ludo Moritz Hartmann rechnete 1908 Kretschmayr den Versuch hoch an, „die Darstellung dieser quellenarmen Zeit lebendig zu gestalten“11 und „sich in der Darstellung von der Langeweile des Gelehrtendeutschs fernezuhalten “12, obwohl Hartmann „die künstlerische Form“ nur mit Einschränkung akzeptierte. Gerade aber diese Form bewunderte 1925 Paul Herre: Er redete von einem „Meisterwerk“, von einem „glänzenden Interpreten“, von „kongenialer Einfuhlung ${ }^{\text {“13 }}$, von einem „farbigen und lebendigen Bericht". ${ }^{14}$

Bei unterschiedlicher Wertung anerkennen also Hartmann und Herre das künstlerische Form- und Einfühlungsvermögen des Verfassers - Qualitäten, die aus italienischer Sicht wiederum vermißt werden: „Manca quell'alito di vita, quel soffio geniale, che trasforma in opera d'arte anche i più astrusi lavori scientifici, e che noi, gente latina, siamo avvezzi ad ammirare nelle opere storiche dei nostri maggiori (...). Architetto sapiente il Kretschmayr si è rivelato; ma (...) non scorgiamo l'artista.“'15 Ein ähnliches Urteil findet sich funfzig Jahre später in einem Literaturbericht von Gina Fasoli: „la preoccupazione di non perdere mai il contatto con la realtà dei fatti, positivisticamente intesa, porta l'Autore ad una innegabile aridità e freddezza di rappresentazione. “16 Und dann geht Frau Fasoli über zu „opere (...) più calde d'interesse“. ${ }^{17}$ Kretschmayr erscheint also als positivistisch, hölzern, kalt. Man fragt sich heute: Ist das Buch wirklich gründlich im Originaltext gelesen und verstanden oder es vielmehr als „deutsch“, d. h. nicht romanisch, vorverstanden worden? Die vergleichende Historiographieforschung muß also einerseits die Bruchstückhaftigkeit und Inkohärenz, andererseits die Kommunikations-, die Miß- und Vorverständnisprobleme in Rechnung stellen. Von diesen isolierten und eher gegenläufigen „Wegen der Forschung“ werden hier einige Aspekte erörtert, die sich unter dem Schlagwort „Die Moderne und ihr Venedig“ zusammenfassen lassen. ${ }^{18}$

10 Daniels, Der Staat (wie Anm. 7), $1 \mathrm{f}$.

11 Ludo M. Hartmann, Rez. Kretschmayr, Geschichte von Venedig. Bd. 1(wie Anm. 9), in: MIÖG 29, 1908, 341-347, hier 343.

12 Ebd. 346.

13 Paul Herre, Rez. Kretschmayr, Geschichte von Venedig. Bd. 2 (wie Anm. 9), in: Preußische Jahrbücher 202, 1925/1, 265-267, hier 265.

14 Paul Herre, Die alte Republik Venedig im Spiegel der jüngsten Geschichtsschreibung, in: Preußische Jahrbücher 237, 1934/3, 116-131, hier 118.

15 Camillo Manfroni, Gli studi storici in Venezia dal Romanin ad oggi, in: Nuovo Archivio Veneto NF. 8, 1908, t. XVI, 352-372, hier 371.

16 Gina Fasoli, La storia di Venezia. Lezioni tenute nella Facoltà di Magistero di Bologna durante l'anno accademico 1957-58. Bologna 1958, 224.

17 Ebd. 225.

18 In Anlehnung an den Titel von Otto Gerhard Oexle, Die Moderne und ihr Mittelalter. Eine folgenreiche Problemgeschichte, in: Mittelalter und Moderne. Entdeckung und Rekonstruktion der mittelalterlichen 


\section{Tafel und Thomas}

Ein wichtiger Zweig der Venedig-Forschung entwickelte sich um die Mitte des vorigen Jahrhunderts in Deutschland aus der Schwärmerei für das Altertum in der Nachfolge von Winckelmann. Dabei ist Friedrich Thiersch zuerst zu nennen (1784-1860). Seit 1815 bemühte er sich, in einem von ihm selbst eingerichteten Institut in München, dem „Athenaeum“, junge Griechen auf das deutsche Universitätsstudium und nach dem Ausbruch des griechischen Unabhängigkeitskrieges 1821 zur Hilfe für ihre Heimat vorzubereiten. In diesem Klima des Philhellenismus sind Gottlieb Lukas Tafel, Georg Martin Thomas und Jakob Philipp Fallmerayer tätig gewesen. Hans-Georg Beck zählt dieses ,Dreigestirn' zu den wichtigsten Wegbereitern für Karl Krumbacher, den Gründer der deutschen Byzantinistik als Wissenschaft. ${ }^{19}$ Alle drei waren miteinander befreundet, und die beiden ersten sind furr die Venedig-Forschung von großer Bedeutung geworden.

Gottlieb Lukas Tafel aus Ulm (1787-1860) wurde seit 1827 ordentlicher Professor furr Alte Literatur in Tübingen. Er begann als Altphilologe und kam dann zur Byzantinistik (unter anderem trug er zur historischen Geographie und zur byzantinischen Reichsgeographie bei, mit der Edition des zweiten Buches von Konstantin Porphyrogennetos, De provinciis regni byzantini). ${ }^{20}$ Georg Martin Thomas aus Ansbach (1817-1887) ging 1835 an die Universităt München, wo er bei Thiersch philologische Vorlesungen hörte. ${ }^{21}$ Mit ihm blieb er in Verbindung, und nach Thierschs Tod war es Thomas, der eine Gedächtnisrede auf diesen am Geburtstagsfest von Maximilian II. bei der Bayerischen Akademie der Wissenschaften hielt. ${ }^{22}$

1850 fuhren Tafel und Thomas zusammen nach Wien, auf der Suche nach literarischen Quellen für die byzantinische Geschichte, und dort stießen sie auf Urkundensammlungen aus Venedig $^{23}$ (Venedig gehörte damals politisch zum Habsburgerreich). Die beiden kamen auf die Idee einer Edition: 1856-1857 gaben sie in drei Bänden die Urkunden zur älteren Handels- und Staatsgeschichte der Republik Venedig mit besonderer Beziehung auf Byzanz und

Welt. Kongreßakten des 6. Symposiums des Mediävistenverbandes in Bayreuth 1995. Hrsg. v. Peter Segl. Sigmaringen 1997, 307-364.

19 Hans-Georg Beck, Die byzantinischen Studien in Deutschland vor Karl Krumbacher, in: XA^IKE Festgabe für die Teilnehmer am XI. Internationalen Byzantinistenkongreß München 15.-20. September 1958. München 1958, 104-109.

20 Ebd. 104-105; Armin Hohlweg, Jakob Philipp Fallmerayer und seine geistige Umwelt, in: Jakob Philipp Fallmerayer. Wissenschaftler, Politiker, Schriftsteller. Hrsg. v. Eugen Thurnier. (SchlernSchriften, Bd. 292.) Innsbruck 1993, 47-73, hier 49-51.

21 Hohlweg, Jakob Philipp Fallmerayer (wie Anm. 20), 51; Henry Simonsfeld, Art. Thomas, Georg Martin, in: Allgemeine Deutsche Biographie. Bd. 54. Leipzig 1908, 697-700.

22 Georg M. Thomas, Gedächtnisrede auf Friedrich von Thiersch. Vorgetragen in der offentlichen Sitzung der kgl. Akadamie der Wissenschaften am 28. November 1860 als am allerhöchsten Geburtsfeste Seiner Majestăt des Königs Maximilian II. von Bayern. München 1860.

23 Gottlieb L. F. Tafel/Georg M. Thomas (Hrsg.), Urkunden zur ălteren Handels- und Staatsgeschichte der Republik Venedig mit besonderer Beziehung auf Byzanz und die Levante. Vom 9. bis zum Ausgang des 15. Jahrhunderts. Bd. 1. Wien 1856, 5-6. 
die Levante heraus. ${ }^{24}$ Die drei Bände erschienen bei der Historischen Kommission der Kaiserlichen Akademie der Wissenschaften in Wien in der Abteilung II ihrer Fontes rerum Austriacarum (also unter den österreichischen Quellen).

In der italienischen Forschung galt die Aufnahme unter die Quellen Österreichs nach nationalen Gesichtspunkten lange Zeit als Stein des Anstoßes. ${ }^{25}$ Infolge der veränderten politischen Lage - 1866 kam Venedig zum vereinten Königreich Italien - stagnierte eine geplante Weiterfuhrung, obwohl Thomas die Arbeit fortsetzte: Erst 1880 und 1899 gab dann endlich die Reale Deputazione Veneta di Storia patria zwei weitere Bände heraus. Sie tragen zwar einen neuen lateinischen, sozusagen neutralen, selbständigen Titel, Diplomatarium Veneto-Levantinum ${ }^{26}$, setzten aber chronologisch die ersten drei Bände fort und wurden auch von Thomas herausgegeben. Die ersten drei Bände erschienen also bei der Akademie in Wien, die letzten zwei bei der Deputazione veneta in Venedig, deren Ehrenmitglied Thomas 1876 geworden war. Mit 778 Urkunden und fast 2500 Seiten sind die funf Bände ein Werk von monumentalem Ausmaß und ein Meilenstein der Venedig-Forschung.

Im Jahre 1860, nach dem Erscheinen der ersten drei Bände, war Tafel gestorben, der eigentliche Anreger des Gesamtunternehmens, und so blieb Thomas als der ausgewiesene Venedig-Spezialist übrig. Es hätte sich nun angeboten, für ihn einen eigenen Lehrstuhl zu errichten, doch Thomas konnte als Protestant im erzkatholischen München noch nicht mal die Venia legendi erhalten. ${ }^{27}$ Der liberal gesinnte bayerische König Maximilian II., der die persönlichen und wissenschaftlichen Qualitäten von Thomas durchaus anerkannte, verschaffte ihm statt dessen eine feste Anstellung an der königlichen Bibliothek. ${ }^{28}$ Thomas blieb also Privatgelehrter und hielt keine öffentliche Vorlesungen an der Universität; sein Hörerkreis beschrănkte sich auf die Mitglieder der Akademie der Wissenschaften. Als Akademie-

24 Dies., Urkunden (wie Anm. 23). 3 Bde. Wien 1856-1857.

25 Bartolomeo Cecchetti, Le pubblicazioni delle società di storia patria del Regno e Venezia rispetto ad esse, in: Atti del Reale Istituto veneto di Scienze, Lettere ed Arti. Ser. 4. Vol. 1. Venedig 1871/72, $1619 \mathrm{f} .:$ „Quando poi il morso della gelosia ci pungeva il core, perché le grandi ale del ,paterno reggime' stendevansi sui nostri tesori storici fino ad involacerli allo sguardo; e quando i documenti del nostro passato, le glorie, le sventure, i nomi e le cose più care di questa terra ci erano tolti per impinguare collezioni di altra storia e di un popolo diverso; noi dovevamo destarci, e ricordare che spettava a noi d'illustrar quelle memorie, che colla sottile ironia d'un padrone prepotente si comprendevano, per esempio, nei fontes rerum austriacarum!“". Vgl. auch Camillo Manfroni, Gli studi storici (wie Anm. 15), 352: „quasi ad affermare il diritto dell'Austria sulle lagune, l'Accademia di Vienna accoglieva nei suoi Fontes rerum austriacarum serie notevoli di documenti veneziani“.

26 Georg M. Thomas (Ed.), Diplomatarium Veneto-Levantinum sive acta et diplomata res Venetas Graecas atque Levantis illustrantia. 2 vol. (a. 1300-1350, 1351-1354). (Monumenti storici pubblicati dalle R. Deputazione veneta di storia patria, ser. I: Documenti, vol. 5, 9.)Venedig 1880/99.

27 So einstimmig Simonsfeld, Art. Thomas, Georg Martin (wie Anm. 21), 697; Beck, Die byzantinischen Studien (wie Anm. 19), 105; Gerhard Grimm, Osteuropa-Traditionen an der bayerischen Landesuniversităt (15. bis 19. Jahrhundert), in: http://www.fak09.uni-muenchen.de/oseg/ (auch in: Geschichte Osteuropas. Zur Entwicklung einer historischen Disziplin in Deutschland, Österreich und der Schweiz, 1945-1990. Hrsg. v. Erwin Oberländer. Stuttgart 1992, 179-189); Hohlweg, Jakob Philipp Fallmerayer (wie Anm. 20), 51.

28 Simonsfeld, Art. Thomas, Georg Martin (wie Anm. 21), 697. 
mitglied hielt er auch eine Festrede zum 19. Geburtstag Ludwigs II. 1864 (das war das Jahr der Thronbesteigung, zwei Jahre vor Königgrätz!). Die Festrede behandelte Die Stellung Venedigs in der Weltgeschichte ${ }^{29}$ und wurde sofort ins Italienische übersetzt. ${ }^{30}$ Zusammen mit einem früheren Werk (Der Doge Andreas Dandolo und die von ihm angelegten Urkundensammlungen zur Staats- und Handelsgeschichte Venedigs) ${ }^{31}$ ist die Rede sehr aufschlußreich für den geistigen Horizont von Thomas und seiner Generation: „Wo immer ein Staat (...) an Macht, Ehre und Ansehen nach außen gewinnt, sei es durch die Energie und Einsicht eines genialen Lenkers, oder durch die freie Entfaltung selbständiger Nationalkraft, da hebt sich auch im Innern der Flug der Geister, und ein edler Wetteifer für das Schöne und Wahre erzeugt neue Triebe und frische Blüten am Baume der Erkenntnis". ${ }^{32}$

Weiter heißt es: „Die italienischen Staaten im Mittelalter, und in besonderer Art die Republik von S. Marco (...), diese Burgen nationaler Gesinnung und reger Strebsamkeit, blieben auch die Träger des geistigen Lebens“. Dies wurde allerdings „genährt und befruchtet von dem Hauche des wieder erwachten classisch-hellenischen Geistes ${ }^{\text {“ }}{ }^{33}$ Venedig wird in eine Reihe mit Rom und Athen gestellt: „Venedig, wie die Stadt am Ilissus, erregen unsere Bewunderung und gewinnen unsere Liebe ${ }^{\text {“ }}{ }^{34}$ Venedig, ,wie einstmals Athen von Aristides bis Perikles ${ }^{435}$, Venedig, „Hellas und Rom ebenbürtig“. ${ }^{36}$

Dies ist eine durchaus positive Darstellung, die mögliche dunkle Seiten übersieht. Die Anschauung ist wortwörtlich sonnig und optimistisch: Das Morgenland als Land, wo die Sonne aufgeht ${ }^{37}$, ist keine Floskel. Die Interpretationsmuster des deutschen Idealismus und der Romantik sind deutlich erkennbar, die politischen Parolen der nachnapoleonischen Ära, Patriotismus (eine spezifische Tugend der Venetianer ${ }^{38}$ ) und Nationalkraft, verbinden sich mit der Begeisterung fur die Antike. Zu dem klassischen Duo Athen-Rom gesellt sich nahtlos Venedig.

29 Georg M. Thomas, Die Stellung Venedigs in der Weltgeschichte. Rede gehalten in der öffentlichen Sitzung der kgl. Akademie der Wissenschaften am 25. Juli 1864 zur Vorfeier des allerhöchsten Geburts- und Namens-Festes Sr. Majestät des Königs Ludwig II. von Bayern. München 1864.

30 Vgl. Riccardo Predelli [ohne Titel], in: Thomas, Diplomatarium (wie Anm. 26), vol. 2, VII-XVII, hier XV (Documento I. Pubblicazioni di G.M. Thomas relative a Venezia).

31 Gottlieb L. F. Tafel/Georg M. Thomas, Der Doge Andreas Dandolo und die von demselben angelegten Urkundensammlungen zur Staats- und Handelsgeschichte Venedigs. (Kgl. bayer. Akad. der Wiss., Hist. Kl., Abh. 8,1.) München 1855. Wie der Titel zeigt, haben Tafel und Thomas auf Dandolo ihr eigenes wissenschaftlich historisches Konzept (Urkunden zur älteren Handels- und Staatsgeschichte der Republik Venedig ) projiziert.

32 Thomas, Stellung (wie Anm. 29), 3.

33 Ebd. 4-5.

34 Ebd. 23.

35 Ebd. 15.

36 Ebd. 5.

37 Ebd. 9.

38 Vgl. Tafell/Thomas, Der Doge Andreas Dandolo (wie Anm. 31), 6. 
Dieses heitere Venedig-Bild begründete aber keine wissenschaftliche Tradition - auch aus ganz praktischen Gründen, da Thomas, wie gesagt, nicht an der Universität arbeitete und so keinen breiten Schülerkreis um sich versammeln konnte.

Diese Möglichkeit ergab sich nur ganz kurze Zeit, denn Thomas erhielt 1862 eine Berufung auf den Lehrstuhl für Griechische Literatur an der Universităt Basel, der er jedoch nicht nachkam. In Basel wäre er Kollege eines anderen grundlegenden Wegbereiters für die Wahmehmung Venedigs geworden: 1855, ein Jahr vor dem ersten Band der „Urkunden“ von Tafel und Thomas, erschien der „Cicerone“ von Jacob Burckhardt (Venedig wurde auch in der fünf Jahre späteren „Kultur der Renaissance in Italien“ behandelt).

\section{Burckhardt}

Der Cicerone ist das Werk, „das die zentralen Quellen für Burckhardts Anschauungen über Venedig liefert. ${ }^{\text {(39 }}$ Danach kann die venezianische Malerei mit der florentinischen insgesamt nicht konkurrieren. ${ }^{40}$ Sie ist die Malerei der „höchsten Augenlust“ ${ }^{\text {41 }}$, „eine Malerei der Form, nicht des Inhalts, und daher auch nicht auf der klassischen Höhe jener Kunst, die beides harmonisch integriert". 42

Venedig selbst ,gilt Burckhardt als reine Kaufmannsstadt; entsprechend ist der Geschmack ihrer Bauherren“43; so „hat die venezianische Architektur den Hautgout des Neureichen, sie zeigt mehr Pracht, mehr Ornament als Harmonie der architektonischen Verhältnisse“. ${ }^{44}$ Burckhardt erläutert: „Wir sagen dies nicht, um dem Beschauer den Genuß zu verderben, sondern um den großen toskanischen Baumeistern neben den venezianischen Dekoratoren ihren Vorrang nicht zu schmälern". 45

„In der Kultur der Renaissance äußert sich Burckhardt des öfteren über Venedig, obwohl die römischen und die florentiner Verhältnisse im Mittelpunkt seiner Betrachtung stehen. “46 Die Grundlage ist der berühmte Vergleich zwischen Florenz und Venedig: „Unter den Städten, welche ihre Unabhängigkeit bewahrten, sind zwei für die ganze Geschichte der Menschheit von höchster Bedeutung: Florenz, die Stadt der beständigen Bewegung, welche uns auch Kunde hinterlassen hat von allen Gedanken und Absichten der einzelnen und der Gesamtheit (...); dann Venedig, die Stadt des scheinbaren Stillstandes und des politischen Schweigens. Es sind die stärksten Gegensätze, die sich denken lassen, und beide sind wiederum mit nichts

39 Grundlegend Bernd Roeck, Jacob Burckhardt und die venezianische Renaissance, in: Renaissance und Renaissancismus von Jacob Burckhardt bis Thomas Mann. Hrsg. v. August Buck. (Reihe der Villa Vigoni. Deutsch-italienische Studien, Bd. 4.) Tübingen 1990, 24-53, hier 40.

40 Ebd. 33.

41 Ebd. $36 \mathrm{f}$.

42 Ebd. 36.

43 Ebd. 40.

44 Ebd. 41.

45 Jacob Burckhardt, Der Cicerone. Eine Anleitung zum Genuss der Kunstwerke Italiens. ND der Urausgabe. Stuttgart 1978, 183.

46 Roeck, Jacob Burckhardt (wie Anm. 39), 40. 
auf der Welt zu vergleichen “47 - also, einerseits „beständige Bewegung“, andererseits „Scheinbarer Stillstand und Schweigen“ (bezeichnenderweise sind die Venezianer nach Burckhardt „Leute mit dem leisen, bedächtigen Schritt und der besonnenen Rede ${ }^{\text {“48 }}$ ).

In bezug auf die ,Staatlichkeit" Venedigs ist sein Urteil positiv: „Was irgend öffentliche Anstalt hieß, konnte in Venedig sein Muster finden“. ${ }^{49}$ Und noch dazu: „Venedig ist der Geburtsort der modernen Statistik“ ${ }^{50}$ Aber Florenz ist doch überlegen durch „die höchste politische Bewußtheit, den größten Reichtum an Entwicklungsformen“ und verdient „in diesem Sinne wohl den Namen des ersten modernen Staates der Welt"“. ${ }^{51}$ Und weiter: „Die Florentiner sind in manchen großen Dingen Vorbild und frühster Ausdruck der Italiener und der modernen Europäer überhaupt“ ${ }^{52}$ Wenn Individualisierung und Rationalisierung die Merkmale der Epoche sind ${ }^{53}$, sollten übrigens die dunklen Schatten der „Freisetzung der Rationalităt als Herrschaftsprinzip ${ }^{\text {(54 }}$ nicht übersehen werden, denn diese Errungenschaften wurzeln in der Triebnatur des Menschen ${ }^{55}$ : in den Stadtrepubliken wie in den Tyrannenstaaten Italiens erscheint, nach Burckhardt, „der moderne europäische Staatsgeist zum erstenmal frei seinen eigenen Antrieben hingegeben; sie zeigen oft genug die fessellose Selbstsucht in ihren furchtbarsten Zügen“. ${ }^{56}$ Dieser „dunkle Grundzug der Epoche ${ }^{\text {“57 }}$ gilt auch für die Beurteilung von Venedig, zum Beispiel für seine auswärtige Politik (,eine völlig objektive [...] Behandlung der internationalen Dinge, [...] aber das Ganze bringt den Eindruck eines bodenloses Abgrundes hervor ${ }^{\text {(58 }}$ ), sowie auch furr das „unterirdische und gewaltsame Tun des Rats der Zehnn" ${ }^{69}$, so Burckhardt.

Zusammenfassend läßt sich für Burckhardt feststellen: der Vergleich mit Florenz; die Florentiner Überlegenheit; die Schattenseiten des „Rationalisierungstrends“, die auch auf Venedig fallen. Diese eher ambivalenten Züge sind in der ganzen auf Burckhardt folgenden Renaissanceforschung zu Venedig weiter nachweisbar.

47 Jacob Burckhardt, Die Kultur der Renaissance in Italien. Hrsg. v. Horst Günther. (Bibliothek der Geschichte und Politik, Bd. 8; Bibliothek deutscher Klassiker, Bd. 38.) Frankfurt a. M. 1989, 68 f.

48 Ebd. 70.

49 Ebd.

50 Ebd. 76.

51 Ebd. 81.

52 Ebd. 91.

53 Vgl. Wolfgang Hardtwig, Jacob Burckhardt und Max Weber. Zur Genese und Pathologie der modernen Welt, in: Umgang mit Jacob Burckhardt. Zwölf Studien. Hrsg. v. Hans Rudolf Guggisberg. Basel 1994, 159-190, hier 169.

54 Wolfgang Hardtwig, Geschichtsschreibung zwischen Alteuropa und moderner Welt. Jacob Burckhardt in seiner Welt. Göttingen 1974, 175.

55 Hardtwig, Jacob Burckhardt (wie Anm. 53), 172.

56 Burckhardt, Die Kultur (wie Anm. 47), 12.

57 Hardtwig, Jacob Burckhardt (wie Anm. 53), 165.

58 Burckhardt, Die Kultur (wie Anm. 47), 97.

59 Ebd. 74. 


\section{Andreas und Simmel}

Die Rezeption der „Kultur der Renaissance“ erfolgte mit einiger Verzögerung: in den ersten 25 Jahren gab es nur vier, um die Jahrhundertwende von 1896 bis 1908 sechs Auflagen. ${ }^{60}$ Genau 1908 erschienen von Willy Andreas „Die venezianischen Relazionen und ihr Verhältnis zur Kultur der Renaissance“" ${ }^{61}$

Die Relazionen sind die Abschlußberichte, welche die Repräsentanten der Republik Venedig bei den verschiedenen Höfen Europas nach Beendigung ihrer Sendung zu erstatten verpflichtet waren (die Entscheidung zu diesem Verfahren setzte mit dem Jahr 1286 ein). Seitdem Ranke sie als überragende Geschichtsquellen wiederentdeckt hatte ${ }^{62}$ - für ihn ,eine noch unbekannte Geschichte Europas ${ }^{\text {“63 }}$-, haben die Forscher immer wieder aus dieser Quelle geschöpft. Sie wurden immer mehr erschlossen und veröffentlicht, daneben auch Urkunden für die Geschichte der einzelnen europäischen Nationalstaaten aus venezianischen Archivbeständen. Vor dieser Welle stand ein in die Zukunft weisender Vorschlag von Adolphe Thiers, dem späteren Ministerpräsidenten und Präsidenten der Republik Frankreich (1871-1878): Überzeugt von der übernationalen Tragweite der Diarii des Marino Sanudo (1496-1533), schlug er den europäischen Regierungen eine gemeinsame Herausgabe der 58 Foliobände vor ${ }^{64}$; ein Projekt, das leider nicht ausgefuhrt wurde. Venedig wurde also gleichsam als europäisches ,Memorienzentrum' entdeckt, Mittelpunkt einer intensiven Quellenerschließung, die an Rom nach der Öffnung der Vatikanischen Archive 1880 denken läßt. Und als in Rom die ersten ausländischen Forschungsinstitute errichtet wurden, gab es gleichermaßen Pläne zu Errichtung von Nationalinstituten in Venedig. Der Vorschlag für Deutschland kam von einem Kunsthistoriker, Gustav Ludwig, und einem Neuzeithistoriker, Paul Herre, nach dem Vorbild des Deutschen Kunsthistorischen Instituts in Florenz. Das auf dem internationalen Historischen Kongreß 1903 Rom vorgestellte Projekt scheiterte aber aus finanziellen Gründen. ${ }^{65}$

Zurück zu Andreas: die besondere Quellengattung der Relazionen, die bisher nur für die politische Ereignisgeschichte erschlossen war, wurde von Andreas unter einem anderen Gesichtspunkt betrachtet. Ziel seiner Arbeit über die Relationen war, „nach ihrem kultur-

60 Ever M. Janssen, Jacob Burckhardt-Studien. T. 1: Jacob Burckhardt und die Renaissance. (Speculum historiale, Bd. 5.) Assen 1970, 7.

61 Willy Andreas, Die Venezianischen Relazionen und ihr Verhältnis zur Kultur der Renaissance. Leipzig 1908. Diese Arbeit ist Andreas' Dissertation. Sie wurde 1943 mit neuem Vorwort und Titel überarbeitet: Willy Andreas, Staatskunst und Diplomatie der Venetianer im Spiegel ihrer Gesandtenberichte. Leipzig 1943. Über Andreas: Eike Wolgast, Art. Andreas, Willy, in: Badische Biographien NF., Bd. 2. Hrsg. v. Bernd Ottnad. Stuttgart 1987, 4-7. Zu ihm demnächst ausfuhrlicher; s. oben Anm. *.

62 Noch früher als Ranke der Schweizer Johannes von Müller: Andreas, Staatskunst (wie Anm. 61), 73-75.

63 So in Rankes Briefen nach Andreas; s. ebd. 76 Anm. 1.

64 Guglielmo Berchet, Prefazione, in: I Diarii di Marino Sanuto (MCCCCXCVI-MDXXXIII). Dall'autografo Marciano Ital. Cl. VII Codd. CDXIX-CDLXXVII. Ed. Rinaldo Fulin u. a.. Vol. 1. Venezia 1879, ND Bologna 1969, $122 \mathrm{f}$.

65 Herre, Die alte Republik Venedig (wie Anm. 14), 117 Anm. 1. 
historischen Werte $\mathrm{zu}$ fragen (...), sie zu begreifen als Ausstrahlungen eines bestimmten Geistes und seiner Art die Dinge zu sehen". ${ }^{66}$ Auch nach Andreas ist Rationalismus das Hauptmerkmal des Zeitalters und die Erscheinungsform der Geschichte Venedigs: „Das politische Weltbild der Venezianer gleicht einem Sonnensystem (...). Die innere Kraft, die das Ganze mit kalter Energie einheitlich zusammenhält, heißt politische Vernunft. ${ }^{667} \mathrm{Er}$ betont den „harte(n) Rationalismus und die zähe Selbstsucht der Realpolitiker“, und von daher stellt er die Venezianer in eine Reihe mit Machiavelli, Bossuet und „den großen Trägern des europäischen Absolutismus". ${ }^{68}$ Zum Rationalismus kommt noch der Individualismus: „Unsere Relazionen führen uns auf der Stelle mitten in das Zeitalter des Individualismus hinein. ${ }^{\text {"69 }}$ Schon im ersten Portrăt (von Karl VIII. und seiner Frau Anne de Bretagne) ist „das Gefühl für die Persönlichkeit als solche (...) durchaus darin wach““ ${ }^{70}$

Ich möchte noch aus der Zusammenfassung zitieren: „Die Relazionen sind Werke eines Geistes, der sich zuversichtlich und verstandessicher der Wirklichkeit bemächtigt“. Er entfaltet sich „voll klarer Ruhe“ und löst „persönliche und sachliche Verhältnisse kühl in ihre einzelnen Größen auf. Die Freude eines vom Unbewußten in die Bewußtheit aufgestiegenen Zeitalters an der Herrschaft des Verstandes atmet aus diesen Berichten (...). Sie haben jene ruhige Săttigung und das gemessene Selbstbewußtsein, die Venedig von der bewegten Schärfe der Florentiner unterscheiden" ${ }^{\text {"71 }}$ - hier klingt Burckhardt an. Ich fahre fort: Sie sind „Kunstwerke einer politischen Kultur“, und „der helle Glanz eines vollausgewachsenen Geschlechtes ruht auf ihnen, vielleicht auch schon die Überklarheit der vollkommen ausgereiften Dinge, die in die Ruhe des Todes übergehen". ${ }^{72}$

Wie diese Zitate zeigen, steht Andreas bei seinem Interpretationshorizont weitgehend in der Nachfolge Burckhardts. Nur wird die ja bei Burckhardt angedeutete dunkle Seite stärker herausgearbeitet: Sie erscheint schon in der Vorrede, wo Andreas die Schwierigkeit seines Vorhabens schildert, die „Quintessenz des Denkens der Venezianer abzuringen. Wenn dies möglich ist! Denn auch hier stehen wir schließlich vor mannigfaltigem Reichtum geistiger Wirklichkeit, deren letzte Triebkrăfte wir nur ahnend in die Helle des Bewußtseins zu ziehen vermögen, wie jene Grundmächte unseres eigenen Daseins, die uns bedrücken und erheben ". ${ }^{73}$ Andreas' Wortschatz ist dementsprechend: Venedig ist geheimnisvoll, von den abgestorbenen Jahrhunderten geprägt ${ }^{74}$; eine Stadt aus ,,seltsamer Versunkenheit ${ }^{\text {(75 }}$ - ein Begriff, Versunkenheit, der aufgrund seiner metaphorischen Eigenschaft sowohl zeitliche wie auch

66 Andreas, Die Venezianischen Relazionen (wie Anm. 61), VI.

67 Ebd. 58.

68 Ebd. $60 \mathrm{f}$.

69 Ebd. 68.

70 Ebd.

71 Ebd. 124.

72 Ebd.

73 Ebd. VII.

74 Ebd. 51.

75 Ebd. 
(tiefen)psychologische Prozesse impliziert. ${ }^{76}$ Versunkenheit und Tod: Venedig wahrte „in den heftigen Erschütterungen (...) seine unnahbare Kälte, eine Ruhe, die noch das sieghafte Lächeln auf den Lippen trug, aber von dem Zeichen des Todes beruhrt war". ${ }^{77}$ Wie gesagt: Andreas' Abhandlung wurde 1908 veröffentlicht; Thomas Manns Der Tod in Venedig erschien nur vier Jahre später.

Und so ist es denn auch kein Zufall, daß ein Klassiker der Soziologie und Kritiker der Moderne sich um dieselbe Zeit ebenfalls über Venedig geäußert hat, Georg Simmel nämlich. 1906 verfaßte er einen Aufsatz uber Florenz ${ }^{78}$, ein Jahr später einen über Venedig, nicht lediglich als mittelalterliches, sondern als historisches Phänomen insgesamt. ${ }^{79}$ In letzterem kommt der Vergleich zu Florenz oft vor, umgekehrt dagegen nicht. Nach Simmel ist Venedig gegenüber der „Kunststadt“ Florenz eine „künstliche Stadt“, ein entseeltes Bühnenbild, eine vom Sein abgetrennte Erscheinung. „Vielleicht liegt hier der tiefste Unterschied zwischen der Architektur von Venedig und der von Florenz. Bei den Palästen von Florenz (...) empfinden wir die Außenseite als den genauen Ausdruck ihres inneren Sinnes (...), die Darstellung einer selbstgewissen, selbstverantwortlichen Persönlichkeit. Die venezianischen Paläste dagegen sind ein preziöses Spiel, schon durch ihre Gleichmäßigkeit die individuellen Charaktere ihrer Menschen maskierend, ein Schleier. “80

Dann kommt die oben erwähnte Trennung zwischen Sein und Schein: „Die Erscheinung lebt wie in ostentativer Abtrennung vom Sein, die Außenseite erhält von ihrer Innenseite keinerlei Direktive und Nahrung (...). Florenz wirkt wie ein Werk der Kunst, (...) Venedig aber ist die künstliche Stadt“, ihr Untergang „hat nur ein entseeltes Bühnenbild, nur die lügenhafte Schönheit der Maske übrig gelassen. Alle Menschen in Venedig gehen wie über die Bühne: in ihrer Geschäftigkeit (...) haben (sie) immer etwas wie Schauspieler, die rechts und links von der Szene nichts sind, das Spiel geht nur dort vor und ist ohne Ursache in der Realităt des Vorher, ohne Wirkung in der Realität des Nachher". ${ }^{81}$

Zusammenfassend stellt Simmel fest: „Alles das erscheint uns, sobald uns das Sein dieser Stadt, das in der Ablösung des Scheins vom Sein besteht, einmal in seinem Bann hat, als etwas nur Zweidimensionales, wie aufgeklebt auf das Wirkliche und Definitive ihres Wesens. ${ }^{\text {“82 } ~ „ D a s ~ T r a g i s c h e ~ a n ~ V e n e d i g “ ~ b e s t e h e ~ d a r i n, ~ „ d a ß ~ d i e ~ O b e r f l a ̈ c h e ~(. . .) ~ s i c h ~ d e n-~}$ noch als ein Vollständiges und Substanzielles gibt ${ }^{483}$, und abschließend fährt Simmel fort: „Daß unser Leben eigentlich nur ein Vordergrund ist, hinter dem als das einzig Sichere der Tod steht - dies ist der letzte Grund davon, daß das Leben, wie Schopenhauer sagt

76 Bernard Dieterle, Die versunkene Stadt. Sechs Kapitel zum literarischen Venedig-Mythos. Frankfurt a. M. u. a. 1988.

77 Andreas, Die Venezianischen Relazionen (wie Anm. 61), 54.

78 Georg Simmel, Florenz [1906], jetzt in: ders., Aufsătze und Abhandlungen 1901-1908. Bd. 2. Hrsg. v. Alessandro Cavalli/Volkhard Krech. (Georg Simmel Gesamtausgabe, Bd. 8.) Frankfurt a. M. 1993, 69-73.

79 Georg Simmel, Venedig [1907], jetzt in: ders., Aufsătze (wie Anm. 78), 258-263.

80 Ebd. 259.

81 Ebd. $259 \mathrm{f}$.

82 Ebd. 260.

83 Ebd. $261 \mathrm{f}$. 
,durchweg zweideutig' ist (...). So ist Florenz, das der Seele die herrlich eindeutige Sicherheit einer Heimat gibt. Venedig aber hat die zweideutige Schönheit des Abenteuers, das wurzellos im Leben schwimmt, wie eine losgerissene Blüte im Meere. ${ }^{\text {(84 }}$

Der Beitrag wird, soweit ich sehe, in der Simmelrezeption eher als „essai esthétique “85 betrachtet, wobei auch Themen der Simmel'schen „Tragödie der Kultur“ spürbar sind. Die traditionellen Topoi des literarischen Venedig-Bildes werden zwar rezipiert (Bühne und Maske, die neuerdings auch im vorletzten Band von E. Crouzet-Pavan sogar ausdrucklich thematisiert worden sind als „une invention de la ville ${ }^{\text {(86. }}$ : die Stadt als Selbstinszenierung), aber sie werden als Ausdruck der Moderne umgedeutet, und danach richten sich auch die Begriffe: Künstlichkeit; Gleichmäßigkeit, die die individuellen Charaktere maskiert; Geschäftigkeit; und dann Oberfläche; Irrealităt des Vorher und Nachher; grundlos und wurzellos: so der unsolide Schein der Moderne. Und wenn ich nicht überinterpretiere, lassen sich sogar die Grundelemente der sogenannten neusachlichen Anthropologie erfassen, deren „große Vermittlerfigur" nach Helmut Lethen ${ }^{87}$ Georg Simmel ist: das Künstlichkeits-Axiom, das Recht zur Verstellung, die Kultur der Oberfläche, die Zeitlosigkeit der Moderne. Die „kalte persona“ der Neuen Sachlichkeit, nämlich die Gestalt eines mobilen Subjekts in einer verhaltensorientierten Zivilisation, klingt vielleicht schon bei Burckhardt und Andreas an, gerade wo Burckhardt die Venetianer als „Leute mit dem leisen, bedächtigen Schritt und der besonnenen Rede“ ${ }^{\text {“88 }}$ schildert, und vielleicht noch deutlicher bei der „unnahbaren Kälte“"89 in der Darstellung von Andreas.

So sind zu Anfang des 20. Jahrhunderts Andreas und Simmel vom vitalen, sonnigen, dabei naiv-optimistischen Bild von Tafel und Thomas weit entfernt. In 50 Jahren hat sich ein Paradigmenwechsel in der Geschichtsauffassung vollzogen: Nach Oexle „begann [er] im Zeichen der raschen Verflüchtigung des Fortschrittsglaubens, die vor allem von der Wirtschaftskrise (...) und den dadurch erzeugten Enttäuschungen und Erbitterungen mächtig gefördert wurde (...). Dazu kamen die als immer belastender empfundenen Wirkungen der zunehmenden Modernisierung der 1880er und 1890er Jahre (...), gegen die sich ein immer heftiger werdender Anti-Modernismus äußerte. ${ }^{“ 90}$ Der Zusammenbruch des Fortschrittsparadigmas wirkte auch auf die Venedig-Rezeption und beeinflußte die Methoden, die Techniken der Betrachter und nicht zuletzt das Objekt selbst, Venedig. Anstelle des Glaubens von Tafel und Thomas an das „Wahre und das Schöne“ kamen der Zweifel bei Burckhardt, des-

84 Ebd. $262 \mathrm{f}$.

85 Stéphane Jonas, Georg Simmel sur l'esthétique des villes historiques italiennes, in: G. Simmel et les sciences humaines. Actes du Colloque G. Simmel et les sciences humaines, 14-15 septembre 1988. Ed. Otthein Rammstedt/Patrick Watier. Paris 1992, 163-178. Vgl. auch Gregor Fitzi, Florenz in der asthetischen Anschauung von Georg Simmel, in: Simmel Newsletter 5/1, 1995, 34-45.

86 Elisabeth Crouzet-Pavan, Venise. Une invention de la ville (XIII'-XV' siècle). Seyssel 1997.

87 Helmut Lethen, Verhaltenslehren der Kälte. Lebensversuche zwischen den Kriegen. Frankfurt a. M. 1994, 81.

88 Burckhardt, Die Kultur (wie Anm. 47), 70.

89 Andreas, Die Venezianischen Relazionen (wie Anm. 61), 54.

90 Oexle, Die Moderne (wie Anm. 18), 329 f. 
sen Vertiefung bei Andreas und schließlich die „Lüge von Venedig“91 bei Simmel (so heißt es wortwörtlich). Die historisch-philologische Wissenschaft von Tafel und Thomas ist bei Andreas (tiefen)psychologisch eingefärbt. Das dreidimensionale Venedig, das Thomas wie durch ein Stereoskop dachte betrachten zu können ${ }^{92}$, schrumpft bei Simmel zur zweidimensionalen Kulisse.

\section{Kretschmayr}

Diese pessimistische Grundeinschätzung fand durch die Niederlage und Katastrophe von 1918 gleichsam eine Bestätigung und provozierte in der Venedig-Forschung eine Umorientierung: „Die Renaissance als Verderberin von Altvenedig“ lautet eine Überschrift, die Heinrich Kretschmayr für den 2. Band seiner Geschichte von Venedig wăhlte. ${ }^{93}$ Dieses abschätzige Urteil durchzieht alle Wertungen wie ein roter Faden: „Nach hartnäckigem Widerstande, widerwillig genug“, habe sich Venedig der Renaissance geöffnet. „Wie hătte es sich nun leichthin der Renaissance erschließen sollen, in deren ganzer Weltanschauung etwas fur sie Feindseliges lag? Und hatte sie Unrecht sich zu wehren? Verdarb dieser neue Geist nicht die Heimatsbaukunst, brachte er nicht ungesunden Luxus statt Wohlhabenheit, zerstörte er nicht die alten guten Sitten des goldenen [14.] Jahrhunderts? (...) Und als sie gesiegt hatte, war es nicht mehr das alte, herbe, harte, fromme Venedig, sondern die neue, verfuhrerisch kosende, aber in tausend Wundern nicht mehr jugendfrische Weltstadt. “94 Und weiter: „Die italienische Renaissance, die Geisteswelt des Westens und des Südens, überwältigte die venezianische Gotik, diese Welt des Nordens und des Ostens, und die lange zögernde und widerspenstige Stadt gab sich ihr endlich hin. Das Verlangen nach einem mehr von Rechten als Pflichten umstandenen Leben und nach einer alle dunkle Problematik in helle Harmonie auflösenden Ausgeglichenheit, das Freiheitsbewußtsein und Weltgefuhhl der sich selbst bestimmenden Persönlichkeit wurde, bei gleichzeitiger Minderung der sittlichen Kräfte, der beherrschende Zug, und der Drang nach Vereinigung von individueller Befreiung und allgemeiner Gebundenheit und nach Verbergung von Zweck und Inhalt hinter der Form die kennzeichnende Eigenschaft (...). ${ }^{\text {c95 }}$

Diese Begrifflichkeit ist so prägnant und so tief von zeitbezogenen Deutungen geprägt, daß sie keine năhere Erlăuterung benötigt - ich zăhle einige Gegensatzpaare einfach auf: Gotik/Renaissance; die Welt des Nordens und des Ostens einerseits, die Welt des Westens und des Südens andererseits (das ist das Nord/Süd-Thema, die Abgrenzung des deutschen Wesens vom französischen und westlichen, der sogenannte deutsche Sonderweg ${ }^{96}$ ); dunkle

91 Simmel, Venedig (wie Anm. 79), 261.

92 Thomas, Die Stellung Venedigs (wie Anm. 29), 5.

93 Kretschmayr, Geschichte von Venedig. Bd. 2 (wie Anm. 9), 480.

94 Ebd. 498.

95 Kretschmayr, Geschichte von Venedig. Bd. 3 (wie Anm. 9), 192.

96 Dazu noch Kretschmayr, Geschichte von Venedig. Bd. 3 (wie Anm. 9), 504: „Uns atmet die Markuskirche den Märchenzauber des Orientes und zugleich den nordischen Geist der Heimat zu. Wir spüren und wissen, sie sei auch von unserer Welt. Und ist es nicht als wollte sie uns ahnen lassen, was aus der 
Problematik/auflösende Ausgeglichenheit; allgemeine Gebundenheit/individuelle Befreiung. Zugespitzt handelt es sich um Stereotypen und Denkformen eines „Mediävalismus ${ }^{697}$, der an der Moderne litt und die Merkmale seiner Zeit trägt: der Zeit, so Kretschmayr 1920, zwei Jahre nach dem Ende des Ersten Weltkrieges, „als dann schier alles niederbrach, was einst unser Stolz und unsere Lust gewesen."98

Alle Zitate stammen aus dem 2. und 3. Band der Geschichte von Venedig, 1920-1934. Das Gesamtwerk besteht aus drei Bänden, der erste erschien 1905 und deckt die Zeit bis 1204 ab; der zweite, funfzehn Jahre später, reicht bis zum Ende des 15. Jahrhunderts; der dritte, wiederum fünfzehn Jahre später, bis 1797, dem Ende der Republik Venedig durch die napoleonische Eroberung. Die Bände verweisen auch mit ihren Erscheinungsdaten auf Zäsuren: der erste vor dem Ersten Weltkrieg, der zweite nach der deutsch-österreichisch-ungarischen Niederlage und der dritte ein Jahr nach Hitlers Machtergreifung. Der Gesamtumfang reicht an die 2000 Seiten heran: ein Monumentalunternehmen, wie das von Tafel und Thomas.

Mit Kretschmayr hat die Auseinandersetzung mit dem Phänomen Venedig keinen Abschluß erreicht. Es folgten weitere Betrachter und andere Themen: Wie anfangs angedeutet, läßt sich das mittelalterliche Venedig unter verschiedenen und vielfältigen Aspekten betrachten - ich erwähne nur die Rolle in der Debatte uber die Entstehung des modernen Kapitalismus und in der Polemik über die Sombartschen Thesen.

Die Arbeit von Kretschmayr wird als Standardwerk immer wieder zitiert, aber kaum vollständig gelesen, noch weniger als Ganzes verstanden; in den romanischen Ländern natürlich wegen der Sprachbarriere. Dem versuchte schon Kretschmayr selbst Abhilfe zu verschaffen: Im Alter arbeitete er noch an einer Übersetzung ins Italienische, aber er verstarb daruber. So wird seinem Werk durch die unvollkommene Rezeption die Anerkennung als Klassiker gemindert, im Gegensatz zu anderen grundlegenden Stadtgeschichten, deren Übertragung ins Italienische vorliegt: der Geschichte Roms von Gregorovius, Florenz' von Davidsohn, Bolognas von Alfred Hessel und Genuas von Georg Caro. ${ }^{99}$

Vermählung nordischen Geistes und orientalischer Einbildungskraft noch erblühen kann?'; und weiter: „Ist es nicht, als ob in dieser Stadt der Farben und Lichter im Ineinanderspielen ihrer Künste sich von der Malerei her etwas ankündigte wie hernach von der Musik her das Gesamtkunstwerk der deutschen Germanen?" Ebd. 505.

97 Oexle, Die Moderne (wie Anm. 18), 329 ff.

98 Kretschmayr, Geschichte von Venedig. Bd. 2 (wie Anm. 9), VII. Über Kretschmayr: Reinhold Lorenz, Art. Kretschmayr, Heinrich, in: Österreichisches biographisches Lexikon 1815-1950. Bd. 4. Wien/Köln/Graz 1969, 263 f. Zu ihm demnächst ausfuhhrlicher; s. oben Anm. *.

99 Ferdinand Gregorovius, Storia della città di Roma nel Medio Evo. Dal secolo V al XVI. Venezia 1866-1876; Robert Davidsohn, Storia di Firenze. Le origini. Firenze 1907-1909; Alfred Hessel, Storia della città di Bologna. Dal 1116 al 1280. Bologna 1975; Georg Caro, Genova e la sua supremazia sul Mediterraneo (1257-1311). (Atti della società ligure di storia patria, 14). Genova 1974/75. Die Einleitung zur Hessel-Übersetzung verfaßte übrigens Gina Fasoli, deren Urteil über Kretschmayr bereits zitiert wurde; s. oben bei Anm. 16. 
Transkulturelle und diachrone Vergleiche 



\section{Hofkulturen im Vergleich}

\section{,Liebe‘ bei den frühen Abbasiden*}

Von

Gadi Algazi

Im folgenden soll über einige Ergebnisse eines gemeinsamen Forschungsprojekts zur vergleichenden Geschichte von Hofkulturen berichtet werden, das an der Universität Tel Aviv im Programm für Kulturforschung entstanden ist. ${ }^{1}$ Vergleiche sind selten wirklich symmetrisch. Im Hinblick darauf haben meine Kollegin Rina Drory und ich uns entschieden, erstens, unter Umkehrung der üblichen Verhältnisse, den Schwerpunkt eindeutig auf den abbasidischen Hof zu legen, wo viele Forschungsansătze noch kaum erprobt wurden, der Materialreichtum jedoch viel verspricht; zweitens, soweit unsere Kompetenzen dies erlauben, die Texte gemeinsam zu lesen, damit der vergleichende Ansatz nicht lediglich beim Abwägen der jeweiligen Forschungsergebnisse bleibt, sondern die Quellenanalyse selbst durchdringt. $\mathrm{Ob}$ es uns gelungen ist, sei zunächst dahingestellt; daß die Arbeit Vergnủgen bereitet, kann ich allerdings bezeugen.

\section{Der Hof als Prägestock klassischer Kultur}

Nachdem sie 750 die Macht im islamischen Reich erobert hatten, schufen die Abbasiden in Bagdad eine Hauptstadt mit enormer Ausstrahlungskraft. Doch nicht nach den Bedingungen der Konzentration politischer Macht und ökonomischer Ressourcen fragen wir ${ }^{2}$, sondern

- Der Text stellt eine leicht uberarbeitete Fassung des Vortrags auf der Berliner Tagung dar; Hinweise auf Quellen und Forschungsliteratur sind dementsprechend auf das allernotwendigste beschrănkt. Eine vollstăndigere Version der hier vorgestellten Thesen: Gadi Algazi/Rina Drory, L'amour à la cour des 'abbasides: Un code de compétence sociale, in: Annales 55, 2000, 1255-1282.

1 Das Projekt wurde von der Israelischen Akademie der Wissenschaften unterstutzt und durch Rina Drory und mich geleitet. Der folgende Text ist zwar von mir verfiaßt worden, stellt aber das Ergebnis unserer gemeinsamen Forschungsarbeit dar. Rina, eine wunderbare Kollegin und unvergeßliche Freundin, starb an einer schweren Krankheit vor dem Erscheinen dieser Zeilen. Ihrem Andenken sind sie gewidmet.

2 Dominique Sourdel, Le Vizirat Abbaside. Damaskus 1959-1960; Jacob Lassner, The Shaping of 'Abbasid Rule. Princeton 1980; Hugh Kennedy, The Early Abbasid Caliphate. A Political History. London 1981, 73-134; Michael G. Morony, Iraq after the Muslim Conquest. Princeton 1984, $70-86$. 
nach der kulturellen Prägekraft des abbasidischen Hofs. Vieles von dem, was wir heute mit der klassischen islamischer. Kultur assoziieren, ist in diesem Kontext entstanden. ${ }^{3}$ Mit ,Kultur' meinen wir weniger die einzelnen Artefakte - kanonische Schriften, Wörterbücher, Enzyklopädien, Gedichte und Paläste -, sondern vielmehr die Repertoires, welche kulturelle Produktion möglich machen: Modelle des Verhaltens und der Interaktion, Prozeduren des Sammelns und Kodifizierens, Sichtweisen der Welt und Konstruktionsweisen der Vergangenheit. Die formative Zeit, in der viele dieser Modelle Gestalt annahmen, läßt sich zwischen der Regierungszeit des Kalifen al-Mahdî und der Ära al-Ma'mûn festmachen, d. h. zwischen dem letzten Drittel des 8. und der ersten Hälfte des 9. Jahrhunderts. Innerhalb dieser relativ kurzen Zeit wurde nicht nur eine raffinierte Hofkultur geschaffen ${ }^{4}$; gleichzeitig wurde ihr Gegenpol, die nomadische, prä-islamische Epoche der Jâhiliyya konstruiert. Sie diente als Gegenfolie zur höfischen Welt der Eleganz, zugleich aber auch als Garant der arabischen Identităt in dem islamischen Vielvölkerreich. ${ }^{5}$ Dieses doppelte kulturelle Projekt hat die islamische Kultur nachhaltig geprägt.

Wir fangen media in re an, mit einem komplexen kulturellen Repertoire, das spezifische Verhaltensweisen, Beziehungsformen und Selbstbilder der Handelnden bündelt - dasjenige von ,Liebe', das am abbasidischen Hof eine bis dahin nicht gekannte Bedeutung erlangte. Nicht psychische Realitäten werden uns beschäftigen, sondern der kulturelle Kode und seine Funktionen. Wir beginnen also mit dem Teil und lassen das Ganze zunächst in der Schwebe, um es im Verlauf der Analyse besser konturieren zu können. ,Europa‘ liefert dabei keine Antworten, sondern eher Vergleichsfälle, Fragen und Forschungsansätze.

Ein Wort zur Quellenlage sei hier eingeschoben. Einerseits imponiert der enorme Reichtum der arabischen schriftlichen Quellen, etwa wenn man die arabischen biographischen Handbücher und genealogischen Nachschlagewerke betrachtet. Andererseits fehlen sowohl Urkunden als auch längere Erzählungen, die es ermöglichen würden, Handlungsabläufe in ihrem sozialen Kontext zu rekonstruieren. Die meisten uns zur Verfügung stehenden Texte bestehen aus relativ kurzen Fragmenten denkwürdiger Sprüche und Interaktionen, die in $a d a b$-Anthologien gesammelt wurden und über die Umstände der geschilderten Handlungen, ihre Hintergründe und Konsequenzen kaum etwas sagen. Die Rekonstruktion der Kontexte der überlieferten Dicta und Facta erfordert daher eine Detektivarbeit, die weitgehend noch $\mathrm{zu}$ leisten ist.

Für unsere Zwecke liefern die adab-Sammlungen immerhin kondensierte Versionen der kulturellen Muster und der typisierten Einstellungen, die zuerst rekonstruiert werden sollen. Zudem hat sich im Verlauf unserer Arbeit herausgestellt, daß eine genaue Prosopographie es doch ermöglicht, im Einzelfall plausibel zu machen, warum ein überlieferter Text einer

3 Vgl. Adam Mez, The Renaissance of Islam. Patna 1937; Gustave E. von Grunebaum, Classical Islam. A History, 600-1258. London 1970, 80-113.

4 Vgl. Jean-Claude Vadet, L'esprit courtois en Orient dans les cinq premiers siècles de l'Hégire. Paris 1968.

5 Rina Drory, The Abbasid Construction of the Jâhilîyya: Cultural Authority in the Making, in: Studia Islamica 83, 1996, 33-49. 
identifizierbaren Person zugeschrieben wird und wie er entsprechend dem Überlieferungszusammenhang unterschiedliche Gestalten annimmt.

\section{Das abbasidische Modell von ,Liebe}

Gegen Ende des 8. Jahrhunderts ergreift ,Liebe“ den Hof der Abbasiden. Zahlreiche Traditionen beschreiben die Höflinge, die mächtigen Wesire und selbst die Kalifen im Zustand des Verliebtseins. ${ }^{6}$ Vergleichbares ist von ihren Vorgängern kaum überliefert. Von Harûn alRashîd wird etwa berichtet, er sei im Hof auf und ab gelaufen, seiner berühmten Selbstbeherrschung beraubt, nachdem ihn seine Geliebte ausgeschimptt hatte. Er fragte die anwesenden Dichter, ob jemand von ihnen seinen Gemütszustand, den er selbst mit Worten weder beschrieb noch benannte, genau treffen könnte. Nachdem der erste es mit einem Liebesgedicht versucht hatte und reichlich belohnt wurde, probierte es auch der zweite, der uns davon berichtet, und wurde ebenfalls großzugig beschenkt. Haran al-Rashîd allerdings sagte schließlich, er selbst sei doch der bessere Dichter, und improvisierte gleich einen Reim, der das ganze Gedicht nach Versmaß und Inhalt abschloß. ${ }^{7}$ Nicht die wirklichen Emotionen des Kalifen sind hier von Belang, sondern die Tatsache, daß ihm ein solcher Zustand legitimerweise zugeschrieben werden konnte. Ein Modell von ,Verliebtsein' mußte schon fest etabliert gewesen sein, damit die Dichter die entsprechenden Symptome an dem Kalifen erkennen und seinen Zustand mit passenden Reimen erfassen konnten. „Liebe' ist offenbar zentraler Bestandteil des Verhaltenskodes am Hof geworden. Das war neu.

Dieses Modell von ,Liebe‘ hatte seine spezifischen Regeln. Man sollte in eine Geliebte verliebt sein, die als schwer erreichbar zu gelten hatte, auch wenn sie etwa in Wirklichkeit unter der Herrschaft des verliebten Mannes stand. Hochgebildete Sklavinnen waren die bevorzugten Partnerinnen. Der Mann sollte die bekannten Symptome der Liebeskrankheit öffentlich unter Beweis stellen - schlaflos, grüblerisch, zerstreut, blaß und abgemagert sein. „Du bist offenbar nie in deinem Leben verliebt gewesen“, sagte Harun al-Rashîd halbscherzend zu seinem Onkel, der für seine Korpulenz bekannt war. „Doch“, erwiderte er, „und in Wahrheit bin ich auch in diesem Moment verliebt. ${ }^{\text {(8 }}$

6 Vgl. etwa Ibrâhim ibn 'Alî al-Husrî, al-Masûn fî sirr al-hawâ al-naknûn. Hrsg. v. 'Abd al-Wâhid Sha'lân. Kairo 1989, 45; 'Alî ibn Muhammad Abû al-Hasan al-Shâbushtî, Kitâb al-diyârât. Hrsg. v. G. 'Awwâd. 3. Aufl. Beirut 1986, 226 f.; Ahmad ibn Muhammad Ibn 'Abd Rabbihi, Kitâb al-'iqd alfarîd. Hrsg. v. Ahmad Amîn/Ahmad al-Zay/Ibrâhîm al-Ibyâr. Bd. 6. Kairo 1965, 457; "Abd al-Rahmân ibn 'Alî Ibn al-Jawzî, Dhamm al-hawâ. Hrsg. v. Ahmad 'Abd al-Salâm 'Atâ. Beirut 1987, 268 f.

7 'Alî b. al-Husayn Abû al-Faraj al-Isbahânî, Kitâb al-aghânî. Hrsg. v. 'Abd Allah 'Alî Muhannâ/Samîr Jâbir. Bd. 23. Beirut 1992, 97 f. Vgl. unter den anderen Varianten bes. Ibn "Abd Rabbihi, al-'iqd al-farîd (wie Anm. 6), 58.

8 Muhammad ibn Ahmad Abû al-Tayyib al-Washshâ', al-Muwashshâ'. Hrsg. v. 'Abd al-Amîr 'Alî Muhannâ. Beirut 1990, 95 f. 
Es ging jedoch um mehr als um die bekannten, vorübergehenden Symptome der ,Liebeskrankheit ${ }^{9}:$,Liebe' sollte in diesem Fall eine dauerhafte und strukturierte Verwandlung des Geliebten zur Folge haben. Sie initiierte die Aufnahme eines umfassenden Bildungsprogramms. Den Hof machen hieß, höfisch werden. Der verliebte Mann sollte ein ganzes kulturelles Repertoire erwerben: Klassische Texte zitieren können, Gedichte verfassen, Briefe schreiben und einen peniblen Kode von Reinlichkeit und Körperkultivierung beachten. Liebe galt nun als der Schlüssel zum Erwerb raffinierter ,Kultur - adab.

Wenn ,Liebe' diese Rolle zukommt, erfordert dies dreierlei: Erstens, der Prozeß des Hofierens muß verlängert werden, wenn erforderlich, durch eine fest kodifizierte Phase der Abweisung des verliebten Mannes; zweitens, die weiblichen Beteiligten müssen mit der entsprechenden kulturellen Kompetenz ausgestattet werden; drittens, gegenüber dem Verliebten sollen sie als handelnde Subjekte agieren können. Nur so konnte sich das Spiel entfalten. Alle drei Aspekte sind in den Quellen gut bezeugt.

Wie neu diese Form von ,Liebe“ war, läßt sich durch einen Vergleich mit der herkömmlichen Kodierung von ,Liebe' in der arabischen Kultur deutlich machen:

(a) An Liebesdichtung hat es in der arabischen Tradition nicht gefehlt; doch vom Prozeß des Hofierens war da äußerst selten die Rede gewesen. Im Zentrum der herkömmlichen arabisch-nomadischen Liebesdichtung stand die Erfahrung des Verlusts der Geliebten und der Sehnsucht infolge des endgültigen Abschieds von ihr. Bei den Abbasiden verschob sich deutlich der Schwerpunkt dessen, was ,Liebe' genannt wurde.

(b) In dem herkömmlichen Modell war der Verliebte von seiner Geliebten durch unüberwindbare soziale Schranken getrennt: $\mathrm{Ihr}$ Stamm, ihre Verwandten und die soziale Zensur standen zwischen ihnen. Bei den Abbasiden wurden dagegen kunstliche Schranken aufgebaut, um den Prozeß in Gang zu halten. Die Geliebte selbst mußte nun launenhaft und anspruchsvoll sein, um den Verliebten anzuspornen, sich selbst zu bilden. An die Stelle der äußeren sozialen Schranken traten ihre Subjektivität und ihre Handlungen.

(c) Dementsprechend waren die Folgen der ,Liebe' fast diametral entgegengesetzt: ,Liebe brachte den Verliebten nach dem herkömmlichen Modell um seinen Verstand, fuhrte ihn in die Wüste, wo er die Gesellschaft von Menschen vermied und mit Tieren lebte. Anders als bei den Abbasiden war ,Liebe' nicht mit der Initiation in die Kultur assoziiert, sondern mit der Rückkehr zur rohen, vorsozialen ,Natur'. ${ }^{10}$

Von einer ,Entdeckung' der Liebe am abbasidischen Hof soll daher keine Rede sein. Es läßt sich jedoch genau beobachten, wie ,Liebe‘ neu modelliert wurde. Ihre Aufwertung zum hoffähigen Modell war verknüpft sowohl mit einer neuen Zuschreibung kultureller Funktionen als auch mit einer neuen Kodierung der damit verbundenen Erfahrung.

9 Hierzu zuletzt: Mary F. Wack, Lovesickness in the Middle Ages. The Viaticum and its Commentaries. Philadelphia 1990, mit weiterführender Literatur.

10 Vgl. etwa Ja'far ibn Ahmad al-Sarrâj, Masâri‘ al-'ushshâq. Bd. 2. Beirut o. J., 91, 101 f., 104-106. 


\section{Liebe als erzieherisches Spiel}

Die Parallelen zwischen dieser Kodienung der Liebe und derjenigen, die besonders seit dem 12. Jahrhundert zunächst an französischen Höfen bezeugt ist, sind unübersehbar. Den Begriff der ,höfischen Liebe' möchten wir in diesem Kontext vermeiden. Unumstritten ist jedoch, daß ,Liebe' mit der dauerhaften Transformation der Person assoziiert wurde, und daß auch hier Hofieren höfisch werden hieß.

Stellvertretend für viele Texte sei hier auf die berühmten Gebote des Liebesgottes ,Amor aus dem ersten Teil des Roman de la Rose verwiesen, den Guillaume de Lorris um 1225 verfaßte. ${ }^{11}$ Hier findet sich ein gestaffeltes Programm zur Umformung des höfischen Liebhabers, welches von außen nach innen voranschreitet: Es fängt bei der Normierung des Redens und dem Verbot männlicher Prahlerei an, die durch stumme Zeugnisse der Eleganz Kleidung und äußere Accessoires - ersetzt werden soll. Vorschriften über Körperpflege und Reinlichkeit fuhhren zum darstellerischen Einsatz des kultivierten Körpers am Hof. Der Text gipfelt in der Strukturierung der inneren Erfahrung des Liebenden durch Gedächtnisübungen und der Erziehung seines Willens, der sich den Geboten des Gabentausches fugen sollte. Hier wie dort gilt ,Liebe' am Hof als anerkannte Motivation zum Erwerb kultureller Kompetenzen. Es scheint daher angebracht, genauere Beobachtungen über erkennbare Differenzen und Gemeinsamkeiten anzustellen.

Die Verwandlung des Verliebten durch den Erwerb kultureller Kompetenz ist in beiden Fällen gut bezeugt; im westeuropäischen Kontext ist jedoch darüber hinaus eine andere Variante der ,pouvoir ennoblissant de l'amour" belegt: Als Liebesdienst macht der Liebende eine Serie von Abenteuern durch, die ihn zum vorbildhaften Ritter werden lassen. Dieses Muster scheint im abbasidischen Kontext zu fehlen. Dies läßt sich auf die strukturelle Differenz zwischen den fragilen Machtzentren im Westen und der relativ hohen Konzentration von Macht im islamischen Reich zurlickfuhren.

Am abbasidischen Hof steht kulturelle Kompetenz eindeutig im Zentrum. Hier kann man kaum behaupten, wie etwa Georges Duby es im Hinblick auf französische Höfe getan hat, fin'amors diene dazu, die Krieger an den Herrscher sanft zu binden, wobei seine Frau ein verlockendes vermittelndes Objekt darstelle. Demnach stellt ,Liebe' eine List der Macht dar, ein „erzieherisches Spiel“, das dem Verliebten Treue und Selbstverzicht beibringt. ${ }^{12}$ Diese

11 Guillaume de Lorris/Jean de Meun, Le Roman de la Rose. Ed. Félix Lecoy. (Classiques français du Moyen Âge, vol. 92, 95, 98.) Paris 1965-1970, vol. 1, Z. 2055-2212. Zum Forschungsstand siehe Hans Robert Jauss, Entstehung und Strukturwandel der allegorischen Dichtung, in: La littérature didactique, allegorique et satirique. Hrsg. v. dems. (Grundriß der romanischen Literaturen des Mittelalters, Bd. 6/1.) Heidelberg 1968, 146-244, bes. 224-244; Karl August Ott, Der Rosenroman. (Erträge der Forschung, Bd. 145.) Darmstadt 1980.

12 Christiane Marchello-Nizia, Amour courtois, société masculine et figures du pouvoir, in: Annales 36, 1981, 969-982; Georges Duby, On Courtly Love, in: ders., Love and Marriage in the Middle Ages. Oxford 1993, 56-63. Beide beruhen auf Erich Köhlers Arbeiten und auf Georges Dubys klassischem Aufsatz: ders., Les ,Jeunes' dans la société aristocratique [1964], in: ders., Hommes et structures du Moyen Âge. Paris 1973, 213-225. 
verlockende Interpretation ist fraglich auch in anderen Hinsichten. Sie beruht auf einer zweifelhaften Auffassung von ,höfischer Liebe' und geht von der Annahme aus, in der Literatur würden soziale Verhältnisse widergespiegelt. ${ }^{13}$ Dennoch kann der konzeptionelle Kern der These bei aller Kritik beibehalten und auf den abbasidischen Fall übertragen werden: ,Liebe' könnte auch hier mit der Reproduktion von Macht zu tun haben.

\section{Liebe, Macht und kulturelle Integration}

Diese Vorstellung bringt die Geschichte vom König Bahrâm Gûr, die in nicht weniger als zehn Fassungen überliefert ist, deutlich zum Ausdruck. ${ }^{14}$ Die Geschichte wird Al-Fadl ibn Sahl (gest. 818) zugeschrieben, dem mächtigen Wesir des Kalifen Al-Ma'mûn. Al-Fadl ibn Sahl, der früher selbst Erzieher des künftigen Kalifen gewesen war, schickte die Jugendlichen seines Hauses zu einem alten Lehrer. Eines Tages, als die Schuler schon weit fortgeschritten waren, fragte sie der alte Scheich, ob irgendeiner von ihnen verliebt sei. Als sie dies verneinten, sagte er ihnen: „Dann verliebt euch!“ Seine Anweisung begründete er damit, daß Liebe ( 'ishq) alle Qualităten hervorbringt: Redegewandtheit, Weisheit, Großzügigkeit, Reinlichkeit, Eleganz und Ambition. Als sie von Al-Fadl ibn Sahl nach dem, was sie gelernt hatten, gefragt wurden, schämten sich die Jugendlichen zunächst, diese Lehre zu wiederholen. Doch Al-Fadl ibn Sahl bestătigte sie und erzählte ihnen die Geschichte vom persischen König Bahrâm Gûr.

Bahrâm Gûrs Sohn war faul und ohne Ehrgeiz; seine Erzieher setzten in den Prinzen keine Hoffnung mehr. Eines Tages erzählten sie seinem Vater, daß der junge Prinz sich zu alledem noch verliebt hatte und nun an nichts anderes dachte als an seine Geliebte. Hier sah Bahrâm Gûr aber die Chance zur Rettung seines Sohns. Er sprach mit der Geliebten und mit ihrem Vater insgeheim die folgenden Spielzüge genau ab: Das Mädchen sollte von dem nichtsahnenden Sohn verlangen, daß er sich ihr würdig zeige, ihn sogar abweisen, um ihn dazu anzustacheln, Bildung, Wissen und Manieren, wie sie einem Herrscher geziemen, zu erwerben. Das tat der Sohn auch - und wurde dadurch würdiger Nachfolger seines Vaters. In der Schlußszene der Geschichte vereinigen sich nicht gleich die Liebenden, sondern zunächst Vater und Sohn - zwei Generationen von Herrschern. Der Sohn erfuhr von seinem Vater, wie jener sich seines Verlangens bediente, und lernte dadurch einiges über die Listen der Macht. Die Figur des weisen persischen Herrschers Bahrâm Gûr verweist gleichzeitig auf die Rahmenerzählung, in der die Geschichte aus dem Mund des weisen abbasidischen Wesirs Al-Fadl ibn Sahl den Jugendlichen erzählt wird. Al-Fadl ibn Sahl fordert sie anschließend auf., den alten Lehrer zu fragen, wieso er sie angewiesen hatte, sich zu verlieben -

13 Vgl. zusammenfassend Rüdiger Schnell, Causa Amoris. Liebeskonzeption und Liebesdarstellung in der mittelalterlichen Literatur. (Bibliotheca Germanica, Bd. 27.) Bern 1985, 81-83, 95-97, 109 f.; wichtige Einwănde schon bei Ursula Peters, Niederes Rittertum oder hoher Adel? Zu Erich Köhlers historisch-soziologischer Deutung der altprovenzalischen und mittelhochdeutschen Minnelyrik, in: Euphorion 67, 1973, 244-260.

14 Hier zusammengefaßt wiedergegeben nach der Version bei al-Husrî, al-Masûn (wie Anm. 6), 47 f.; vgl. Ibrâhîm b. Muhammad al-Bayhaqî, al-Mahâsin wa'l-masâwi'. Beirut 1970, 171-173. 
und jener antwortet mit derselben überlieferten Geschichte von Bahrâm Gür. Somit wird sie doppelt legitimiert - als das Wort der Macht und der Weisheit. Sie verknüpft spezifische Modelle vom ,Verliebtsein' mit der Aneignung kultureller Kompetenz und stellt diese Kompetenz als notwendige Voraussetzung fur die Tradierung sozialer Macht dar. Hatte „Liebe aber bei den Abbasiden auch jenseits der Welt der Erzählung etwas mit der Reproduktion von Macht zu tun?

Diese Frage kann positiv beantwortet werden, vorausgesetzt, daß Macht nicht zu eng aufgefaßt wird und auf Treue und Dienst reduziert bleibt. Kodifizierte kulturelle Kodes konnten eine strategische Rolle bei der Stabilisierung zentraler Herrschaft im islamischen Reich spielen. Sie erlaubten die dauerhafte Integration der aus heterogenen ethnischen Gruppen zusammengesetzten abbasidischen Elite. Für die Mächtigen persischer und arabischer Herkunft stellte zwar auch der Islam einen wichtigen gemeinsamen Nenner dar; durch ihn konnten sie sich jedoch nicht deutlich vom Rest der Gesellschaft absetzen; er war auch mit der Gefahr schwieriger theologischer Auseinandersetzungen stets verbunden. Adab, raffinierte Kultur, konnte dagegen zentraler Bestandteil der Identităt der neuen Elite werden. „Liebe' funktionierte als Chiffre für ihren Erwerb. ,Verliebtsein' signalisierte, daß man sich die kulturellen Kodes aus freien Stücken zu eigen machte, nicht um dem Herrscher zu gefallen - wie einige Höflinge doch zugeben mußten ${ }^{15}$-, sondern der Geliebten zuliebe. Kulturen stellen Menschen spezifische ,Vokabulare von Motiven' zur Verfugung, mit denen sie ihr Verhalten in spezifischen Situationen begründen können. ${ }^{16}$ Am abbasidischen Hof ist ,Verliebtsein' ein anerkanntes, ehrenhaftes Motiv geworden, sich kulturelle Repertoires anzueignen.

Die neue politische Rolle von adab - raffinierter Kultur, mit humanitas ohne weiteres übersetzbar ${ }^{17}$ - kommt klar zum Ausdruck in einem Wortwechsel zwischen dem Statthalter von Bagdad, 'Abd Allah ibn Tâhir (gest. 864), und dem Gelehrten al-Zubayr ibn Bakkâr (gest. 870). „Wir sind vielleicht im Hinblick auf unsere Herkunft (nasab) entfernt“, soll Ibn Tâhir gesagt haben, „aber durch unsere Bildung (adab) eng verwandt.“18 Ibn Tâhir war persischer Herkunft; die Tâhiriden, ehemalige Klienten ihrer arabischen Patrone, stiegen seit vier Generationen auf und verbanden politische Macht mit reger Aktivität als Kulturmäzene. ${ }^{19}$ Der angesprochene Gelehrte, al-Zubayr ibn Bakkâr, war dagegen ein Mann von Herkunft, Sprößling der altarabischen Elite, und zugleich ein angesehener Gelehrter, der für seinen Anteil an der Überlieferung beduinischer Traditionen und altarabischer Dichtung

15 Ahmad ibn Muhammad Abû 'Abd Allah Ibn al-Faqîh, Kitâb al-Buldân. Hrsg. v. Yûsuf al-Hâdî. Beirut 1997, 57.

$16 \mathrm{Da}$,Liebe' in der Geschichtsschreibung zur Erklärung politischer Auseinandersetzungen herangezogen wurde, hat Julie Meisami aufgezeigt und dabei auch auf das Schicksal des oben erwăhnten Wesirs Al-Fadl ibn Sahl hingewiesen: Julie Scott Meisami, Mas'ûdî on Love and the Fall of the Barmakids, in: Journal of the Royal Asiatic Society, 2, 1989, 252-277.

17 Vgl. Robert A. Kaster, ,Humanitas' and Roman Education, in: StorStor 9, 1986, 5-15.

18 Yâqût ibn 'Abd Allah al-Hamawî, Mu'jam al-udabâ' aw irshâd al-arîb ilâ ma'rifat al-adîb. Bd. 3. Beirut 1991, 348.

19 Clifford E. Bosworth, The Tahirids and Arabic Culture, in: ders., Medieval Arabic Culture and Administration. London 1982, 45-79. 
bekannt war. In diesem überlieferten Dialog stellt also der ,Neuankömmling' persischer Herkunft gegenüber dem arabischen Gelehrten $a d a b$ - raffinierte Kultur - als das neue Vergesellschaftungsprinzip dar, das nasab - angesehene Herkunft - in den Hintergrund zu drăngen vermag.

Erweist sich der Ansatz, ,Liebe' am Hof im Zusammenhang mit der Reproduktion von Macht zu sehen, als derart fruchtbar im islamischen Kontext, so läßt die Analyse zugleich Rückfragen in Hinblick auf westeuropäische Verhältnisse aufkommen. Kann es nicht sein, daß auch hier die Aneignung kultureller Kodes eine wichtigere politische Rolle spielte, als oft angenommen wird? Hat Duby durch einen engen Begriff von Macht, der zu stark auf persönliche Bindung an den Herrscher abhebt, die politische Dimension kultureller Integration nicht gebührend beachtet? Ebendies scheinen mir manche neuere Forschungen zu suggerieren, etwa die ăußerst anregenden Untersuchungen von Stephen Jaeger. ${ }^{20}$

\section{Frauen als Akteurinnen}

Über den möglichen Zusammenhang zwischen dem vermeintlich verbesserten Status von Frauen am Hof und dem Aufkommen höfischer Modelle von ,Liebe' ist in der Forschung lang diskutiert worden. In ihrer starken Form wurde die These in letzter Zeit zurückgewiesen, doch viele Fragen bleiben nach wie vor offen. Im islamischen Kontext erlaubt es der Forschungsstand noch weniger, begründete Aussagen über den historischen Wandel der Spielräume von Frauen in unterschiedlichen Positionen zu machen. ${ }^{21}$

Was ergibt in diesem Zusammenhang der Vergleich mit dem abbasidischen Hof? Hier nahmen freie Frauen an dem neuen Spiel kaum teil; bevorzugte Mitspielerinnen waren hochgebildete Sklavinnen (jawârî). ${ }^{22}$ Um deren Gunst konkurrierten die mächtigsten Männer am Hof. Dieser Tatbestand scheint meines Erachtens darauf hinzudeuten, daß der vermeintlich verbesserte Status von Frauen kaum als Ursache fur das Aufkommen von ,Liebe' am Hof gelten kann. Die enormen Machtdifferenzen zwischen den Beteiligten machen dies deutlich.

Zugleich zeichnet sich dadurch eine andere Forschungsrichtung ab: Statt anzunehmen, daß es der existierende soziale Status von Frauen war, der das neue Spiel von ,Liebe ermöglichte, könnte man die Hypothese formulieren, daß es das Spiel selbst war, welches es notwendig machte, passende Spieler zu finden. Die Funktion von ,Liebe‘ am Hof beim

20 Charles Stephen Jaeger, The Origins of Courtliness. Civilizing Trends and the Formation of the Courtly Ideals (939-1210). Philadelphia 1985; Josef Fleckenstein, Miles und clericus am Königs- und Fürstenhof. Bemerkungen zu den Voraussetzungen, zur Entstehung und zur Trägerschaft der höfischritterlichen Kultur, in: Curialitas. Studien zu Grundfragen der höfisch-ritterlichen Kultur. Hrsg. v. dems. (VMPIG, Bd. 100.) Göttingen 1990, 302-325.

21 Leila Ahmed, Women and Gender in Islam: Historical Roots of A Modern Debate. New Haven/London 1992, 79-101; Fatima Mernissi, The Forgotten Queens of Islam. Minneapolis 1993, 9-67.

22 Vgl. Abd al-Kareem Heitty, The Contrasting Spheres of Free Women and Jawâri in the Literary Life of the Early Abbasid Caliphate, in: Al-Masâq 3, 1990, 31-51; über die Rolle von Gesangssklavinnen (qiyyân) vgl. Abdallah Cheikh-Moussa, Figures de l'esclave chanteuse à l'époque 'abbâside, in: Figures de l'esclave au Moyen-Âge et dans le monde moderne. Ed. Henri Bresc. Paris 1996, 31-76. 
Erwerb raffinierter Kultur erforderte es, daß die weiblichen Mitspielerinnen mit kultureller Kompetenz ausgestattet wurden. Das Spiel konnte sich ebenfalls nicht entfalten, solange ihnen kein beträchtlicher Handlungsspielraum zugewiesen wurde. Die künstliche Außerkraftsetzung der bestehenden Machtdifferenzen zwischen den Akteuren war Vorbedingung dafurr, daß der Prozeß des Hofierens initiiert werden konnte. Demnach ergibt sich der Spielraum der beteiligten Frauen aus der Logik des Spiels selbst. Das kulturelle Modell vom ,Lieben spiegelte nicht die bestehenden Machtverhältnisse wider, sondern formte sie in einem bedeutenden Maße um.

\section{,Liebe' und die aktive Aneignung sozialer Kompetenz}

Voraussetzung dafür war aber, daß ,Liebe' ein ernstes und wichtiges Spiel geworden war. Bei den frühen Abbasiden war sie nicht lediglich ein beliebtes literarisches Motiv oder eine anerkannte Motivation, sondern zugleich ein praktiziertes Modell sozialer Beziehungen. Dies verlangt nach einer weiteren Erklärung, die auf bisher nicht angesprochene Dimensionen der Hofkultur verweist. Höfische Kultur erschöpfte sich nicht in Eleganz und Wissen. ${ }^{23}$

In seinem umfassenden Werk über den höfischen Lebensstil schrieb al-Washshâ' gegen Ende des 10. Jahrhunderts, die Menschen von Kultur rechneten nur diejenigen zu ihresgleichen, welche die Regeln der Liebenden und Gebildeten befolgen. Sie zeichneten sich nicht nur durch ihre feinen Manieren und Bildung aus; sie seien auch in der Lage, ihre Absichten gut zu verbergen und raffinierte Strategien zu erdenken. Dank ihrer Selbstbeherrschung, Leutseligkeit und Klugheit erreichten sie ihre Ziele. ${ }^{24}$ Demzufolge verfuggen sie über die soziale Kompetenz, die dem spezifischen sozialen Raum des Hofes entspricht. Sie beherrschen nicht nur die kodifizierten Normen, sondern auch die schwer zu formulierenden Strategien, die es ermöglichen, sich am Hof geschickt zu bewegen.

Daher unsere letzte These: Neben ihrer expliziten Funktion im Vokabular der Motive der Akteure am abbasidischen Hof hatte ,Liebe' auch eine weitere, weniger sichtbare Funktion: Sie war zugleich der ideale Spielplatz, auf dem soziale Fähigkeiten erprobt und eingeschliffen werden konnten. Für Höflinge, die mit launenhaften Patronen zu tun hatten, war die Beziehung mit einer unberechenbaren Geliebten eine lehrreiche Übung. Beim Hofieren lernten sie nicht nur die expliziten Regeln der Eleganz, sondern übten zugleich die ungeschriebenen Künste der Hofpolitik: Verschlüsselte Botschaften zu vermitteln, mit indirekten Anspielungen und zur Schau gestellten Mienen zu operieren, eine Annäherung zu riskieren, um Gunst zu werben, ohne das eigene Gesicht zu verlieren. Wenn junge britische Aristokraten durch Übungen in Latein und Sport dazu vorbereitet werden sollten, uber ein Weltimperium zu herrschen, warum sollten abbasidische Höflinge sich die nötige soziale Kompetenz nicht durch ,Liebe ${ }^{6}$ aneignen? Dies erfolgt am besten nicht dadurch, daß formalisierte

23 Die hier vorgenommene analytische Unterscheidung zwischen den sichtbaren, kodifizierten Segmenten von Kultur, die die Akteure oft für ihre ,Kultur' deklarieren, und den impliziten, schwer kodifizierbaren kulturellen Modellen wird năher ausgefüht in Gadi Algazi, Kulturkult und die Rekonstruktion von Handlungsrepertoires, in: L'homme 11, 2000, 105-119. 
Regeln einstudiert werden. Wichtiger fur die aktive Aneignung sozialer Kompetenz sind learning by doing und die gedankliche Entfaltung möglicher Spielzüge und ihrer Konsequenzen im Medium literarischer Narrativen. ,Liebe' stand fur beides.

Es versteht sich, daß die Grenzen zwischen ,Spiel' und ,Realität' stets fließend waren; Liebesbeziehungen konnten sich oft mit Patronageverhältnissen, Allianzen und Rivalităten am Hof vermischen. Doch gerade die Ritualisierung der Spielregeln und möglicherweise auch die Bevorzugung unfreier, oft zu diesem Zweck ausgebildeter Frauen als Mitspielerinnen ermöglichten es, sich auf diesem Spielplatz mit relativer Sicherheit die Strategien der höfischen Politik zu eigen zu machen. ,Liebe' stellte in der Tat auch bei den Abbasiden ein erzieherisches Spiel dar, aber nicht im Sinne der Einübung von Unterordnung und Dienst. Vielmehr bestand ihre Funktion sowohl in der Vermittlung expliziter Normen als auch in der Einübung sozialer Strategien. Darauf wiesen die immer wieder zitierten Sprüche und Gedichte hin, indem sie die Verwandlungskraft der Liebe verherrlichten. Doch sie taten es nur indirekt und zugleich lenkten sie davon ab, indem sie stets nur auf die kodifizierten kulturellen Normen verwiesen: Was sie zu einer dramatischen Verwandlung der Person stilisierten, bestand vielmehr in der allmählichen Aneignung und Einübung höfischer Repertoires aufgrund eines schon vorhandenen Habitus. Dies scheint uns auch furr andere Hofgesellschaften zu gelten, bedarf allerdings weiterer eingehender Untersuchungen.

Schließlich läßt sich diese Interpretation ebenfalls mit der Geschichte von Bahrâm Gûr exemplifizieren. Es sind nämlich zwei Lehren, die aus der Geschichte gezogen werden konnten: Zum einen zeigte sie die Kraft der Liebe, Mitglieder der höfischen Elite anzuspornen, sich kulturell zu distinguieren. Zum anderen aber wurde eine politische Lektion erteilt, ein Beispiel fur den strategischen Gebrauch der Emotionen gegeben. Der wirkliche Held der Geschichte ist nicht der verliebte Prinz, sondern der vorausschauende König. 


\title{
Frühes und spätes Mittelalter in Skandinavien - ein möglicher Vergleich?
}

\author{
Von
}

Tore Nyberg

Das Mittelalter in der skandinavischen Geschichte ist in den verschiedenen skandinavischen Lehrtraditionen unterschiedlich betrachtet und behandelt worden. Ein Blick auf die neuere Geschichte der funf Staaten, die sich heute zu Skandinavien oder zu „dem Norden“ zăhlen: Dănemark, Norwegen, Island, Schweden, Finnland, macht überaus deutlich, daß sich diese funf Kulturmilieus in ziemlich verschiedener Verfassung befanden, als der Durchbruch der kritischen historischen Wissenschaft im 19. Jahrhundert erfolgte. Norwegen mit Island war seit dem 14. Jahrhundert eng mit Dänemark verbunden. Die Unabhängigkeit ab 1814 ließ das für Norwegen heroische norröne Mittelalter in das Blickfield rücken, dessen Literatur die Isländer überliefert hatten - die nun allerdings politisch bei Dänemark blieben. Das Mittelalter festigte sich ganz zentral im neuen nationalen Geschichtsverständnis Norwegens. ${ }^{1}$ Für die dänische Lehrtradition nach 1864 war es von Bedeutung, daß die Quellen zur nationalen mittelalterlichen Geschichte reichlich flossen. Sowohl die großen Erzähler wie Saxo Grammaticus als auch die urkundlichen Quellen wurden herangezogen, um ins Gedächtnis zu rufen, daß Dänemark im Mittelalter die fuhrende Macht des skandinavischen Nordens war. ${ }^{2}$ In Schweden dagegen erschien das Mittelalter als barbarisch und archaisch im Vergleich zur schwedischen Großmachtzeit des 16. und 17. Jahrhunderts. Der Versuch, auf schwedische Verhältnisse durch Analogie mit dem Bild der isländischen Literatur zu schließen, schlug fehl. ${ }^{3}$ Die umfassende religiöse Literatur des mittelalterlichen Schweden wirkte im kulturradikalen Milieu eher störend. Dagegen zog Finnland, 1809 als Teilstaat des Zarenreiches entstanden und 1918 unabhängig geworden, das Mittelalter für den Aufbau einer nationalen Geschichtsschreibung heran, ohne sich mit der schwedischen Großmachtzeit des 17. Jahrhunderts zu identifizieren. ${ }^{4}$

I Beispiele: Peter Andreas Munch, Det norske Folks Historie. T. I. Bd. 1-2; T. II. Christiania 1852/55; Rudolf Keyser, Norges Historie. Bd. 1. Kristiania 1866; Johan Ernst Sars, Udsigt over den norske Historie. Bd. 1-2. Kristiania 1873/77.

2 Beispiele: Hans Olrik, Konge og Præstestand i den danske Middelalder. Bd. 1. København 1892; Johannes Steenstrup, Danmarks Riges Historie. Bd. 1. København 1901.

3 Hans Emil Hildebrand, Sveriges medeltid. Bd. 1-3. Stockholm 1884-1917.

4 Beispiel: Eirik Hornborg, Finlands hävder. Bd. 1-4. Helsingfors 1929-1933; 2. Aufl. 1944. 
Obwohl die Historiker immer wieder Elemente aus der Welt des Spătmittelalters herausholten, um das Mittelalter als solches zu charakterisieren, galt das Spätmittelalter, im Sinne der Geschichtsdeutung der lutherischen Staatskirchen Skandinaviens, als Verfallszeit, die die Reformation erforderlich machte. Man griff in Norwegen und Dänemark auf die Könige des 11. und 12. Jahrhunderts zurück, in Schweden auf die Epoche der Aufzeichnung der Provinzgesetze im 13. und 14. Jahrhundert. ${ }^{5}$ Demgegenüber wurden die Fehden zwischen den aristokratischen Machtgruppienungen im 15. Jahrhundert meist negativ gesehen. ${ }^{6}$ Die bürgerliche Stadtkultur diente stattdessen als positive Kennzeichnung furr das Spätmittelalter. ${ }^{7}$

Älteres und jüngeres Mittelalter in Skandinavien waren auf diese Weise schon längst gefärbt und als verschiedenartige Größen behandelt worden.

Zuerst zum älteren Mittelalter: Wegen der zeitlichen Nähe zur Missionszeit war in Skandinavien das Frühmittelalter mit der Glaubensveränderung verknüpft. Man konnte es als heroischen Glaubenskampf, als mythische oder barbarische Übergangszeit, oder als Öffnung zu Europa herausstellen. Quellenarmut auf weiten Strecken ließ jedoch auch eine erkenntnismäßige Skepsis aufkommen. Es war verhängnisvoll, daß bei vielen Historikern um die Mitte des 20. Jahrhunderts die Vorstellung herrschte, daß ein sicheres Wissen vom skandinavischen Frühmittelalter nicht zu erreichen sei. Wer sich damit beschäftige, lasse - so der Argwohn - die Wissenschaft der Phantasie weichen. Besonders trugen die Brüder Lauritz und Curt Weibull zu dieser Skepsis bei, nachdem sie mit ihrer speziellen Methode den Quellenwert von Saxo Grammaticus, der isländischen Sagas und vieler hagiographischer Quellen angezweifelt hatten. ${ }^{8}$ Die Skepsis brachte die Frühmittelalterforschung in Verruf. Nur einige Kirchen- und Religionshistoriker und Archäologen versuchten, den Raum auszufullen, den die Historiker leer ließen. Namen wie die des norwegischen Literaturhistorikers Fredrik Paasche, des schwedischen Kirchenhistorikers Knut B. Westman und ebenso des schwedischen Archäologen Holger

5 Adolf Ditlev Jørgensen, Den nordiske Kirkes Grundlæggelse og første Udvikling. København 18741876; Hildebrand, Sveriges medeltid (wie Anm. 3).

6 Das Paradigma bestand seit Erik Gustaf Geijer, Svenska folkets historia (1832), in: ders., Samlade skrifter. Bd. 5. Stockholm 1873. Es wurde nur teilweise ubenwunden durch Studien wie Gösta Kellerman, Jakob Ulvsson och den svenska kyrkan under äldre sturetiden 1470-1497. Uppsala 1935; Sven Ulric Palme, Riksföreståndarvalet 1512. Studier i nordisk politik och svensk statsrătt 1470-1523. (Uppsala Universitets Arsskrift, Bd. 7.) Uppsala 1949; Gunnar T. Westin, Riksföreståndaren och makten. Politiska utvecklingslinjer i Sverige 1512-1517. Lund 1957; ders., Maktkamp i senmedeltidens Sverige. Uppsatser och studier. Stockholm 1971.

7 Claes Theodor Odhner, Bidrag till svenska städernas och borgarståndets historia fore 1633. Uppsala 1860; Hans Emil Hildebrand, Stockholms historia. Stockholm 1897; Birger Nerman, Det forntida Stockholm. Stockholm 1922.

8 Curt Weibull, Saxo. Kritiska undersőkningar i Danmarks historia från Sven Estridsens dőd till Knut VI. Lund 1915. Beiträge von Lauritz Weibull in der Zeitschrift Scandia (ab 1928), spăter gesammelt in ders., Nordisk historia. Forskningar och undersökningar. Bd. 1-3. Stockholm 1948/49. Ungeachtet der Ernüchterung, die die Bruder Weibull von ihrer schonischen Warte aus unter allen nationalistisch gefärbten Historikern des Nordens herbeiriefen, zeichnete sich besonders Lauritz Weibull durch ausgezeichnete Quelleneditionen aus, z. B.: Necrologium Lundense - Lunds domkyrkas nekrologium. Lund 1923. 
Arbman sind hier zu nennen. ${ }^{9}$ Oft fehlten die Anregungen zum fruchtbaren synchronen Vergleich mit dem europäischen Geschehen.

Dann zum jüngeren Mittelalter: Dort fühlte man sich erkenntnismäßig sicherer, denn die Quellen fließen auf weiten Strecken reichlich. Auf der anderen Seite unterließ man hier öfters, nach dem Sinn und dem Wert der Epoche zu fragen - hatte man sich ja doch schon festgelegt auf die Auffassung, daß das Spätmittelalter lediglich ein Übergang, eine Vorbereitung auf die Reformation sei, auf den Staat der fruhen Neuzeit. ${ }^{10}$

Bei einem Vergleich zwischen frlihem und spätem Mittelalter in Skandinavien gilt es, sich solcher zeittypischen Fixierungen zu entledigen und grundsätzlich die beiden Epochen als gleichwertig zu behandeln. Dies fordert wiederum, die Entwicklungsperspektive fallenzulassen. Der Vergleich wird unmöglich, wenn man daran festhält, das Spätmittelalter habe sich aus dem Frühmittelalter oder die Reformation aus dem Spätmittelalter ,entwickelt'. In den vergangenen etwa vierzig Jahren hat man unter Historikern und Archäologen größeres Verständnis für die Selbstăndigkeit, die Autonomie beider Epochen gezeigt. ${ }^{11}$ Heute würde zum Beispiel ein Archäologe, der ein wikingerzeitliches oder fruhmittelalterliches Gräberfeld untersucht, niemals seine Schlußfolgerungen per Analogie auf das Spätmittelalter übertragen. Ein Kunsthistoriker, der die kirchliche Bauernmalerei des 15. Jahrhunderts studiert, weiß auch sehr wohl, daß in der romanischen Kunst und Skulptur ein ganz anderes Verständnis vom Bild und von der sakralen Darstellung vorherrschte - eine direkte Übertragung seiner Ergebnisse auf die Malerei des 11. Jahrhunderts erweist sich als unmöglich.

\section{Gemeinsame Elemente}

Nun setzt ein Vergleich immer einige gleichwertige Elemente in den zu vergleichenden Erscheinungen voraus. Für Skandinavien liegt eine leicht erkennbare Klammer für die mittelalterlichen Jahrhunderte darin, daß alle drei damaligen Königreiche - Norwegen allerdings als Teil der dănisch-norwegischen Doppelmonarchie - ihr Kirchenwesen in lutherische Staatskirchen umgewandelt haben. Die katholische Form des Christentums kennzeichnet deshalb in ganz Skandinavien ausschließlich das Mittelalter, denn in der Perspektive des 19. Jahrhunderts galt mit der Errichtung der reformatorischen Staatskirchen die katholische Religion ein für

9 Fredrik Paasche, Norges og Islands litteratur inntil utgangen av middelalderen. (Norsk Litteraturhistorie. Bd. 1.) Oslo 1924; Knut Bernhard Westman, Den svenska kyrkans utveckling från St. Bernhards tidevarv till Innocentius III. Stockholm 1915; Holger Arbman/Martin Stenberger, Vikingar i västerled. Stockholm 1935; vgl. Holger Arbman, The Vikings. (Ancient Peoples and Places, vol. 21.). London 1961.

10 Dies gilt jedoch nicht für den Kirchenhistoriker Yngve Brilioth, Den senare medeltiden 1274-1521. (Svenska kyrkans historia, Bd. 2.) Stockholm 1941; es ist jedoch bezeichnend, daß für Bd. 1 dieser Geschichte der schwedischen Kirche kein Bearbeiter gefunden werden konnte (vgl. Anm. 9).

11 Für Schweden kann hier auf den Sonderforschungsbereich „Projektet Sveriges kristnande“ hingewiesen werden, aus dem wenigstens fünf bedeutende Monographien hervorgegangen sind (vgl. Anm. 41), und auf der anderen Seite auf das dänische Forschungsvorhaben (netværk) zur Spätmittelalterforschung, das von der Universităt Aarhus initiiert wurde (vgl. Anm. 44). 
allemal als überwunden. Sie wurde offiziell verboten, ihre Ausübung mit Strafen belegt. Der kirchengeschichtliche Aspekt ist also unumgänglich für die Kennzeichnung des skandinavischen Mittelalters überhaupt.

Damit wurde auch das Papsttum ausschließlich zu einem Element des Mittelalters. Das Mittelalter konnte nach der Reformation als Papismus deklariert werden; die Epoche erhielt dadurch den unverdienten Ruf, vom Anfang der Missionszeit bis zur Einführung der staatlichen Reformation in gleicher Weise ,unter dem Papsttum' gestanden zu haben - eine Wahnvorstellung, die immer noch in weiten Kreisen tief verwurzelt ist.

Dazu kommt das Regierungssystem. Der König regiere mit dem Rat seiner Vertrauten oder im Reichsrat, in dem der jeweilige Erzbischof und die Bischöfe ihre festen Sitze hätten; der Adel mache ihm sowohl Gesetzgebungsgewalt als auch Exekutive streitig, so betrachtete man durchgehend das mittelalterliche Königtum, in Kontrast zu dem der frühen Neuzeit und in Kontrast zum Absolutismus. ${ }^{12}$ Das Reisekönigtum des älteren Mittelalters wurde lange nur als wirtschaftliche Belastung des Königtums gesehen ${ }^{13}$, die Art, wie sich Kopenhagen und Stockholm langsam zu königlichen Residenzstädten entwickelten, sah man deterministisch als noch sehr unvollkommene Schritte auf dem Wege zur ,Hauptstadt' an. Eine demütigende Schwäche des Königtums war in den Augen vieler Historiker des 19. und 20. Jahrhunderts immer noch ein das ganze skandinavische Mittelalter unterschiedlich prägendes Element. Dafür räumte man gerne dem mittelalterlichen Regierungshandeln Pracht und verschwenderische Freigiebigkeit ein, sah darin jedoch meist kindliche ,Primitivität' der Gesellschaft, in Kontrast zu ,Reife' und ,Erwachsensein' des Staatssystems der fruhen Neuzeit. Wurde das Mittelalter unter positiven Vorzeichen gesehen, dann wurden Rittertum und wehrhafte Adelskultur als Kennzeichen der Epoche angefuhrt. In neueren, sozialrevolutionären Deutungen des skandinavischen Mittelalters wurden die Begriffe des feudalen Oberklassenstaates mit negativen Vorzeichen eingesetzt.

In sozialer und demographischer Hinsicht dagegen hat man schon lange keinen Bruch mehr in der Reformationszeit aufrechterhalten können. Da das Agrarsystem sich vom 14. bis zum 18. Jahrhundert nicht wesentlich änderte, ist dieses Element eher zu einem Unterscheidungsmerkmal für das Spätmittelalter im Vergleich zum Frühmittelalter geworden, so wie es Erik Ulsig 1968 darstellen konnte. ${ }^{14}$ Ulsig konnte dabei auf eine Formel bringen, wie man im skandinavischen Spätmittelalter, an der Stelle des Gutshofssystems des fruhen Mittelalters, den steuerbegünstigten Adelssitz mit den vielen untergebenen und abgabepflichtigen Bauemhöfen vorfindet.

12 Charakteristisch für Dănemark: Aksel Erhardt Christensen, Kongemagt og Aristokrati. København 1945; für Schweden: Hans Jägerstad, Hovdag och råd under äldre medeltid. Lund 1948; für Norwegen Knut Helle, Konge og gode menn. Oslo 1972.

13 In Dănemark Thomas Riis, Det middelalderlige danske rejsekongedømme indtil 1332, in: Middelalder, metode og medier. Festskrift til Niels Skyum-Nielsen. Hrsg. v. Karsten Fledelius/Niels Lund/Herluf Nielsen. København 1981, 115-136, mit Bibliographie.

14 Erik Ulsig, Danske adelsgodser i middelalderen. (Skrifter udgivet af det Historiske Institut ved Københavns Universitet, Bd. 2.) København 1968. 


\section{Königtum und Kirche}

Welche Möglichkeiten des Vergleichs bestehen dann zwischen Früh- und Spätmittelalter in Skandinavien? Zunächst ist der kirchengeschichtliche Aspekt nicht wegzudenken. Ein Vergleich öffnet unsere Augen für die Frage, wie sich die katholische Religion in der Missionsepoche und in der Zeit des fruhen Königtums von ihrer Entfaltung und Praxis im Spätmittelalter unterscheidet. Zum zweiten ist die unreflektierte Hinnahme eines mittelalterlichen Königtums als solches - als ob es diese verbindende Klammer gäbe - problematisch geworden. Es wird klar, daß das Königtum nicht unverändert bleibt, nur weil der König mit dem aus Europa eingefuhrten Begriff eines rex bezeichnet wird. Zum dritten werden wir uns dann auch bewußt, daß eine einzige Formel nicht ausreicht, um das Zusammenwirken des Königs mit seinen Ratgebern durch die gesamten fünfhundert Jahre des skandinavischen Mittelalters zu bezeichnen.

Prufen wir als Beispiel die Unterordnung der Kirche unter das fruhe Königtum. Arbeiten von Knut Helle, Erich Hoffmann, Per Sveaas Andersen, Kristin Drar, Carsten Breengaard, Thomas Lindkvist, Åke Hyenstrand, Dick Harrison, Birgit und Peter Sawyer, Per Olof Sjöstrand und anderen ${ }^{15}$ haben in den letzten Jahrzehnten unser Verständnis vom christlich gewordenen Königtum in Skandinavien im Verhältnis zur neuen Staatsreligion vertieft. In vorchristlicher Zeit hatte der König eine Schlüsselstellung beim Kult inne, insbesondere beim Odinskult, der einem Staatskult nahekam. ${ }^{16}$ Das Studium der nordischen heiligen Könige zeigt, daß noch lange Zeit nach Annahme des Christentums sowohl Könige und Königsanwärter als auch der Adel der drei Königreiche Norwegen, Dänemark und Schweden - einschließlich der hohen kirchlichen Würdenträger - die Schlüsselrolle des Königs beim Kult aufrechterhalten

15 Knut Helle, Norge blir en stat 1130-1319. (Handbok i Norges historie. Bd. I, 3.) Oslo 1964, 2. Aufl. 1974; Erich Hoffmann, Königserhebung und Thronfolgeordnung in Dänemark bis zum Ausgang des Mittelalters. (Beiträge zur Geschichte und Quellenkunde des Mittelalters, Bd. 5.) Berlin 1976; Per Sveaas Andersen, Samlingen av Norge og kristningen av landet 800-1130. (Handbok i Norges historie, Bd. 2.) Oslo 1977; Kristin Drar, Konungens herravälde såsom răttvisans, fridens och frihetens beskydd. (Bibliotheca Historico-Ecclesiastica Lundensis, Bd. 10.) Stockholm 1980; Carsten Breengaard, Muren om Israels hus. Regnum og sacerdotium i Danmark 1050-1170. København 1982; Thomas Lindkvist, Plundring, skatter och den feodala statens framvaxxt. (Opuscula Historica Upsaliensia, Bd. 1.) Uppsala 1988 ff.; Ake Hyenstrand, Sverige 989. Makt och herravälde. (Stockholm Archaeological Reports, vol. 24.) Stockholm 1989; ders., Lejonet, draken och korset. Sverige 500 1000. Lund 1996; Dick Harrison, The early state and the towns. Forms of integration in Lombard Italy A. D. 568-774. (Lund studies in international history, vol. 29.) Lund 1993; Birgit Sawyer/Peter Sawyer, Medieval Scandinavia. From Conversion to Reformation, circa 800-1500. (The Nordic Series, vol. 17.) Minneapolis/London 1993; Per Olof Sjöstrand, Den tidigmedeltida statsbildningsprocessen och den östra rikshalvan, in: Historisk Tidskrift for Finland 79, 1994, 530-573.

16 Kristian Hald, The Cult of Odin in Danish Place-names, in: Early English and Norse Studies presented to Hugh Smith. Ed. Arthur Brown/Peter Foote. London 1963, 99-109; Eyvind Fjeld Halvorsen, Art. Oðinn, in: Kulturhistorisk leksikon for nordisk middelalder. Bd. 12. København 1967, 503-509; Gro Steinsland, Det hellige bryllup og norrøn kongeideologi. Oslo 1989, 2. Aufl. 1991. 
wollten. ${ }^{17}$ Eine Königskrönung und -salbung nach europäischem Vorbild wird 1163 oder 1164 in Norwegen, 1170 in Dänemark und 1210 in Schweden erstmalig bezeugt. ${ }^{18}$ Rivalisierende Kreise gruppierten sich um König oder Königsanwärter und standen oft mit kontinentaleuropäischen Mächten in Verbindung. Der norwegische Kirchenkampf unter König Sverre (gest. 1202) mündete im 13. Jahrhundert in einen Sieg des Königtums über die gregorianisch denkende kirchliche Hierarchie. ${ }^{19}$ Ebenso endete der dänische Kirchenkampf um 1300 mit einem teuer erkauften Triumph des Königs über Erzbischof Jens Grand im Prozeß an der päpstlichen Kurie. $^{20}$ Mit kräftigen und brutalen Zügen vereinnahmte das schwedische Königtum unter Magnus Birgersson Ladulås Ende des 13. Jahrhunderts das Erbe des heiligen Königs Erik von Uppsala ${ }^{21}$, wobei es sich zweier Neuerungen bediente: der neuen Institution einer Hauptstadt - Stockholm - und eines neuen Mönchsordens - der Franziskaner. ${ }^{22}$ In allen drei Reichen erfolgte in diesem Zeitraum der Ausbau eines Kanzleiwesens und einer Steuerorganisation, wie fưr die schwedische Kanzlei Åke Ljungfors, später Jan Öberg und Herman

17 Erich Hoffmann, Die heiligen Könige bei den Angelsachsen und den skandinavischen Völkern. Königsheiliger und Königshaus. (Quellen und Forsch. zur Geschichte Schleswig-Holsteins, Bd. 69.) Neumünster 1975; ders., Politische Heilige in Skandinavien und die Entwicklung der drei nordischen Reiche und Völker, in: Politik und Heiligenverehrung im Hochmittelalter. Hrsg. v. Jürgen Petersohn. (VuF, Bd. 42.) Sigmaringen 1994, 277-324; André Vauchez, La sainteté en Occident aux derniers siècles du Moyen Âge. (Bibliothèque des écoles françaises d'Athènes et de Rome, vol. 241.) 2. Aufl. Paris 1994; Rory W. McTurk, Scandinavian sacred kingship revisited, in: Saga-Book of the Viking Society for Northern Research 24, 1994, 19-32; Tore Nyberg, Autour de la Sacralité Royale en Scandinavie, in: AHC 27/28, 1995/96, 177-192.

18 Norwegen: Egil Nygaard Brekke, Magnus Erlingssons kroningsår, in: Historisk Tidsskrift [Oslo] 40, 1960/61, 1-24, und weitere Diskussion über die zeitliche Ansetzung der Krönung zwischen Ólafia Einarsdóttir und Odd Sandaaker, Magnus Erlingssons kroning, en politiserende sagatradition?, in: Historisk Tidsskrift [Oslo] 77, 1998, 181-196; Dänemark: Breengaard, Muren (wie Anm. 15); Schweden: Bengt Thordeman, Kungakröning och kungakrona i medeltidens Sverige, in: Arkeologiska forskningar och fynd. Hrsg. v. Mărten Stenberger. Stockholm 1952, 305-320; Per Beskow, Art. Kröning, in: Kulturhistorisk leksikon for nordisk middelalder. Bd. 9. København 1964, 497-502.

19 Helle, Konge (wie Anm. 12).

20 Benedicte Fonnesbech-Wulff(Hrsg.), Hellere fanden selv end Erik på tronen! Konflikten mellem Jens Grand og Erik Menved 1294-1302. (Odense University Studies in History and Social Sciences, vol. 214.) Odense 1999.

21 Die Entwicklung der Heiligenlegende von St. Erik wurde eingehend von Einar Carlsson, Translacio archiepiscoporum. (Uppsala Universitets Ársskrift, Bd. 2.) Uppsala 1944, untersucht. Seine Meinung, daß Mitte des 13. Jh. eine neue Stufe in der Kultentwicklung Eriks einsetzte, wird heute von den meisten Forschern geteilt. Vgl. Jean-Marie Maillefer, Saint Eric de Suède: une mythologie politique et dynastique. Étude critique d'une hagiographie royale, in: Razo. Cahiers du Centre d'études médiévales de Nice 8, 1988, 87-101.

22 Am Grab des Königs in der Stockholmer Franziskanerkirche wurde sein Gedächtnis gefeiert, vgl. Toni Schmid, Franziskanische Elemente im mittelalterlichen Kult Schwedens, in: Franziskanische Studien 24, 1937, 59-86; 25, 1938, 134-161; ders., Birgitta och hennes uppenbarelser. Lund 1940, hier 64-68. 
Schück, für die dänische Kanzlei Niels Skyum-Nielsen und für das dänische Steuersystem neuerdings Niels Lund gezeigt haben. ${ }^{23}$

In jeder Hinsicht ist hier das Spätmittelalter anders. Ab 1319 folgte in Dänemark ein demütigender Abstieg des Königtums, in Schweden und Norwegen die Vormundschaftsregierung für den Kinderkönig Magnus Eriksson, was die Rollen von König und Kirche im skandinavischen Norden ganz umkehrte. Wir finden Waldemar IV. von Dänemark durch das halbe Europa reitend auf dem Wege nach Avignon, wo er in päpstlichen Begünstigungen Rückendeckung gegen seine Feinde, besonders gegen die Hanse, suchte ${ }^{24}$ Wir finden den schwedischen König Mitte des 14. Jahrhunderts vor der päpstlichen Kurie hoch verschuldet und in den Bann getan ${ }^{25}$, während die adelige Birgitta Birgerstochter gegen ihn wütete. ${ }^{26}$ Die ökonomische und demographische Krise des 14. Jahrhunderts traf Norwegen besonders schwer. ${ }^{27}$ Dynastische Verbindungen führten zur nordischen Union von Kalmar ${ }^{28}$, die Norwegen als eigenständige Macht für Jahrhunderte ausschaltete und Schweden-Finnland gegen Dänemark-Norwegen in einen ewigen Bruderkrieg verwickelte. Mit der Reduktion der nordischen Mächte auf zwei Blöcke erstarkte die kirchliche Organisation, da der Erzbischof in Abwesenheit des Königs den Vorsitz im jeweiligen Reichsrat innehatte. ${ }^{29}$ Charakteristische Unterschiede zum Fruhmmittelalter sind damit gegeben. Es handelt sich in beiden Epochen zwar um das gleiche Königtum, jedoch wurde es nun nach mehrmaligem Dynastiewechsel anders ausgeübt. ${ }^{30}$ Die Kirchenorganisation war die gleiche, die Besetzung der Bistümer erfolgte jedoch nun auf ganz andere Weise, da sich

23 Ake Ljungfors, Bidrag till svensk diplomatik före 1350. Lund 1955; Jan Oberg, Königliche Kanzlei und Diplomatik in Schweden bis um 1250. (Filologiskt arkiv, Bd. 19.) Stockholm 1974; Herman Schück, Rikets brev och register. Arkivbildande, kansliväsen och tradition inom den medeltida svenska statsmakten. (Skrifter utgivna av Svenska Riksarkivet, Bd. 4.) Stockholm 1976; Niels Skyum-Nielsen, Den danske konges kancelli i 1250'erne, in: Festskrift til Astrid Friis. Hrsg. v. Svend Ellehøj/Svend Gissel/Kund Vohn. København 1963, 225-245; Niels Lund, Lið, leding og landeværn. Hær og samfund i Danmark i ældre middelalder. Roskilde 1996.

24 Sven Tägil, Valdemar Atterdag och Europa. (Bibliotheca historica Lundensis, Bd. 9.) Lund 1962; Niels Bracke, Die Regierung Waldemars IV. (Kieler Werkstücke, Reihe A, Bd. 21.) Frankfurt a. M. 1999.

25 Michael Nordberg, I kung Magnus tid. Norden under Magnus Eriksson 1317-1374. Stockholm 1995, 241-256.

26 Negativ dargestellt von Nordberg, I kung Magnus tid (wie Anm. 25); vgl. Schmid, Birgitta (wie Anm. 22); John Lind, Magnus Eriksson som birgittinsk konge i lyset af russiske kilder, in: Birgitta, hendes værk og hendes klostre i Norden. Hrsg. v. Tore Nyberg. (Odense University Studies in History and Social Sciences, vol. 150.) Odense 1991, 103-128.

27 Ole Jørgen Benedictow, The Medieval demographic system of the Nordic countries. Oslo 1993.

28 Aksel Erhardt Christensen, Kalmanunionen og nordisk politik 1319-1439. København 1980. Lars-Olof Larsson, Kalmarunionens tid. Från drottning Margareta till Kristian II. Stockholm 1997.

29 In Schweden: Jöns Bengtsson Oxenstierna (1449-1457) und Jakob Ulvsson (1471-1515); in Norwegen: Erik Valkendorf (1510-1522) und Olav Engilbriksson (1523-1538); in Dănemark: Birger Gunnersen (1498-1519).

301448 wurde der Oldenburger Christian zum König gewăhlt. In einer separaten Wahlhandlung nahm Karl Knutsson vom Geschlecht der Bonde in Schweden die Königsmacht und übte sie in Konkurrenz mit den Oxenstierna und den Wasa aus. In Dănemark mußten die Oldenburger sich vor allem mit Mitgliedern der Familien Rosenkrantz und Gyldenstjerne auseinandersetzen. 
die Beteiligung des Königs daran wegen der päpstlichen Jurisdiktionsgewalt grundlegend geändert hatte. Denn im Fruhmittelalter lag der königliche Einfluß auf die Kirche offen und diente dem Herrscherstatus des Königs, wăhrend im Spätmittelalter der König nur auf Umwegen, letztendlich kraft der neuen Institution des Wiener Konkordates von 1448, das gleiche erreichen konnte. ${ }^{31}$ Damit trat eine Wandlung bei der Amtsausübung der Bischöfe ein. Dem Königsgefolge des Frühmittelalters, dem auch Bischöfe angehören konnten, steht der aristokratische Reichsrat des Spätmittelalters gegenüber, in dem alle Bischöfe als Ranghöchste ihren festen Sitz und Einfluß hatten. Die kirchlichen Würdenträger trugen also ihre Titel wie in früheren Zeiten, verhielten sich aber anders zueinander, weil die realen Machtverhältnisse andere waren.

Zahlreiche Historiker, wie zum Beispiel Sven Ulric Palme, Gösta Kellerman, Birgitta Fritz, Jens E. Olesen, bemühten sich um die Erforschung der politischen Macht der Ratsaristokratie Skandinaviens im Spätmittelalter. ${ }^{32}$ In ihren Forschungen bleibt zwar die ständige Konkurrenz zwischen weltlicher und geistlicher Macht ein Hauptthema, wie sie sich auf allen Ebenen abspielte: zwischen König und Erzbischof, zwischen Bischöfen und den Inhabern der hohen Reichsämter. Jedoch geht es auch um die Auseinandersetzungen zwischen den aristokratischen Familien, die die Ämter in beiden Bereichen besetzten. Die unterschiedliche Orientienung dieser hochadeligen Familien drückt sich öfter in dem jeweiligen Anschluß an bestimmte kirchliche Zentren oder Klöster aus. ${ }^{33}$ Das Bürgertum der wenigen Städte erhielt erst im Spätmittelalter einen Einfluß auf politische Entscheidungen - in Schweden waren es die Bürger von Stockholm ${ }^{34}$, in Dänemark die von Malmö und Kopenhagen ${ }^{35}$, in Norwegen die von Oslo, Tønsberg und die Deutschen in Bergen. ${ }^{36}$

Nicht immer jedoch behandelten Historiker die interne Spannung zwischen weltlich und geistlich in der spätmittelalterlichen Kultur und Gesellschaft als ein Hauptthema. In der nationalen Perspektive des 19. Jahrhunderts schien es manchem Historiker einfacher und einleuchtender, die Kriege des Spätmittelalters als nationalen Kampf zwischen Schweden und Dänemark-Norwegen zu verstehen. Eine Stütze fand dieses Deutungsmodell zum Beispiel beim

31 Niels Knud Andersen, Senmiddelalderen 1241-1448. (Den danske Kirkes Historie. Hrsg. v. Hal Koch, Bd. 2.) København 1962.

32 Kellerman, Jakob Ulvsson (wie Anm. 6); Sven Ulric Palme, Sten Sture den äldre. Stockholm 1968; Birgitta Fritz, Hus, land och län. Förvaltningen i Sverige 1250-1434. (Stockholm Studies in History, vols. 16, 18.) Stockholm 1972/73; Jens E. Olesen, Rigsråd - Kongemagt - Union. Studier over det danske rigsråd og den nordiske kongemagts politik 1434-1449. Aarhus 1980; ders., Unionskrige og Stændersamfund. Bidrag til Nordens historie i Kristian I's regeringstid 1450-1481. Aarhus 1983.

33 Als Beispiel für Dănemark: Kaare Rübner Jørgensen, Mariager klosters oprettelse og etablering (til ca. 1490), in: Birgitta, hendes værk og hendes klostre (wie Anm. 26), 231-279.

34 Nils Ahnlund, Stockholms historia fore Gustav Vasa. Stockholm 1953.

35 Henrik Lundbak, ...Såfremt som vi skulle være deres lydige borgere. Rådene i København og Malmø 1516-1536 og deres politiske virksomhed i det feudale samfund. (Odense University Studies in History and Social Sciences, vol. 88.) Odense 1985.

36 Arne Odd Johnsen, Tønsberg gjennom tidene. Oslo 1971; Knut Helle, Kongssete og kjøpstad. Fra ophavet til 1536. (Bergen bys historie, Bd. 1.) Bergen 1979. Arnved Nedkvitne/Per G. Norseng, Byen under Eikaberg. Fra byens oppkomst til 1536. (Oslo bys historie, Bd. 1.) Oslo 1990. 
schwedischen Historiker Ericus Olai, der in den sechziger Jahren des 15. Jahrhunderts in seiner Cronica Regni Gothorum alle schlechten Eigenschaften den Dänen, alle guten den Schweden zuschrieb. $^{37}$

Sicher ist also ein Vergleich zwischen den zentralen politischen Institutionen der skandinavischen Königreiche im 12.-13. mit denen im 15. Jahrhundert möglich. Er müßte funktional vorgehen, indem die Brennpunkte der politischen Entscheidungen im jeweiligen System zu lokalisieren, die Hintergründe der Entscheidungen und ihr Kontext zu umreißen wären. Fallgruben verbergen sich dabei offensichtlich im Bereich der Semantik: Deckt sich der Inhalt politischer Begriffe des 15. Jahrhunderts, wie zum Beispiel regmum oder ius regale, mit dem der gleichen Begriffe in Frühmittelalter? Sind bestimmte Ämter, die einmal mit Leben, Macht und Einfluß verbunden waren, zu leeren Formeln geworden, oder beinhalteten oder beanspruchten sie reale Macht, entsprechend derjenigen, die sie einmal entstehen ließ? War es also ein wichtiger Einschnitt, wenn Königin Margarete I. nach ihrer Machtübernahme in Schweden 1389 die Reichsämter nicht mehr besetzen ließ - oder war es eine Geste ohne politische Bedeutung? ${ }^{38}$

\section{Gruppe und Gesellschaft}

Ich werde ein zweites Beispiel nehmen: das Problem des Zugehörigkeitsgefühls verschiedener Bevölkenungsschichten der mittelalterlichen Gesellschaft zu verschiedenen Gruppen oder Interessenverbänden, nach der Anregung von Susan Reynolds' Kingdoms and Communities. ${ }^{39}$

In der Missionszeit des 10.-12. Jahrhunderts trat die Kirche in die skandinavische Gesellschaft ein mit ihrer aus römischer Tradition uberlieferten Einteilung in Bistümer, oft in Propsteien unterteilt, die jeweils einem bepfründeten prepositus anvertraut waren. ${ }^{40}$ Es gab daneben das englische Modell der Minster-Kirchen, in denen eine Gruppe von Geistlichen residierte, die ein größeres Gebiet seelsorgerisch betreuten, ohne es in Untersprengel aufzuteilen. In Skandinavien überlagerten die Pfarreien eine althergebrachte Einteilung der dichtbevölkerten Gebiete in Länder und Hundertschaften, die zwecks Organisation von Schiffsbau und Seekriegsaufgebot in weitere kleine Einheiten unterteilt waren, normalerweise in enger Anlehnung an alte Gaugebiete, sogenannte bygder. Ob man in der Missionszeit in größeren Abständen besondere Taufkirchen errichtet hat, bleibt ungewiß. Verschiedene Theorien wurden

37 Ericus Olai, Chronica Regni Gothorum. Hrsg. v. Ella Heuman/Jan Öberg. (Studia latina Stockholmiensia, vols. 35, 39.) Stockholm 1993/95; Erik Lönnroth, Ericus Olai som politiker, in: Kungliga Humanistiska Vetenskaps-Samfundet i Uppsala. Årsbok 1952. Uppsala 1952, 149-171.

38 William Christensen, Dansk Statsforvaltning i det 15. Arhundrede. København 1903, ND 1974. Vivian Etting, Margrete den Første. En regent og hendes samtid. 2. Aufl. Kobenhavn 1997.

39 Susan Reynolds, Kingdoms and Communities in Western Europe, 900-1300. 2. Aufl. Oxford/New York 1997.

40 Troels Dahlerup, Det danske Sysselprovsti i Middelalderen. København 1968. 
vorgelegt - diejenige der Hundertschaftskirchen oder Gaukirchen, der sogenannten fylkeskirker, könnte für Teile Norwegens zutreffen. ${ }^{41}$

Zur Einteilung der skandinavischen Länder in Bistümer legte 1971 Jan Arvid Hellström eine Studie vor, in der er die bekannten Bistümer des skandinavischen Nordens mit denjenigen Provinzen oder Regionen verglich, die wir aus Traditionsquellen kennen. ${ }^{42}$ Die meisten Bistümer Skandinaviens stellten nach seiner Meinung naturgegebene, voneinander durch Hindernisse wie Wasser oder große Wälder abgetrennte Einheiten dar, denen er einen vorchristlichen Status und ein Thing, eine Vollversammlung der freien Mănner, zuschrieb. Hellström postulierte als Hauptregel die Annahme des Christentums durch gemeinsamen Beschluß solcher Versammlungen. Damit wird auch das Zugehörigkeitsgefuhl aller Männer zu solchen Provinzen oder Regionen vorausgesetzt.

Das Christentum, das nach Skandinavien gelangte, kannte aber noch keine Einteilung des Landes in Pfarreien. Diese erfolgte im 12. Jahrhundert, als die Kirchen noch aus Holz gebaut wurden. Mit dem Bau von Steinkirchen auf Pfarrebene jedoch, der überall in Skandinavien gleichzeitig einsetzte, festigte sich die Zugehörigkeit von jedem Haushalt auch noch zu einer bestimmten Pfarrei, furr deren Kirche und Pfarrer der Zehnt zu zahlen war. Mit den steinernen Kirchen, die weitgehend heute noch dort stehen, wo sie im 12. Jahrhundert gebaut wurden, erreichte man den Abschluß der Eingliederung jedes Einzelnen in das Gefuge der kirchlichen Struktur. Die Forscher, die sich gegenwärtig mit dieser Problematik beschäftigen, neigen zu dem Deutungsmodell der weitverbreiteten Privatkirche, wo die adeligen oder großbăuerlichen Kirchherren selber ihre Pfarrer einsetzten und in Zucht hielten, nach dem Vorbild, wie der König die Bischöfe ernannte und sie unter seinem Gehorsam hielt. Erst mit dem Erstarken der Pfarrgemeinden und der Schwăchung des Eigenkirchenwesens kăme dann die communitas der Pfarreinwohner dazu, an den lokalen Entscheidungen mitzuwirken. ${ }^{43}$

Eine ganz andere Antwort erhalten wir, wenn wir die gleiche Frage nach dem Zugehörigkeitsgefuhl in den Pfarrgemeinden im 15. Jahrhundert aufwerfen. Hier war nun die Pfarreinteilung seit Generationen fest verwurzelt, und die Zugehörigkeit des Einzelnen zu einer bestimmten Pfarrei und seine Unterordnung unter die Autorităt des Pfarrers stand fest, bedingt durch die Zahlung des Zehnten. Jedoch nimmt man gleich wahr, daß ein Eingliederungsprozeß des ganzen Volkes in eine kirchliche Struktur, an deren Spitze Bischof und König stünden, jetzt weit entfernt ist. Man kann höchstens vom Hineinerziehen der Kinder, der Jugend und der Dienstleute in das Christenleben der Pfarrei sprechen. Die Selbstverwaltung der Pfarrei ist längst reguliert, die Pröpste, später die Offizialen des Bischofs, unternehmen ihre Visitationen, um die Verwaltung der Zehnteinnahmen zu uberwachen. Suchen wir nach einem wirklichen Prozeß, vergleichbar mit dem der Pfarreingliederung der ganzen Bevölkerung im Frühmit-

41 Gustav Indrebø, Fjordung. Bergen 1935; Stefan Brink (Hrsg.), Jämtlands kristnande. (Projektet Sveriges kristnande. Publikationer, Bd. 4.) Uppsala 1996. Ebbe Nyborg, Kirke - sognedannelse - bebyggelse, in: Hikuin 12, 1986, 7-20.

42 Jan Arvid Hellström, Biskop och landskapssamhälle i tidig svensk medeltid. (Răttshistoriskt bibliotek, Bd. 16.) Stockholm 1971.

43 Nyborg, Kirke (wie Anm. 41); Eivind Claesson, Cuius ecclesiam fecit. Romanska kyrkor i Västergötland. Licentiatavhandling i Medeltidsarkeologi. Lund 1989. 
telalter, dann finden wir etwas ganz anderes: Wir finden die Gilden in Stadt und Land, wir finden die Stiftungen, die Errichtung der Seitenaltäre und die Entfaltung der verschiedenen Heiligenkulte. Wir finden das Geldsammeln für den Einkauf eines Altarstückes mit geschnitzten Heiligenfiguren oder für einen Maler, der den Kirchen mit ihrem neu eingesetzten Gewölbe eine neue künstlerische Ausstattung geben soll. ${ }^{44}$ Wir finden die Mendikanten überall auf ihren Predigtfahrten mit einer lebendigen Botschaft des Christentums, so wie die Pfarreinwohner es von ihrem Pfarrer nicht hören können. ${ }^{45}$ Neue Devotionsformen entstanden, wie die Marienandachten oder das Rosenkranzgebet, und gaben Anlaß zur Gründung neuer Gilden und Bruderschaften. ${ }^{46}$

Obwohl also die Pfarreien des 15. Jahrhunderts die gleichen geblieben sind wie im 12. Jahrhundert, ist die Gesamtlage eine andere. Träger des religiösen Zugehörigkeitsgefulhls sind nicht mehr der König und die von ihm eingesetzten Bischöfe, sondern der Pfarrer, einzelne Mendikanten oder ihre Klöster und im engeren Kreis die eigene Gilde oder Bruderschaft. Zum Pfarrer kann man nun sogar durch direkte Verhandlung am päpstlichen Hof aufsteigen. Der Bischof nimmt an der Politik des Reiches und des Königs teil und vertritt dabei des öfteren die Interessen seiner Familie. Dem König ist die Christianisierung des Volkes nicht wie im Frühmittelalter ein Anliegen, das seine Stellung unterbauen oder sein Ansehen im Ausland verbessern könnte. ${ }^{47}$ Im Volke ist ein gemeinschaftserzeugender Prozeß im Gange, wie im Frühmittelalter, aber unter ganz anderen Vorzeichen und sich auf ganz andere Schlüsselfiguren stützend.

Auf ăhnliche Weise kann man sich den Vergleich zwischen der Bedeutung des Papsttums im frühmittelalterlichen und im spätmittelalterlichen Skandinavien vorstellen. Die Päpste waren im 11. und 12. Jahrhundert bemüht, Neuland im Norden Europas zu erobern und es für das Christentum zu sichern. Sie gaben Weisungen, vermittelten Grundnormen des kanonischen Rechts an skandinavische Herrscher und Bischöfe und versuchten, die kirchliche Gerichtsbarkeit funktionsfähig zu machen. ${ }^{48}$ Über den Peterspfennig hinaus ${ }^{49}$ hatten sie aber noch keine

44 Lars Bisgaard, Sogn, faellesskab og gavegivning i dansk senmiddelalder, in: Danmark og Europa i Senmiddelalderen. Hrsg. v. Per Ingesman/Bjørn Poulsen. Aarhus 2000, 336-360.

45 Jørgen Nybo Rasmussen, Die Bedeutung der nordischen Franziskaner für die Stădte im Mittelalter, in: Bettelorden und Stadt. Bettelorden und städtisches Leben im Mittelalter und in der Neuzeit. Hrsg. v. Dieter Berg. Werl 1992, 3-18.

46 Sven-Erik Pernler, Rosenkransfromhet i senmedeltidens Sverige, in: Maria i Sverige under 1000 år. Hrsg. v. Sven-Erik Brodd/Alf Härdelin. Skellefteå 1996, 557-582.

47 Stephen Neill, A History of Christian Missions. (The Pelican History of the Church, vol. 6.) 2., rev. Aufl. Harmondsworth 1986. Birgit Sawyer/Peter Sawyer/Ian Wood (Ed.), The Christianization of Scandinavia. A Symposium Report. Alingsås 1987; Bertil Nilsson, Sveriges kyrkohistoria I. Missionstid och tidig medeltid. Stockholm 1998.

48 Schon seit den Schreiben Papst Gregors VII. an König Svend Estridsen 1075 und 1077: Diplomatarium Danicum. Bd. I, 2. Hrsg. v. Lauritz Weibull. København 1963, Nr. 11, 21-24, Nr. 17, 35-37, und an die Könige von Schweden: Johan Gustaf Liliegren (Ed.), Diplomatarium Suecanum. Bd. 1: 817-1285, Stockholm 1829, Nr. 24 f.., vgl. ebd. z. B. Nr. 41 und 54 aus der Zeit Papst Alexanders III., Nr. 93-95 aus der Lucius' III. Vgl. für Papst Innocenz III.: Torben Nielsen, Bispe-translationer, politisk tænlening og kanonisk ret hos pave Innocens III i perioden 1198-1200. Diss. phil. Aarhus 1996. 
Ressourcen und keine Ideologie, die es ihnen erlaubt hätten, ein ganz Skandinavien umfassendes Steuer- oder Abgabensystem in Kraft zu setzen. Ganz anders die nach Avignon blühende päpstliche Verwaltung und ihre Folgen für Skandinavien, die sich erstmalig nach dem Konzil von Vienne bemerkbar machten. ${ }^{50}$ Nur ein systematischer Vergleich Punkt fur Punkt könnte den Kontrast in seiner überwältigenden Fülle vor Augen bringen. Königin Margarete I., Christian I. von Oldenburg und Sten Sture, der schwedische Reichsverweser am Ende des 15. Jahrhunderts, manipulierten das Papsttum mit Geschicktheit auf eine Weise, die nicht unbedingt auf den religiösen Respekt oder die innere Achtung für den Papst schließen läßt, die doch bei den Machthabern des Fruhmittelalters festzustellen sind. ${ }^{51}$

Die wenigen Andeutungen, die ich hier gegeben habe, sollten deutlich machen, wie ein Vergleich zwischen zwei Epochen in der Geschichte eines und desselben Kulturgebietes sinnvoll und ergiebig sein könnte. Jeder Vergleich setzt in den beiden zu vergleichenden Perioden einige identische Komponenten voraus. Identisch sind in diesem Falle, außer den physischkulturgeographischen Faktoren, zusätzlich noch die Lebenswerte und Zielsetzungen bei der Formung der Menschen in dieser Gemeinschaft der skandinavischen Völker, im Rahmen derjenigen Mischung von katholischem Christentum und alten Überlieferungen, die sie beide zu den beiden Zeitpunkten umschließt. Letztendlich haben wir es mit den sich nur langsam verändernden epochalen Mentalităten zu tun. Der Vergleich ist sinnvoll und könnte bei systematischer Anwendung fruchtbar sein.

49 Tore Nyberg, König Knut der Heilige, Teuzo und der Peterspfennig aus Dănemark, in: ArchHPont 23, 1985, 359-365.

50 Yngve Brilioth, Den påfliga beskattningen af Sverige intill den stora schismen. Diss. phil. Uppsala 1915; Carl Axel Ekbom, Viennetionde och hundaresindelning. Studier rörande Sveriges äldsta politiska indelning. (Răttshistoriskt bibliotek, Bd. 23.) Stockholm 1974.

51 Michael Linton, Drottning Margareta, fullmäktig fru och rătt husbonde. (Studia Historica Gothoburgensia, Bd. 12.) Aarhus 1971, hier 129-156; Beata Losman, Norden och reformkoncilierna 14081449. (Studia Historica Gothoburgensia, Bd. 11.) Göteborg 1970; Palme, Sten Sture (wie Anm. 32). 


\title{
Comparative History of the Medieval Church's Marriage System
}

\author{
Von \\ David L. d'Avray
}

This paper will attempt to illustrate three different kinds of comparative history: comparisons between different regions in the same period; comparisons of the same genre in a medieval and in a later period; and, finally, the kind of comparison which attempts to establish unique features of one culture within world history. I will ask how far medieval Canon law differed from the sacred laws of other world religions, concentrating on Islam and Hinduism. Curiously, my British medievalist colleagues tend to look for comparisons, if they look for them at all, in the works of anthropologists studying village societies. Yet comparisons with other sophisticated legal systems based on written texts believed to be revealed are immensely illuminating. We should not look for universal ,laws of society'. ${ }^{1}$ Instead I will use Weber's method, and construct an ideal type of sacred law, with the ultimate aim of distinguishing what was specific about the medieval European variant of it. We all invoke the name of Weber, but we need to follow him further into the study of other religions. Before turning to comparisons on a world-historical scale, however, I want to begin at a provincial, i.e. a European level. My first comparison will be of a methodologically conventional sort. The pattern will be familiar: two European regions from the same general period. The period is the later Middle Ages (including the thirteenth century). The regions are England and Italy.

\section{Comparisons between different regions in the same period. Marriage ceremonies in England and Italy ${ }^{2}$}

There is much modern scholarly confusions about the medieval Church's rules after 1215 for contracting a legal marriage. Paradoxically, some scholars who are not deeply acquainted

1 For an intelligent example of the misguided attempt to formulate laws like those of the natural sciences, see Rodney Stark/William S. Bainbridge, A Theory of Religion. New Brunswick 1996.

2 This section gives the conclusions of David L. d'Avray, Marriage ceremonies and the church in Italy after 1215, in: Marriage in Italy, 1300-1650. Ed. Trevor Dean/Kate J. P. Lowe. Cambridge 1998, $107-115$. 
with the scholarly literature get the right answer precisely because they do not know enough to be mislead by the leading historians of Canon law, some of whom need to be corrected on this point. My conclusions will only be of interest to scholars who are learned enough to have been mislead by some otherwise excellent works of erudition. Furthermore the subject tends to get entangled with an entirely separate matter: the validity of clandestine marriages. Naturally I am aware that simple consent sufficed to make a valid marriage before the Council of Trent in Catholic Europe (and until the mid-eighteenth century in England). My topic is not validity but legality. A mutual consent in the present tense, unplanned and in secret, was enough to make a valid marriage in the eyes of the medieval Church, but not to make a legal marriage, at least after Lateran IV. ${ }^{3}$ The question is, what did Lateran IV demand for legality. Did it demand marriage in Church? Leading modern specialists have assumed that it did: one finds the assumption in Dauvillier ${ }^{4}$, Brundage ${ }^{5}$, even perhaps by implication Helmholz. ${ }^{6}$ Others realize that it did not: notably Joyce ${ }^{7}$ and (a little less clearly, but by implication) Gaudemet. ${ }^{8}$ One leading authority seems to imply opposite conclusions within the same article. $^{9}$

So what were the rules about church weddings and the presence of the priest? There is some unambiguous synodal legislation for at least some parts of England, requiring the presence of a priest. ${ }^{10}$ What of Italy? It is a well-known fact that secular marriage ceremonies were perfectly normal. Was the Church's law being broken?

Almost certainly not, though the answer might vary from diocese to diocese. The central fact is this: no historian has yet been able to point to any general law making a church ceremony or the presence of a priest obligatory. The relevant decree from Lateran IV ${ }^{11}$ says nothing about the ceremony: it concentrates on the period before marriage and on the publication of the banns. A more striking piece of evidence is a passage from Hostiensis, doyen of thirteenth-century Canon lawyers. ${ }^{12} \mathrm{He}$ lists a series of requirements for a marriage:

3 Some people have difficulty with the distinction between ,legality and ,validity'. The following example may help: to celebrate mass during an interdict might be illegal, but the consecration of the host would still be valid.

4 D'Avray, Marriage Ceremonies (cited in note 2), 107 note 1.

5 Ibid., 108 note 5.

6 Richard H. Helmholz, Marriage Litigation in Medieval England. Cambridge 1974, 27 at note 9: which could be read to mean that the Lateran Council's decree (X.4.3.3) demanded the blessing of a priest (an uncharacteristic unclarity in a superb book).

7 D'Avray, Marriage Ceremonies (cited in note 2), 108 note 2.

8 Ibid., 108, at notes 6 and 7.

9 Christiane Klapisch-Zuber, Zacharie, ou le père évincé. Les rites nuptiaux toscans entre Giotto et le concile de Trente, in: Annales 34, 1979, 1216-1243, discussed in d'Avray, Marriage Ceremonies (cited in note 2), 108-111. Note also her remark about „la bénédiction nuptiale, nécessaire à ses [the Church's] yeux“; ibid. 1232.

10 Frederick M. Powicke/Christopher R. Cheney, Councils and Synods, with other documents relating to the English Church. Vol. 2: A. D. 1205-1313. Oxford 1964, Part I, 521-522 [33]; Part II, 996 [7].

11 X.4.3.3; Aemilius Friedberg (Ed.), Corpus Iuris Canonici. Vol. 2: Decretalium collectiones ... Leipzig 1881, reprinted Graz 1959, cols. 679-680.

12 Discussed in d'Avray, Marriage Ceremonies (cited in note 2), 112-113. 
benediction in facie ecclesie, permission by those who have control of the bride, dowry, abstention from sex two or three days after the wedding - and then says that it is not a sin to omit these. In short, no obligation to have the marriage blessed by a priest.

The implications are not trivial. In Italy, a marriage contracted in front of a notary did not imply indifference or hostility to Church authority. It was not a symptom of the lay" spirit. But it was certainly less ,ecclesiastical' than in England. (One is reminded of the marriage of Parzifal in Wolfram's poem. The marriage was religious, but ecclesiastics play no part in it.) This difference can be seen as a special case of a more general contrast between England and Italy, or even perhaps between northern and southern Europe. Universities and Learning are clerical in Northern Europe, but much more secular in Italy. In Italy it was even possible for a married layman (Johannes Andreae) to reach the top as a Canon lawyer.

Such comparisons draw attention to the specificities of different regions. Sometimes one can go further. An external and visible contrast can have consequences which are less visible, because they affect the meaning of social action, rather than its externals. The historian may have to infer such changes in meaning indirectly. Here is a case in point, also involving England and Italy.

Italy or parts of it at least had a well developed clan structure. This was explored by Jacques Heers, who tended to generalize from it to Europe as a whole. ${ }^{13}$ For later medieval England it does not work. The nuclear family is primary, and clans in the sense of the term used by Heers ${ }^{14}$ are hardly to be found. ${ }^{15}$

This has implications for a connected sphere. The Church's exogamy rules were universal in the Latin west. England and Italy were from this point of view the same: one could not marry anyone with whom one shared a common great great grandfather or -mother (or the widow, widower, or former sexual partner of such a person). To be more precise, only a papal dispensation made such a marriage possible.

So far, so uniform. I would suggest however that there may have been an important difference at the level of the meaning behind external action. I am here thinking of the ,reception“ side of meaning: how the rationality of the papal exogamy rules was perceived on the receiving end. The official rationale of the rules was that they promoted peace. Exogamy multiplied marriage bonds between clans. This line of thought can be found in Augustine's City of God (book 16, chapter 16). It was familiar in the thirteenth century and earlier. ${ }^{16}$

13 Jacques Heers, Family Clans in the Middle Ages. A study of political and social structures in urban areas. Amsterdam/Oxford 1977, a slightly revised edition of the French edition: Le clan familial au Moyen Âge. Étude sur les structures politiques et sociales des milieux urbains. Paris 1974.

14 Heers' usage is not too far off the following definition by an influential anthropologist: „Higher order units often consisting of several lineages in which common descent is assumed but cannot necessarily be demonstrated"; Robin Fox, Kinship and Marriage. An Anthropological Perspective. Cambridge $1983,49$.

15 Barbara A. Hanawalt, The Ties that Bound. Peasant Families in Medieval England. New York/Oxford 1986, ch. 5, esp. 83, 89. A lecture by Lee Patterson made me think about this contrast.

16 It was to be found for instance in the Gratian's Decretum: C. 35, Q. 1, c. 1; Aemilius Friedberg (Ed.), Corpus Iuris Canonici. Vol. 1: Decretum Magistri Gratiani. Leipzig 1879, reprinted Graz 1959, col. 1262. 
Now in Italy this rationale would have made evident sense. Marriages were systematically used to end conflicts between clans. ${ }^{17}$ In England, however, the rationality would have been much less apparent. People might have understood the theory but it would not have been reinforced by social experience.

\section{Comparisons extending beyond the Middle Ages but within a precisely defined genre}

So far we have investigated comparisons between different regions in the same period: synchronic comparisons. Now I will deal with a particular sort of diachronic comparison. This consists of finding genres which can be recognized as the same over a very long period of time: ,longue durée $e^{6}$ genres. The form, aim, and setting in life has to be fairly constant for this to work. Academic commentaries on Aristotle or the Bible would be examples. One could pick a key passage in a commented text, a passage relevant to some major theme in the history of ideas; then one could take ,snapshots' of the genre at two widely separated points in its history. That gives two sorts of results. It establishes prima facie continuities. If the same topoi are present in two centuries far apart, the chances are that the topoi were present in the intervening period. That can be tested by soundings in the history of the genre between the two point initially chosen. However, the ,two snapshot' approach also draws attention to changes in ideas.

To give an example from my own past research. ${ }^{18}$ From around 1200 until modern times it was customary to preach about marriage on the second Sunday after Epiphany, the Sunday when the pericope of the marriage feast of Cana was read. This holds good for Catholic Europe and probably for Lutheran Europe too. (Luther retained the medieval cycle of pericopes.) In model sermon collections enormous numbers of sermons on marriage for this Sunday survive. The materials for the longue durée history of marriage preaching are thus practically unlimited. One way to deal with almost infinite mass of raw data is to use the two snapshot' method. I chose the thirteenth and the seventeenth centuries, restricting myself to France. The results were very interesting. There were striking continuities. In both periods, the goodness of marriage and married love were emphasized. But the contrasts were perhaps even more interesting. In the seventeenth century preachers laid great emphasis on grace and vocation. In the thirteenth century little is said about grace, and the idea of marriage as vocation is apparently absent.

These absences are important negative facts; and negative facts of this kind can hardly be established without the help of the comparative method. One is also presented with an

17 Carol Lansing, The Florentine Magnates. Lineage and Faction in a Medieval Commune. Princeton 1991, 125-128; Daniel Waley, Siena and the Sienese in the Thirteenth Century. Cambridge 1991, 121, 143. Cf. Anthony Molho, Marriage Alliance in Late Medieval Florence. Cambridge/Mass. 1994, 344.

18 David L. d'Avray, The Gospel of the Marriage Feast of Cana and Marriage Preaching in France, in: The Bible in the Medieval World. Essays in Memory of Beryl Smalley. Ed. Katherine Walsh/Diana Wood. (Studies in Church History Subsidia, vol. 4.) Oxford 1985, 207-224. 
agenda for research. When and why did the idea of ,vocation' become prominent in Catholic thought about marriage?

I have two answers to suggest. The influence of Luther could have played a role. He was a great advocate of the ,vocation' idea. His opponents may have learned from him, though more research is needed to establish the links.

Changing attitudes to the priesthood in Counter-Reformation Europe could also have been an influence. In the aftermath of the Council of Trent the status of the priesthood was raised and the idea of vocation to the priesthood emerged. (I think it hardly existed in the Middle Ages, though something very much like the idea of a monastic vocation was current from the twelfth century on.) In seventeenth-century France it became a commonplace that one should not become a priest unless one had a ,vocation' from God. ${ }^{19}$ Once this line of thinking had been developed with respect to the priesthood, it would have been easy to transfer them to the main alternative, the sacrament of marriage.

\section{Sacred Marriage Law in World Religions}

The type of comparative history just discussed takes its starting point from precise analysis of a tightly defined genre. I now want to turn to a broader field. Medievalists have an immense amount to leam from comparisons between christian institutions in their period and roughly similar phenomena in other world religions. As I stated at the start of the paper, the aim is not to establish general laws. It is to work out the specificities of each system against the background of their common features. For instance, comparisons between medieval European christian and buddhist monasticism are fascinating. The parallels are amazing, the differences all the more interesting.

The same may be said of sacred law in Hinduism, Islam and the Christian Middle Ages. Here our concern is with marriage law, but one cannot isolate the topic from sacred law in general. As suggested above, so vast a comparative topic can be best approached by using Max Weber's method of ideal types. He himself devoted a most valuable section of Wirtschaft und Gesellschaft to sacred law. ${ }^{20}$ The following ,ideal type ${ }^{6}$ is not directly taken from Weber but is constructed very much in his spirit. ${ }^{21}$

19 Cf. René Taveneaux, Le Catholicisme dans la France classique, 1610-1715. Vol. 1. Paris 1980, 158-159.

20 See below, note 30.

21 In constructing the table I have found the following useful: Islamic law: Joseph Schacht, An Introduction to Islamic Law. Oxford 1964; M. Mustafa Al-Azami, On Schacht's Origins of Muhammadan Jurisprudence. $2^{\text {nd }}$ ed. Oxford etc. 1996; Émile Tyan, Histoire de l'organisation judiciaire en pays d'Islam. $2^{\text {ime }}$ éd. rev. et corr. Leiden 1960; Colin Imber, Ebu's-su'ud. The Islamic Legal Tradition. Edinburgh 1997; Ziba Mir-Hosseini, Marriage on Trial. A Study of Islamic Family Law. Iran and Morocco Compared. London 1993; Hindu law: Robert Lingat, The Classical Law of India. Berkeley 1973; Srikanta Mishra, Ancient Hindu Marriage Law and Practice. New Delhi 1994; Tryambakayajvan. The Perfiect Wife (Stridharmapaddhati). Translated with introduction by I. Julia Leslie. New Delhi 1995 (this is in fact a combination of translation and commentary). For western Canon law the 


\section{IDEAL TYPE OF SACRED LAW}

1. Divine order permeating the universe

Islam: Islam

Hinduism: Dharma

Canon law: Ius divinum/lus naturale

\section{Written revelation}

Islam: Koran

Hinduism: Veda, Sruti

Canon law: Bible

\section{Revelation by tradition}

Islam: Sunna, Haddith

Hinduism: Smrti embodied in Dharma sutras \& Dharma sastras

Canon law: Sancti Patres (i.e. patristic writings)

\section{Good custom}

Islam: Sunna - wider sense

Hinduism: Sad-acara

Canon law: Consuetudo

\section{Divinely guided interpreters of revelation}

Islam: Imam, Caliph, Shayk al-Islam

Hinduism: Parisad, Sankaracarya

Canon law: Popes and councils

6. Legal treatises with more than private authority

Islam: e.g. Epitome of Quduri

Hinduism: e.g. Laws of Manu

Canon law: Gratian's Decretum

\section{Special techniques of interpretation}

Islam: kiyas

Hinduism: mimamsa

Canon law: ,quaestio' method etc. 
(This is not an exhaustive schema, obviously. For instance, one could add:

Unanimity as Criterion of True interpretation

Islam: ijma

Hinduism: ,doctrine of consensus ${ }^{6}$

Canon law: Vincentian Canon; Concordia discordantium canonum

However I have found it a somewhat less relevant to the topic of marriage.)

The schema or ideal type of sacred law fits the medieval Canon law of marriage well. Most of the elements of our ideal type can be found without difficulty (correspondences with the table will be indicated by numbers in heavy type). For instance, in Distinctio VIII of Gratian's Decretum ${ }^{22}$ we find the assumption of a natural law ${ }^{23}$ comparable to Dharma and ,Islam" (confer 1 in the table). Augustine, the leading Latin representative of patristic ,tradition', is repeatedly cited as an authority (3). Augustine closely links divine law (1) with the scriptures (2). ${ }^{24}$ Not only Patristic but also papal authority is invoked (5). ${ }^{25}$

Gratian's Decretum itself rapidly took on a more than private authority (6). In Causa 27, Quaestio 2, c. $39^{26}$ we find a quaestio about consummated and non-consummated marriage in which contrasting authorities are confronted and the ,scholastic' method employed to get out of the impasse (7). The differences (discussed earlier in this paper) between regional rules about how a marriage should be contracted (priest versus notary) are an example of custom (4).

Against the backcloth of these generic similarities, let us turn to a document, Ms. British Library Cotton Cleopatra E. 1, fol. $194 \mathrm{v}-195 \mathrm{r} .{ }^{27}$ It is worth dwelling on the bull, because the formal legal structures and procedures it reveals have no parallels to my knowledge in the religious legal systems of Islam or Hinduism. I doubt if many historians of Canon law or papal diplomatic have asked themselves how unique the structures they study are in the world history of religions. They may take uniqueness for granted. The list of parallels given above shows one should do no such thing. But once the historian becomes aware of farreaching parallels and correspondences, the distinctive features take on a new interest. The Weberian comparative historian stands between old-fashioned specialists who do not want to know about anything outside their field, and generalisers who are after general laws of

22 Friedberg, Corpus (cited in note 16), cols. 12-16.

23 C. I. Iure diuino omnia sunt communia omnibus: iure uero constitutionis hoc meum, illud alterius est (...) C. II. Aduersus naturale ius nulli quicquam agere licet (...) Cum autem Deus aliquid contra morem aut pactum quorumlibet iubet, etsi numquam ibi factum est, faciendum est; ibid. cols. 12-13.

24 Diuinum ius in scripturis diuinis habemus, humanum in legibus regum. Unde quisque possidet, quod possidet? Nonne iure humano? Nam iure diuino „Domini est terra et plenitudo eius. “ [Psalm. 23,1]; ibid. col. 13.

25 C. V. (...) Item Gregorius VII. Wimundo Auersano Episcopo; ibid. col.14.

26 Ibid. col. 1074.

27 Calendered in Jane Sayers, Original Papal Documents in England and Wales from the Accession of Pope Innocent III to the Death of Pope Benedict XI (1198-1304). Oxford 1999, 203, no. 453. The bull has folio numbers because it is bound into a volume. 
society. The comparative historian looks for regularities as the first stage towards establishing individualities.

Ms. British Library Cotton Cleopatra E. 1, fol. 194v-195r, is a massive charter consolidating all the documents which had played a part in the process leading up to the annulment of Henry III's putative marriage with Joan of Ponthieu. ${ }^{28}$ The marriage was evidently invalid, incidentally, and no one has quite explained why Henry III went to so much trouble to get this officially recognized. The sequence of events seems to have been as follows. The story began a long time before the documents contained in the bull were issued. On April 81235 Henry III wrote to Joan of Ponthieu enclosing a letter for her to send to the pope, asking for the marriage they had contracted to be confirmed (this was necessary because they were related within the forbidden degrees). ${ }^{29}$ By July 161235 Henry was writing to representatives at the papal curia to stop progress towards a dispensation. ${ }^{30}$ We know that one motivation was that he had decided in the meantime to marry Eleanor, the daughter of the Count of Provence.

Long after his marriage to Eleanor of Provence, in a letter of February 121250 , Henry set in motion a long sequence of legal operations. ${ }^{31} \mathrm{He}$ gave his proctor Johannes Capelli full power to have the matter dealt with by the pope or any other judges. This letter is one of the many contained in Ms. British Library Cotton Cleopatra E. 1, which is a veritable archive of documents relating to the annulment and a monument to formal legal rationality. Henry's letter is quoted in the middle of the bull lines (25-28) as an insert in a long document or letter which contains other relevant documents and which is itself contained in the final bull, which is rather like an archival Russian doll. Innocent appointed the Archbishops of York and Hereford as juges delegate, adding that if they could not both carry out the task, one or other of them could proceed on his own (lines 8-10). Subsequent proceedings are recounted in a long letter from the bishop of Hereford Peter of Aigueblanche - a letter which contains many other letters, just as it is itself contained in Innocent IV's letter. In July 1251 they sent a letter to the provost of Beverly, instructing him to cite Henry III and his wife to appear at

28 This monumental bull has not been edited, but some of the individual bulls which it contains are in print. I have used Thomas Rymer (Ed.), Foedera conventiones, literae, et cujuscunque generis acta publica inter reges Angliae et alios quosvis imperatores, reges, pontifices, principes vel communitates ab ineunte saeculo duodecimo videlicet ab anno 1101 ad nostra usque tempora habita aut tractata. Vol. 1. 3. ed. Hague 1739. I give in square brackets the relevant page references to Thomas D. Hardy, Syllabus (in English) of the Documents relating to England and other Kingdoms contained in the collection known as „Rymer's Foedera“, 1066-1377. Vol. 1. London 1869. Hardy enables one to trace a given document in the various different editions of Rymer. Dr. Nigel Ramsay drew my attention to this invaluable reference work. For the context of the bull see Margaret Howell, Eleanor of Provence. Queenship in Thirteenth-Century England. Oxford 1998, 58-59.

29 Hardy, Syllabus (cited in note 28), 36.

30 Ibid.

31 Much earlier moves in the same direction may be followed up in Rymer through Hardy, Syllabus (cited in note 28), 37 (April 27) (the calendar description is misleading, in that the pope's letter did not settle the case but commissioned an investigation.). I know of no evidence that anything resulted from these moves. 
Sens at a specified date for the case to be heard quantum exegerit ordo juris et dictaverit calculus rationis (lines 11-13). Then the Archbishop of York formally excused himself by letter (lines 13-15), and the bishop of Hereford proceeded on his own in accordance with Innocent IV's original letter. Bishop Peter's next step (as recorded in the Ms. British Library Cotton Cleopatra E. 1 bull) was to command the prior of the Cistercian house of HauteCombe to go to Joan, who was now Queen of Castile, and summon her to appear through a suitable proctor at the same judicial rendezvous in Sens (lines 15-18). The Prior of HauteCombe reported in formal terms by letter that he and another monk of Haute-Combe had indeed gone in person to the Queen of Castile and summoned her. She received the summons „benignly", but said that Henry III was her blood relation in the fourth degree and that in no way was she going to go or send anyone to Sens or anywhere else or involve herself in the business (lines 18-21).

Peter duly tumed up at Sens for the appointed day (19 March 1252) and called on three assessors to sit in judgement with him. They took testimony. Both the Prior of Haute-Combe and his fellow monk Thomas swore that they had summoned the Queen of Castile as set out in the prior's letter. Peter was also able to inspect letters from the queen herself. However, Peter of Aigueblanche also feels it necessary to quote in full a letter from the Abbot of Haute-Combe confirming that he had given permission to the prior and his companion to give sworn testimony in this case (lines 21-25). Then Peter reports that Henry III's proctor came forward with the king's letter empowering him to handle the case. The letter is quoted (lines 25-28), as we noted above. Peter of Aigueblanche and his assessors inspected it and put their seals on it. In view of the Queen of Castile's „contumacy“ and the procurator's demand for justice they agreed to hear the procurator's witnesses. Peter reports that the witnesses swore on the gospels to tell the truth. He refers to depositions sealed with his seal and those of the assessors. After the depositions had been written down, we are told, they were carefully inspected and ,published once, and again, and after that". The 5th of April (diem mercurii ante Ramos palmarum) was fixed for a verdict.

At this point the long letter (lines 7-32) summarising the process up to the depositions ends. It is dated to the 20th of March, 1252. Then the letter from the King's proctor (asking for an annulment and that witnesses be heard) is quoted in full (lines 32-37), apparently in a document in which it is followed only by a statement by Peter of Aigueblanche and his assessors that they were there when this document of the proctors was put forward and that their seals are attached.

Next come the depositions (lines 37-53). They are full of genealogical detail and a good source for the history of memory and written record. (Most rely on memory and fama publica; however the last witness, a canon, said that his testimony was not only based on publicam famam and witnesses, but also on a chronicle that he had seen at St. Denis: line 53). The depositions prove the consanguinity between Henry III and Joan far beyond any reasonable doubt. At the end it is stated that they were „subsequently published“, and the day of the sentence is named; and Peter of Aigueblanche and his successors say that they have authenticated the testimonies with their seals. The date that follows is the 19th of March: the 
day before the long letter from Peter which summarised so much of the process, including this part.

There follows another long document which is in effect the final sentence. This has been printed, both in Rymer's Foeder ${ }^{32}$, and in a volume of Hereford Charters. ${ }^{33}$ It too summarises the whole process (and includes King Henry's procurator's long submission). It says that after discussion with the assessors and others leamed in the law (jurisperitis), Peter pronounces Henry's marriage to Joan null and his marriage to Eleanor valid. The assessors say they have added their seals. A list of witnesses follows.

On August ${ }^{34} 291252$ Innocent IV confirmed Peter of Aigueblanche's sentence. Two days later he wrote to the Archbishop of Canterbury and the Bishop of Chichester, telling them to publish the sentence and punish anyone who gave King Henry and his family any trouble regarding this sentence.

That was still not the end. On 20 May 1254 another papal bull was issued. This is the monster bull in Ms. British Library Cotton Cleopatra E. 1. It includes all the documents summarised above, from Henry's commission to his procurator Capelli to Peter of Aigueblanche's final sentence at Sens. ${ }^{35}$ These documents are surrounded as it were by a final papal confirmation of the sentence. This is almost the same as the confirmation letter of August 29 1252, but with a significant difference: after the words processum approbantes eundem (lines 6-7) the pope inserts the clause ac supplentes de plenitudine potestatis defectum, si quis in hoc fuit (line 7): an ultimate insurance against any legalistic quibble that might be held to invalidate Peter of Aigueblanche's sentence.

These document illustrates some features of medieval sacred marriage law, and of Canon law in general, which mark it out from the other sacred laws discussed above. ${ }^{36}$

a) We are in the realm of instrumental rather than value rationality - Zweckrationalität rather than Wertrationalität. Before he changed his mind and married Eleanor of Provence, Henry III had begun the process of getting a dispensation for Joan of Ponthieu. A dispensation would have been possible because the exogamy rules were regarded as a matter of Zweckrationalität rather than Wertrationalität. ${ }^{37}$

b) Henry felt the need to go to the pope and submit to an elaborate procedure to get the marriage annulled, even though it was obviously invalid by the laws of the time. He does not simply summon a compliant council of bishops, as a twelfth-century king would have done.

32 Rymer, Foedera (cited in note 28), 164; cf. Hardy, Syllabus (cited in note 28), 47.

33 William W. Capes, Charters and Records of Hereford Cathedral. Hereford 1908, 90-92.

34 Rymer, Foedera (cited in note 28), 169; Hardy, Syllabus (cited in note 28), 48.

35 Thus: all except the two mentioned in the previous paragraph.

36 Cf. Max Weber, Wirtschaft und Gesellschaft. 5. rev. ed. Tübingen 1972, 480: „Das kanonische Recht des Christentums nahm gegenüber allen anderen heiligen Rechten eine mindestens graduelle Sonderstellung ein. Es war zunächst in beträchtlichen Partien wesentlich rationaler und stărker formal juristisch entwickelt als die anderen heiligen Rechte." Weber's whole discussion of sacred law (ibid. $468-482$ ) is relevant. Though overtaken in details his basic insight remains valid in my view, especially if approached in an eirenic spirit.

37 Cf. Hubert Kroppmann, Ehedispensubung und Stauferkampf unter Innozenz IV. Ein Beitrag zur Geschichte des päpstlichen Ehedispensrechtes. Berlin 1937, passim. 
c) Actions in four different countries played a part in the formal procedures: England (the king); Italy (the pope); Spain (Joan, queen of Castille), and France (the trial).

d) These procedures are formal. ${ }^{38}$ With enough time and sufficient knowledge of Canon law one could probably discover a general legal rule behind each of the stages in this procedure. For instance, it was clearly important that the Queen of Castille, formerly Joan of Ponthieu, be invited to the hearing and ,contumaciously' refuse. As it happened, it would appear that everyone knew that she had no intention of contesting the case. Nevertheless there was a Canon law rule that Receptio testium contra non contumacem, lite non contestata, in causa matrimoniali est nulla. ${ }^{39}$ So the judge delegate made sure that procedure was kept in scrupulous conformity with this legal rule.

e) These formal procedures too are a matter of instrumental rather than value rationality. They procedural rules so scrupulously followed were not a matter of divine command. They were administrative procedures established by the papal government. They are man-made rules designed to produce a formally watertight process of proof. And they seem familiar in this respect, because this is the formalism of modern secular legal systems.

f) Their formality and their rigidity are a fine example of bureaucratic rationality. It is a feature of bureaucratic rationality that man made rules are observed as scrupulously as if they were were values.

The foregoing draws attention to some of the features which distinguish the marriage law of the medieval church from its counterparts in Hinduism and Islam:

- Canon law includes a vast quantity of Zweckrationalität, more than in other sacred laws, those of Hinduism and Islam at least, where the religious law and fundamental value come close to being identified. The instrumental rationality of Canon law is not unprincipled. On the contrary, its whole purpose was orientated towards values. However, its rules were not identified with those values. The medieval church's law combines the features of sacred laws listed in our schematic ideal type with the formal bureaucratic legal rationality of modern secular legal systems. The procedures of other sacred laws are also formal, or can be, but their formality is thought to derive ultimately from revelation. In Canon law they are manmade. Zweckrationalität rather than Wertrationalität is their justification.

- Bureaucratically organized justice at a distance marks out medieval Canon law from other sacred laws. With the other sacred laws the judge who made the decision would usually be local, and there would be no appeal. True, Islam had the Mazalim system (in Egypt of the pre-Ottoman period). ${ }^{40}$ However, this seems to have been more like a regular audience to settle injustices not rectified at a lower level. It reminds one more of St. Louis dispensing justice at the oak of Vincennes. It cannot be compared with the enormous volume of business done via the papal court by papal judges delegate. Similarly, the Sheik-al-Islam of the

38 Weber, Wirtschaft (cited in note 36), 396: „Formal' aber ist ein Recht insoweit, als ausschliesslich eindeutige generelle Tatbestandsmerkmale materiell-rechtlich und prozessual beachtet werden.“

39 Cf. Extravagantes of Gregory IX: X.2.6.4, Friedberg, Corpus (cited in note 11), cols. 261-263.

40 Cf. Tyan, Histoire de l'organisation (cited in note 21). 
Ottoman empire bears only a superficial similarity to the centralization of Canon law. This grand mufti of the Ottomans gave judgements, but they had no formal legal force. They were like the ,opinions' that barristers give in English Common law, or Professors in Roman law regions. Moreover many of these opinions were laconic, and the number delivered in a day is staggering. It is actually an attractive system but totally different from the Canon law combination of local and central justice. The Canon law system was an inspired administrative device for exercising centralized justice with local knowledge at relatively small expense. It seems hard to find a parallel in other world religions. ${ }^{41}$

- The Canon law of marriage made kings go through the hoops of papal bureaucracy. It is a remarkable fact that sovereigns submitted themselves to such procedures. They became skilled at working the system, but it was not their system and they had to play by the pope's rules. I know of no parallel to this. In other religious systems holy men exercise charismatic authority over rulers (or try to and pay for it, as John the Baptist did). But the routine bureaucracy of papal law is a different matter.

The foregoing contrast is itself an ideal type, proposed in the hope that it will be modified. Then, if the general contrast stands up to more precise investigation, the task will be to explain the distinctiveness of Canon law. These are large tasks, but important ones. Without comparative history they cannot even be defined.

We have looked at (1) synchronic comparison of European regions, (2) diachronic comparisons within the longue durée history of a defined genre, one which started in the Middle Ages but extended into modern times, and finally, (3) a comparison between the sacred law of three great world religions. The first kind of comparison has often proved its value. For most people, comparative history means this sort of comparative history. The second kind has great potential. Concentration on a specific genre brings rigour to the analysis. Done properly, it should ensure that the historian compares like with like. Furthermore it provides a way to overcome the divide between medieval and later history. Many genres cut right through the traditional periodisation. Even the Reformation does not necessarily mark a break. It would in fact be particularly interesting to see how far the topoi of medieval preaching continued to be used in Lutheran preaching. The retention by Lutheran protestants of the medieval cycle of liturgical readings is an opportunity for the historian. One could pick a Sunday with an interesting pericope, and see if Lutheran preachers handled it in a radically different way.

41 It was all the more remarkable because the central papal administration was financially and even bureaucratically primitive in the thirteenth century - very far from Weber's ideal type of a bureaucracy. See for instance Brigide Schwarz, Die Organisation kurialer Schreiberkollegien von ihrer Entstehung bis zur Mitte des 15. Jahrhunderts. (Bibliothek des deutschen historischen Instituts in Rom, Bd. 37.) Tübingen 1972, who emphasizes the inefficiency and primitive character of the papal chancery, dispelling the assumption that it functioned more or less like a modern bureaucracy; - or, on the remuneration of members of the papal court in kind rather than by salaries, Ludwig Dehio, Der Übergang von Natural- zu Geldbesoldung an der Kurie, in: VSWG 8, 1910, 56-78, e.g. 57: „Noch am Ende des 13. Jahrhunderts herrscht das Naturalsystem absolut". 
The third kind of comparison appears to be impossibly ambitious. But there is an incomparable tool which makes it more possible. Weber's Wirtschaft und Gesellschaft is in effiect an history of the world on analytical rather than narrative principles; or rather: it is a handbook of idealtypes to make it easier for historians to write history in a world-historical perspective. The aim is ultimately to understand and explain particularities (sometimes vast ones: the specific characteristics of a whole cultural system). One cannot do that without first establishing similarities. Developing Weber's ideal types of sacred law, I have tried to show how much medieval Canon law shared with other systems of sacred law, and then to bring out its distinctiveness. The explanation of these differences must be left for another occasion. 



\title{
Medieval Societies and Historiography
}

\author{
Von
}

\author{
Sverre Bagge
}

In the following, I shall compare four historiographical traditions: (1) Byzantium, (2) feudal Europe, represented by Germany, (3) the northern periphery, represented by Norway and Iceland, and (4) Italy in the later Middle Ages and the Renaissance. The advantage of such a comparison is that all four traditions are derived from or at least influenced by, ancient historiography, combined with Christianity, while at the same time the difference between the respective societies is sufficient to pose the question about the relative importance of intellectual traditions versus social conditions as the explanation of a particular historiographical tradition.

The answer, of course, largely depends on the aspect of historiography one wants to focus on. My focus is on ,making sense of history', more specifically on the relationship between society and the individual. What is history really about? Is it just an account of individuals and their achievements, or is there some transpersonal structure or institution that serves to give such acts meaning? In order to answer this question, we cannot confine ourselves to key concepts or explicit statements in the texts; we have to deal with the narrative, not from a stylistic or literary point of view but as evidence of a particular mode of thought. William Brandt's analysis of medieval historical thought ${ }^{1}$, long neglected but now the subject of increasing interest, is an important contribution to this field of research. Brandt distinguishes between a secular and a clerical "mode of thought", and finds little understanding of the actors' aims and intentions and little connection between the various events narrated in either of them. The aim of the secular or aristocratic author is "to celebrate, not to explain“. The clerical author, who represents a diffierent mental outlook from that of his aristocratic counterpart, does try to explain but hardly in a way that makes sense of the events from a political and military point of view. To a medieval clerical chronicler, the world is essentially static, and historical events are temporary changes in the normal order of things. The explanation of these changes is usually sought in particular qualities in the persons or objects that bring them about and therefore tends to be tautological. ${ }^{2}$ In Brandt's opinion, both the aristocratic

1 William Brandt, The Shape of Medieval History. New Haven 1966.

2 Brandt, The Shape (cited in note 1), $33 \mathrm{ff} ., 59 \mathrm{ff}$. 
and the clerical way of writing history are thus evidence of a „mode of perception“" totally different from our own.

Brandt's understanding of medieval narrative receives some support from recent studies in renaissance historiography. According to Donald Wilcox, the great diffierence between medieval and renaissance historiography is the renaissance historians' ability to combine vivid narrative of concrete episodes with overall meaning or "plot“. In the Middle Ages, both these qualities are to be found, but they are not combined. ${ }^{3}$ Mark Phillips applies the same understanding to the development of historical narrative from Villani via Bruni to Machiavelli and Guicciardini ${ }^{4}$, in which he characterises the diffierence between the two epochs as one between ,representation“ and „argument", a distinction inspired by Erich Auerbach's characterisation of Gregory of Tours as opposed to classical, Roman narrative. Gregory's Latin is „barbarian“, his narrative episodic and, in addition, sometimes so obscure as to be incomprehensible, and it is difficult to make any sense of his chaos of detail. Observation of small, concrete details, often told in a vivid way, despite the barbarism, has replaced the overall view of great military and political events in Roman historiography. Thus, Gregory not only represents the ruin of classical culture but also the beginning of a new one. ${ }^{6}$ In a similar way, Phillips describes renaissance historiography as based on argument, i.e. instead of the vivid chaos of individual episodes in the Middle Ages - the representation -, we find a narrative organized in the Roman way, focused on the most important matters and presenting the events from one, single perspective.

Medieval historiography shows great variety, and the characterisations referred to above may easily be dismissed as exaggerated or superficial. Nevertheless, there is something to be said in favour of Wilcox's and Phillips' view of the contrast between medieval and renaissance historiography; at least, the distinction between representation and argument is useful as a starting-point. As for Brandt, he may with some justice be accused of falling in the same trap as the critical scholars of the nineteenth and early twentieth century, regarding medieval accounts of politics as naive because they do not correspond to modern ideas of how politics is conducted. Brandt shows fairly well that medieval historiography does not make sense according to our modern criteria, but is less concerned with how it made sense according to

3 Donald Wilcox, The Sense of Time in Western Historical Narratives from Eusebius to Machiavelli, in: Classical Rhetoric and Medieval Historiography. Ed. Ernst Breisach. Kalamazoo 1985, 167-235.

4 Mark Phillips, Machiavelli, Guicciardini, and the Tradition of Vernacular Historiography in Florence, in: AHR 84, 1979, 86-105; id., Representation and Argument in Florentine Historiography, in: StorStor 10, 1986, 48-63.

5 Erich Auerbach, Mimesis. Dargestellte Wirklichkeit in der abendländischen Literatur. Bern 1946, 78-94.

6 To what extent this represents an adequate understanding of Gregory, is doubtful but shall not be discussed here. For a recent attempt to trace Gregory's understanding of history and the ultimate aims of his narrative, see Martin Heinzelmann, Gregor von Tours (538-594). „Zehn Bücher Geschichte“. Historiographie und Gesellschaftkonzeption im 6. Jahrhundert. Darmstadt 1994. As shall be illustrated later, e.g. in the discussion about Thietmar of Merseburg, ,episodic' or ,chaotic ${ }^{6}$ narratives are rarely so devoid of coherence and „argument" as they immediately appear. „Representation“ and „argument“ will therefore rarely appear in pure form in practice. 
medieval criteria. The value of his work therefore lies more in its general approach than its conclusions. Moreover, although some medieval chroniclers may correspond to Brandt's description - and to Auerbach's of Gregory of Tours' „barbarism“ - they are hardly representative of the period as a whole. In particular, it would seem appropriate to look for changes in the writing of history in the high Middle Ages.

In order to compare the four historiographical traditions mentioned above, I shall take as my starting-point an example of a parallel situation within each of them, i.e. a change of regime. I shall start with the most classisistic as well as the most distant from the rest of Europe, i.e. the Byzantine. The tradition must also be considered the oldest, although the work to be discussed, Anna Komnene's Alexiad ${ }^{7}$, written in the first half of the twelfth century, is later than some of the Western works I shall discuss, as well as belonging to a politically more ,advanced' society.

\section{Politics in the Byzantine Empire: Anna Komnene}

The first three books of the Alexiad may be termed biography in the sense that they deal with Alexios rather than with the history of the Roman Empire. Anna starts with three stories from Alexios's youth, before his accession to the throne, which show him distinguishing himself in the service of the Empire; they are the first three of his „labours of Hercules“. But they are not integrated into the history of the Empire; Anna only gives the names of the emperors under whom they took place (Michael VII Doukas and Nikephoros Botaneiates), adding some general references to the precarious state of the Empire. After these stories, however, Anna directly turns to imperial history, first describing the state of the Empire metaphorically as illness in the body, then introducing the villain of the first part of her story, Robert Guiscard, Alexios's main enemy during his first years as emperor. Thus, she gives a double background to her main story of Alexios's reign; she deals both with Alexios's youth and the crisis in the Empire, but does not immediately connect the two.

The second book establishes the connection between Alexios and the Empire, dealing with his coup d'etat. The story is told in considerable detail and is one of the masterpieces of the Alexiad. Clearly, Anna's account is favourable to Alexios, and she is at pains to show that he behaves justly and honourably. She does not, however, exploit the possibility the story of Robert Guiscard has given her to show that Alexios acted according to the interests of the Empire. Instead, she defends his coup by presenting it as the only way for Alexios and his brother Isaak to escape the intrigues of the Emperor's two favourites Borilos and Germanos who plot to have the two brothers blinded. This justification may be an indication of the limits to Anna's ,imperial perspective', but also reflects the fact that a coup d'état in Byzantium was not regarded in a very negative way; it was actually a fairly normal way of acce-

7 Anne Comnène, Alexiade. Ed. \& transl. Bernard Leib. Vol. 1-4. Paris 1967-76 (references are to this edition, book, chapter and sub-chapter); English translation: The Alexiad of Anna Comnena. Transl. Edgar Robert Ashton Sewter. Harmondsworth 1987. German translation, with comments: Anna Komnene, Alexias. Transl. Diether Reinsch. Cologne 1996. 
ding to the throne. ${ }^{8}$ There were no very definite rules about how to succeed to the imperial office in Byzantium, in contrast to the prestige, power, and elaborate ceremonial surrounding the office itself. The attitude to the imperial power seems almost Hobbesian; the holder of the office was entitled to absolute obedience from his subjects, until he was deposed and replaced by someone else who had the same rights. It was important for Anna to point out that the Komnenoi brothers had sufficient reasons for behaving as they did, as they had previously been favoured by the Emperor Nikephoros Botaneiates, but she needed not go out of her way to justify them.

As for Anna's attempt to present the Komnenoi brothers as acting in self-defense, some objections may be raised against her story. She repeatedly asserts that the "slaves" plotted against them and tried to blind them without any real attempt being made. Alexios is even able to free himself from their charges before the Emperor at the very moment when he is assembling troops to stage his coup. ${ }^{9}$ From a political point of view it is not always easy to follow the moves. There are digressions, and not all details are equally relevant. Nevertheless, it is a brilliant story, full of concrete and vivid detail, showing how Alexios and his brother manage to build up a network of allies inside and outside Constantinopel, gather an army, and finally force their entry into the capital and depose Nikephoros.

One of the most memorable scenes in this story is when the old emperor has been persuaded to abdicate after Alexios's troops have entered the city. Having given up his imperial dignity, he hurries away from the palace to the cathedral Hagia Sophia, but forgets that he is still wearing the imperial robes: Borilos, turning on him and touching the embroidered work fastened round his arm with pearls, wrenched it off, sarcastically remarking in his mocking way, ,This sort of thing really fits us now.' Botaneiates entered the great church of God, Santa Sophia, and there for a time he remained. ${ }^{10}$

Botaneiates is taken captive by Alexios's men and is forced to become a monk - the better of the alternative fates facing a deposed emperor; the worse was to be blinding. After a short passage on the shifts of fortune, Anna gives her last glimpse of him. Being asked by one of his friends if he finds the change tolerable, he answers: Abstinence from meat is the only thing that worries me; the other matters cause little concern. ${ }^{11}$

This remark may almost be compared to Shakespeare's famous comic scenes in the midst of his tragedies. It not only serves as a relaxation, however, but sets the whole story of the coup in a kind of ironic perspective: such efforts, dangers, and bloodshed to depose a man

8 By contrast, Anna has greater problems with the fact that Alexios's troops sacked Constantinopel after entering the city, and tells that Alexios took upon him a strict penance to atone for this sin; Alexiade (cited in note 7), III.5.1. Apparently, the rule of the game was to wait for the emperor's surroundings to come to an arrangement with the pretender or, at least, to keep the soldiers in stricter control after taking the city.

9 Ibid. II.4.3.

10 Ibid. II.12.6: ò ठÉ Bopĩ

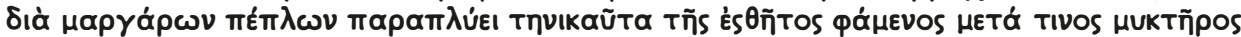

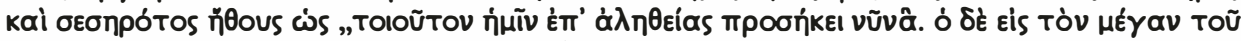

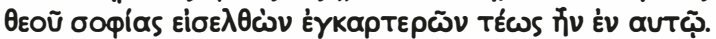

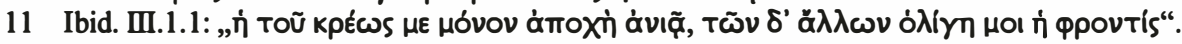


whose only reason for keeping to the imperial throne was the opportunity to eat meat! The irony lies not only in these final words but in Anna's whole portrait of Botaneiates, who is described with a combination of pity and contempt. She recognizes his strength and ability in his youth, and she does not hold him responsible for the persecution of the Komnenoi. But towards the end of his life he is a pathetic figure, manipulated by the evil „slaves“, weak, and indecisive. In this way he also becomes a symbol of the disease in the imperial body which Anna has already described, and a striking contrast to the vigorous young man who now ascends to the imperial throne.

Anna gives a realistic and shrewd analysis of the various political moves that finally secured the Komnenoi's and Alexios's success. Anna clearly knows the Byzantine court and administration from within. She is able to describe it in a convincing manner and show why Alexios succeeded. Personal connections are essential. Alexios belongs to a distinguished family, whose members have won military glory, a connection that apparently explains his own military promotion at an early age. But the Komnenoi have no great influence in the capital. Here Alexios's great advantage is his connection with the Doukas family through his marriage to Irene. Most of the prominent men he persuades to join him are in one way or other connected to this family. The Doukas would also seem to be natural allies for a pretender trying to depose Botaneiates, as he had himself deposed a Doukas emperor, a fact Anna points out and her readers were no doubt well aware of.

However, family ties are not enough. Most of the leading men in Constantinople were in some way or other related by blood or marriage, which did not prevent them from fighting or plotting against one another. The crucial test for a pretender is how he is able to exploit his connections. In her detailed narrative Anna shows the Komnenoi's, and particularly Alexios's, ability in this respect, describing how the brothers secured the cooperation of various prominent members of the bureaucracy and the aristocracy in the capital. Alexios's most important qualities are his generosity and his sense of psychology. Anna devotes a long passage to the former quality, using it to explain concrete cases of people joining him. Ultimately, generosity is the quality in a leader that corresponds to a rational choice view of political allegiance and leadership: People follow the leader who will give them most in return. Anna shows convincingly that this „law" applies in Byzantine society. Generosity is also a quality that can be said to have a more general appeal: the generous man is admired and followed, not only because such behaviour pays off, but because generosity is a noble quality that excites admiration. Anna implies that Alexios scores on both points. She gives a fairly detailed and sober account of the concrete promises he has to give in order to gain adherents. She refers to several direct promises of promotion to high office in the imperial bureaucracy, promises that entailed considerable expense once they had to be fulfilled. Nor were the promises always easily compatible. Thus, in order to achieve an agreement with his rival Melissenos, who was besieging Constantinople with a rebellious army at the same time, he has to promise him the rank of Caesar - the second to the emperor in the Byzantine status system. On the other hand, he had promised his brother Isaak the rank next to himself. 
Alexios solves the dilemma by inventing a new title, sebastokrator, for Isaak. ${ }^{12}$ However, promises have to be fulfilled at high costs, in prestige as well as in money, so it is important not to make more of them than needed to achieve one's aim. Consequently, both the power and resources of the person in question and the time of his ,conversion' is important. The latter point is illustrated by the case of Botaneiates, who starts negotiations too late, when Alexios's victory is secured and Botaneiates has nothing to offier.

Alexios's psychological skill is repeatedly stressed by Anna throughout the Alexiad. Not all the examples she adduces are equally convincing; Alexios is deceived several times. In many cases, however, she is able to show by concrete examples that Alexios's skill in this field is more than a general assertion. One of the best in the story about the coup is the dialogue with the Empress Maria Doukas, a Georgian woman, who had been married to Michael Doukas and after his deposition (1078) to Nikephoros. The Komnenoi brothers knew her in advance, as Isaak was married to her cousin. The decisive moment, however, comes when the two parties discover that they have common interests. Nikephoros, being old and childless and without hope of an issue, decides to appoint a relative as his successor, to the detriment of the Empress' own son, Constantine. The Empress is deeply worried by the rumours of this decision, not only because of the frustration of her plan to have her son made emperor but also out of fear for his safety. The Komnenoi brothers understand from the Empress' mood and behaviour that something grieves her, despite the fact that she has revealed her sorrow to no one. They approach her, asking what is the matter. She refuses to tell, pointing out that the fact that she lives in a foreign country, surrounded by strangers, that she has many worries and expect more to come, is sufficient to make her sorrowful. The brothers listen in deep silence and then leave. However, they return the next day, and, having already guessed the truth, urge her to confide in them. Anna explicitly points to their skill in divining people's secret thoughts from brief remarks - and in hiding their own thoughts and intentions. The brothers succeed and enter an agreement with the Empress. ${ }^{13}$

As appears even more clearly from Michael Psellos's Chronographia, hiding one's own motives and divining those of others were essential to success, often also to survive, in Byzantine courtly society. Without such qualities, according to Anna - and here there is every reason to trust her opinion - Alexios would never have been able to ascend the throne.

Thus, Anna gives a perfectly plausible and psychologically convincing account of intrigues and political manoeuvres in contemporary Byzantium. Her story as a whole, which consists of individual episodes, shows in detail how the brothers succeeded. The individual dramatic episodes gain their real meaning by being links in a chain of events leading to Alexios's installment on the imperial throne. In her account of Alexios's coup, Anna consistently writes political history.

Given the fact that Alexios's coup takes place within a highly organised, bureaucratic state, its ,individualistic ${ }^{6}$ character is surprising. The moral defence for Alexios's course of action is the danger to himself, not the deep crisis in the Empire. In the account of how he

12 Ibid. III.4.1-3.

13 Ibid. II.2.1-3. 
persuades people to follow him, there is no mention of the need for a new leader. Having established Alexios on the throne, however, Anna turns to the political situation, systematically describing the problems of the Empire: an empty treasury and enemies in the East as well as in the West. The following account of Alexios's reign as a whole is largely focused on how he solves these problems. First, he defends the Empire against Robert Guiscard (Books III-VI, 1081-1085). Then he spends more than ten years mainly occupied by the threats to the northern borders from Hungarians and various Slavonic peoples (Books VI-X, 1085-1096). Finally, he turns his attention to the East, but then immediately afterwards has to deal with the crusaders. The relationship to the crusaders and the Turks forms the main content of the rest of the work (Books X-XV, 1097-1118). Here two external successes receive particularly great attention, the peace treaties with Bohemund in 1108 and with the Turkish sultan in 1116. Thus, the Alexiad as a whole deals with Alexios's restoration of the Empire. Towards the end of her work, Anna points to his success in carrying out this task, although her celebration is mixed with pessimism because of what she regards as the decline caused by her hated brother John II's reign (1118-1143). ${ }^{14}$

\section{Politics in a Pre-State Society: Thietmar of Merseburg and Snorri Sturluson}

While Anna Komnene's account of the coup represents a curious mixture of clientelism and politics in a highly developed bureaucratic system, the former dominates in the two examples to be discussed in the following, Thietmar of Merseburg's account of the election of Henry II in 1002 and Snorri Sturluson's account in Heimskringla of King Olav Haraldsson's (1015-30) conquest of Norway in $1015 .^{15}$

Thietmar's story of Henry's way to the throne ${ }^{16}$ has the form of a detailed narrative, apparently listing everything of any importance that happened in Germany between the death of Otto III on 24 January $1002^{17}$ and the surrender of Hermann, the last of Henry's rivals, on 1 October the same year. ${ }^{18}$ Thietmar's narrative may be compared to the numerous narrative sequences found in medieval art, in the early Middle Ages in the form of book illustrations or reliefs on reliquaries or other valuable objects, later on in the form of glass paintings: A

14 The reason for this hatred was that Anna wanted her husband, Nikephoros Bryennios, to succeed her father instead of John; cf. Alexiade (cited in note 7), Introduction, xviii-xx; Georgina Buckler, Anna Comnena. Oxford 1968, 40-46. In contrast to Anna's view, John's reign is regarded by contemporaries as well as by modern historians as the peak of the Komnenoi revival.

15 For the following, see also Sverre Bagge, Icelandic Uniqueness or a Common European Culture? The Case of the Kings' Sagas, in: Scandinavian Studies 69, 1997, 418-442.

16 Thietmari Merseburgensis episcopi Chronicon. Hrsg. Robert Holtzmann. (MGH SS rer. Germ. [9].) Berlin 1955, IV.50-56, V.1-22. Thietmar (975-1018) was bishop of Merseburg from 1009 and composed his chronicle from then and until his death. It is a combination of a diocesan chronicle and a history of the German rulers from Henry I (919-936) until Henry II (1002-1024). I treat Thietmar as well as other German historical writers in greater detail in the forthcoming book: Sverre Bagge, Kings, Politics, and the Right Order of the World in German Historiography 950-1150.

17 Chronicon (cited in note 16), IV. 49.

18 Ibid. V. 22. 
large number of sequences follow one another, all of them being the same size and presenting a static picture. The parts seem to be more important than the whole. This is clearly representation rather than argument. On the other hand, the narrative is not particularly vivid. We get concrete information about a number of details, but we hardly get emotionally involved.

Two features are particularly noteworthy in Thietmar's narrative. First, the story of the accession is broken off by a long digression after Thietmar's account of Otto's funeral. ${ }^{19}$ Admittedly, Thietmar makes it clear that he breaks off the story and that the beginning of Book V is a direct continuation of where he left off in Book IV. Second, there is no general connection between the length and detail of the individual episodes and their importance for the question of succession. This is particularly clear in the account of the murder of one of the two rival pretenders, Ekkehard. Thietmar insists that there was no connection between this murder and the struggle for the succession, which is relevant enough, given the fact that Henry is Thietmar's hero and that Thietmar wants to clear him of any suspicion of being guilty of the crime. However, he does not stop there, but gives a detailed account of the murder itself, as well as the ensuing conflicts between Ekkehard's family and the murderers. ${ }^{20}$

Thus, the immediate impression of Thietmar's account is that a story' of the royal succession emerges almost accidentally, so that it takes a modern historian to arrange Thietmar's mass of detail in a way that makes clear how and why Henry triumphed over his rivals. This impression is not quite correct. Thietmar does indicate that he wants to tell a continuous story, even pointing to the main explanation of Henry's success, God's intervention. God wanted Henry to rule, in particular because He had elected him as His instrument in restoring the diocese of Merseburg - Thietmar's own - which, as the result of a terrible crime, had been abolished in the reign of Otto II (973-983). However, there are few direct references to God's intervention in Thietmar's concrete narrative. By contrast, if we read the story carefully, Thietmar emerges as a fine observer of contemporary politics, showing clearly how Henry moves systematically to secure the throne for himself. Henry gets hold of the royal insignia immediately after Otto's death; he works systematically on the princes and magnates by giving gifts and promises to gain their support, and instead of directly attacking his rivals, he moves around in the country in order to receive acclamation at as many local assemblies as possible. This strategy works; after Ekkehard's death, his other rival, Hermann, finds himself isolated and sees no other option than to seek reconciliation with Henry, which he gets, on quite favourable terms.

Snorri's story of Olav Haraldsson's succession ${ }^{21}$ is also episodic and is also based on an idea of divine intervention. On his way to Jerusalem, Olav has a dream, telling him to return

19 Ibid. IV. 55-75.

20 Ibid. V. 3-7.

21 Snorri Sturluson, Heimskringla. Saga ins helga Óláfs konungs. Ed. Finnur Jónsson. 2 vol. Copenhagen 1893-1900, ch. 29-53. For the following, see also Sverre Bagge, Society and Politics in Snorri Sturluson's Heimskringla. Berkeley/Los Angeles/Oxford 1991, 90 ff. Snorri Sturluson (1179-1241) is considered the greatest Old Norse historian. He was one of the most powerful Icelandic magnates and played a prominent part in the struggles for power in Iceland during the first half of the thirteenth 
to Norway to become king there for ever. ${ }^{22}$ Olav breaks off his journey but does not go directly to Norway; he fights for some time in France and then in England, supporting the sons of King Ethelred against King Cnut. Seeing that their cause is hopeless, he finally leaves for Norway which at the time is ruled by members of another dynasty, the earls Svein and his nephew Håkon, under Danish supremacy. The following account of Olav's conquest of Norway is also episodic. However, instead of Thietmar's series of small ,vignettes', Snorri concentrates his narrative in a few great ,scenes' which he describes in vivid detail: (1) the ambush for Earl Håkon who is taken captive and forced to give up his claim on Norway, (2) Olav's meeting with his stepfather Sigurd Syr, gaining him the support of the petty kings of Eastern Norway, (3) the ,excursion' northwards to Trøndelag, (4) the battle of Nesjar in the southeast, where Olav defeats his second adversary, Earl Svein, (5) the final acceptance of Olav as king of Norway.

These great ,scenes' are all clearly ,representation', making the persons and their actions vivid and concrete. Details about dress and food are inserted, partly for vividness, partly to increase the drama by retardation, and speeches and dialogues are used for maximum effect: The young Earl is led before Olav, and the king touches his hair and praises his beauty, while hinting that he may have reached a point when he will neither have defeat nor victory any more. The speeches and dialogues between Olav, his mother, and his stepfather Sigurd bring out the contrast between the two former's ruthless ambition and willingness to die rather than give in, and the careful and prudent Sigurd. The deliberation scene between the petty kings of the East places the young pretender's claim in a wider political perspective: which is the more advantageous from point of view of the petty kings, being subordinated to a distant king who does not interfere much, or supporting the one who is likely to win and sharing the fruits of his victory?

However, these ,scenes' also form part of a larger story, showing how Olav gains hold of Norway step by step. This story is brought in perspective by Snorri's presentation of the relative strength of Olav and his adversaries: on the one hand Olav with his two ships, admittedly in the possession of plenty of gold, on the other the tight network between the earls and the greatest magnates of the country who are enormously wealthy and powerful. ${ }^{23}$ This is a struggle between David and Goliath, and Snorri may well have intended his account of Olav's victory to demonstrate that Olav's victory, like David's, was the result of God's support. Nevertheless, his story is also intended to explain in purely human and political terms how Olav won. Capturing Håkon eliminates an important rival while at the same time demonstrating Olav's luck, which proves essential in gaining him the support of the kings, magnates, and people in the East. This support in turn enables him to defeat his enemies at Nes jar. The expedition to Trøndelag in between is less successful and rather serves as a kind of first skirmish between Olav and his enemies.

In this way, Snorri's use of representation to some extent serves the purpose of argument. Snorri writes political history, showing how Olav, through a combination of luck and skill,

century. In Heimskringla he treats the history of the Norwegian dynasty from its mythical ancestor, the god Odin, until 1177.

22 Heimskringla (cited in note 21), ch. 18.

23 Ibid. ch. 21-23, cf. ch. 46. 
wins a sufficient number of victories to receive the support of the majority of the population of Norway. The amount of detail and vividness of the individual episodes describing this process is largely determined by their relative importance for the final result.

The similarity between the political systems described by Thietmar and Snorri is striking. There are no firm rules of succession, no central assembly with the right to decide, and no very firm loyalties. Most powerful men support the candidate most likely to further their interests, i.e. the one who is (1) generous, and (2) likely to win. Consequently, „nothing succeeds like success", and when Henry and Olav have gained a significant advantage over their rivals, most men rally to their support.

This similarity is confirmed by other passages of the two works we have compared, as well as by other historical works within the two traditions. Both traditions belong to a period prior to the introduction of the fully developed ideology of Christian kingship. This is quite clear in the case of Iceland which was without a king until 1262, whereas royal unction was not firmly established in Norway until 1247. With some exceptions, the idea of Christian kingship is not very prominent in the kings' sagas. ${ }^{24}$ Ottonian Germany had behind it a long tradition of Christian monarchy, and royal unction had been firmly established since the accession of Otto I in 936. Nevertheless, the idea of the king as the Lord's Anointed, holding an office on God's behalf, has only partially penetrated Thietmar's work and is of slight importance in his predecessor Widukind. Thus, Widukind describes Otto the Great as an enormous, lion-like man whose strength, warlike qualities, and sharp, piercing eyes terrorise his enemies, whereas his kindness and generosity to his friends have no limits. ${ }^{25}$ This is the Germanic chieftain and charismatic warlord, not the Christian rex iustus, and parallels are easily to be found in the sagas. The description of the „game of politics“ between these warlords also resemble that of the sagas. In Widukind and even more so in Thietmar, there is an awareness that the king has the just cause in internal conflicts with rivals and aristocratic rebels. Nevertheless, these latter are noble and respectable men who fight for their legitimate interests, in the same way as the king's rivals in the sagas.

Thus, in both cases we have to do with the idea of politics as a competition between individual actors who fight for concrete, personal interests and who attract friends and allies through generosity and a charismatic personality. In both cases we also have to do with a community transcending these individual interests, expressed in the contrast between internal and external struggles. In Widukind, the Saxons stand united against the barbarian Slavs, fighting them ruthlessly. ${ }^{26}$ The difference from the neighbouring peoples, the Danes and the Swedes, is less in the sagas, but there are many expressions of Norwegian superiority over

24 Sverre Bagge, From Gang Leader to the Lord's Anointed. Odense 1996, 52-85, 94-106, 147-160.

25 Widukindi Monachi Corbeiensis Rerum gestarum Saxonicarum libri tres. Hrsg. Paul Hirsch. (MGH SS rer. Germ. [60].) Hannover 1935, II. 36, 96 f. Widukind's work was most probably composed in 967/68; cf. Helmut Beumann, Widukind von Korvey. Untersuchungen zur Geschichtsschreibung und Ideengeschichte des 10. Jahrhunderts. Weimar 1950, 178-205.

26 Beumann, Widukind (cited in note 25), 205-207; Bagge, Kings, Politics (cited in note 16). 
them, although the Norwegians do not always present a united front against these external enemies. ${ }^{27}$

As for the narrative form of the two stories, both are heirs to Gregory of Tours' „,barbarisation" of Roman historiography. They have an episodic structure, they are more inclined towards representation than argument, and, closely related to these features, they lack an impersonal protagonist. On the other hand, Snorri's story is clearly more successful as representation, containing vivid story-telling and concrete and memorable ,scenes ${ }^{6}$. It is also more successful as argument; the representation serving to emphasize the main stages in the political ,plot' about Olav's rise to power. Thus, although the understanding of the political mechanisms is largely the same in Thietmar's and Snorri's stories, they are made far more explicit in Snorri's account.

The vivid narrative and the ability to tell a good story is common to most writers of the kings' sagas as well as the sagas of the Icelanders. There is greater difference as to what extent they are also able to integrate the episodes in longer narrative sequences. It is not difficult to find examples of episodic or even - from a modern point of view - chaotic narrative in the sagas. Nevertheless, the most mature and elaborate of them, such as Heimskringla, by far surpass the early medieval German historiography in this respect. Thus, the integrated narrative of Olav's life and reign in Heimskringla is not confined to stories like the one we have just examined; the whole saga is constructed as a plot, showing Olav's increasing power during the first ten years of his reign and its decline during the last five. Furthermore, Olav's fall is prepared by a number of episodes, reaching back to his successful years and showing how he ran into conflict with the most important magnates of the country one by one, until he faced the overwhelming strength of his enemies at Stiklestad and was killed. ${ }^{28}$

However, the integration stops at a certain level. Tactics is more important than strategy in the sagas. The actors have no great political or ideological project they want to achieve; they fight for their own power within a fairly static system, not in order to bring about a new constitution or a new social order or bring a new class or social group into power. Consequently, the sagas have no impersonal protagonist; the largest unit organising an integrated story is the life or reign of an individual king. Heimskringla is not the history of the Norwegian nation and even less of the Norwegian ,state'; it is the history of the Norwegian dynasty, in which the connection between the individual reigns depends on the personal relationship between the rulers and their men. Joint rule or struggles between pretenders may create a continuous story from one rule to the other, but normally, the reign of a king is a self-contained unit which may even be divided into a number of fairly separate stories.

In a similar way, the episodes from Thietmar are fairly representative of Ottonian historiography. Generally, Thietmar's chronicle is not only episodic; it is full of the most fantastic stories of dreams, miracles, and portents, and in some cases, as the account of Henry I's reign (919-936), the politics is almost drowned in devotion and piety. On the other hand, all

27 Bagge, Society and Politics (cited in note 21), $100 \mathrm{ff}$.; id., Nationalism in Norway in the Middle Ages, in: ScanJH 20, 1995, 1-18.

28 Bagge, Society and Politics (cited in note 21), 34-43. 
these references to the supernatural do not prevent Thietmar from giving a lot of information on contemporary politics, and his account of the rest of Henry's reign gives similar information on the Ottonian political system as the story of his succession to the throne. ${ }^{29}$ Widukind's work has greater thematic unity, dealing respectively with the early history of the Saxon people (first half of Book I) and its two great rulers, Henry I (second half of Book I) and Otto I (Books II and III). Digressions and religious comments are few, but the structure is basically episodic. Some episodes are vivid and dramatic, others more dry, but there are few longer, integrated stories of wars and political confrontations and no attempt to give an integrated account of a whole reign or of the main features of the development of the Saxon political community.

Surely, medieval, and particularly early medieval historiography rarely offers explicit explanations of why people behaved the way they did, and when it does, usually explains the actions in terms of ,private' and, individual' motives: anger, pride, hatred, or love. The reason is hardly that the writers were primitive and did not understand what went on around them, but (1) that historiography was exemplary and that the ,quality' of individual acts was consequently more important than their motives and consequences, and (2) that contemporary politicians were actually governed largely by ,private ${ }^{6}$ or ,individual ${ }^{6}$ motives. In this way, historical texts can form an important corrective to the conclusion ,constitutional historians" have often drawn on the basis of charters and documentary evidence of an impersonal, long-term, and bureaucratic behaviour in the Middle Ages, similar to more recent periods.

The account of political manoeuvring in the western tradition, represented by Thietmar and Snorri, resembles the way in which Anna Komnene describes Alexios's coup. In both traditions, the emphasis is on personal relationships, and the throne is a ,prize the pretenders seek to gain by building up alliances and outmanoeuvring their rivals. By contrast, the political community and its interests play a subordinate role. Admittedly, Byzantium had a tradition of stateness' and bureaucracy going back to late Antiquity. ,Bureaucracy' should not, however, be understood in a Weberian sense; it was rather a kind of clientelism masked as a hierarchy of officers in the service of the state. ${ }^{30}$ Byzantinists have also noted an increasing emphasis on individuals rather than the state in Byzantine historiography ${ }^{31}$ which is also prominent in Anna's account of Alexios's coup.

29 Chronicon (cited in note 16), V-VIII. For early medieval German politics, see Gerd Althoff, Otto III. Darmstadt 1996; id., Spielregeln der Politik im Mittelalter. Darmstadt 1997; Bagge, Kings, Politics (cited in note 16).

30 Hans-Georg Beck, Ideen und Realităten in Byzanz. Gesammelte Aufsătze. (Variorum Collected Studies, vol. 13.) London 1978, no. XI, 1-32; id., Das Byzantinische Jahrtausend. München 1978, 33-86.

31 Jakov Ljubarskij, „Writers' Intrusion“ in Early Byzantine Literature, in: XVIIIth International Congress of Byzantine Studies. Moscow 1991, 433-456; id., Man in Byzantine Historiography from John Malalas to Michael Psellos, in: Homo Byzantinus. Papers in honor of Alexander Kazhdan. Ed. Anthony Cutler/Simon Franklin (Dumbarton Oaks Papers 47, 1992.), 177-186; Roger Scott, The Classical Tradition in Byzantine Historiography, in: Byzantium and the Classical Tradition. Ed. Margaret Mullett/Roger Scott. Birmingham 1981, 61-74. 
If we look at our three stories within the overall context of the works to which they belong, the difference becomes greater. What strikes an observer familiar with Western historiography when reading Anna Komnene, is her concern with the state or the Empire. When eventually having brought Alexios on the throne, Anna continues by describing the deep crisis in the Empire and how step by step Alexios managed to overcome it. For all its personal emphasis, the Alexiad is certainly a portrait of a great statesman, not of a chieftain fighting for individual glory. The idea of a crisis in the Empire is strong in Anna Komnene, and she clearly regards Alexios's reign as an - at least partly - successful attempt to solve it. Consequently, she must also have regarded the coup in this perspective, despite her failure to mention this aspect directly in her account of it.

Ideas of state, empire, or political community are far weaker in Thietmar and Snorri. Neither Henry II nor Olav Haraldsson are saviours of the realm in a period of crisis, nor do Thietmar and Snorri regard internal struggles during an interregnum as a disaster. Admittedly, we do find the idea of the ruler being responsible for a larger community in both works, but this community is less institutionalised than in Anna, and the difference between the community as a whole and its individual members is consequently less.

On the other hand, the idea of God's election of the ruler is stronger in Thietmar and Snorri than in Anna. Anna occasionally refers to God's protection of Alexios, but not to God's election of him in connection with his rise to power. By contrast, Thietmar and Snorri explicitly refer to God's election of respectively Henry and Olav. The idea of kings and emperors as God's elected was of course widespread in Byzantium as well as in the West throughout the Middle Ages. In both areas it could be combined with ,rational choice' politics and clientelism. Generally, however, this latter aspect was stronger in connection with the actual succession in Byzantium. Dynastic continuity had greater importance in the West; firm rules for the succession were eventually laid down, so that struggles for the throne became rarer. In contrast to Byzantium, it became the exception that a king was deposed or killed by his rivals or subjects. The two examples discussed above both took place before this development. Thietmar's account clearly shows that there was no fixed procedure for royal elections, apart from the political reality that the king must have the support of a majority of the great and influential men in the realm. Nor was kingship hereditary in any direct sense, although direct descendants of the previous king in practice had a strong claim. ${ }^{32}$ The reason for the open situation in 1002 was that the previous king, Otto III, had suddenly died without issue. Henry II, who succeeded him, was his second cousin. In early eleventh

32 There is an extensive literature on German royal elections. Some important contributions are collected in Eduard Hlawitschka, Königswahl und Thronfolge in ottonisch-frühdeutscher Zeit. Darmstadt 1971. See also Ulrich Reuling, Die Kur in Deutschland und Frankreich. Untersuchungen zur Entwicklung des rechtsförmlichen Wahlaktes bei der Königserhebung im 11. und 12. Jahrhundert. (VMPIG, Bd. 64.) Göttingen 1979; id., Zur Entwicklung der Wahlformen bei den hochmittelalterlichen Königserhebungen im Reich, in: Wahlen und Wăhlen im Mittelalter. Hrsg. v. Reinhard Schneider/Harald Zimmermann. (VuF, Bd. 37.) Sigmaringen 1990, 227-270. 
century Norway there was apparently no real royal dynasty at all ${ }^{33}$, although Snorri, writing under the influence of the thirteenth century ideology of dynastic continuity, clearly believed that there was, without suppressing the fact that there were also frequent struggles between pretenders.

Thietmar's account, however, gives evidence of an important difference from Byzantine conditions, a difference that became greater during the following period: having first ascended to the throne, the king has a fairly protected position, as the Lord's Anointed. He can be opposed, even through armed rebellion, but he cannot be replaced as easily as the Byzantine emperor. There is no Hobbesian situation, neither in the sense that the ruler is absolute, nor in the sense that his legitimacy depends on his actual power. These two aspects are clearly connected. The king's limited power and the possibility of opposition reduce the need for deposing him. The idea of the king ruling on God's behalf and under his protection is therefore combined with a relative weak royal power.

This idea is also, in what to us seems a curious way, combined with a clientelistic attitude. God resembles a great patron, favouring his earthly clients; $\mathrm{He}$ is not the representative of a strictly objective justice known from later ages. It is therefore no coincidence that Thietmar combines the idea of God's election of Henry with an account of his tactical manoeuvring on his way to the throne. In Snorri, the idea of God as the king's protector is generally not strongly present; Olav, the national saint and the eternal king of Norway, forms an exception as the one who is chosen to complete the Christianisation of the country. By contrast, Sverris saga which is slightly earlier than Heimskringla, resembles Thietmar in its strong emphasis on God's ,personal' election of its protagonist, without the corresponding emphasis on the ruler of an organised community. ${ }^{34}$

\section{Transpersonality and the State}

Larger and more impersonal political structures did eventually emerge during the Middle Ages, even in Western Europe, and were reflected or anticipated or both in the historiographical tradition. The main ideological foundation for the idea of the state or the political community in the early Middle Ages was the Christian religion, with its ideas of the king as God's representative on earth; it was not existing bureaucratic structures or classical ideas of res publica or bonum commune, although the latter admittedly did exist already during the Carolingian Empire, together with the religious ideology. In the following period, there was a decline, of which Widukind and Thietmar may serve as examples. A new breakthrough came in mid-eleventh century Germany, with Wipo's Gesta Chuonradi (c. 1040), in which

33 Claus Krag, Norge som odel i Harald Hårfagres ætt. Møte med en gjenganger, in: Historisk tidsskrift [Oslo] 68, 1989, 288-302; Bagge, Society and Politics (cited in note 21), 130.

34 Sverris saga. Ed. Gustav Indrebø. Kristiania (= Oslo) 1920; Bagge, From Gang Leader (cited in note 24), 52-65. 
the hero, Conrad II (1024-1039), is portrayed as the representative of what in Tellenbach's terminology can be termed ,the right order of the world“. 35

Wipo represents a radical shift from his predecessors, from the idea of the king as a charismatic warrior and great patron to the fully developed Christian ideal of the rex iustus which penetrates the whole work. Wipo's initial statement of the crisis as a consequence of the interregnum not only forms the background of Conrad's election but of the whole work. Royal government means a systematic effiort to restore or establish cosmos against the threatening forces of chaos, and Wipo's work deals with how Conrad carried out this task. The challenge facing him is to establish peace, order, and objective justice. Further, there is a close connection in this respect between God and the king, both representing objective justice. When Conrad occasionally fails, Wipo consistently seeks the explanation in some sin the emperor has committed for which he receives his just punishment. In this way, Wipo not only lays the foundation for future defense of the monarchy; he also exposes it to attacks from a potential opposition. His strong combination of God's protection of the king with the idea of objective justice raises the question of what would happen to an unjust king, and his distinction between the royal office and the king's person gives room for playing the two off against each other. Both were to happen during the Investiture Contest.

In the field of historiography, Lampert of Hersfeld's Annales, written around $1080^{36}$, presents the foremost example of the dangers inherent in Wipo's doctrine. Lampert takes over Wipo's general ideology of the king as God's representative on earth and responsible for objective justice. His problem is that, in his opinion, the actual king, Henry IV, does not exercise this function. Consequently, he can no longer be king, but has to be replaced by someone else. However, this ,someone else', in the shape of an individual person, i.e. the anti-king Rudolf of Rheinfelden, only emerges at the very end of Lampert's work, at the meeting in Forchheim in March, 1077. In Lampert's actual narrative, which mainly deals with the dramatic events 1073-1077, „the right order of the world“ is represented by a collective group, the princes and magnates, first of Saxony, then of Germany as a whole. This is not only the result of an emergency situation; in Lampert's view, the res publica is represented, not only by the king, but by the king together with the „people“, i.e. the aristocracy. In this way, Lampert takes a considerable step forward in the direction of an ,impersonal' $^{\text {' }}$ or ,institutional' understanding of the state. From a historiographical point of view, the consequence of this step is that Lampert is able to create a consistent narrative with ,the right order of the world", expressed in these constitutional principles, as the ,protagonist", in which the individual episodes become moves in the great struggle between this order and its adversaries.

35 Wipo, Gesta Chuonradi, in: Wiponis Opera. Hrsg. Harry Bresslau. (MGH SS rer. Germ. [61].) 3th ed., Hannover/Leipzig 1915, 1-62. For the term, see Gerd Tellenbach, Church, State, and Christian Society at the Time of the Investiture Contest. Oxford 1959 [German original 1936], 1 and passim.

36 Lamperti Annales, in Lamperti Monachi Hersfeldensis Opera. Hrsg. Oswald Holder-Egger. (MGH SS rer. Germ. [38].) Hannover/Leipzig 1894, 1-304. 
Otto of Freising's Gesta Frederici ${ }^{37}$, written in 1157-1158, forms a kind of synthesis of the various trends represented by his predecessors. Otto tries to unite the opposing parties of the Investiture Contest, the pope and the emperor as well as the monarchy and the aristocracy. He develops further the ideas of the right order of the world, the king as God's representative on earth, and objective justice, arranging them in a mighty system and placing them within the history of salvation, while in addition using them to show Germany's superiority over its neighbouring countries. Like Lampert, he regards the res publica as being ruled by the king in cooperation with the „people“, but to his great satisfaction, there is no opposition between the two, as Frederick Barbarossa is a thoroughly just and constitutional king. Otto develops further his predecessors' idea of the right order of the world, showing in greater detail how it corresponds to the hierarchical society of contemporary Germany which forms the golden mean between the tyranny of Hungary and the anarchy of Italy.

These ideas form the basis of an integrated historical narrative which differs considerably from Lampert's. Where Lampert's narrative, with some exceptions, is fairly straighforward and ,literal', emphasising causes, effects, and motives, Otto's is largely based on allegory and typology, intended to bring out the moral and eschatological aspect of the events. Thus, Frederick's and his ancestors' justice and wisdom are emphasised through a series of contrasts with the members of the old, Salian dynasty; God's intervention in Frederick's favour is expressed in episodes of a half-miracular character; and the account of the first four years of his reign - the only Otto managed to cover - is built up according to the moral challenges facing him: healing the division between God's two servants on earth, the pope and the emperor, creating peace among the princes of Germany, and introducing the right order of the world in the chaos and anarchy of Italy.

The development of the Old Norse saga literature later in the thirteenth century forms a parallel to eleventh and twelfth century Germany. The trends in Heimskringla towards the idea of the king as God's representative on earth are fully developed in the saga of Håkon Håkonsson (Hákonar saga), written in 1264-1265, shortly after the king's death in $1263 .{ }^{38}$ This saga still retains important elements of the ,classical' saga tradition in language, narrative style, and, to some extent, content. The saga mainly deals with political and military action, rather than government and administration. There are glimpses of a patron-client relationship between Håkon and his men, admissions of Håkon's imperfect control of his army in the descriptions of warfare, and a clear awareness of the importance of generosity and success in gaining adherents and winning political and military confrontations. However, the Christian and royalist ideal of the rex iustus determines the presentation of the king to a far greater extent than in the earlier sagas, including the one about Håkon's grandfather and predecessor Sverre. ${ }^{39}$ The picture of Håkon in Hákonar saga is mainly a portrait of the rex iustus and head of state, while the real man remains an elusive figure. The social context of

37 Ottonis et Rahewini Gesta Frederici I Imperatoris. Hrsg. Georg Waitz/Bernhard von Simson. (MGH SS rer. Germ. [46].) Hannover/Leipzig, 1912. For the following, see Sverre Bagge, Ideas and narrative in Otto of Freising's Gesta Frederici, in: JMedH 22, 1996, 345-377.

38 Bagge, From Gang Leader (cited in note 24), 89-160.

39 Ibid. 13-88, and, for an explicit comparison with Hákonar saga, 156-160. 
Hákonar saga is a more hierarchical society in which the king governs as the representative of the dynasty and by virtue of his divine election. His authority does not depend on his performance in open confrontations with other men; on the contrary, such confrontations would endanger the royalist ideology and are therefore suppressed in the saga.

Thus, the difference between Sverris saga and Hákonar saga demonstrates the decline of individualism accompanying the growth of the state and the new concept of the royal office. Instead of focusing on the king's personal performance and dramatic episodes in war, Hákonar saga applies a ,general staff perspective'. And while the king's personality is often hidden behind the royal office and the rex iustus ideology, the concept of a collective royal government offers new possibilities of analysing strategy and politics in a long-term perspective and thereby of focusing more closely on the plans and intentions of kings, political leaders, and generals. Although the narrative of Hákonar saga is also fairly episodic, these features imply a clearer concept of the political community or state than in the earlier saga literature. Håkon Håkonsson is portrayed as God's instrument in making a particular area of Christendom, the kingdom of Norway, conform to the right order of the world.

It seems likely that we can trace a similar development in other European countries with the emergence of a more organised monarchy. Still, some kind of intermediate level between the lofty concept of the right order of the world and the individual leader seems to be lacking, i.e. the concept of a particular state or nation. To find such an entity, we have to turn to the Italian Renaissance.

\section{The Florentine Republic as an Impersonal Protagonist}

The Historia Florentini populi, by Leonardo Bruni (1374-1444), written around 1440, deals with the history of the city from its foundation until the year 1402. In the following I shall discuss a parallel example to those discussed earlier, i.e. the ,revolution' in Florence 12931295 , when the "people“ (popolo) barred the magnates from political office and introduced the constitution that still existed during Bruni's lifetime. Bruni begins his story by pointing to the Florentine people's external triumphs during the previous years. Having defeated Arezzo and shown themselves superior in the war against Pisa, the Florentine people begin to regard themselves more highly, and to turn from external wars to internal liberty. ${ }^{40}$ Thus, the self-esteem of the Florentine people is enhanced by the external successes, and they start to assert themselves in internal matters as well.

According to Bruni, the nobility had for a long time oppressed the people and created internal struggles and unrest. After a description of these evils, Bruni introduces the man

40 Maiora de se se populus sapere coepit, ac ab externis bellis ad intestinam libertatem respicere; Leonardo Bruni, Historiarum Florentini populi libri XII. Ed. E. Santini. Vol. 19. (Rerum Italicarum Scriptores, vol. 3.) Città di Castello 1934, Lib. IV, 81. For the following account of Bruni, see Sverre Bagge, Medieval and Renaissance Historiography: Break or Continuity?, in: The Individual in European Culture. Ed. Sverre Bagge (The European Legacy 2, 1997), 1336-1371. For Bruni as a historian, see also Donald Wilcox, The Development of Florentine Humanist Historiography in the 15th Century. Cambridge/Mass. 1969, 32-129. 
who started to remedy them, Giano della Bella. Giano, himself belonging to the nobility, sympathises with the people and takes the initiative to reform the city of Florence. ${ }^{41}$ Bruni attributes to Giano a long speech in which he outlines the problems facing the city and the reforms he proposes to remedy them, reforms that were actually introduced when Giano came to power. ${ }^{42}$ Rather than focusing on the sufferings and difficulties of individual citizens, Giano places his proposals within the framework of a republican ideology, concerned with the city as a whole. A good citizen should place his city before his own private interests, as Giano does when taking this initiative, and which he urges his fellow citizens to do when reforming the republic. It will no doubt improve the conditions even of individual citizens if they are liberated from the tyranny of the nobles, but some of them may have to make great sacrifices in order to achieve this aim. However, such sacrifices are necessary for the sake of the city as a whole; the liberation of the city is not only a benefit but a moral duty.

Through this initiative, Giano succeeds in liberating the people and introducing a new constitution. However, his own career as the leader of Florence is of short duration. A conflict arises because of the acquittal of a noble accused of a crime, and friends and foes of Giano confront one another arms in hands. The confrontation would no doubt have resulted in a major battle, had not Giano refused to shed the blood of his fellow citizens, instead choosing voluntary exile. Bruni attributes to him the noble words that he cedes to the calumnies of his adversaries. He, who has been the author and the promoter of judgements, will never act against them, and he will not use arms for fear of setting an example for men who want to usurp power in the republic by the use of arms. He leaves the city, trusting that his innocence and the benefits he has conferred on the people, will bring him back. ${ }^{43}$ Despite this noble gesture, the city is still at the brink of civil war, until some wise and moderate men manage to cool the tempers. Afterwards, steps are taken to bring about the return of Giano, but his adversaries manage to make Pope Boniface issue a letter forbidding it, and Giano dies in exile. ${ }^{44}$

If we compare this story with those discussed previously in this article, its idealistic character is striking. Politics is not - or should not be - about the interests of individuals, but about those of the community as a whole, and Bruni's story of Giano is intended to show how the good citizen should place the community above his own interests and those of his class. In this respect, Bruni resembles authors like Wipo and Otto of Freising, but unlike them, his criterion for good government and correct political behaviour is not the religious concept of the right order of the world, but a concrete, human community, the republic of Florence. Bruni has almost completely eliminated God from his historical account, not because he did not believe in Him, but because his protagonist was the Florentine people and

41 Historiarum Florentini populi libri (cited in note 40), IV, 81.

42 Ibid. IV , 81-83.

43 Ibid. IV, 86.

44 Ibid. IV, $86 \mathrm{f}$. 
its achievements. ${ }^{45}$ Not only is God eliminated but also His traditional representative on earth, the king. This, however, is no novelty in Bruni but is there also in his medieval predecessors, and goes back to the twelfth and thirteenth centuries, when the Italian cities gained their independence from the largely nominal superiority of the Emperor. The republican constitution and the absence of a single, permanent ruler must nevertheless have contributed to the ,personification' of the Florentine republic which is prominent in Bruni's work.

The ,idealism' as well as the novelty of Bruni's account become even clearer if we compare it to earlier accounts of the same events, by Dino Compagni (d. 1324) and Giovanni Villani (d. 1348), the latter of whom was also Bruni's main source. ${ }^{46}$ Both Compagni and Villani refer to God's intervention in human affairs and judge people's actions in terms of Christian morality, but they are also, like Bruni, concerned with what serves the political community. What is most striking in their actual narrative, however, is their greater realism and emphasis on concrete interests. The revolution of 1293 is the result of discontent among a considerable part of the people who react spontaneously against the magnates; they have no need of Giano to remind them of what is wrong. Giano does become their leader and he does sacrifice his own interests to those of the people, but he is a less central figure in Compagni's and Villani's accounts than in Bruni's. While Bruni regards the revolution of 1293 as the awakening of the Florentine people and the new constitution as the one that serves the interests of the community as a whole, Compagni and Villani regard it more in terms of a class struggle, although their sympathy with the people make them give a largely favourable account of Giano and his followers.

There is thus no question of medieval naïveté and moralism being replaced by a deeper understanding of society and political behaviour in the Renaissance, at least not in the early Renaissance, represented by Bruni. If we regard the description of individual interests and tactical manoeuvring as a more realistic account of politics than attributing to people idealistic motives, then surely Compagni's and Villani's accounts surpass that of Bruni. Admittedly, modern historians may tend to exaggerate these ,realistic ${ }^{6}$ aspects of politics and neglect the importance of patriotism, honour, and great ideological programmes in history. In this case, however, there is little to suggest that Bruni has given a more correct account of the events of 1293-1295 than his predecessors, as the changes he has made in Villani's account are not the result of any new information but solely of his patriotic and moralistic aim with his work.

However, Bruni's patriotic idealism has important consequences for the way in which he creates a story out of the numerous events he includes in his work. As Phillips has pointed

45 On the gradual elimination of God from Florentine from the early fourteenth century onwards, see Louis Green, Chronicle into History. Cambridge 1972; Bagge, Medieval and Renaissance Historiography (cited in note 40), 1349-1351.

46 Dino Compagni, Cronica. Ed. Gino Luzzato. Torino 1968; English translation: Dino Compagni, Chronicle of Florence. Transl. with intr. Daniel E. Bornstein. Philadelphia 1986; Giovanni Villani, Nuova Cronica. Ed. Giuseppe Porta. 3 vol. Parma 1990/91; English translation: Villani's Chronicle. Being Selections from the First Nine Books of the Croniche Fiorentine of Giovanni Villani. Transl. Rose E. Selfe. Ed. Philip H. Wicksteed. New York 1907. 
out, Bruni's narrative represents a radical change compared to that of his medieval predecessors, a change from ,representation' to ,argument'. He drastically reduces the amount of detail, thus making his narrative clearer, but also less vivid and emotional. Villani's and particularly Compagni's account of the events around 1300 gives a fascinating picture of clans, families, factions, and classes and their mutual enmity and friendship, struggles and alliances - a description resembling the day-to-day report of a journalist about a society with which he is deeply familiar. By contrast, Bruni is always at a distance, regarding the events in a long-term perspective. This change forms a close parallel to the change taking place in contemporary art, from the crowded pictures, full of picturesque detail, of the Middle Ages, to those of the early Renaissance which are characterised by the central perspective and by strict economy in the number of figures and objects. However, the change is not only the result of new aesthetic ideals but has to do with a new understanding of society and politics, expressed in Bruni's focus on the city as an institution on the one hand, and a limited number of individuals on the other. In this respect, Bruni represents the reversal of the change from Roman historiography introduced by Gregory of Tours; the state once more becomes the central subject of historical narrative and the criterion for what is relevant.

These features of Bruni's narrative appear even more clearly towards the end of his work, which forms its climax and where Bruni deals with Florence's struggle for her existence against the tyrant Giangaleazzo Visconti, Duke of Milan. In contrast to what is usually to be found in medieval historiography, the war against Giangaleazzo is consistently described from a ,general staff-perspective': Bruni focuses on strategy rather than tactics, battles are fairly briefly described, no individual episodes are included, and the main emphasis is on the skill of the leaders. ${ }^{47}$ Diplomacy and politics receive an equally prominent treatment as the war itself. Giangaleazzo attempts a ,salami tactics", encircling Florence by allying himself with various smaller cities in its vicinity or establishing pro-Milanese governments there through coups. In his account of the war itself, Bruni repeatedly stresses the importance of keeping a stronghold in Lombardy; if Giangaleazzo has peace at home while the Florentines have to carry the burden of war in Tuscany, the city will sooner or later be worn out and be forced to sue for peace. Consequently, Bruni shows in detail the efforts of the Florentines to aid their allies in Lombardy and keep a constant pressure on Giangaleazzo in this region.

Considering Bruni's generally patriotic-idealistic attitude, his account of the republic's desperate struggle for its existence is surprisingly sober and matter-of-fact; Bruni usually leaves the events to speak for themselves and emphasizes the tactical and strategic moves from both sides. In some cases, however, notably in speeches, he expresses his own understanding of the significance of the conflict. When Florence's ally Bologna despairs about the city's ability to continue the war, sending an embassy to Florence with this message, Bruni attributes to the Florentines a speech that puts the war into the right patriotic perspective: when freedom is destroyed, everything is destroyed, and the pain the Bolognese suffer now is comparable to the pain a patient has to suffer to be cured. ${ }^{48}$ At the same time, the Floren-

47 Wilcox, The Development (cited in note 40), 94-98.

48 Historiarum Florentini populi libri (cited in note 40), X, $251 \mathrm{f}$. 
tines as well as the Bolognese are aware of the importance of money for waging war, as wars are nowadays fought, not with muscles but with money $(. . .)^{49}$, i.e. the soldiers are mercenaries, not the citizens themselves. Bruni sees no opposition between the exalted republican values and the down-to-earth question of the economic resources necessary to wage war. The Florentines do not deny the importance of wealth for waging war, but they refuse to believe that the resources of such a great and wealthy city as Bologna are really exhausted. The Bolognese's defaitism must be the result of lack of will, of not seeing the crucial importance of the war they are waging. Bruni's account thus contains a close connection between republican patriotism and political realism. The Florentine republic is not an assembly of idealists praising patriotism, sacrifices, and republican virtues; it is led by experienced and astute politicians who combine their occasional references to ideals and principles with concrete and realistic advice on how to act in political and military contexts.

Bruni develops further the problems as well as the advantages of republican government by drawing attentions to two individuals, Rainaldo Gianfigliazzi and Donato Acciaiuoli. In a speech, the former points to the difficulties facing a republic when fighting a tyrant ${ }^{50}:$ the Florentine people refuse to consider the future, and more clear-sighted leaders dare not come forward, fearing to be accused of being warmongers. This is less dangerous when fighting another republic but very dangerous when fighting a tyrant who can act secretly and prepare for the future without fearing popular opinion. The latter, Donato Accaiuoli, is a man of high integrity. Being disillusioned by his fellow citizens' low moral standards, he attempts a coup against the government towards the end of 1395 but fails. ${ }^{51}$

Gianfigliazzi's speech in a certain sense forms a contrast to the previous one by the Florentines, directed to the Bolognese. He has no doubt with regards to the virtues of republicanism, but is aware that a tyranny has certain advantages. In particular, he is concermed with a problem Bruni touches upon in several passages of his work, the relationship between the individual and society in a republic. A republic will inevitably limit the possibility of individuals to assert themselves, as is evident in the case of Donato Acciaiuoli. If there is too much of such limitation, however, the republic will suffer. In his Florentine history Bruni gives a sufficient number of examples that individuals put themselves forward on behalf of the republic to modify Gianfigliazzi's thesis, the latter's own action and analysis of the situation being one of them. As usual in the speeches composed by Bruni, the general patriotic or constitutional discussion is accompanied by an analysis of the concrete political and military situation and recommendations for further action.

Bruni quotes no direct counterargument to Gianfigliazzi's admittance that tyranny has certain advantages in foreign policy. However, the end of his work forms an eloquent comment on it. In 1402, Giangaleazzo has finished his encircling of Florence, inflicted a crushing defeat on a Florentine army, and captured Bologna. Florence is in a desperate situation when suddenly an embassy from Milan arrives, suing for peace. Later, the Florentines learn the reason for this surprising step. Giangaleazzo has suddenly turned seriously ill and fears

49 Cum igitur bellum per hoc tempus non lacertis sed pecuniis geratur (...); ibid. X, 251.

50 Ibid. IX, 276-278.

51 Ibid. XI, $268 \mathrm{f}$. 
for the future of his two little sons in case of his death. He is actually dead when the peace treaty is concluded. The Milanese are plunged into a succession crisis and have to give up all thought of war and foreign conquest. A government by one man has the advantage of quick decisions and secrecy in foreign policy, but is disastrous when such a man suddenly dies. By contrast, republics may be slow, but they never die. In this way, Bruni ends his work by once more emphasizing the transpersonal character of his protagonist, the Florentine republic.

\section{Bruni's Contribution to the Development of Historiography}

Bruni's account of the war against Giangaleazzo gives a similar impression as his treatment of the events around 1300. From a literary point of view, his account is clearer, contains less detail, and is less vivid than those of his medieval predecessors. From a historical point of view, Bruni plays down Compagni's and Villani's emphasis on groups, focusing on the one hand on a few, prominent individuals, on the other on the city as a whole. This emphasis on the city as a whole is probably Bruni's most original achievement compared to his medieval predecessors. It enables him to create a more integrated and continuous story, with the Florentine people as the protagonist. As for the individuals, Bruni's aim is not to depict them in their uniqueness and show the complexity of their character, but to show their importance, positively or negatively, for the republic. The crucial question to Bruni is how the individual can contribute to the welfare of the republic, not the actual motives that may explain his actions. Like his medieval predecessors, Bruni is of course fully aware that individuals often act to serve their own interests, as for instance Giangaleazzo Visconti, but he regards these interests as opposed to those of the community, in a similar way as his medieval predecessors regard them as opposed to the right order of the world. However, his stricter arrangement of his narrative and greater selectivity in the material he includes, allow him to focus more explicitly on the relationship between these interests and those of the community. Consequently, a number of examples of individual behaviour are shown as models or as wamings.

The war against Giangaleazzo offers a better opportunity for Bruni to show his ability for consistent narrative than the episodes examined earlier. This war was sufficiently close in time for Bruni to rely on his own memory and oral sources, while in the former case, he depended almost exclusively on Villani. Consequently, he is able to represent the war as one, continuous story, mixing a terse account of political and military events with speeches and episodes which show the fundamental republican values at stake. In this part of his work, he develops further his idea of the transpersonal republic of Florence which gives his history a coherence that his medieval predecessors lack. However, Bruni is, with some justice, criticized by Machiavelli for playing down the internal struggles in the city. ${ }^{52}$ By contrast,

52 Niccolò Machiavelli, Istorie Fiorentine. Ed. Francesco Flora/Carlo Cordiè, in: Tutte le opere di Niccolò Machiavelli. Vol. 2. Verona 1950, 3-434, proemio, 5; English translation: Florentine Histories by Niccolo Machiavelli. Transl. Laura F. Banfield/Harvey C. Mansfield jr. Princeton 1988. See Bagge, Medieval and Renaissance Historiography (cited in note 40), 1356-1365; id., Actors and Structures in Machiavelli's Istorie Fiorentine (forthcoming). 
Compagni and Villani show more realism and a more ,sociological' approach. It is therefore no coincidence that Machiavelli builds heavily on Villani. Machiavelli reintroduces classes and groups and makes the changing relationship between them the key to the understanding of the changing regimes in the city. He regards the relationship between the city and its individual citizens not primarily in moral terms, but in terms of how the city should be arranged so as to make the best possible use of their qualities, including their pride and egotism. And finally, he reintroduces the grotesque and emotional detail and the element of chance of his medieval predecessors in his narrative, in order to emphasize the limits to human and rational control over historical events. In short, he turns away from Bruni's republican optimism and gives his history of Florence a darker shade, in accordance with the precarious existence of the Italian city states during the invasions of the European great-powers in the early sixteenth century.

\section{Between Ancient Tradition and Contemporary Society}

From a literary point of view, the four historiographical traditions discussed in the previous pages derive from the same source, i.e. ancient historiography. Quotations and allusions to various Latin historians are common in authors like Widukind, Thietmar, and Lampert, and to Greek ones in Anna Komnene. By contrast, there is little to indicate direct influence from any particular Latin historian in the Old Norse sagas, but the genre as a whole shows influence, direct or indirect, from the classical tradition, for instance in the characterisations and the use of speeches. To the last author discussed here, Bruni, the whole tradition of classical historiography, Greek as well as Latin, was available. His main model was Livy, whom he and his contemporaries considered the greatest of the ancient historians. ${ }^{53}$

The relationship between the authors discussed here and ancient historiography has not been much in focus in the preceding pages. No doubt, such an examination would be an important contribution to understanding the similarity as well as the difference between them. Nevertheless, it will hardly be able to give a complete explanation. Such an explanation must be sought, not in the classical tradition itself but in the classical tradition as seen through the eyes of people with their background in a particular society. Anna Komnene must have acquired much of her literary skill from reading ancient Greek historians ${ }^{54}$, but the main source for her account of Alexios's coup must have been her familiarity with the Byzantine political system, if not directly eyewitness reports from the event. Whatever their dependence on Roman models, the German historians of the tenth and eleventh centuries and the Icelandic saga writers of the thirteenth show an understanding of society and political behaviour which they could hardly have derived from ancient sources but which fits well in

53 Wilcox, The Development (cited in note 40), $34 \mathrm{ff}$.

54 On Anna's reading and literary models, see Buckler, Anna Comnena (cited in note 14), 165-208. Of historians, she seems to have used Thucydides, Polybios, and Plutarch, although there is no question of direct borrowing (ibid. 205-208). For an extreme version of the view that Byzantine writers depended on classical models rather than personal observation, see Cyril Mango, Byzantine Literature as a Distorting Mirror. An Inaugural Lecture. Oxford 1975. 
with early medieval society in Western Europe. While the actual political manoeuvring shows considerable similarity to the one described by Anna, their understanding of society is different. The emphasis on the pretenders' as well as their ,elector's' individual interests is stronger, and the idea of an organised state or society weaker. There are collective interests, but they are not qualitatively different from individual ones. When an idea of an organised society eventually did develop in the west, it had less to do with a particular country than with Christendom as a whole, expressed in the concept of the right order of the world.

Our last author, Leonardo Bruni, who uses Livy as his main model, is probably the most direct heir to the classical tradition. Once more, however, the source is insufficient to explain the arrangement of his work. Although there is clearly a similarity between the way Livy and Bruni make their respective cities the protagonist of an integrated story, showing their external expansion and internal growth, this way of reading Livy presupposes an understanding of history nurtured in the particular environment of republican Florence in the first half of the fifteenth century. This can be shown by a comparison with another ,Livian' historian from the eleventh century, i.e. Lampert. Lampert was thoroughly familiar with Livy's First Decade, and his Latin style was largely inspired by Livy. ${ }^{55}$ He may also have derived some of his republican or constitutionalist ideas from him. But Germany or Saxony is not represented as an organic unity in the same way as Rome in Livy's account. Nor is the narrative organised in the distanced, Livian way, although there are some trends in this direction compared to his predecessors.

By contrast, all these elements are there in Bruni. His love for Livy as well as his real source of inspiration should therefore be sought in the republican patriotism of contemporary Florence, or, in Hans Baron's much discussed concept of „civic humanism“" ${ }^{56}$ On the one hand, fifteenth century Florence was more of an organised state than the city in the thirteenth century and even more than the kingdoms dealt with by the German and Old Norse historians discussed above. On the other hand, Bruni's ,organic' concept of Florence and his message about the city as the main object of its inhabitants' loyalty may be an ideology intended to support the prevailing oligarchic government. Bruni achieves this aim partly by depicting its leaders as the representatives of the city as a whole, partly by emphasizing the common duty of all the inhabitants towards their fatherland, so as to avoid internal divisions which had been a major problem throughout Florentine history. ${ }^{57}$

\section{Conclusion}

This article has briefly discussed four historiographical traditions between the eleventh and the fifteenth century on the basis of a small number of examples and consequently cannot claim completeness or representativity. Nevertheless, I hope to have focused on some

55 Tilmann Struve, Lambert von Hersfeld. Persönlichkeit und Weltbild eines Geschichtsschreibers am Beginn des Investiturstreites, in: HessJbLG 19, 1969, 13-21.

56 Hans Baron, The Crisis of the Early Italian Renaissance. Princeton 1966. Cf. e.g. Quentin Skinner, The Foundation of Modern Political Thought. Vol. 1: The Renaissance. Cambridge 1978, 69-112.

57 Bagge, Medieval and Renaissance Historiography (cited in note 40), 1367 with ref. 
characteristic features that can be discussed and developed further. I also hope to have shown the relevance of historiography for comparative research about medieval societies. Admittedly, there has been an increasing and largely well founded scepticism towards the factual information contained in narrative sources since the breakthrough of modern, critical scholarship in the early nineteenth century. Historiography is nevertheless a goldmine of information about ideas, attitudes and mentalities, including views on politics, the political community, and political behaviour. Despite a number of important studies, particularly in Germany, much remains to be done with this rich material. State formation is not only a matter of institutional change, but also of changing attitudes. While lawyers and political theorists are excellent sources for the more explicit aspects of these changes, the challenges facing a historical writer when organising his narrative may often give important information about more vague and implicit notions. By analysing historical narrative, we may therefore gain a better understanding of the more fundamental changes accompanying the rise of the medieval and renaissance state. 



\title{
Familienkonflikt und Brudermord in der Wenzel-Hagiographie
}

\author{
Zwei Modelle des Martyriums
}

Von

Marina Paramonova

In diesem Beitrag werden zwei Modelle für die hagiographische Repräsentation eines Ereignisses analysiert, des Mordes nämlich an dem böhmischen Fürsten Wenzel. Diese Modelle entstanden zur gleichen Zeit, sie unterscheiden sich aber prinzipiell voneinander. Ihr Vergleich ermöglicht es, die Grenzen zu markieren, die einer Gesellschaft bei der Entfaltung ihrer literarischen Kultur gesetzt sind. Es geht dabei um verschiedene Techniken der Umwandlung, die eine reale Geschichte in eine ,narrative‘ Erzählung erfährt, sowie um den Sinn, der den realen Ereignissen dabei zugeteilt und aus dem der Gebrauch von Normen des sozialen Handelns abgeleitet wird.

Die mittelalterliche Hagiographie stellt eine eigenartige Erfahrung der Wirklichkeitsaneignung im Kontext normativer Erzählung dar. ${ }^{1}$ Die Wirklichkeit wurde im hagiographischen Text vom Standpunkt des religiösen Bewußtseins eingeschätzt und im Prozeß der

1 Jedes reale Ereignis kann in narrativen Texten ganz verschieden dargestellt werden. Das in schriftlicher Form fixierte Ereignis wandelt sich in eine narrative ,Erzăhlung', indem es seinen Inhalt und Sinn ändert, was durch die Logik der zu transformierenden Erzăhlung bedingt wird. Die Transformation der ,realen“ Geschichte in eine ,narrative' Geschichte ist nicht so sehr mit der Änderung des Sinns als - ihrem Wesen nach - mit ihrer Deutung verbunden. Durch die Einführung der formalisierten Motive und Einschătzungen in die Darstellung der ,realen' Situation modellierte die Erzăhlung ein normatives Verhalten, das andere Gründe hatte, als eine Erfiahrung einer gegebenen sozialen Tradition. Zum Problem der Reprăsentation der Wirklichkeit s. grundsătzlich: Erich Auerbach, Mimesis. Dargestellte Wirklichkeit in der abendländischen Literatur. (Sammlung Dalp, Bd. 90.) 2. verb. und erw. Aufl. Bern 1959; zur Benutzung des Konzepts ,Sitz im Leben' für mittelalterlichen Viten: Thomas J. Heffernan, Sacred Biography. Saints and their Biographers in the Middle Ages. New York/Oxford 1988, 51 ff., 69, $185 \mathrm{ff}$.; für altrussische und slawische Literatur: Gail Lenhoff, Early Russian Hagiography. The Lives of Prince Fedor the Black. (Slavistische Veröff., Bd. 82.) Wiesbaden 1997, 17 ff.; ders., The Martyred Princes Boris and Gleb. A Socio-Cultural Study of the Cult and Texts. (UCLA Slavic Studies, vol. 19.) Columbus/ Ohio 1989. 
Auseinandersetzung mit den Lebenssituationen unter den Kategorien religiöser Ethik rationalisiert. Das Studium der gleichen Lebensgeschichte von Heiligen in mehreren Viten ist nicht nur wichtig fur die Erkenntnis der verschiedenen hagiographischen Zyklen in ihrer Entwicklung; solch ein Vergleich kann vielmehr auch die Wertesysteme und Rationalisierungen der Wirklichkeit erhellen, über die Menschen und Menschengruppen in ihren jeweiligen Lebenslagen verfugt haben.

Im Jahre 929 n. Chr. (935/936 nach anderen Versionen) wurde der böhmische Herrscher Wenzel aus der Přemyslidendynastie vom eigenen Bruder Boleslav getötet. ${ }^{2}$ In den hagiographischen und historiographischen Traditionen wird Boleslav nicht nur die Initiierung, sondern auch die Teilnahme am Mord seines älteren Bruders zugeschrieben. Die konkreten Umstände von Wenzels Ermordung sowie von seinem Leben sind in späteren Texten überliefert und können deshalb nicht genau rekonstruiert werden. In jedem Fall ging dem Mord vielleicht ein Konflikt voraus, in den die Mitglieder der regierenden Familie sowie die Adligen aus deren Umfeld einbezogen waren.

Die Geschichte von Wenzel und sein Bild in den hagiographischen Texten sind interessant, weil es sich um den seltenen Fall eines Martyriums handelt, das im Kontext eines Familienkonflikts stand. ${ }^{3}$ An den ersten Wenzelsviten läßt sich analysieren, auf welche Weise die typische Konfliktsituation in einer regierenden Familie ${ }^{4}$ in einer religiösen, didak-

2 Die wichtigsten Arbeiten: Václav Chaloupecký (Hrsg.), Prameny X. století legendy Kristiánovy o svatém Václavu a svaté Ludmile. (Svatováclavský sborník, Bd. 2: Svatováclavská tradice, T. 2.) Prag 1939; Josef Pekaŕ, Die Wenzels- und Ludmila-Legenden und die Echtheit Christians. Prag 1906; Josef Vajs (Hrsg.), Sbomík staroslovanských literárních památek o svatém Václavu a svaté Lidmile. Prag 1929; Milos Weingart, Pruní ‘esko-církevněslovanská legenda o svatém Václavu. Rozbor filologický. V Praze 1934; Heinrich G. Voigt, Die von dem Premysliden Christian verfasste und Adalbert von Prag gewidmete Biographie des Heil. Wenzel und ihre Geschichtsdarstellung. Prag 1907; Svátováclavský Sborník. Na památku 1000. výrocí smrti Knížete Václava Svatého. Bd. I/1. Prag 1934; František Graus, Die Nationenbildung der Westslawen im Mittelalter. (Nationes, Bd. 3.) Sigmaringen 1980; ders., St. Adalbert und St. Wenzel. Zur Funktion der mittelalterlichen Heiligenverehrung, in: Europa Slavica - Europa Orientalis. Fschr. für Herbert Ludat zum 70. Geburtstag. Hrsg. v. Klaus-Detlev Grothusen/Klaus Zernack. (Osteuropastudien der Hochschulen des Landes Hessen, Rh. 1: Gießener Abhandlungen zur Agrarund Wirtschaftsforschung des europäischen Ostens, Bd. 100.) Berlin 1980, 205-231; Dušan Třeštík, Počatki Přemyslovcủ. Prag 1981.

3 S. für die angelsächsische Hagiographie: Susan J. Ridyard, The Royal Saints of Anglo-Saxon England. Cambridge 1988; David W. Rollason, Saints and Relics in Anglo-Saxon England. Oxford 1989; ders., The Mildrith Legend. A Study in early medieval Hagiography in England. Leister 1982, 73-87; Christine E. Fell (Ed.), Edward, King and Martyr. Leeds 1971.

4 Zu Erzăhlungen uber Familienkonflikte s. z. B.: Passio Sigismundi regis. Hrsg. v. Bruno Krusch, in: MGH SS rer. Merov. 2. Hannover 1888, 329-340; für das 10. Jh.: Die Lebensbeschreibungen der Königin Mathilde. Hrsg. v. Bernd Schütte. (MGH SS rer. Germ. [66].) Hannover 1994; Ruotgers Vita des Erzbischofs Bruno von Köln. Hrsg. v. Irene Ott. (MGH SS rer. Germ. [10].) Köln 1958; Die Lebensbeschreibung der Kaiserin Adelheid von Abt Odilo von Cluny (Odilonis Cluniacensis abbatis Epitaphium domine Adelheide auguste). Bearb. v. Herbert Paulhart, in: Fschr. zur Jahrtausendfeier für die Kaiserkrönung Ottos des Großen. T. 2. (MIÖG, Ergänzungsbd. 20/2.) Graz/Köln 1962/63, $27-45$. 
tischen Erzählung verarbeitet und zum Gegenstand für die moralische Erklärung von Ereignissen wurde.

Die frühere Wenzelshagiographie ist in vielerlei Hinsicht ein bemerkenswerter Komplex von Schriftdenkmälern. ${ }^{5}$ In einer Zeit, die ungefáhr von der Mitte des 10. bis zur Mitte des 11. Jahrhunderts reicht, wurden sechs umfangreiche Viten ${ }^{6}$ zusammengestellt; fünf davon sind Originalwerke, wăhrend die sechste die Übersetzung einer der lateinischen Lebensbeschreibungen ins Altslawische darstellt. Mindestens zwei dieser sechs Werke wurden außerhalb Böhmens geschrieben. Es handelt sich dabei um das italienische Umfeld Ottos II., auf dessen Befehl der Bischof von Mantua, Gumpold, um 982 eine Lebensbeschreibung schuf, sowie um das Kloster in Monte Cassino, wo einige Jahrzehnte später ein anderer Text entstand, die Laurentius-Legende. Erhalten geblieben ist auch ein Beitrag der deutschen Geistlichkeit zur Entwicklung des Wenzelskultes. Die erste lateinische Heiligenvita, Crescente fide ${ }^{7}$, wurde wahrscheinlich durch einen bayerischen Kleriker in den siebziger Jahren unmittelbar in Prag oder in Regensburg geschrieben. ${ }^{8}$ Zwei der drei anderen ,böhmischen' Wenzelsviten stellen Originale und ihrem Inhalt nach ganz verschiedene Werke dar, die entsprechend in Kirchenslawisch und in Latein abgefaßt wurden. Bei der dritten handelt es sich um eine slawische Übersetzung der Vita nach Gumpold. ${ }^{9}$

Die Viten lassen die Schlußfolgerung zu, daß das letzte Drittel des 10. Jahrhunderts eine wichtige Periode in der Ausbildung des Kultes war. Gerade zu jener Zeit geht die Verehrung von Wenzel über den Rahmen einzelner kirchlicher Gemeinden hinaus; es beginnt der ,öffentliche‘ Kult. Zu den ,Hauptschöpfern' des Wenzelskultes, der ein religiöses Symbol

5 Chaloupecký, Prameny (wie Anm. 2); Pekar̆, Die Wenzels- und Ludmila-Legenden (wie Anm. 2); Vajs, Sbornik (wie Anm. 2); Staroslověnské legendy ceského původu. Nejstarší kapitoly z dějin cesko-ruských kulturních vztahů. Hrsg. v. Emilie Blahova/Vaclav Konzal/Aleksandr I. Rogov. Praha 1976; Skazanija o naČle Čěsskogo gosudarsta v drevnerusskoj pis'mennosti. Predislovie, kommentarii i perevod Aleksandr I. Rogova. Moskva 1970.

6 Die lateinischen Viten werden zitiert nach: Vitae Sanctorum. (FRB, Bd. I/2.) Praha 1873. Die altslawischen (kirchenslawischen) Viten werden zitiert nach: Sborník staroslovanských (wie Anm. 2).

7 Jaroslav Ludvikovský, Nove zjištený rukopis Legendy Crescente fide a jeho význam pro datování Kristiána, in: Listy Filologické 81, 1958, 56-68; s. die beiden Rezensionen - „bayerische“ und „böhmische“ - in: FRB. Bd. I/2, 183-190, und Chaloupecký, Prameny (wie Anm. 2), 493-501.

8 Sie wurde wahrscheinlich für die deutsche kirchliche Gemeinde in Prag bestimmt, die sich mit der Evangelisierung Böhmens vor der Gründung des Bistums beschäftigte; s. dazu: František Graus, Böhmen zwischen Bayern und Sachsen. Zur böhmischen Kirchengeschichte des 10. Jahrhunderts, in: Historica $17,1969,5-42$.

9 Druhá staroslovanská legenda o sv. Václavu. Bearb. v. Josef Vašica, in: Sborník staroslovanských (wie Anm. 2), 84-124. Dieser Text, der wahrscheinlich in der 2. Hälfte des 11. Jh. im Sazava-Kloster geschaffen wurde, zeugt von der Assimilation des ,entlehnten' Werkes durch das böhmische, kirchliche Milieu sowie auch durch dessen ,Sonderkreis'-Geistlichkeit, die die Traditionen der slawischen Schriftlichkeit und der slawischen Liturgie unterstützte. Wahrscheinlich wurde hier auch der slawische Wenzels-Kanon geschrieben (Kánon ke cti sv. Václava, in: ebd. 139-145). S. auch Chaloupecký, Prameny (wie Anm. 2), 401-455; Jaroslav Ludvikovský, The Great Moravia Tradition, in: Magna Moravia. Hrsg. v. Josef Macurek. Prag 1965, 525-566.; Aleksandr I. Rogov, Slovanské legendy z doby vzniku ceského státu a jejich osudy na Rusi, in: Staroslovenské legendy (wie Anm. 5), 11-53. 
Böhmens entstehen läßt, werden zwei Kräfte: das Prager Bistum und die italienischen Kirchenzentren, die mit den politischen Strategien Ottos II. und Ottos III. verbunden waren. ${ }^{10}$ Die Aktivität des Prager Bistums, genauer gesagt seines zweiten Bischofs Adalbert (982-997), läßt sich mit der Schöpfung von mindestens zwei Lebensbeschreibungen belegen. ${ }^{11}$ Dazu gehören die sogenannte Christians-Legende, die für die praktische Tătigkeit des Bistums bestimmt war und die Vita Wenzels mit derjenigen seiner Großmutter Ludmila umschlo $\beta^{12}$, sowie die Passio, die in Monte Cassino von dem Mönch Laurentius geschrieben wurde. ${ }^{13}$ Die Aktivität der italienischen Geistlichkeit ${ }^{14}$, die mit der religiösen und politischen Zielen der spätottonischen Zeit verbunden waren, hat sich in den Gumpold- und LaurentiusLegenden niedergeschlagen. Das Interesse am Bild des böhmischen Heiligen wurde hier wohl durch die ,Propaganda' von seiten des Prager Bistums (bzw. Adalberts persönlich) bestimmt. Zugleich ist darin eine Tendenz zur Teilnahme an der Kultentwicklung der ,örtlichen' Heiligen im ,slawischen Raum' enthalten, der an den Grenzen des Reiches lag. Diese Tendenz erreichte ihren Höhepunkt in der Regierungszeit Ottos III. um die Jahrtausendwende und dauerte auch nach dem Tod des Kaisers an. ${ }^{15}$ In gewissem Maße war der Wenzelskult ebenso wie derjenige Adalberts das Erzeugnis eines Systems politischer und kultureller Kommunikation, das sich im Kontext der spätottonischen Ostpolitik formierte.

10 Walter Franke, Romuald von Camaldoli und seine Reformtätigkeit zur Zeit Ottos III. (Hist. Studien, Bd. 107.) Berlin 1913; Bernard Hamilton, The Monastery of S. Alessio and the Religious and Intellectual Renaissance of Tenth-Century Rome, in: Studies in Medieval and Renaissance History 2, 1965, 263-310. Über die ,Ostpolitik' dieser Zeit: Johannes Fried, Otto III. und Boleslaw Chrobry. Das Widmungsbild des Aachener Evangeliars, der „Akt von Gnesen“ und das frühe polnische und ungarische Königtum. Eine Bildanalyse und ihre historischen Folgen. (Frankfurter hist. Abh., Bd. 30.) Stuttgart 1989; ders., Theophanu und die Slawen. Bemerkungen zur Ostpolitik der Kaiserin, in: Kaiserin Theophanu. Begegnung des Osten und Westens um die Wende des ersten Jahrtausends. Gedenkschrift des Kölner Schnütgen-Museums zum 1000. Todesjahr der Kaiserin. Hrsg. v. Anton von Euw/Peter Schreiner. Bd. 2. Köln 1991, 361-370.

11 Wahrscheinlich auch in der Schöpfung der Translations-Legende Licet plura; vgl. Pekar̆, Die Wenzelsund Ludmila-Legenden (wie Anm. 2), 385-388, und der Gumpold-Legende, vgl. Jaroslav Ludvíkovský, Crescente fide, Gumpold a Kristián, in: Sborník Prací Filosofické faculty Brněnske University D1, $1955,57-63$.

12 Křištanův. Život sv. Ludmily a sv. Václava. Pł̌eložil Josef Truhlár̆, in: FRB. Bd. I/2, 199-227 [Christian]; Kristianová Legenda: zivot a umucení svatého Václava a jeho báby svaté Ludmily. Ed. Jaroslav Ludvikovský. Prag 1978.

13 Vavřince, Mnicha sv. Benedikta, Utprení sv. Václava. Přeložil Josef Truhláŕ, in: FRB. Bd. I/2, 167-182 [Laurentius]. Über die italienischen Beziehungen Adalberts s. Karl Bosl, Das Kloster San Alessio auf dem Aventin zu Rom. Griechisch-lateinisch-slavische Kontakte in römischen Klöstern vom 6./7. bis zum Ende des 10. Jahrhunderts, in: Beiträge zur Südosteuropa-Forschung. Hrsg. v. Hans Georg Beck/Alois Schmaus. (Beitrăge zur Kenntnis Südosteuropas und des Nahen Orients, Bd. 10.) München 1970, 15-28; Rostislav Nový, Slavníkovci v rané středovekých Čechách, in: Slávníkovci ve středovekém písemnictví. Hrsg. v. dems. Prag 1987, 11-92.

14 Auch die spătere Legende Oportet nos fratres: Pekar̆, Die Wenzels- und Ludmilalegenden (wie Anm. 2), 42 ff.

15 Die ,italienischen' Wenzelsviten (Gumpold- und Laurentius-Legende) markieren den Anfang dieser Praktiken während der Regierungszeit Ottos II. und belegen deren weitere Wirksamkeit. 
Zwei der sechs in der Anfangsperiode des Kults entstandenen Lebensbeschreibungen wurden also in der kirchenslawischen Sprache, die anderen vier in Latein geschrieben. Die Sprachdifferenzierung spiegelt eine kulturelle Verschiedenheit der sozialen Schichten wider, in denen sich die Bildung des Kultes vollzog. Neben den lateinischen Geistlichen bestanden im Böhmen des 10./11. Jahrhunderts kirchliche Gemeinschaften, die sich an die Tradition des altslawischen Schriftums hielten. ${ }^{16}$ Aber nach der Sprache lassen sich Kultentwicklung und Hagiographie nicht klar sortieren. Fün Texte (vier lateinische Viten und die Übersetzung von Gumpold) bilden nämlich eine einheitliche Tradition des hagiographischen Modells. ${ }^{17}$ Die frühere lateinische Hagiographie schuf eine Art Repräsentationskanon des ,Bildes ${ }^{6}$ und der ,Geschichte ${ }^{6}$ von Wenzel ${ }^{18}$, indem sie diesen als vorbildlichen Christen und dessen Ermordung als religiöses Märtyrertum darstellte.

Zugleich blieb aber eine der fruheren Lebensbeschreibungen außerhalb des Rahmens derjenigen Schriften, die das ,offizielle‘ Modell ausbildeten. Der nach Meinung mehrerer Wissenschaftler chronologisch erste Text mit der Beschreibung des Todes Wenzels wurde altslawisch geschrieben und die „Erste altslawische Legende“ genannt. ${ }^{19}$ Diese Vita übte praktisch keinen Einfluß auf die Bildung der lateinischen Wenzelslegende aus. Nur einige Entlehnungen daraus lassen sich in den anderen Lebensbeschreibungen ausmachen.

Es wäre angebracht zu klären, weshalb die Geschichte der Ermordung Wenzels am Anfang der literarischen Tradition in zwei Varianten in Erscheinung tritt. Waren dabei ,objektive' Faktoren entscheidend, also die Opposition rivalisierender ,Gruppen ${ }^{620}$ in der böhmischen Gesellschaft des 10. Jahrhunderts, oder handelt es sich um die Ausdifferenzierung literarischer Potentiale, die durch die Verschiedenheit der Sprachen bedingt war? Angesichts der knappen Informationen, über die wir im Hinblick auf die böhmische Gesellschaft der damaligen Zeit verfugen, kann die erste Frage aber kaum beantwortet werden. Andererseits ist deutlich, daß weder sprachliche noch ideologische Differenzen den Einfluß

16 S. zu diesem Problem: Ludvikovský, Great Moravia Tradition (wie Anm. 9), 525 ff.; Rogov, Slovanské legendy (wie Anm. 9), 11 ff.

17 Die konzeptuelle Verschiedenheit dieser Texte spiegelt Unterschiede in den Strategien der sozialen und kirchlichen Gruppen wider, die an der Entwicklung des Kultes beteiligt waren. Die genetische und typologische Verwandtschaft dieser Texte weist auf das Zusammenwirken einzelner sozialer Gruppen bei dessen Entwicklung hin.

18 Graus, St. Adalbert (wie Anm. 2); ders., La sanctification du souverain dans l'Europe centrale des $X^{\text {ime }}$ et $\mathrm{XI}^{\mathrm{e} m e}$ siècles, in: Hagiographie, cultures et societés. $4^{\mathrm{e}}-12^{\mathrm{e}}$ siècles. Actes du Colloque organisé à Nanterre et à Paris (2-5 mai 1979). Paris 1981, 559-572.

19 Die verschiedenen Redaktionen bei: Sbornik staroslovanských (wie Anm. 2), die russischen Legenden: Ruské redakce původní staroslov. legendy o sv. Václavu. Bearb. v. Nikolai J. Serebrjanskij, in: ebd. 9-28 (Vostokov-Legende: ebd. 14-20; Menäen-Legende: ebd. 20-28); die kroatisch-glagolitische Legende: Charvátskohlaholská redakce původní staroslov. legendy o sv. Václavu. Bearb. v. Josef Vajs, in: ebd. 29-43. Rekonstruktion des Archetyps: Weingart, První Cesko-církevněslovanská legenda (wie Anm. 2), 973-998. S. zur Interpretation und Datierung: Skazanija o nacale (wie Anm. 5).

20 Als solche traten vermutlich sowohl kirchliche Gemeinden auf, die durch die Zugehörigkeit zur lateinischen oder altslawischen literarischen Tradition geteilt wurden, wie auch geschlossene Gemeinschaften des böhmischen Klerus und des „Hofkreises' der böhmischen Herrscher, die ihre Versionen der historischen Ereignisse vorschlugen. 
der Ersten altslawischen Legende auf die lateinischen Viten und die altslawische Übersetzung der Gumpold-Legende verhindert haben. Konzeptuell blieb die Erste altslawische Legende gleichwohl eigenartig und ohne Nachahmung. Es hat keinen Sinn, die Ursachen furr die konzeptuelle Dualität der Wenzelshagiographie in ,objektiven' sozialen Konflikten zu suchen. Wahrscheinlich sind sie eher in den Texten selbst zu finden, die verschiedene Erfahrungen bei der Wahrnehmung der Wirklichkeit und derer Kodierung in den religiös-sittlichen Diskurs widerspiegelten.

Die Erste altslawische Legende ist der kürzeste der frühen Texte, der in drei Versionen erhalten ist, in zwei russischen und in einer kroatisch-glagolitischen. Dabei gelten die Vostokovlegende und die kroatische Legende als die fruhesten und wahrscheinlich dem Archetyp am meisten nahestehenden. Die Divergenzelemente dieser zwei Texte sind in der Regel zweitrangig. In der altrussischen Tradition wurde die Erste altslawische Legende nicht nur hagiographischen Texten über Wenzel zugrundegelegt ${ }^{21}$, sondern auch als literarisches Modell verwendet für Berichte über zwischenfürstliche Konflikte. ${ }^{22}$

In der narrativen Struktur des Textes kann man vier Fragmente unterscheiden, die dessen inhaltlichen und rhetorischen Aufbau bestimmen. Das erste stellt eine Erzăhlung über den vorbildlichen und frommen Herrscher Wenzel dar. ${ }^{23}$ Das zweite bietet die Geschichte der Feindschaft zwischen den Brüdern und der Ermordung Wenzels. ${ }^{24}$ Das dritte Fragment, eng mit dem vorangegangenen verbunden, thematisiert die Missetaten Boleslavs, die dieser nach dem Tod Wenzels beging. ${ }^{25}$ Eine Art Epilog bildet die Reue Boleslavs und die Verehrung Wenzels. ${ }^{26}$ Die Geschichte von der Ermordung Wenzels teilt den Text in zwei Abschnitte ein: Der erste bietet eine Beschreibung des Lebens und der Tugenden des frommen Herrschers, der zweite die eigentliche narrative Darstellung des Konflikts von seiner Entstehung bis zum Abschluß, der von der symbolischen,Versöhnung' Wenzels und Boleslavs gekrönt wird.

21 Proložní legendy o sv. Lidmile a o sv. Václavu. Bearb. v. Nikolai J. Serebrjanskij, in: Sborník staroslovanských (wie Anm. 2), 47-68, hier 65-68.

22 Rogov, Slovanské legendy (wie Anm. 9), 27 ff.; Das kann über die slawische Übersetzung Gumpolds nicht gesagt werden. Entlehnungen aus dieser Übersetzung in der russischen literarischen Tradition kamen nur als äußerst seltene Bruchstücke vor. In jedem Fall wurde dieser Text von den russischen Autoren nicht als ein narratives Modell benutzt. S. zu diesem Problem: Norman W. Ingham, Czech Hagiography in Kiev, in: Die Welt der Slaven 10, 1965, 166-182; ders., The Martyred Prince and the Question of Slavic Cultural Continuity in the Early Middle Ages, in: Medieval Russian Culture. Ed. Henrik Bimbaum/Michael S. Flier/Daniel B. Rowland. Berkeley/London 1984, 31-53; Roman Jakobson, Minor Narrative Sources for the Early History of the Slavic Church. (Harvard Slavic Studies, vol. 2.) Cambridge 1954, 39-73, hier 47-62.

23 Ruské redakce (wie Anm. 19), 14-17, 20-24; Charvátskohlaholská redakce (wie Anm. 19), 36-39.

24 Ruské redakce (wie Anm. 19), 16-18; 21-25; Charvátskohlaholská redakce (wie Anm. 19), 40 f.

25 Ruské redakce (wie Anm. 19), 18 f., 25-28; Charvátskohlaholská redakce (wie Anm. 19), 41-43.

26 Ruské redakce (wie Anm. 19), 20, 28; Charvátskohlaholská redakce (wie Anm. 19), 43. 
Den Schwerpunkt des ersten Teils der Ersten altslawischen Legende bildet die Charakterisierung Wenzels, dem alle Tugenden eines frommen Herrschers zugeschrieben werden. ${ }^{27}$ Die Mitteilungen über Wenzels Leben sind verschiedenartig. Erwähnt werden Wenzels Familienmitglieder, sein Vater Vratislav, seine Mutter Drahomíra und seine Großmutter Ludmila. Aber keinesfalls hat der Text den Charakter einer ,Familienchronik ${ }^{6}$ oder ,historischen' Chronik; er enthält nämlich im Unterschied zu den lateinischen Viten keine Zeugnisse über die ,Verwandtschaft' der handelnden Person, die über diejenigen Handlungen hinausgehen, die irgendwie mit dem Schicksal Wenzels in Verbindung stehen. ${ }^{28}$ Meist wird Drahomíra erwăhnt: Sie sollte für ihre Söhne die Vormundschaft übernehmen und das Land während der Minderjährigkeit Wenzels regieren sowie sich um den Leichnam des Sohnes sorgen. ${ }^{29}$

Eine Reihe von Elementen bestimmen den Status Wenzels als Herrscher. Er wird als Vratislavs älterer Sohn genannt ${ }^{30}$, der nach dem Tod seines Vaters den Thron bestieg. Die Erste altslawische Legende schneidet das Thema der Legitimität Wenzels als Fürst nicht an, sondern beschränkt sich auf die Thronfolge des älteren Sohnes als soziale Praktik. ${ }^{31}$ Die Legende erwăhnt, daß nach seiner Thronbesteigung der Bruder ,unter Wenzels Befehl leben mußte" und Wenzel selbst seine Leute zu verwalten begonnen habe. ${ }^{32}$ Wenzels Position als Herrscher wird vor allem an den Bezeichnungen fur ihn deutlich; die Titel „Fürst“, „Machthaber", „Herr" verdeutlichen in erster Linie seine Macht über eine bestimmte Gemeinschaft der ,eigenen Leute‘. Im Text wird der Überlegenheit Wenzels als Herrscher über seine Nächsten keine besondere Aufmerksamkeit geschenkt. Der Mangel jeglicher Differenzierung zwischen den verwandtschaftlichen Beziehungen und der Machtunterordnung ${ }^{33}$ kommt in

27 Wenzel wurde als „seliger" und ,heiliger" Fürst bezeichnet. Es sind aber gleichzeitig keine deutlichen Züge der Gleichstellung Wenzels mit einem Heiligen im Text zu finden. Das Andachtsgebet wendet sich nicht an Wenzel; Ruské redakce (wie Anm. 19), 19 f., 27 f.; Charvátskohlaholská redakce (wie Anm. 19), 42 f.

28 Der Text enthălt Erwăhnungen der Eltern, wenn die Rede von der Geburt, der Taufe und von dem Ritual des Haareschneidens ist, sowie des Vaters und der Großmutter, wenn es sich um Wenzels Ausbildung handelt; Ruské redakce (wie Anm. 19), 14 f., 21 f.; Charvátskohlaholská redakce (wie Anm. 19), $36 \mathrm{f}$.

29 Ruské redakce (wie Anm. 19), 15 f., 18, 21,26 f.; Charvátskohlaholská redakce (wie Anm. 19), 37-42. Es gibt im Text auch Hinweise auf den Konflikt mit den beiden Söhnen (mit Wenzel: Ruské redakce [wie Anm. 19], 15 f., 22 f.; Charvátskohlaholská redakce [wie Anm. 19], 38, mit Boleslav: Ruské redakce [wie Anm. 19], 18 f., 26 f.; Charvátskohlaholská redakce [wie Anm. 19], 41 f.) und auf die Freude über die Frömmigkeit Wenzels: Ruské redakce (wie Anm. 19), 16, 23; Charvátskohlaholská redakce (wie Anm. 19), 38.

30 Anders nur in der Prolog-Erzăhlung; vgl. Proložní legendy (wie Anm. 21), 67.

31 Ruské redakce (wie Anm. 19), 15, 21; Charvátskohlaholská redakce (wie Anm. 19), 37. Die Ausnahme bildet nur die Menăenfassung. Hier verwandelt sich das Ritual des Haareschneidens in eine Zeremonie des kirchlichen Segens Wenzels, die - so im Kontext - von Wenzels Vater initiiert wurde und die Thronerbfolge sichern sollte; Ruské redakce (wie Anm. 19), $20 \mathrm{f}$.

32 Ruské redakce (wie Anm. 19), 15, 21; Charvátskohlaholská redakce (wie Anm. 19), 39.

33 Das ist aber wichtig fur die lateinische Hagiographie; s. auch die Passio Eadwardi: Edward, King and Martyr (wie Anm. 3), 1 ff. 
der logischen Undeutlichkeit bei der Erzählung über die Familienkonflikte zum Ausdruck: Die Ursachen der Feindschaft zwischen Wenzel und seiner Mutter sowie zwischen Boleslav und dessen Bruder und Mutter werden im Text nur auf die Verleumdungen der Ratgeber zurückgefuhrt.

Einen bedeutenden Teil unter den Merkmalen Wenzels machen diejenigen aus, die Wenzels Beteiligung an den kirchlich-religiösen Praktiken zu erkennen geben. Es handelt sich vor allem um die Taufe und um das Ritual des Haareschneidens ${ }^{34}$, bei dem der Schwerpunkt auf dem Segen des Bischofs liegt. Ausführlich wird auch Wenzels Lese- und Schreibunterricht im Altslawischen und im Lateinischen beschrieben. Seine Erfolge in der Aneignung des Lateinischen, Griechischen und Altslawischen ${ }^{35}$ werden nicht nur hervorgehoben, sondern auch als religiös bedeutsam dargestellt, da sie Wenzels Interesse an den Grundlagen der Glaubenslehre bestätigten.

Wenzels ,Tugenden' können in zwei Gruppen eingeteilt werden: die persönliche Frömmigkeit und die Sorge um die Kirche. Die Auszeichnungen der erste Kategorie werden im Lob der Barmherzigkeit akzentuiert, das sich im evangelischen Topos vom Schutz und Almosen für sozial Elende und Pilger sowie für die Geistlichkeit erschöpft. ${ }^{36} \mathrm{Zu}$ der zweiten Kategorie gehören die Teilnahme Wenzels an der Errichtung von Kirchen, an der Heranziehung des Klerus oder an der Gestaltung des kirchlichen Lebens. ${ }^{37}$ Die Gestaltung des kirchlichen Lebens gehört nach der Meinung des Verfassers zu den wichtigsten Zügen Wen$\mathrm{zels}^{38}$, was seinen Ausdruck insbesondere in der Stilistik dieser Erzählung findet: In allen Fassungen wird der Superlativ gebraucht, um die Schwerpunkte bei dieser Tätigkeit zu zeigen.

Die Aufzăhlung der religiösen Taten Wenzels ist folgerichtig, sie umfaßt praktisch alle formell möglichen Äußerungsformen der Frömmigkeit. Darüber hinaus wird gerade Wenzels Gläubigkeit zur Verallgemeinerung von Urteilen über ihn gebraucht. ${ }^{39}$ Solche Systematisierung kann von den Bemühungen des Verfassers zeugen, ein normatives Bild vom christlichen Herrscher zu schaffen. Aber Wenzels Charakteristik hat eine andere Logik als das Prinzip der formellen Typisierung. Die Wenzelslegende begründet in der Schilderung seines Lebens die Wichtigkeit verschiedener religiösen Praktiken im Lebenszyklus des Herr-

34 Josef Pekar̆, Svatý Václav, in: Svátováclavský Sborník. Bd. I/1 (wie Anm. 2), 9-102, hier 29, Anm. 20; Skazanija o načale (wie Anm. 5), C. 56; Josef Vajs, Postřžiny sv. Václava, in: Casopis katolického duchovenstva 95, 1929, 48-63; Max Büdinger, Zur Kritik der altböhmischen Geschichte, in: Zeitschrift für die österreichischen Gymnasien 8, 1857, 512-515.

35 Ruské redakce (wie Anm. 19), 14 f., 21; Charvátskohlaholská redakce (wie Anm. 19), 37. „Griechische Bücher" werden nur in den russischen Redaktionen erwăhnt (ebd. 15-21), wie auch in der Übersetzung Gumpolds (Druhá staroslovanská legenda [wie Anm. 9], 94).

36 Ruské redakce (wie Anm. 19), 15 f.., 22-24; Charvátskohlaholská redakce (wie Anm. 19), 37-39.

37 Es wird von Wenzels Teilnahme am Gottesdienst erzăhlt, nămlich von seinem regelmäßigen Besuch der von ihm in verschiedenen Orten errichteten Kirchen. Ruské redakce (wie Anm. 19), 16, 21 (s. auch $17 \mathrm{f}$.); Charvátskohlaholská redakce (wie Anm. 19), 38 f.; s. auch $40 \mathrm{f}$.

38 Ruské redakce (wie Anm. 19), 16, 24; Charvátskohlaholská redakce (wie Anm. 19), 39.

39 Ruské redakce (wie Anm. 19), 15 f., 19; Charvátskohlaholská redakce (wie Anm. 19), 39, 42. 
schers. ${ }^{40}$ Der Verfasser nimmt die Religiosität nicht als eine heroische Tugend, sondern als ein Element des Alltags wahr, das vor allem mit den Verwandtschaftsbeziehungen verbunden ist. ${ }^{41}$

Bemerkenswert sind zwei Aspekte in dem Modell eines frommen Herrschers, das in der Ersten altslawischen Legende geschaffen wurde. Zum einen sind seine religiösen Tugenden eben als Tugenden eines Heiligen nicht konzeptualisiert. Weder religiöse Tugenden noch Hinweise auf Gottes Vorsehung beweisen eine besondere Stellung Wenzels als eines Heiligen und Auserwählten in bezug auf das Modell eines ,guten Christen' ${ }^{42}$ Zum anderen leidet das Modell eines frommen Herrschers an bestimmender Eindeutigkeit. Die Wenzelslegende enthält praktisch keine allgemeingültige Charakteristierung Wenzels als eines weltlichen Herrschers. Die Hervorhebung der religiösen und die Beseitigung der weltlichen Aspekte bei der Rekonstruktion des Bildes ist durch das traditionelle hagiographische Schema einer linearen Gegenüberstellung von geistlichen Verdiensten und weltlicher Stellung nicht $\mathrm{zu}$ erklären. ${ }^{43}$ Zur Interpretation kann vielmehr die Tatsache dienen, daß der Verfasser das Problem einer religiösen Umdeutung der weltlichen Funktionen des Herrschers nicht beachtet und die Herrschaftspraktiken als eine selbstverständliche Gegebenheit außerhalb des Rahmens der Erzählung läßt. ${ }^{44}$

Die Darstellung des ,christlichen Herrschers' ist nur eines der Elemente im narrativen Programm der Ersten altslawischen Legende, in dem der Konflikt zwischen den Brüdern Wenzel und Boleslav einen zentralen Platz einnimmt. ${ }^{45}$ Indem der Verfasser die Geschichte des Mordes an Wenzel erzählt, ändert er wesentlich die Thematik und Stilistik der vorangegangenen Darstellung. Der Beschreibung der frommen Taten folgt die Erzählung über eine Reihe von Missetaten Boleslavs. Diese Teile der Lebensbeschreibung werden mittels einer religiösen Interpretation der Ereignisse korreliert: Der erste Teil handelt von den gottgefalligen Taten Wenzels, der zweite von den Untaten, die durch die Verleumdungen des Teufels hervorgerufen worden waren. ${ }^{46}$

$40 \mathrm{Zu}$ den Entwicklungsstufen gehören die Taufe, das Haareabschneiden (der kirchliche Segen), der Unterricht in den Grundlagen der Glaubenslehre, die Fürsorge für die Kirche und deren Geistliche, fromme Taten und die Teilnahme an kirchlichen Riten und letzten Endes die kirchliche Beerdigung und das christliche Gedenken.

41 Bemerkenswert ist, daß anders als in den lateinischen Viten im Zusammenhang mit Wenzels Religiosităt hier nie der Aspekt der Askese thematisiert wird.

42 Anders im slawischen Wenzels-Kanon: Kánon ke cti sv. Václava (wie Anm. 9), 137 ff.

43 Die Antinomie, weltlich-geistlich' ist der Ideologie der Legende fremd.

44 Das fehlende, aber offenkundig gemeinte Modell eines, weltlichen Herrschers' stattet der Autor im gesamten Text mit Elementen religiösen Charakters aus.

45 In diesem Zusammenhang ist die Tatsache bemerkenswert, daß es sich in der aus der VostokovLegende entstandenen kurzen Prologlegende ausschließlich um den Konflikt der Brüder und die Ermordung Wenzels handelt, während die Darstellung Wenzels als eines frommen Christen völlig ausgespart bleibt; Proložní legendy (wie Anm. 21), 65 ff.

46 Das spiegelt sich in einer Symmetrie der die Brüder betreffenden Metaphern wider: Einem der Brüder wird Gottesgunst erwiesen, der andere wird vom Teufel in Versuchung geführt; Wenzel tut das Gute, Boleslav und seine Anhänger schmieden eine feindselige Verschwörung. Recht oft werden Wenzels 
Verschieden ist auch die eigentliche narrative Struktur dieser Teile der Vita. Der folgerichtigen Darstellung mit umfangreichen deskriptiven Elementen folgt eine fragmentierte ,Erzăhlung der Ereignisse', deren logische und chronologische Verbindungen zwischen einzelnen Episoden nicht immer klar sind. ${ }^{47}$ Die Überzeugungskraft der Details, die Zersplitterung der Taten der handelnden Personen, die Fülle der direkten Rede schaffen einen Wirklichkeitseffekt in der Darstellung der Ereignisse. Sie können aber gleichermaßen die Kenntnisse des Verfassers widerspiegeln wie auch literarische Elemente darstellen. Davon zeugt insbesondere der Unterschied in den Details der verschiedenen Fassungen der Vita. ${ }^{48}$

Wenzels Ermordung wird in religiösen Kategorien bewertet, aber bei der Angabe von Handlungsmotiven wird kein einziges Mal der religiöse Diskurs benutzt. Im Unterschied zu den lateinischen Viten hat Wenzels Frömmigkeit keinen Zusammenhang mit seinem Mord. Sie dient weder als Grundlage seines Martyriums noch als Ursache für seinen Konflikt mit den rebellischen ,Großen' und seinem Bruder. Wenzels Untergang trăgt keine selbständige ethische Bedeutung - weder eine im eigentlichen Sinne religiöse noch eine sozial bedeutsame. Er geht als Opfer der Umstände zugrunde, seinen Aktionen sind jegliche Motivationen des freiwilligen Martyriums ${ }^{49}$ entzogen: Er möchte dem Tod entgehen, aber das gelingt ihm nicht. ${ }^{50}$ Auch als ein anschauliches Beispiel für die religiöse Verurteilung von Gewalttaten und Blutvergießen ist Wenzels Auftreten durch den Verfasser nicht dargestellt: Dem Bruder leistet er erfolgreichen Widerstand, und er erliegt erst den zu Hilfe gekommenen Handlangern Boleslavs. ${ }^{51}$ Darüber hinaus wird die Bewertung der Taten Boleslavs als Sünde ${ }^{52}$

Feinde unzweideutig „Teufel“ genannt; Ruské redakce (wie Anm. 19), 15-17, 22, 24; Charvátskohlaholská redakce (wie Anm. 19), 37, 39.

47 Manchmal ăhnelt sie einer Zusammenstellung von fragmentarischen, schnell nacheinander folgenden Angaben, wie z. B. in der Erzăhlung über die Vorbereitung des Mordes an Wenzel. So wechseln hier die Angaben über die Absichten von Boleslav und dessen Anhängern mit Angaben über Wenzels Taten; dabei fehlt zwischen ihnen jegliche grammatische oder logische Verbindung. Ruské redakce (wie Anm. 19), 16 ff., 24 ff.; Charvátskohlaholská redakce (wie Anm. 19), 39.

48 Der ,Realismus' der Erzăhlung kann sowohl das Festhalten-Wollen der realen Ereignisse als auch die Vorstellung des Autors wiedergeben, wie die Wirklichkeit nach seiner Meinung eigentlich gewesen sein sollte. In diesem Sinne ist die Darstellung der Ereignisse als eine authentische Widerspiegelung der Wirklichkeit in der Ersten altslawischen Legende ebenso problematisch wie in den lateinischen Legenden.

49 Dieses Motiv ist wichtig für die lateinischen Legenden und den slawischen Kanon: Kanon ke cti sv. Václava (wie Anm. 9), 137-145; s. auch: Pekař, Svatý Václav (wie Anm. 34), 89; Josef Vašica, Zur großmährischen und alttschechischen Hymnodie, in: Das heidnische und das christliche Slaventum. Acta 2. Congressus internationalis Historiae Slavicae Salisburgo-Ratibonensis anno 1969 celebrati. Bd. 2: Das christliche Slaventum. Beiträge zur literarischen Bildung der Slaven zur Zeit ihrer Christianisierung. Wiesbaden 1970, 159-163.

50 Ruské redakce (wie Anm. 19), 16 ff., 25 ff.; Charvátskohlaholská redakce (wie Anm. 19), 39 ff. Der einzige kurze Hinweis auf die Mőglichkeit, den Untergang Wenzels als einen freiwilligen Akt zu deuten, ist die Aussage, da $B$ er sich auf Gott verlie $B$, auch nachdem er von dem geplanten Attentat unterrichtet worden war. Aber gleichzeitig wird im Text präzisiert, daß der Fürst dieser Bedrohung keinen Glauben schenkte.

51 Ruské redakce (wie Anm. 19), 18, 26; Charvátskohlaholská redakce (wie Anm. 19), 41.

52 Ruské redakce (wie Anm. 19), 16, 19 f., 24, 28; Charvátskohlaholská redakce (wie Anm. 19), 38, 43. 
nicht weiter bekräftigt, denn sie werden nie als Resultate einer feindseligen Haltung gegenüber dem Glauben und - mit Ausnahme der brüderlichen Loyalităt - als Verstőße gegen Glaubensgebote charakterisiert.

Es ist anzumerken, daß fur die Konfliktdeutung hier nie die Denkfigur des dem Teufel widerstehenden Heiligen benutzt wird, während sie in den lateinischen Legenden den zentralen Platz einnimmt. ${ }^{53}$ Boleslav selbst ist eher ein Opfer des Teufels als ein Repräsentant des Bösen. Die Rivalităt Boleslavs und Wenzels hat keinen religiösen Untergrund: Die Rebellion der Gefolgschaft und Boleslavs wird weder als Konflikt der Feinde des Glaubens gegen einen,Gerechten' noch als ein Werkzeug des Teufels im Kampf gegen einen Heiligen, einen Träger der Gottesordnung, artikuliert. ${ }^{54}$ Die Antinomie der religiösen Einschătzungen fußt auf keiner Gegenüberstellung von religiös-ethischen Modellen: Sie wird als Schema nicht ausgewertet, ist also kein Werkzeug der Formalisation in bezug auf den Sinn des Konflikts. Wie werden dann im Text das Wesen des Konflikts und seine Ursprünge verstanden? Welche ethische und soziale Problematik hebt der Verfasser darin hervor, wenn er die christlich-moralische Sprache gebraucht?

Die Analyse zeigt hier, daß die Erste altslawische Legende keine klare formale Deutung der Konfliktursachen enthält. Die Taten Boleslavs werden wiederholt auf ein Eingreifen des Teufels und die Aufhetzung durch die bösen Ratgeber zurlckgefuhrt. In der kroatischen und der Menäen-Redaktion ${ }^{55}$ wird teilweise erklärt, warum sich Boleslav überreden ließ: Man habe ihm nämlich gesagt, daß der Bruder und die Mutter seine Ermordung beabsichtigten. Gleichzeitig enthălt die Vostokov-Redaktion eine eigenartige Inversion dieser Episode: Wenzels Gefolgschaft beschuldigt Boleslav und Drahomíra derselben Pläne. ${ }^{56}$ Das Fehlen irgendwelcher Erklärungen regt die Forschung gegenwärtig zu einer den Text ergänzenden Deutung von Ursachen und Umständen des Konflikts an. Dabei folgt man dem Verfasser der Minäen-Redaktion. Der russische Verfasser erklärt Boleslavs Feindschaft mit Analogien der ihm bekannten Boris-und-Gleb-Legende ${ }^{57}$, genauer: mit dem Wunsch Svjatopolks, seine Brüder zu ermorden und allein zu regieren. $\mathrm{Zu}$ einer rechtspolitischen Einschätzung gehört es, das Auftreten der furrstlichen Gefolgschaft gegen ihren Herrscher zu verurteilen. Der

53 Auch die englische Passio Edwardi mit der Erzăhlung, wie der König von seiner Stiefmutter ermordet wurde, die den Thron furr ihren eigenen Sohn okkupieren wollte, enthält keine ausfuhrliche Gegenüberstellung des Helden und seiner Feinde als religiöse Antipoden. Indem aber der Text bestimmte Elemente einer eigentlich politischen Erklärung des Mordes bewahrt, fuhrt er doch auch ein religiőses Motiv ein: Die Taten der Stiefmutter und ihrer Helfer werden als Ausdruck der Unzufriedenheit des Teufels mit der gutherzigen und frommen Regierung Edwards gedeutet; Edward, King and Martyr (wie Anm. 3), $3 \mathrm{f}$.

54 Anders als z. B. im Wenzels-Kanon.

55 Ruské redakce (wie Anm. 19), 22 f.; Charvátskohlaholská redakce (wie Anm. 19), 38.

56 Ruské redakce (wie Anm. 19), 15. Dabei ist es bezeichnend, daß keiner dieser Texte irgendeinen Kommentar zur Nachricht über die Verschwörung von Verwandten enthält. Alle Rezensionen füren sămtliche Erlauterungen dazu auf Verleumdung zurück.

57 Ebd. 24. 
Aufstand gegen den Herrscher wird mit Judas' Verrat $^{58}$ und weiter mit der jüdischen Verschwörung gegen Christus ${ }^{59}$ verglichen. Mit dieser - im gesamten Text einzigen - formalisierten Verallgemeinerung werden die dargestellten Ereignisse indes eher bewertet denn erklärt. $^{60}$

Das Motiv der bösen Ratgeber taucht wiederholt auf und ersetzt funktional die Erklärung der mit der Familienfeindschaft verbundenen Taten sowohl Boleslavs als auch Wenzels. Die Unklarheiten in der Lebensbeschreibung sowie die Mängel in der Deutung der Konfliktursachen können kaum mit dem etwaigen Motiv des Verfassers erklärt werden, aus Furcht vor dem noch lebenden Boleslav, dem Brudermörder und Fürsten, dessen Absichten zu verschleiern und dessen Verantwortung auf Boleslavs Ratgeber umzulenken. Denn der Verfasser bewertet bei der Darstellung der Ereignisse Boleslavs Taten ja eindeutig als Sünde. Plausibler erscheint die Deutung, daß prinzipielle Diskursspezifika der Ersten altslawischen Legende zugrundeliegen: Erstens wird der Sinn des Konflikts tatsächlich nicht in einer religiösen oder politischen Opposition gesehen; zweitens erfolgt die Deutung von Ereignissen nicht nach den Regeln rationaler, moralischer Kasuistik, also der Notwendigkeit, konkrete Handlungen mit formalen ethischen Normen und Regeln zu konfrontieren. Der Verfasser bleibt im Rahmen einer konkreten Situation. Er artikuliert in religiösen Toposkategorien die moralische und religiöse Bedeutung der Ereignisse, tut es aber nur in dem Maße, wie diese Bedeutung seiner eigenen Wahrnehmung einer konkreten Situation angepaßt werden kann. Unter anderem ist die Benutzung von zwei äußerst wichtigen und besonders breit entfalteten figurativen Angleichungen in der Legende recht bemerkenswert: Die Verschwörung gegen Wenzel wird gleich an drei Stellen mit der Verschwörung der Juden gegen Christus identifiziert $^{61}$ und Wenzels Tod den Leiden Christi und der Märtyrer angeglichen. ${ }^{62}$ In beiden Fällen ist beachtenswert, daß der Verfasser auf die Ähnlichkeit einer realen und einer typischen Situation hinweist und das Ebenbild der beiden bezeichnet - des Verrats am Herm durch

58 Ebd. 15, 22; Charvátskohlaholská redakce (wie Anm. 19), 38. Wahrscheinlich wurde es aus kirchlichen Gesetzen entlehnt: Dušan Třeštik, Miscellaniae k I Staroslovanské legendæ̌ o sv. Václavu, in: Československý Casopis historický 15, 1967, 337-342; Graus, La sanctification (wie Anm. 18), $560,564$.

59 Ruské redakce (wie Anm. 19), 17, 19, 24-26; Charvátskohlaholská redakce (wie Anm. 19), 39, 43.

60 Der Kontext gibt keine Antwort auf die Frage, welche Handlungen der Großen gemeint sind. War es eine Aufhetzung des Fürsten zu bösen Taten? Schließlich werden die Großen kritisiert, weil sie sowohl die Feindschaft zwischen Wenzel und seiner Mutter provoziert als auch Boleslav aufgehetzt hătten. War es im eigentlichen Wortsinn ein Aufstand gegen den Füsten, (,sie haben den eigenen Fürsten ermordet", schreibt der Verfasser) und wenn ja: wodurch wurde er hervorgerufen? Die russischen Fassungen schreiben, daß Wenzel den Großen zu jung war, aber dies prăzisiert nur die politische Konstellation und nicht die Ursachen der Ermordung. Ist diese Beschuldigung auch auf Boleslav bezogen, dessen Beratung mit den Großen der jüdischen Verschwörung gleichgesetzt wird?

61 Ebd. Das Verhalten der Ratgeber wird nicht nur mit den Taten des Judas verglichen, sondern auch mit denen der Juden, die Christus dem Gericht des Pilatus ausgeliefert hătten. Dasselbe Verfahren wird in der lateinischen Christian-Legende benutzt, aber die Deutungen selbst und deren interpretatorische Weiterverwendungen unterscheiden sich grundlich von denen in der Ersten altslawischen Legende; vgl. Křistanủv (wie Anm. 12), c. 7, 218.

62 Ruské redakce (wie Anm. 19), 19, 26; Charvátskohlaholská redakce (wie Anm. 19), 43. 
seine Umgebung in dem einen Fall und die Ungerechtigkeit des Untergangs wegen des Verrats im anderen Fall. Aber die Prozedur der Typisierung bleibt nicht darauf beschränkt. Im Grunde genommen sehen wir nicht nur, wie der Verfasser biblische Parallelen zieht, um den zu beschreibenden Ereignissen eine religiöse Bedeutung zu verleihen, sondern auch, wie er eine Annäherung der archetypischen Objekte als solche an die darzustellende Situation unternimmt. Der Text verurteilt unzweideutig die Situation des ,Verrats', die am häufigsten durch den Begriff „,böser, feindseliger Rat" beschrieben wird. ${ }^{63}$ Damit ist ein Verstoß gegen die dem Fürsten geschuldete Loyalităt gemeint. Dabei werden aber die Grundlagen der sozialen Solidarität nicht formalisiert, sondern als eine selbstverständliche Gegebenheit wahrgenommen: Der Verfasser verzichtet darauf, jegliche allgemeinen Prinzipien zu umreißen, deren Übertretung den Konflikt hervorruft. Die Natur dieses Konflikts bleibt irrational, denn seine Herkunft kann nur durch den Einbruch des übernatürlichen Teufelswillens gedeutet werden. ${ }^{64}$

Dabei bildet die Geschichte der Brüderfeindschaft einen bedeutsamen Kern der Legende, was u. a. die russischen Prologlegenden deutlich genug bestätigen, die das Motiv der bösen Ratgeber als Erklărungsmittel eliminieren. ${ }^{65}$ Um die Logik der Wahrnehmung und der Widerspiegelung der Ereignisse in der Ersten altslawischen Legende zu begreifen, muß man die Besonderheiten der eigentlich narrativen Struktur der Erzählung über die Ermordung Wenzels beachten. Einen wesentlichen Zug dieser Erzählung bildet die direkte Vereinigung von drei Konflikten, in denen die Familienmitglieder zusammenstoßen: Wenzel mit Drahomíra, Wenzel mit Boleslav, Drahomíra mit Boleslav. Der erste dieser Konflikte ist mit höchster Knappheit dargestellt und im Grunde genommen in die Beschreibung des Konflikts zwischen den Brüdern eingeschlossen. ${ }^{66}$ Die zwei weiteren sind praktisch in einen einzigen Bericht zusammengefaßt: Boleslavs Absicht, seine Mutter zu ermorden, folgt direkt auf die Ermordung seines Bruders. ${ }^{67}$ In den Beruhrungspunkten dieser Episoden verliert der Text seine Folgerichtigkeit, die einzelnen Linien des Sujets kreuzen sich und werden vermischt. Eine derartige ,Desorganisation' der narrativen Struktur ist keine einfache formal-literarische Besonderheit des Textes. Sie gibt seinen Bedeutungskern wieder, und zwar die Wahmehmung aller drei Episoden als der ihrer Natur nach ähnlichen Beispiele der Feindschaft innerhalb einer Familie.

Der Anfang der Erzählung über die Vorbereitung der Ermordung Wenzels zieht drei selbständige Episoden zu einem einheitlichen Ganzen zusammen. Vor der ersten Erwăhnung von Boleslavs Absicht und damit in unmittelbarer Verbindung wird ganz kurz die ,Rebellion' der Elite gegen Wenzel beruhrt. ${ }^{68}$ Die begonnene Geschichte des Konflikts zwischen den Brüdern wird ihrerseits durch eine kurze Mitteilung über die Feindschaft Wenzels gegen seine Mutter unterbrochen. Diese Feindschaft kommt mit der Reue Wenzels und seiner Versöh-

63 Ruské redakce (wie Anm. 19), 17, 24 f.; Charvátskohlaholská redakce (wie Anm. 19), 39.

64 Ruské redakce (wie Anm. 19), 15-17, 22, 24 f.; Charvátskohlaholská redakce (wie Anm. 19), 38 f.

65 Proložní legendy (wie Anm. 21), 65-67.

66 Ruské redakce (wie Anm. 19), 15 ff., 22 ff.; Charvátskohlaholská redakce (wie Anm. 19), 38 ff.

67 Ruské redakce (wie Anm. 19), 18, 26 ff.; Charvátskohlaholská redakce (wie Anm. 19), 41 ff.

68 Ruské redakce (wie Anm. 19), 15, 22; Charvátskohlaholská redakce (wie Anm. 19), 38. 
nung mit Drahomíra zum Abschluß. ${ }^{69}$ Dann kehrt der Verfasser wieder zu Boleslav und seinen Ratgebern zurück und erzăhlt folgerichtig die Ermordung des Fürsten. Diese Knappheit des Textes deckt die prinzipielle Homogenität der Wahmehmung zweier Situationen der Feindschaft Wenzels gegen die Mutter und der Brüderfeindschaft - durch den Verfasser auf. Beide Konflikte sind demnach Feindschaften innerhalb der Familie und kirchlich gesehen Sünde. Daneben gibt es im Text nicht nur einen Vergleich, sondern auch eine Gegenüberstellung des Verhaltens beider Brüder. Wenzel verkörpert den richtigen Weg zur Überwindung der Krise, d. h. Sündenreue und Versőhnung mit der Mutter; Boleslav steht hingegen für den negativen Weg, der zum Brudermord und zur Ausdehnung der Gewalttaten sowohl innerhalb als auch außerhalb der Familie führt.

Man kann noch einen Bruch in der Darstellung erkennen: Die Mitteilung uber den Tod des Helden wird mehrmals wiederholt und mit episodischen Erzählungen uber die Verfolgung der Anhänger Wenzels, das Schicksal des Leichnams und die Repressalien gegen Drahomíra unterbrochen. Die Abweichung von der Folgerichtigkeit der Darstellung entstellt die lineare Zeitperspektive der Ereignisse - die Übeltaten Boleslavs werden nicht nach der Ermordung Wenzels geschildert, sondern um den Mord konzentriert und erweisen sich dabei als zusammengebundene Elemente einer einheitlichen Handlung. Nicht zufallig folgt die abschließende Feststellung des Todes Wenzels ${ }^{70}$ nach der Beschreibung dieser verschiedenartigen und zeitlich zerstreuten Ereignisse. In ihrer Gesamtheit bilden gerade diese Ereignisse einen einheitlichen Akt des Brudermordes. Im weiteren wird aber die Folgerichtigkeit der Schilderung durch den Epilog wiederhergestellt, der uber die Reue Boleslavs und über die Überfuhrung des Leichnams Wenzels zum Ort der ewigen Ruhe im Prager Veitsdom informiert. Diese Episode ist gleichermaßen der letzte Akzent in der Geschichte der Bestattung Wenzels wie auch in der Geschichte der Familienfeindschaft.

Das Motiv der Reue Boleslavs ist für die Bedeutungsstruktur der Legende wichtig: Nicht zufällig wird es als Zeichen der Hinwendung zum Gerechten (d. h. zu Wenzel) gedeutet; es bestimmt auch die Überfuhrung des Leichnams nach Prag. ${ }^{71}$ Der Text erhält zwei Bedeutungsschwerpunkte: Der erste ist die Angleichung von Wenzels Tod an die Leiden Christi, der zweite die Reue Boleslavs. Beide Elemente werden zur Quintessenz der didaktischen Auswertung des Textes: die Verurteilung der Familienfeindschaft und die Versőhnung als ein religiös bedeutsamer Akt. Als wichtigste Besonderheit in der allgemeinen Struktur des Legendentextes bleibt die prinzipielle Ähnlichkeit des Konflikts zwischen Wenzel und Drahomíra und zwischen Boleslav und Wenzel. Dieses Schema bei der Schilderung der

69 Ruské redakce (wie Anm. 19), 15, 23; Charvátskohlaholská redakce (wie Anm. 19), 38. Dazu wird eine Erzăhlung über neue fromme Taten Wenzels beigefügt, was im Grunde genommen das Thema der Versöhnung fortsetzt; Ruské redakce (wie Anm. 19), 16, 23 f.; Charvátskohlaholská redakce (wie Anm. 19), $38 \mathrm{f}$.

70 Ruské redakce (wie Anm. 19), 19, 27 f.; Charvátskohlaholská redakce (wie Anm. 19), 42 f.

71 Ruské redakce (wie Anm. 19), 19 f., 28 f.; Charvátskohlaholská redakce (wie Anm. 19), 43. Diese Bedeutung ist $u$. a. auch in der Prologlegende über die Überführung Wenzels genau widergespiegelt; Proložní legendy (wie Anm. 21), 67 f. 
Familienfeindschaft ist mit drei untereinander verbundenen religiösen Akten identifiziert: Versuchung, Sünde und Reue.

In der Moralisierung der Familienfeindschaft identifiziert der Verfasser die Prinzipien der Familiensolidarităt und der Loyalităt mit der Befolgung der Gottesordnung und der Glaubensvorschriften; er wertet den religiös-moralischen Diskurs für die Bestimmung des Systems der Verbote im Rahmen der traditionellen Beziehungen, d. h. der Verwandtschaftsbeziehungen, aus. Die Idee, daß die Verwandtschaftsbeziehungen fur die Erhaltung der sozialen und religiösen Ordnung von fundamentaler Bedeutung sind, wird vom Verfasser mit Verweis auf die Autorität der Heiligen Schrift sowie auf die moralische Einschätzung der Ereignisse zum Ausdruck gebracht. Eine Schlüsselbedeutung für das Verständnis der Ideologie in der Ersten altslawischen Legende hat der Textanfang, der dem eigentlichen Erzăhlen uber die Ereignisse vorausgeht und eine Einfuhrung in die vorgeschlagene Deutung des Sinnes darstellt. Diese kurze Einleitung stellt eine Kompilation aus Bibelzitaten dar ${ }^{72}$, die den konzeptuellen Anfangssinn teilweise ändert oder wenigstens verengt. Die Zitate sind so ausgewählt, daß sie den Verfall von Verwandtschaftsbeziehungen als Sünde erscheinen lassen können. Der Verfasser bringt die dargestellte Geschichte typologisch in Wechselbeziehung mit der biblischen Prophezeiung. Der Verfall von verwandtschaftlichen Bindungen wird mit der biblischen Weissagung über den Sieg des Bösen ${ }^{73}$ und die Strafe der Schuldigen gedeutet. Weiter beurteilt der Verfasser nach der religiösen Kategorie der Sünde auch Tugenden und Taten der handelnden Personen, die nur mit der Aufrechterhaltung des Familieneinvernehmens zu tun haben. So wird im Text Wenzels Verhalten gegenüber seiner Mutter als religiöse „Nächstenliebe“ und als Einhaltung der Gebote gekennzeichnet ${ }^{74}$, und Feindschaft und Feindseligkeit werden anhand der Konflikte zwischen Wenzel und seiner Mutter bzw. Boleslavs mit Wenzel und der Mutter als Sünde sowie als ein Ergebnis teuflischer Eingebung beurteilt. Dem Text bleibt aber zugleich eine andere Konzeption der Verwandtschaftsbeziehungen fremd, und zwar die Idee einer Unterordnung unter die religiöse Pflicht. $^{75}$

Die Antinomie des gerechten und ungerechten Verhaltens wird in religiösen Sentenzen und Metaphern vorgestellt, obwohl die Einschätzung der Handlungen Wenzels, Boleslavs und Drahomíras im Grunde genommen durch die Normen nicht nur der religiösen Ethik, sondern auch durch die der Familiensolidarität bestimmt wird. Nicht zufällig benutzt der slawische Text fur die Definition der Helden - im Unterschied zu den lateinischen Legenden - statt der universellen ethischen Prädikate oder Metaphern ständig die Begriffe, die deren

72 Ruské redakce (wie Anm. 19), 14, 20; Charvátskohlaholská redakce (wie Anm. 19), 36.

73 Wenn der Verfasser eine breitere und universelle Voraussage des Zerfalls von sozialen Kontakten und des moralischen Verfalls ,am Ende dieser Welt" aus dem 2. Paulus-Brief an Timotheus (3, 1-3) zitiert, beschränkt er den Sinn dieser Vorhersage auf den Zerfall der Verwandtschaftsbeziehungen und ändert somit den allgemeinen Sinn des Bibeltextes.

74 Ruské redakce (wie Anm. 19), 16, 23; Charvátskohlaholská redakce (wie Anm. 19), 38.

75 Hippolyte Delehaye, Les passions des martyrs et les genres littéraires. Bruxelles 1921; ders., Sanctus. Essai sur le culte des saints dans l'antiquité. (Subsidia hagiographica, vol. 17.) Bruxelles 1927; Heffernan, Sacred Biography (wie Anm. 1), 157 ff. 
Verwandtschaft bezeichnen („Bruder“, „Mutter“). In der Ersten altslawischen Legende besitzt der ,Verwandtschaftsdiskurs' eine wesentliche Eigentümlichkeit: Er setzt keine Formalisierung der Verwandtschaftsbeziehungen durch irgendwelche Normen des Verhaltens voraus. Die Verwandtschaftssolidarität wird als fundamentale und irrationale Gemeinsamkeit wahrgenommen, fur deren Beschreibung vor allem Begriffe aus der Sphäre der emotionalen Năhe - der Liebe oder der Feindschaft und Feindseligkeit - benutzt werden.

Indem der Verfasser der Ersten altslawischen Legende die Geschichte der Familienfeindschaft darstellt, moralisiert er deren Sinn, überträgt die Einschätzung der Ereignisse in die Sprache der christlichen Kategorien, vernachlässigt aber im Grunde das eigentlich ethische und formalisierende Potential der christlichen Reflexion. Die Verwandtschaftsbeziehungen werden vom Verfasser nicht so sehr erklärt als vielmehr mythologisiert, indem er ihre Bedeutung als wichtigstes Element der religiös sanktionierten Weltordnung anerkennt. Als die am deutlichsten formulierte, sozial bedeutsame ,Empfehlung' des Textes kann die Verurteilung der Feindschaft innerhalb einer Verwandtschaftssippe bestimmt werden. Der Text weiht mit der Autorität der religiösen Begriffe die traditionellen Modelle und Praktiken, indem er ihnen Elemente der Ordnung beisteuert, aber er eröffnet keine Wege zu deren echten systematischen Revision im Kontext der religiös-ethischen Normen.

Die in den lateinischen Legenden vorhandene Erzählung über Wenzel unterscheidet sich dem Sujet nach nicht allzusehr von der Erzählung in der Ersten altslawischen Legende ${ }^{76}$, und doch trägt die Deutung der Ereignisse einen prinzipiell anderen Charakter. Dabei beschränken sich die Unterschiede keineswegs auf die Darstellung der einzelnen Personen. Es handelt sich um eine andere Art der Wahrnehmung, Schilderung und Deutung der Ereignisse, d. h. um eine andere narrative Strategie. Die lateinische Legenden, die das Bild und die Geschichte Wenzels reproduzieren, gleichen Wenzel konsequent einem typischen Heiligenmodell an. Die Legenden beschränken sich nicht auf die Verherrlichung Wenzels ${ }^{77}$, sondern beweisen seinen heiligen Status durch die Gesamtheit der signa (der Zeugnisse seiner Auserwăhltheit) und der ethischen Kennzeichen (d. h. der ihm zugeschriebenen Tugenden). Eine systematische Betrachtung der religiösen Charakteristika und Motivationen erlaubt es, den Sinn der Geschichte des Brudermordes ganz anders zu artikulieren, als es in der Ersten altslawischen Legende der Fall ist. Die Geschichte hört auf, von einem Familienkonflikt zu handeln, und gewinnt die Bedeutung der typischen Reproduktion eines universalen Modells des Kampfes zwischen Gut und Böse, zwischen Gott und Teufel. ${ }^{78}$ Die Verteilung der Rol-

76 Sie enthălt gleichartige Elemente der beschriebenen Ereignisse: Wenzels Geburt in einer Fürstenfiamilie, seine Thronbesteigung, die Schilderung seiner frommen Taten, die Konflikte mit der Mutter, dem Bruder und den Mitgliedern der Elite, die tragischen Folgen der Ermordung Wenzels fur dessen Anhänger, die Erdbestattung und spătere Überfuhrung der Leiche nach Prag.

77 Život sv. Václava. Pł̌eložil Josef Truhlár̆, in: FRB. Bd. I/2 [Crescente fide], 183-190, hier 190: apud eundem clementem patrem sis idoneus interventor; Gumpoldủv život Václava knižete Českého. Přeložil František J.. Zoubek, in: ebd. [Gumpold], Prologus, 147: per suffragia dilecti tui Vencezlavi militis; c. 24, 163: post constantissimi triumphum athletae; c. 22, 161, u. a. m. Vgl. auch: Kristanův (wie Anm. 12), c. 7, 219, u. a.; Vavł̌ince, Mnicha sv. Benedikta (wie Anm. 13), c. 11, 178.

78 Z. B. in Crescente fide: Semper contra antiquum hostem scutum fidei sumebat et invisibile spiritus sancti gladium, quod est verbum dei; Život sv. Václava (wie Anm. 77), 186; diabolo fiebant plurima 
len im Rahmen dieses Konflikts auf die Teilnehmer der, realen` Ereignisse gibt die von den Texten vorgeschlagene Bewertung der Taten vor.

Der Schlüssel zum ideologischen Programm der Texte ist die von diesen Texten modellierte Gestalt des Heiligen. Zwei Aspekte haben dabei eine prinzipielle Bedeutung. Der erste besteht darin, daß Wenzel als ein mustergültiger Christ dargestellt wird, dessen Frömmigkeit nicht nur in verschiedenartigen Taten zum Ausdruck kommt, sondern ihn auch direkt an den konsequenten Asketismus und die religiöse Buße eines Kirchendieners heranrückt. ${ }^{79}$ Zweitens vergegenwärtigen alle Legenden das Problem der Korrelation zwischen der Stellung eines Heiligen und derjenigen eines Herrschers. ${ }^{80}$ Und je nachdem, wie dieses Problem gelöst wird, werden auch die Gesamtkonzeption der Heiligkeit und die ethische Deutung der Geschichte aufgebaut, die um die Ermordung des Heiligen kreist.

Die Heiligkeit des Helden ist sowohl eine mystische, übernatürliche Gabe als auch Ergebnis der Befolgung von Normen des religiösen Lebens. Alle Texte vermerken die ursprüngliche Hinneigung des Helden zum Glauben und kennzeichnen ihn demnach als einen „Gottesauserwăhlten“. ${ }^{81} \mathrm{Thr}$ Bild von einer Mission des Heiligen konkretisieren die Legenden in verschiedenen Formeln: Der Heilige zeuge von dem unaufhörlichen Wirken Gottes unter den Menschen (Laurentius-Legende ${ }^{82}$ ); er erscheine als ein furr alle belehrendes Muster des frommen Lebens (Gumpold-Legende ${ }^{83}$ ); er erfulle die Funktionen der Verbrei-

detrimenta; ebd. 185; in der Christian-Legende: miles Christi quanta domino militans detrimenta zabulo intulerit, quantosque manipulos Christi in horreo ipsius fidelis servus aggregarit; Krištanův (wie Anm. 12), c. 6, 213.

79 Crescente fide: perversus est a clericis, et est monachus; Život sv. Václava (wie Anm. 77), 185; $H i$ quoque omnes magistri mirabantur in doctrina eius (ebd.); s. auch bei Křištanův (wie Anm. 12), c. 5 , 210; c. 7, 217, und Gumpoldův život (wie Anm. 77), c. 8, 152 f.; c. 11, 154; c. 14, 157.

80 Z. B. Crescente fide: Tum praedictus illustris puerulus permanens in principatu minime discessit a disciplina. Fidelis namque erat et sapiens, et verax in sermone, et iustus in iudicio; Život sv. Václava (wie Anm. 77), 183; sed et in quadragesimali tempore per arduum callem pergebat de civitate in civitatem ad ecclesias pedester discalceatus, ita ut radicitus in eius vestigiis cruor apparebat; ebd. 184. Gumpold: sed hoc ambiguum non diu mediastinum tractatus, quam sagaciter arripiens callem, ut neque hoc seculariter agendum omisisset, vel istud ob coelestia tendendum a se neglegi in futurum non expavisset; Gumpoldủv život (wie Anm. 77), c. 5, 149. Vgl. Ruotgers Vita (wie Anm. 4), c. 14, 13: ornanda interius, numienda in secularibus, ornanda in spiritualibus; $\mathbf{s}$. auch Friedrich Lotter, Die Vita Brunonis des Ruotger. Ihre historiographische und ideengeschichtliche Stellung. Bonn 1958, 122 f.; ders., Das Bild Brunos I. von Köln in der Vita des Ruotger, in: Jahrbuch des Kölnischen Geschichtsvereins 40, 1966, 19-40; s. auch die Vita Edwardi regis qui apud Westmonasterium requiescit: Mulierem inquam cunctis nobilibus matronis siue regie et imperatoriae dignitatis personis in exemplo uirtutis et honestatis anteponendam, tam ad Christiani cultus religionem quam ad mundi dignitatem seruandam; The Life of King Edward who rests at Westminster. Attributed to a monk of St. Bertin. Ed. Frank Barlow. $2^{\text {nd }}$ ed. Oxford 1992, 64.

81 Z. B. Crescente fide: dei inspiratione; Život sv. Václava (wie Anm. 77), 184, dei instinctu (ebd. 183); Gumpold: deo dilectum Vencezlaum; Gumpoldův život (wie Anm. 77), c. 3, 148; deo plenus iuvenis (ebd. c. 7, 150); Christian: olym electus dux beatus Wenceslaus; Křistanův (wie Anm. 12), c. 5, 209; vir deo carus armis fidei repellens; ebd. c. 5, 210, u. a.; vgl. auch Vavrince, Mnicha sv. Benedikta (wie Anm. 13), Prologus, 167 ff.; c. 6, 173; c. 9, 176.

82 Vavřince, Mnicha sv. Benedikta (wie Anm. 13), Prologus, $167 \mathrm{f}$.

83 Gumpoldủv život (wie Anm. 77), Prologus, 147. 
tung des Glaubens und der Überwindung des Übels. ${ }^{84}$ Bei all ihren Unterschieden weisen die Texte gleichermaßen auf die eschatologische Natur eines Heiligen hin. Die Aufzählung der Tugenden umreißt die Gestalt eines mustergultigen Christen. ${ }^{85}$ Das Thema des Martyriums ist in den Legenden nur eines der Elemente im Gesamtaufbau, gedeutet als eine weitere Bestătigung der religiösen Auserwăhltheit, des Gehorsams und der religiösen Verpflichtung des Helden. Eine Ausnahme bildet nur die Laurentius-Legende, in der das Martyrium zum zentralen Element der Heiligkeit wird, das alle ubrigen Eigenschaften der Gestalt zusammen$\mathrm{faßt}^{86}$

Die Frömmigkeit eines Heiligen wird durch einen standardisierten Satz von Eigenschaften gekennzeichnet, der in allen Texten reproduziert wird. Die Verfasser unterstreichen die Begabung Wenzels beim Erlernen der Glaubenssätze und bei der Umformung der gewonnenen Kenntnisse in ethische und moralische Grundsătze. ${ }^{87}$ Die persőnliche Religiosität ist entsprechend der Topik der Mönchsfrömmigkeit stilisiert ${ }^{88}$ und besteht aus dem Gebetsdienst $^{89}$, dem heimlichen Besuch der Kirche ${ }^{90}$, der (heimlichen) Erfullung bestimmter

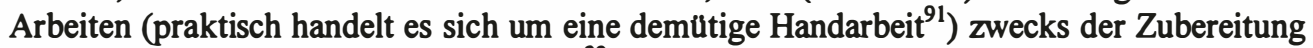
von Wein und Brot fur das Abendmahl ${ }^{92}$, aber auch dem Fasten. Bis auf die LaurentiusLegende schildern alle Legenden den Heiligen als einen Asketen, und Crescente fide treibt

84 Z. B. Křstanův (wie Anm. 12), c. 5, 210: Princeps siquidem noster, qui a nobis in regni fastigio sublimatus est, peruersus a clericis et ceu monachus factus, per abruptam et adswetam vitiorum nostrorum semitam nos gradi non sinit.

85 Robert Folz, Les saints rois du Moyen Âge en Occident. VI $-\mathrm{XIII}^{\mathrm{e}}$ siècles. (Subsidia hagiographica, vol. 68.) Bruxelles 1984, 33 ff., 56 ff. Vgl. auch die spăteren Legenden, etwa: Ut annuntietur, in: Paul Devos, Le dossier de saint Wenceslas dans un manuscrit du XIII' siècle (codex bollandianus 433), in: Analecta Bollandiana 82, 1964, 87-131; Oriente iam sole, in: Pekar̆, Die Wenzels- und LudmilaLegenden (wie Anm. 2), 409-430; Carolus IV., Hystoria nova de sancto Wenceslao martyre, duce Bohemorum, in: Die St. Wenzelslegende Kaiser Karls IV. Einleitung, Texte, Kommentar. Hrsg. v. Anton Blaschka. (Quellen und Forsch. aus dem Gebiete der Geschichte. Bd. 14.) Prag 1934, 64-80.

86 Vavřince, Mnicha sv. Benedikta (wie Anm. 13), Prologus, 167 f.; (...) quem olim noverat ad suae participium lucis fore quandoque cum martyrii laurea perventurum (ebd. c. 3, 170); (...) qui perenniter regnaturus cum sanctis meruit martyribus coronari (ebd. c. 3, 171); beatissimus martyriali sit laurea coronatus (ebd. c. 11,178); s. auch ebd. cc. 4, 5, 9-11.

87 Život sv. Václava (wie Anm. 77), 183-185; Gumpoldủv život (wie Anm. 77), c. 4, 149; c. 13, 155 u. a; Krrištanúv (wie Anm. 12), c. 3, 205; c. 5, 209 f.; c. 6, 213; Vav̛rince, Mnicha sv. Benedikta (wie Anm. 13), c. 4, $171 \mathrm{ff}$.

88 Die Laurentius-Legende bildet hier eine Ausnahme.

89 Život sv. Václava (wie Anm. 77), 183-185; Gumpoldủv život (wie Anm. 77), c. 4, 149; c. 12, 155 u. a; Kłištanův (wie Anm. 12), c. 5, 210; c. 6, 213.

90 Život sv. Václava (wie Anm. 77), 184; Gumpoldủv život (wie Anm. 77), c. 8, 152; Krił̌stanův (wie Anm. 12), c. 6, 214; Vavřince, Mnicha sv. Benedikta (wie Anm. 13), c. 4, $171 \mathrm{ff}$.

91 So bes. bei: Gumpoldúv život (wie Anm. 77), c. 8, 153.

92 Život sv. Václava (wie Anm. 77), 184 f.; Gumpoldủv život (wie Anm. 77), c. 8, 152 f.; Křšstanủv (wie Anm. 12), c. 6, $214 \mathrm{f}$. 
diese Eigenschaft bis zum äußersten, wobei auch die persönliche Keuschheit des Helden unterstrichen wird. ${ }^{93}$

Ein weiteres wichtiges Element der Frömmigkeit ist die regelmäßige, die Anforderungen an Laien übertreffende Teilnahme am kirchlichen Ritual- und Liturgieleben. ${ }^{94}$ Den Helden kennzeichnet eine lebhafte, intensive Beziehung zum Klerus: Teilnahme an Unterhaltungen und Disputen, Anwerbung von Klerikern und Gelehrten aus verschiedenen Ländern für Böhmen, Achtung der bischöflichen Autorität. ${ }^{95}$ Wegen dieser mustergültigen Frömmigkeit wird Wenzel - trotz seines Laienstatus' - auf die Stufe des Klerus gestellt, d. h. auf die der ,berufsfrommen' Geistlichen. Die konsequente Assoziation eines heiligen Laien mit einer asketischen Art der Frömmigkeit (diese Verbindung kennzeichnet alle Legenden außer der Laurentius-Legende) findet Parallelen in der lateinischen Hagiographie des 10. und beginnenden 11. Jahrhunderts. Manche Legenden dieser Zeit zeugen von der Konstituierung einer neuen Auffassung von Heiligkeit. Im Rahmen dieser Auffassung entsteht das Modell einer ,mustergültigen Frömmigkeit' in der Laienwelt, das den Rahmen der früheren mönchsasketischen Heiligkeitskonzeption überwindet. Gleichzeitig folgte die neue Konzeption der Bedeutungsdominante der älteren, die eine Identität der mustergültigen Frömmigkeit und der persönlichen Askese prätendierte. ${ }^{96}$

$\mathrm{Zu}$ den wichtigsten Charakterzügen Wenzels gehören Taten, die ihn als Förderer des kirchlichen Lebens auszeichnen. Alle Legenden benutzen den Topos seiner Sorge um die Kirche und den Klerus einschließlich der Gründung von neuen Kirchen, materieller Fürsorge

93 Vulto procerus, et corpore castus, ita ut coelebs libenti animo optabat vite finire; Život sv. Václava (wie Anm. 77), 186. Anders in der Christian-Legende und in der slawischen Übersetzung Gumpolds; vgl. Druhá staroslovanská legenda (wie Anm. 9), c. 16, 106.

94 Dieses Motiv wird besonders in der Christian-Legende hervorgehoben: Krištanův (wie Anm. 12), c. 7, $217 \mathrm{f}$.

95 Život sv. Václava (wie Anm. 77), 185 ff; Gumpoldủv život (wie Anm. 77), c. 7, 151 ff.; c. 12, 154 ff; c. 15, 157; c. 16, $157 \mathrm{ff}$; Krištanúv (wie Anm. 12), c. 3, 205; c. 5, 209 f.; c. 6, 213 ff. Anders bei Vavłrince, Mnicha sv. Benedikta (wie Anm. 13), cc. 4 f, 172 ff.

96 Patrick Corbet, Les saints ottoniens. Sainteté dynastique, sainteté royale et sainteté féminine autour de l'an mil. (Francia, Beih. 15.) Sigmaringen 1986, 233 ff.; Claude Carozzi, La vie du roi Robert par Helgaud de Fleury. L'historiographie en Occident du $V^{\text {ime }}$ au XV'me siècle, in: Annales de Bretagne 87, 1980, 219-235; ders., Le roi et la liturgie chez Helgaud de Fleury. in: Hagiographie, cultures et societés. Paris 1981, 417-432; Jean Chelini, La vie religieuse des laïcs dans l'Europe carolingienne. Diss. phil. Paris 1979; Frantisek Graus, Volk, Herrscher und Heiliger im Reich der Merowinger. Studien zur Hagiographie der Merowingerzeit. Prag 1965; Joseph-Claude Poulin, L'ideal de sainteté dans l'Aquitaine carolingienne. Quebec 1975; Derek Backer, „Vir Dei“. Secular Sanctity in the Early Tenth Century, in: Popular Belief and Practice. Ed. Geoffrey J. Cuming. Cambridge 1972, 41-53; Janet L. Nelson, Royal Saints And Early Medieval Kingship, in: Sanctity and Secularity. The Church and the World. Ed. Derek Baker. Oxford 1973, 39-44; Friedrich Lotter, Das Idealbild adliger Laienfrömigkeit in den Anfängen Clunys. Odos Vita des Grafen Gerald von Aurillac, in: Benedictine Culture (750-1050). Ed. Willem Lourdaux/Daniel Verhelst. Leuven 1983, 76-95; Joel T. Rosenthal, Edward the Confessor and Robert the Pious. 11th Century Kingship and Biography. (Medieval Studies, vol. 33.) Toronto 1971, 7 ff.; Pierre Riché, Ecoles et enseignement dans le Haut Moyen Âge. Fin du V siècle - milieu du XI ${ }^{e}$ siècle. Paris 1989, 305. 
für den Klerus sowie der Pflege der Glaubensverbreitung unter der Bevölkerung. ${ }^{97} \mathrm{Zu}$ den Besonderheiten von zwei Texten - der Christian-Legende und der Gumpold-Legende - kann man auch die Ablehnung der Heidenkulte durch Wenzel zählen. ${ }^{98}$ Hier wird das mustergültige Verhalten des Heiligen an der damals gegebenen kirchlichen Situation in Böhmen gezeigt. ${ }^{99}$ Wenzel wird als Hauptforderer der Kirche in Böhmen vorgestellt. ${ }^{100}$ Daneben erhält dieses Motiv in den lateinischen Texten eine ergänzende Aufgabe. Wenzels Tätigkeit, die in den Kontext der Erzählung über die Bekehrung und die frommen Taten seiner Vorfiahren eingeschlossen ist ${ }^{101}$, erhält den Rang des Hauptereignisses in der christlichen Geschichte Böhmens. ${ }^{102}$

Eine besondere Kategorie der frommen Taten bilden Barmherzigkeit und Wohltätigkeit. ${ }^{103}$ Alle Texte nennen ohne Ausnahme unter den gepriesenen Tugenden Mitleid und Barmherzigkeit Wenzels mit den Kranken, sozial Gedemütigten, Benachteiligten und Verurteilten. Das Thema der Barmherzigkeit kreuzt sich mit den Motiven der Almosenfreigiebigkeit und der Sorge um das Wohlergehen des Klerus. ${ }^{104}$ Die Barmherzigkeit ${ }^{105}$ mit den

97 Das Motiv der Sorge für das kirchliche Leben ist ein typisches Charakteristikum des frommen Herrschers, ein wichtiger Bestandteil der kirchlichen Konzeption der Funktionen der Macht und eines der populärsten Motive der königlichen Hagiographie; vgl. dazu die Titel in Anm. 96.

98 Kř̉šnunv (wie Anm. 12), c. 6, 215, u. a.; Gumpoldủv život (wie Anm. 77), c. 13, 156.

99 S. z. B. die Viten Adalberts: S. Adalberti Pragensis episcopi et martyris vita prior. Hrsg. v. Jadwiga Karwasinska. (MPH NS., Bd. 4/1.) Warschau 1962; S. Adalberti Pragensis episcopi et martyris vita altera auctore Brunone Querfurtensi. Hrsg. v. Jadwiga Karwasinska. (MPH NS., Bd. 4/2.) Warschau 1969, 3-41. Das Vorhandensein dieses Themas zeugt vom bewußten Bestreben der Kirche, auf die weitere Beschränkung traditioneller Praktiken hinzuwirken, und nicht nur derjenigen, die mit dem Kult im engeren Sinne verbunden waren.

100 Das erinnert auch an die Behauptungen der Ersten altslawischen Legende.

101 Život sv. Václava (wie Anm. 77), 183; Gumpoldủv život (wie Anm. 77), cc. 1-3, 147 ff.; Kłrištanův (wie Anm. 12), cc. 2-5, 202 ff;; Vavłince, Mnicha sv. Benedikta (wie Anm. 13), cc. 2 f., 170 ff.

102 Siehe auch die spătere Tradition, z. B.: Von sant Wentzlaus dem künig, in: Der Heiligen Leben. Bd. 1: Der Sommerteil. Hrsg. v. Margit Brand u. a. (Texte und Textgeschichte, Bd. 44.) Tübingen 1996, 578-580, hier 579.

103 Vgl. zu diesem Thema: Corbet, Les saints ottoniens (wie Anm. 96), 94 ff; Lothar Bornscheuer, Miseriae regum. Untersuchungen zum Krisen- und Todesgedanken in den herrschaftstheologischen Vorstellungen der ottonisch-salischen Zeit. (Arbeiten zur Frihmittelalterforschung, Bd. 4.) Berlin 1968, 157 ff; Carozzi, La vie (wie Anm. 96); Helmut Richter, Die Persönlichkeitsdarstellung in cluniazensischen Abtsviten. Diss. phil. Erlangen-Nürnberg 1972; Poulin, L'ideal de sainteté (wie Anm. 96), $81 \mathrm{ff}$.

104 Kr̉štanúv (wie Anm. 12), c. 3, 205 f. Vgl. zu Ludmila: Die Lebensbeschreibung der Kaiserin Adelheid (wie Anm. 4), cc. 4, 11, 13, 20. Zum Begriff pauperes Christi: Pierre-André Sigal, Pauvreté et charité aux XI'me et XII'ime siècles d'après quelques textes hagiographiques, in: Etudes sur l'histoire de la pauvreté. Ed. Michel Mollat. Vol. 1. Paris 1974, 141-162.

$105 \mathrm{Karl} \mathrm{Bosl}$, Potens und Pauper. Begriffsgeschichtliche Studien zur gesellschaftlichen Differenzierung im frühen Mittelalter und zum „Pauperismus“ des Hochmittelalters, in: Alteuropa und die moderne Gesellschaft. Fschr. Otto Brunner. Red. Alexander Bergengruen/Ludwig Deike. Göttingen 1963, 61-87; Jacques Fontaine, Hagiographie et politique de Sulpice Severe à Venance Fortunat, in: Revue d'histoire de l'Eglise de France 62, 1976, 113-140; Hans Hubert Anton, Fürstenspiegel und Herr- 
Benachteiligten, eine Tugend des Heiligen, die dessen Funktion beim Ausgleich sozialer Ungerechtigkeit charakterisiert, wird in den einzelnen Texten verschieden gedeutet. Es ist merkwürdig, daß die in Böhmen verfaßten Legenden dieses Thema nur formal als einen unentbehrlichen Topos der mustergültigen Frömmigkeit reproduzieren, indem sie die eigentliche ,soziale' Barmherzigkeit von der Sorge für die Kirche nicht unterscheiden. Die Gumpold- und Laurentius-Legenden betonen sogar den eigentlichen sozialen Tenor dieses Motivs, d. h. die Funktionen der Obhut und des Schutzes.

Dabei assoziieren beide Autoren das Motiv mit verschiedenen Tätigkeitstypen. Für den Verfasser aus Monte Cassino ist dies eine Tătigkeit, die mit der sozialen Gönnerschaft im eigentlichen Wortsinne verbunden ist und den Ausgleich der ,untersten' Schicht mit der Elite voraussetzt: Wenzel zieht die „Armen“ den „Vornehmen“ vor, verteilt auf die „Armen“ sein Vermögen, bildet aus den „Armen“ sein Umfeld. ${ }^{106}$ Das Thema der Barmherzigkeit, gedeutet als enge Beziehung mit den sozial Gedemütigten und als konkrete Wohltätigkeit, war der früheren Wenzelshagiographie fremd, erhielt aber in der späteren hagiographischen Tradition eine wesentliche Bedeutung. ${ }^{107}$

Gumpold versetzt das Motiv der Barmherzigkeit von der Ebene der sozialen Wohltätigkeit auf diejenige sozialer Herrscherpflichten: Freigiebigkeit bei Schenkungen, Schutzgewährung, Verteilung der Geschenke sowohl auf die Vornehmen als auch auf die Armen und Barmherzigkeit im Gerichtsverfahren. Die Barmherzigkeit mit Verhafteten und Verurteilten, die Milderung der Rechtssprüche und die Gleichberechtigung der Armen und der Vornehmen vor Gericht ${ }^{108}$ werden zu den wichtigsten Eigenschaften Wenzels in Gumpolds Werk. Eine der fundamentalen christlichen Tugenden legt Gumpold als Basis für die Verwirklichung von Herrscherfunktionen: der Rechtsprechung und der Aufrechterhaltung der Gerechtigkeit in der Gesellschaft. ${ }^{109}$ Der gemeinsame Zug der Texte von Laurentius und Gumpold besteht darin, daß die religiöse Tugend des Mitleids und der Barmherzigkeit von beiden Verfassern nicht nur als eine einfache fromme Praxis, sondern auch als die wichtigste Pflicht eines christlichen Herrschers gedeutet wird, eine Pflicht, die aus der Veränderung und der Vervollkommnung überlieferter sozialer Normen besteht. ${ }^{110}$

Bei der Beurteilung der Frömmigkeit des Heiligen lassen die lateinischen Legenden gleichzeitig sowohl die Kontinuităt des allgemeinen Schemas als auch den Unterschied in der Akzentuierung erkennen. Die Aussonderung irgendeines Themas (z. B. der persönlichen

scherethos in der Karolingerzeit. (Bonner Hist. Forsch., Bd. 32.) Bonn 1968; Egon Boshof, Königtum und Königsherrschaft im 10. und 11. Jahrhundert. (EdG, Bd. 27.) München 1993.

106 Vavřince, Mnicha sv. Benedikta (wie Anm. 13), c. 4, 171 f.; c. 6, 173. Laurentius verbindet das Motiv der Barmherzigkeit mit dem Thema der Freigiebigkeit, die als Bereitschaft gedeutet wird, das eigene Vermögen aufzuopfern. Es ist die einzige frühe Wenzels-Legende, in welcher der Topos der frommen Armut betont und mit sozialem Inhalt versehen ist. Vgl. Crescente fide: Cilicio aspero subtus indutus, desuper vestibus regalibus circumamictus; Život sv. Václava (wie Anm. 77), 184.

107 Z. B. Von sant Wentzlaus (wie Anm. 102), 578.

108 Gumpoldủv život (wie Anm. 77), cc. 5-8, 149 ff.; vgl. Vajs, Sborník (wie Anm. 2), c. 5, 91 ff.

109 Gumpoldủv život (wie Anm. 77), c. 5-7, 149 ff.

110 Die Tugend der „Barmherzigkeit“ wird von der religiösen in die soziale Sphăre übertragen und mit der Vervollkommnung der „Brăuche“ des sozialen Lebens und des „Rechts“ in Ubereinstimmung mit dem christlichen Gesetz verbunden. 
Askese in Crescente fide; Bekämpfung der üblen, heidnischen Sitten und Teilnahme an liturgischen und rituellen Handlungen in der Christian-Legende ${ }^{111}$; Barmherzigkeit im Gerichtsverfahren in der Gumpold-Legende; soziale Obhut und Auserwähltheit für Martyrium in der Laurentius-Legende) spiegelt die Unterschiede im intellektuellen, sozialen und geistigen Kontext jeder der genannten Legenden wider. Daneben wird aber die Idee der übernatürlichen Herkunft der Tugenden des Heiligen und der religiösen Natur seiner Mission zum fundamentalen Prinzip für die Repräsentation der Gestalt Wenzels bei allen Legendenverfassern. Seine Religiosität wird als Gottesdienst (officium divinum) gekennzeichnet $^{112}$, der auf der Verwirklichung grundlegender Tugenden fußt: Demut, Barmherzigkeit und Mitleid. ${ }^{113}$

Ein wichtiges Element bei der Gestaltung der Figur Wenzels ergibt sich aus dem Problem des Verhältnisses zwischen Heiligkeit und Herrschaft. Die Frage der Vereinbarkeit bzw. der gegenseitigen Durchdringung beider markiert die Scheidelinie, die die Texte in zwei Gruppen teilt: Auf einer Seite befindet sich Crescente fide, auf der anderen die vier späteren Legenden.

Vorerst sind zwei Züge zu nennen, die alle Texte gemeinsam haben: Zum ersten enthält keiner von ihnen detailliertere Berichte über die ,politischen' Taten des Helden, d. h. über Militäraktionen, die Praxis der Verwaltung und des Gerichtsverfahrens, die gesetzgebende Tătigkeit usw. Handlungen, die Funktionen der Macht im strengen Sinne des Wortes betreffen, werden nur knapp und selten erwähnt. Sie tragen eher deklarativen als erzählenden Charakter und sind meist um die Episoden des Konflikts mit den ,Nächsten' gruppiert. Diese Texte schildern den heiligen Herrscher nicht gemäß seinem ,eigentlichen' Status als Laien ${ }^{114}$, sondern als Heiligen, der auch die Pflichten des Herrschers ausübt. Aber im Unterschied zur Ersten altslawischen Legende regen diese Texte zur Frage nach der religiösen Bewertung der weltlichen Macht an. Zum zweiten gehen alle Texte vom Schema der Gegenüberstellung religiöser und weltlicher Elemente aus. Sie unterstreichen den Dualismus der Gestalt Wenzels, der religiösen Dienst mit weltlicher Macht vereinbart. Die Konzepte der Herrschaft und des Religionsdienstes sind überall voneinander getrennt, aber es erweist sich, daß die Formel ihrer Gegenüberstellung in den verschiedenen Texten nicht einheitlich ist. ${ }^{115}$ Das hagiogra-

111 Dazu Giulia Barone, Les épitomés dominicains de la vie de saint Wenceslas, in: Faire croire. Modalités de la diffusion et de la réception des messages religieux du $\mathrm{XII}^{\mathrm{e}}$ au $\mathrm{XV}^{\mathrm{e}}$ siècle. Table ronde, Rome, 22-23 juin, 1979. (Collection de l'Ecole Française de Rome, vol. 51.) Rom 1981, 167-187, hier 186 f.; Corbet, Les saints ottoniens (wie Anm. 96), 223 Anm. 63.

112 Z. B. in der Christian-Legende: discere legem domini nostri Jesu Christi et obtimperare mandatis illius; Křistanův (wie Anm. 12), c. 5, 210.

113 Die Tugenden (humilitas, misericordia, oboedientia) dienen nicht nur einfach der Markierung der jeweiligen Taten, sie bestimmen die Motivation des Auftretens, sind also der Kode der einer Person eigenen Ethik; s. z. B. Gumpoldův život (wie Anm. 77), c. 8, 153.

114 Folz, Les saints rois (wie Anm. 85), $71 \mathrm{ff}$.

$115 \mathrm{Zu}$ diesem Thema: Erich Auerbach, Literatursprache und Publikum in der lateinischen Spătantike und im Mittelalter. Bem 1958, 65-134. Bornscheuer, Miseriae regum (wie Anm. 103), 65 ff.; Corbet, Les saints ottoniens (wie Anm. 96), 120 ff., 156 ff.; Graus, Volk (wie Anm. 96), 410. 
phische Modell ,Mönch auf dem Thron' erweist sich als außerordentlich flexibel und mehrdeutig in seinem Inhalt. ${ }^{116}$

Crescente fide bildet das Schema der Gegenüberstellung von Heiligkeit und Herrschaft am konsequentesten aus und zieht die Motive zusammen, die die Unvereinbarkeit religiöser und weltlicher Tätigkeit demonstrieren. Das Streben des Helden hin zum geistlichen Dienst wird durch das Motiv der unwilligen Thronbesteigung fortgesetzt; die Erfullung der Pflichten eines Herrschers wird dem religiösen und asketischen Dienen gegenübergestellt. Diese Parallelisierung erhält gar den Sinn eines Gegensatzes beider Tătigkeitsformen: Als Asket werde Wenzel zu einem ,schlechten' Herrscher (,durch die Kleriker verdorben und einem Mönch angeglichen"). ${ }^{117}$ Der Topos der Vernachlässigung der weltlichen zugunsten der geistlichen Pflichten wird bei der Beurteilung des Helden zum Grundzug. Die Antinomie des ,Weltlichen ${ }^{6}$ und ,Geistlichen' setzt in dieser Legende vollkommen die Antinomie ,Religionsdienst' und ,weltliche Macht', ,asketische Selbstlosigkeit' und ,Machtlust' voraus. Diese letztere sei ein ausschließliches Attribut der „Feinde“ Wenzels. ${ }^{118}$ Die Gestalt des Heiligen ist in Crescente fide nur eine Ableitung von der traditionellen Klosterkonzeption von Heiligkeit, wo diese ein ideales Modell des asketischen Verzichts auf die Welt zugunsten des Religionsdienstes darstellt.

Die drei übrigen Texte repräsentieren ein kompliziertes Schema in bezug auf das Verhältnis von Heiligkeit und Herrschaft. ${ }^{119}$ Die Texte demonstrieren verschiedene Möglichkeiten, wie das Ausgangsmodell - Unvereinbarkeit der Mission eines Heiligen mit den Pflichten eines Herrschers - transformiert werden kann. Sowohl die Gumpold- als auch die ChristianLegende bewahrt alle durch Crescente fide eingefuhrten Motive der Gegenüberstellung, während die Laurentius-Legende sie von vornherein eliminiert. Diese Legende ist der einzige Text, der die Belehrung durch einen Geistlichen erwähnt ${ }^{120}$, die Wenzel im Verlauf der Taufe vor der Machtubernahme erhielt ${ }^{121}$; hier wird der Heilige auch systematisch als rex betitelt. Wahrscheinlich handelt es sich um die Nachahmung des kirchlichen Verfahrens des

116 Baker, „Vir Dei“ (wie Anm. 96); Graus, Volk (wie Anm. 96), 310 ff.; Nelson, Royal Saints (wie Anm. 96), $42 \mathrm{ff}$.

117 Quia princeps debebat esse, perversus est a clericis, et est monachus; Život sv. Václava (wie Anm. 77), 185; Wenzel will auch nach Rom pilgern; ebd. 187.

118 Das dualistische Schema der Legende fußt im Grunde auf der formellen, kirchlichen Zweiteilung der Tătigkeitssphären in eine religiőse und eine weltliche, wobei nur die erste imstande sei, die Bedingungen fur einen vollwertigen Gottesdienst sicherzustellen.

119 Das ist vor allem damit verbunden, daß die ,Herrschaftsvorstellungen' ihre Sinnkohärenz verlieren. Die Legenden verwenden das rex iustus-Modell; s. dazu Erna Buschmann, Ministerium Dei idoneitas. Um ihre Deutung aus den mittelalterlichen Fürstenspiegeln, in: HJb 82, 1963, 70-102; Otto Eberhardt, Via regia. Der Fürstenspiegel Smaragds von St. Mihiel und seine literarische Gattung. (Münstersche Mittelalter-Schriften, Bd. 28.) München 1977.

120 Tu modo promissum ne spernas, postulo, regnum, sed pius incedens miseris iugiter miserere; Vavłince, Mnicha sv. Benedikta (wie Anm. 13), c. 4, 171.

121 Ebd. c. 4, 171 f. Laurentius geht, wie es scheint, von der Anerkennung der konstituierenden Rolle der Kirche bei der ,Schöpfung' eines legitimen christlichen Herrschers aus. 
,Machtantritts' durch den Verfasser, obwohl dieses Verfahren nichts gemeinsam hatte mit der tschechischen Realität dieser Zeit.

Die Gumpold- und die Christian-Legende verzichten auf das Motiv der kirchlichen Sanktion von Macht. Sie halten sich konsequent an das Schema, das die hierarchischen Beziehungen zwischen den zwei Sphären der Tätigkeit Wenzels festsetzt. Gleichzeitig zerstören die Legendenverfasser die scharfe Antinomie dieser Beziehungen durch andere Konzepte; sie entdecken Bedingungen, bei welchen sich Macht und Heiligkeit als miteinander vereinbar erweisen. Die Möglichkeit der Existenz einer weltlichen Macht, die auch die religiösen Aufgaben erfullt, wird von beiden Verfassern anerkannt. Anzumerken ist aber, daß das Konzept der ,gerechten Macht', das furr beide Texte gleich wichtig ist, bei Gumpold und Christian verschieden ausgefullt wird.

Wenn Gumpold Wenzels Umgang mit der Zerrissenheit seiner Lage beschreibt, sieht er die Weisheit des Helden in der Identifizierung der Macht- und der Religionspflicht. ${ }^{122}$ Die Religionspflicht wird als Verantwortlichkeit des Herrschers furr die Sünden und Übeltaten seines Volks definiert ${ }^{123}$, und der Inhalt seiner Mission läuft auf die Erhaltung des Friedens und die Abwendung des Übels in der ihm anvertrauten Gesellschaft hinaus. ${ }^{124}$ Somit demonstriert die Gumpold-Legende eine logische Konsequenz, die es erlaubt, zu einer anderen Konzeption der Heldengestalt überzugehen, ohne das ideologische Modell des Textes zu ignorieren, der ihm als Quelle diente (Crescente fide).

Im Unterschied zu Gumpold glaubt der Verfasser der Christian-Legende in den Funktionen des Herrschers eher eine historisch-eschatologische als eine ethische Bedeutung zu erkennen. Hier muß man die Christian-Legende als eine einheitliche, ideologisch ausgerichtete Komposition betrachten. ${ }^{125}$ Der Verfasser gliedert Wenzels Geschichte in den Kontext eines Berichts ein, der mit der Bekehrung Mährens zum Christentum beginnt, mit der Geschichte um die Taufe des böhmischen Fürsten Bořivoj, dem Gedeihen seiner Sippe sowie dem Leben und Martyrium der Fürstin Ludmila fortgesetzt wird und mit der Wenzelsepisode und den Wenzelswundern zum Abschluß kommt. ${ }^{126}$ Der Verfasser beschränkt sich nicht auf eine schlichte Darstellung der Ereignisse, er wăhlt ganz konkrete Begebenheiten aus und beurteilt sie ausfuhrlich vom moralisch-religiösen Standpunkt aus. Worin besteht aber die Logik der Zusammenfassung dieser einzelnen Episoden zu einem einheitlichen Bericht?

122 Gumpoldův život (wie Anm. 77), cc. 5 f., 12, 13. Quam gravibus tunc perturbantis molestiae diversitatibus principis novelli benignitas, terreno iure suspecto, intrinsecus angeretur, non est admirandum, quoniam coelestia prae ceteris intuendo mente devota proposuit, ut quamvis publicae utilitati providendae debitor extitisset, dei tamen praedulci ocsequio uti primis se annis implicavit, potius despecto secularifastigio, non repudavit; ebd. c. 5, 149.

123 Ebd. c. 5, 149.

124 Ebd., c. 5, 149; c. 7, 151; c. 13, 155 f.

125 Vgl. zu verschiedenen Deutungen der Legende Josef Pekar̆, Nejstarši kronika ceská. Praha 1903; Rudolf Turek, Pođatky ceské vzdélanosti. Prag 1988, 143; Herman Kolln, Die Wenzelslegende des Mönchs Christian. Kopenhagen 1996, 17.

126 Sie stellt eine eigentumliche, knappe Geschichte Böhmens und seiner Herrscher von der Früh- bis zur Abfassungszeit dar. 
Den Kern der historischen Konzeption bildet das Motiv des ewigen eschatologischen Ringens von Gut gegen Böse, Gott gegen Teufel, was auch an Beispielen demonstriert wird. ${ }^{127}$ Die in der Legende dargestellte ,Geschichte der Gesellschaft' vereinbart lineare Dimension und zyklischen Aufbau - alle in der Legende dargelegten Episoden sind im Grunde genommen nach einem einheitlichen Schema ausgerichtet, sie sind typologisch aneinander und an die ,Figuren' der heiligen Geschichte angeglichen. Zum Hauptsujet, das der Reproduktion unterliegt, wird der Zusammenstoß von gerechten und ungerechten Herrschern. ${ }^{128}$ Im Text der Christian-Legende kann man eine Wiederholung des Schemas von gerechten und ungerechten Herrschern entdecken, und zwar mit einer fast synonymischen Verteilung der Tugenden und Funktionen ${ }^{129}$, etwa in der mährischen Geschichte, in der Geschichte Bořivojs, in der Geschichte Ludmilas und derjenigen Wenzels. ${ }^{130}$ Indem der Verfasser also eine Kette typischer Situationen konstruiert, macht er die ,frommen' Herrscher, die Wenzels Vorgänger waren, zu dessen Prototypen und gleicht ihre Funktionen den Aufgaben des Schutzes von ,Glauben' und ,Gottesgesetz' in der Gesellschaft an. ${ }^{131}$ Die eschatologische Begründung der religiösen Aufgaben eines ,gerechten' Herrschers wird zu einem typischen Attribut Wenzels; in seiner Geschichte werden alle Fäden des Berichts zusammengezogen. ${ }^{132}$ Somit treffen sich die durch verschiedene Perspektiven gekennzeichneten Ansichten aller drei Legenden in einem gemeinsamen Schnittpunkt - in der Anerkennung der religiösen Rechtfertigung und in der ,Nützlichkeit' der Herrschaftsfunktionen.

Die in den Legenden angelegte Rechtfertigung der Macht ist ein religiös-ethischer Kode, dem der Herrscher in seiner Tätigkeit untersteht. Man kann drei Aspekte des von den Legenden geschaffenen ethischen Modells eines ,mustergültigen' Herrschers freilegen. Erstens handelt es sich um eine vorbildliche persönliche Religiosität; zweitens befolgt der Herrscher in seinen Handlungen nicht die ,Sittennormen', sondern die Anforderungen des Religionsgesetzes; drittens geht es um das Verhältnis des Herrschers zur ,Macht', die den Prioritäten des eigentlichen religiösen Dienstes untergeordnet ist. Alle Texte (außer Crescente fide), die die ,Macht‘ zum funktionellen Element des Bildes machen, beschränken sich nicht auf eine entsprechende Erweiterung der ,Tugenden' des Helden; sie verwandeln die religiösen Tugenden in ein unentbehrliches Element des gerechten Herrschers. ${ }^{133}$ Der

127 Es ist auch für die Gegenwart des Verfassers aktuell; Křstanův (wie Anm. 12), c. 1, 202, u. a. m.

128 Dieses Schema ist typologisch an die Antinomie von Teufel und Gott angeglichen. Zur Antinomie tyrannus (Teufel) - legitimus rex (Gott) s. Graus, Volk (wie Anm. 96), 418 ff.

129 Vgl. die Beobachtungen von Martin Heinzelmann, Gregor von Tours (538-594). „Zehn Bücher Geschichte“. Historiographie und Gesellschaftskonzept im 6. Jahrhundert. Darmstadt 1994.

130 Vgl. Krristanův (wie Anm. 12), cc. 1 ff.

131 Vgl. den „mährischen Fürsten“ (ebd. c. 1, 201 f.), Bơ̌ivoj (ebd. c. 2, 203 f.), Ludmila (cc. 3 f., 204 ff.).

132 Wenn er zum Herrscher wird, erhält er den Status des Leiters der seiner Obhut anvertrauten Gesellschaft auf dem Wege der Überwindung des Bösen: Semper contra antiquum hostem scutum sumens fidei, cumque framea spiritus sancti, quod verbum dei est, incessanter aereas expugnans mundi huius potestates; Krristanův (wie Anm. 12), c. 6, 215.

133 Zur Frömmigkeit im Konzept des rex iustus vgl. Graus, Volk (wie Anm. 96), 350 ff.; Eugen Ewig, Zum christlichen Königsgedanken im Frühmittelalter (zuerst 1956), in: ders., Spätantikes und fränki- 
religiöse Eifer und die Regelung des Kirchenlebens sind nicht nur einfache ,Zeichen ${ }^{\text {' der }}$ Frömmigkeit, sondern sie bezeichnen die kardinale Tugend eines christlichen Herrschers, seine Demut (humilitas), die Anerkennung seiner religiösen Unterwerfung unter Gott. ${ }^{134}$ Die Aktualisierung der Motive persönlicher Frömmigkeit in den Wenzel-Legenden spiegelt deren doppelte Ausrichtung wider: Einerseits setzten sie nach wie vor das mönchisch-asketische Modell der Hagiographie fort, das die Tugenden eines Heiligen und eines Herrschers voneinander trennt ${ }^{133}$, andererseits enthalten sie das Spezifikum damaligen politischen Denkens, das auch in der Praxis der herrscherlichen Selbstrepräsentation zutage trat. ${ }^{136}$

Die Wenzels-Legenden schildern den Helden als Herrscher nicht nur vermittels seiner religiösen Taten, sondern auch anhand der weltlichen Aktivitäten. ${ }^{137}$ Die Gesamtbeurteilung seiner Tătigkeit läuft auf die Feststellung hinaus, daß in seinem Land Frieden und Ruhe geherrscht haben. ${ }^{138}$ Gumpold und Laurentius geben umfangreiche Beschreibungen der Taten Wenzels, die im Grunde genommen der Kompetenz des Herrschers unterliegen: Rechtsprechungsakte und Schenkungen an Personen seiner Umgebung. Der Unterschied der drei späteren Legenden zu Crescente fide besteht darin, daß sie den ,Willen' Wenzels zur Ausübung der Herrschaft demonstrieren. Gumpold und Christian vermerken eindeutig die Bereitschaft Wenzels, sein Recht auf Herrschaft zu schützen - auch wenn dabei Gewalt gegen die Feinde gebraucht werden muß. ${ }^{139}$

Die eigentlich weltliche Tătigkeit Wenzels unterliegt in den Legenden keiner umfassenden Beurteilung; mehr noch, die traditionellen Praktiken der Macht werden in diesem Zusammenhang in einer transformierten Form dargestellt. Vielmehr berauben die Legenden diese Tătigkeit praktisch dessen, was das eigentliche Spezifikum der ,politischen` Aktivität

sches Gallien. Gesammelte Schriften. Bd. 1. (Francia, Beih. 3/1.) Zürich/München 1976, 3-71, hier 39 ff.; Anton, Fürstenspiegel (wie Anm. 105); Eberhardt, Via regia (wie Anm. 119).

134 Humilitas wurde vom kirchlichen Denken als die wichtigste religiös-ethische Norm gedeutet, die die Grenze der Erhabenheit der weltlichen Macht bestimmt und gleichzeitig die christliche Erhabenheit des mit dieser Macht bedachten Herrschers vorherbestimmt; vgl. Auerbach, Literatursprache (wie Anm. 115), 43-45; Bornscheuer, Miseriae regum (wie Anm. 103), 68-76; Corbet, Les saints ottoniens (wie Anm. 96), 174-176; Graus, Volk (wie Anm. 96), 411 ff., 432 ff.; Ewig, Zum christlichen Königsgedanken (wie Anm. 133).

135 Graus, Volk (wie Anm. 96), 418 ff.; ders., La sanctification (wie Anm. 18).

136 Die herrscherliche Demonstration extremer Religiosität und Demut war in der spätottonischen Zeit ein Merkmal nicht nur der literarischen Stilisierungen (vgl. Poulin, L'ideal de sainteté [wie Anm. 96]; Lotter, Das Idealbild [wie Anm. 96], 76-95 u. passim), sondern auch der Riten des politischen Alltags; vgl. Gerd Althoff, Otto III. Darmstadt 1996, 191 ff.; Rudolf Schieffer, Von Mailand nach Canossa. Ein Beitrag zur Geschichte der christlichen Herrscherbuße von Theodosius dem Großen bis zu Heinrich IV., in: DA 28, 1972, 333-370.

137 Alle Legenden beinhalten folgende gemeinsame Elemente: die Abstammung des Heiligen aus einer Herrschersippe, die gesetzmäßige Thronbesteigung, die Akzentuierung seines hohen sozialen Status, der Verkehr mit der vornehmen Schicht der Gesellschaft und die Teilnahme am Gerichtsverfahren.

138 Gumpoldův život (wie Anm. 77), c. 6, 149; c. 7, 150 ff.; c. 13, 156: Pacis amor domi forisque in regno ferveat.

139 Ebd. c. 13, 155 ff.; Kłristanúv (wie Anm. 12), c. 5, 210 f.; Laurentius berührt dieses Thema indirekt; Vavłince, Mnicha sv. Benedikta (wie Anm. 13), c. 5, 173; c. 8, 175. 
bildet: die Anwendung von Gewalt. ${ }^{140}$ Die Verfasser streben systematisch danach, die Gewalttaten durch Aktionen der Barmherzigkeit zu ersetzen oder die Gewaltanwendung als unvermeidlich darzustellen. ${ }^{141}$ Am bezeichnendsten ist in dieser Hinsicht die GumpoldLegende, in der die Richtertätigkeit Wenzels ausführlich geschildert wird. Sein Abscheu gegen Gewalttaten und seine Barmherzigkeit gegenüber den Beschuldigten und Verurteilten werden mit allen möglichen Mitteln akzentuiert. ${ }^{142}$ Außerdem trifft man in diesen Legenden auf eine entschiedene Mißbilligung des Mordes. ${ }^{143}$ Am überzeugendsten ist dies beim Tod Wenzels ausgedrückt: Wenzel weigert sich, auch zum Zweck des eigenen Schutzes eine Waffe gegen seinen Bruder zu gebrauchen, um sich nicht durch die Sünde des Mordes zu beflecken. ${ }^{144}$ Aber die Problematisierung der Gewalt in den Legenden kann nicht allein auf den Ersatz des ethischen Kodes der Macht durch Kirchenkonventionen beschrănkt werden. Der Sinn ist viel breiter, er setzt eine bewußte Gegenüberstellung von traditionalem Verhalten und demjenigen eines mustergültigen christlichen Herrschers voraus. ${ }^{145}$

Die Frage nach der Rolle der Tradition bei der Rechtfertigung von Herrschertaten wird in allen Legenden aufgeworfen: Der Held erscheint als ein Herrscher, der gleichzeitig in Übereinstimmung mit der Sitte agiert als auch ihr zuwiderhandelt. Das Pathos der Legenden ist in hohem Grade gegen den absoluten Wert der traditionellen Herrschaftspraktiken gerichtet und fordert deren Wandel durch die Einhaltung der christlichen Normen. ${ }^{146}$

140 Vgl. Legenda sancti Stephani regis maior et minor, atque legenda ab Hartvico episcopo conscripta. Bearb. v. Emma Bartoniek, in: Scriptores Rerum Hungaricarum tempore ducum regumque stirpis Arpadianae gestarum. Bd. 2. Hrsg. v. Emericus Szentpétery. Budapest 1938, 363-440.

141 Z. B. Život sv. Václava (wie Anm. 77), 186; Gumpoldủv Život (wie Anm. 77), c. 7, 151; c. 13, 155; c. 14, 157; Krištanův (wie Anm. 12), c. 5, 211.

142 Dem Thema der Befreiung aus dem Gefängnis sind auch die Wunder gewidmet. In der GumpoldLegende sind diese Wunder mit Wenzels Aufgaben als Fürst verbunden: Gumpoldủv život (wie Anm. 77), cc. 24, 27, 29. Vgl. auch: Ut annuntietur (wie Anm. 85), 120-125; Die Chronik der Böhmen des Cosmas von Prag. Hrsg. v. Bertold Bretholz. (MGH SS rer.Germ. [2].) Berlin 1923, lib. 2, c. 47, 154. In diesem Fall folgen die Legenden der traditionellen Topik der hagiographischen Texte, wo die „Barmherzigkeit“ der Gewalt gegenübergestellt und die Funktion des Heiligen als Helfer aller Bedürftigen gedeutet wird.

143 Karl Leyser, Warfare in the Western European Middle Ages. The Moral Debate, in: ders., Communications and Power in Medieval Europe. The Gregorian Revolution and Beyond. Ed. Timothy Reuter. London 1994, 189-203.

144 Gumpoldủv život (wie Anm. 77), c. 19, 160; Křistanův (wie Anm. 12), c. 7, 219.

145 Die gleichartige Motivation erscheint auch in: Abonis Vita s. Eadmundi, in: Three Lives of English Saints. Ed. Michael Winterbottom. (Toronto medieval Latin texts, vol. 1.) Toronto 1972, 65-87, hier c.10, 78 f. Vgl. Beda Venerabilis. Historia ecclesiastica gentis Anglorum. Ed. Bertram Colgravel Roger A. B. Mynors. Oxford 1969, lib. 3, c. 6.

146 In der Gumpold-, der Christian- und der Laurentius-Legende gewinnt diese Zwiespältigkeit die Form einer direkten Deklaration über die Pflicht des Herrschers, die Sitten zu wechseln, wenn sie den religiösen Normen widersprechen, obgleich der Herrscher dabei das Risiko eingeht, als ein ,schlechter Leiter' vor seinen Untertanen zu erscheinen. Gumpoldủv život (wie Anm. 77), cc. 5, 7, 12 f. Křištanủv (wie Anm. 12), c. 5, 210; s. a. ebd. c. 1, 201; c. 2, 203 f; Vav̛̌ince, Mnicha sv. Benedikta (wie Anm. 13), c. 7, 174; c. 8, 175. 
Die Konsequenz in der Schilderung des idealen christlichen Herrschers als einer Antithese zum traditionellen Herrscherbild drückte sich in der allen Legenden gemeinsamen Idee aus, daß es sein Attribut sei, die Macht als solche zu vernachlăssigen. ${ }^{147}$ Seine wahre Absicht sei die ,Befreiung' von den Pflichten des Herrschers und die Annahme der Mönchswürde. ${ }^{148}$ Zur erhabensten Form des Verzichts auf Macht um des Religionsdienstes willen wird das Martyrium, das als ein heldenhafter und bewußter Akt der Bevorzugung der „Himmelskrone" vor der Krone eines irdischen Herrschers vorgestellt ist. ${ }^{149}$ Darin kann man wohl eine wichtige Besonderheit des Modells eines heiligen Herrschers erkennen. Als dessen Zentralschema erscheint die Gegenüberstellung von Religionsdienst und Macht auf. Aber die Antinomie gilt nicht mehr allein dem,Äußeren'. Indem sie die erwähnten Begriffe voneinander trennt, fügt sie sich in die Konzeption der gerechten Macht als solcher ein. ${ }^{150}$

Die Repräsentation Wenzels als eines Heiligen und gerechten Herrschers hat für die Rekonstruktion seiner Familienkonflikte und deren Deutung durch die lateinischen Legenden entscheidende Bedeutung. Alle Texte - außer der Laurentius-Legende - berichten über zwei Konflikte mit Wenzels Beteiligung. Der erste ist durch die Feindschaft zwischen dessen Mutter und der Elite, der zweite durch die Machtansprüche Boleslavs gekennzeichnet, die von seiner Gefolgschaft unterstützt wurden. Die Laurentius-Legende faßt die Episoden der ,Rebellion“ der Elite und Boleslavs zusammen ${ }^{151}$. Die Christian-Legende vereinigt demgegenüber das Komplott Drahomíras gegen Ludmila, das mit der Ermordung letzterer zum Abschluß kommt, mit der Feindschaft gegen Wenzel. ${ }^{152}$ Die lateinischen Texte dramatisieren die Szene der Ermordung Wenzels, stilisieren sie konsequent als eine religiös bedeutsame und symbolische Tat, während das Verhalten des Helden als ein mystischer, ethischer, ja heroischer Akt des Martyriums gedeutet wird. ${ }^{153}$

147 Wenzel demonstriert nicht nur eine bewußte Subordination der Macht unter den religiösen Dienst, sondern auch die Abwesenheit von Machtsucht: Nicht zufälig besteht das Zentralmotiv bei der Gegenüberstellung Wenzels und seiner Feinde in der Antithese eines, demütigen' Herrschers und derjenigen Herrscher, die nach Macht streben; Gumpoldủv život (wie Anm. 77), cc. 12 f., 15, 17. Kłristanův (wie Anm. 12), cc. 4-6; Vav̛rince, Mnicha sv. Benedikta (wie Anm. 13), c. 5, 172 f.

$148 \mathrm{Zu}$ Wenzels Wunsch, nach Rom pilgern, s. Život sv. Václava (wie Anm. 77), 186: voluit ire Romam, ut papa eum indueret vestibus monasticis; vgl. Gumpoldův život (wie Anm. 77), c. 17, 158; Krištanův (wie Anm. 12), c. 6, 216.

149 Život sv. Václava (wie Anm. 77), 186 ff.; Gumpoldův život (wie Anm. 77), cc. 15, 17-19. Křištanův (wie Anm. 12), c. 6, 216; c. 7, 219: Sicque ducatu terrenae nobilitatis, quo quondam strenuae pollebat, contempto, regnum celeste dux et martyr verus intravit. S. bes. bei Vavrince, Mnicha sv. Benedikta (wie Anm. 13), c. 11, 178. Vgl. auch Folz, Les saints rois (wie Anm. 85), 62 ff.; Graus, Volk (wie Anm. 96), $350 \mathrm{ff}$.

150 Die ideellen Modelle der Texte haben auch die Funktion sozialer Vorschriften: der ethischen Disziplin des Herrschers und der Beschränkung der sozialen Gewalt und der Machtwillkür.

151 Vavřince, Mnicha sv. Benedikta (wie Anm. 13), cc. 6-8, $174 \mathrm{ff}$.

152 Krištanův (wie Anm. 12), cc. 4 f., $207 \mathrm{ff}$.

153 S. auch Kánon ke cti sv. Václava (wie Anm. 9). Im Unterschied zur Ersten altslawischen Legende zweigen die lateinischen Texte die Episoden der Feindschaft und der Ermordung nicht thematisch und vom Standpunkt ihrer Bedeutung als besondere narrative Fragmente ab, sondern gliedern sie im 
Im Vergleich zur Ersten altslawischen Legende scheinen für die lateinischen Legenden drei Aspekte der Repräsentation von Familienfeindschaft wichtig zu sein: Erstens lehnen die Verfasser das Konzept der Verwandtschaft als eine bedeutsame Kategorie konsequent ab und verwenden jegliche damit korrelierenden Beurteilungen bei der Beschreibung der Beziehungen Wenzels zu seinen Verwandten nur äußerst sparsam. Zweitens benutzen die Legenden bei der Deutung der Motive und der Beziehungen ebenso konsequent politische und religiöse Kategorien; das heißt, daß sie im Grunde die konkrete Analyse der Familienbeziehungen von der traditionellen Beurteilung der Verwandtschaft abtrennen. Drittens geben sie bei der Beurteilung der Familienkonflikte rationale Erklärungen an, insbesondere zu deren Ursachen und den Motiven der Beteiligten. Die Legenden errichten ein vielstufiges und hierarchisiertes System von Bedeutungskategorien, angefangen bei den religiös-mystischen und eschatologischen bis zu den rechtspolitischen.

In allen lateinischen Legenden werden die eigentlichen Verwandtschaftsbeziehungen Wenzels nur sehr knapp charakterisiert. Es wird nur darauf hingewiesen, daß bestimmte Personen in enger Verbindung zu dem Heiligen stehen: sein Vater, seine Mutter, seine Großmutter, sein Bruder. Neben Crescente fide fuhren auch alle ubrigen Texte manche Charakteristika der Verwandtschaft als eines spezifischen ethischen und emotionalen Beziehungssystems ein: Die Christian- und die Laurentius-Legende merken an, daß Wenzel seinen Bruder liebte, ihn gutherzig behandelte und sich um dessen sittliche Besserung sorgte. ${ }^{154}$ Entsprechende Motive der Verwandschaftsnăhe sind bei den Beziehungen zur Mutter ${ }^{155}$ und Großmutter aufzuspüren. Das ausdrucksvollste Mittel zur Bezeichnung des Verwandtschaftsspezifikums ist in den Legenden das Motiv das Widerstreben Wenzels, von seinem Bruder ermordet zu werden. ${ }^{156}$ Aber die Verwandtschaftssolidarität ist kein bedeutsames Konzept, das dem Zusammenwirken des Helden mit seinen Verwandten einen Sinn verleiht. Es ist auffallig, daß die Verfasser auf andere wichtigere Parameter dieser Beziehungen hinweisen. ${ }^{157}$ Alle Legenden werten religiöse und ethische Kriterien der Vertraulichkeit oder der Feindschaft in den Beziehungen zwischen den Verwandten als besonders wichtige Elemente aus. So werden z. B. die Beziehungen zwischen Wenzel und seinen Gegnern, Mutter und Bruder, entsprechend der Antinomie ,mustergultiger Christ ${ }^{6}$ - ,Gegner des Glaubens ${ }^{6}$ dargestellt. ${ }^{158}$ In den einzelnen Texten hat der konkrete Inhalt dieses Schemas seine eigenen, manchmal sehr unterschiedlichen Schattierungen. Die Beurteilungen der Mutter, des Bruders

Gegenteil in den einheitlichen Stoff des der Demonstration von Tugenden und „Taten“ Wenzels gewidmeten Berichts ein.

154 Kłrǐtanův (wie Anm. 12), c. 6, 216; Vav̛̌ince, Mnicha sv. Benedikta (wie Anm. 13), cc. 5-6, 173.

155 Krrištanův (wie Anm. 12), cc. 5, 215; 7, 219.

156 Ipse vero sciebat, et sicut homo in aestu diei foemilem metens sitiet aquam, ita ipse procul dubio desiderabat martyrium percipere; sed non de manu fratris suis, quia diligebat eum, et sciebat ob hoc eum minime evadere gehennam perpetuam; Život sv. Václava (wie Anm. 77), 186; vgl. Vavřince, Mnicha sv. Benedikta (wie Anm. 13), cc. 10 f., $177 \mathrm{f}$.

157 Unter anderem wird auch der Statusaspekt, die herrscherliche Überordnung Wenzels gegenüber Bruder und Mutter, unverkennbar unterstrichen: Vavrince, Mnicha sv. Benedikta (wie Anm. 13), c. 4, 172; c. 5, 173; c. 8, 175; Gumpoldův život (wie Anm. 77), c. 15, 157; c. 17, 158.

158 Gumpoldův život (wie Anm. 77), cc. 12 f., 19 f. Křštanův (wie Anm. 12), cc. 4-7. Vav̛̌ince, Mnicha sv. Benedikta (wie Anm. 13), cc. 6-8. 
und der Gefolgschaft sind in einem Spektrum vom buchstäblich verstandenen „Heiden“ bis zum „Pharisäer“" (d. h. einem falschen, unechten Christen ${ }^{159}$ ) angeordnet.

Bemerkenswert ist die Tatsache, daß die Gegenüberstellung nicht nur auf formalen religiösen Einschätzungen, sondern auch auf einer Spiegelsymmetrie der Persönlichkeitsbeurteilungen fußt, also auf den eigentümlichen Kodes der handelnden Personen. Wenzel erscheint als ein demütiger Christ, der seine Pflicht erfullt, indem er von Liebe und Wohlwollen durchdrungen ist, während seine Mutter und sein Bruder von Tollheit, Hochmut und Machtbegierde besessen sind. ${ }^{160}$ Demgegenüber sind Wenzels Nähe zu Ludmila und seine Liebe zu ihr durch die Übereinstimmung der religiösen und ethischen Charakteristika bedingt. ${ }^{161}$ Die Idee der Verwandtschaft als einer zweifellos wechselseitigen Nähe wird durch die Konzeption der Verwandtschaftsbeziehungen einer geistlichen Gemeinschaft ersetzt. Gleichzeitig stellt die Pflicht der Mutter und des Bruders gegenüber Wenzel nicht eigentlich eine verwandtschaftliche, sondern eine Statusverpflichtung dar, die von diesen verletzt wird, als sie anstreben, Wenzels Vollmachten einzuschränken und ihm die Macht zu rauben. Somit werden die Familienbeziehungen durch formale Normen geregelt und hängen von der Erfullung der Pflichten ab: Liebe und Loyalität werden durch die Mißachtung der mit ihnen verbundenen Kategorien zerstört. Nicht zufällig legen die Verfasser Wenzel eine zornige Beschuldigung der Mutter in den Mund, die mit der Formel der Abdankung ${ }^{162}$ fast identisch ist und Boleslav entrechtet, Bruder genannt zu werden. ${ }^{163}$ Die Rationalisierung der Verwandtschaft als ein System, das universalen ethischen und rechtlichen Normen untergeordnet ist, kommt z. B. darin zum Ausdruck, daß die Verfasser feindliche Handlungen Wenzels gegen seine Mutter nicht verschweigen und dieselben rechtfertigen, da sie durch deren eigenes Verhalten motiviert seien. ${ }^{164}$ Somit wird die Natur der Familienfeindschaft

159 So bei Krištanův (wie Anm. 12), c. 7, 218.

160 Siehe z. B. über Boleslav in Crescente fide: frater eius iunior et peior nomine Bolezlavus diabolica fraude deceptus, cum impiis malignum inierunt consilium contra praedictum virum beatum, ut eum perderent; Život sv. Václava (wie Anm. 77), 186; in der Gumpold Legende: in regnum nimiae peruersitatis duce Bolezlavo, saevitiaque eius; Gumpoldův život (wie Anm. 77), c. 20, 161; principis tyrannidem metuentes (ebd. c. 23, 162); dux vesanus (...), rapidissima succensus ira (ebd. c. 26, 163 f).

161 Krištanův (wie Anm. 12), cc. $4 \mathrm{f}$.

162 Z. B. in Crescente fide: mater eius (...) incredula dei; Život sv. Václava (wie Anm. 77), 185; Wenzel convocavit omnes viros suos et matrem, et exprobravit incredulitatem illorum et duritiam cordis (...); bei Gumpold: Enimvero execrabilis memoriae genitrix mea sectae vitali, quam pro toto posse confiteri, colere, corde tenus sequi et amare insto, et posthac aliorsum inrevocabilis instabo, mordaciter invidens, eosdem diversorum clericos ordinum, quia mecum sentire non negant, ope terrena privatos, regno severius eiectum iri molitur; Gumpoldủv život (wie Anm. 77), c. 11, 154; vgl. Krištanův (wie Anm. 12), c. 3, 207; c. 5, 210.

163 Krłištanův (wie Anm. 12), c. 7, 218: ante noctem siquidem frater s. martyris, non iam frater, sed peruersus parricida. S. auch Vav̛́ince, Mnicha sv. Benedikta (wie Anm. 13), c. 8, 175.

164 Die Verfasser entheben Drahomíra und Boleslav nicht von der Verantwortung für die Entfesselung des Konflikts und beseitigen das fur die Erste altslawische Legende funktionell wichtige Element der bösen Ratgeber als der ursprünglichen Ursache des Bösen. 
entmythologisiert, sie nimmt die Gestalt eines Systems von rationalen Ursachen und von differenzierten Motiven der Beteiligten an.

Die Konfliktursachen werden von den Verfassern deutlich benannt, obwohl es bei deren Identifizierung verschiedene Ansichten gibt. Gemeinsam ist allen Texten die Behauptung eines prinzipiellen religiös-eschatologischen Hintergrundes für die Konflikte: Es sei der Kampf des Teufels gegen einen Heiligen. Zur typischen Verkörperung dieses Kampfes wird die Gegenüberstellung eines Gerechten und einiger Sünder; als letztere erscheinen Wenzels Gegner. Eine bemerkenswerte rhetorische Besonderheit der lateinischen Texte, die sie von der Ersten altslawischen Legende unterscheidet und auf grundlegenden Differenzen in der Logik der Konfliktwahmehmung basiert, ist der Hinweis auf ein direktes Eingreifen des Teufels vermittels der Feinde Wenzels. ${ }^{165}$ Das strenge Schema der eschatologischen Opposition verändert die moralisch-religiösen Bewertungen der Ereignisse in fundamentaler Weise. Die Verwandtschaftsloyalităt gilt nicht mehr als Ausgangspunkt und Maßstab für Gerechtigkeit oder Sündhaftigkeit. Alle Verfasser erwähnen außer den geistlichen auch die eigentlich politischen Motive. Die wichtigsten davon seien die Unzufriedenheit der Elite mit dem Auftreten des Fürsten und das Streben Boleslavs, an die Macht zu gelangen. ${ }^{166}$ In allen Legenden kommt die rechtliche Verurteilung der Feinde Wenzels zum Ausdruck. Ihr Auftritt sei eine Rebellion gegen den gesetzmäßigen Herrscher. Nach der Deutung der Gumpold-, Christian- und Laurentius-Legende war der politische Konflikt als solcher nicht zufällig, vielmehr hatte er tiefigreifende religiös-ethische Wurzeln. Die Verfasser dieser Legenden bauen konsequent einen Gegensatz auf zwischen dem gerechten Herrscher und denen, die eine ungerechte Macht verkörpern. Mit dem Kampf gegen letztere werde eine religiöse Pflicht erfüllt, die mit dem Schutz der Gesellschaft gegen das Böse verbunden sei. ${ }^{167}$

Der Untergang Wenzels selbst wird als ein religiös bedeutsames Ereignis geschildert. Darüber hinaus sei das Martyrium Wenzels ein Zeichen der mystischen Auserwăhltheit und ein Akt des Religionsdienstes. ${ }^{168}$ Das Martyrium kennzeichnet auch die höchste Tapferkeit

165 Was aber die Erste altslawische Legende betriff, so bezieht sich die Metapher „Teufelshetze“ ausschließlich auf die Gegner des Heiligen, vor allem auf Boleslav. Das verleiht der religiösen Auslegung der Ereignisse in der slawischen Legende einen anderen Inhalt als in der lateinischen Tradition. Der Teufel handelt gegen Boleslav, um ihn vom rechten Weg (d. h. von der Aufrechterhaltung des Gleichgewichts in den Verwandtschaftsbeziehungen) abzubringen.

166 Die Laurentius- und die Christian-Legende präzisieren dies dahingehend, daß die Unzufriedenheit der Elite mit der Mißbilligung der Regierung Wenzels motiviert wird: Ein solcher Herrscher wäre imstande, ihre Rechte einzuschrănken oder sie der Möglichkeit zu berauben, sich den üblen Gewohnheiten zu ergeben.

167 Der politische Hintergrund des Konflikts trägt laut Crescente fide einen formellen, situativen Charakter. Die - dem Machtanspruch gleichgestellte - Macht sei ein Attribut ausschließlich der Feinde des Heiligen, das in sich die Begriffe des Weltlichen und des Sündigen aufnimmt. Der Heilige widersteht den Feinden nicht als Herrscher, sondern als ein religiöser, selbstloser Kämpfer, was dem politischen Konflikt seinen eigenen ethischen Inhalt entzieht; vgl. auch Vavrince, Mnicha sv. Benedikta (wie Anm. 13), c. 6, 173 ff.

168 Die Szene der Ermordung wird symbolisch der liturgischen Handlung angeglichen, und am ausdrucksvollsten ist dabei die Christian-Legende. 
und Tugend des ,gerechten' Herrschers, der auf den Kampf um die Macht verzichtet und die Himmelskrone der irdischen vorzieht. Dann erscheint Wenzel endlich als ein mustergültiger Christ, der die heiligen Vorschriften befolgt ${ }^{169}$ und den eigenen Tod hinnimmt, um die Sünde des Blutvergießens zu vermeiden. Das Motiv des von Wenzel nicht begangenen Brudermordes erfullt in dieser Bedeutungspolyphonie die Funktion, die Gerechtigkeit des Helden und die Sündhaftigkeit seines Bruders zu unterstreichen. Wenzels Tod hat ebenso wie sein Leben im Grunde genommen nichts mit einer moralischen und religiösen Sicht auf Verwandtschaft und Familienloyalität zu tun.

Die frühere hagiographische Tradition hat bei allen konzeptuellen Unterschieden der einzelnen lateinischen Texte ein invariantes narratives Modell der Geschichte des Heiligen geschaffen, das grundsătzlich von der Ersten altslawischen Legende abweicht. Wenn man die Entstehung der Ersten altslawischen Legende im Böhmen der zweiten Hälfte des 10. Jahrhunderts als höchstwahrscheinlich anerkennt, so kann das Verhältnis dieser Legende zu der lateinischen Hagiographie als das des ,marginalen' zu den ,kanonischen' Berichten definiert werden. Der im Rahmen der lateinischen hagiographischen Tradition entwickelte Kanon, der hier wegweisend wurde, erwies sich furr eine Verbindung mit dem anderen Modell als ungeeignet.

Alle lateinischen Legenden befolgen bei der Darstellung Wenzels und seiner Geschichte das Mimesis-Prinzip, d. h. sie suchen Wenzel der typischen Gestalt eines mustergültigen Christen und von Gott Auserwählten ähnlich zu machen. Darin liegt ihr Unterschied zur Ersten altslawischen Legende. Dieser Text reproduziert die Ereignisse in Form einer Erzählung, indem der Verfasser von der ursprünglichen Bedeutung dieser Ereignisse - der Familienfeindschaft - ausgeht und sie mit religiösen Gestalten und Wertungen überblendet, oder anders gesagt: ein bestimmtes Wertesystem mit der Sprache eines anderen kostümiert. In der lateinischen Hagiographie sehen wir einen anderen Mechanismus beim Aufbau der narrativen und ideologischen Struktur. Als Vorlage wird das durch den religiösen Diskurs selbst gebildete Modell des religiös Auserwählten genommen, das verschiedene Topoi, Modelle und Konzepte nach sich zieht. Die Komposition und das spezifische Gewicht dieser Elemente sind in den einzelnen Texten verschieden, aber die wesentlichen Merkmale des konzeptuellen Schemas bleiben allen gemeinsam. Es ist gerade dieses Schema, das Auslese und Bewertung des Stoffs, d. h. analytische und sinnstiftende Prozeduren der Materialverarbeitung, bestimmt. Wenn auch die Wenzelsgeschichte Elemente der Familienfeindschaft bewahrt, hört sie im Grunde auf, eine solche Geschichte zu sein. Thre Bedeutung wird durch ein ganz anderes Wert- und Logiksystem bestimmt, da die Kriterien selbst den Rahmen der Erfahrung überschreiten.

Die Erste altslawische Legende enthält keine direkte Verherrlichung Wenzels als Heiligen und fixiert wohl nur den Ausgangspunkt für die Entwicklung, in der der Fürst den Ruf eines Heiligen erhält. Allerdings mußte ihr moralisches Programm mit den Konventionen lateinischer Hagiographie in Widerspruch geraten. Es ist in diesem Zusammenhang merkwürdig,

169 Vavrince, Mnicha sv. Benedikta (wie Anm. 13), c. 11, 178: pro mandatorem Christi observatione, pro Christo perpeti, pro veritate, quae utique Christus est. 
daß die Erste altslawische Legende in der russischen Kirchentradition als eine vollwertige Legende wahrgenommen wurde, hier in einer bedeutenden Anzahl von Abschriften erhalten ist und die Konstituierung des hagiographischen Modells für die fürstlichen Märtyrer Gleb und Boris beeinflußte. Gerade die Erste altslawische Legende wurde offenbar zum Schlüsselelement bei der sogenannten Kontinuităt des hagiographischen Modells zwischen dem böhmischen und dem altrussischen Fürstenkult.

Als sich hundert Jahre später (in den dreißiger Jahren des 11. Jahrhunderts) die russische Hagiographie der Ermordung der jüngeren Söhne Vladimirs durch ihren älteren Bruder Svjatopolk nach dem Tod des Vaters (1015) zuwandte, hat sie in ähnlicher Weise die religiöse und die ,familiäre' Seite der Ereignisse für identisch erklärt. Im Vergleich mit dem tschechischen Verfasser haben die beiden berühmten russischen Legenden ${ }^{170}$ aber in den Gestalten der ermordeten Fürsten eine viel stärkere und ausdrucksvollere Repräsentation des Ideals der Verwandtschaftsloyalität und -liebe geschaffen. Ihnen gelang eine präzise Verschmelzung der Motive einer religiösen Heldentat und der Bruderliebe, indem sie das freiwillige Martyrium mit dem Verzicht auf Feindschaft identifizierten. Ungeachtet der offensichtlichen inneren Verwandtschaft der böhmischen und russischen Kulte sowie des Umstandes, daß sie gemeinsam den Typus des im Zuge einer Familienfeindschaft ermordeten fürstlichen Märtyrers hervorgebracht haben, kann natürlich nicht von irgendeiner Einheitlichkeit der slawischen Kultur gesprochen werden. Es ist aber unbestreitbar, daß die russischen Verfasser mit der Ersten altslawischen Legende ein literarisches Muster besaßen, das es ihnen erlaubte, die Situation eines Brudermordes innerhalb einer regierenden Familie zu moralisieren, die im russischen sozialen Leben typisch war. Ebenso wie die Schöpfer der Ersten altslawischen Legende - und im Unterschied zu den Autoren der lateinischen Texte besaßen die russischen Verfasser kein intellektuelles Werkzeug, um die Ereignisse zu formalisieren und so die Familienfeindschaft rationalisieren und transzendent deuten zu können. Die russischen Verfasser haben deshalb ein anderes Modell für den religiösen Diskurs um die Idiome der Verwandtschaft und der Verwandtschaftsloyalităt entwickelt.

170 Ludolf Müller (Hrsg.), Die altrussischen hagiographischen Erzählungen und liturgischen Dichtungen über die Heiligen Boris und Gleb. (Slavische Propyläen, Bd. 14.) München 1967 (Übers. ins Deutsche aus: Dimitrii Ivanovič Abramovič, Žitija svyat mučenikov Borisa i Glieba i služby im. [Pamiatniki drevne-russkoj literatury, Bd. 2.] Petrograd 1916). 



\title{
Les idoles musulmanes
}

\author{
Images et réalités
}

Von

Svetlana Luchitskaja

Les chroniques des croisades qui reflètent les conflits entre le monde chrétien et le monde musulman contiennent beaucoup de détails fantastiques comme, par exemple, les dialogues imaginaires entre les musulmans et les chrétiens, les descriptions fantastiques du culte musulman auquel l'on attribue les traits païens, les récits fictifs sur les batailles etc. L'historien positiviste qui s'est accoutumé de chercher des ,faits' préféra de négliger ces fables et ces racontars qui l'empèchent d'accéder à la ,réalité vraie“ de „,ce qui s'est effectivement passé" (,wie es eigentlich gewesen"). Mais cette description de la réalité ,à l'extérieur' imprime la marque des représentations et des traditions de notre propre culture. Tenter d'interpréter la réalité ,à l'intérieur' - c'est-à-dire prendre en considération le contexte légendaire des chroniques et de restituer la perception subjective de la réalité par les chroniqueurs est une autre chose. Ainsi nous devrons poser le problème autrement - on s'attachera moins à restituer des,faits' que la perception des ces faits par les chroniqueurs, d'accentuer moins le réel que l'intelligible.

Un historien qui se plonge dans la lecture des chroniques de la Première croisade est surpris par les descriptions étranges des mosqués musulmanes dans lequelles selon les récits des chroniqueurs on pouvait voir de grandes statues de Mohammed couvertes d'or et d'argent. La description la plus détaillée d'une telle statue se trouve dans l'œuvre Les gestes de Tancrède du chroniqueur normand Raoul de Caen. L'admirateur exalté de son héros nous donne la description brillante des événements dont le participant était Tancrède. Quand les croisés sont entrés à Jérusalem, le 15 juillet 1099, Tancrède était aux premiers rangs et il fut le premier à faire irruption dans la mosquée al-Aksa, l'ex-temple de Solomon. Ce qu'il a vu là dépassait les rêves des croisés cupides. Les murs de la mosquée étaient recouverts d'argent, et au centre, sur le trône, s'élévait la statue argentée, enveloppée dans les draps de pourpre, couverte d'or et de pierres précieuses. C'était la statue de Mohammed. Bouleversé et étonné par cet incroyable spectacle, Tancrède commence à réfléchir à haute voix:

Qui-est-ce qui? Quelle image est là, sur l'élevation (sublimis imago)? Qu'est-ce que signifie cette représentation (effigie)? D'où sont ces pierres précieuses, cet or? Pourquoi ce pourpre? Serait-ce par hasard l'image de Mars, ou celle d'Apollon? Car ce ne saurait être celle du Christ; je ne retrouve point les insignes du Christ, ni la croix, ni la couronne, ni les clous, ni le flanc percé;ce n'est donc point le Christ, mais plutôt un premier Antichrist, ce 
Mahomet pervers, ce Mahomet dangereux (...). O scandale! Le convive de l'enfer, l'hôte de Pluton, est en possession de la citadelle de Dieu, il est le dieu de l'ouvrage de Salomon. ${ }^{1}$

Dès que l'ordre est donné, les chevaliers de Tancrède l'accomplissent avec un zèle extraordinaire. La statue de très grandes dimensions - selon le récit du continuateur anonyme de Pierre le Tudébode elle était tellement lourde que seuls six hommes forts pouvaient la bouger et dix pouvaient la soulever ${ }^{2}$ - est renversée, sa tête est coupée et brisée en petits morceaux; l'or, l'argent et les autres pierres précieuses sont distribués parmi les guerriers. Ce n'est pas par hasard que le chroniqueur en rapportant cet épisode a souligné le luxe et la richesse du culte musulman puisque dans l'imaginaire chrétien le monde musulman était toujours représenté comme l'univers de la richesse fabuleuse et de l'exotisme. ${ }^{3}$

Le passage de Tancrède que l'on vient de lire reflète l'aspect événementiel de l'image peinte par les chroniqueurs. Mais que pouvons-nous dire aujord'hui de cette image? Comment expliquer l'origine de cette description défigurée et phantasmatique du culte musulman? Comment la statue de Mohammed a-t-elle pu se trouver dans la mosquée musulmane, si le Coran défendait les représentations figurées du prophète? Nous allons tâcher de répondre à toutes ces questions, et pour ce faire, nous chercherons de considérer ce passage de la chronique dans les contextes historiques différents et de découvrir son sens.

\section{La réalité historique et les récits des chroniqueurs}

Pour tenter à répondre à ces questions l'historien aura à s'attacher aux réalités historiques, et dans sa démarche rationnelle s'efforcera de découvrir les événements réels qui sous-tendent les récits. Ainsi je séparerai les ,res factae“, pour reprendre l'expression de Cicéron, et les „res fictae“. De telle sorte je formulerai autrement la question: premièrement, la statue de Mohammed existait-elle en réalité, deuxièmement, les chroniqueurs l'ont-ils réellement vue?

Voyons maintenant les faits historiques. Raoul de Caen qui nous a consigné ce récit, a rédigé sa chronique entre 1112 et 1118 , cela veut déjà dire qu'il ne fut pas le témoin direct de la Première croisade. ${ }^{4}$ En effet, parmi les témoins oculaires seul Foucher de Chartres parle de la statue de Mohammed, en nous rapportant que les Saracènes font dans ce temple les offres selon leur usage superstitieux. ${ }^{5}$ Tous les autres chroniqueurs-témoins oculaires $-\mathrm{y}$ compris Anonyme, Tudebode, Raimond d'Aguilers - gardent le silence à ce sujet. Donc, la première explication relèverait des ,res fictae“ et qu'il ne s'agirait que d'une invention de la

1 Radulfi Cadomensis Gesta Tancredi, dans: Recueil des historiens des croisades. Historiens occidentaux. Vol. 3. Paris 1866, cap. CXXIX, 695.

2 Tudebodus imitatus et continuitatus Historia Peregrinorum, dans: ibid., cap. CXXIV, 222-223: (...) videt simulacrum argenteum Machumeth (...) stans in excelso throno, quod videlicet tanti erat, ponderus erat ut vix sex viri fortissimi ad portandum, vix etiam decem ad levandum sufficerent (...).

3 Norman Daniel, Heroes and Saracens. An Interpretation of the chansons de geste. Edinburgh 1984.

4 Cf. Laetitia Boehm, „Die Gesta Tancredi“ des Radulf von Caen. Ein Beitrag zur Geschichtsschreibung der Normannen um 1100, dans: HJb 75, 1956, 47-72.

5 Fulcherii Carnotensis Historia Hierosolymitana. Hrsg. Heinrich Hagenmeyer. Heidelberg 1913, lib. I, cap. XXVI, 5. 
part des chroniqueurs qui n'ont jamais été à Jérusalem et qui étaient peu familiarisés avec la situation réelle au Proche Orient. Ce point de vue qui est le mien a déjà été exprimé par l'historienne anglaise Rosalind Hill, la première à s'intéresser de près à ces récits, que l'on pourrait tenir pour phantasmatiques. ${ }^{6} \mathrm{C}$ 'est aussi le point de vue de Dana C. Munro qui partait des mêmes prémisses de sens commun (sensus communis). Il a supposé que de telles erreurs provenaient des observations directes des chroniqueurs. Selon Munro la vénération de certains animaux qui existait chez les Bédouins a été transportée par les chroniqueurs au monde musulman entier. ${ }^{7}$ Dans la lumière de ces suppositions l'épisode mentionné trouve son interprétation claire et nette. En effet, nous avons tout lieu à supposer que de telles fables et de tels épisodes phantasmatiques ont été rapportés par les écrivains qui n'avaient pas de contacts directs avec le Proche Orient et qui connaissaient très mal les réalités du monde musulman. De telles interprétations partent des prémisses théoriques singulières - on donne la préeminence aux observations des témoins oculaires. Les participants des événements sont plus importants que les narrateurs. C'est dans leurs récits qu'on peut découvrir les „res factae“ tandis que les récits des narrateurs ne sont que les „res fictae“. Le critère principal est l'expérience directe. On objectera quand-même qu'une telle opinion est contraire aux données des sources. Foucher de Chartres bien qu'il tait le participant de la Première croisade et a vécu en Orient rapporte dans sa chronique l'existence de l'idole dans la mosquée. L'historien italien, Ugo Monneret de Villard, a essayé de réconcilier ces renseignements contradictoires. Selon son avis il existe certains clichés littéraires qui pouvaient passer d'une chronique à l'autre. ${ }^{8}$ Les descriptions des idoles donc peuvent être considérées comme les stéréotypes littéraires typiques des chroniques des croisades. Mais cette explication, elle aussi, me semble peu suffisante. Car les clichés, eux-mêmes, sont une partie intégrante du système des représentations, et il faudrait d'abord s'interroger pourquoi les chroniqueurs utilisaient justement ces clichés et ces stéréotypes littéraires.

Une autre interprétation à mon avis contestable bien que très passionnante, a été proposée par l'historienne de l'art Xenia Muratova. Elle part à peu près des mêmes prémisses que Dana C. Munro et les autres jadis et aujourd'hui Rosalind Hill. Selon Muratova, il faut percevoir le récit de Raoul de Caen littéralement. Elle a supposé que c'est le fait réel qui a été enregistré dans la chronique. Selon l'opinion de l'historienne la description de l'idole est tellement nette, précise er réaliste qu'elle ne peut pas être expliqué ni comme le stéréotype littéraire ni comme une pure phantaisie - la statue de l'idole, donc, se trouvait réellement dans ce temple. Xenia Muratova note la similitude de la description de Raoul de Caen avec l'un des motifs iconographiques de l'art antique - les représentations de Jupiter Capitole. Des statues du Jupiter étaient très souvent placées dans les temples de Palestine. C'étaient des statues colossales de marbre vêtus en draps de pourpre et installées sur les points d'élévation. L'historienne suppose qu'une pareille statue se trouvait dans le Temple de

6 Rosalind Hill, The Christian Views of the Muslims at the time of the First crusade, dans: The Eastern Mediterranean Lands in the Time of the Crusades. Ed. Peter M. Holt. Warminster 1977, 1-8.

7 Dana C. Munro, Western Attitudes Toward Islam during the Crusades, dans: Speculum 6, 1931, 329_ 345. Selon Munro l'usage des Bédouins de la vénérer certains animaux était attribué aux musulmans.

8 Ugo Monneret de Villard, Lo studio dell'islam. Città di Vaticano 1944. 
Solomon, ensuite la mosquée Al-Aqsa. ${ }^{9}$ Plus tard ce fait réel rapporté par les croisés témoins oculaires - s'est entouré des détails phantastiques et se mêle des détails des légendes populaires de Mohammed, des récits de la tradition orale etc. Le point de vue pareil a été exposé dans le livre de l'historien russe Michail Zaborov qui a émis l'opinion que la statue du prophète est demeurée intacte dans le temple de Jérusalem, malgré, comme il l'écrivait, „toutes les vicissitudes et grâce à sa massivétéc. 10

Mais cette interprétation littérale ne semble pas assez convaincante. Tout d'abord il est douteux que les musulmans puissent tolérer la présence de l'idole dans un tel lieu sacré comme la mosquée Al-Aksa qui était en effet très importante dans le système du culte musulman. J. Folda a dressé dans son livre récent le bilan de ces interprétations diverses de ce passage en disant, lui-même aussi, qu'il est tout-à-fait raisonnable de supposer que les statues romanes pouvaient se trouver dans le Haram-es-Serif en 1099 et, peut-être, une statue pareille, le plus probable, de Jupiter Capitole, se trouvait là-bas. Mais, a-t-il lui-même ajouté, cette supposition reste très incertaine parce que les renseignements sur les traits iconographiques de cette image sont très pauvres.

En poursuivant notre démarche qui tente à découvrir les réalités historiques à travers les récits des chroniqueurs nous sommes en droit de proposer encore une interprétation. Si l'on part du sens commun, on peut vraiment supposer que les faits réels auraient influencé la représentation de l'idolâtrie dans les chroniques des croisades. Le passage étrange pouvait être inspiré par l'expérience directe des croisés. On sait que jusqu'au début du XII ${ }^{\mathrm{e}}$ siècle à Cadiz se trouvait la statue colossale d'Hercules. Les croisés on pu la voir lors de leur passage par cette ville pendant leurs expéditions vers la Terre Sainte. L'ainsi dite version de Pseudo-Turpin de la Chanson de Roland rapportait, elle aussi, de la statue d'Hercules. On croyait, selon Pseudo-Turpin, que la clef va tomber des mains de la statue au moment de la naissance du roi français qui sera destiné à reconquérir les terres de l'Espagne aux Saracènes (c'était l'allusion à Charlemagne, sans doute). La statue fut détruite au milieu du XII siècle. ${ }^{12}$

Toutes les explications que nous avons citées ci-haut, malgré leur diversité ont quelque chose de commun. Ces interprétations sont concentrées à la recherche des réalités qui pouvaient se réfléter dans les chroniques. Les chroniques sont considérées comme le miroir de la réalité ,objective‘. Mais il est impossible de considérer les descriptions des écrivains comme la fonction directe de l'expérience réelle des médiévaux. Les hommes médiévaux interprétaient les événements, le monde qui les entourait, en s'appuyant non sur l'expérience réelle,

9 Xenia Muratova, Western Chronicles of the First Crusade as sources for the history of art in the Holy Land, dans: Crusader art in the 12th century. Ed. Jaroslav Folda. (International Studies, vol. 152.) Oxford 1982, 47-69.

10 Michail A. Zabroov, Vvedenie v istoriografiju krestovych pochodov: latinskaja chronografija XI -XIII vekov. Moscou 1966, 219-220 [en russe].

11 Amin Maalouf, Les croisades vues par les Arabes. Paris 1983, 67.

12 Quae scilicet clavis (...) a manu eius cadet anno quo rex futurus in Gallia natus fuerit (...); Historia Caroli Magni et Rotholandi ou chronique du Pseude-Turpin. Ed. Cyril Meredith-Jones. Paris 1936, 103. 
mais aussi sur la tradition, donc, ils interprétaient la réalité dans les catégories du passé. Les représentations médiévales du monde et en particulier de la religion des autres étaient moyennées par le nombre des traditions et des influences. Il me semble que la tentative de l'interprétation de cet épisode par les influences des traditions culturelles diverses nous approchera à la compréhension adéquate du passé. Autrement dit, on s'intéressera à la question suivante - les croisés, quand ils se sont mis au contact avec l'autre culture et les autres pratiques religieuses, quels préjugés envers cette culture pouvaient-ils apporter et de quelles sources pouvaient-ils puiser ces préjugés?

\section{L'islam et l'église chrétienne}

Donc, on tâchera de lier la description défigurée du culte musulman avec les représentations propres aux médiévaux et le système des valeurs qui dominait leur conscience. C'est une banalité de rappeler que le trait particulier de la conception du monde chrétienne est par excellence religieuse et qu'il est pour cette raison tout-à-fait naturel pour les hommes médiévaux de considérer les représentants de l'autre religion comme les païens ou les hérétiques. À cela la raison principale que la religion était considérée comme le critère le plus important de l'altérité. À l'époque du Moyen Âge „les Autres“ ce sont tout d'abord les nonchrétiens - les hétérodoxes, les hérétiques, les juifs, les païens et de ce fait-même idolâtres. La religion chrétienne s'oppose à l'idolâtrie et à toute forme indue de l'adoration des créations en lieu et place du Dieu, l'idolâtrie est attribuée au Diable. Dans la conception chrétienne de l'Autre il y a la seule caractéristique qui est démoniaque. ${ }^{13}$ L'Autre est donc toujours l'incarnation du péché et du Satan. La conception de l'Autre est en ce sens l'ontologie de la démonologie. Ce sont, bien sûr, les représentations très générales de cette époque. Tout de même il n'est pas encore clair de quelles traditions culturelles provient cette étrange idée de l'idolâtrie dans les mosquées.

Si la religion était, pour ainsi dire, le critère principal de l'altérité, il est tout-à-fait rationnel de supposer l'influence de la tradition ecclésiastique. Et en vérité, dans les ouvrages des pères d'église occidentale ainsi qu'orientale se reflètent les représentations défigurées des musulmans. C'est déjà Jean le Damascène qui dans son ouvrage De haeresibus a nommé les musulmans les idolâtres. ${ }^{14}$ À l'époque du IX ${ }^{\mathrm{e}}$ siècle l'écrivain Nicétas le Byzantin note que les musulmans à Mecque vénérent l'idole créée à l'image de la statue de Vénus. Il entendait par-là la vénération de la pierre noire de Kaaba qu'il a identifié au culte de Vénus. ${ }^{15}$ L'écrivain byzantin Euthyme le Zygabène qui vivait à l'époque d'Alexis le Comnène à la fin du $\mathrm{XI}^{\mathrm{e}}$ siècle a rédigé le grand ouvrage dirigé contre les hérétiques - l'ainsi dite Panoplia dogmatique où la grande place était assignée à la caractéristique de l'islam. Dans son

13 Bernard Mc Grane, Beyond Anthropology. Society \& the Other. New York 1989, IX.

14 Ioanni Damasceni De Haeresibus Liber, dans: Migne, Patrologia Graeca 94, col. 766.

15 Nicetas Confutatio libri Mohamedis, dans: Migne, Patrologia Graeca 105, col. 720. Voir aussi: Jean Flori, La caricature de l'islam dans l'Occident médiéval, dans: Aevum 66, 1992, 245-256. 
ouvrage il nous rapporte que les Saracènes adoraient l'étoile matinale de Vénus qu'ils nommaient, comme il l'écrit, dans leur langue, Chabar. ${ }^{16}$

La tradition chrétienne occidentale partageait les mêmes opinions. C'est à l'époque du $\mathrm{XII}^{\mathrm{e}}$ siècle que l'écrivain espagnol Pierre Alphonsi ayant exposé la doctrine de l'islam dans son ouvrage Dialogus Petri et Moysii attribue l'idolâtrie à l'islam. ${ }^{17}$ C'est indubitable que l'église façonnait certaines attitudes socio-culturelles envers l'islam et certains stéréotypes idéologiques étaient assez profondement ancrés dans la conscience des croisés. Dans l'atmosphère apocalyptique de la croisade, dont les événements s'identifiaient avec la fin du monde, il est tout-à-fait probable que la tradition ecclésiastique eschatologique exerçait sur les récits des chroniqueurs la plus grande influence.

\section{L'islam et le Satan}

Il est indubitable que les motifs et les images eschatologiques étaient présentes dans la conscience des croisés. Les représentations défigurées du culte musulman pouvaient surgir à la croisée de plusieurs influences culturelles. La tradition d'identification de Mohammed avec l'Antichrist est de la provenance ancienne dans la culture médiévale. La pensée apocalyptique médiévale a subi un grand épanouissment en Espagne du IX ${ }^{\mathrm{e}}$ siècle. Dans leurs ouvrages les écrivains chrétiens Euloge et Alvar de Cordove considéraient Mohammed comme l'incarnation de l'Antichrist et interprétaient son apparition comme le témoignage du rapprochement de la fin du monde. ${ }^{18}$ Ils tiraient des preuves de l'Ancien Testament. Alvare de Cordove interprète dans cet ésprit apocalyptique le passage connu du Livre de Daniel (7,3-24) où il s'agit de la vision des quatre animaux, il identifiait la quatrième bête à Mohammed, et l'an de la mort du prophète au chiffre de la bête apocalyptique - six cent soixante-six. $^{19}$

$\mathrm{Au} \mathrm{XII}{ }^{\mathrm{e}}$ siècle l'abbé de Cluny, Pierre le Vénérable qui désirait familiariser les chrétiens occidentaux avec la doctrine de l'islam et qui a favorisé la traduction du Coran en latin, confirmait dans son ouvrage Contra Sectam Sarracenorum que Satan a pris Mohammed pour instrument. Selon l'opinion de Pierre le Vénérable Mahomet grâce à son sermon a réussi à mettre à la disposition du Diable un tiers du genre humain en ayant arraché du Christ et soumis au pouvoir de Diable la population innombrable. Mohammed selon l'opinion de

16 Marie-Thérèse d'Alverny, La connaissance de l'islam en Occident du $\mathrm{XI}^{\mathrm{e}}$ au milieu du $\mathrm{XI}^{\mathrm{e}}$ siècle, dans: L'Occidente e l'islam nell'alto Medioevo. Vol. 1 (SSCI, vol. 12.) Spoleto 1965, 593. Voir aussi: Jean Flori, „Oriens horribilis“...Tares et défauts de l'Orient dans les sources relatives à la première croisade, dans: Orient und Okzident in der Kultur des Mittelalters / Monde oriental et monde occidental dans la culture medievale. 31. Jahrestagung des Arbeitskreises „Deutsche Literatur des Mittelalters“, Greifswald - Ajaccio, 15.-29. September 1996. (Wodan, Bd. 68; Greifswalder Beiträge zum Mittelalter, Bd. 55.) Greifswald 1997, 45-56.

17 Petri Alphonsi ex Judeo Christiani, dans: Migne, Patrologia Latina 157, col. 597.

18 Jessica A. Coope, The Martyrs of Cordoba. Community \& Family Conflicts in an Age of Mass Conversion. London/Lincoln 1995.

19 Alvari Cordubensis Indiculus Luminosus, dans: Migne, Patrologia Latina 121, col. 535. 
l'abbé de Cluny n'est pas l'Antichrist lui-même, mais il anticipe son apparition, il est son précurseur. ${ }^{20}$ À la suite de ses prédecessuers espagnols Pierre le Vénérable envisage l'islam dans la perspective eschatologique.

À la veille de la première croisade on croyait que tout le monde sera la scène de la bataille finale entre le Christ et l'Antichrist. Cette bataille aura lieu, bien sûr, à Jérusalem, et c'est là où l'Antichrist menera la guerre non seulement contre les juifs et les infidèles, mais aussi contre les chrétiens. ${ }^{21}$ C'est pourquoi que leur présence dans la ville est indispensable et même la conquête de Jérusalem est la prémisse nécessaire pour que les événements de la fin du monde soient accomplis. C'est à Jérusalem, comme l'on croyait, que les événements de l'Apocalypse auront lieu. Avant la parution de l'Antichrist le dernier empéreur viendra à Jérusalem pour déposer sur le mont Olivier le sceptre et la couronne. La tradition apocalyptique se reflète grandement dans le traité De ortu et tempu Antichristi du moine Adso Derviensis, qui dit que l'empéreur avant son arrivée é Jérusalem remportera la victoire sur les musulmans. ${ }^{22}$ Ensuite les non-croyants seront convertis au christianisme après quoi suivra la bataille entre l'Antichrist et les chrétiens. ${ }^{23}$ La situation de la croisade renforçait les humeurs eschatologiques. L'impression des contemporains que les temps sont accomplis et que bientôt tout le monde sera la scène de la bataille finale entre les forces du Mal et les forces du Bien se reflète très nettement dans les chroniques des croisades. ${ }^{24}$ Dans les écrits du pape la libération de la Terre Sainte des musulmans est considérée comme la victoire sur l'Antichrist. ${ }^{25}$ Les motifs et les images élaborés dans la tradition culturelle précédente étaient actualisés instantanément dans l'atmosphère apocalyptique de la croisade. ${ }^{26}$ Le temps courant était le temps eschatologique. L'épisode de la chronique était destiné à une telle perception typique de l'époque. Les lecteurs médiévaux pouvaient considérer l'épisode décrit dans la chronique comme la prophétie accomplie néotestamentaire de la parution de l'Antichrist l'homme de péché, fils de la perte (homo peccati, filius perditionis; $2^{\mathrm{e}}$ Théssal., 3) qui s'installera au Temple du Dieu (...) comme le Dieu, en se donnant pour le Dieu (ita in

20 Petrus Venerabilis Libri duo contra sectam Sarracenorum, dans: Migne, Patrologia Latina 189, col. 649; Jean-Pierre Torrell/Denys Bouthillier, Une spirtualité de combat. Pierre le Vénérable et sa lutte contre l'islam, dans: Revue thomiste 77, 1977; 80, 1980; James Kritzeck, Peter the Venerable and Islam. Princeton 1964.

21 Paul Alphandery/Alphonse Dupront, La Chrétienté et l'idée de Croisade. (Bibliothèque de „L'évolution de l'humanité", vol. 10.) Paris 1995, 51-52.

22 Adso Derviensis. De ortu et tempori Antichristi. Necnon et tractatus qui ab eo dependunt. Ed. Daniël Verhelst. (Corpus Christianorum. Continuatio Medievalis, vol. 45.) Turnhout 1976, cap. XILV.

23 Dupront, La Chrétienté (voir note 21), 40.

24 Guiberti Novigenti Historia quae dicitur Gesta Dei per Francos, dans: Recueil des historiens des croisades. Historiens occidentaux. Vol. 4. Paris 1879, 137-140.

25 Cf.. les lettres d'Innocent III, dans: Migne, Patrologia Latina 216, col. 828-830.

26 Rainer Christoph Schwinges, Kreuzzugsideologie und Toleranz. Studien zu Wilhelm von Tyrus. (Monographien zur Geschichte des Mittelalters, Bd. 15.) Stuttgart 1977, 120 f. Voir aussi: John Victor Tolan, Muslims as Pagan Idolators in Chronicles of the First Crusade, dans: Western views of Islam in medieval and early modern Europe. Perception of other. Ed. David R. Blanks/Michael Frassetto. New York 1999, 97-117. 
templo Dei sedeat ostendens se quia sit Deus). L'attente de la fin des temps et de la bataille contre l'Antichrist pouvaient engendrer de telles descriptions des idoles dans les mosquées. Les hommes médiévaux, en général, vivaient dans l'attente du rapprochement du règne de l'Antichrist, et le temps que les chroniqueurs concevaient n'étaient pour eux que la continuation des temps bibliques. L'anachronisme était le trait particulier de leur vision du monde. Peut-être, les observations directes contredisaient-elles l'interprétation des événements, et il n'y avait pas de statue dans la mosquée, mais elle devait exister dans l'imagination eschatologique des croisés. C'est ainsi que l'épisode de la chronique de Raoul de Caen pouvait être interprété par les contemporains.

\section{La croisade et la Chanson de Roland}

En essayant d'expliquer la parution de cet étrange épisode nous risquons d'énoncer encore une supposition. Les chroniqueurs nous donnent les descriptions fantastiques des usages et des traditions, des croyances et de la vie quotidienne des musulmans. Le dégré de leur défiguration des réalités du monde musulman est énorme. En décrivant les éléments du culte musulman, ils donnent plutôt libre cours à leur imagination, mais en s'appuyant sur la tradition, et notamment, sur la tradition littéraire. C'est dans la poésie épique en ancien français que les musulmans se sont représentés comme les idolâtres et c'est dans les chansons de geste que nous pouvons trouver des parallèles à notre sujet. En effet, les chansons de geste parlent assez souvent de grandes statues de Mohammed que les Saracènes installent dans leurs mosquées. Les idoles dont nous parlent les chansons de geste sont toujours de grandes dimensions et sont ornées d'une manière ostentatoire: elles sont couvertes d'or et d'argent et emmitouflées dans les draps de pourpre. ${ }^{27}$ Les murs où se trouvent les idoles sont ornés par les images des oiseaux, des poissons et des animaux. ${ }^{28}$ Dans les chansons de geste les statues du prophète sont installées sur les colonnes taillées de marbre de diffiérentes couleurs. Elles sont très souvent attachées sur le socle de cristal et couvertes de la soie. ${ }^{29}$ Dans certaines chansons de geste on parle des statues de marbre du Mohammed et emitoufflées dans les draps et ornées de pierres précieuses, devant les statues sont posés les candélabres. ${ }^{30}$ Même l'aspect extérieur de ces statues et des ces idoles nous rappellent les descriptions des idoles dans les chroniques. Il y a dans les chansons de geste les passages complètement identiques à l'épisode rapporté dans la chronique de Raoul de Caen. La chanson de geste Fierabras

27 Cf. Aliscans: chansons de geste. Ed. François Guessard/Anatole de Montaiglon. (Les anciens poètes de la France, vol. 10.) Paris 1870, repr. Nendeln/Liechtenstein 1966, col. 9630: En la mahomerie, la ou Mahomes fu.

28 Le siège de Barbastre: chanson de geste du XII ${ }^{e}$ siècle. Ed. Joseph-Louis Perrier. Paris 1926, col. 991.

29 Maugis d'Aigremont: chanson de geste. Ed. Philippe Vernay. (Romanica Helvetica, vol. 93.) Berne 1980, col. 1641: (...) sur V colonbes tailliées par mestrie. - Blois et jaunes et vermeilles et indes; Les enfances Guillaume: chanson de geste du XIII ${ }^{\mathrm{e}}$ siècle. Ed. Patrice Henry. (Société des Anciens Textes Français. Publication, vol. 75.) Paris 1935, col. 227: A set colonbres an taillieies de maibre. - Cincante oies chescune an son estaige. - Les trois sont verde et le quatre sont jaune.

Le siège de Barbastre (voir note 28), col. 1012. 
nous raconte que les chevaliers francs Roland, Ogier et Olivier selon le concours des circonstances se trouvent dans une cave où ils découvrent de vrais trésors - les statues luxueuses couvertes d'or des dieux musulmans - Apollin, Tervagant et Margot. Ainsi se suit le partage du butin - chacun des chevaliers prend une statue - Roland s'approprie d'Apollin, Ogier - de Margot et Olivier - de Tervagant, et ils chargent sur leurs dos les idoles en or. ${ }^{31}$ On voit que dans les chanons de geste ainsi que dans les chroniques des croisades se réproduit au fond le même modèle narratif.

On peut continuer de tracer les parallèles entre les ouvrages historiques et littéraires. Dans la Chanson de Roland l'émir musulman Baligant parle de sa vénération des idoles musulmanes de Mohammed, Apollin et Tervagant et promet de faire leurs idoles en or s'ils l'aident à remporter la victoire sur les chrétiens. ${ }^{32}$ Avant de se mettre en marche à l'expédition militaire les Saracènes installent l'idole de Mahomet sur la plus haute tour et, comme nous rapporte l'auteur, il n'y a aucun païen qui ne l'adorat et ne fasse prières devant lui. ${ }^{33}$ Nous trouvons dans les chansons de geste ainsi que dans les chroniques les allusions constantes à l'idolâtrie des musulmans. Parfois les chroniqueurs parlent des drapeaux musulmans avec l'image du prophète. Pierre le Tudébode nous rapporte que les musulmans à la vue de l'étendart des chrétiens lèvent au-dessus des murs de la ville le drapeau fixé sur lance avec l'image de Mohammed. Les chansons de geste mentionnent aussi les drapeaux musulmans avec l'image du prophète musulman, de Tervagant et des autres dieux musulmans. ${ }^{34}$ Les exemples cités témoignent que les mêmes motifs conventionnels et les mêmes sujets sont typiques des ouvrages historiques et littéraires.

L'idolâtrie musulmane est le sujet où les traditions historique et littéraire se croisent. On peut tracer les parallèles entre les unes et les autres en étudiant des autres thèmes propres à ce sujet. Très souvent on décrit dans les chroniques les mosquées musulmanes, elles-mêmes, qui se situent devant les portes des villes. Les chroniqueurs les appèllent machomaria ou machumaria. ${ }^{35}$ Ils décrivent cette appellation du nom de Mohammed en entendant par-celà

31 Fierabras: chanson de geste. Ed. Auguste Kroeber/Gustave Servois. (Les anciens poètes de la France, vol. 4, no. 1.) Paris 1860 , v. 5286-5296.

32 Chanson de Roland. Ed. Alexandre de Laborde. Paris 1932, v. 3492-3493: mi damnedeu, jo vos ai mult sevit; Tutes tes ymagines ferai d'or fin.

33 Mahumet levent en la plus halte tur; (...) ad paien nel prit e ne l'aort; ibid. v. 853-855.

34 Petri Tudebodi Historia de Hierosolymitano itinere. Ed. John Hugh Hill. (Documents relatifs à l'historie des croisades, vol. 12.) Paris 1977, cap. IV: Saraceni hoc videntes similiter pergebant per muros civitatis Machomet in quadam hasta deferentes uno panno coopertum; cf. Chanson de Roland (voir note 32), v. 3267-3269: E l'estandart Tervagan e Mahum E un'ymagene Apolin le Felun; Aliscans (voir note 27), v. 9995: En la targe le roi est eseris Apolins, - Tervagans et Mahons en son gonfanon mis.

35 Roberti Monachi Historia Hierosolymitana, dans: Recueil des historiens des croisades. Historiens occidentaux. Vol. 3. Paris 1866, lib. IV, cap. XXII; ibid. lib. VII, cap. VII: Subterraverant quippe illa ultra pontem ad Machumariam; Radulfi Cadomensis Gesta Tancredi (voir note 1), cap. XLIX: fanum, quod vulgo Machummariam vocant (...). 
que l'on adorait le prophète comme l'idole. C'est aussi le topos connu des chansons de geste, où les temples musulmans sont aussi nommés machomaria ou synagogues. ${ }^{36}$

La défiguration de la religion aconique et monothéiste de l'islam se manifieste dans le fait que le polythéisme leur est attribué. En effiet, les chroniqueurs ne discernent pas très nettement l'idolâtrie et le polythéisme. Les passages dans lesquels les musulmans sont représentés comme les polythéistes adorant une vraie multitude des dieux, sont assez fréquents dans les chroniques de la Première croisade. Chez l'Anonyme l'émir de Mossoul Karbouka jure par le nom de Mahomet et les autres dieux. Le vizir al-Afdal s'exclame aussi après sa défaite: $O$ Mahomet et nos autres dieux $?^{37}$ On trouve le même motif dans les chansons de geste. Dans la chronique de Pierre le Tudébode les musulmans appèlent au secours Mahomet et les autres dieux. ${ }^{38}$ Dans Fierabras les musulmans jurent par Mahomet et Tervagant, Apollin et Margot qui sont considérés comme les dieux les plus importants du panthéone islamique. ${ }^{39}$ Les chansons de geste soulignent constamment que les musulmans préferent le polythéisme tout en empruntant les noms des dieux musulmans des diverses sources - à partir des dieux du panthéon classique - Jupiter, Apollon et Mars jusqu'aux païens comme Néron ou les personnages apocalyptiques comme Apollin. On mentionne très souvent le Dieu du nom Tervagant dont l'étymologie n'est pas claire. ${ }^{40}$ Le plus souvent sont mentionnés Tervagant, Apollon et Mars comme la trinité mauvaise qui est considérée comme le pendant de la Trinité catholique chrétienne. On voit que les chroniques ainsi que les chansons de geste partagent les mêmes représentations du polythéisme des musulmans.

On pourrait poser la question: est-ce que cette coïncidence frappante entre les descriptions de Mohammed dans les chansons de geste et les descriptions des chroniques fortuite? Les chansons de geste ainsi que les chroniques sont très proches quant à leur contenu. Dans les ouvrages littéraires et historiques se reflète la lutte entre les chrétiens et les musulmans: dans les chroniques il s'agit des croisades tandis que dans les chansons de geste on parle des événements de la reconquête ou des expéditions de Charlemagne. Il est bien connu que la majorité des chansons de geste en ancien français ont été composées vers la fin du XI' siècle, mais elles ont été rédigés à l'époque des croisades quand la confrontation entre l'Orient et

36 Cyril Meredith-Jones, Conventional Saracen of the Songs of Geste, dans: Speculum 17, 1942, 201-225; Chanson de Roland (voir note 32), v. 3663.

37 Gesta Francorum et aliorum Hierosolimitanorum / The Deeds of the Franks and the other pilgrims to Jerusalem. Ed. Rosalind Hill. London 1962, repr. Oxford 1979, 52: juro vobis per Machimet et per omnia deorum nomina.

38 Petri Tudebodi Historia (voir note 34), 147: O Muchammad et dii nostri!

39 Fierabras (voir note 31), 476, 551: Par la foi que je doi Mahom et Tervagant; v. 5288-5290: En une cambre vint ou Mahomet esta. Apolins et Margos, u l'ors reflambas.

40 Le siège de Barbastre (voir note 28), col. 5471: Mahon et Tervaant (...); Les enfiances Guillaume (voir note 29), col. 1840: par Tervagan le saige; Chanson de Roland (voir note 32), v. 2469. De l'étymologie des noms des dieux musulmans voir: Charles Pellat, L'idée de Dieu chez les „Sarrasins“ des chansons de geste, dans: Studia islamica 23, 1965, 5-42. Il y a une théorie de l'origine arabe des noms de deux musulmans: Paul Casanova, Mahom, Jupn, Apollon, Tervagant, dieux des Saracènes, dans: Mélanges Hartwig Derenbourg (1844 - 1908). Recueil de travaux d'érudition dédiés à la mémoire d'Hartwig Derenbourg par ses amis et ses élèves. Paris 1909, 391-395. 
l'Occident a suscité la nouvelle vague de l'intêret à la lutte contre les Saracènes. ${ }^{41}$ On peut supposer que les chroniqueurs pouvaient connaître certains sujets et motifs de la tradition orale. Les chansons de geste se formaient dans la tradition folklorique, et leur formation s'achève justement à l'époque des croisades. Les historiens de la littérature, en traçant ces liens entre littérature et histoire, notent que les croisades ont laissé une très forte empreinte à l'interprétation dans la poésie épique de l'époque des Carolingiens. ${ }^{42}$ Mais il faudrait supposer que ce processus était mutuel. Non seulement l'époque des croisades a laissé l'empreinte à la tradition littéraire, mais la littérature, elle-même, favorisait la ré-interprétation des réalités historiques de l'époque. Les chansons de geste existaient dans la tradition orale plus tôt que les chroniques ont été rédigées. La tradition épique même dans sa forme orale, coopérait à la tradition historique. ${ }^{43}$ Nous pouvons découvrir les traces de cette coopération dans les chansons de geste.

Les parallèles entre les chroniques et les chansons de geste que nous avons pu établir, sont assez curieuses. Elles permettent de dire que dans beaucoup d'égards les descriptions des musulmans dans les chroniques sont marquées par l'influence des tropes et des conventions des chansons de geste. Ce n'est pas par hasard que le grand médiéviste français Paul Rousset a dit que sans la Chanson de Roland il n'y aurait pas de croisade. ${ }^{44}$ À mon égard il s'agit non de l'influence des modèles, mais plutôt de la conception du monde particulière des chroniqueurs. Ne serait-il pas plus légitime de supposer qu'il s'agit de la fiction inconsciente? À l'époque du Moyen Âge la frontière entre fiction et réalité, entre les res factae et les res fictae, ne passait pas là où elle passe aujourd'hui. Les chroniqueurs écrivaient les ouvrages historiques et ils devaient décrire les événements réels, mais ils ne distinguaient pas assez nettement entre la légende et les renseignements historiques. La frontière entre la tradition littéraire et la tradition historique était assez floue à l'époque du Moyen Âge. C'est pour cette raison que nous découvrons soit dans les chroniques soit dans les ouvrages littéraires des épisodes étrangers qui sont le produit de fantasie des auteurs.

\section{L'Ancien Testament et les représentations chrétiennes de l'islam}

Bien sûr, la tradition littéraire, sur laquelle s'appuyaient les descriptions des musulmans dans les chroniques, estompait la réalité. Mais on peut rappeler les héritages plus anciens et surtout l'héritage judéo-chrétien le plus lointain de la chrétienté médiévale. Et pour ça il faut

41 Jean Flori, L'idée de croisade dans quelques chansons de geste du cycle de Guillaume d'Orange, dans: Medioevo Romanzo 21, 1997, 476-495.

42 Andrei D. Mikhailov, L'épopée héroïque française. Moscou 1996 (en russe).

43 Cette observation concerne non seulement les chroniques des croisades. Rita Lejeune a révélé les motifs épiques et hagiographiques dans les chroniques du XII siècle: Rita Lejeune, Recherches sur le thème: les chansons de geste et l'histoire. Liège 1948. Voir aussi: Michael J.. Bennett, First Crusader's Images of Muslims: The Influence of Vernacular Poetry?, dans: Forum for Modern Language Studies 22, 1986, 101-122; Jean Flori, De la chronique de croisade à l'épopée ... ou bien l'inverse?, dans: Perspectives Médiévales 20, 1994, 36-44.

44 Paul Rousset, Histoire d'une idéologie. La croisade. Paris 1983, 51. 
rappeler l'importance capitale de la Bible. Les références bibliques sont essentielles pour la consience médiévale. Il est tout-à-fait légitime de supposer que les chroniques et les chansons de geste pouvaient s'orienter dans ce cas vers les modèles vétéro-testamentaires (Exode 20, Lévitique 19, Dieutéronome 4) où les images des païens enfoncés dans les péchés et se prosternant devant les idoles, immolant les sacrifices sont créés, leurs idoles et leurs temples doivent être détruites selon l'écriture. Le Vieux Testament interdit de faire des images „sculptées“ et d'adresser un culte aux images. Les textes bibliques expliquent également les origines de l'idolâtrie: elle apparaît le plus souvent comme l'expression du polythéisme, du culte des „faux dieux“, ce qu'illustrent principalement les épisodes du Veau d'or (Exode 32) et du songe de la statue d'or de Nabuchodonosor (Daniel 3,1). Ces modèles bibliques doivent être bien connues par les chroniqueurs. Il se peut qu'ils s'orientaient vers ces modèles bibliques en décrivant le culte des musulmans.

\section{Christianitas - paganitas}

En essayant de découvrir la réalité nous nous heurtons à un nouvel obstacle: la façon de s'exprimer des chroniqueurs, le vocabulaire des pères d'église. Par exemple, les musulmans sont nommés pagani, gentiles, leur culte et leurs images sont désignés effigies, imago, simulacrum, leur religion gentilium ritus ${ }^{45}$, idolatria, superstitio ${ }^{46}$ etc. L'église a élaboré ce discours beaucoup plus tôt - dans sa lutte contre la culture païenne des paysans. ${ }^{47}$ Il est frappant que les représentations et le vocabulaire de la culture ecclésiastique savante qui décrit les paysans et la religion des musulmans, restent les mêmes. L'hagiographie du haut Moyen Âge donna d'abondants témoignages sur les „idoles“ et les statues détruites avec un zèle farouche par les saints missionnaires. Nous retrouvons dans les textes hagiographiques des passages très rassemblants à ceux de la chronique de Raoul de Caen où les chrétiens détruisent les idoles païennes. C'est ainsi que la vie de Ste Catherine nous rapporte de la martyre chrétienne qui brise les statues en or et en argent des dieux païens. ${ }^{48}$ St George renverse les statues antiques et les réduisent en poussière. ${ }^{49}$ Les auteurs font là aussi référence du panthéon classique - Mercure, Jupiter, Apollon sont les dieux vénérés par les paysans. L'église suivait partiellement des modèles très anciens remontant à l'époque où le paganisme était effectivement la cible privilégiée de l'église. Ces modèles élaborés à l'époque du haut Moyen Âge, sont aussi utilisés par les chroniqueurs. En décrivant la réalité ils donnent libre cours à leur imaginaire, en s'appuyant sur la tradition. De même que les auteurs du Moyen Âge ignoraient la religiosité paysanne en s'orientant vers l'image classique du paganisme, les chroniqueurs, eux aussi, ignorent la culture des musulmans en stylisant la figuration du monde musulman selon les principes de la tradition culturelle et en décrivant le culte des

45 Alberti Aquensis Historia Hierosolymitana, dans: Recueil des historiens des croisades. Historiens occidentaux. Vol. 4. Paris 1879, lib. VI, cap. XXII.

46 Fulcherii Camotensis Historia Hierosolymitana (voir note 5), lib. I, cap. II, XXVI.

47 Jean-Claude Schmitt, Les idoles chrétiennes, dans: L'idolâtrie. Paris 1990, 107-119.

48 Hippolyte Delehaye, Les passions des martyrs et les genres littéraires. Bruxelles 1921, 299.

49 Delehaye, Les passions (voir note 48), 300. 
musulmans comme une espèce du paganisme. Sous la plume du chroniqueur les faits réels deviennent les formules rhétoriques loin de la réalité.

Mais l'opposition „christianitas - paganitas“ propre à la culture médiévale reste essentielle. L'iconographie confirme cette observation. La miniature de la Chanson de Roland représente le culte musulman comme étant de l'idolâtrie. L'idole - l'idole du prophète, bien sûr - est representé sous la forme d'un animal (vraisemblablement un cochon) couché sur la colonne de marbre antique. ${ }^{50}$ On pourrait dire que les traditions diverses se reflètent dans cette représentation. La tradition littéraire selon laquelle Mohammed était dévoré par les cochons, la tradition ecclésiastique selon laquelle les musulmans sont idolâtres, et aussi l'attribution du paganisme aux musulmans. La culture musulmane n'est pour l'imaginer que la continuation de la culture antique paienne. À cet égard l'islam pour eux n'est que la survivance du paganisme. L'homme médiévale interprète le monde islamique selon les catégories „christianitas - paganitas“.

\section{La conception chrétienne de l'image sacrée et les „idoles“}

Et pourtant, si l'on veut dresser le bilan de toutes les interprétations possibles de cet étrange passage de Raoul de Caen, l'observation la plus vraisemblable paraît étre suivante: il est, enfin, tout-à-fait légitime de supposer que les traits particuliers du culte chrétien - la présence des images des saints, des statues et des sculptures dans les églises chrétiennes était une des prémisses de la perception du culte musulman. L'abondance des sculptures dans les églises frisait en effet l'idolâtrie. Même le clergé s'en rendait bien compte. Bernard d'Angers, par exemple, l'auteur du Liber miraculorum Sancte Fidis voyageant en 1020 en Auvergne notait partout les statues d'or ornées de pierres précieuses. Il les comparait avec les idoles païennes. Il y a dans le Liber miraculorum le dialogue remarquable entre Bernard d'Angers et son compagnon. En regardant la statue de St Geraud dans une église d'Auvergne il s'adresse en souriant à son compagnon: Que penses-tu de cette idole? Jupiter et Mars auraient-ils estimé indigne d'eux d'une telle statue? ${ }^{51}$ C'est étonnant que le saint père prononce devant l'image du saint presque les mêmes mots que Tancrède a prononcé en regardant la statue du Mahomet. Donc, les représentations de son propre culte, du culte chrétien influençaient de telles descriptions de l'idolâtrie musulmane. L'on sait combien les images et les représentations des saints ont été utilisées dans le culte chrétien; et dans cet esprit justement les chrétiens par rapport aux musulmans pouvaient être pris pour des idolâtres. Cette idole a été très richement argumentée dans le livre récent de Michael Camille The Gothic Idol et elle est confirmée par nos sources. ${ }^{52}$ Le statut de l'image provoquait beaucoup de problèmes au sein de la chrétienté. La question de l'idolâtrie était assez actuelle. La littérature liturgique et théologique consacrée à cette question est inépuisable, et la question la plus

50 Biblioteca Palatina, cod. Germ. 112. On parle aussi de l'assimilation de l'islam au paganisme antique dans les chroniques des croisades; voir: Tolan, Muslims as Pagan Idolators (voir note 26).

51 Liber miraculorum Sanctae Fidis. Ed. Auguste Bouillet. (Collection des textes pour servir à l'étude et à l'enseignement de l'histoire, vol. 21.) Paris 1897, 46-49.

52 Michael Camille, The Gothic Idol. Ideology and Image-making in Medieval art. Cambridge 1989. 
souvent discutée était la suivante: comment distinguer les images vraies des images fausses? L'attitude offensive envers l'idolâtrie (le cas de la chronique de Raoul de Caen l'illustre bien) révèle une incertitude quant à ses propres pratiques de l'image. C'était, peut-être, une façon d'accuser l'autre (e.g. les musulmans) pour mieux se disculper du soupçon de l'idolâtrie. Que les musulmans aient été, autant que les païens, tenus pour les idolâtres, peut paraître paradoxal, puisqu'il s'agit de la religion aconique; l'on sait que les musulmans, euxmêmes, tenaient très souvent les pratiques chrétiennes pour idolâtres. Ce n'est pas un hasard si l'auteur arabe Ibn-al-Athîr écrit dans sa chronique que les chrétiens ont décoré leurs églises par les images et les statues et qu'ils ont même gravé les représentations des animaux sur les colonnes de marbre (c'est ainsi qu'il percevait l'ornement roman) ${ }^{53}$ À la différence de l'islam il y avait dans le culte chrétien de l'Europe occidentale des représentations sculptées et des figurations du Christ et des saints. Les personnages de l'Ancien et du Nouveau Testament étaient représentés en images, dans les églises chrétiennes on pouvait voir des statues et des sculptures des saints. Les statues du Christ et de la sainte Vierge à Winchester, par exemple, ont fait une très grande impression sur les chroniqueurs normands. ${ }^{54}$ Cette particularité du culte chrétien exerçait, bien sûr, une très grande influence sur la perception de la religion de l'autre. Camille écrit dans son livre, avec beaucoup de justesse, que les chrétiens étaient en quelque sorte sous l'empire des images. ${ }^{55} \mathrm{Ce}$ n'est donc pas surprenant qu'ils aient transposé sur le culte musulman leurs propres représentations du culte religieux. Dans leurs descriptions des mosquées musulmanes le culte chrétien jouait le rôle du modèle absent. Je veux dire que grâce à l'inconnu, le connu se trouvait sollicité, au détriment du réellement vu. Le monologue de Tancrède devant la statue est très typique. Il le prononce en demeurant sur le territoire de la montagne Moria, lieu sacré par excellence et où se trouve la mosquée d'AlAqsa. ${ }^{56}$ Est-ce que c'est là que la statue était placée? Le chroniqueur Foucher de Chartres la place dans le Templum Domini - le point plus important pour le culte chrétien. Voici qui est très significatif. Tancrède en réflechissant sur le sens de l'image du prophète Mohammed émet la supposition que la statue qui est devant lui est la représentation du Christ. Ici Mohammed est considéré comme le pendant du Christ, et sa statue décrite dans les récits des chroniqueurs correspond, sans doute, à la statue du Christ dans l'église chrétienne (comme, par exemple, la trinité mauvaise des musulmans est le pendant de la Trinité chrétienne). L'église chrétienne condamnait, sans doute, l'idolâtrie, mais les frontières entre les images fausses et les images vraies était très floue, et il était assez difficile de les distinguer. Le monologue de Tancrède est consacré à cette question - le chevalier énumère même les signes d'après lesquels on pourrait établir, si l'image est vraie ou fausse. En décrivant l'idolâtrie dans le système de valeurs de l'Autre les chroniqueurs pouvaient répudier absolument le sens des images, mais dans le culte de l'Autre. Ils répudiaient ce culte par le biais

53 Ibn al-Athir. Kâmil at-Tawîrikh, dans: Chroniques arabes des Croisades. Ed. Francesco Gabrieli. Paris $1977,195$.

54 Charles Reginald Dodwell, Ango-Saxon Art: A New Perspective. London 1985.

55 Camille, The Gothic Idol (voir note 52), XXVI.

56 Cf. Sylvia Schein, Between Mount Moriah and the Holy Sepulcre: The Changing Traditions of the Temple in the Central Middle Ages, dans: Traditio 40, 1984, 175-185. 
de la transfiguration et de l'inversion de son sens. C'est cela que fait Tancrède en prononçant devant la statue le monologue remarqué et en attribuant à cette image le sens eschatologique, en le nommant Antichrist et idole. L'idée générale est l'opposition, et c'est justement un tel travestissement qui est compréhensible pour la conscience chrétienne. En effiet, le chroniqueur crée une sorte de contre-image, l'image fausse dont le sens où pouvaient le comprendre les chrétiens médiévaux. En même temps ce passage de Raoul de Caen ainsi que le discours de Tancrède est la tentative de l'auto-détérmination par rapport à l'Autre. Et c'est pour cela que tout est construit dans ce discours en fonction de principe de l'inversion - on oppose le Christ et l'Antichrist, le culte luxueux des musulmans et le culte modeste de la chrétienté. L'image peinte par le chroniqueur est l'image-miroir du culte chrétien.

Donc, le passage étrange des chroniques de la Première croisade peut être expliqué si nous l'examinons non comme un ,puits' des renseignements ou un récit de l'événement qui s'est effectivement passé, mais plutôt comme le trait de la conscience médiévale. Il faudrait donc envisager le récit du chroniqueur à travers le prisme de sa propre culture. Le passage cité est très significatif à cet égard. Il nous témoigne que l'image de l'Autre à l'époque médiévale est colorée des représentations religieuses. L'Autre est considéré, dans la perspective eschatologique, comme l'incarnation du Mal démoniaque ou bien comme le signe du royaume imminent de l'Antichrist. L'image de l'Autre est interprétée dans le contexte de l'opposition "christianisme - paganisme“ qui est très typique de la culture médiévale - on attribue aux musulmans l'idolâtrie, le polythéisme, la démonolatrie. Le passage de Raoul de Caen nous permet d'éclaircir les traits dominants des représentations médiévales de l'Autre. En décrivant cet épisode - on l'a vu - les chroniqueurs préféraient plutôt de réproduire les stéréotypes idéologiques et les récits fantastiques propres à la tradition littéraire et idéologique précédente en répétant soit les clichés empruntés chez les pères d'église soit les sujets et les motifs conventionnels de la poésie épique que de transmettre une réalité vecue. On pourrait dire que l'argument décisif pour eux était un argument d'autorité, non d'expérience. ${ }^{57} \mathrm{La}$ vérité d'ordre idéologique emporte sur l'exactitude objective. Ils savent d'avance ce qu'ils vont trouver; l'expérience concrète pour eux est là pour illustrer une vérité qu'on possède, c'est-à-dire la représentation propre au christianisme médiévale selon laquelle les musulmans sont les païens et les idolâtres. L'image peinte par les chroniqueurs s'inscrit naturellement dans leur vision du monde où tout est ordonné et reconnaissable et trouve sa place dans l'hiérarchie des choses. Par conséquent, l'altérité culturelle n'est pas prise en considération; par contre les modèles de sa propre culture sont transposés à l'Autre. Que ce soit paradoxal, mais les chroniqueurs afin de créer ,l'effet du réel' apportent dans leurs récits la fiction inconsciente en soumettant leurs descriptions aux principes de la figuration du monde musulman qui existent dans la tradition culturelle. Donc, les faits historiques sont soumis à la ré-interprétation et à la transformation de la réalité

57 Gilbert Larochelle, Image et représentation de l'Autre: l'Amérique du Nord imagine l'Amérique du Sud, dans: Diogène 157, 1992, 33; Tzvetan Todorov, The Conquest of America. The Question of the Other. New York 1984, 21. Todorov a montré que c'est grâce à son orientation vers l'autorité que Colomb a pu découvrir l'Amérique. Voir aussi: Jean Flori, La caricature (voir note 15). 
vecue dans l'esprit de la culture médiévale même dans les ouvrages historiques qui prétendent de réfleter la ,réalité".

Il est temps de clore notre exposé. Les croisés, quant ils sont venus en Terre Sainte, étaient déjà ,préparés' à une certaine perception du culte musulman. Les stéréotypes idéologiques qui dominaient leur conscience et leur propre vision du monde ont pré-établi une telle perception du monde islamique et les ont conduits à créer une telle image des musulmansidolàtres. Est-ce que la statue de Mohammed se trouvait en effet sur la montagne Moria? Il n'y a pas, probablement, de réponse à cette question; une chose est claire - la statue du prophète musulman existait dans l'imagination des croisés grâce aux traditions culturelles et grâce aux traits particuliers du culte chrétien. 
Bilaterale Vergleiche 



\title{
Divisions of Territory in the early Middle Ages
}

\section{England and Scotland compared}

\author{
Von \\ Geoffrey W. S. Barrow
}

If an English gentleman in the seventeenth or eighteenth century encountered another English gentleman whom he did not know - in London, say, or at Bath, or some other place where people were apt to congregate - he might have addressed the stranger with these

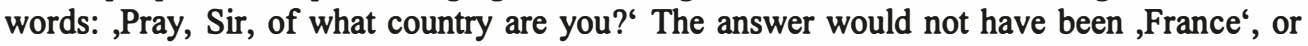
,Denmark', or ,the Grand Duchy of Tuscany': on the contrary, it would have been ,Kent' or ,Somerset', or ,Yorkshire'. ${ }^{1}$ The division of England into what, since the twelfth century, it has been normal to call ,counties' (comitatus) was absolutely fundamental - so much so that it was not usual for a county to be confused with an earldom (also comitatus) in common usage. The region or area from which a man or woman came, where they had probably been born and from which they would derive their speech, customs and attitude towards other regions, was known as their country; from c. 1500 to 1800 England was a collection of ,countries' ${ }^{2}$ Today the only trace of this usage to survive appears when we speak of ,the West Country' (noun) or of ,west country traditions, speech etc.' (adjective). It is no longer possible to use ,North Country' or ,South Country' as nouns, but they can still be adjectives. (For some reason not clear to me there never has been an ,East Country').

I This usage is reflected in numerous sepulchral monuments of the period, to be found in parish churches, in which a Latin inscription uses the word ager, ,district' or ,territory', to convey the sense of ,county'. Examples may be found in John Bridges/Peter Whalley, The History and Antiquities of Northamptonshire. Vol. 1. Oxford 1791, 354b, 414b, 483b, 556b, 564a, 605b and elsewhere. A parallel usage in Scotland is seen in Lachlan Shaw, The History of the Province of Moray. Edinburgh 1775, IX: „The Name (Extent, Situation, Division) of the Country of Moray".

2 The Oxford English Dictionary. Vol. 3. $2^{\text {nd }}$ ed. Oxford 1989, s.v. ,country‘, I, 2 (a). 
The organization of England south of the Rivers Tees and Ribble into counties dates from the reign of Edward the Elder (899-924). ${ }^{3}$ If one takes only England south of the River Thames, together with East Anglia, it goes back to the fifth and sixth centuries. By the date of the famous Domesday Survey (1086), it is clear that the county basis for territorial division had become firmly established. ${ }^{4}$ All that had to be added to produce the situation familiar until 1974 were Lancashire and the four northernmost counties of Northumberland, County Durham, Cumberland and Westmorland. These northern divisions emerged gradually during the twelfth century and had become definitively established in the period c. $1180-1200 .^{5}$

An arrangement which, broadly speaking, held good for some ten centuries of English history must prompt us to ask how naturally or organically it had developed from an earlier pattern. The routes along which the German (or at least Germanic-speaking) migrants penetrated the island of Britain, and the manner in which these new settlers were organized both socially and politically, have been the object of intense investigation during the past twenty to thirty years. This modern re-assessment has not fundamentally overturned the chronology of Old English settlement as found in the work of Hodgkin ${ }^{6}$, Stenton ${ }^{7}$ and Myres $^{8}$; we may still place the adventus Saxonum (in the broadest sense) between c. 400 and 550. What the new work has revolutionized is, first, the stories of early conquests under named leaders in

3 Frank M. Stenton, Anglo-Saxon England. Oxford 1943, 317-335. For reasons of personal convenience I have used the second edition (1947), but readers are referred to the third edition (1971), where the passage relevant here occurs on 336-339.

4 Victoria History of the Counties of England (1900s), under the various counties (usually in vol. 1); Vivian H. Galbraith, The Making of Domesday Book. Oxford 1961, 7-8, 59-66; id., Domesday Book: its place in administrative history. Oxford 1974, 37-46.

5 See volumes published for the Pipe Roll Society as follows (cited by king and regnal year): Cumberland: PR 23 Henry II, 120-123 (but note that the comitatus de Coplanda, i.e. ,county of Copeland', appears under Yorkshire in 1190 [Great Roll of the Pipe 1 Richard I, 88], while Copeland was treated as part of Cumberland in 1185 [PR 31 Henry II, 186]). Lancashire: Great Roll of the Pipe 1 Richard I, 18-19: comitatus de Lancastra, 1190. Northumberland: apparently treated as a county from early in the reign of Henry II although not so called. Sheriffs of Cumberland and Northumberland are mentioned casually in 1184 (PR 30 Henry II, 42). Westmorland: the communitas of Westmorland is referred to in 1190 (Great Roll of the Pipe 1 Richard I, 89). By 1207-1208 Cumberland, Lancashire, Northumberland and Westmorland all seem to have been treated as standardised counties (see Memoranda Roll, $10 \mathrm{John}, 32-33$, 41, and also, in the same volume, Curia Regis Roll for Hilary Term 7 Richard I, 112, 116). For the consolidation of ,St. Cuthbert's Land' (= County Durham) into a county in the last decade of the twelfth century see Victoria County History. Vol. 2. Durham 1907, 144-146.

6 Robert H. Hodgkin, A history of the Anglo-Saxons. $3^{\text {rd }}$ ed. Oxford 1952, repr. 1967.

7 Stenton, Anglo-Saxon England (cited in note 3).

8 Robin G. Collingwood/John N. L. Myres, Roman Britain and the English Settlements. Oxford 1936, 325-456. See now John N. L. Myres, The English Settlements. Oxford 1986. I have used the paperback edition (1989) as re-issued in 1998. For the earliest large-scale Germanic settlements in Britain see 84-103. See also Peter Salway, Roman Britain. Oxford 1981, paperback 1998, 462-501. Myres's work seems to stress unduly the catastrophic nature of the end of Romano-British society, while Salway's book suffers from the author's practice, all too common among English scholars, of using ,Britain' for what later became England or England and Wales. 
Kent, Sussex, Hampshire and the wider Wessex - these stories have mostly been blown out of the window by healthy scepticism '; and, secondly, our knowledge through archaeology of the invaders' material culture, of armour, weapons, jewellery and other grave goods, of their pottery, domestic utensils and dwellings. ${ }^{10}$ There is also a much clearer understanding of the close and continuing relationship, not always friendly, which must have obtained in many regions of southern Britain, even in the east, between Germanic settlers and British - decreasingly Romano-British - natives.

The incoming Germanic settlers organized themselves into kingdoms. ${ }^{11}$ It has to be admitted that we know little about the origins of these kingdoms, but at least we can ask how far they conformed to the tribal pattern of Roman Britain. This had never been obliterated by the imperial divisions, both military and political, which produced such concepts as Britannia Prima (Superior), Maxima Caesariensis, Britannia Secunda (Inferior) or the somewhat fugitive Valentia. ${ }^{12}$ To some extent continuity from Roman Britain into Anglo-Saxon England was the inevitable result of geography. South Britain has a number of well-marked peninsulas which must have dictated settlement even allowing for a North Sea and Channel coastline markedly different from the one we have today. ${ }^{13}$ Most obviously, Kent, Caesar's Cantium, was the tribal territory of the Cantiaci ${ }^{14}$ and Kent - at least east Kent - became the earliest Germanic kingdom to be established in Britain (later fifth century). ${ }^{15}$ At the opposite end of south Britain an even more conspicuous peninsula, Cornwall and Devon, was inhabited by the Dumnonii, who have left their name in Devon. ${ }^{16}$ The Germanic settlement in Devon may be dated nearly two centuries later than that of Kent. ${ }^{17}$ Cornwall, remarkably, was never settled by Germanic-speaking invaders, even although it was formally ,conquered' by the West Saxon King Egbert towards the end of his reign (c. 838). ${ }^{18}$

9 Steven Bassett (Ed.), The Origins of Anglo-Saxon Kingdoms. Leicester 1989, 58-64, 84-88.

10 Myres, The English Settlements (cited in note 8), cites much of the literature dealing with these aspects, in footnotes and in his bibliography (228-240). Several of his chapters contain discussions of pottery, jewellery and other examples of material culture.

11 Despite the thorough re-examination of the evidence which the scholars contributing to Bassett, The Origins (cited in note 9), have carried out, it remains true that the precise process by which Germanic settlers transformed themselves into kingdoms is obscure or simply unknown. Myres, The English Settlements (cited in note 8), suggests that the Roman imperial defensive organization of the ,Saxon Shore' (litus Saxonicum) may have underlain the emergence of Sussex, Kent, Essex and East Anglia. This would not explain how Wessex, Middle Anglia, Mercia or Deira emerged as kingdoms, save perhaps by imitation.

12 Salway, Roman Britain (cited in note 8), 29, maps VII (c), (d); Bassett, The Origins (cited in note 9), 202-204.

13 Collingwood/Myres, Roman Britain (cited in note 9), map VI (to face p. 359). For a pioneer attempt to reconstruct $5^{\text {th }}-6^{\text {th }}$ century English coastlines see John R. Green, The Making of England. London 1882,32 and elsewhere.

14 Bassett, The Origins (cited in note 9), 55-74.

15 Ibid. 64-65; Myres, The English Settlements (cited in note 8), 113-114, 122-128.

16 Barbara A. E. Yorke, Wessex in the early Middle Ages. Leicester 1995, 4-5, 15-19.

17 Ibid. 60, 84-86.

18 Ibid. 95. 
Between the River Thames and the Wash what we now call East Anglia, with Essex, forms another inescapable peninsula, settled by people of mixed Saxon, Angle and probably Frisian origin during the course of the late fifth and earlier sixth centuries. ${ }^{19}$ Northward again, between the Wash and the River Humber, the kingdom or province of Lindsey, with a name derived from the Romano-British settlement of Lindum Colonia, now Lincoln, also forms a peninsula, more conspicuous in the first millennium than nowadays because of a much lower coastline which left the modern Holland division of Lincolnshire largely under the sea. ${ }^{20}$

Finally, we should note that Wales constitutes a large peninsula west of the Rivers Severn and Dee much of whose land area is higher and hillier than most of England east of Devon and south and east of the Pennine massif. It is in no way surprising that people coming from flat lands east of the North Sea made little or no headway in ,Highland Zone' Britain. Peninsulas tended to impose unity of settlement, but this held good for Celtic-speaking natives as well as for Germanic-speaking incomers.

At first sight, it would seem that the Anglo-Saxons divided the southern part of the island of Britain in very much the same way as their predecessors, the Romano-Britons, had divided this territory. The names Kent (Cantium), Wight (Vectis) and Devon (Dumnonii) were preserved for identical or almost identical districts. Even the South Saxons seem to have occupied the tribal territory of the Regnenses (i.e. Sussex) ${ }^{21}$, while the Gewissae and the Jutes took over the territory of the Belgae and of Vectis, and turned the cantonal capital of the Belgae (Venta Belgarum) into Wintan-ceaster, i.e. Winchester, just as further west a chief place of the Dumnonii, Isca Dumnoniorum, was turned into Isca-ceaster >Icsa-ceaster $>$ Exonchester $>$ Exeter. ${ }^{22}$ We have noticed that the Anglian kingdom of Lindsey bore the name of Romano-British Lindum; and the Old English name for York, Eoforwic, was surely an adaptation of Romano-British Eburacum. ${ }^{23}$

That is all at first sight. On a slower second glance, continuity with the Romano-British past is not seen to have been the keynote of territorial division in early Dark Age Britain. The territorial names we are all familiar with are overwhelmingly the names of peoples or tribes, or else the names of Mercian and Middle Anglian boroughs around which strong rulers had arranged a pattern of dependent districts. And even the tribal names possess a peculiarity which points unmistakably to arrangements falling into place at a relatively late period in the long-drawn-out process of settlement. Although there are within the territorial framework two generic names, Angle and Saxon, which were brought with the settlers and

19 Barbara A. E. Yorke, The kingdom of the East Saxons, in: Anglo-Saxon England 14, 1985, 1-36.

20 For the estimated coastline, c. 200, of the south of Lindsey, see Bassett, The Origins (cited in note 9), 203 (figure 14).

21 Ibid. 57-58, 75-83; Myres, The English Settlements (cited in note 8), 135 and map 2.

22 Yorke, Wessex (cited in note 16), 4-5 (figures 2, 3); Eilert Ekwall, Concise Oxford Dictionary of English Place-Names. $4^{\text {th }}$ ed. Oxford 1960, s.v. Exeter".

23 Ibid. s.v. ,York'. The modern name is derived from the Scandinavian form Jorvik. 
referred to the territories, Angeln and Saxony (Nieder-Sachsen), from which they came ${ }^{24}$, the great majority of territorial names in southern Britain refer to the situation within Britain itself. Thus, Sussex - the South Saxons - was named for Saxons who dwelt to the south of other Saxons in Britain, Wessex - West Saxons - for those to the west of Middle Saxons and East Saxons (Middlesex, Essex) and so conversely. North of Essex were people - Angles and perhaps Frisians - who were so anonymous and self-effacing (or alternatively so arrogant?) that they had no other name than ,the folk (das Volk), who became ,North Folk' (Norfolk) and ,South Folk' (Suffiolk) merely according to whether they lived north or south of the River Waveney and River Little Ouse. West of East Anglia were the ,Middle Angles', but they and the name Middle Anglia were really ephemeral; the early tribal names applying to this large area have either vanished or else survived only in place-names of which Spalding and Wisbech are perhaps the best known. ${ }^{25}$

Westward again from ,Middle Anglia' lay the wide territory of greater Mercia. Once again, the best-known name was adopted with reference to the local situation: the Mircnasaete were those Angles who dwelt among the border (mearc) with active and hostile British tribes or kingdoms further west. The large, apparently Anglian, people or tribe of the Hwicce occupied the middle Avon valley and the long limestone escarpment called Cotswold (nowadays ,the Cotswolds'). Absorbed by Mercia by the end of the eighth century, the Hwicce (who fascinate present-day historians) are remembered only in the name of Wychwood Forest. ${ }^{26}$ West of the River Severn (or along its middle reaches) the Wreocensaete (called after the Romano-British settlement of Viroconium and commemorated in the name Wroxeter) and the Magonsaete of Herefordshire have vanished without significant trace. $^{27}$

North of the River Humber, the great Old English historian Bede, the monk of Jarrow, could think of no better name for the territory and its kingdom than Northumbria and Northumbrians (Nordanhymbre), even though he was in no doubt that these people were Anglian. ${ }^{28}$ It is true that he preserves two important territorial names, Deira and Bernicia, which are neither Roman nor Old English and therefore must be Brittonic or P-Celtic. ${ }^{29}$ For

24 Angeln is in Schleswig: Bede's form for the name (in Latin) is Angulus; see: Bede's Ecclesiastical History of the English People. Ed. Bertram Colgrave/Roger A. B. Mynors. Oxford 1969, 50.

25 The geographical relationship of the early Saxon kingdoms within southern Britain might conceivably be explained by the defence system of the Saxon Shore, manned by Saxons, as suggested by Myres, The English Settlement (see note 11), but this cannot explain Wessex or East Anglia. For the Middle Anglian tribes mentioned here see Bassett, The Origins (cited in note 9), 160-161; Cyril Hart, The Tribal Hidage, in: Transactions of the Royal Historical Society. $5^{\text {th }}$ ser. $21,1971,137,143-144$.

26 Ibid. 148-150; Bassett, The Origins (cited in note 9), 6-17, 138-139, 176-177; Julian Whybra, A lost English county. Winchcombeshire in the $10^{\text {th }}$ and $11^{\text {th }}$ centuries. Woodbridge 1990; Herbert $P$. $R$. Finberg, The Early Charters of the West Midlands. Leicester 1961.

27 Hart, Tribal Hidage (cited in note 25), 139; Bassett, The Origins (cited in note 9), 171-201.

28 Bede's Ecclesiastical History (cited in note 24), I, 15, 25. See also John N. L. Myres, The Teutonic Settlement of Northern England, in: History, new ser. 20, 1935/36, 250-262.

29 Bede's Ecclesiastical History (cited in note 24), III, 1. Strictly speaking, Bede gives the names of Deira and Bernicia only in the genitive plural, i.e. of peoples, not territories. For a suggestion as to the 
all we know, these may be genuinely territorial names, names simply applied to particular areas or regions. It has not proved possible to relate them to any tribal or territorial names recorded from Roman Britain. ${ }^{30}$ The powerful confederation of tribes which gave the Roman invaders much trouble in the first century, the Brigantes, seem to have been essentially located in Yorkshire. Bede's Deira, with the addition of the remarkably long-surviving British kingdom of Elmet or Loidis (Leeds), seems to correspond closely to Yorkshire, but the boundary between the Brigantes and the next tribe to the north, the Votadini (in later Welsh, Gododdin), was more likely to have been the River Wear than the River Tees. We have no convincingly early name for north-west England. Cumbria (in use today) and Cumberland both contain some form of cymry (,we, the people,' i.e. ,Britons'), but although this is almost certainly a name of considerable antiquity its early geographical application is obscure. ${ }^{31}$ Probably it was originally used to cover a very wide region inhabited by people recognised as Celtic-speaking by Germanic-speaking Angles, who were anxious to overrun their territory permanently.

It will not have escaped the notice of keen Anglo-Saxonists that I have not so far used the word ,shire'. The word poses a slight problem for the historian. ${ }^{32}$ For the past millennium at least, ,shire' has been used to denote the standard English administrative district through which royal government has been communicated to the people and within which the people have had access to law and justice, have paid their taxes, and have in olden times performed military service. For much of this long period ,shire' has been equivalent to, almost synonymous with, ,county'. But before ,shire' had come to mean ,county' in the more or less modern sense the word was applied to a much smaller unit of agrarian exploitation and of extensive lordship - normally royal lordship. ${ }^{33}$ I shall not be discussing these smaller shires, since this paper is concerned with the major territorial divisions. But it is worth pointing out that the differences and distinctions between ,large' and ,small' shires were not fundamental - the origins of at least some larger shires may be found in smaller ones; and the etymological sense of the word scir, a division, an area set apart, must surely be identical for both large and small shires. It may also be of interest that when applied to the smaller units, possibly at an earlier period than when used of counties, the word shire does not seem to have been popular south of the Thames or in East Anglia. ${ }^{34}$ We find it in Gloucestershire ${ }^{35}$,

meaning of Deira see Albert H. Smith, The Place-Names of the East Riding of Yorkshire and York. English Place-Name Society. Cambridge 1937, 12. For the name Bernicia see Kenneth H. Jackson, Language and History in Early Britain. Edinburgh 1953, 701-705. Jackson refutes arguments attempting to relate Bernicia to the tribal name Brigantes. For Deira see ibid. 419-421.

30 The tribes of second century Britain south of the Antonine Wall are shown on map V of Salway, Roman Britain (cited in note 8). None of their names corresponds to either Deira or Bernicia.

31 Jackson, Language and History (cited in note 29), 663; Ekwall, Concise Oxford Dictionary (cited in note 22), s.v. ,Cumberland'. Ekwall rightly saw that the name was applied to the whole kingdom of ,Strathclyde' before becoming restricted to the land south of Solway and Esk.

32 Geoffrey W. S. Barrow, The Kingdom of the Scots. London 1973, 7-68, esp. $19-67$.

33 Ibid. 9-13; Ekwall, Concise Dictionary (cited in note 22), s.v. ,scir‘.

34 I have not found any examples of its use in Norfolk or Suffolk, or in the territory of southern England from Dorset to Kent. 
Berkshire $^{36}$, Middlesex ${ }^{37}$ and Esse ${ }^{38}$, and from Lancashire and Yorkshire northward without a break as far as the Moray Firth. ${ }^{39}$ In Kent the ,lathes', for which the county was famous in the later Middle Ages and early modern period, almost certainly filled the place taken by shires further north. Elsewhere in southern England (although rarely), and abundantly from the northern midlands into Yorkshire (with occasional occurrences further north), the term ,soke' (socn) seems to have been used as equivalent to shire. Of course, all these three words, shire, lathe and soke, are now, and have been for a long time, obsolete, in the sense I have given them. But in well-known place-names they can die very hard: the Soke of Peterborough survived into modern times as a minor county, and Hallamshire, the district of Sheffield, is known throughout the world for its knives and other steelware.

Here, then, I use the word ,shire' as equivalent to ,county'. The characteristic way in which the English parcelled out their country, Engla-land, England, ,the land of the Angles', into counties derived from the tremendous effort made by the West Saxon kings, Alfred the Great, his daughter Æthelflaed, ,lady of the Mercians' (d. 918), his son Edward the Elder and his grandsons, Athelstan, Edmund and Eadred, to save their country from Danish conquest and in so doing establish a political ascendancy over almost all of what has been recognised since the twelfth century as England. ${ }^{40}$

Already in Alfred's reign fortified centres, burh (boroughs), were being established in many parts of Wessex. Protection was afforded by strong earthen walls, ditches, and timber palisades. Within these defences people could carry on their business, whether trading or craftsmanship or praying and offering the mass, in comparative security from Danish or Hiberno-Norse attacks. ${ }^{41}$ When the worst of the danger was over, by the turm of the ninth and tenth centuries, the combined West Saxon and Mercian forces pushed across midland England, and the West Saxon monarchy was able to assert its supremacy. The upshot, largely the work of Edward the Elder, King Alfred's son (899-934), was the establishment of more or less standardized units to which it was evidently natural to apply the word shire. ${ }^{42}$

Right across midland England (i.e. old Mercia and ,Middle Anglia') there emerged the familiar pattern of very roughly equal areas dependent on boroughs and named after them: Chester (Cheshire), Derby, Nottingham, Lincoln - so large that Lindsey, with its Danish ,thirds' or ,ridings', long remained distinct from the parts of Kesteven and Holland -, Shrewsbury (Shropshire), Stafford, Leicester, Hereford, Worcester, Warwick, Northampton,

35 Albert H. Smith, The Place-Names of Gloucestershire. English Place-Name Society. Cambridge 1964, part II, 19; part III, 68 (Kendleshire); Ekwall, Concise Oxford Dictionary (cited in note 22), s.v. ,Pinnock'; Whybra, A lost English county (cited in note 26).

36 Margaret Gelling, The Place-Names of Berkshire. English Place-Name Society. Cambridge 1973, part I, 97 (Sheerlands).

37 Tottenhamshire occurs c. 1300, see Barrow, Kingdom of the Scots (cited in note 32), 9-10.

38 Ibid. 10 and note 18 (Walthamshire).

39 Ibid. 18-54.

40 Stenton, Anglo-Saxon England (cited in note 3), chapters VIII and X and esp. 336-339; Charles $S$. Taylor, The Origin of the Mercian Shires, in: Gloucestershire Studies. Ed. Herbert P. R Finberg. Leicester 1957, 17-45.

41 Yorke, Wessex (cited in note 16), 112-123.

42 Taylor, The Origin (cited in note 40). 
Huntingdon, Cambridge, Gloucester, Oxford, Buckingham, Bedford and Hertford. ${ }^{43}$ This pattern, highly artificial though it was, has survived, wellnigh intact, till the end of the second millennium. It rapidly influenced the older major divisions of southern and southeastern England. Former kingdoms, Kent, Sussex and Essex, were assimilated into the pattern, as were the still rather puzzling and anomalous districts of Middlesex and Surrey. In Wessex even the word shire (perhaps not so uncouth as record seems to suggest) ${ }^{44}$ made its appearance in Hampshire (i.e. Hamtun-scir, from Southampton) and Berkshire (Bearrocscir, district of the ridge or hill top, i.e. the Berkshire Downs) while the territory of the Wilsaetan, dwellers in the Wylye valley, became Wiltun-scir, Wiltshire. Otherwise the old settler and even older Brittonic tribal names survived in Dorset, Somerset and Devon, while beyond lay ,Cornavia of the foreigners', Cornwalh, Cornwealas or Cornwall. The old East Anglian kingdom was easily shired as Norfolk and Suffolk. It required the collapse of the Danish kingdom of York (954) to bring Yorkshire into the scheme. It retained its three Danish ,thirds' or ,ridings' thereafter, each of which was easily equivalent to any of the newfangled county-type shires to the south. ${ }^{45}$ As we have seen, Lancashire (Lancaster-shire), Westmorland $(=$,the land of people dwelling west of the Pennine moors'), Cumberland, Northumberland and the conspicuously anomalous ecclesiastical palatinate of Durham were not brought within the shire scheme before c. 1200; but their broad conformity to it thenceforward is not in doubt. ${ }^{46}$

To sum up. The territorial division of England in the early Middle Ages owed little to preAnglo-Saxon - i.e. Roman or Romano-British - arrangements. The earliest divisions were tribal, and those which endured were made relatively late in the long process of Germanic settlement. Most of those familiar today - and the national pattern as a whole - date from the tenth century. A very small number of divisions, such as Kent, have their origins before the Christian Era; some others, such as Northumberland and Lancashire, cannot be traced in anything like their present form before the twelfth century.

When we attempt a comparison of English with Scottish experience in the matter of territorial divisions, we are first of all struck by the paucity of evidence north of the Border. For Scotland we have no land charters before the last decade of the eleventh century, and very few before c. 1150 . We have no law codes before the twelfth century and few which carry any authority before the thirteenth. There are scarcely any early geographical descriptions. Although Adamnán's Life of Columba is thirty years earlier than Bede's Historia Ecclesiastica, and is informative and reliable, it is much narrower in scope both chronologically and geographically. There are whole areas of Scotland, e.g. Galloway and the south

43 The earliest dates at which the names of these shires appear are given in Ekwall, Concise Dictionary (cited in note 22).

44 The word is used in the laws of Alfred the Great, king of Wessex (871-899). See Dorothy Whitelock (Ed.), English Historical Documents c. 500-1042. London 1955, 378-379, chapters 37, 37 (1).

45 Henry C. Darby/Ian S. Marwell (Ed.), The Domesday Geography of Northern England. Cambridge 1962.

46 James C. Holt, The Northerners. Oxford 1961, 198-199, 200-204, 223, 226-227. 
west, or the northern Hebrides and the Northern Isles, about which, in the Dark Ages, there is virtually no information or evidence other than the strictly archaeological.

Despite the silence of the sources, it is possible to see some fixed points between Ptolemy $(100 \times 150)^{47}$, who is almost as full for northern Britain as for southern, and the end of the eleventh century. The modern Scottish Gaelic for Scotland, Alba, seems to have been applied in early times to the country north of the Firths (,estuaries') of Clyde and Forth. ${ }^{48}$ The Clyde-Forth line was historically crucial, as the Emperor Antoninus Pius appreciated in A.D. 143 when he ordered three of his legions to construct a turf wall and ditch from Old Kilpatrick on the north bank of the Clyde to Kinneil (literally ,Wall's End') on the south shore of the Forth (60 kilometres). In its Latin form, Albania, the name Alba has survived with its old meaning only in the title normally bestowed by the reigning sovereign upon his or her second-born son, ,duke of Albany ${ }^{69}$ (That has not been done by the present queen, possibly because it is held by the peerage authorities that an heir of Johann Leopold Albert Wilhelm Ferdinand Victor, prince of Saxe-Coburg and Gotha, born 1906, is lawfully duke of Albany). ${ }^{50}$

If Albany, a descriptive, intrinsically territorial name, applied to the country north of Clyde and Forth, what term or terms were used for the country to the south? The tribal name Votadini, which as we have noted reached as far south as the River Wear in modern County Durham, seems to have applied to people who dwelt south of the Firth of Forth, from around Edinburgh (,fortress of the district called Eidyn') eastward and southward. The name passed into early Welsh as Gododdin and into Old Irish or Gaelic as Fotudán. It was certainly obsolete long before Bede wrote his history in $731 .^{51}$ It is clear that for Bede the whole country from the English River Tees as far as a line somewhere west of Edinburgh (perhaps the River Avon?) constituted Bernicia. ${ }^{52}$ Bede gives us no name for the territory forming present-day north-west England nor for present-day south-west Scotland. In his short

47 See Claudii Ptolemaei Geographiae codex Urbinas graecus 82. Hrsg. Joseph Fischer. (Codices e Vaticanis selecti, Bd. 19.) Leipzig 1932. See also Ian A. Richmond, Ancient geographical sources for Britain north of Cheviot, in: Roman and Native in North Britain. Ed. id. Edinburgh 1958, 131-149; Albert L. F. Rivet/Colin Smith, The Place-Names of Roman Britain. London 1979, 103-147.

48 The name Albion, which underlies Alba, comes from Himilco the Carthaginian, c. 500 B.C., and was applied to the whole island of Britain. For the use of Alba in the sense of Scotland north of Clyde and Forth, see William J. Watson, History of the Celtic Place-Names of Scotland. Edinburgh 1926, 11-12; see also 6, 10 .

49 Archibald H. Dunbar, Scottish Kings, 1005-1625. $2^{\text {nd }}$ ed. Edinburgh 1906, 166, 201, 273. Charles I's second son James (d. 1701) and Queen Victoria's fourth son Leopold were created duke of Albany. The title was also used in the Jacobite royal line after 1701.

50 George E. Cokayne, The complete peerage of England, Scotland, Ireland, Great Britain and the United Kingdom. Vol. 1. London 1910, 87. According to Bernard Burke, A genealogical and heraldic dictionary of the peerage and baronetage, together with memoirs of the privy councillors and knights. London 1931, the second duke of Albany of the Victorian creation ( ${ }^{*} 1884$ ) was removed from the Roll of U.K. Peers on 28 March 1919. This family had descendants into the 1940s.

51 There is no trace of the name ,Votadini' (or its later variants) in Bede's Ecclesiastical History. For Votadinian territory Bede regularly uses the tribal name Bernicii, for which see note 29 above.

52 See, e.g., Bede's Ecclesiastical History (cited in note 24), 212 note 1. 
passage about the mysterious Saint Nynia (Ninian), Bede tells us of Candida Casa (aet tham hwitan aerne, Whithorn), but he does not tell us where Candida Casa was. ${ }^{53}$ A name never used by Bede, although it was surely in existence in his days, is Lothian. ${ }^{54}$ For some centuries this Brittonic name, which seems to have originated as the name of a stream rising in the Pentland Hills south of Edinburgh, has denoted the territory between the Forth and the Pentland, Moorfoot and Lammermuir Hills, stretching from west of Linlithgow to Cockburnspath. In the twelfth and thirteenth centuries it was possible to use the name Lothian for the whole south-eastern part of Scotland as far as the River Tweed. It was never used of any territory south of the Tweed, in what is now England. Lothian must be regarded as one of the major territorial divisions of early medieval Scotland.

The south-west of Scotland offers so few early sources that tracing its earliest known territorial divisions is a difficult task. The Brittonic term Cymry, from which the names Cumbria and Cumberland are derived, would surely have come into use as soon as the Germanic settlers of Bernicia began to push into Lothian, around the beginning of the seventh century. But Cumbria (as distinct from Cumbraland, modern Cumberland) hardly appears in sources earlier than c. $1100 .^{55}$ In a reliable document of c. 1120 Cumbria is called a regio, ,kingdom', and is firmly linked to the diocese whose episcopal see was Glasgow, far to the north of the territory now called Cumbria. ${ }^{56}$ It has in fact been normal to equate the earlier ,Cumbria' - no longer used for a Scottish region after the mid-twelfth century - with Strathclyde, literally the valley of the River Clyde. In some ways Strathclyde is an even more elusive name than Cumbria: it has certainly never been in use from the twelfth century down to comparatively recent times. ${ }^{57}$ But there are sound enough reasons for believing that from the sixth century a dynasty of kings, usually styled ,of Strathclyde' by modern historians, and based on the fortress of Alclud (,Rock of Clyde'), otherwise Dumbarton, ruled a large territory stretching from Loch Lomond southward to the English Lake District. ${ }^{58}$ It was with this dynasty that the shadowy but nevertheless historical founder and patron saint of the diocese of Glasgow, Kentigern (d. 612) was associated in late and somewhat unsatisfactory Vitae. Despite the difficulties involved in the interpretation of inadequate source material we may, I believe, place Cumbria among the recognised major territorial divisions of what is now

53 Ibid. III, 4.

54 Watson, Celtic Place-Names (cited in note 48), 101; Geoffrey W. S. Barrow, Midlothian - or the shire of Edinburgh?, in: Book of the Old Edinburgh Club 35, 1985, 141-148.

55 Charles Phythian-Adams, Land of the Cumbrians. Aldershot 1996, 110-129.

56 Geoffrey W. S. Barrow (Ed.), The Charters of King David I. Woodbridge/Rochester/New York 1999, no. 15.

57 Strathclyde is not listed in: Ordnance Gazetteer of Scotland. A Survey of Scottish Topography, statistical, biographical, and historical. 6 vol. Ed. Francis H. Groome. New ed. London 1894/95. William J. Watson did not deal with the name in his authoritative and comprehensive study of the Celtic placenames of Scotland (cited in note 48). For earlier medieval occurrences see William F. Skene (Ed.), Chronicles of the Picts, Chronicles of the Scots, and other early memorials of Scottish history. Edinburgh 1867, 15, 124, 407.

58 Alan MacQuarrie, The kings of Strathclyde, c. 400-1018, in: Medieval Scotland. Crown, Lordship and Community. Ed. Alexander Grant/Keith J. Stringer. Edinburgh 1993, 1-19. 
Scotland in the earlier medieval period. We should, however, note that as soon as the twelfth-century kings created sheriffdoms, closely resembling English counties and based upon royal castles such as Lanark and Dumfries, and simultaneously created large compact feudal lordships such as Annandale and Liddesdale, the extensive region of Cumbria disappeared, and the name became confined to England, in the form ,Cumberland'.

That left a need to find a name for the country, largely hilly and inaccessible, south and west of the new royal sheriffdoms. From the twelfth century to the present day the name of this territory has been Galloway, the precise meaning of which is still under debate. ${ }^{59}$ Just as there were a larger and a smaller Lothian and Cumbria so also there were in the twelfth century a larger and a smaller Galloway, the former comprising almost the whole of south-west Scotland from Cunningham (north Ayrshire) to Annandale, the latter restricted to the diocese of Whithorn (or Galloway), approximately equivalent to the secular lordship of Galloway, first encountered in the twelfth century. Of the three major territorial divisions which made up southern Scotland in the earlier medieval period none had an unequivocally tribal name, although it is possible that both Cumbria and Galloway refer, somewhat obliquely, to the inhabitants rather than their territory. As soon as we drop from major divisions to those lesser ones which were probably more familiar in daily life we see that they were overwhelmingly geographical - Merse, Tweeddale, Teviotdale, Eskdale, Douglasdale etc. We know, moreover, that this admittedly almost inevitable division by river valleys was not a peculiarity of English-speakers. The earliest Annandale charter $(1124)^{60}$ shows that the pretwelfth century names for Annandale and Nithsdale were Estrahanent (for Brittonic ystrad Anant) and Stranit or Stradnut (for Q-Celtic $s[t] r a t h-N i t$, perhaps for an earlier Brittonic ystrad Nud).

For Scotland north of Clyde and Forth, including Kintyre and all the islands, the Roman geographers used almost entirely tribal names. Even Orcades, for the Northern Isles, is possibly tribal - ,pig people' - although Ebudae for the Western Isles seems to be territorial. ${ }^{61}$ Ptolemy names sixteen tribes for the whole of Scotland (not counting Orcades), twelve for the north. Most prominent and long-lasting were the Caledonii (Caledones). We do not know whether they really were the biggest tribe, and in any event the territorial name Cale-

59 Watson, History (cited in note 48), 172-174, reviews the evidence for the origin and meaning of the name Galloway. The commonest forms of the name before the thirteenth century point clearly to Gaelic gall-Gháidhil, ,foreign Gael', i.e. (presumably) Gaels or Scots who had settled among foreigners, in this case Norse or Viking incomers. But Daphne Brooke, in: Wild Men and Holy Places. St. Ninian, Whithorn and the Medieval Realm of Galloway. Edinburgh 1994, 60-61, 72-73, argues strongly that the name Galloway might be a gaelicized form of the Brittonic (i.e. P-Celtic) name for Galloway, deriving from Caledon(ia). See the same author's article ,Gall-Gaidhil and Galloway', in: Galloway. Land and Lordship. Ed. Richard D. Oram/Geoffrey Stell. Edinburgh 1991, 97-116, esp. 110-111.

60 Charters of David I (cited in note 56), no. 16; cf. ibid. no. 210, where the place-name has become vallis de Anant.

61 Watson, History (cited in note 48), 28. More recently, William B. Lockwood, On the early history and origin of the names Orkney and Shetland, in: Namn och Bygd 68, 1980, 19-35, has argued that Orkney is derived from a pre-Celtic word for ,headland' (referring to the prominent cliffs and hills of Hoy), and is thus geographical, not tribal. 
donia became obsolete after c. 400 and only returned as a modern reinvention. ${ }^{62} \mathrm{An}$ indication of their locality is given by the survival of the tribal denomination in the Perthshire place-names Dunkeld and Schiehallion (respectively ,fortress' and ,fairy hill' of the Caledonians). For the Dark Age and early medieval period we have to rely on much later sources, the earliest of which evidently relate to those successors and descendants of the twelve or thirteen tribes who since the end of the third century had been known collectively as Picti, Picts. This was possibly a nickname, but if so a nickname destined to become permanent and widely known.

The major territorial division of northern Scotland which is easiest to place in both a historical and geographical context is Argyll. The name means ,shore of the Scots' and must have been given by the Scots themselves, Q-Celtic speakers who seem to have been migrating from north-east Ireland (Ulster) into south-west Scotland from c. 450 or a little earlier. ${ }^{63}$ Most if not all these Scottish migrants belonged to the tribe of Riata, and their share of land was Dálriata, both in Antrim and in Scotland. But probably because the name Dálriata persisted in Ireland, its use in Scotland faded quite early, leaving the convenient and no doubt popular name Argyll to survive until the present day. As far as the rest of Scotland north of Clyde and Forth is concerned, the earliest layer of territorial divisions to be preserved in our sources insists on a sevenfold disposition which was preserved in tradition until the thirteenth century or later. Cat or Catenes (Caithness), the northernmost division, was certainly

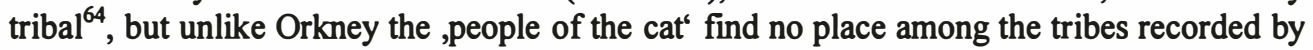
classical writers, nor did they survive under that name into the Middle Ages.

Moving from north to south ${ }^{65}$, we see that the name Fidach (,wooded country'?) seems to be applied to Moray and Easter Ross; Cé would have covered Mar and Buchan (i.e. West and East Aberdeenshire); Cirech or Circhenn evidently applied to Angus with the Mearns (i.e. from Aberdeen to the River Tay at Dundee); Fib was certainly Fife - including the small district of Kinross and, perhaps, Clackmannan; Fortriu (genitive Fortrenn) embraced Strathearm and Menteith (southern Perthshire); and finally Fotla - a poetical name for Erin or Ireland - was used for Atholl (ath fhotla $=$, new Ireland').

While we need not doubt that this list of seven territories comes from a relatively early source it is not likely to go back to the time of St. Columba (Colum Cille) to whom it was attributed. He died in 597, and the list could perhaps belong to the eighth or early ninth century. The real difficulty involved in this source is that only five of its names are known

62 Tacitus uses the name Caledonia in his De vita Agricolae (ed. Robert M. Ogilvie/Ian A. Richmond. Oxford 1967), but most Roman writers prefer the tribal names Caledones or Caledonii; Watson, History (cited in note 48), 19-22. The name was revived by Renaissance scholars in the sixteenth century and immortalized by Walter Scott's lines „O Caledonia, stern and wild, meet nurse for a poetic child!" (Lay of the Last Minstrel 1805, Canto 6, II).

63 Alan O. Anderson, Early Sources of Scottish History. Vol 1. Edinburgh 1922, cxviii; Watson, History (cited in note 48), 120-121; John Bannerman, The Scots of Dalriada, in: Who are the Scots? Ed. Gordon Menzies. London 1971, 66-72.

64 Watson, History (cited in note 48), 30.

65 Anderson, Early Sources (cited in note 63), cxvii, note 2. 
from other early writings or from later, including present-day, usage. These are Caithness (which once included Sutherland), Circhenn, which was used of Angus and Mearns (sixthseventh century), Fotla (if we may equate it with Atholl), Fortriu, used for the kingdom of the southern Picts down to c. 800, and Fife which like Caithness and Atholl is still in use today. The only name on the list to be found in the work of a classical author is Fortriu (genitive Fortrenn), reasonably identified with the tribal name Verturiones found in the Historia Augusta of Ammianus Marcellinus (c. 368?). ${ }^{66}$

From the later twelfth century we have a recorded tradition which appears closer to reality, yet incorporates territorial names which were surely already many centuries old. ${ }^{67}$ In order to keep to the sevenfold tradition while nevertheless listing the major regions as they really were, the De situ Albanie names a pair of territories for each of six out of the seven divisions, with Caithness as the seventh. The twelve remaining territories were as follows (from north to south): Ross, Moray, Buchan, Mar, Mearns, Angus, Atholl, Gowrie, Strathearn, Fife, Fothrif and Menteith. Except for Mearns and Fothrif, this is a list of early medieval Scottish earldoms, but for the purposes of this paper it is more relevant to recognize that, including Mearns, De situ Albanie probably gives a list of pre-twelfth century mórmaerdoms, i.e. districts governed by a mórmaer (,chief officer'), a rank evidently inherited from the kingdom of the Picts. ${ }^{68}$ De situ Albanie was perhaps composed by Master John ,the Scot', sometime chancellor to Bishop Robert of St. Andrews (d. 1159) and himself bishop of Dunkeld from 1183 to $1203 .^{69}$ With its information, derived in part at least from a knowledgeable native Scotsman Andrew bishop of Caithness (c. 1145-84), formerly a Benedictine monk of Dunfermline ${ }^{70}$, we are surely on much safer ground than with the Irish tradition already described.

Of the names from De situ not already looked at, Ross (,moorland'?), Moray (,seaboard settlement'), Buchan and Mar (unexplained), Mearns (,stewartry'), Angus and Gowrie (possibly personal names), Strathearn (,valley of the River Earn'), Menteith (,boggy land of the

66 Ammiani Marcellini rerum gestarum libri qui supersunt. Ed. Charles U. Clark. Berlin 1910/15.

67 Anderson, Early Sources (cited in note 63), cxv-cxviii, 135-137. There is a curious discrepancy in De situ Albanie between the basic list of seven provinces (six of which have sub-provinces) on the one hand and, on the other, the explanation of their location and boundaries (by Bishop Andrew of Caithness). This omits Caithness, surprisingly, and includes Argyll, and fails to make clear which provinces are meant by ,Tay to Isla' and ,Spey to Drumalban'. Unfortunately we do not have a perfect text of De situ Albanie, as is shown by the omission of the words „la mer de Escoce, anglice“ in the text in Skene's edition (cited in note 57), 136, line 12 from foot.

68 The word mórmaer is found in Irish sources almost, if not quite, exclusively referring to persons in Scotland.

69 Donald E. R. Watt, A Biographical Dictionary of Scottish Graduates to 1410. Oxford 1977, 485-488, s.v. (1) ,Scot, John'; also 426-427, s.v. (1) ,Nepos Episcopi, John'. St. Andrews tradition portrays John the Scot as exceptionally learned and the author of several works (now lost). The author of De situ Albanie was not a Scot, because he describes Bishop Andrew of Caithness as a Scot (i.e. exceptional). Bishop John ,the Scot', despite his by-name, was an Englishman from Cheshire.

70 John Dowden, The Bishops of Scotland. Glasgow 1912, 232; Anderson, Early Sources (cited in note 63), cxvii-cxviii. 
River Teith'), Fothrif (now obsolete: ,subordinate settlement'), and Fife (unexplained) seem for the most part to be territorial and descriptive. Most if not all surely go back to the Pictish period before Kenneth Mac Alpin gained control of northern Scotland c. 842. The statement published by William Watson 74 years ago still holds good today in spite of extensive placename study in the intervening period: „tribal and sept names (...) have not influenced the existing territorial names to any great extent. The great majority of these are descriptive.“71

In the matter of territorial divisions, between the end of the Roman Empire in the west and the twelfth century, England and Scotland provide a few interesting comparisons but above all present a striking contrast. The major territorial divisions of England epitomize the history of two processes, on the one hand tribal settlement, in its second stage and within a south British context, on the other hand military defence against a ruthless, determined - and in the long run victorious - enemy. The corresponding divisions in Scotland surely reflect the fact that despite invasion and settlement by several quite sharply distinct peoples speaking and using sharply distinct languages - in particular a substantial and culturally dominant settlement by the Irish of Dálriata - the population remained fundamentally indigenous. This seems essentially true even when one allows that Shetland may be a tribal name ${ }^{72}$ and that Argyll, ,the shore of the Gael', is a name of closely comparable type to the English East Anglia or Wessex. When modern scholars attempt to construct maps of England, Scotland and Ireland in the Dark Ages and earlier Middle Ages, those for England tend to show blocks of immigrant peoples, embryonic nations perhaps, which ultimately coalesce. Those for Ireland tend to show a broad pattern of tribes, each one acknowledging a common agnatic ancestor, forming and reforming kaleidoscopically across the landscape - in Ireland, ancestry was all. ${ }^{73}$ Those for Scotland tend to treat the physical, geographical features as fundamental and therefore to present territories as fixtures.

71 Watson, History (cited in note 48), 100.

72 Alexander Fenton, The various names of Shetland. Edinburgh 1973, esp. tables I, IV. Lockwood, On the early history (cited in note 61), 30-34, argues that Shetland has developed from a Pictish tribal name, possibly involving a word meaning, cat'.

73 See, for example, Art Cosgrove (Ed.), A New History of Ireland. Vol. 2. Oxford 1987, map I (2-3); Annette J. Otway-Ruthven, A History of Medieval Ireland. London/New York 1968, map of Ireland in 1300 following 408; Alfred P. Smyth, Celtic Leinster. Towards an historical geography of Early Irish Civilization. Dublin 1982, maps IV, V, VII-X. 


\title{
Außenblicke für das eigene Herz
}

\section{Vergleichende Wahrnehmung politischer Ordnung im hochmittelalterlichen Deutschland und Frankreich}

\author{
Von
}

Bernd Schneidmüller

Historisches Vergleichen hat eine lange Geschichte. Meist betrieb man es mit klaren Absichten. Die Ansätze, die in diesem Band verfolgt und in der künftigen Forschung weiterentwickelt werden, sind gewiß neu und fruchtbar. Doch sie besitzen Vorbilder in der jüngeren Forschungsgeschichte wie in mittelalterlichen Wahrnehmungen. Deren Methoden und Ziele sollen hier exemplarisch betrachtet werden, indem das vergleichende Rückblicken historisiert und der kritische Diskurs des Historikers mit der Vergangenheit weitergetrieben wird. Gegenstand der Untersuchung ist die Art und Weise, wie neuzeitliche Historiker und mittelalterliche Menschen den Blick auf den anderen zur Stilisierung eigener Unverwechselbarkeit und zur Stillung ihrer politischen wie kulturellen Wünsche genutzt haben. Dafür wird die vergleichende Wahrnehmung politischer Ordnung im hochmittelalterlichen Deutschland und Frankreich in wichtigen Etappen verfolgt, in der Betrachtung von Blicken neuerer und älterer Betrachter auf Forschungsgeschichte, Heilsgeschichte, Reichsgeschichte, Verfassungsgeschichte und Emotionsgeschichte. Der Rahmen eines zum Aufsatz ausgearbeiteten Vortrags erforderte Beschränkung, so daß hier ein erster Versuch für ein längerfristig angelegtes Projekt vorgelegt wird.

\section{Der Nachbar fürs eigene Herz}

In der Geschichte politischer und kultureller Kontakte zwischen Deutschland und Frankreich führten Fremdwahrnehmungen immer wieder zu Vergleichen. Sie dienten kaum wertfreier Erkenntnis. Vielmehr wurden sie zur Stilisierung eigener Vorzüge oder als Mahnung an die Wir-Gruppe formuliert. So hatte schon Tacitus in seiner Germania gearbeitet. Zielrichtung und Selektion ähnelten sich, ob in den Schriften deutscher Revolutions-Touristen nach 1789, bei Madame de Staël oder in den scheinbar nüchternen Wissenschaften vom Mittelalter. Die deutsche Frankreichforschung vom 19. bis zum 20. Jahrhundert blieb anhaltend von aktuel- 
len Sehnsüchten geleitet. Fasziniert schaute sie auf die scheinbar geradlinige Entfaltung französischer Staatlichkeit oder auf die französische Nationsbildung, im europäischen Kontext eindeutig ein Sonderfall. Doch aus den Erfahnungen eigener Verspätung erhob man den westlichen Nachbarn zum Idealfall. ${ }^{1}$ An ihm durfte man eigene Defizite oder Dimensionen kultureller Rückständigkeit studieren. ${ }^{2}$ Bis heute beschäftigt das Leiden an mangelnder Staatlichkeit die deutsche Mediaevistik. Verspätungen oder Rückständigkeiten, insbesondere ein Zivilisations- und Kulturgefälle werden im Blick auf das Europa der verschiedenen Geschwindigkeiten konstatiert, manchmal auch publizistisch genutzt.

Der Zauber machtvoller Entfaltung des französischen Königsstaats bei gleichzeitigem Zerbrechen des imperialen Modells der Staufer prägte eine vornehmlich etatistisch ausgerichtete Geschichtsschreibung. $\mathrm{Da}$ sich im Imperium traditionelle Formen konsensualer Herrschaft erhielten, daß auf der Reichsebene - anders als in den Territorien - die Durchsetzungsfähigkeit gelehrter Juristen nicht zügig genutzt wurde, daß das Königtum den gleichmäßigen Zugriff auf das ganze Reich verlor - all das trug Züge des Versagens. ${ }^{3}$ Darum geriet die deutsche Spätmittelalterforschung in ihr bekanntes Schattendasein, aus dem sie erst in den letzten Jahrzehnten aufbricht. Unsere französischen Nachbarn durften sich dagegen des Wachsens eigener Staatlichkeit seit den Zeiten Philipps II. Augustus versichern. Dafur debattierten sie fruher heftig über die angemessene Beurteilung ihrer angeblichen feudalen Anarchie des 9. bis 11. Jahrhunderts. ${ }^{5}$

Die unterschiedliche wissenschaftliche Durchdringung der verschiedenen mittelalterlichen Jahrhunderte in Deutschland und Frankreich ist ebensowenig Zufall wie der Versuch insbesondere der deutschen Mediaevistik in der ersten Hälfte des 20. Jahrhunderts, aus Vergleichen Erklärungsmodelle für den eigenen historischen Platz zu entwickeln. Ich nenne als Beispiele für anderes nur die beiden Aufsätze, die Walther Kienast 1933 und 1942 über den französischen Staat im 13. Jahrhundert oder über Französische Krondomäne und deutsches

1 Joachim Ehlers, Die deutsche Nation des Mittelalters als Gegenstand der Forschung, in: ders., Ausgewählte Aufsătze. Hrsg. v. Martin Kintzinger/Bernd Schneidmüller. (Berliner Hist. Studien, Bd. 21.) Berlin 1996, 344-398.

2 Peter Moraw, Über Entwicklungsunterschiede und Entwicklungsausgleich im deutschen und europäischen Mittelalter. Ein Versuch, in: Über König und Reich. Aufsätze zur deutschen Verfassungsgeschichte des späten Mittelalters. Hrsg. v. dems./Rainer Christoph Schwinges. Sigmaringen 1995, 293-320.

3 Bernd Schneidmüller, Konsensuale Herrschaft. Ein Essay über Formen und Konzepte politischer Ordnung im Mittelalter, in: Reich, Regionen und Europa in Mittelalter und Neuzeit. Fschr. für Peter Moraw. Hrsg. v. Paul-Joachim Heinig u. a. (Hist. Forsch., Bd. 67.) Berlin 2000, 53-87.

4 Robert-Henri Bautier (Ed.), La France de Philippe Auguste. Le temps des mutations. (Colloques internationaux du Centre national de la recherche scientifique, vol. 602.) Paris 1982; Jean Favier, Le temps de principautés de l'an mil à 1515. (Histoire de France, vol. 2.) Paris 1984; Colette Beaune, Naissance de la nation France. Paris 1985.

5 Ferdinand Lot, Fidèles ou vassaux? Essai sur la nature juridique du lien qui unissait les grands vassaux à la royauté depuis le milieu du $\mathrm{LX}^{e}$ jusqu'à la fin du XII' siècle. Paris 1904; Karl Ferdinand Werner, Naissance de la noblesse. L'essor des élites politiques en Europe. Paris 1998. 
Reichsgut in der Historischen Zeitschrift publizierte. ${ }^{6}$ Den vergleichenden Ansatz verfolgte Kienast bis an sein Lebensende, am deutlichsten in den zwei Auflagen seines Buches Deutschland und Frankreich in der Kaiserzeit ${ }^{7}$, in kontrovers diskutierten Arbeiten über die gestaltende Rolle der "Volksstămme“ in der frühen deutschen und französischen Geschichte $^{8}$, in einer materialreichen Analyse des Herzogstitels ${ }^{9}$ wie in nachgelassenen Studien zur unterschiedlichen Ausgestaltung der frănkischen Vasallităt. ${ }^{10}$ Sămtliche Arbeiten unterscheiden sich nicht nur methodisch von den sozialgeschichtlich angelegten komparatistischen Forschungen in Frankreich, wie sie etwa Marc Bloch publizierte ${ }^{11}$; vielmehr tritt auch die unterschiedliche Zielrichtung der Beschăftigung mit dem Nachbarn als Botschaft an die eigene, nationale Wissenschaft klar hervor.

Aus dem Wissen um gemeinsame Wurzeln im fränkischen Großreich der Karolinger folgte 1990 das Buch von Carlrichard Brühl über Deutschland - Frankreich. Die Geburt zweier Völker, das wenig später in französischer Übersetzung vorgelegt wurde. ${ }^{12}$ Die zugespitzten Thesen wurden in Deutschland kontroverser als in Frankreich diskutiert. ${ }^{13}$ Das erklärt sich nur teilweise aus der besonderen Position des Autors in der deutschen Mediaevistik. Es hat mehr mit dem unterschiedlichen nationalen Selbstverständnis und der dafür genutzten Instrumentalisierung des Mittelalters zu tun. Wăhrend hier das mittelalterliche Imperium im 19. Jahrhundert zum Zielpunkt nationaler Hoffnungen erwuchs ${ }^{14}$, speiste sich das franzősische Selbstbewußtsein aus vielfăltigeren Quellen und gründete auf dem Wissen

6 Walther Kienast, Der französische Staat im 13. Jahrhundert, in: HZ 138, 1933, 457-519; ders., Französische Krondomäne und deutsches Reichsgut, in: HZ 165, 1942, 110-117.

7 Walther Kienast, Deutschland und Frankreich in der Kaiserzeit (900 bis 1270). Leipzig 1943; ders., Deutschland und Frankreich in der Kaiserzeit (900-1270). Weltkaiser und Einzelkönige. 3 Bde. (Monographien zur Gesch. des Mittelalters, Bd. 9.) 2. Aufl. Stuttgart 1974-1975.

8 Walther Kienast, Studien über die französischen Volksstümme des Frühmittelalters. (Pariser Hist. Studien, Bd. 7.) Stuttgart 1968. Dazu kritisch François Louis Ganshof, Stämme als „Träger des Reiches"?, in: ZRG GA 89, 1972, 147-160; Karl Ferdinand Werner, Völker und Regna, in: Beiträge zur mittelalterlichen Reichs- und Nationsbildung in Deutschland und Frankreich. Hrsg. v. Carlrichard Brühl/Bernd Schneidmüller. (HZ, Beih. NF., Bd. 24.) München 1997, 15-43.

9 Walther Kienast, Der Herzogstitel in Frankreich und Deutschland (9. bis 12. Jahrhundert). Mit Listen der ältesten deutschen Herzogsurkunden. München/Wien 1968.

10 Walther Kienast, Die fränkische Vasallität. Von den Hausmeiem bis zu Ludwig dem Kind und Karl dem Einfältigen. Hrsg. v. Peter Herde (Frankfurter Wissenschaftliche Beiträge. Kulturwissenschaftliche Rh., Bd. 18.) Frankfurt a. M. 1990.

11 Marc Bloch, La société féodale. Paris 1939/1940 (dt:: Die Feudalgesellschaft. Stuttgart 1999).

12 Carlrichard Brühl, Deutschland - Frankreich. Die Geburt zweier Völker. Köln/Wien 1990 (frz.: Naissance de deux peuples. Français et Allemands [ $\mathrm{XX}^{\mathrm{e}}-\mathrm{XI}^{\mathrm{e}}$ siècle]. Paris 1994).

13 Positionen der Diskussion sind dokumentiert in: Carlrichard Brühl/Bernd Schneidmüller (Hrsg.), Beiträge zur mittelalterlichen Reichs- und Nationsbildung in Deutschland und Frankreich. (HZ, Beih. NF., Bd. 24.) München 1997.

14 Reinhard Elze/Pierangelo Schiera (Ed.), Italia e Genmania. Immagini, modelli, miti fra due popoli nell'Ottocento: il Medioevo. (Annali dell'Istituto storico italo-germanico in Trento; Contributi, vol. 1.) Bologna/Berlin 1988; Gerd Althoff(Hrsg.), Die Deutschen und ihr Mittelalter. Themen und Funktionen modemer Geschichtsbilder vom Mittelalter. Darmstadt 1992. 
um lange historische Überlegenheit im europäischen Rahmen. Das 20. Jahrhundert begründete dann unterschiedliche Fachtraditionen. In der ersten Jahrhunderthälfte verlor die deutsche Geschichtswissenschaft ihre methodische Innovationsfähigkeit. ${ }^{15}$ Wer nach dem Zweiten Weltkrieg Anschluß an den Fortschritt gewinnen wollte, mußte als Mediaevist nach Westen schauen. Die Spieglerfunktion von Kulturvergleichen ist dem selbstkritischen Verfasser dieser Zeilen bekannt, so daß er zugespitzt formulieren kann: An Frankreich wuchs die deutsche Mittelalterforschung von den sechziger bis in die achtziger Jahre des 20. Jahrhunderts. Darum arbeitete sie wohl auch intensiver an Vergleichen zwischen Deutschland und Frankreich, vielleicht sogar am französischen Nationalbewußtsein, als es die westlichen Fachkolleginnen und Fachkollegen taten.

Wie Zwerge auf den Schultern der Forschungsgeschichte stehend, lohnt sich das Nachdenken über die Gründe für solche Quantităten und Blickrichtungen, auch über unser heutiges Interesse am europäischen Vergleichen. Hilfreich für das Gespräch von Geschichte und Wissenschaftsgeschichte bleibt die Kenntnis mittelalterlicher Wahmehmungen und Vergleiche, die hier im Zentrum stehen sollen. Dabei sind weniger die markigen Sprüche gegenseitiger Abneigung von Völkern oder Gruppen zu sammeln, die Paul Kirn 1943 als Indizien für seine Frühzeit des Nationalgefühls zusammenstellte. ${ }^{16}$ Für Auto- und Heterostereotype, für Scherz und Ernst in der Völkercharakteristik ${ }^{17}$ gibt es lange Vorbildreihen seit der Antike und bedrückend stimmende Nachfolger in der Neuzeit. Solche Emotionen sind zwar nicht auszublenden. Sie sollen aber immer in ihrer positiven Funktionalität für den eigenen Verband wie furr den Aufbau von Wir-Bewußtsein bedacht werden. ${ }^{18}$ Es geht um die Kenntnis vergleichenden Beobachtens wie um seine positive Wirkung für den Aufbau von Identität. Im Interesse an dieser Verknüpfung unterscheiden wir uns von manchen Sammlungen politischer, historischer oder kultureller Urteile über Fremde im Mittelalter: Aus der Beobachtung der „Eigenart des anderen im eigenen Blick“ wollen wir nicht nur Haß oder Bewunderung, sondern die vergleichende Wahrnehmung politischer Ordnung in ihrer zeitgenössischen Funktionalität studieren.

15 Winfried Schulze, Deutsche Geschichtswissenschaft nach 1945. München 1993; Georg G. Iggers, Geschichtswissenschaft im 20. Jahrhundert. Ein kritischer Überblick im internationalen Zusammenhang. Göttingen 1993; Willi Oberkrome, Volksgeschichte. Methodische Innovation und völkische Ideologisierung in der deutschen Geschichtswissenschaft 1918-1945. (Kritische Studien zur Geschichtswissenschaft, Bd. 101.) Göttingen 1993; Otto Gerhard Oexle, Geschichtswissenschaft im Zeichen des Historismus. Studien zu Problemgeschichten der Moderne. (Kritische Studien zur Geschichtswissenschaft, Bd. 116.) Göttingen 1996; Winfried Schulze/Otto Gerhard Oexle (Hrsg.), Deutsche Historiker im Nationalsozialismus. 2. Aufl. Frankfurt a. M. 2000.

16 Paul Kirn, Aus der Frühzeit des Nationalgefühls. Studien zur deutschen und französischen Geschichte sowie zu den Nationalitătenkämpfen auf den britischen Inseln. Leipzig 1943; Ludwig Schmugge, Über „nationale" Vorurteile im Mittelalter, in: DA 38, 1982, 439-459.

17 Hans Walther, Scherz und Emst in der Völker- und Stămme-Charakteristik mittellateinischer Verse, in: AKG 41, 1959, 263-301.

18 Joachim Ehlers, Die Entstehung der Nationen und das mittelalterliche Reich, in: Ausgewählte Aufsătze (wie Anm. 1), 399-413. 


\section{Der deutsche Tyrann und der allerchristlichste König}

Am Anfang standen Gemeinsamkeiten. Das fränkische Reich bildete für lange Zeit den Identitäts-, Kommunikations- und Handlungsrahmen. Die Osterweiterung in karolingischer Zeit band das Land jenseits des Rheins ins Gefüge der Großreichsbildung ein, machte es dann auch zum Objekt der Reichsteilungen in der Königsfamilie, die nicht auf geographische, kulturelle, ethnische oder sprachliche Gegebenheiten Rücksicht nahm. Aus den Zufällen der Teilung unter Brüdern und der Überlebensfähigkeit einzelner Zweige der karolingischen Familie erhielt West- und Mitteleuropa sein langwirkendes Gepräge. Das Wissen um die Herkunft aus gemeinsamen Wurzeln verlosch nie vom 9. bis zum 20. Jahrhundert, so daß der Vergleich zwischen Westfranken und Ostfranken, zwischen Frankreich und Deutschland vom Mittelalter bis zur Moderne stets von anderen Voraussetzungen ausgehen mußte als der Vergleich zwischen Altbayern und Island. Die alte Einheit schürte in den späteren Zerfallsprodukten Emotionen, nötigte zum Nachdenken über die Rechtmäßigkeit der Sukzession wie Tradition und zwang zur Auseinandersetzung mit dem alten Allgemeinen und dem neuen Besonderen. Vergleiche entstanden darum nicht wertfrei, sondern ruhrten an die Substanz eigener Identităt, die sich vom 9. bis zum 13. Jahrhundert der fränkischen Vergangenheit kaum entledigen konnte und wollte.

Dabei hatte der Zerfall des karolingischen Großreichs lange gedauert ${ }^{19}$, wirksame Identitäten der handelnden Adelsverbände offenbar ${ }^{20}$ und $888 \mathrm{zu}$ einem keineswegs logischen Ende gefuhrt. Ein Zeitgenosse wie Regino von Prüm beklagte noch Jahre nach dem - erst aus der Rückschau endgültigen - Zerfall des karolingischen Großreichs das Fehlen eines legitimen Erben und eines sich gleichsam aufdrängenden Frankenherrschers: „Nach seinem [Karls III.] Tod lösten sich die Reiche, die seinem Gebot gehorcht hatten, wegen des Fehlens eines legitimen Erben aus dem Verbund in Teile auf und erwarteten nicht mehr einen natürlichen Herm. Vielmehr begann ein jedes, sich einen König aus dem Inneren zu erwählen. Das rief große Kriegswirren hervor, nicht weil es keine fränkischen Fürsten gegeben hätte, die durch Adel, Tapferkeit und Weisheit die Reiche hätten beherrschen können, sondern weil unter ihnen die Gleichheit an Abstammung, Würde und Macht die Zwietracht vermehrte. Niemand war den anderen so überlegen, daß sich die übrigen dazu bequemt hätten, sich seiner Herrschaft zu unterwerfen. Denn die Francia hätte viele zur Reichsregierung geeignete Fürsten hervorgebracht, wenn das Schicksal sie nicht im Wettstreit der Kraft zum

19 Walter Schlesinger, Die Auflösung des Karlsreiches, in: Karl der Große. Lebenswerk und Nachleben, Bd. 1.: Persönlichkeit und Geschichte. Hrsg. v. Helmut Beumann. Düsseldorf 1965, 792-857.

20 Ursula Penndorf, Das Problem der „Reichseinheitsidee“ nach der Teilung von Verdun (843). Untersuchungen zu den späten Karolingern. (Münchener Beiträge zur Mediävistik und RenaissanceForschung, Bd. 20.) München 1974; Franz-Reiner Erkens, Divisio legitima und unitas imperii. Teilungspraxis und Einheitsstreben bei der Thronfolge im Frankenreich, in: DA 52, 1996, 423-485; ders., Einheit und Unteilbarkeit. Bemerkungen zu einem vielerörterten Problem der frühmittelalterlichen Geschichte, in: AKG 80, 1998, 269-295. 
gegenseitigen Verderben bewaffnet hätte.“'21 Der Bruch, der später zum Reichsvergleich führte, gestaltete sich im 9. Jahrhundert nicht als zwangsläufige Folge von Geschichte. Selbst nach 888 bewahrten sich Ostfranken und Westfranken, Deutschland und Frankreich über Jahrzehnte die Reflexe gemeinsamer Vergangenheit, aktualisiert in zahlreichen Begegnungen von Herrschern und Adelsverbänden. ${ }^{22}$

Doch im frühen 11. Jahrhundert brach eine lange und intensive Beziehungsgeschichte ab, das Interesse am Nachbarn verblaßte ganz deutlich. ${ }^{23}$ Schlagartig setzte es an der Wende vom 11. zum 12. Jahrhundert wieder ein, als der Kampf zwischen Kaiser und Papst, zwischen regnum und sacerdotium, zum europäischen Ereignis erwuchs. Eine breit gesicherte, empirische Grundlage über den entsprechenden Berichtshorizont deutscher Chronisten steht zwar noch aus. ${ }^{24}$ Doch ihr Interesse am westlichen Nachbarn beschränkte sich eher auf sporadische Hinweise. Weitaus größere Beachtung, in mittelalterlichen Chroniken wie in modernen Analysen, fand das mittelalterliche Imperium im Westen. Die neuere Forschung interessierte sich im Nachkriegsdeutschland dafür, wie die eigene glanzvolle Kaiserzeit im mittelalterlichen Frankreich betrachtet wurde. ${ }^{25}$ Sie wurde vielfach fündig, weil sich die Ausbildung französischer Identität seit der Kaiserkrönung Ottos des Großen 962 vor der Folie imperialer Ansprüche vollzog.

21 Post cuius mortem regna, que eius ditioni paruerant, veluti legitimo destituta herede, in partes a sua compage resolvuntur et iam non naturalem dominum prestolantur, sed unumquodque de suis visceribus regem sibi creari disponit. Quae causa magnos bellorum motus excitavit; non quia principes Francorum deessent, qui nobilitate, fortitudine et sapientia regnis imperare possent, sed quia inter ipsos aequalitas generositatis, dignitatis ac potentiae discordiam augebat, nemine tantum ceteros precellente, ut eius dominio reliqui se submittere dignarentur. Multos enim idoneos principes ad regni gubernacula moderanda Francia genuisset, nisi fortuna eos aemulatione virtutis in pernitiem mutuam armasset, Regino von Prum, Chronicon cum continuatione Treverensi. Hrsg. v. Friedrich Kurze. (MGH SS rer. Germ. [50].) Hannover 1890, 129.

22 Ingrid Voss, Herrschertreffen im frühen und hohen Mittelalter. Untersuchungen zu den Begegnungen der ostfränkischen und westfrănkischen Herrscher im 9. und 10. Jahrhundert sowie der deutschen und französischen Könige vom 11. bis 13. Jahrhundert. (AKG, Beih. 26.) Köln/Wien 1987.

23 Bernd Schneidmüller, Wahmehmungsmuster und Verhaltensformen in den fränkischen Nachfolgereichen, in: Deutschland und der Westen Europas im Mittelalter. Hrsg. v. Joachim Ehlers. (VuF) [im Druck].

24 Eine erste Zusammenstellung bei Joachim Ehlers, L'image de la monarchie française dans l'historiographie de l'Empire ( $\mathrm{X}^{\mathfrak{e}}$ et $\mathrm{XI}^{\mathrm{e}}$ siècles), in: L'historiographie médiévale en Europe. Ed. JeanPhilippe Genet. Paris 1991, 119-127.

25 Ursula Helbig, Die Stellung der westeuropäischen Mächte England und Frankreich zum Reichs- und Kaisergedanken in der Zeit der Sachsen und Salier. Diss. phil. (masch.) Leipzig 1945; Ulrich Turck, Das Bild der Deutschen und der Deutschen Geschichte von 843 bis 1152 in der zeitgenössischen französischen Historiographie. Ein Beitrag zur Frage des deutsch-franzősischen Verhältnisses in der Zeit der Entstehung des Deutschen Reiches und Frankreichs. Diss. phil. (masch.) Bonn 1955; Gian Andri Bezzola, Das Ottonische Kaisertum in der französischen Geschichtsschreibung des 10. und beginnenden 11. Jahrhunderts. (Veröff.. des Instituts für Österreichische Geschichtsforschung, Bd. 18.) Köln/Graz 1956; Karl Ferdinand Werner, Das hochmittelalterliche Imperium im politischen Bewußtsein Frankreichs (10.-12. Jahrhundert), in: HZ 200, 1965, 1-60. 
Die Betrachtung des spätsalischen Kaisertums zielte im Westen in eine eindeutige Richtung. Französische Quellen stilisierten in der ersten Hălfte des 12. Jahrhunderts Kaiser Heinrich V. als Unruhestifter in Kirche und Reich, als deutschen Tyrannen, als Verrăter, als zweiten Judas. $^{26}$ Das Bündnis des Reformpapsttums mit dem kapetingischen Königtum, 1107 in Saint-Denis unter Ruckgriff auf karolingische Traditionen und unter Betonung der beständigen Treue der fränkisch-französischen Herrscher gegenüber den Nachfolgern Petri vom 8. bis zum 12. Jahrhundert geschlossen und von Suger von Saint-Denis in eindeutiger Zielsetzung überliefert ${ }^{27}$, dieses Bündnis wurde zum Ausgangspunkt des politischen Urteils: Aus ihrem Widerstand gegen die rechtmäßigen Päpste gerieten die beiden letzten salischen Kaiser in heilsgeschichtlichen Verruf. Der vergleichende Blick auf herrscherliche Gehorsamsleistungen gegenüber der Kurie schuf neue Werte und frisches Selbstbewußtsein.

Auch wer nie einen Kaiser gesehen hatte, durfte das gewaltsame Vorgehen gegen Papst und Kardinäle im Jahr 1111 als das Wüten des großen Verräters, als das Handeln unmenschlicher Hunde, als Verhalten barbarischer Deutscher brandmarken. Daraus resultierte zu Recht die Kinderlosigkeit Heinrichs V. Das imperiale stemma gelangte 1125 an einen anderen Herrscher. ${ }^{28}$ In Frankreich, das seit 987 in lückenloser Folge von kapetingischen Vätern und Söhnen regiert wurde, durfte man den Zusammenhang von Hinterhältigkeit und Kinderlosigkeit eher als anderswo sehen. Befriedigt stellte Suger von Saint-Denis fest, daß Heinrich V., Unruhestifter in Kirche und Reich, binnen Jahresfrist nach seinem Frevel starb. ${ }^{29}$ Dagegen erwuchs die eigene Francia zur „Herrin der Welt", zur terrarum domina. ${ }^{30}$ In das Negativurteil über Heinrich bezog Suger die Deutschen insgesamt ein. Im Bericht von einer Gesandtschaft deutscher Reichsfursten nach Châlons-en-Champagne trat ihre Plumpheit und Kulturlosigkeit hervor. Besonders deutlich galt das fur Herzog Welf V. von Bayern,

26 Heinrich Banniza von Bazan, Die Persönlichkeit Heinrichs V. im Urteil zeitgenössischer Quellen. Diss. phil. Berlin 1927; Bernd Schneidmüller, Regni aut ecclesie turbator. Kaiser Heinrich V. in der zeitgenössischen französischen Geschichtsschreibung, in: Auslandsbeziehungen unter den salischen Kaisern. Geistige Auseinandersetzung und Politik. Hrsg. v. Franz Staab. (Veröffentlichung der Pfälzischen Gesellschaft zur Förderung der Wissenschaften in Speyer, Bd. 86.) Speyer 1994, 195-222.

27 Cum quibus de statu ecclesie, ut sapiens sapienter agens, familiariter contulit eosque blande demulcens, beato Petro sibique ejus vicario supplicat opem ferre, ecclesiam manutenere, et, sicut antecessorum regum Francorum Karoli Magni et aliorum mos inolevit, tyrannis et ecclesie hostibus et potissimum Henrico imperatori audacter resistere, Suger von Saint-Denis, Vita Ludovici Grossi. Ed. Henri Waquet. (Les classiques de l'histoire de France au moyen âge, vol. 11.) 2. Aufl. Paris 1964, cap. 10, 54. Zu Autor und Werk Michel Bur, Suger abbé de Saint-Denis, régent de France. Paris 1991.

28 Die Belege bei Schneidmüller, Regni aut ecclesie turbator (wie Anm. 26), 205-209.

29 Imperator ergo theutonicus, eo vilescens facto et de die in diem declinans, infra anni circulum extremum agens diem, antiquorum verificavit sentenciam, neminem nobilem aut ignobilem, regni aut ecclesie turbatorem, cujus causa aut controversia sanctorum corpora subleventur, anni fore superstitem, sed ita vel intra deperire, Suger von Saint-Denis, Vita Ludovici Grossi (wie Anm. 27), cap. $28,230$.

30 Transeamus, inquiunt, audacter ad eos, ne redeuntes impune ferant quod in terrarum dominam Franciam superbe presumpserunt. Senciant contumacie sue meritum, non in nostra sed in terra sua, que jure regio Francorum Francis sepe perdomita subjacet, ut, quod ipsi furtim in nos machinabantur atemptare, nos in eos coram retorqueamus; ebd. cap. 28, 222. 
so groß wie breit, ein lărmender Prahlhans, dem stets ein Schwert vorangetragen wurde. Eigentlich war der Welfe Sohn eines halb-italienischen Vaters und einer flandrischen Grafentochter, geschiedener Mann der tuskischen Markgräfin Mathilde, Sproß einer kirchentreuen Familie. Doch 1107 wurde er als typischer Deutscher gebraucht, Sinnbild einer Politik der bloßen Gewalt ${ }^{31}$, die sich 1111 dann im römischen Überfall auf Papst und Kardinäle entlud; im geliehenen Latein Lucans prangerte der Benediktinerabt den furor teutonicus an. ${ }^{32}$

Der wurde ein zweites Mal zum willkommenen Berichtsanlaß, als 1124 ein Einfall Heinrichs V. in Frankreich drohte. In einem wohlinszenierten Akt bedienten sich König Ludwig VI. und Abt Suger des heiligen Dionysius als Beschützer des Königreichs und einigten ganz Frankreich hinter der Lehnsfahne von Saint-Denis gegen die deutschen Feinde. ${ }^{33}$ Ihre Leichen hätte Suger gerne den Wölfen und Raben zum Fraß gegeben; ihr Land gehörte nach königlichem Recht den Franken oder Franzosen. ${ }^{34}$ Wen traf also die Schuld an der ,deutschfranzösischen Erbfeindschaft‘? Unsere Amtsvorgänger hätten aus Sugers Vita klare Antworten präsentiert. ${ }^{35}$ Natürlich gab es über die Jahrhunderte viele Nachschreiber solcher Tiraden; ein Referat der Forschungsgeschichte wäre ermüdend, da es in den bekannten Klischees der angeblichen deutsch-französischen ,Erbfeindschaft' verharrte. Doch der Abt von Saint-Denis zielte im 12. Jahrhundert über die Affekte auf ganz anderes: Im Blick auf den Nachbarn traten ihm die historischen Kontinuitäten von Franken und Franzosen, die Würde

31 Ubi cum dominus papa aliquantisper demoraretur, ex condicto ipsi imperatoris Henrici legati, non humiles, sed rigidi et contumaces, cum apud Sanctum Memmium hospitia suscepissent, relicto inibi cancellario Alberto, cujus oris et cordis unanimitate ipse imperator agebat, ceteri ad curiam multo agmine, multo fastu, summe falerati devenerunt. Hi siquidem erant archiepiscopus Treverensis, episcopus Alvertatensis, episcopus Monasteriensis, comites quamplures, et cui gladius ubique preferebatur dux Welfo, vir corpulentus et tota superfitie longi et lati admirabilis et clamosus, qui tumultuantes magis ad terrendum quam ad raciocinandum missi viderentur. Singulariter et solus Treverensis archiepiscopus, vir elegans et jocundus, eloquentie et sapientie copiosus, gallicano coturno exercitatus, facete peroravit, domino pape et curie salutem et servitium ex parte domini imperatoris deferens, salvo jure regni; ebd. cap. 10,56. Zu Welf V. Bernd Schneidmüller, Die Welfen. Herrschaft und Erinnerung (819-1252). (Urban-Taschenbücher, Bd. 465.) Stuttgart/Berlin/Koln 2000, 150 ff.

32 Necdum dominus papa post missam episcopalia deposuerat indumenta, cum inopinata nequitia, ficta litis occasione, furor Theutonicus frendens debachatur, Suger von Saint-Denis, Vita Ludovici Grossi (wie Anm. 27), cap. 10, 64. Vgl. Mireille Schmidt-Chazan, Le point de vue des chroniqueurs de la France du Nord sur les Allemands dans la première moitié du XII ${ }^{\mathfrak{e}}$ siècle, in: Centre de recherches relations internationales de l'Université de Metz. Travaux et Recherches 1973/2. Metz 1974, 13-34.

33 Suger von Saint-Denis, Vita Ludovici Grossi (wie Anm. 27), cap. 28, 230. Vom Akt von Saint-Denis kündet auch eine Urkunde Konig Ludwigs VI.: Recueil des actes de Louis VI roi de France (11081137). 4 vol. Ed. Jean Dufour. Paris 1992-1994, hier vol. 1, Nr. 220 (mit den Vorbemerkungen).

34 Aliorum autem perita severitas persuadebat eos diutius expectare, ingressos marchie fines, cum jam fugere intercepti nequirent, expugnatos prosternere, tanquam Sarracenos inmisericorditer trucidare, inhumata barbarorum corpora lupis et corvis ad eorum perhemnem ignominiam exponere, tantorum homicidiorum et crudelitatis causam terre sue defensione justificare, Suger von Saint-Denis, Vita Ludovici Grossi (wie Anm. 27), cap. 28, 222.

35 Vgl. Otto Cartellieri, Abt Suger von Saint-Denis 1081-1151. (Hist. Studien, Bd. 11.) Berlin 1898; Kirn, Frühzeit des Nationalgefuhls (wie Anm. 16), $80 \mathrm{ff}$. 
der eigenen Herrscher und das Bewußtsein der eigenen beständigen Treue Frankreichs gegenüber Kirche und Papst um so glanzvoller hervor.

Auch auf dem ersten Kreuzzug hatten sich die Franci als gehorsame Söhne der Kirche erwiesen, die Gesta Dei per Francos vollbracht. Thre heilsgeschichtliche Sendung wurde nun offenkundig, als die Franzosen zu einem von Gott geliebten Volk erwuchsen. ${ }^{36}$ Dem entsprach die Idee, daß der eigene Herrscher als Nachfolger Schutz spendender Frankenherrscher der allerchristlichste König sei, der rex christianissimus. ${ }^{37}$ Auch die Reformpäpste sprachen ihren Beschützer so an, Herrscher über ein Volk und ein Reich, das sich einer ungebrochenen Geschichte seit der fränkischen Landnahme und der Übernahme der katholischen Taufe erfreute. Lange Erfahrungen und europäische Vergleiche hatten den Sinn fur die eigene Würde geschärft: Wer den anderen fest im vorgefertigten Blick hatte, der konnte den eigenen Platz in Welt und Heil um so besser feiern.

\section{Gleiche Wurzeln - verschiedene Triebe}

Als sich Historiographen des 12. Jahrhunderts die Geschichte ihrer Reiche sicherten, stießen sie in Deutschland und Frankreich auf gleiche Wurzeln und unterschiedliche Triebe. Wie andere Zeiten auch war das 12. Jahrhundert ein Erinnerungsjahrhundert ${ }^{38}$ : Man rang um die angemessene, also um die eigene Memoria. Vieles wurde nun aufs Pergament geschrieben, was bisher im Vorbewußten verblieben war. Die seit dem 10. Jahrhundert gelebte Ranggleichheit von imperium und regnum nötigte allmăhlich zur systematischen Erfassung. Also geriet die gemeinsame Vergangenheit aus fränkischen Wurzeln klarer in den Sinn. Bei der Spurensuche entstand das historische Urteil, die Konkurrenz um Geschichte.

Hugo von Fleury schrieb sein Wissen um die Anfänge der Reiche und Nationen nieder: Unter Karl dem Kahlen trennten sich Kaisertum und Königtum. Das imperium verblieb den Deutschen, die fränkische Tradition und das Königtum den Franzosen. Heute fâllt es den meisten Historikern schwer, solch klare Worte zu formulieren und dem 9. Jahrhundert überhaupt einen angemessenen Platz in der Ethnogenese der europäischen Nationen zuzubilligen.

36 Gens Francorum, gens transmontana, gens, sicuti in pluribus vestris elucet operibus, a Deo electa et dilecta, tam situ terrarum quam fide catholica, quam honore sanctae Ecclesiae, ab universis nationibus segregata, Robertus monachus, Historia Iherosolimitana, in: Recueil des historiens des croisades. Historiens occidentaux. Vol. 3. Paris 1866, I 1, 727. - Apostolicae nempe sedis pontificibus ab antiquo consuetudinarium fuit, si quam sunt passi a finitima gente molestiam, auxilia expetere semper a Francis. Stephanus et Zacharias pontifices uterque sub Pipino et Karolo regibus confugium fecit ad ipsos, Guibert von Nogent, Dei Gesta per Francos. Ed. Robert B. C. Huygens. (Corpus Christianorum. Continuatio Mediaeualis, vol. 127A.) Turnhout 1996, II 1, 108.

37 Jean de Pange, Le roi très chrétien. Paris 1949; Percy Ernst Schramm, Der König von Frankreich. Das Wesen der Monarchie vom 9. zum 16. Jahrhundert. 2 Bde. 2. Aufl. Darmstadt 1960, 145 ff., 252 f.; Beaune, Naissance (wie Anm. 4), 207 ff.; Marc Bloch, Les rois thaumaturges. Paris 1924 (dt.: Die wundertătigen Könige. München 1998); Joachim Ehlers, Der wundertătige König in der monarchischen Theorie des Früh- und Hochmittelalters, in: Reich, Regionen und Europa (wie Anm. 3), 3-19.

38 Hans-Werner Goetz, Geschichtsschreibung und Geschichtsbewußtsein im hohen Mittelalter. (Orbis mediaevalis, Bd. 1.) Berlin 1999, bes. $97 \mathrm{ff}$. 
Das Wissen um die lange Dauer der Gemeinsamkeiten bis ins 12. Jahrhundert ${ }^{39}$ hat die faktische Kraft der Trennung ubertüncht. Noch im 12. Jahrhundert entdeckte das RuckwärtsBlicken, das Geschichte aus der Gegenwart ordnete, in den karolingischen Reichsteilungen vernünftigerweise die Urgrïnde des Neuen. Niemand wird heute mehr ernsthaft im Jahr 843 die Geburt der deutschen und französischen Geschichte erblicken, wie das frühere Historiker und Germanisten erwogen. ${ }^{40}$ Doch die gleichsam zwanghafte Vernachlässigung des 9 . Jahrhunderts als ethnogenetisch produktive Epoche durch die modernen „Spätdatierer“ auf 888 bis 11./12. Jahrhundert hat jede ernsthafte Berücksichtigung mittelalterlicher Ordnungsversuche verschüttet. Halten wir darum getrost fest, daß Hugo von Fleury die Trennung zwischen imperium und regnum in die Zeit Karls des Kahlen rückte. Bei feinsinnigen Studien über die Anfänge der deutschen und französischen Geschichte möchte man gleichzeitig so naiv werden wie Hugo von Fleury und so schlau wie seine gegenwärtigen Kritiker, die das 9. Jahrhundert noch so ganz der fränkischen Geschichte zuschreiben wollen.

Als Otto von Freising über den Zusammenhang von fränkischer und deutscher Geschichte grübelte, war man sich im mittelalterlichen Westen sicher. Um die Jahrtausendwende hatte Gerbert von Aurillac seinem ottonischen Gönner versichert, daß das römische Reich „unser" sei. ${ }^{41}$ Dafür wußte man in Frankreich seit der Mitte des 10. Jahrhunderts, seit der Geschichtsschreibung Flodoards von Reims oder Richers von Saint-Remi/Reims, wem die fränkische Geschichte gehörte, nämlich den Franzosen, den Franci zwischen Maas und Loire. ${ }^{42}$ Doch die hochmittelalterliche Rangkonkurrenz und das Lesen in alten Chroniken zwangen im 12. Jahrhundert zur weiteren Präzisierung.

War Karl der Große eher rex Francorum oder imperator Romanorum? Was wußte man im 12. Jahrhundert, im Zeitalter der vielen Karlserben mit ihrer großen Sehnsucht nach dem idealen christlichen Herrscher ${ }^{43}$, schon vom Ringen des Jahres 801 um den angemessenen Kaisertitel? Freilich schrieben die hochmittelalterlichen Chronisten deutlich nieder, daß Karl beides war, Frankenkönig und Römerkaiser. Sein Erbe wurde gespalten, das Frankenreich für den Westen, das Kaiserreich für den Osten. So vermochte man das Wissen um die Geschichte wie um die politische Ordnung in Europa zu vereinen und zu trennen. Der Chronist von Morigny bezeichnete den König der Deutschen als Schutzherm der Römer, weil er Amtsnachfolger des Frankenkönigs Karl war. ${ }^{44}$ Französische Chronisten erklärten seit dem

39 Brühl (wie Anm. 12), 715 ff.

40 Theodor Mayer (Hrsg.), Der Vertrag von Verdun. Leipzig 1943.

41 Nostrum, nostrum est Romanum imperium, Gerbert, Libellus de rationali et ratione uti. Praefatio, in: Lettres de Gerbert (983-997). Ed. Julien Havet. Paris 1889, 236-238, hier 237.

42 Bernd Schneidmüller, Französisches Sonderbewußtsein in der politisch-geographischen Terminologie des 10. Jahrhunderts, in: Beitrăge zur Bildung der französischen Nation im Früh- und Hochmittelalter. Hrsg. v. Helmut Beumann. (Nationes, Bd. 4.) Sigmaringen 1983, 49-91.

43 Robert Folz, Le souvenir et la légende de Charlemagne dans l'Empire germanique médiéval. (Publications de l'Université de Dijon, vol. 7.) Paris 1950; Robert Morissey, L'empereur à la barbe fleurie. Charlemagne dans la mythologie et l'histoire de France. Paris 1997.

44 Zum Investiturstreit: Erat autem inter summum sacerdotem et regem Teutonicorum, qui per Karoli Magni regis Francorum successionem patricius Romanorum erat, gravissima (...) dissensio, La chronique de Morigny. Ed. Léon Mirot. 2. Aufl. Paris 1912, II 7, 25. 
11. Jahrhundert Frankreich und Deutschland als Produkte der karolingischen Reichsteilungen. Schon Ademar von Chabannes meldete im 11. Jahrhundert, daß die französischen Könige seit Karl dem Kahlen niemals wieder das Imperium erlangt hätten. ${ }^{45}$ Hugo von Fleury ließ seine Linie der neueren Könige der Franken/Franzosen (moderni reges Francorum) mit Karl dem Kahlen beginnen, weil sich in seiner Zeit - bis zur Gegenwart fortdauernd - das regnum Francorum vom imperium Romanorum getrennt hätte. ${ }^{46}$ Und Andreas von Marchiennes meldete im Anschluß an Sigebert von Gembloux bei der Reichsbeschreibung Karls des Kahlen, daß der exklusive Name Francia seit dem 9. Jahrhundert an diesem Teil des alten Frankenreichs hafte (In qua parte ex tunc et modo nomen Francie remansit) ${ }^{47}$

Im Imperium reflektierte damals Otto von Freising über Römerreich, Frankenreich und deutsches Reich wie über den Anteil von Nachfolgeherrschaften am Vorgängerensemble. Das war durchaus neu in der Historiographie, die sich aus den immer deutlicher wahrgenommenen Realitäten der mittelalterlichen Nationsbildung um die Ordnung der Geschichte und um den Zugriff auf die je eigene Vergangenheit bemühte. Breite empirische Studien über die hochmittelalterliche Wahmehmung der Entstehung Deutschlands und Frankreichs stehen noch aus, da sich die Forschung zuvorderst auf Perzeptionen des 9./10. Jahrhunderts und eigene Urteilssysteme konzentrierte. Exemplarisch werden hier einige Aussagen des 12./13. Jahrhunderts vorgestellt. Otto von Freising war bei seiner Beschreibung der karolingischen Teilungen und der westfränkisch-französischen Geschichte noch weit von einer einheitlichen Begrifflichkeit entfiernt: Frankenreich, Gallien, Reich Karls, Westreich, westfränkisches Reich, Franzien wechseln sich nicht gerade konsequent $\mathrm{ab}^{48}$, ganz anders als in der zeitgenössischen französischen Historiographie, die den Frankennamen exklusiv für das eigene Reich reklamierte. ${ }^{49}$

45 Interea, Carolo Calvo de seculo migrante, regnavit pro eo in Francia filius ejus Ludovicus Balbus; nec ultra imperium accepit aliquis de regibus Francie, Ademar von Chabannes, Chronicon. Ed. Pascale Bourgain mit Richard Landes/Georges Pon. (Corpus Christianorum. Continuatio Mediaeualis, vol. 129.) Turnhout 1999, III 20, 139.

46 Ab illo tamen die usque nunc manet regnum Francorum ab imperio Romanorum seiunctum atque divisum; Hugo von Fleury, Liber qui modernorum regum Francorum continet actus. Hrsg. v. Georg Waitz, in: MGH SS 9. Hannover 1851, 376-395, hier 376.

47 Andreas von Marchiennes, Historiae Franco-Merovingicae synopsis, seu historia succincta de gestis et successione regum Francorum, qui Merovingi sunt dicti ... Hrsg v. Raphael de Beauchamps. Douai $1633,557-883$, hier 726.

48 Otto von Freising, Chronica sive historia de duabus civitatibus. Hrsg. v. Adolf Hofmeister. (MGH SS rer. Germ. [45].) 2. Aufl. Hannover/Leipzig 1912, ausgewăhlte Beispiele: occidentalia regna (VI 1, 262; VI 3, 265); occidentale/orientale regnum (VI 5, 267; VI 9, 270; VI 11, 272; VI 15, 276); regnum Karoli (VI 2, 263); occidentalis Francia (VI 5, 267); orientalis Francia (VI 7, 269); regnum Francorum (VI 5, 267); orientalis/orientalium rex (VI 6, 268); occidentalis rex (VI 8, 270); occidentales Franci (VI 8, 270); rex Franciae/Francorum = westfränkischer König (VI 12, 273; VI 13, 273); rex Galliae (VII 2, 311); regnum Gallici regis (VII 18, 334); regnum Germaniae (VI 18, 278).

49 Margret Lugge, „Gallia“ und „Francia“ im Mittelalter. Untersuchungen über den Zusammenhang zwischen geographisch-historischer Terminologie und politischem Denken vom 6.-15. Jahrhundert. (Bonner Hist. Forsch., Bd. 15.) Bonn 1960, 160 ff. 
Mit den eigenen historischen Wurzeln - jenem multipluralen Gefüge von fränkischer Vergangenheit, römischem Kaisertum und geteiltem frănkischen Namen - tat sich der schreibende Reichsbischof in der Mitte des 12. Jahrhunderts indes schwer. In seine Gedanken von der Unbeständigkeit der Welt fügte Otto die Nachricht von der endgültigen Aufteilung des Frankenreichs im 9. Jahrhundert ein: „Von da an gab es nach der Reichsteilung nur noch zwei Reiche, ein östliches und ein westliches. Das östliche umfaßt den Teil Ludwigs und Lothars mit Aachen, dem Sitz des Frankenreichs (sedes regni Francorum), und der Herrschaft über die Stadt Rom, das westliche, das bis heute Frankenreich genannt wird, weil das andere Römerreich heißt, umfaßt den Teil Karls. “ ${ }^{50}$ Doch auf die fränkische Tradition mochte der Chronist keineswegs verzichten, wenn er in anderen Zusammenhängen von der Translation des Kaisertums von den Römern auf die Franken oder von Gebietsverlusten des kläglich gespaltenen regnum Francorum = ostfränkisches Reich berichtete. ${ }^{51}$ Dafur wurden Anteile an der fränkischen Geschichte quantifiziert! Als Kaiser Lothar I. das ihm zugefallene regnum, ohnehin nur ein Drittel des Frankenreichs, noch unter seine drei Söhne aufteilte, klagte Otto von Freising: „Siehe, wie tief ist doch das römische Kaisertum gesunken: nach der Teilung des Frankenreichs in drei Teile ist es nur noch ein Drittel des Drittels. “52

Die Wurzeln der deutschen Geschichte verband der Chronist erstmals mit der Herrschaft Amulfs von Kämten: „Amulf also herrschte über ganz Ostfranken, das jetzt deutsches Reich genannt wird: Bayern, Schwaben, Sachsen, Thüringen, Friesland und Lothringen. “53 Für das 10. Jahrhundert postulierte Otto die Verknüpfung römischer, fränkischer und deutscher Geschichte. In der Namenwahl blieb er indes ausdrücklich unentschieden, machte vielmehr seine Meinung kund, daß das (neue) deutsche Reich einen Teil des (älteren) Frankenreichs darstelle. Die oft besprochene differenzierte Darlegung zum Beginn der liudolfingischen Herrschaft soll auch hier zitiert werden: „Von da an rechnen manche nach dem Reich der Franken das der Deutschen. Sie sagen, deshalb habe Papst Leo in päpstlichen Erlassen Heinrichs Sohn Otto den ersten König der Deutschen genannt. Denn Heinrich, von dem wir hier handeln, soll die ihm vom Papst angebotene Würde abgelehnt haben. Ich aber bin der Meinung, daß das Reich der Deutschen, das jetzt, wie man sieht, im Besitze von Rom ist, ein Teil des Frankenreichs ist. Jedenfalls umfaßte (...) zur Zeit Karls das Frankenreich ganz Gallien, also das keltische, belgische und lugdunensische, sowie ganz Germanien vom Rhein bis nach Illyrien. Als das Reich dann unter seinen Enkeln aufgeteilt wurde, wurde das eine

50 Exhinc diviso regno regna modo duo, orientale ac occidentale, quorum alterum partem Lodewici ac Lotharii sedemque regni Francorum, palatium Aquis, ac imperium urbis Romae habet, aliud vero occidentale, quod adhuc Francorum, eo quod istud Romanorum vocatur, appellatum partem Karoli tenet, inveniuntur, Otto von Freising, Chronica (wie Anm. 48), V 35, 259. Übersetzung (hier wie in der Folge in modifizierter Form) nach: Otto Bischof von Freising, Chronik oder die Geschichte der zwei Staaten. Übersetzt v. Adolf Schmidt. Hrsg. v. Walther Lammers. (Ausgewăhlte Quellen zur deutschen Geschichte des Mittelalters, Bd. 16.) 3. Aufl. Darmstadt 1974, 427.

51 Chron. V 36, 260; VI Praef., 262.

52 Vide, ad quantum defectum Romanum imperium devenerit, ut in tres partes Francorum regno diviso terciae partis tercia pars fuerit, Chron. VI 1, 262.

53 Porro Arnolfus totam orientalem Franciam, quod modo Teutonicum regnum vocatur, id est Baioariam, Sueviam, Saxoniam, Turingiam, Fresiam, Lotharingiam, rexit, Chron. VI 11, 272. 
das östliche, das andere das westliche, beide aber Frankenreich genannt. Als nun im Ostreich, das Reich der Deutschen heißt, Karls Geschlecht ausstarb, während im westfränkischen Reich mit Karl [„dem Einfältigen"] noch ein Nachkomme Karls regierte, folgte dort als erster aus dem Volk der Sachsen Heinrich. Sein Sohn Otto, der das von den Langobarden usurpierte Kaisertum wieder an die Franken, nämlich die deutschen Ostfranken, brachte, ist vielleicht der erste König der Deutschen genannt worden, nicht weil er als erster bei den Deutschen herrschte, sondern weil er nach denjenigen, die nach Karl Karle oder Karolinger wie die Merowinger nach Merowech genannt wurden, als ein aus anderem, nämlich sächsischem Blut geborener das Kaisertum an die deutschen Franken zurückholte. Wie aber damals, als nach dem Aussterben der Merowinger die Karolinger ihre Nachfolger wurden, dennoch das Frankenreich bestehen blieb, so ubernahmen beim Aussterben der Karolinger die Ottonen, wenn auch aus anderem Geschlecht und anderer Zunge, dennoch das eine [identische] Reich."54

Noch einmal griff Otto von Freising zum Jahr 964 die Translatio des Römerreichs über Franken und Langobarden auf, um das ,Zielvolk', Deutsche oder doch wieder Franken, offenzulassen. ${ }^{55}$ Der ăhnlichen Abfolge im Namen, vom Reich der Franken zum Reich der Deutschen, entsprach die Parallelität dynastischer Anfänge, denn wie Karl Martell herrschte Otto der Erlauchte zwar „ohne Königsnamen“, doch faktisch wie ein König. ${ }^{56}$ Als erster „Deutscher" erlangte Otto der Große jedenfalls das Kaisertum ${ }^{57}$, das unter Konrad II. indes wieder an einen Abkömmling „,bedeutendster Fürsten Galliens, die dem alten Geschlecht der Trojaner entsprossen und vom seligen Remigius getauft worden waren,“ fiel. Seine Gemahlin Gisela - hier griff Otto von Freising den Lobpreis Wipos auf - komme direkt „aus dem

54 Exhinc quidam post Francorum regnum supputant Teutonicorum. Unde filium eius Ottonem in decretis pontificum Leonem papam primum regem Teutonicorum vocasse dicunt. Nam iste, de quo agimus, Heinricus oblatam sibi a summo pontifice dignitatem renuisse perhibetur. Michi autem videtur regnum Teutonicorum, quod modo Romam habere cernitur, partem esse regni Francorum. Denique, ut in superioribus patet, tempore Karoli regni Francorum tota Gallia, id est Celtica, Belgica, Lugdunensis, omnisque Germania, a Rheno scilicet ad Illiricum, terminus fuit. Dehinc diviso inter filiorum filios regno aliud orientale, aliud occidentale, utrumque tamen Francorum dicebatur regnum. In orientali ergo, quod Teutonicorum dicitur, deficiente Karoli stirpe primus, manente adhuc in occidentali Francia ex successoribus Karoli Karolo, ex gente Saxonum successit Heinricus. Cuius filius Otto, quia iam imperium a Longobardis usurpatum reduxit ad Teutonicos orientales Francos, forsan dictus est primus rex Teutonicorum, non quod primus apud Teutonicos regnaverit, sed quod primus post eos, qui a Karolo Karoli vel Karolingi, sicut et a Meroveo Merovingi, dicti sunt, ex alio, id est Saxonum, sanguine natus imperium ad Teutonicos Francos revocaverit. Sicut autem Merovingis defcientibus ac Karolis succedentibus regnum tamen mansit Francorum, sic et Karolis decedentibus ex alia familia seu lingua in uno tamen regno Ottones subintroiere, Chron. VI 17, 276 f.

55 Chron. VI 22, 285.

56 Chron. VI24, $286 \mathrm{f}$.

57 Istius filius Otto Magnus post multos triumphos primus ex Teutonicis post Karolos capto Berengario Romanis imperavit, Chron. VI 24, 287. 
alten und ruhmreichen Blut der Karolinger“" ${ }^{58}$ Ganz folgerichtig brachte Konrads und Giselas Sohn Heinrich III. wieder das Karolingerblut auf den Thron: „In ihm kam die kaiserliche Würde, die über lange Zeit der Nachkommenschaft Karls entglitten war, wieder an das edle und alte Geschlecht Karls zuruck.“59

In solchen Worten - eigene Zutat Ottos in weitgehend übernommenen Textpassagen aus Vorlagen - manifestierte sich gewiß der Stolz des Autors, der in weiblicher Linie von Heinrich III. abstammte. Die Meldung von der Wiederkehr des Karolingergeschlechts auf den Thron des römisch-deutschen Reichs verdient aber deshalb besondere Beachtung, weil sie Jahrzehnte vor der Ausbildung der französischen Reditus-Vorstellung, nach der in Ludwig VIII. wieder ein Sproß Karls des Großen das Königtum erlangte, formuliert wurde. In solchen dynastischen Modellen spiegelten sich im 12./13. Jahrhundert zum einen das hohe Ansehen des Karolingers als eines idealen christlichen Herrschers, zum anderen - wenigstens indirekt - auch die Konkurrenz der karolingischen Nachfolgereiche um den exklusiven Zugriff auf die vornehme frănkische Vergangenheit. ${ }^{60}$

Im 12. Jahrhundert mühte man sich also in Deutschland wie in Frankreich um die Quantifizierung und Geographisierung der fränkischen Erbschaft. Kaum jemand hat sich bisher für diese erste Debatte um die gemeinsame Geschichte ausfuhrlicher interessiert. Nahmen all die vielen Ringer um die fränkische, französische oder deutsche Geschichte die hochmittelalterlichen Quellen nicht mehr ernst? Kam das Gefühl dafür abhanden, daß sich verschiedene Spätere um die je gleiche Vergangenheit stritten? Besitzt jedes Jahrhundert die Gnade des Neuanfangs beim Instrumentalisieren vergleichender europäischer Geschichte?

Immerhin, seit dem 12. Jahrhundert wurde deutlich über das Ende der fränkischen und den Beginn der französischen oder der deutschen Geschichte nachgedacht. Aus den Vergleichen begannen die nationalen Sonderwege des Mittelalters, gegenüber der gemeinsamen Vergangenheit gedrittelt, gehälftet, differenziert, unsicher im Urteil. Leichter hatten es dabei die Eindeutigen, also die Franzosen: Ihnen gehörte ihr Reich, ihr Volk, die Nachfolge im regnum Francorum als dem Erbe Karls. Den Griff aufs ferne römische imperium überließen sie den Deutschen, die daraus im 13. Jahrhundert gleichsam heilsgeschichtliche Modelle ausbildeten. ${ }^{61}$ In Frankreich regierte, das propagierte Andreas von Marchiennes im späten

58 Hic [Konrad II.] (...) ex parte matris a probatissimorum Galliarum principum, qui ex antiqua Troianorum stirpe descenderant et a beato Remigio baptizati fuerant, originem trahens, uxorem Gisilam nomine de antiquo et glorioso Karolorum sanguine oriundam habuit, Chron. VI 28, 291.

59 In ipsoque dignitas imperialis, quae per longum iam tempus a semine Karoli exulaverat, ad generosum et antiquum germen Karoli reducta est, Chron. VI 32, 297.

60 Bernd Schneidmüller, Sehnsucht nach Karl dem Großen. Vom Nutzen eines toten Kaisers für die Nachgeborenen, in: GWU 51, 2000, 284-301.

61 Zur Chronistik seit der zweiten Hälfte des 13. Jh. Hermann Heimpel, Alexander von Roes und das deutsche Selbstbewußtsein des 13. Jahrhunderts, in: AKG 26, 1936, 19-60; Leonard E. Scales, France and the Empire: the Viewpoint of Alexander of Roes, in: French History 9, 1995, 394-416; Anette Baumann, Weltchronistik im ausgehenden Mittelalter. Heinrich von Herford, Gobelinus Person, Dietrich Engelhus. (Europäische Hochschulschriften III, Bd. 653.) Frankfurt a. M. u. a. 1995; Klaus Peter Schumann, Heinrich von Herford. Enzyklopädische Gelehrsamkeit und universalhistorische Konzep- 
12. Jahrhundert und in seiner Folge die hofnahe französische Chronistik, das Karolingerblut $^{62}$, im Imperium allenfalls Männer in bloßer Amtstradition. Der Zauber des Bluts und damit das zukunftsweisende europäische Konzept der Dynastie mit seiner eindeutigen Thronfolgeregelung gehörte dem Westen!

\section{Wahl oder Blut - imperialer Vorrang oder dynastischer Segen?}

Heftige Debatten der Fürsten über ihre herrschergelöste Verantwortung für Reich und Gemeinwohl wurden im letzten halben Jahrhundert salischer Herrschaft gefuhrt. ${ }^{63} \mathrm{Im}$ Westen beachtete man sie nicht, auch nicht das Selbstverständnis antisalischer Königserhebungen aus dem Wahlgedanken. Das salische Jahrhundert in glatter genealogischer Folge verdeckte die Faktizität der Adelswahl, die sich nach dem Tod Heinrichs V. um so eindrucksvoller entfaltete.

Reflexe fing die Narratio de electione Lotharii ein. ${ }^{64}$ Lothars Erhebung und die Nachfolge Konrads III. $1138^{65}$ legten den Zeitgenossen plötzlich die Unterschiedlichkeiten der Thronfolge in Deutschland und Frankreich offen. Gewiß mochten sie auf bloßen biologischen Zufällen beruhen. Heinrich V. und Lothar III. hinterließen keine Söhne, während den Kapetingern bis ins fruhe 14. Jahrhundert das große Glück legitimer Erben beschieden war. Gleichwohl nutzten auch in Frankreich die herrschenden Väter bis zu Ludwig VII. 1179 die Mitkönigserhebung ihrer Söhne durch Wahl zur Integration des Reichs in die Monarchie. ${ }^{66}$ Doch der Kreis der Königswähler und überhaupt der Fürsten bei Hof verkleinerte sich

tion im Dienste dominikanischer Studienbedürfnisse. (Veröff. der Hist. Kommission für Westfalen, Bd. 44; Quellen und Forsch. zur Kirchen- und Religionsgeschichte, Bd. 4.) Münster 1996.

62 Karl Ferdinand Werner, Andreas von Marchiennes und die Geschichtsschreibung von Anchin und Marchiennes in der zweiten Hälfte des 12. Jahrhunderts, in: DA 9, 1952, 402-463; ders., Die Legitimităt der Kapetinger und die Entstehung des Reditus regni Francorum ad stirpem Karoli, in: Die Welt als Geschichte 12, 1952, 203-225; Gabrielle M. Spiegel, The Reditus regni ad stirpem Karoli Magni: A New Look, in: French Historical Studies 7, 1971, 145-174.

63 Gerd Althoff, Spielregeln der Politik im Mittelalter. Kommunikation in Frieden und Fehde. Dannstadt 1997, 126-153; Jutta Schlick, König, Fürsten und Reich. Zur Entwicklung von Königsherrschaft, Fürstenverantwortung und Reichsverständnis 1056-1159. Diss. phil. München 1999 (in Druckvorbereitung: Mittelalter-Forsch., Bd. 7).

64 Narratio de electione Lotharii in regem Romanorum. Hrsg. v. Wilhelm Wattenbach, in: MGH SS 12. Hannover 1856, 509-512. Vgl. Ulrich Reuling, Die Kur in Deutschland und Frankreich. Untersuchungen zur Entwicklung des rechtsförmlichen Wahlaktes bei der Königserhebung im 11. und 12. Jahrhundert. (VMPIG, Bd. 64.) Göttingen 1979; ders., Zur Entwicklung der Wahlformen bei den hochmittelalterlichen Königserhebungen im Reich, in: Wahlen und Wăhlen im Mittelalter. Hrsg. v. Reinhard Schneider/Harald Zimmermann. (VuF, Bd. 37.) Sigmaringen 1990, 227-270.

65 Ulrich Schmidt, Königswahl und Thronfolge im 12. Jahrhundert. (Forsch. zur Kaiser- und Papstgeschichte des Mittelalters, Bd. 7.) Köln/Wien 1987.

66 Andrew W. Lewis, Royal Succession in Capetian France. Studies in Familial Order and the State. (Harvard Historical Monographs, vol. 100.) Cambridge/London 1981. 
bestăndig ${ }^{67}$, anders als im Imperium, wo die offenen Nachfolgeregelungen des 12. Jahrhunderts einen großen Partizipationswillen freisetzten.

Was für das 10. bis 12. Jahrhundert als Indiz für die abnehmende Integrationsfähigkeit französischer Könige zu deuten ist, sollte sich bei der ersten Sohnesfolge ohne formliche Wahl zu Lebzeiten des Vaters als Schlüssel für künftige politische Erfolge erweisen. Als in Frankreich der Sanktionsbereich der Monarchie allmăhlich auf ihren Legitimationsbereich anwuchs, war die Nachfolge im Königsamt zur Sache der Königsfamilie geworden. 1223 hinterließ Philipp II. Augustus das gemehrte Reich unangefochten dem Sohn.

Im Imperium prägte der Fürstenkonsens die staufische Herrschaft. Aus ihm erwuchsen Recht und Anspruch auf Partizipation bei der Thronfolgeregelung. Der Thronstreit von 1198 schuf hier kein neues Recht, führte aber zu Bewußtwerdung, Formulierung und Systematisierung von Normen und Ansprüchen. ${ }^{68}$ Während man hier über Formen, Orte, Symbole und Personen stritt, nahm im Westen das Glück des allerchristlichsten Königs Philipp II. seinen Lauf.

Doch wußten die Zeitgenossen überhaupt von den Unterschieden bei der Thronfolgeregelung? Die Quellen bieten erstaunliche Antworten, insbesondere auch zur Entwicklung von Deutungsmustern. Im 12. Jahrhundert dachte man nämlich nicht nur über die Teilung der fränkischen Vergangenheit nach, sondern auch über verschiedene Formen und Konzepte gegenwärtiger politischer Ordnung.

Verwundert erkannte der Chronist aus Morigny die Zäsur von 1125 im Imperium. Dort herrsche Lothar als König der Deutschen wie als Schutzherr und Kaiser der Römer „durch Wahl, nach Art seines Volkes“, per electionem, more gentis illius. ${ }^{69}$ Abt Suger von SaintDenis formte aus der bloßen Wahrnehmung gleich ein politisches Urteil fur seinen eigenen Herrschaftsbereich, als er von den Nachfolgeregelungen der Jahre 1125 und 1135 in Deutschland und England berichtete. Fehlende Nachkommenschaft (successiva prolis) bedeute eine Katastrophe, die ein Reich fast in den Ruin seiner Existenz führen könne, ad status sui ruinam. Im Gegensatz zu Deutschland und England müßten Franzosen ein solches Unglück freilich nicht befürchten, denn sie erfreuten sich einer ordentlichen und tüchtigen Nachkommenschaft ihrer Könige. ${ }^{70}$

67 Jean-François Lemarignier, Le gouvernement royal aux premiers temps capétiens (987-1108). Paris 1965.

68 Steffen Krieb, Vermitteln und Versöhnen. Konfliktregelung im deutschen Thronstreit 1198-1208. (Norm und Struktur, Bd. 13.) Köln/Weimar/Wien 2000.

69 Rex Alamannorum, patricius ac imperator Romanorum, qui post Henricum illum, qui Rome Paschalem secundum dolo captum incarceravit, per electionem, more gentis illius, in Germania regnabat, La chronique de Morigny (wie Anm. 44), II 15, 55.

70 Imperium siquidem Romanorum, regnum etiam Anglorum in defectu successiva prolis multa incommoda fere usque ad status sui ruinam sustinuisse conspicantes, quanto eorum regnorum indigenas super his dolore audiebant, tanto regis et regni successibus omnium et singulorum com[m] doditatibus applaudebant, Suger von Saint-Denis, De glorioso rege Ludovico, Ludovici filio, in: Suger, Cuvres. Vol. 1. Ed. Françoise Gasparri. (Les classiques de l'histoire de France au moyen âge, vol. 37.) Paris 1996, 156-177, hier cap. 1, 158. Den Vergleich zu den Turbulenzen im anglonormannischen Königtum zieht Suger so: Que quidem pericula Francorum solatia existebant, cum illi ex defectu hec sustinerent, 
Der zeitgenössisch wahrgenommene mos von Wahl- oder Erbrecht trennte fortan das Imperium von den europäischen Königreichen. Daraus muß man nicht gleich weitläufige Gedankengebäude von fürstlichem Eigennutz und geschwächter Monarchie entwickeln. Im 12. Jahrhundert war man vielmehr stolz auf das kraftstrotzende fürstliche Wahlrecht. Im Bericht von der Königswahl Friedrichs I. Barbarossa 1152 lobte Bischof Otto von Freising die Besonderheiten seines Reiches: „In Frankfurt konnte am 4. März, am Dienstag nach Okuli, trotz der ungeheuren Ausdehnung des transalpinen Reiches - es ist wunderbar zu sagen - die gesamte fürstliche Kraft mit einigen Baronen aus Italien gleichsam zu einem Körper vereinigt werden. Dort berieten die Füsten über die Königswahl. Denn dieses Recht, daß nämlich das Königtum nicht nach der Blutsverwandtschaft weitergegeben wird, sondern daß die Könige durch die Wahl der Fürsten eingesetzt werden, beansprucht das römische Reich als besonderen Vorzug. “71

Die integrierende Bedeutung der Königswahl für den Zusammenhalt des weiten Reichs tritt hier ebenso zutage wie das Wissen um den besonderen Rang des römischen Imperiums in einer Welt von Königreichen. Erst viel später wurde das Argument umgedreht: Die Praxis jahrhundertelanger Kurfurstenwahlen machte den Nachgeborenen das Reich zum monsterähnlichen Gebilde, langsam, ineffektiv, rückständig. Doch im 12. Jahrhundert hielt es die zeitgenössische Effektivitäts-Evaluation noch aus. Von einem principum robur als zukunftsgestaltender Kraft konnte bei den damaligen französischen Mitkönigserhebungen wahrlich nicht die Rede sein.

Seit dem 13. Jahrhundert brachte man die von Otto von Freising gefeierten Besonderheiten sogar mit ehrwürdiger Stiftung in Verbindung. Von Kaiser Karl dem Großen, von Kaiser Otto III., vom heiligen Kaiser Heinrich II. sei das Kurfurstenkollegium als das entscheidende Organ politischer Willensbildung eingerichtet worden. ${ }^{72}$ Fast gleichzeitig verbreitete sich in Frankreich die in Flandern entwickelte Idee von der Rückkehr des kapetingischen Königtums zum Blut der Karolinger. Später monumentalisierte Ludwig der Heilige diese Lehre in einer neuen Grablegeordnung der reges Francorum in Saint-Denis: In zwei

Franci vero tante et tam egregia prolis successione congratularentur et congauderent, ebd. cap. 3, 162.

71 III. Nonas Martii, id est tercia feria post ,Oculi mei semper', in oppido Franconefurde de tam inmensa Transalpini regni latitudine universum, mirum dictu, principum robur non sine quibusdam ex Italia baronibus tamquam in unum corpus coadunari potuit. Ubi cum de eligendo principe primates consultarent - nam id iuris Romani imperii apex, videlicet non per sanguinis propaginem descendere, sed per principum electionem reges creare, sibi tamquam ex singulari vendicat prerogativa -, tandem $a b$ omnibus Fridericus Suevorum dux, Friderici ducis filius, petitur cunctorumque favore in regem sublimatur, Otto von Freising und Rahewin, Gesta Friderici I. imperatoris. Hrsg. v. Georg Waitz. (MGH SS rer. Germ. [46].) Hannover/Leipzig 1912, II 1, 102 f.

72 Armin Wolf, Die Entstehung des Kurfürstenkollegs 1198-1298. Zur 700-jährigen Wiederkehr der ersten Vereinigung der sieben Kurfursten. (Hist. Seminar NF., Bd. 11.) Idstein 1998, 48 f., 162 f. Zur Datierung auf Otto III. und Heinrich II. vgl. auch Winfried Becker, Der Kurfürstenrat. Grundzüge seiner Entwicklung in der Reichsverfassung und seine Stellung auf dem Westfälischen Friedenskongreß. (Schriftenreihe der Vereinigung zur Erforschung der neueren Geschichte e. V., Bd. 5.) Münster 1973, 23-25; Bernd Schneidmüller, Reichsnähe - Königsferne: Goslar, Braunschweig und das Reich im späten Mittelalter, in: NdsJb 64, 1992, 1-52, hier 4 f. Das vergleichende Studium mittelalterlichen Erinnerungswissens vom Ursprung der eigenen Verfassung bleibt ein dringendes Desiderat. 
Reihen wurden die im Königskloster bestatteten Könige und Königinnen geordnet, vom Hauptaltar aus links die Merowinger und Karolinger, rechts die Kapetinger. Die dazwischen liegenden Gräber Philipps II. Augustus und Ludwigs VIII. schufen die räumliche wie dynastische Verbindung. ${ }^{73}$

Seit der Wende vom 12. zum 13. Jahrhundert argumentierte man im Reich wie in Frankreich auch vergleichend mit solchen Unterschieden. Als im Jahr 1196 Kaiser Heinrich VI. mit den Fürsten seinen Erbreichsplan verhandelte, sprachen die Marbacher Annalen von „einem neuen und unerhörten Gesetz für das römische Reich“. Der Kaiser wollte nämlich mit den Fürsten bestätigen, daß ,im römischen Reich, wie auch in Frankreich und in anderen Königreichen, die Könige nach Erbrecht einander folgten" ${ }^{74}$ Noch wurde das Argument nüchtern vorgetragen. Dem Annalisten floß, anders als modernen Historikern, nicht das Urteil in die Feder, das dynastische Prinzip bedeute Modernisierung, während die Fürstenwahl gemeinschaftszersetzende Rückständigkeit signalisiere. Aus den Erfahrungen späterer Jahrhunderte wollte man dann freilich von der prerogativa wenig wissen. Schon 1239 - so weiß es jedenfalls Matthaeus Parisiensis - trugen Gesandte König Ludwigs IX. von Frankreich in Verhandlungen mit Kaiser Friedrich II. vor, ihr Herr sei aus der Linie königlichen Bluts zur Herrschaft gelangt und darum vornehmer als irgendein Kaiser, der nur aus freiwilliger Wahl hervorgehe. ${ }^{75}$

So spiegelten die Marbacher Annalen bereits erste Denkwege monarchischer Effizienz. Der Vergleich wurde jedenfalls zum Argument. Eindrucksvoll dokumentiert dies ein französisches Zeugnis von 1220. Es stammt nicht von irgendeinem Schreiber, über dessen Informationsgrad oder Hofnähe lange zu debattieren wäre, sondern aus der Kanzlei König Philipps II., auf Weisung des Kanzlers vom Kanzleischreiber Stephan von Gallardon ins Register E notiert. ${ }^{76}$ Dieses Register, Zeugnis administrativer Modernität, enthielt vor allem

73 Joachim Ehlers, Kontinuităt und Tradition als Grundlage mittelalterlicher Nationsbildung in Frankreich, in: Ausgewählte Aufsătze (wie Anm. 1), 288-324, hier 308. Vgl. auch Alain Erlande-Brandenburg, Le roi est mort. Études sur les funérailles, les sépultures et les tombeaux des rois de France jusqu'à la fin du XIII' siècle. (Bibliothèque de la société française d'archéologie, vol. 7.) Genève 1975; Mario Kramp, Kirche, Kunst und Königsbild. Zum Zusammenhang von Politik und Kirchenbau im capetingischen Frankreich am Beispiel der drei Abteien Saint-Denis, Saint-Germain-des-Prés und Saint-Remi/Reims. Weimar 1995.

74 Ad eandam curiam imperator novum et inauditum decretum Romano regno voluit cum principibus confirmare, ut in Romanum regnum, sicut in Francie vel ceteris regnis, iure hereditario reges sibi succederent, Annales Marbacenses qui dicuntur. Hrsg. v. Hermann Bloch. (MGH SS rer. Germ. [9].) Hannover/Leipzig 1907, 68.

75 Credimus enim dominum nostrum regem Galliae, quem linea regii sanguinis provexit ad sceptra Francorum regenda, excellentiorem esse aliquo imperatore, quem sola provehit electio voluntaria, Matthaeus Parisiensis, Chronica majora. Vol. 3. Ed. John Richards Luard. (Rerum Britannicarum medii aevi scriptores, vol. 57, 3.) London 1876, 626. Vgl. Jacques Le Goff, Ludwig der Heilige. Stuttgart 2000 (zuerst frz:: Saint Louis, Paris 1996), 130.

76 Les registres de Philippe Auguste. Publié par John W. Baldwin avec le concours de Françoise Gasparri/Michel Nortier/Elisabeth Lalou, sous la direction de Robert-Henri Bautier. Vol. I: Texte. (Recueil des historiens de la France. Documents financiers et administratifs, vol. 7.) Paris 1992. Vgl. John W. Baldwin, The Government of Philip Augustus. Foundations of French Royal Power in the 
Urkundenabschriften, aber auch Listen, Prophezeiungen und einen europäischen Herrschaftsvergleich. In Verzeichnissen wurden Herrschernamen zusammengestellt, vielleicht Memorierhilfen, auf jeden Fall eindrucksvolle Zeugnisse amtsbezogenen historischen Wissens in der kapetingischen Kanzlei. ${ }^{77}$ Im genannten Register E wie im Register C hatten die Schreiber Namenreihen nebeneinander gestellt. Zunächst kamen die französischen Könige (Nomina regum Francorum qui venerunt de Troia) von den trojanischen Anfängen bei Pharamund uber die Merowinger, Karolinger und Kapetinger bis zur Gegenwart. Ihnen stellten die königlichen Spurensucher die Reihe der römischen und byzantinischen Kaiser von Julius Caesar bis zum 813 verstorbenen Basileus Michael I. zur Seite. Für Irene trugen sie die Translation des imperium Romanum ad reges Francorum ein, nämlich zu Karl dem Großen. Dessen kaiserliche Nachfolger fehlen freilich. Augenscheinlich setzten die reges Francorum mit Karl dem Großen die alten Traditionen fort. ${ }^{78}$

Ein Beispiel furr diese parallelen Listen wird in Transkription (am Ende des Textes) beigefügt. Deutlich tritt das Weglassen der ostfränkisch-deutschen Nachfolger der karolingischen Könige hervor. Eine parallele, für diesen Beitrag zusammengestellte Liste der ostfränkischdeutschen und der westfränkisch-französischen Herrscher evoziert den Vergleich (Beilage 2). Die wesentliche Botschaft dieser modernen Konkordanz erkennt man sofort. Die französischen Könige lebten und herrschten länger als ihre deutschen Amtskollegen! In einem nahezu identischen Zeitraum von fast drei Jahrhunderten (von 983/987 bis 1270/1273) regierten im Osten nämlich einundzwanzig Könige, Gegenkönige und Mitkönige aus mehreren Familien. Im Westen - läßt man zwei schon zu Lebzeiten der Văter verstorbene Mitkönige einmal beiseite - begegnen ganze neun Könige aus einer Familie. Der vergleichenden Mittelalterforschung sind solche Verschiedenheiten natürlich längst aufgefallen. Wollte man nicht einfach nur die größere biologisch-genetische Robustheit kapetingischer Männer postulieren, so behalf man sich mit Spekulationen über die erheblichen Reisestrapazen der ostfränkisch-deutschen Herrscher in einem Reich von der Elbe bis nach Mittelitalien, von der Maas bis an die Oder. In der Tat zwang die bescheidene kapetingische Krondomäne in der weiteren Île-de-France zu größerer Beschränkung, verhinderte gefährliche Alpenübergănge und begünstigte früh die Herausbildung von Paris als königlichem Zentralort. ${ }^{79}$ Doch bei schlüssigen Deutungen des Zahlenverhältnisses blieben immer Fragezeichen, denn gerade fleißige Italienfahrer wie Otto I., Heinrich IV. oder Friedrich I. herrschten durchaus lange.

Middle Ages. Berkeley/Los Angeles/London 1986; Elizabeth A. R. Brown, La notion de la légitimité et la prophétie à la cour de Philippe Auguste, in: La France de Philippe Auguste. Le temps des mutations. Ed. Robert-Henri Bautier. (Colloques internationaux du Centre national de la recherche scientifique, vol. 602.) Paris 1982, 77-110.

77 Bernd Schneidmüller, Die Gegenwart der Vorgănger: Geschichtsbewußtsein in den westfränkischfranzösischen Herrscherurkunden des Hochmittelalters, in: Hochmittelalterliches Geschichtsbewußtsein im Spiegel nichthistoriographischer Quellen. Hrsg. v. Hans-Werner Goetz. Berlin 1998, 217-235.

78 Les registres (wie Anm. 76), $349 \mathrm{ff}$.

79 Carlrichard Brühl, Fodrum, gistum, servitium regis. Studien zu den wirtschaftlichen Grundlagen des Königtums im Frankenreich und in den fränkischen Nachfolgestaaten Deutschland, Frankreich und Italien vom 6. bis zur Mitte des 14. Jahrhunderts. 2 Bde. (Kölner Hist. Abh., Bd. 14.) Köln/Graz 1968. 
Entscheidend für das Vergleichen ist aber, daß die Unterschiede nicht erst in moderner Rückschau hervortreten. Vielmehr wurden sie schon den Menschen des Hochmittelalters evident und nötigten zur Erklärung. Im Register E hielt die kapetingische Kanzlei die Beobachtung wie ihre Deutung bereit. Die ungewöhnliche Langlebigkeit kapetingischer Herrscher fiel nämlich bereits dem königlichen Kanzler bei einem Vergleich mit den Amtsdaten umwohnender Fürsten auf, als er die Namen der vornehmen Könige Frankreichs und ihre Amtsdauer zusammenstellte: Geringe Zahl der Könige und langes Leben waren im Gegensatz zu den römischen Kaisern und umwohnenden Königen zu vermelden. Die Gründe dafür suchte die Königskanzlei freilich nicht in herrscherlicher Beschaulichkeit einer kleinen Krondomäne mit bequemen Reisewegen. Sie fand vielmehr eine plausiblere Erklärung: Die Feinheit reiner Frömmigkeit und der Fleiß zum schöpferischen Guten ließen die französischen Könige über alle anderen irdischen Könige hinaus- und in die besondere Gnade Gottes hineinwachsen. ${ }^{80}$

Noch viele Beispiele für vergleichende Beobachtungen des 13. Jahrhunderts wären anzufugen. Damals verbreitete sich das Deutungsmuster von sacerdotium, imperium und studium in Italien, Deutschland und Frankreich als Versuch zur angemessenen Aufteilung der einen europäischen Geschichte. ${ }^{81}$ Die Instrumentalisierung einer heftig postulierten imperialen Vergangenheit bei Jordan von Osnabrück oder Alexander von Roes wirkte bereits verkrampft, angesichts des faktischen französischen Vorrangs in der abendländischen Christenheit eher aufgeregt-bemüht. ${ }^{82}$ Interessant sind die Bemühungen gleichwohl, weil sie historisches Vergleichen aus erkennbaren Absichten fur die eigene Gegenwart nutzbar machten.

Uns mögen heute Theorien und Methoden einer Empirie von Regierungsjahren und heilsgeschichtlichen Bewährungen ebensowenig gesichert erscheinen wie der Kampf um das

80 Nomina eciam illustrium regum Francie et quamdiu unusquisque regnum habuerit latius describuntur, ex quorum paucitate regum et suorum prolixitate dierum in respectu Romanorum principum et aliorum regum circumstancium, quorum in hoc provinciali nomina non habentur, potes comprehendere manifeste quod eorundem regum Francie Ille in cujus manu vita et mors aliorum annos dimidians vitam protelaverit eos usque in senectam et senium non relinquens propter sue purioris eleganciam pietatis et molite industriam bonitatis, qua se murum et defensionem domus Israel exibentes, sanctam Jhesu Christi sponsam Dei Ecclesiam semper uberiori affectione pre ceteris terre regibus pie dilectionis brachiis confoverunt ut de ipsa dilectione pura et munda operis verax exibitio veracius astruit argumentum, Les registres (wie Anm. 76), 592.

81 Verum res publica ecclesie Romane residet in Europa, principaliter tamen in Romanorum regno et Francorum. Que regna in tres partes dividuntur, hoc est in Italiam, Teutoniam et in Galliam. Nam pater et filius et spiritus sanctus unus deus ita disposuit, ut sacerdotium regnum et studium una esset ecclesia. Cum ergo fides Christi hiis tribus regatur principatibus, sacerdotio regno et studio, et sacerdotium fidem teneat in Italia, et regnum eandem teneri imperet in Teutonia, et studium ipsam tenendam doceat in Gallia, manifestum est, quod in hiis tribus provinciis principalibus residet res publica fidei christiane, Alexander von Roes, Noticia seculi. Hrsg. v. Herbert Grundmann/Hermann Heimpel. (MGH Staatsschriften des späteren Mittelalters 1.) Stuttgart 1958, cap. 12, 159. Vgl. Herbert Grundmann, Sacerdotium - Regnum - Studium. Zur Wertung der Wissenschaft im 13. Jahrhundert, in: AKG 34, 1951, 5-21.

82 Belege bei Heimpel, Alexander von Roes (wie Anm. 61); Scales, France and the Empire (wie Anm. 61). 
rechte Erbe Karls des Großen. Doch die mittelalterlichen Vergleiche europäischer Geschichte verraten uns etwas von Realităten wie Absichten. Und sie belehren uns über fruhere Formen wie Methoden der historischen Komparatistik, die den Nachbarn nur in eigenen Denkkategorien betrachten konnte und ihre Beobachtungen mit bestätigender wie belehrender Absicht der eigenen Wir-Gruppe präsentierte. Vielleicht könnten die alten Beispiele für unsere neuen Wege zu Theorie, Methode und Praxis des Vergleichens in den europäischen Geschichtswissenschaften folgende Botschaften transportieren: Gegenwart und Zukunft der vergleichenden Mediaevistik haben ein lange Vorgeschichte. Der kritische Diskurs des Historikers mit seinen europäischen Gegenständen muß weiterentwickelt werden, indem er seine aktuellen Fragestellungen wie Methoden als Glied einer in die Zukunft weisenden Forschungs- und Wahmehmungsgeschichte historisiert. Dabei ist beständige Selbstironie durchaus geboten. 
Beilage 1: Parallele Liste der Könige Frankreichs und der Kaiser; aus: Kanzleiregister E Philipps II. Augustus; Paris, AN, JJ 26, fol. 304'.

NOMINA REGUM FRANCIE

Pharamondus primus rex Sarracenorum

in Francia regnovit annis $X X$.

Clodion XX.

Cerovveus XVII.

Childericus XXIIII.

Clodoveus primus rex Christianorum XXX.

Clotarius LI.

Chilpericus XXIII.

Clotarius XLIIII.

Dagobertus XLIIII.

Clodoveus XVI.

Clotarius III.

Theodoricus XIX.

Clodoveus II.

Childebertus XVII.

Dagobertus $V$.

Chilpericus hic alienus $V$.

Theodoricus filius Dagoberti

Chidricus Hildrici filius Theodorici, sed eo manente rege regnavit Karolus Tutides et post eum

Ppepinus filius Karoli Tutidis factus est rex dejecto Hilderico XVI.
NOMINA IMPERATORUM - ANNOS, MENSES, DIES

Julius Cesar regnavit $V$.

Augustus Cesar LVI., VI., XIIII.

Tiberius Cesar XXIII., -, XXXVII.

Gaius Calligula III., X., XLI.

Claudius XIII., VII., LIIII.

Lero [verschrieben aus: Nero] XIII., VII., VIII.

GALBA I., IV., LXVIII

Otho

Vitellus -, VIII., -

Vespasianus LX., XI., LXXIX.

Titus II., II., LXXUX.

Domitianus $X V$., $V$., $X C V$.

Nerva I., II., XCVI.

Trajanus XVIII., VI., CXIIII.

Helius Adrianus XXI., -

Antonius Pius XXII., -

Marcus Antonius Verus XVIII., -

Lutius Antonius XIII., -

Helius Pertinax -, VI., -

Julianus -, VII., -

Severus Pertinax XVII., - 
Karolus magnus rex et imperator XLVII.

Ludovicus pius rex et imperator XXVI.

Ludovicus balbus rex et imperator II.

Callomannus $X$.

Ludovicus qui nil fecit VI.

Karolus simplex $X$.

Robertus alienus III.

Radulphus alienus XIII.

Ludovicus filius Karoli XIX.

Lotharius XX.

Ludovicus $L X$.

Karolus frater eius dim.

Hugo Chapetus LX.

Karolus frater eius dim. [Abschreibfehler statt: Robertus XXUX et dim.]

Henricus XXV.

Philippus L.

Ludovicus Grossus XXX.

Ludovicus vir sanctus XLVI.

Philippus vir per Dei gratiam

victoriosus XLIIII.
Antoninus Caracalla VII., -

Sacrinus I., -

Marcus Aurelius

Antoninus Heliogabalus IIII. -

Aurelius Alexander filius Maminie XIII., -

Maximinus III., -

Gordianus VI., -

Philippus cum Philippo filio primus christianorum imperator VII., -

Secius I., -

Gallus cum Volusiano filio II., -

Valerianus cum Galieno filio XV., -

Claudius I., -

Quintillus I.,-

Aurelianus $V .,-$

Tacitus VI., -

Florianus

Erobus VI., -

Varus cum Carino et Numeriano filiis II., -

Diocletianus et Maximianus Herculius XX., -

Valerius Maximianus et Constantinus V., -

[Fortsetzung zwischen den beiden Kolumnen] [Blattende] 
Beilage 2: Regierungszeiten deutscher und französischer Herrscher im Vergleich (983/9871270/73)

DEUTSCHE HERRSCHER 983-1273

Liudolfinger:

Otto III. (983-1002)

Heinrich II. (1002-1024)

Salier:

Konrad II. (1024-1039)

Heinrich III. (1039-1056)

Heinrich IV. (1056-1106)

Heinrich V. (1106-1125)

Gegenkönige gegen Heinrich IV.:

Rudolf von Rheinfelden (1077-1080)

Hermann von Luxemburg (1081)

Süpplingenburger:

Lothar III. (1125-1137)

Staufer:

Konrad III. (1138-1152)

Friedrich I. Barbarossa (1152-1190)

Heinrich VI. (1190-1197)

Philipp von Schwaben (1198-1208)

Welfe:

Otto IV. (1198-1218)

Staufer:

Friedrich II. (1212-1250)

Heinrich (VII.) (1222-1235, gest. 1242)

Konrad IV. (1250-1254)

Gegenkönige gegen die Staufer,

nachstaufische Könige:

Heinrich Raspe (1246-1247)

Wilhelm von Holland (1248-1256)

Richard von Cornwall (1257-1272)

Alfons von Kastilien (1257, gest. 1284)
FRANZÖSISCHE HERRSCHER 987-1270

Kapetinger:

Hugo Capet (987-996)

Robert II. (996-1031)

Heinrich I. (1031-1060)

Philipp I. (1060-1108)

Ludwig VI. (1108-1137)
Ludwig VII. (1137-1180)

Philipp II. Augustus (1180-1223)
Ludwig VIII. (1223-1226)

Ludwig IX. (1226-1270)

Nicht berücksichtigt sind vier zu Lebzeiten der Văter verstorbene, nicht selbstăndig regierende Mitkönige: Konrad, Sohn Heinrichs IV. (1087-1093); Heinrich, Sohn Konrads III. (1147-1150); Hugo, Sohn Roberts II. (1017-1025); Philipp, Sohn Ludwigs VI. (1129-1131). 


\title{
Höfische Feste im Europa des 15. Jahrhunderts*
}

\author{
Von
}

Karl-Heinz Spieß

Die politische und soziale Führungsposition des Adels bildet ein wesentliches Charakteristikum der Geschichte Europas im Mittelalter. In fast allen Ländern gab es diese Oberschicht, die sich durch gemeinsame Ideale und Lebensformen von dem Rest der Bevölkerung abgrenzte. ${ }^{1}$ Angesichts der europäischen Dimension des Phänomens ,Adel' erscheint es mir reizvoll, die bei allen Gemeinsamkeiten der ritterlich-höfischen Kultur ${ }^{2}$ hervortretenden nationalen oder regionalen Differenzierungen herauszuarbeiten und nach den Gründen für diese unterschiedlichen Ausprägungen zu fragen. ${ }^{3}$

- Die Vortragsform wurde weitestgehend beibehalten. Da die Literatur zu den Themenbereichen ,Hof" und ,Fest' in der europäischen Dimension überreich vorhanden ist, mußte der Apparat auf das Notwendige beschränkt werden.

1 Vgl. als jüngsten monographischen Überblick aus europäischer Perspektive Jonathan Dewald, The European Nobility, 1400-1800. (New Approaches to European History, vol. 9.) Cambridge 1996, und die Sammelbände von Otto Gerhard Oexle/Werner Paravicini (Hrsg.), Nobilitas. Funktion und Repräsentation des Adels in Alteuropa. (VMPIG, Bd. 133.) Göttingen 1997, und Hans-Ulrich Wehler (Hrsg.), Europäischer Adel 1750-1950. (GG, Sonderheft 13.) Göttingen 1990 (darin vor allem Otto Gerhard Oexle, Aspekte der Geschichte des Adels im Mittelalter und in der Frühen Neuzeit, 19-56).

2 Vgl. Josef Fleckenstein (Hrsg.), Das ritterliche Turnier im Mittelalter. Beiträge zu einer vergleichenden Formen- und Verhaltensgeschichte des Rittertums. (VMPIG, Bd. 80.) Göttingen 1985; ders. (Hrsg.), Curialitas. Studien zu Grundfragen der höfisch-ritterlichen Kultur. (VMPIG, Bd. 100.) Göttingen 1990; Maurice Keen, Das Rittertum. München/Zürich 1987; Werner Paravicini, Die ritterlich-höfische Kultur des Mittelalters. (EdG, Bd. 32.) München 1994; Werner Rösener (Hrsg.), Jagd und höfische Kultur im Mittelalter. (VMPIG, Bd. 135.) Göttingen 1997.

3 Ansätze hierzu auf dem Feld der Familienstruktur bei Karl-Heinz Spieß, Familie und Verwandtschaft im deutschen Hochadel. 13. bis Anfang 16. Jahrhundert. (VSWG, Beih. 111.) Stuttgart 1993. Vgl. auch die noch unpublizierten Beiträge von Marie-Therèse Caron, Chris Given-Wilson und Karl-Heinz Spieß für die Sektion „The Family Structure of the European Nobility in the Later Middle Ages“ auf dem International Medieval Congress 1993 in Leeds. Zu verweisen ist auch auf die unterschiedlichen Zugangsweisen zum Adel im mittelalterlichen Europa. Vgl. demnächst Karl-Heinz Spieß, Aufstieg in den Adel und Kriterien der Adelszugehörigkeit im Spätmittelalter, in: Zwischen Adel und Nichtadel. Hrsg. v. Peter Johanek/Kurt Andermann. (VuF, Bd. 53.) Sigmaringen 2001. Regionale Unterschiede im französischen 
Die höfischen Feste der Fürsten und Könige eignen sich hervorragend für einen solchen europäischen Vergleich, weil sie nicht isoliert voneinander stattfanden. Die internationalen Heiratsbeziehungen ${ }^{4}$ und die durch Gesandte ${ }^{5}$, Musiker ${ }^{6}$ oder Hofleute ${ }^{7}$ vermittelten Informationen fuhrten dazu, daß man in den einzelnen Dynastien Europas über die Gestaltung der Feste bei den Nachbarn Bescheid wußte oder zumindest wissen konnte. ${ }^{8}$ Gab es demnach eine europäische Konkurrenz in bezug auf Pracht und Ehre bzw. die entsprechenden Festmedien und eine daraus resultierende weitgehende Homogenităt der hochadeligen Feste? Zur Beantwortung dieser Frage können prinzipiell alle Feiern herangezogen werden, die von einem Fürsten- oder Königshof maßgeblich gestaltet und nicht zuletzt bezahlt wurden, wie zum Beispiel Tumiere, Krönungen, Hochzeiten oder Begräbnisse. Aus diesem Tableau der höfischen Feste werden im folgenden die Hochzeiten herausgegriffen, weil sie als herausragende Ereignisse fur die jeweilige Dynastie gut dokumentiert sind und sich im Falle internationaler Ehen als potentielle Vermittlungsträger für neue Festmedien anbieten.

Der feierliche Einzug eines Königs oder Fürsten in eine Stadt gehört strenggenommen nicht zu den höfischen Festen, da er wesentlich von den betreffenden Bürgern organisiert

Adel werden deutlich bei Marie-Therèse Caron, La noblesse dans le duché de Bourgogne. 1315-1477. Lille 1987, und Philippe Contamine, La noblesse au royaume de France de Philippe le Bel à Louis XII. Paris 1997.

4 Vgl. Karl-Heinz Spieß, Unterwegs zu einem fremden Ehemann. Brautfahrt und Ehe in europäischen Fürstenhäusern des Spätmittelalters, in: Fremdheit und Reisen im Mittelalter. Hrsg. v. Irene Erfen/KarlHeinz Spieß. Stuttgart 1997, 17-36.

5 Z. B. Gigliola Soldi Bondinini, Aspects de la vie des cours de France et de Bourgogne par les dépêches des ambassadeurs milanais (seconde moitié du XV' siècle), in: Adelige Sachkultur des Spätmittelalters. (Veröff. des Instituts für mittelalterliche Realienkunde Österreichs, Bd. 5.) Wien 1982, 195-214.

6 Vgl. Sabine Žak, Musik als „Ehr und Zier“ im mittelalterlichen Reich. Studien zur Musik im höfischen Leben, Recht und Zeremoniell. Neuss 1979; Richard Walsh, Music and Quattrocento diplomacy: The singer Jean Cordier between Milan, Naples and Burgundy in 1475, in: AKG 60, 1978, 439-442; Higini Anglès, Cantors und Ministrers in den Diensten der Könige von Katalonien-Aragonien im 14. Jahrhundert, in: Bericht über den Musikwissenschaftlichen Kongreß in Basel 26. bis 29. September 1924. Leipzig 1925, 56-66.

7 Vgl. Heinrich Finke, Des aragonesischen Hofnarren Mossén Borra Berichte aus Deutschland (1417, 1418), in: HJb 56, 1936, 161-173; Richard Walsh, The Coming of Humanism to the Low Countries. Some Italian Influences at the Court of Charles the Bold, in: Humanistica Lovaniensia. Journal of NeoLatin Studies 25, 1976, 146-197.

$8 \mathrm{Am}$ besten läßt sich dies an der schnellen Verbreitung von Turniermoden, Kunstgegenstănden oder höfischen Motiven erkennen. Vgl. zur Entstehung und Rezeption der Tafelrundenturniere Keen, Das Rittertum (wie Anm. 2), 143 ff., und Stephan Selzer, Artushöfe im Ostseeraum. Ritterlich-höfische Kultur in den Städten des Preußenlandes im 14. und 15. Jahrhundert. (Kieler Werkstücke, Reihe D: Beiträge zur europäischen Geschichte des späten Mittelalters, Bd. 8). Frankfurt a. M. 1996, 45 ff.; zur Verwendung von Bildteppichen Wolfgang Brassat, Tapisserien und Politik. Berlin 1992, 42 ff., und Wolfger A. Bulst, Das Olympische Turnier des Hercules mit den Amazonen. Flämische Tapisserien am Hofe der Este in Ferrara, in: Italienische Frührenaissance und nordeuropăisches Spătmittelalter. Hrsg. v. Joachim Poeschke. München 1993, 203-234; zu dem Motiv der Neun Helden und Neun Heldinnen Horst Schroeder, Der Topos der Nine Worthies in Literatur und bildender Kunst. Göttingen 1971, und Ingrid Sedlacek, Die Neuf Preuses. Heldinnen des Spätmittelalters. (Studien zur Kunst- und Kulturgeschichte, Bd. 14.) Marburg 1997. 
wurde ${ }^{9}$, doch kann er nicht ganz von der Betrachtung ausgeschlossen werden, da er sich mit dem Einzug der Braut bei der Hochzeit vermischen konnte. ${ }^{10}$ Zudem kam es zu Eingriffen des Hofes in die städtische Repräsentation. ${ }^{11}$

Das 15. Jahrhundert bietet sich vor allem deshalb als Untersuchungszeitraum an, weil erst für diese Zeit ausführliche Festbeschreibungen vorliegen. ${ }^{12}$ Zum anderen treten im Verlauf dieses Jahrhunderts mit dem Vordringen der Renaissance neue Festelemente auf, deren Rezeption oder Ablehnung ein helles Licht auf das Problem des Kulturtransfers wirf. ${ }^{13}$ In der Forschung sind die höfischen Feste des 15. Jahrhunderts - mit Ausnahme des Sonderfalls Burgund ${ }^{14}$ - bislang recht stiefmütterlich behandelt worden ${ }^{15}$, weil die glanzvollen

9 Vgl. Winfried Dotzauer, Die Ankunft des Herrschers. Der fürstliche „Einzug“ in die Stadt (bis zum Ende des alten Reiches), in: AKG 55, 1973, 245-288; Alois Niederstätter, Königseinritt und -gastung in der spätmittelalterlichen Reichsstadt, in: Feste und Feiern im Mittelalter. Hrsg. v. Detlef Altenburg/ Jörg Jamut/Hans-Hugo Steinhoff. Sigmaringen 1991, 491-500; Bernard Guenée/Françoise Lehoux, Les entrées royales françaises de 1328 à 1515. Paris 1968; Bonner Mitchell, The Majesty of the State. Triumphal Progresses of Foreign Sovereigns in Renaissance Italy (1494-1600). (Biblioteca dell',,Archivum Romanicum“, Serie I: Storia, letteratura, paleografia, vol. 203.) Florenz 1986; Gordon Kipling, Enter the King. Theatre, Liturgy, and Ritual in the Medieval Civic Triumph. Oxford 1998.

10 Mitchell, The Majesty (wie Anm. 9), 14 f., und Kipling, Enter the King (wie Anm. 9). $188 \mathrm{ff} ., 209 \mathrm{ff}$,, beziehen die Brauteinzüge ein.

11 Vgl. Gordon Kipling, The Triumph of Honour. Burgundian Origins of the Elizabethan Renaissance. Leiden 1977, 72 ff., am Beispiel der Inszenierung des Einzuges von Katharina von Aragón in London 1501.

12 Zusammenstellungen von Festberichten des 15. Jh. für Deutschland bei Kurt Enke, Deutsche höfische Festlichkeiten um die Wende des 15. Jahrhunderts (1450-1530). Diss. phil. München 1923 (handschriftlich), IV ff.; Gerhard Pietzsch, Die Beschreibung deutscher Fürstenhochzeiten als musikgeschichtliche Quellen, in: Anuario Musical 15, 1960, 21-62; Karl-Heinz Spieß, Kommunikationsformen im Hochadel und am Königshof im Spätmittelalter, demnächst in: Form und Funktion politischer Kommunikation im Mittelalter. Hrsg. v. Gerd Althoff. (VuF, Bd. 51.) Sigmaringen 2001; Hinweise für Italien bei Marialuisa Angiolillo, Feste di corte e di populo nell'Italia del primo Rinascimento. (Teatro, vol. 3.) Rom 1996; Maria Pia Mussini Sacchi, Feste per nozze nella seconda metà del Quattrocento, in: Città e Corte nell'Italia di Piero della Francesca. Ed. Claudia Cieri Via. Venedig 1996, 399-412; Alexandra Ortner, Petrarcas „Trionfi“ in Malerei, Dichtung und Festkultur. Untersuchung zur Entstehung und Verbreitung eines florentinischen Bildmotivs auf cassoni und deschi da parto des 15. Jahrhunderts. Weimar 1998, 188 ff.; Philine Helas, Lebende Bilder in der italienischen Festkultur des 15. Jahrhunderts. Berlin 1999, 191 ff. (Quellenabdrucke in Auszügen). Zu Burgund s. unten Anm. 14. Für die ältere Zeit vgl. Franz-Reiner Erkens, Fecit nuptias regio, ut decuit apparatu. Hochzeitsfeste als Akte monarchischer Repräsentation in salischer Zeit, in: Feste und Feiern (wie Anm. 9), 401-421.

13 Vgl. Jacob Burckhardt, Die Kultur der Renaissance in Italien. (Bibliothek der Geschichte und Politik, Bd. 8.) Hrsg. v. Horst Günther. Frankfurt a. M. 1989, 353 ff.; Roy Strong, Feste der Renaissance 14501650. Kunst als Instrument der Macht. Freiburg/Würzburg 1991, 15 ff.

14 Vgl. als Auswahl Johan Huizinga, Herbst des Mittelalters. Studien über Lebens- und Geistesformen des 14. und 15. Jahrhunderts in Frankreich und in den Niederlanden. Hrsg. v. Kurt Köster. (Kröners Taschenausgabe, Bd. 204.) 11. Aufl. Stuttgart 1975 (zuerst niederld.: Herfsttij der Middeleeuwen. Studie over levens- en gedachtenvormen der veertiende en vijftiende eeuw in Frankrijk en de Nederlanden, Haarlem 1919); Otto Cartellieri, Am Hofe der Herzöge von Burgund. Basel 1926; Agathe Lafor- 
Feste des 16. und 17. Jahrhunderts den Blick auf sich gezogen haben. ${ }^{16}$ So gibt es bislang nur eine vergleichende monographische Untersuchung der deutschen höfischen Festlichkeiten im 15. Jahrhundert, nămlich die handgeschriebene Münchner Dissertation von Kurt Enke aus dem Jahr 1923. ${ }^{17}$ Wenn man sich uberhaupt mit den spätmittelalterlichen deutschen Festen auseinandergesetzt hat, dann meist vor der Folie der Renaissancefeste. ${ }^{18}$ Was Gordon Kipling seinem 1998 erschienenen Buch Enter the King. Theatre, Liturgy, and

tune-Martel, Fête noble en Bourgogne au XV' siècle. Le banquet du Faisan (1454): Aspects politiques, sociaux et culturels. Montreal/Paris 1984; Werner Paravicini, The Court of the Dukes of Burgundy: A Model for Europe?, in: Princes, Patronage, and the Nobility. The Court at the Beginning of the Modern Age c. 1450-1650. Ed. Ronald G. Asch/Adolf M. Birke. Oxford 1991, 69-102; Jean-Marie Cauchies (Ed.), Fêtes et cérémonies aux $\mathrm{XIV}^{e}-\mathrm{XVI}^{e}$ siècles. (Publications du Centre Européen d'Etudes Bourguignonnes, vol. 34.) Neuchâtel 1994; Danielle Régnier-Bohler (Ed.), Splendeurs de la cour de Bourgogne. Récits et chroniques. Paris 1995; Birgit Franke, Feste, Turniere und städtische Einzüge, in: Kunst der burgundischen Niederlande. Hrsg. v. ders./Barbara Welzel. Berlin 1997, 65-84; Gert Melville, Rituelle Ostentation und pragmatische Inquisition. Zur Institutionalităt des Ordens vom Goldenen Vließ, in: Im Spannungsfeld von Recht und Ritual. Soziale Kommunikation in Mittelalter und Früher Neuzeit. Hrsg. v. Heinz Duchhardt/Gert Melville. (Norm und Struktur, Bd. 7.) Köln/Weimar/Wien 1997, 215-271. Zur burgundischen Seitenlinie Brabant vgl. Anne Chevalier-de Gottal, Les fêtes et les arts à la cour de Brabant à l'aube du XV' siècle. (Kieler Werkstücke, Reihe D: Beitrăge zur europăischen Geschichte des Mittelalters, Bd. 7.) Frankfurt a. M. 1996.

15 Vgl. Melville, Rituelle Ostentation (wie Anm. 14), 238: „Eine hinreichende Gesamtanalyse des höfischen Festes im Spătmittelalter ist (...) noch Desiderat.“ "Siehe vorlăufig den knappen Überblick von Jacques Heers, Fêtes, jeux et joutes dans les sociétés d'Occident à la fin du Moyen Âge. (Conférence Albert-Le Grand 1971.) Montreal/Paris 1982. In dem Bändchen von Richard Alewyn/Karl Sälzle, Das große Welttheater. Die Epoche der höfischen Feste in Dokument und Deutung. Hamburg 1959, wird nur ein Fest des 15. Jahrhunderts eingehend geschildert, wobei es sich bezeichnenderweise um das burgundische Fasanenfest zu Lille handelt. Einen Überblick für Böhmen bietet František Šmahel, Die königlichen Feste im mittelalterlichen Böhmen, in: Bohemia 37, 1996, 271-290.

16 Neben den Arbeiten von Burckhardt, Die Kultur (wie Anm. 13), Strong, Feste (wie Anm. 13), und Karl Vocelka, Habsburgische Hochzeiten 1550-1600. Kulturgeschichtliche Studien zum manieristischen Repräsentationsfest. (Veröff. der Kommission für neuere Geschichte Österreichs, Bd. 65.) Wien/Köln/Graz 1976, seien hier nur zwei große Sammelwerke angefuhrt: Jean Jacquot (Ed.), Les Fêtes de la Renaissance. 3 vol. Paris 1956-1975; August Buck/Georg Kauffmann/Blake L. Spahr/Conrad Wiedemann (Hrsg.), Europäische Hofkultur im 16. und 17. Jahrhundert. 3 Bde. (Wolfenbüttler Arbeiten zur Barockforschung, Bde. 8-10.) Hamburg 1981.

17 Enke, Deutsche höfische Festlichkeiten (wie Anm. 12). Vgl. jetzt Andreas Ranft, Feste des deutschen Adels am Ausgang des Mittelalters, Form und Funktion, in: Il tempo libero. Economia e società (Loisirs, Leisure, Tiempo Libre, Freizeit). Secc. XIII-XVIII. Ed. Simonetta Cavaciocchi. (Istituto internazionale di storia economica „F Datini“, Prato, Serie II: Atti delle „Settimane di Studi“ e altri Convegni, vol. 26.) Prato 1995, 245-256.

18 Vgl. Maximilian Buchner, Die Amberger Hochzeit (1474), in: ZGO 64, 1910, 584-604; 65, 1911, 95-127, hier 117: „All diese deutschen festlichen Veranstaltungen freilich stehen, was feinen Geschmack betriff, um ein Erkleckliches den Hochzeitsfeiern nach, die um dieselbe Zeit an italienischen Fürstenhöfen veranstaltet wurden: hier hatte sich eben der Geist der Renaissance (...) heimisch gemacht (...)“; und Peter Amelung, Festlichkeiten an den Höfen, in: Württemberg im Spätmittelalter. Katalog. Bearb. v. Joachim Fischer/Peter Amelung/Wolfgang Irtenkauf. Stuttgart 1985, 66: „Einen Vergleich mit den glanzvollen Festen, die zu dieser Zeit am burgundischen Hof und vor allem an den italienischen Renaissancehöfen gefeiert wurden, halten diese deutschen Feste nicht aus.“ 
Ritual in the Medieval Civic Triumph vorangestellt hat, gilt deshalb auch für die höfischen Feste insgesamt: „Almost without exception, modern writers have found these shows interesting only when they cease being ,medieval' in substance and begin to adopt classical ideas and political imagery.“19 Ungeachtet der harschen Kritik, die Jacob Burckhardt und vor allem Johan Huizinga an den burgundischen Hoffesten übten, die ihnen im Vergleich zu den italienischen Renaissancefesten platt, geschmack- und stillos erschienen ${ }^{20}$, haben gerade diese Feierlichkeiten in jüngerer Zeit das Interesse der Forschung erregt. Die überaus eindrucksvolle Prachtentfaltung, die bei dem Fasanenfest zu Lille im Jahr $1454^{21}$, bei der Hochzeit Karls des Kühnen mit Margarethe von York $1468^{22}$ und bei dem Zusammentreffen Karls des Kühnen mit Kaiser Friedrich III. in Trier $1473^{23}$ demonstriert wurde, hat die Frage aufgeworfen, ob nicht die italienische, sondern die burgundische Festkultur als Modell fur Europa anzusehen ist. Während Gordon Kipling in seinem anderen Buch The Triumph of Honour. Burgundian Origins of the Elizabethan Renaissance nachweisen konnte, daß in England burgundische Vorbilder zumindest gleichrangig neben italienischen Einflüssen standen $^{24}$, ist die Frage fur Deutschland noch unbeantwortet. In seinem neuesten, noch unpublizierten Aufsatz Die zwölf, Magnificences' Karls des Kühnen hat Werner Paravicini zwar vor ungeprüfter Annahme burgundischer Einmaligkeit und Vorbildfunktion gewarnt und damit das Fragezeichen hinter seinem wegweisenden Beitrag The Court of the Dukes of Burgundy: A Model for Europe? erneuert, doch zugleich die Vermutung geäußert, die Brügger Hochzeit von 1468 könne am Anfang der großen Fürstenhochzeiten im Reich stehen. ${ }^{25}$

19 Kipling, Enter the King (wie Anm. 9), 9.

20 Vgl. Huizinga, Herbst (wie Anm. 14), 367 ff.; Burckhardt, Die Kultur (wie Anm. 13), 401 f.

21 Vgl. Lafortune-Martel, Fête noble (wie Anm. 14).

22 Vgl. Richard Vaughan, Charles the Bold. The Last Valois Duke of Burgundy. London 1973, $48 \mathrm{ff}$;; Christine Weightman, Margaret of York, Duchess of Burgundy 1446-1503. Gloucester/New York 1989, 30 ff. Demnächst Werner Paravicini, Die zwölf „Magnificences“ Karls des Kühnen, in: Form und Funktion politischer Kommunikation im Mittelalter. Hrsg. v. Gerd Althoff. (VuF, Bd. 51.) Sigmaringen 2001, und Harm von Seggern, Herrschermedien im Spätmittelalter. Studien zur Informationsvermittlung im burgundischen Staat unter Herzog Karl dem Kühnen. Diss. phil. Trier 1999 (masch.). Beiden Autoren danke ich sehr herzlich für die Überlassung der ungedruckten Manuskripte, nach denen ich zitiere.

23 Vgl. Franz Lindner, Die Zusammenkunft Kaiser Friedrich III. mit Karl dem Kühnen von Burgund im Jahre 1473 zu Trier. Diss. phil. Greifswald. Cöslin 1876; Paravicini, Die zwölf „Magnificences“ (wie Anm. 22), $27 \mathrm{ff}$.

24 Kipling, Triumph (wie Anm. 11), 3 ff.

25 Vgl. Paravicini, Court (wie Anm. 14), 93: „All this makes it probable that there was a Burgundian influence on the courts of Germany though we do not yet possess any real proof. It is interesting to note that the first great German princely wedding, at Bayern-Landshut in 1475, followed only a few years upon Charles the Bold's wedding ceremony in Bruges in 1468.“; ders., Die zwölf „Magnificences“ (wie Anm. 22), 55. Zur Fortsetzung der Debatte vgl. die Diskussion zum Vortrag von Werner Paravicini, Deutsche Adelskultur und der Westen im späten Mittelalter, in: Konstanzer Arbeitskreis für mittelalterliche Geschichte. Protokoll Nr. 376 über die Arbeitstagung auf der Insel Reichenau vom 5.-8. Oktober 1999 „Deutschland und der Westen Europas im Mittelalter, Teil II: Hoch- und Spätmittelalter", 41 ff. In dem Vortrag äußert sich Werner Paravicini noch skeptischer als zuvor zum 
Auch sein Schüler Harm von Seggern hält es in seiner noch ungedruckten Dissertation zur Informationsübermittlung im burgundischen Staat Karls des Kühnen für möglich, daß die Nachrichten über die Brügger Hochzeitsfeierlichkeiten des Jahres 1468 die Fürsten im Reich dazu angeregt haben könnten, den burgundischen Herzog zu ubertreffen. ${ }^{26} 1474$ und 1475 wurden nämlich in Amberg ${ }^{27}$, Urach ${ }^{28}$ und Landshut ${ }^{29}$ drei große Fürstenhochzeiten begangen, von denen die Landshuter zumindest in bezug auf die Teilnehmerzahl die Brügger Hochzeit weit in den Schatten stellte. ${ }^{30}$

Aus dieser Forschungssituation ergibt sich meine Fragestellung: Gab es strukturelle und qualitative Unterschiede bei den europäischen Hochzeitsfeiern? Wenn ja, worin bestanden diese Unterschiede, und vor allem: worin waren sie begründet? Zur Beantwortung dieser Fragen werden die Brügger Hochzeit von 1468 und die Landshuter Hochzeit von 1475 einander gegenubbergestellt und dann in das jeweilige Umfeld eingeordnet. Um zu prufen, ob auftretende Unterschiede entwicklungsgeschichtlich bestimmt sind, erfolgt anschließend eine knappe Würdigung zweier 25 Jahre später in Deutschland und Italien gefeierter Hochzeiten. Ein Blick in das 16. Jahrhundert beendet den Beitrag.

Die Brügger Hochzeit von 1468 begann mit der Ankunft Margarethes von York und ihrer englischen Begleitung in Sluis, dem Brügger Vorhafen, am 25. Juni. ${ }^{31}$ Am folgenden Tag wurde sie von ihrem Bräutigam Karl dem Kühnen, der Mutter des Fürsten, Isabelle von Portugal, und dessen Tochter Maria begrüßt, am Abend gab es noch einmal ein Treffen mit

Problem der Nachahmung der burgundischen Hochzeiten von 1468 im Reich. Für die Übersendung des Manuskripts sei dem Verfasser herzlich gedankt.

26 Von Seggern, Herrschermedien (wie Anm. 22), 294.

27 Vgl. Buchner, Hochzeit (wie Anm. 18); ders., Quellen zur Amberger Hochzeit von 1474, in: AKG 6, 1908, 395-438.

28 Vgl. Paul Friedrich Stälin, Die Heirath des Württembergischen Grafen, nachherigen Herzogs, Eberhard im Bart mit der Markgrăfin Barbara Gonzaga von Mantua im Jahre 1474, in: Württembergische Jahrbücher für Statistik und Landeskunde 1872, 3-17; Amelung, Festlichkeiten (wie Anm. 18), 70 ff.

29 Sebastian Hiereth, Herzog Georgs Hochzeit zu Landshut im Jahre 1475. Eine Darstellung aus zeitgenössischen Quellen. 4. Aufl. Landshut o. J. Da Hiereth an einigen Stellen zusammenfaßt bzw. normalisiert, ist ergănzend der Abdruck des Berichtes von Hans Seybold, in: Beytrăge zur vaterländischen Historie, Geographie, Statistik und Landwirtschaft. Hrsg. v. Lorenz Westenrieder. München 1789, 105-221, heranzuziehen.

30 Bei der Landshuter Hochzeit wurden 6560 auswärtige Gäste gezăhlt, in Brügge waren nach einer groben Schătzung zwischen 2500-3200 Hochzeitsgäste anwesend, von denen aber 1300 bis 1800 vom burgundischen Hof selbst gestellt wurden. In Urach ist nur die Zahl der Gästepferde bekannt, die sich auf 4280 belief. Vgl. Hiereth, Hochzeit (wie Anm. 29), 82; von Seggern, Herrschermedien (wie Anm. 22), 276 f.; Amelung, Festlichkeiten (wie Anm. 18), 72. Für weitere Teilnehmerzahlen bei Hochzeiten und methodische Überlegungen zur Berechnung vgl. Spie $\beta$, Kommunikationsformen (wie Anm. 12), $2 \mathrm{f}$. Zu den Gründen für die vergleichsweise geringe Gästezahl in Brügge s. unten bei Anm. 51 .

31 Die Darstellung beruht in erster Linie auf der ausfuhrlichen Schilderung des an der Ausrichtung beteiligten Olivier de la Marche: Memoires d'Olivier de la Marche. Ed. Henri Beaune/Jules d'Arbaumont. Vol. 3. Paris 1885, 101-201, sowie Weightman, Margaret of York (wie Anm. 22), $48 \mathrm{ff}$., und Paravicini, Die zwölf „Magnificences“ (wie Anm. 22), 11 ff. Eine Zusammenstellung aller Festbeschreibungen bietet von Seggern, Herrschermedien (wie Anm. 22), $265 \mathrm{f}$. Zu de la Marche vgl. Danielle Quérnel, Olivier de la Marche ou „L'espace de l'artifice“, in: Fêtes et cérémonies (wie Anm. 14), 55-70. 
dem in geringer Begleitung erschienenen Herzog. Am 27.6. erfolgte im kleinen Kreis das gegenseitige Ehegelöbnis, worauf der Herzog für vier Tage nach Brügge abreiste. Am 2.7. besuchte Karl erneut Margarethe, kam aber wiederum nach Brügge zurück, denn am 3.7. trafen sich der aus Brügge kommende Herzog und die aus Sluis mit dem Schiff anreisende Margarethe in Damme, wo dem Brautpaar der kirchliche Segen durch den Bischof von Salisbury zuteil wurde. Nach dem Kirchgang kehrte Karl sofort zurück nach Brügge, so daß Margarethe ihren feierlichen Einzug in Brügge wie ihre Schwiegermutter 38 Jahre zuvor allein hielt. Klerus, Adel, Bürgerschaft und die Abordnungen der ausländischen Kaufleute empfingen die neue Herzogin mit größter Pracht. Wie bereits zuvor in Sluis waren auf ihrem Weg lebende Bilder zu sehen, die fast alle auf die Vermählung Bezug nahmen. Die Stoffe entstammten meist der Bibel, zum Beispiel die Hochzeit Salomos oder die Hochzeit von Kanaa, und wurden mit Spruchbändern erläutert. ${ }^{32}$ Im Schloß angekommen, in dessen Hof Weinbrunnen aufgebaut waren, nahmen Männer und Frauen das Essen getrennt ein, der Herzog aß sogar ganz für sich in einem kleinen Saal.

Am Nachmittag begann bereits das Tumier, bei dem der Herzog erstmals an diesem Tag öffentlich mit seiner Gemahlin zu sehen war. Das feierliche Bankett fand für die gesamte Festgemeinschaft in der eigens errichteten gewaltigen Holzhalle statt, die ungewöhnlich kostbar geschmückt und mit Teppichen behängt war. Die Bildthemen der Tapisserien griffen die der lebenden Bilder auf. Sie kreisten um Esther, Jason mit dem Goldenen Vlies und Troja, die in enger Beziehung zur burgundischen Dynastie gesehen wurden und diese überhöhen sollten. ${ }^{33}$ Auf den Tischen standen Schaugerichte: dreißig Schiffe mit goldener und blauer Farbe überzogen, von denen jedes Namen und Wappen einer der Herrschaften des Herzogs trug, weiterhin dreißig riesige Pasteten in der Form großer Burgen, die Wappen und Namen der wichtigsten Städte des Herzogtums zeigten. ${ }^{34}$

Zwischen den Gängen gab es drei lebende „entremets“ oder Intermedien, das sind aufwendige Darbietungen. ${ }^{35}$ So traten auf: ein Einhorn, auf dem ein Leopard saß, später ein

32 Bei den „Lebenden Bildern“ handelt es sich um bühnenartige Gerüste, auf denen lebende Menschen eine mehrfigurige Szene darstellten. Wăhrend in Frankreich und den Niederlanden bei den „tableaux vivants“ die Bilder fest installiert waren, handelt es sich bei den englischen ,pageants“ und den italienischen „rappresentazione“ hăufig um mobile Konstruktionen, die zudem durch Gestik, Musik oder Vortrag von Versen multimedial erweitert werden konnten. Vgl. Max Herrmann, Forschungen zur deutschen Theatergeschichte des Mittelalters und der Renaissance. Berlin 1914, 364 ff., und Helas, Bilder (wie Anm. 12), 3 ff. Die ăltesten zeitgenössischen Darstellungen von „tableaux vivants“ schildern den Einzug Johannas von Kastilien in Brüssel am 9.12.1496. Abbildungen aus der Handschrift (Berlin, Staatliche Museen, Kupferstichkabinett, MS 78 D5) finden sich bei Herrmann, $367 \mathrm{ff} .$, Helas $277 \mathrm{f}$., und Wim Blockmans, Le dialogue imaginaire entre princes et sujets: Les joyeuses entrées en Brabant en 1494 et en 1496, in: Fêtes et cérémonies (wie Anm. 14), 37-53, hier 50 ff.

33 Vgl. Birgit Franke, Tapisserie - „portable grandeur“ und Medium der Erzăhlkunst, in: Kunst (wie Anm. 14), 121-139.

34 Vgl. die gemăß der Beschreibung angefertigten Illustrationen bei Lafortune-Martel, Fête noble (wie Anm. 14), $201 \mathrm{ff}$.

35 Zur Entstehung und Verwendung der entremets vgl. Lafortune-Martel, Fête noble (wie Anm. 14), 25 ff., Franke, Feste (wie Anm. 14), 67 ff.; Bonner Mitchell, Les intermèdes au service de l'etat, in: Fête et cérémonies (wie Anm. 14), 117-131. 
singender Löwe in der Größe eines Pferdes, auf dem sich eine Zwergin befand und schließlich ein Dromedar mit einem fremdartig gekleideten Mann, der aus zwei Körben bunt bemalte Vögel holte und an die Gäste verteilte. Erst um drei Uhr nachts zog man sich in die Gemächer zurück, wobei die Brautleute offenbar zum ersten Mal die Nacht gemeinsam in einem Zimmer verbrachten.

Von Montag, dem 4. Juli, bis zum 12. Juli zogen sich die weiteren Festtage hin, die im wesentlichen von den mit theatralischen Elementen angereicherten Turmieren und den abendlichen Banketten ausgefullt wurden. An drei Abenden wurden in zwölf Akten die Taten des Herkules aufgefuhrt. ${ }^{36}$ Die „entremets“ bestanden unter anderem aus einem flügelschlagenden Greif, aus dessen Schnabel bei jeder Öffnung lebende Vögel flogen, einem riesigen Turm, aus dem Tiere Musik machten und einem gewaltigen Wal, aus dem Ritter kamen, die sich bekämpften. Das Fest endete mit einem großen Mittagessen, bei dem die Herolde und Spielleute reich beschenkt wurden.

Wie gestaltete demgegenüber einer der reichsten und mächtigsten Fürsten des Reiches die Vermählung seines Sohnes mit der Tochter des polnischen Königs? Die beruhmte Landshuter Hochzeit, die Herzog Ludwig von Bayern-Landshut fur seinen Sohn Georg im Jahr 1475 ausrichtete, begann mit der Ankunft der Braut am 14.11. kurz vor Landshut. ${ }^{37}$ Vor der Braut waren die Gäste eingetroffen, zu denen außer Kaiser Friedrich III. und seinem Sohn Maximilian Fürstinnen und Fürsten aus den vornehmsten Häusern des Reiches, aus Sachsen, Kurpfalz, Brandenburg, Bayern, Österreich, Württemberg und Baden zăhlten. Hinzu kamen sechs Bischöfe als geistliche Reichsfursten, so daß insgesamt 26 Reichsfursten versammelt waren, zu denen sich noch acht Fürstinnen gesellten. Jeder Fürst war mit stattlichem Gefolge erschienen, wodurch die Zahl der Gäste auf über 6000 anstieg. Markgraf Albrecht Achilles brachte 1370 Pferde mit, der Kaiser 567 Pferde, der Pfalzgraf 510 usw. Als die Braut sich năherte, ritten ihr die jungen Fürsten mit etwa 1000 Pferden entgegen, um sie zu begrüßen. Dann stieß der Wagentroß auf den Kaiser und die bei ihm weilenden Fürsten, die von Markgraf Albrecht Achilles zum Empfang aufgestellt worden waren. Braut und Bräutigam begrüßten sich, worauf sich die Wagen der Braut, die Fürsten und sämtliche Gefolgschaften furr den Einzug in die Stadt formierten. Anders als in Brugge gab es keine besondere Ehrung durch die Bürger. An der Stadtkirche warteten die Fürstinnen und Gräfinnen, um ihrerseits die Braut willkommen zu heißen. Anschließend erfolgte das beiderseitige Ehegelöbnis in der Kirche, worauf sich jeder zu seiner Herberge begab, um dort das Essen einzunehmen. Am Abend erschienen alle zum Hochzeitstanz. Zu fortgeschrittener Stunde brachten die Fürstinnen und Fürsten das Brautpaar in das Schlafgemach zum sogenannten Beilager, d. h. die Brautleute legten sich in das Bett, eine Decke wurde über sie geschlagen, worauf die Anwe-

36 Vgl. Myriam Cheyns-Condé, L'adaptation des „Travaux d'Hercules“ pour les fêtes du mariage de Marguerite d'York et de Charles le Hardi à Bruges en 1468, in: Fête (wie Anm. 14), 71-80.

37 Die Schilderung beruht auf Hiereth, Herzog Georgs Hochzeit (wie Anm. 29), und dem Bericht Seybolds (wie Anm. 29). Eine analysierende Beschreibung auch bei Spieß, Kommunikationsformen (wie Anm. 12), $4 \mathrm{ff}$. 
senden den Raum verließen. Auf diese Weise wurde der rechtliche Vollzug der Ehe öffientlich gemacht. ${ }^{38}$

Der nächste Morgen begann wiederum mit einem rechtlich relevanten Akt, nämlich der Aushändigung der Morgengabe durch den Ehemann ${ }^{39}$, anschließend überreichten die Fürsten und Gesandten ihre Hochzeitsgeschenke. Nach dieser Zeremonie ging die Festgemeinschaft zum feierlichen Gottesdienst, wobei die Landshuter Zünte mit brennenden Kerzen Spalier standen. Auf den Kirchgang folgte das Hochzeitsbankett, das aber die Männer und Frauen getrennt in eigens dafür hergerichteten Räumlichkeiten einnahmen. ${ }^{40}$ Man speiste an einzelnen Tischen, die mit jeweils funf Personen besetzt waren. In bezug auf das Festessen wird nur die Speisenfolge für erwähnenswert gehalten, so daß offensichtlich keine besondere Unterhaltung geboten wurde. Nach dem Essen fand auf dem Marktplatz das Turnier statt, an dem sich auch der Brăutigam beteiligte. Am Abend gab es kein offizielles Programm mehr, d. h. man $a ß$ jeweils in der eigenen Herberge. Der dritte Tag war tagsüber dem Tumier gewidmet, während am Abend ein festlicher Tanz angeboten wurde. An dessen Ende fand ein Tanzwettbewerb der adeligen Frauen statt, bei dem sich 81 weibliche Paare dem Kaiser und dem Grafen von Werdenberg als Schiedsrichter stellten. Am vierten Tag gab es zwar noch Turnierdarbietungen, zugleich begann jedoch die Abreise der Gäste.

$\mathrm{Da} ß$ die Landshuter Hochzeit nur in bezug auf die Anwesenheit des Kaisers und die Zahl der Gäste aus den deutschen Fürstenhochzeiten herausragt, zeigen die Festbeschreibungen der ein Jahr vorausgegangenen Amberger und Uracher Hochzeit. ${ }^{41}$ Beide dauerten ebenfalls vier Tage und waren identisch in der Abfolge. In Amberg fand allerdings am Abend des dritten Tages zusätzlich ein Tanz statt, bei dem die Herzogin Mechthild von Österreich eine Neuheit kreierte, da zuerst jeder für sich allein tanzen sollte. In Urach bestand die Novität darin, daß die aus Italien stammende Braut mit ihrem Bruder Rudolfo Gonzaga einen welschen Tanz vorfuhrte.

In Amberg wurde bei dem Festbankett ein Schauessen vorgefuhrt, das von vier Rittern hereingetragen wurde. Darin saßen zwei Knaben, einer sang, einer schlug die Laute, es rannte ein lebendiger Hase heraus und Vögel flatterten empor. In Urach gab es zwei Schauessen; in dem einen saßen drei Sänger, bei dem anderen handelte es sich um eine Burg mit einem Springbrunnen, und um die Burg lief ein Wassergraben mit lebendigen Fischen. Leider kennen wir nicht die Zahl der Gäste in Urach, sondern nur die der mitgebrachten

38 Zum Beilager vgl. Franz Rodeck, Beiträge zur Geschichte des Eherechts deutscher Fürsten bis zur Durchführung des Tridentinums. Diss. phil. Münster 1910, 40 ff., und Jörg Wettlaufer, Beilager und die Bettleite im Ostseeraum (13. bis 19. Jahrhundert). Eine vergleichende Studie zur Wandlung des Eheschließungsrechts im Spätmittelalter und in der frühen Neuzeit, in: Tisch und Bett. Die Hochzeit im Ostseeraum seit dem 13. Jahrhundert. Hrsg. v. Thomas Rijs. (Kieler Werkstücke, Reihe A, Bd. 19.). Frankfurt a. M. 1998, 81-127, hier 88 ff.

39 Zur Morgengabe im Hochadel vgl. Spie $\beta$, Familie (wie Anm. 3), 141 ff.

40 Vgl. Sebastian Hiereth, Die Landshuter Hochzeit als Organisationsproblem, in: Österreichische Osthefte 18, 1976, 31-37.

41 Die Schilderung beruht auf der in Anm. 27 und 28 zitierten Literatur sowie Adolf Mettler, Des Grafen Eberhard im Bart Hochzeit zu Urach im Jahre 1474, in: Württemberg 3, 1931, 76-82, und der Handschrift HSTA Stuttgart, A 602 WR 373 d, deren Edition vom Verfasser vorbereitet wird. 
Pferde, nämlich 4280; in Amberg dürften es nicht viel weniger gewesen sein. ${ }^{42}$ Die Bürger der beiden Stădte wurden zur Aufrechterhaltung der Ordnung herangezogen, ansonsten nahmen sie nur indirekt teil, indem sie kostenlos Essen und Wein erhielten.

Die drei geschilderten Fürstenhochzeiten zu Amberg, Urach und Landshut lassen ein gemeinsames Festmuster erkennen, das fur das 15. Jahrhundert so typisch war, daß Kurfurst Albrecht Achilles es in folgende Worte fassen konnte: Am Sonntag kommt man und am Montag sticht man, am Dienstag rennt man und am Mittwoch zieht man fort. ${ }^{43}$

Die vielgerühmte Brugger Hochzeit von 1468 verliert etwas von ihrer Einmaligkeit, wenn man sie in Beziehung setzt zur Prachtentfaltung an den anderen Höfen Frankreichs, insbesonders dem Renés von Anjou ${ }^{44}$, und außerdem mit zeitgenössischen Hochzeitsfeiern in Italien $^{45}$ oder Portugal ${ }^{46}$ vergleicht. Als Eleonore von Portugal 1451 in Lissabon durch einen

42 Rang der Gäste und somit Zahl der Begleiter waren in Urach und Amberg ungefähr gleich.

43 Politische Correspondenz des Kurfürsten Albrecht Achilles. Bd. 2. Hrsg. v. Felix Priebatsch. (Publicationen aus den K. Preußischen Staatsarchiven, Bd. 67.) Leipzig 1897, Nr. 225, 237 f. Der Ausspruch bezieht sich mit dem Zusatz „das ist die weiß hynnen“ auf die Mark Brandenburg, ist aber auch für die anderen Regionen zutreffend. Die Hochzeiten in Urach und Amberg begannen tatsächlich ebenfalls am Sonntag und endeten am Mittwoch, in Landshut feierte man jedoch von Dienstag bis Freitag, weil sich der Reisezug der Braut aus Polen verspătet hatte. Ursprünglich wollte man das Fest eine Woche früher beginnend mit der Ankunft am Sonntag begehen. Vgl. Hiereth, Herzog Georgs Hochzeit (wie Anm. 29), 34, $40 \mathrm{f}$. Weitere Stichproben haben bestätigt, daß man sonntags anreiste und montags die Hochzeit feierte. Bemerkenswert ist die Konzentration des Markgrafen auf das Turniergeschehen, die sich auch bei anderen Fürsten erkennen läßt, in diesem Fall aber auch durch den auf Turnierfragen abhebenden Briefkontext mitbedingt wurde.

44 René von Anjou (1409-1480) war Mittler zwischen der italienischen, provenzalischen und französischen Kultur. Ein eingehender Vergleich der an seinem Hof gepflegten Festformen mit der burgundischen Hofkultur brächte sicherlich fruchtbare Ergebnisse uber die gegenseitige Beeinflussung der in einem ständigen Rangwettstreit befindlichen Höfe. Vgl. vorlăufig Albert Lecoy de la Marche, Le roi René. Sa vie, son administration, ses travaux artistiques et littéraires. 2 vol. Paris 1875, ND Genf 1969; Françoise Piponnier, Costume et vie sociale. La cour d'Anjou-Provence. La vie artistique sous le règne de René. Paris 1985, 46 ff. zu den großen höfischen Festen, die vor dem Fasanenfest und der Hochzeit von 1468 gefeiert wurden; Christian de Mérindol, Les joutes de Nancy, le pas de Saumur et le pas de Tarascon, fêtes de chevalerie à la cour du roi René (1445-1449), in: Fêtes et cérémonies (wie Anm. 14), 187-199. Das Turnier von Nancy wurde anläßlich der Vermählung von Renés Tochter Margarethe mit König Heinrich VI. von England begangen.

45 Vgl. z. B. die Hochzeitsfeiem 1441 in Rimini für Sigismondo Malatesta und Polissena Sforza bei Luigi Tonini, Rimini nella Signoria de Malatesta. T. 2. Rimini 1882, 127 ff.; 1465 in Neapel für König Alfons von Aragón und Ippolita Maria Sforza bei Carlo Canetta, Le „sponsalie“ di Casa Sforza con Casa d'Aragona, in: Archivio Storico Lombardo 9, 1882, 136-144; 10, 1883, 769-782; 1468 in Mailand für Galeazzo Maria Sforza und Bona von Savoyen, die mit ungeheurem Aufwand vorbereitet, aber wegen der Pest dann doch nur in kleinem Rahmen abgehalten wurde, bei Gregory Lubkin, A Renaissance Court. Milan under Galeazzo Maria Sforza. Berkeley/Los Angeles/London 1994, 49 ff.; 1469 in Florenz für Lorenzo de' Medici und Chiara Orsini bei Nicole Carew-Reid, Fete e politica a Firenze sotto Lorenzo il Magnifico, in: Quaderni medievali 24, 1987, 25-55, hier 30 f.; 1473 in Ferrara für Ercole d'Este und Eleonore von Aragón bei Luigi Olivi, Della nozze di Ercole I d'Este con Eleonora d'Aragona, in: Memorie della Regia Academica in Modena, Serie II, vol. V, Modena 1887. 15-68; Clelia Falletti, Le feste per Eleonora d'Aragona da Napoli a Ferrara (1473), in: Teatro e culture della 
Prokurator mit Friedrich III. vermählt worden war, veranstaltete ihr Bruder König Alfons von Portugal ein gewaltiges Fest, um seine Schwester zur Brautfahrt nach Italien zu verabschieden. Es dauerte elf Tage, an denen lebende Bilder zu sehen waren, unter anderem sämtliche Könige Portugals, die sieben Kurfürsten, die Friedrich III. wählten, dreizehn Propheten, die dem Brautpaar eine gute Zukunft voraussagten, ja man scheute sich nicht, die künftige Kaiserkrönung mit Papst und Kardinälen durch verkleidete Personen darzustellen. Es trat ein Drache auf, der vierzig Ritter trug, ein von achtzig Leuten gezogener Riesenelefant, ein Einhorn, auch der König von Troja sowie Hector, Priamos und Ajax gaben sich die Ehre. Für das Turnier war eine hölzerne Burg errichtet worden, in der der König übernachtete; das Bankett fand in einem zweiten, eigens erbauten Palast statt, der mit kostbaren Textilien geschmückt war. Der portugiesische König setzte weiterhin sämtliche Exotik ein, die sein Reich zu bieten hatte, denn es traten Sarazenen, Afrikaner und die Eingeborenen von den Kanaren mit ihren typischen Gesängen und Tänzen auf. Dank einer kunstvollen Maschinerie schwebte ein als Engel verkleideter Junge von dem Kirchturm des Domes herab und streute Rosen über Eleonore. Bei all den Spektakeln war die Bevölkerung Lissabons teilweise als Mitwirkende, in der Masse zumindest als Zuschauer beteiligt, da die Vorfuhrungen in der Regel im Freien auf dem Domplatz oder anderen Plätzen stattfanden. Der engere Kreis der Feiernden bestand aus den Angehörigen des Hofes, auswärtige Fürsten waren offenbar nicht geladen. ${ }^{47}$

Auch wenn die Hochzeiten nur in aller Kürze geschildert werden konnten, so dürfte deutlich geworden sein, daß von einer Homogenität der höfischen Feste in Europa kaum die Rede sein kann. Auf den ersten Blick stimmen zwar die Festelemente Gottesdienst, Bankett, Tanz und Turnier überein, bei näherem Hinsehen kristallisieren sich jedoch zwei unterschiedliche Festmuster heraus, die im folgenden beschrieben und analysiert werden sollen.

rappresentazione. Lo spettacolo in Italia nel Quattrocento. Ed. Raimondo Guarino. Bologna 1988, 121-140; Barbara Di Pascale, Banchetti Estensi. La spettacolarità del cibo alla corte di Ferrara nell Rinascimento. Imola 1995, 18 ff.; Thomas Tuohy, Herculean Ferrara. Ercole d'Este, 1471-1505, and the Invention of a Ducal Capital. Cambridge 1996, 62 ff., 264 ff. Für Nachweise für Hochzeiten nach 1473 vgl. unten Anm. 51, 52, 58 und S. 355 f. Herm Thomas Willich, Berlin, sei an dieser Stelle herzlich für die Beschaffung der in Greifswald schwer zugänglichen italienischen Literatur gedankt.

46 Vgl. Maria J. Palla, Manger et boire au Portugal à la fin du Moyen Âge. (Senefiance, vol. 38.) Aix-enProvence 1996, 95-123, hier 104 ff.; Antonio H. de Oliveira Marques, A sociedade medieval Portuguesa. Aspectos de vida quotidiana. 4. Aufl. Lissabon 1981, 20 ff., 119 ff. mit dem Abdruck von Festschilderungen der Hochzeiten zwischen João I. und Philippa von Lancaster (Porto, 1396), Duarte I. und Leonore von Aragón (Coimbra, 1428), Alfonso und Isabella von Kastilien (Sevilla, 1490). Herm Jürgen Herold, Greifswald, sei herzlich für die Übersetzung der portugiesischen Quellentexte gedankt.

47 Die Schilderung beruht auf dem zeitgenössischen Bericht von Nikolaus Lanckmann von Falkenstein, der mit anderen Eleonore von Portugal abholte: Nikolaus Lanckmann von Falckenstein, Historia desponsationis et coronationis Friderici III. et conjugis ipsius Eleonorae, in: Scriptores Rerum Austriacarum. Hrsg. v. Heinrich Pez. Leipzig 1725, 569-606, hier 577 ff. Eine neuere Edition mit portugiesischer Übersetzung und Ergänzungen: Leonor de Portugal, Imperatriz da Alemanha. Diário de Viagem do Embaixador Nicolau Lanckmann de Valckenstein. Ed. Aires A. Nascimento. (Coleç̧ão Medievalia, vol. 6.) Lissabon 1992. Leider konnte ich im Nationalarchiv in Lissabon keine Quellen zu den Feierlichkeiten finden; in Gavreta 17, Maco 2 und 3, sind nur Urkunden und Quittungen im Umfeld des Ehevertrages überliefert. 
Das Modell ,Brügge' bezog die jeweilige Stadtbevölkerung mit ein, die einen aktiven Part bei der Ausschmückung zum Empfang und bei der inhaltlichen Gestaltung der allegorischen „tableaux vivants“ übernahm. Die Funktion des Einzugs als Huldigung und Anerkennung der Herrschaft vermischte sich mit dem Empfang der Braut und steigerte somit die Ausstrahlung und Pracht des Ereignisses. Diese Symbiose zwischen Fürst und Stadt ist übrigens bei den italienischen Stadtstaaten Bologna oder Ferrara noch auffálliger. ${ }^{48}$

Das Modell ,Landshut' war dagegen exklusiver auf den Adel ausgerichtet, da die Bürger nicht aktiv an den Feierlichkeiten teilnahmen. ${ }^{49}$ Insofern konnte eine deutsche Fürstenhochzeit auch in einer Stadt außerhalb des eigenen Territoriums stattfinden, was bei dem Festtypus ,Brügge‘ kaum denkbar war. ${ }^{50}$

Ein zweiter struktureller Unterschied bestand in der Zusammensetzung der eigentlichen Festgemeinschaft. Bei dem Modell ,Brügge' waren als Gäste so gut wie nie fürstliche Standesgenossen, sondern hauptsächlich die Angehörigen des Hofes und der Adel aus dem eigenen Territorium präsent. ${ }^{51}$ Dieser zur Teilnahme verpflichtete Zuschauerkreis war an die allegorische Überhöhung des Fürsten und seiner Dynastie gewöhnt. Da der Hof an allen Festen des Fürsten teilnahm, war aber leicht die Gefahr der Wiederholung oder gar der Langeweile bei ausbleibenden Überraschungseffekten gegeben. Insofern gab es zusătzlich zur Prestigekonkurrenz mit auswärtigen Höfen eine interne Steigerungsdynamik. Man kann sie

48 Bei der Hochzeit von Annibale Bentivoglio und Lucrezia d'Este 1487 diente die ganze Stadt Bologna als Bühne. Vgl. Gabriele Cazzola, „Bentivoli machinatores“. Aspetti politici e momenti teatrali di una festa quattrocentesca bolognese, in: Biblioteca teatrale 23/24, 1979, 14-38, hier 18 ff.; Tuohy, Herculean Ferrara (wie Anm. 45), 236 ff. Vgl. auch Ortner, Petrarcas „Trionfi“ (wie Anm. 12), 188, mit dem Hinweis, daß die neuaufgestiegenen Fürsten traditionelle Feste in eine persönliche Machtdemonstration umwandelten. Am Ende des 15. Jh. ănderte sich jedoch die Festpraxis: Das Fest verlagerte sich in Mailand, Mantua oder Urbino vom Platz vor der Kathedrale in das Schloß. Vgl. Pierre Racine, Fêtes à la cour de Ludovic le More, in: Fêtes et cérémonies (wie Anm. 14), 203-219, hier $216 \mathrm{f}$.

49 Selbst bei dem Adel wurde der Grad der Beteiligung nach dem Stand variiert, die Rolle der eingeladenen Stadtvertreter erschöpfte sich in der Überreichung von Geschenken. Vgl. Spieß, Kommunikationsformen (wie Anm. 12), $7 \mathrm{ff}$.

50 Vgl. Otto Reinhard Redlich, Die Hochzeit Herzogs Wilhelm IV. von Jülich-Berg mit Markgrăfin Sibilla von Brandenburg am 8.7.1481 in Köln, in: Zeitschrift des Bergischen Geschichtsvereins 37, 1904, 270-301; für weitere Beispiele vgl. Spieß, Familie (wie Anm. 3), 127.

51 Von Seggern, Herrschermedien (wie Anm. 22), 272 ff., hat den Kreis der Brugger Festgäste analysiert, der sich aus dem englischen Brautgefolge, fremden Kaufleuten und Gesandten sowie dem burgundischen Hof und Stăndevertretern aus Burgund zusammensetzte. Wie de la Marche (Memoires d'Olivier de la Marche [wie Anm. 31], 112) mitteilt, waren mit den Bischöfen von Metz, Verdun, Cambrai, Utrecht und Tournai nur geistliche Fürsten anwesend, wobei der von Cambrai als natürlicher Sohn des Herzogs Johann Ohnefurcht zur Familie gehörte. Die italienischen Festberichte zăhlen außer eventuell mitgereisten Angehörigen der Braut in der Regel nie Mitglieder der großen Familien Italiens als Festgäste auf, dagegen sandten zahlreiche Fürsten und Stădte Botschaften ,per honorare le nozze“; s. oben Anm. 45 und als weiteres Beispiel die Schilderung der Hochzeit von Gian Francesco Gonzaga und Isabella d'Este 1490 in Mantua bei Bernadino Zambotti, Diario Ferrarese dall'anno 1476 sino al 1504. Bearb. v. Guisepppe Pardi. (Muratori, Rerum Italicarum Scriptores, vol. 24/7/2.) Bologna 1937, $213 \mathrm{ff}$. Der einzige furstliche Gast war Guidobaldo von Montefeltro, der als Ehemann von Elisabetta Gonzaga zur engeren Familie gehörte. 
gut in Mailand ${ }^{52}$, Ferrara ${ }^{53}$, London ${ }^{54}$, aber vor allem in Burgund beobachten. Immer sollte ein Fest gefeiert werden, wie man es nie zuvor am Hof gesehen hatte. Die Brügger Hochzeit mußte deshalb die Selbstdarstellung auf die Spitze treiben, weil man das eigene Fasanenfest in Lille 14 Jahre zuvor zu überbieten hatte. ${ }^{55}$ Davor lagen das Bankett fur René von Anjou 1435 und die Hochzeit von Philipp dem Guten und Isabelle von Portugal im Jahr $1430^{56}$, davor wiederum im Jahr 1409 die Hochzeit Antons von Burgund mit Elisabeth von Görlitz. ${ }^{57}$ Jedesmal steigerte man den Aufwand, um den Hof zu überraschen, den gewachsenen Status nach außen zu demonstrieren und die eigene Herrschaft im Land zu festigen.

Warum fehlten in Mailand 1468 die Gonzaga oder d'Este, warum der Herzog von der Bretagne, der von Savoyen oder die Anjou in Brügge? Offenbar weil diese Feste so sehr die Erhőhung des Gastgebers und seiner Braut in den Vordergrund stellten, daß die Anwesenheit von Standesgenossen oder gar Ranghöheren nicht opportun war. Als Ersatz für persönliche Präsenz dienten Gesandtschaften. ${ }^{58}$ Die sinnlich wahmehmbare Pracht zielte in erster Linie auf den eigenen Hof und das eigene Territorium. Für die Propaganda nach außen sorgten dagegen die mündlichen Berichte der Gesandten oder spezielle Festberichte. ${ }^{59}$

52 Die Prachtsteigerung zwischen der Hochzeit Galeazzo Sforzas (1468) und der Ludovico Sforzas (1491) ist augenfallig. Vgl. Lubkin, A Renaissance Court (wie Anm. 45), 49 ff., und Racine, Fêtes (wie Anm. 48), 204, 211 f. Die Quellen zur Hochzeit von 1491, die durch die Beteiligung von Leonardo da Vinci an der Gestaltung bekannt geworden ist, sind jetzt bequem zugănglich: Festa di Nozze per Ludovico il Moronelle testimonianze di Tristano Calco, Giacomo Trotti, Isabella d'Este, Gian Galeazzo Sforza, Beatrice de' Contrari, e altri. Ed. Guido Lopez. Mailand 1976.

53 Di Pascale, Banchetti (wie Anm. 45).

54 Sydney Anglo, Spectacle, Pageantry, and Early Tudor Policy. Oxford 1969, zeichnet sehr gut die Steigerung von Heinrich VII. auf Heinrich VIII. nach.

55 Lafortune-Martel, Fête (wie Anm. 14).

56 Vgl. Richard Vaughan, Philip the Good. The Apogee of Burgundy. London 1970, $142 \mathrm{ff}$;; Claudine Lemaire/Michèlle Henry, Isabella de Portugal, Duchesse de Bourgogne, 1397-1471. Brüssel 1991, $31 \mathrm{ff}$. , hier 31: „Philippe voulut donner à son troisième mariage plus d'éclat qu'aux deux premiers.“

57 Vgl. Chevalier-de Gottal, Les fêtes (wie Anm. 14), 116 ff. Zuvor war bereits von Philipp dem Kühnen eine prächtige Hochzeitsfeier für seinen zweiten Sohn Antoine in Arras veranstaltet worden, für die allerdings nur die Rechnungen vorliegen. Vgl. Marie-Thérèse Caron, Une fête dans la ville en 1402: le mariage d'Antoine comte de Rethel à Arras, in: Villes et sociétés urbaines au Moyen Âge. Hommage à Monsieur le Professeur Jacques Heers. (Cultures et civilisations médiévales, vol. 11.) Paris 1994, 173-183.

58 Vgl. die Nachweise in Anm. 45 und 51. Als weiteres Beispiel sei die Hochzeit von Roberto Malatesta und Elisabetta von Montefeltro 1475 in Rimini angefuhrt. Der Brăutigam ,mandò suoi mandati a invitare tutte le Potenze d'Italia e Baroni, e gran Signori“, aber statt des im folgenden genannten Königs von Neapel, Herzogs Galeazzo von Mailand, Herzogs Ercole d'Este und des Markgrafen von Mantua usw. kamen nur deren Botschaften. Man kann sich auch kaum vorstellen, daß Galeazzo Sforza an der Seite von Roberto Malatesta durch die für den Brăutigam in Rimini errichteten Triumphbögen geschritten wăre. Besonders geehrt wurde der einzige anwesende Fürst, der Herzog von Urbino, bei dem es sich allerdings um den Brautvater handelte. Vgl. Tonini, Rimini (wie Anm. 45), 351 ff., mit Auszilgen aus dem Festbericht von Broglio und Helas, Lebende Bilder (wie Anm. 12), 147 f.

59 Zur Verbreitung dieser Berichte am Beispiel der Brügger Hochzeit von 1468 vgl. Paravicini, Die zwölf „Magnificences“ (wie Anm. 22), 12 f., und von Seggern, Herrschermedien (wie Anm. 22), 265 ff. 
In krassem Gegensatz zu den um die triumphale Inszenierung eines einzelnen Fürsten kreisenden Festgemeinschaften an den genannten Höfen stehen die deutschen Fürstenhochzeiten, die den seltenen Anlaß zur persönlichen Begegnung zahlreicher Reichsfürsten mitsamt ihren Familien lieferten. Zu diesen Festen wurde man nicht verpflichtend eingeladen ${ }^{60}$, sondern es handelte sich um eine freiwillige Zusammenkunft einer Gruppe von Standesgenossen, die in Landshut über dreißig und in Amberg über zwanzig Personen umfaßte. ${ }^{61}$ Zwar stand die gastgebende Dynastie im Mittelpunkt, aber der Ausrichter des Festes durfte die Selbstdarstellung nicht auf die Spitze treiben, wollte er die Mitfürsten nicht verprellen. Die fürstlichen Gäste erhielten deshalb genügend Freiraum zur eigenen Repräsentation, die sich in der Größe und qualitativen Zusammensetzung ihres Gefolges ausdrückte. Jeder Fürst versuchte, seine Bedeutung mit Hilfe seiner Klientel zu demonstrieren, indem er möglichst viele Grafen und Freiherren, Ritter und Edelknechte in seinen Farben gekleidet mit sich fuhrte. ${ }^{62}$ Kurfürst Albrecht Achilles von Brandenburg hat diese Absicht im Vorfeld der Landshuter Hochzeit in der Einladung an Graf Ludwig von Isenburg-Büdingen, mit ihm dort als sein Gefolgsmann zu feiern, deutlich artikuliert: Er wolle sehr köstlich und stattlich zur Hochzeit kommen ,als der freundt, der auch gesehen will werden. ${ }^{663}$ Kaum eine deutsche Hochzeitsbeschreibung verzichtet deshalb auf eine Aufzăhlung der jeweiligen fürstlichen Gefolgsleute, die genau nach ihrem Rang geordnet werden. Die Selbstdarstellung der furrstlichen Gäste durch ihr Gefolge ist auch der Grund für die hohen Teilnehmerzahlen. Da der Gastgeber den Gästen nicht die Zahl der Begleiter vorschreiben konnte und wollte ${ }^{64}$, multiplizierte jeder eingeladene Fürst die Zahl der Anwesenden beträchtlich. Die Vermutung Harm von Seggerns, in Amberg und Landshut habe man durch die hohe Zahl der Teilnehmer die Brügger Hochzeit übertrumpfen wollen ${ }^{65}$, trifft deshalb nicht den Kern des Problems.

Warum ließen sich die Fürsten bei den Hochzeiten nicht durch die aufwendigen „entremets" und die Theaterauffuihrungen unterhalten, sondern begnügten sich mit den traditionellen Schauessen und deren Überraschungspotential? Der Grund kann nicht der Mangel an

60 Vgl. Werner Paravicini, Invitations au mariage. Pratique sociale, abus de pouvoir, interêt de l'état à la cour des ducs de Bourgogne au XV siècle, in: Académie des Inscriptions et Belles-Lettres. Comptes rendus 1995. Paris 1995, 687-711.

61 König Matthias Corvinus von Ungarn, der 1476 als Aufsteiger den Hochadel durch seine prunkvolle Hochzeit mit Beatrix von Neapel beeindrucken wollte, ließ sich die Einladungen an die Könige und Fürsten Europas über $20000 \mathrm{fl}$. kosten. Von den sämtlich geladenen geistlichen und weltlichen Fürsten Deutschlands kam mit Herzog Christoph von Bayern nur ein einziger, der zudem kein Regent war. Vgl. Peter Eschenloer's, Stadtschreibers zu Breslau, Geschichten der Stadt Breslau oder Denkwürdigkeiten seiner Zeit vom Jahre 1440 bis 1479. Bd. 2. Hrsg. v. Peter Eschenloer/Johann Gottlieb Kunisch. Breslau 1828, 340, und die Teilnehmerliste in: Beyträge (wie Anm. 29), Bd. 3. München 1790, 120.

62 Vgl. Spieß, Kommunikationsformen (wie Anm. 12), 4.

63 Politische Correspondenz (wie Anm. 43), Nr. 152, 178 Anm. 1.

64 Vgl. Hiereth, Herzog Georgs Hochzeit (wie Anm. 29), 33. Vgl. auch die Überlegungen Markgraf Johanns von Brandenburg, wieviele Begleitpersonen die zu seiner Hochzeit eingeladenen Fürsten wohl mitbringen könnten. Codex diplomaticus Brandenburgensis. Hrsg. v. Adolph Friedrich Riedel. 3. Hauptteil. Bd. 2, Berlin 1860, Nr. 107, 141.

65 Von Seggern, Herrschermedien (wie Anm. 22), 294. 
Information ubber diese Festmedien gewesen sein, denn schließlich war der in Urach auftretende Bräutigam Graf Eberhard von Württemberg zuvor schon zweimal in Italien gewesen und hatte am Hof seiner Frau Barbara Gonzaga in Mantua Gelegenheit zum Kennenlernen anderer Festformen gehabt. ${ }^{66}$ Ebenso hătte man in Heidelberg bzw. Amberg durchaus von der Brügger Hochzeit erfahren können. ${ }^{67}$ Auch Matthias Corvinus verzichtete 1476 bei seiner Heirat mit Beatrix von Neapel auf diese Festelemente, obwohl schon vorher enge Beziehungen zu Italien bestanden. ${ }^{68}$

Für die Zurückhaltung gegenüber aufwendigen theatralischen Effekten muß es deshalb andere Gründe gegeben haben. Einer liegt offenbar in der unterschiedlichen Struktur der Höfe begründet. Solche Intermedien machten ja nur Sinn, wenn sie von allen Festbesuchern verfolgt werden konnten. Bei den Hochzeiten nach dem Modell ,Brügge' war dies der Fall, weil sich alle Gäste in einem Raum befanden. Bei den deutschen Fürstenhochzeiten saßen das Hochzeitspaar und die Gäste jedoch selbst bei dem zentralen Festbankett nach dem Geschlecht getrennt in unterschiedlichen Raumen. ${ }^{69}$

Die Ursache hierfur kann kaum logistischer Art gewesen sein. Zwar gab es Raumprobleme, aber man hätte sicher auch wie in Brügge und Lissabon ein Holzhaus bauen und dort eine gemeinsame Tafel installieren können. Die Aufteilung der Festgemeinschaft ist offenbar bewußt erfolgt, weil auch ansonsten die Frauen im Frauenzimmer separat am Hofleben teilnahmen. In den zeitgenössischen Quellen gibt es immer wieder Hinweise darauf, wie streng abgeschlossen die Frauenzimmer an den deutschen Höfen waren und wie frei sich die Frauen im Vergleich dazu an den Höfen in Italien und Frankreich bewegen konnten. ${ }^{70}$ Nur der Tanz

66 Peter Amelung/Wolfgang Irtenkauf, Person und Familie Graf Eberhards im Bart, in: Württemberg im Spătmittelalter (wie Anm. 18), $11 \mathrm{ff}$.

67 Gesandte Pfalzgraf Friedrichs I. waren in Brügge anwesend. Vgl. von Seggern, Herrschermedien (wie Anm. 22), 277. Bei „Frederik le Palatin“, den Olivier de la Marche als Teilnehmer einer Turniergruppe nennt, kann es sich schon wegen des fehlenden Titels und des rangniedrigen Umfeldes nicht um den Kurfürsten selbst handeln, wie Martina Backes, Das literarische Leben am kurpfälzischen Hof zu Heidelberg im 15. Jahrhundert. (Hermaea NF., Bd. 68.) Tübingen 1992, 40, meint. Siehe Memoires d'Olivier de la Marche (wie Anm. 31), 193. Es handelt sich in Wirklichkeit um den pfalzischen Ritteradeligen Friedrich von Flersheim, der längere Zeit am burgundischen Hof weilte. Vgl. demnächst Paravicini, Adelskultur (wie Anm. 25).

68 Vgl. die in Anm. 61 genannten Festberichte und den Katalog: Matthias Corvinus und die Renaissance in Ungarm 1458-1541. (Katalog des Niederösterreichischen Landesmuseums NF., Bd. 118.) Wien 1982.

69 Vgl. Hiereth, Herzog Georgs Hochzeit (wie Anm. 29), 64 ff.; Amelung, Festlichkeiten (wie Anm. 18), 71; Buchner, Quellen (wie Anm. 27), 420 f. Vgl. auch den Bericht eines kastilischen Adeligen über eine Hochzeit am Hofe König Albrechts II. 1438 in Breslau: „Es war um die Abendzeit, als man sich zur Tafel setzte; die Damen speisten für sich und der Neuvermăhlte mit den Herren." In: Karl Stehlin/'Rudolf Thommen, Aus der Reisebeschreibung des Pero Tafur, 1438 und 1439, in: BaslerZ 25, 1926, 45-107, hier 91.

70 Maximilian I. schildert offenbar erstaunt nach seiner Ankunft in Burgund die Bewegungsfreiheit der Hofdamen: Daz frawenzimmer nichts bey den tag verspert die nacht uber. es ist daz gantz haus vol iung frowen und frowen bey XL. sie muegen auch den gantzen taag uberahl im haus umblauffen. 
löste die Distanz fur kurze Zeit auf. Es mußte also in Deutschland erst ein Mentalitätswandel in bezug auf die Anwesenheit von Frauen bei den Banketten erfolgen, bevor man einem gemeinsamen Festpublikum aufwendige „entremets“ oder Theaterstücke präsentieren konnte. Die Schauessen bei den Fürstenhochzeiten konnten dagegen von allen Teilnehmern bewundert werden, weil sie durch die Räume getragen wurden. ${ }^{71}$

Ein zweiter Grund fur das Fehlen dieser theatralischen Elemente liegt möglicherweise noch viel tiefer. Die Hochzeiten dienten den Fürsten zur zeremoniellen Selbstdarstellung und Selbstvergewisserung. Zwar waren die anwesenden Adeligen insgesamt in die Choreographie des Festes einbezogen, aber die maßgeblichen Handlungsträger waren die Fürsten allein. ${ }^{72}$ Bei dem Betrachten eines Schauspiels wären die Fürsten jedoch zu passiven Rezipienten geworden. Selbst wenn die auf der Bühne ablaufenden Szenen der eigenen Verherrlichung dienten, änderte dies nichts daran, daß ein Fürst auf diese Weise vom Geschehen ausgegrenzt, zum bloßen Zuschauen gezwungen wurde. ${ }^{73}$ Die spätmittelalterlichen Reichsfursten wollten aber selbst Akteure sein und nicht Zuschauer. Sie gestalteten deshalb das Fest gemeinschaftlich in eigener Person. So fungierte in Landshut Albrecht von Achilles als Zeremonienmeister der Fürsten bei dem Empfang der Braut, organisierten die Fürsten den Tanzwettbewerb oder folgten in Amberg der Anweisung einer Fürstin und probierten deren originelle Neuschöpfung aus, genauso wie sie selbstverständlich persönlich am Turmier teilnahmen. Bei dem Festtyp ,Landshut' standen demnach die Fürsten im Zentrum, sie unterhielten sich selbst und feierten sich selbst in der Gemeinschaft. Bei dem Modell ,Brügge' dagegen war alles auf das gastgebende Fürstenpaar und dessen Glorifizierung ausgerichtet. Als Mittel dieser Verherrlichung dienten die „Lebenden Bilder“ bei dem Einzug, vor allem aber die Auffuhrungen bei den Banketten, die deshalb immer neue Spektakel bieten mußten. Wie sehr in Burgund das Zuschauen im Vordergrund stand, zeigt die Einrichtung von Zuschauergalerien im Festsaal. ${ }^{74}$

Eine weitere wichtige Funktion kam der deutschen Fürstengemeinschaft als Zeuge und Umstand bei den Rechtsakten Trauung und Beilager zu, während bei den burgundischen und italienischen Hochzeiten die Trauung in den Hintergrund trat und das formelle Beilager ganz fehlte. ${ }^{75} \mathrm{Da}$ in erster Linie nur die Fürsten Zugang zu dem Raum besaßen, in dem das Beilager stattfand ${ }^{76}$, wurde deren tragende Rolle bei dem Fest noch einmal betont. Für die deut-

Maximilians I. vertraulicher Briefwechsel mit Sigmund Pruschenk Freiherm zu Stettenberg. Hrsg. v. Victor von Kraus. Innsbruck 1875, 28. Vgl. hierzu auch Spieß, Brautfahrt (wie Anm. 4), 32 f.

71 Vgl. Hiereth, Herzog Georgs Hochzeit (wie Anm. 29), 27; Buchner, Quellen (wie Anm. 27), 421.

72 Vgl. Spieß, Kommunikationsformen (wie Anm. 12), 7 ff.

73 Vgl. zu dieser Problematik am Beispiel der Rolle des Fürsten im zentralperspektivischen Illusionstheater der Barockzeit Jörg Jochen Berns, Die Festkultur der deutschen Höfe zwischen 1580 und 1730.

Eine Problemskizze in typologischer Absicht, in: Germanisch-Romanische Monatsschrift NF. 34, 1984, 295-311, hier $307 \mathrm{ff}$.

74 Vgl. Lafortune-Martel, Fête (wie Anm. 14), 84 f.

75 Immerhin informierte Galeazzo Sforza seine Hofleute brieflich über Zeit und Ort des Ehevollzugs mit Bona von Savoyen. Vgl. Lubkin, Court (wie Anm. 45), 53.

76 Vgl. Enke, Deutsche höfische Festlichkeiten (wie Anm. 12), 65 f.; Hiereth, Herzog Georgs Hochzeit (wie Anm. 29), 58, 97; Buchner, Quellen (wie Anm. 18), 418; Politische Correspondenz (wie 
schen Fürstenhochzeiten trifft offensichtlich die These von Herfried Münkler zu, wonach erst an der Wende vom Spätmittelalter zur Fruhen Neuzeit die zeremonialisierte Macht, bei der die Machtausübenden stets Akteure in einem vorgegebenen Regelsystem blieben, überlagert worden sei durch eine instrumental-strategische Machtvisualisierung, die auf die eine Seite Akteure und auf die andere Seite Zuschauer treten ließ. ${ }^{77}$ Diese Visualisierung der Macht des gastgebenden Fürsten ließ sich - das sei nochmals betont - leichter bewerkstelligen, wenn er selbst der ranghöchste Zuschauer war, während bei einem von Standesgenossen getragenen Fest in dieser Hinsicht Widerstände zu erwarten gewesen wären. Es bedurfte offenbar des gesteigerten Souveränitătsbewußtseins der deutschen Fürsten im 16. Jahrhundert, um diese Barriere vor einer Selbstüberhöhung zu überwinden ${ }^{78}$ Möglicherweise ist dies ein Grund dafur, daß sie nur selten noch persönlich an den Hochzeiten ihrer Standesgenossen teilnahmen, sondern jetzt auch wie bei dem Festtyp ,Brugge' Gesandtschaften schickten.

Um 1500 scheint dagegen die alte Festpraxis noch zu bestehen. Die Torgauer Hochzeit von 1500 verlief in den vorgezeichneten Bahnen. Man begann wie gewohnt am Sonntag, speiste immer noch getrennt und ergötzte sich an den Schauessen; allerdings turnierte man einen Tag länger und schmückte die Räume mit Tapisserien. Zwanzig Mitglieder des Fürstenstandes, die ein Gefolge von 10500 Pferden aufgeboten hatten, bezeugten die Trauung und das Beilager. ${ }^{79}$ Ein Blick auf die 1502 in Ferrara gefeierte Hochzeit zwischen Alfonso d'Este und Lucrezia Borgia demonstriert noch einmal die Gleichzeitigkeit des Ungleichzeitigen. Beim Einritt in die Stadt wurde die Braut mit antikisierenden Triumphbögen und Vorfuhrungen geehrt, 110 Schauspieler traten in den funf Komödien des Plautus auf, die neben lustigen Zwischenspielen an den Abenden vorgefuhrt wurden, und anstelle eines Turniers der Festteilnehmer fuhrten zwei Ritter auf der Piazza einen Schaukampf durch. ${ }^{80}$

Eine Annäherung der beiden Festmodelle fand erst in der zweiten Hälfte des 16. Jahrhunderts statt, wobei die Mittlerfunktion Maximilians und besonders Karls V. in

Anm. 43), Nr. 238, 253-259, hier 255, 258 f. Bezeichnenderweise lautet die zeitgenőssische Bezeichnung für die Fürstenhochzeit „Beilager“.

77 Vgl. Herfried Münkler, Die Visibilităt der Macht und Strategien der Machtvisualisierung, in: Macht der Öffentlichkeit - Öffentlichkeit der Macht. Hrsg. v. Gerhard Göhler. Baden-Baden 1995, 213-230, hier $220 \mathrm{f}$.

78 Vgl. Rainer A. Müller, Der Fürstenhof in der Frühen Neuzeit. (EdG, Bd. 33.) München 1995, 8 ff.; Ernst Schubert, Fürstliche Herrschaft und Territorium im spăten Mittelalter. (EdG, Bd. 35.) München 1996, $82 \mathrm{ff}$.

79 Der Festbericht und ergănzende Akten befinden sich im Thüringischen Hauptstaatsarchiv Weimar, Ernestinisches Gesamtarchiv, Reg. D. 46. Ein Abdruck des Festberichts in: Neu eröffnetes Historisches und Politisches Archiv. Hrsg. v. Burcard Gotthelf Struve. Teil 1. Jena 1718, 48-114. Vgl. auch Carl August Hugo Burkhardt, Die Vermăhlung des Herzogs Johann von Sachsen 1. bis 5. Mărz 1500, in: Neues Archiv für Sächsische Geschichte und Altertumskunde 15, 1894, 283-298.

80 Vgl. den ausfuhrlichen zeitgenössischen Bericht von Sanuto, in: I diarii di Marino Sanuto. Ed. Nicolò Barozzi. Vol. 4. Venedig 1880, Sp. 222-230, und die englische Übersetzung bei James Dennistoun, Memoirs of the Dukes of Urbino from 1440 to 1640. Vol. 1. London 1851, 441-448. Weiterhin den Bericht von Zambotti, Diario Ferrarese (wie Anm. 51), 318 ff. Für weitere Details und den politischen Kontext vgl. Maria Bellonci, Lucrezia Borgia. La sua vita e i suoi tempi. Verona 1960, $198 \mathrm{ff}$. 
Rechnung zu stellen ist, dessen antik-mythologische Einzüge stilbildend wirkten. ${ }^{81}$ Die berühmte Münchner Fürstenhochzeit von 1568 setzte mit dem Feuerwerk, mit den Triumphbögen, die die Wittelsbacher als Nachfahren des Aeneas feierten, mit dem Auftritt römischer Konsuln bei dem Turnier, besonders aber mit der von Jesuiten aufgefuhrten Tragödie auf der Basis des Samsonstoffes, die durch die Chöre Orlando di Lassos in ihrer Wirkung verstärkt wurde, neue Maßstăbe für die höfischen Feste in Deutschland. ${ }^{82}$ Dennoch hielt diese Hochzeit nicht den Vergleich mit den zeitgenössischen italienischen aus, so daß man in Dresden 1589 noch einen Schritt weiterging und mit Nossini einen italienischen Festarrangeur verpflichtete. ${ }^{83}$ Damit sind wir aber schon an der Schwelle zur Barockzeit angelangt.

Der Vergleich der europăischen Fürstenhochzeiten erwies die Existenz zweier verschiedener Festmodelle. Als Gründe dafür sind zu nennen: die andersartige Einbeziehung der Stadtbevölkerung, die Unterschiede bei der Integration der Frauen in die Hofgesellschaft, die Zusammensetzung der Festgemeinschaften sowie eine andere Auffassung vom Fürstentum. Es ist wohl kein Zufall, daß die neuen Festmedien in erster Linie von Aufsteigern in Italien und Burgund zur Legitimation ihrer Macht genutzt worden sind. ${ }^{84}$ So wie König Ludwig XI. von Frankreich es sich leisten konnte, weit hinter der Prachtentfaltung des burgundischen Herzogs zurückzubleiben ${ }^{85}$, so haben vielleicht auch die deutschen Fürsten gelassen auf den Glanz der Malatesta oder Sforza reagiert. Man sollte künftig die Andersartigkeit der deutschen Fürstenhochzeiten nicht mehr einseitig als Rückständigkeit

81 Vgl. Enke, Deutsche höfische Festlichkeiten (wie Anm. 12), 54 ff.; Strong, Feste (wie Anm. 13), 136 ff.; Pierre Du Colombier, Les triomphes de l'empereur Maximilien I ${ }^{\text {er }}$, in: Fêtes et cérémonies au temps de Charles Quint. Ed. Jean Jacquot. Paris 1960, 99-112; Sydney Anglo, Le Camp du Drap d'Or et les entrevues d'Henri VIII et de Charles Quint, in: ebd., 113-134.

82 Es existiert ein sehr detaillierter Festbericht: Die Münchner Fürstenhochzeit von 1568. Massimo Troiano: Dialoge. Hrsg. v. Horst Leuchtmann. München/Salzburg 1980, mit einem ausfuhrlichen Nachwort: $418 \mathrm{ff}$. Zur Einordnung des Festes vgl. Berndt Ph. Baader, Der bayerische Renaissancehof Herzog Wilhelms V. (1568-1579). Ein Beitrag zur bayerischen und deutschen Kulturgeschichte des 16. Jhdts. (Akademische Abh. zur Kulturgeschichte V, Bd. 3.) Leipzig/Straßburg 1943, 33 ff.; Eberhard Straub, Repraesentatio Maiestatis oder churbayerische Freudenfeste. Die höfischen Feste in der Münchner Residenz vom 16. bis zum Ende des 18. Jahrhunderts. (Miscellanea Bavarica Monacensia, Bd. 14.) München 1969, $147 \mathrm{ff}$. Die Vorbildwirkung entfaltete sich schon 1571 bei der Hochzeit Karls II. von Innerösterreich mit Maria von Bayern in Wien. Vgl. Vocelka, Hochzeiten (wie Anm. 16), $55 \mathrm{ff}$.

83 Vgl. Straub, Repraesentatio (wie Anm. 82), 157 f.

84 Vgl. Paravicini, Die zwölf "Magnificences“ (wie Anm. 22), 53 f., der außer Karl dem Kühnen, Galeazzo und Ludovico Sforza Lorenzo de' Medici, Ercole d'Este und Eduard IV. von England namentlich nennt. Für England wăre auch noch der erste König aus dem Haus Tudor, Heinrich VII., anzufuhren. Vgl. Anglo, Spectacle (wie Anm. 54), 1, der Heinrich VII. als „a moderately obscure magnate" bezeichnet; und Kipling, Triumph (wie Anm. 11), $5 \mathrm{ff}$.

85 Vgl. Paravicini, Die zwölf „Magnificences“ (wie Anm. 22), 54. Demnăchst Werner Paravicini, Königliche Schlichtheit und herzogliche Pracht: Ludwig XI. und Karl der Kühne im Vergleich, in: Principes. Dynastien und Hőfe im spăten Mittelalter. Hrsg. v. Cordula Nolte/Karl-Heinz Spieß/RalfGunnar Werlich. Sigmaringen 2002. 
interpretieren ${ }^{86}$ Viele Aspekte des Themas konnten allerdings gar nicht angesprochen werden. So wurde die soziale Kohäsion der deutschen Fürsten sicher dadurch gefördert, daß sie auch bei den Hof- und Reichstagen gesellig miteinander verkehrten ${ }^{87}$ und vor allem auch eine politische Handlungsgemeinschaft bildeten ${ }^{88}$ Außerdem wären die Unterschiede bezüglich der persönlichen Gefährdung der Teilnehmer bei den welschen und deutschen Turmieren und ihre Auswirkungen auf die Festatmosphäre zu prüfen. ${ }^{89}$ Weitere Festbeschreibungen müssen erst noch ediert und deren interdisziplinäre Untersuchung vorangetrieben werden, ehe man zu den Ergebnissen für die höfischen Feste des Spätmittelalters gelangt, wie sie für die Renaissancefeste bereits vorliegen.

86 Vgl. die in Anm. 18 zitierten Aussagen.

87 Vgl. Albrecht Pius Luttenberger, Pracht und Ehre. Gesellschaftliche Repräsentation und Zeremoniell auf dem Reichstag, in: Alltag im 16. Jahrhundert. Studien zu Lebensformen in mitteleuropäischen Stădten. Hrsg. v. Alfred Kohler/Heinrich Lutz. (Wiener Beitrăge zur Geschichte der Neuzeit, Bd. 14.) München 1987, 291-326.

88 Vgl. Ernst Schubert, König und Reich. Studien zur spätmittelalterlichen deutschen Verfassungsgeschichte. (VMPIG, Bd. 63.) Gőttingen 1979, 297 ff.; Karl-Friedrich Krieger, Konig, Reich und Reichsreform im Spätmittelalter. (EdG, Bd. 14.) München 1992, 37 ff., 46 f.

89 Vgl. Enke, Deutsche höfische Festlichkeiten (wie Anm. 12), 68 ff. 



\title{
Auf der Suche nach der nationalen Identität im Mittelalter
}

\author{
Der Fall Polen
}

Von

Jerzy Strzelczyk

Polen ist heutzutage weitgehend ein Einvölkerstaat, der Anteil anderer Nationalitäten ist gering. Der jetzige Zustand ist das Nebenergebnis des Zweiten Weltkrieges und von dessen politischen und ethnisch-demographischen Folgen. In der Zwischenkriegszeit (1918-1939) war die Situa-

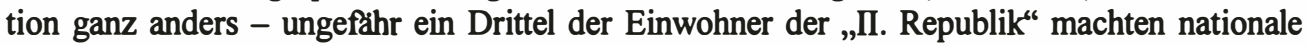
Minderheiten aus, vor allem die Ukrainer, Juden, Litauer, Weißruthenen und Deutschen. In der altpolnischen Zeit, bis zum Untergang der polnisch-litauischen Adelsrepublik am Ende des 18. Jahrhunderts, war die Lage zeitlich und răumlich wechselnd. Dasselbe betrifft die ethnischen Verhältnisse im Mittelalter, die das Thema dieses Vortrags sind.

Die Geschichte Polens im Mittelalter läßt sich klar in zwei Hauptperioden gliedern: die der Herrschaft der Piastendynastie (bis 1370) und die der Herrschaft des Hauses Anjou (13701386) und Jagiellonen (1386-1572). Während fast der gesamten Piastenperiode war Polen in ethnischer wie in konfessioneller ${ }^{1}$ Hinsicht ein weitgehend einheitlicher Staat.

Es muß einfuhhrend etwas über die Quellenlage gesagt werden. Ihre prinzipiellen Mängel sind wohl allgemeineuropäischer Natur, im Falle Polens vor dem 15. Jahrhundert sind sie jedoch besonders gravierend. Ich meine damit sowohl das äußerste Defizit der Quellen, wie auch deren soziale und regionale Einschränkungen. Andererseits: Trotz vielen Spezialarbeiten und einer begrenzten Anzahl von mehr synthetisierenden Versuchen allgemeinen Charakters wăre

1 Die konfessionelle Problematik, obwohl wichtig, wird hier nur am Rande behandelt; Näheres in: Jerzy Strzelczyk, Auf dem Wege zur Republik vieler Völker und Konfessionen. Katholiken und Orthodoxe in Polen im späten Mittelalter, in: Toleranz im Mittelalter. Hrsg. v. Alexander Patschovsky/Harald Zimmermann. (VuF, Bd. 45.) Sigmaringen 1998, 275-295. Zu einem anderen, gleichwohl in diesem Aufsatz nur kursorisch behandelten Problem: ders., Die Wahmehmung des Fremden im mittelalterlichen Polen, in: Die Begegnung des Westens mit dem Osten. Kongreßakten des 4. Symposions des Mediävistenverbandes in Köln 1991 aus Anlaß des 1000. Todesjahres der Kaiserin Theophanu. Hrsg. v. Odilo Engels/Peter Schreiner. Sigmaringen 1993, 203-220. 
es schwer, den Forschungsstand als einigermaßen befriedigend zu bezeichnen ${ }^{2}$, und was den Stand der Erforschung des 15. Jahrhunderts betrifft, läßt er besonders viel zu wünschen übrig. Die wichtigste und in bezug auf die früheren Entwicklungsphasen praktisch einzige Quellengruppe, die die Erforschung der Selbstbewußtwerdungs-Prozesse im mittelalterlichen Polen überhaupt möglich macht, sind erzăhlende Quellen - Historiographie und Hagiographie, erst langsam wird zunehmend der Anteil solcher Quellenarten wie Urkunden (Intitulationen und Arengen $^{3}$ ), Siegel ${ }^{4}$, Münzen, plastische Darstellungen, im 15. Jahrhundert auch des theoretischen und politischen Schriftums ${ }^{5}$, der staatlichen und synodalen Gesetzgebung usw. bemerkbar.

\section{Ursprüngliche Einheit}

Bis etwa zur Mitte des 13. Jahrhunderts war Polen in ethnischem Sinne ein Einheitsstaat. ${ }^{6}$ Die sprachliche, nationale und religiöse Einheit der polnischen Gesellschaft wurde in nur geringfügigem Maße durch die damals nicht sehr zahlreichen jüdischen Gemeinden durchbrochen, die ausschließlich in größeren Städten zu finden waren und die sich von der Außenwelt in eigenen Ortsgemeinden ghettoartig abschlossen. Seit der zweiten Hälfte des 12. Jahrhunderts, und in weitaus größerem Umfang dann im 13. Jahrhundert, tauchte hingegen - insbesondere in Schlesien - auf dem Lande wie vor allem in den Städten das deutsche Element auf. Diesem Element schreibt man nicht ohne Grund eine bedeutende Rolle zu, sei es in wirtschaftlich-organisatorischer Hinsicht oder auch im Hinblick auf die nationale Selbstfindung des polnischen Staatsvolkes, das sich der eigenen Identität in dem Maße bewußt wurde, wie es die deutschen Siedler als Kontrast zur eigenen Lebensweise kennenlernte. Das Empfinden von Selbst- und Anderssein verband sich naturgemäß nicht selten mit Abneigung gegen die Fremden, die im Vergleich mit der abhängigen einheimischen Bevölkerung rechtlich bessergestellt waren und zudem anfangs in weitgehender Isolation von der polnischen Bevölkerung lebten.

Abgesehen von der jüdischen Bevölkerung haben diese Wandlungen zu keiner konfessionellen Differenzierung innerhalb der polnischen Territorien gefuhrt, denn in dieser Hinsicht gab es zwischen Polen und Deutschen natürlich keine größeren Unterschiede, sieht man einmal von geschichtlich oder regional bedingten Differenzen ab, wie der in Polen traditionellen Verpflich-

2 Als eine durchaus nützliche (vor allem für nichtpolnische Forscher), wenn auch thematisch begrenzte Einführung in die Probleme der mittelalterlichen Historiographie Polens kann hier auf den Polen betreffenden Teil der Monographie Norbert Kersken, Geschichtsschreibung im Europa der „nationes“. Nationalgeschichtliche Gesamtdarstellungen im Mittelalter. (Münstersche Hist. Forsch., Bd. 8.) Köln/Weimar/Wien 1995, verwiesen werden.

3 Vgl. neuestens den ersten Versuch, die Arengen der polnischen Herrscherurkunden als mentalitătsgeschichtliche Quelle zu erforschen: Tomasz Nowakowski, Idee areng dokumentów książąt polskich do połowy XIII wieku. Bydgoszcz 1999.

4 Vgl. Zenon Piech, Ikonografia pieczęci Piastów. Kraków 1993.

5 Unter einem wichtigen Aspekt vgl. zuletzt: Thomas Wünsch, Konziliarismus und Polen. Personen, Politik und Programme aus Polen zur Verfassungsfrage der Kirche in der Zeit der mittelalterlichen Reformkonzilien. (Konziliengeschichte, Rh. B: Untersuchungen, Bd. 7.) Paderborn u. a. 1998.

6 In diesem Teil wiederhole ich teilweise meine Erörterungen aus dem ersten in Anm. 1 zitierten Aufsatz. 
tung zur Zahlung des Peterspfennigs oder auch den von den deutschen Usancen abweichenden Fasttagsregelungen. Die Wahmehmung solcher Unterschiede konnte indessen sehr wohl zu einer Vertiefung des Gefuhls der Fremdheit beitragen.

Polen zur Zeit der Piastenherrschaft kannte im Prinzip auch nicht das Problem der Ketzerei und - abgesehen von der heidnischen Reaktion in den dreißiger Jahren des 11. Jahrhunderts der Apostasie. ,Ketzereien' der Waldenser und der Beginen kamen in Polen in vorhussitischer Zeit nur vereinzelt vor, konzentriert auf Schlesien, und stellten weder furr die polnische Kirche als Institution noch für die Gläubigen als Personen eine wirkliche Herausforderung dar. Dies um so weniger, als die vermutlich ohnehin nicht sehr zahlreichen Anhänger dieser Bewegungen aller Wahrscheinlichkeit nach aus den Kreisen der Einwanderer aus dem Westen stammten und offenbar kaum Kontakte zu der polnischen Umgebung besaßen. Das Problem der „Apostaten“ - Ruthenen und Armenier - gewann erst nach dem Anschluß Rutheniens an Polen Bedeutung, also erst unter der Herrschaft von Kasimir dem Großen und besonders dann nach dem Abschluß der Union mit Litauen. Das Hussitentum erschien noch später und hatte in Polen eine nur zweitrangige Bedeutung

\section{Selbstbestimmungsfaktoren}

Die Voraussetzungen der Gestaltung des nationalen Selbstbewußtseins der Polen im Mittelalter sind nicht leicht zu bestimmen. Die Probleme beginnen schon bei der Betrachtung des geographischen Rahmens. Einerseits gehörte (und gehört) zu den Besonderheiten der polnischen Geschichte das Fehlen der deutlich erkennbaren natürlichen Grenzen im Osten und im Westen, bei dem Vorhandensein solcher Grenzen im Norden und im Süden. Im Gegensatz zu Böhmen hat Polen damit den Charakter eines Übergangslandes gehabt. Trennte also die Sudeten- und Karpatengrenze die Einwohner Polens wirklich von den ihnen ethnisch und sprachlich eng verwandten Tschechen und Slowaken ab, so bildeten die Oder und der Bober nur relativ kurz die Grenze zwischen den slawischen Völkern und slawischen politischen Bildungen, um später, nach der Eingliederung der sorbischen und elbslawischen Territorien in die deutschen Herrschaftsstrukturen und folglich besonders nach der zunehmenden deutschen Kolonisierung, die Qualität einer grundlegenden politischen und zivilisatorischen Scheide anzunehmen. Beginnend mit der zweiten Hälfte des 12. Jahrhunderts, besonders aber seit der Mitte des 13. Jahrhunderts, nahm diese Grenze einen ausgesprochen dynamischen Charakter ein, indem sie sich im Westen und im Norden (der Deutsche Orden!) zuungunsten Polens verschob, um sich erst in der zweiten Hälfte des 15. Jahrhunderts furr etwa drei Jahrhunderte zu stabilisieren. ${ }^{7}$ Von der Verschiebung der polnischen Ostgrenze ${ }^{8}$, beginnend mit den vierziger Jahren des 14. Jahrhunderts, infolge der Inkorporationen, und besonders infolge der polnisch-litauischen Union, war schon kurz die Rede; auf die Einzelheiten braucht hier nicht ausfuhrlich eingegangen zu werden.

7 Vgl. Gerard Labuda, Polska granica zachodnia. Tysiąc lat dziejów politycznych. Poznań 1971, 2. Aufl. 1974.

8 Vgl. Gotthold Rhode, Die Ostgrenze Polens. Politische Entwicklung, kulturelle Bedeutung und geistige Auswirkung. Bd. 1: Im Mittelalter bis zum Jahre 1401. Köln 1955; Klaus Zernack, Polen und Rußland. Zwei Wege in der europăischen Geschichte. Berlin 1994. 
In der polnischen historischen Forschung wurde gelegentlich die angenommene „organische Einheit" der „polnischen Mutterländer“ (macierzyste ziemie Polski) hervorgehoben, nicht ohne Einfluß der Theorien des geographischen Determinismus. ${ }^{9}$ Dem Argument der Einheit der hydrographischen Systeme kann jedoch unschwer das Argument der landschaftlichen Differenzierung der polnischen Gebiete gegenübergestellt werden, die im Mittelalter wohl zweifelsfrei noch ausgeprägter war als heutzutage. Ohne sich auf Einzelheiten einzulassen, sei hier nur auf die weitgehende Andersartigkeit der natürlichen Gegebenheiten Südpolens (die spät besiedelten Gebirgsgebiete ausgenommen) einerseits, Mittel- und Nordpolens andererseits hingewiesen.

Schon um das Jahr 1000 waren alle westslawischen Stämme, die von der Sprachwissenschaft zur sogenannten ostlechitischen ${ }^{10}$ Gruppe gerechnet werden, im Rahmen des polanischen Staates vereinigt. Am Rande sei hier bemerkt, daß das Territorium dieses Staates, den durch die baltischen Stämme (Pruzzen und Jatvjager) bewohnten Nordosten ausgenommen, fast genau dem heutigen Staatsgebiet Polens entspricht. Es wäre allerdings unmöglich, die praktische Bedeutung der „ostlechitischen“ sprachlichen Einheit bzw. Verbundenheit zu ermessen; es ist nicht ausgeschlossen, daß wir es hier eher mit einem Forschungspostulat als mit einem wirklichen Selbstbestimmungsfaktor zu tun haben. Einerseits sind nämlich noch heute die Unterschiede zwischen den einzelnen slawischen Sprachen, besonders zwischen den westslawischen, relativ gering, und im Mittelalter müssen sie noch unbedeutender gewesen sein, so daß es wohl keine nennenswerten gegenseitigen Verständigungsprobleme gegeben haben kann, andererseits waren schon damals auch im Bereich der polnischen Sprache dialektische Besonderheiten vorhanden (wie zum Beispiel das sogenannte Masurieren in Masowien und in Kleinpolen, das in Großpolen unbekannt war), die zwar die gegenseitige Verständigung nicht zu gefăhrden imstande waren, sicher aber als Unterscheidungsmerkmale wahrgenommen wurden.

Vom Standpunkt unseres Themas ist es wohl zulässig, die an sich bestimmt hochinteressante, von František Graus übrigens schon erforschte und beschriebene Entwicklung des Gefuhls einer allgemeinslawischen, meistens auf die West-, eventuell auch auf die Südslawen begrenzten Einheit ${ }^{11}$ auszuklammern. Wenn überhaupt, erschienen solche ,weltfernen ${ }^{6}$ Ideen praktisch nur in manchen intellektuellen Kreisen, obwohl sie gelegentlich auch zu politischen Zwecken instrumentalisiert wurden. Eine Genealogie der slawischen (und sonstigen) Völker in der ältesten russischen Chronik (Anfang des 12. Jahrhunderts), Povest vremennych let, ausgenommen, erschienen deutlichere Symptome eines gesamtslawischen Selbstbewußtseins erst seit der zweiten Hälfte des 13. Jahrhunderts in Böhmen, und stärker in den folgenden zwei Jahrhun-

9 Vgl. Władystaw Semkowicz, Geograficzne podstawy Polski Chrobrego, in: Kwartalnik Historyczny 39, 1925, 258-314.

10 Der Name ist eine moderne gelehrte Bildung, etymologisch weist er auf Lech hin - das sagenhafte Eponym Polens (zuerst bezeugt im 14. Jh., früher als Ethnonym - Lechici/Lechiten).

11 František Graus, Die Nationenbildung der Westslawen im Mittelalter. (Nationes. Historische und philologische Untersuchungen zur Entstehung der europäischen Nationen im Mittelalter, Bd. 3.) Sigmaringen 1980, bes. 130-137. Schon früher ansatzweise: Gerard Labuda, Okres „wspólnoty“ słowiańskiej w świetle źródeł i tradycji historycznej, in: Slavia Antiqua 1, 1948, 181-227 (erneut in: ders., Fragmenty dziejów Słowiańszczyzny Zachodniej. T. 1. Poznań 1960, 34-86); Andrzej Feliks Grabski, „Lingua sclavonica“" w poglądach polskich i zachodnioeuropejskich (XI-XV w.), in: Rozprawy Komisji Językowej Łódzkiego Towarzystwa Naukowego 16, 1970, 253-267. 
derten. In Polen ist die sogenannte Großpolnische Chronik, wohl aus dem 14. Jahrhundert, das einzige, wenn auch bedeutsame Beispiel solcher Geisteshaltung. ${ }^{12}$

Nun ist es an der Zeit, zu den Bedingtheiten politischer Natur überzugehen. Die Stammesstruktur der später polnischen Gebiete ist nur unzureichend bekannt, sie scheint jedenfalls auf namhafte lokale Unterschiede in der Entwicklung der sozialen Verhältnisse in der Zeit vor der Gestaltung des fruhpolnischen Staates hinzuweisen. Von den ,großen Stămmen“, Stammesbünden, deren Existenz etwa im 9. Jahrhundert auf den größeren Fortschritt der Integrationsprozesse hinweisen könnte, bezeugen die zeitgenössischen Quellen nur drei: die Wislanen, die Goplanen und die Lendzianen (Lendizen). Aufgrund der glaubwürdigen späteren Überlieferung oder fundierter gelehrter Hypothesen fugt man meistens noch dazu: die Polanen in Großpolen, die Slenzanen in Niederschlesien, die Masowien und die Pomoranen, obwohl die Zugehörigkeit der letztgenannten zum polnischen Stammesverband zumindest zweifelhaft ist. Dank des „Bayerischen Geographen“ ist die Stammesstruktur Schlesiens noch am besten bekannt. Dorthin gehören die Stammesnamen, die ,kleine', elementare, ursprüngliche Stammesbildungen bezeichnen: die Slenzanen (in partikularer Sicht), Dziadoszanen, Opolanen, Golensizen, die rätselhaften Lupiglaa, Bobrzanen und Trzebowianen. Im Gegensatz zu Schlesien wurden in Kleinpolen nur die Wislanen an der Oberweichsel, um Krakau und Sandomierz, urkundlich bezeugt. Östlich von diesen, an der Grenze zur Rus', wohnten die Lendzianen, die ihren Namen den nördlichen (Litauen), östlichen (Rus') und südöstlichen (Ungarn) Nachbarn Polens zur Bezeichnung aller polnischen Stämme gegeben haben.

Es wird vermutet, daß der erste Versuch einer Konsolidierung im größeren Maßstab von den südpolnischen Wislanen ausgegangen sei, sowie daß dieser Versuch infolge der Nordexpansion des Großmährischen Reiches von jenseits der Karpaten während der Herrschaft Svatopluks gegen Ende des 9. Jahrhunderts nur räumlich begrenzte und keine dauerhaften Erfolge hatte. Das habe wahrscheinlich die Expansion der Polanen erleichtert bzw. erst ermöglicht, die ursprünglich wohl nur ein relativ bescheidenes Gebiet um Gnesen, Posen, Ostrów Lednicki und Giecz innehatten. ${ }^{13}$ Mit Gnesen verband auch eindeutig die polnische Tradition die Anfange des eigenen Staatswesens und der in Polen bis zum Jahre 1370 herrschenden Dynastie. Es verdient in diesem Zusammenhang Erwăhnung, daß Magister Vincentius (Wincenty Kadłubek), der an der Wende vom 12. zum 13. Jahrhundert den Versuch unternahm, die Anfange Polens in Krakau zu lokalisieren, dabei nicht an die dortigen wislanischen Traditionen anknüpte, sondern einfach die Polanen und die Piasten von Gnesen und Großpolen nach Krakau versetzte.

12 Vgl. Jerzy Strzelczyk, Westslawische Reminiszenzen der Großpolnischen Chronik, in: Beiträge zur Archăologie und Geschichte Nordostniedersachsens. Berndt Wachter zum 70. Geburtstag. Hrsg. v. Wolfgang Jürries. (Schriftenreihe des Heimatkundlichen Arbeitskreises Lüchow-Dannenberg, H. 8.) Lüchow 1991, 145-154.

13 Obwohl der Polanenname im ursprünglichen, stammesbezogenen Sinne quellenmäßig nicht bestătigt wurde, hat die von Johannes Fried, Der hl. Adalbert und Gnesen, in: Archiv für mittelrheinische Kirchengeschichte 50, 1998, 41-70, hier 44 ff., aufgestellte These, die die bloße Existenz der Polanen negiert, wenig Chancen auf allgemeine Akzeptanz. 
„Kadłubek schreibt so, als ob er ein gebürtiger Polane, in Krakau niedergelassen, gewesen

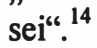

„Der erste frühe Piastenstaat“ ist also von Gnesen aus entstanden (Südpolen - KrakauerSandomirer Land und Schlesien - gehörte zunächst zu Böhmen und wurde erst gegen Ende der achtziger Jahre des 10. Jahrhunderts von den Piasten erobert) und umfaßte gegen Ende der Herrschaftszeit Mieszkos I. (gest. 992) alle „polnischen“ Stämme um. Die Eroberungen Bolesław Chrobrys (992-1025) im Westen (die Lausitzen, das Milzenerland), Süden (Böhmen, Nordmähren, Slowakei) und Osten (die sogenannten Czerwieńsk-Burgen) haben sich als vorubergehend erwiesen, auch Pommern fiel rasch von dem polnischen Verband ab. Nach der großen sozial-politischen Krise der dreißiger bis vierziger Jahre des 11. Jahrhunderts ist „der zweite frühe Piastenstaat" entstanden, der in begrenzterem Umfang (zunächst - bis 1054 - ohne Schlesien), allerdings mit dem am Anfang des 12. Jahrhunderts eingegliederten Pommern, bis zur ersten Hälfte des 12. Jahrhunderts bestehen blieb, den immer stärker werdenden dezentralistischen Tendenzen zum Trotz. Das sogenannte Statut oder Testament Bolesławs Krzywousty (Schiefmund) (gest. 1138), das versuchte, diese Tendenzen mit dem von einem namhaften Teil der polnischen ,politischen Nation“ empfundenen Bedürfnis nach der Einheit in merkwürdiger Weise zu versöhnen, fuhrte die Polyarchie ein, und zwar in der Form des Prinzipats: jeweils der älteste aus dem Piastenhaus sollte als Senior die Oberherrschaft (Seniorat) ausüben. Damit wurde der Prozeß und die Zeit der politischen Zersplitterung Polens begonnen, die sich zunehmend (obwohl mit einer lokal und zeitlich verschiedenen Dynamik) vertiefte - eine Tatsache von außerordentlicher Bedeutung in der Geschichte Polens. Diese Periode des politischen Polyzentrismus wird gewöhnlich auf die Jahre 1138 (1146) bis 1320 datiert und in folgende Phasen geteilt: (1) das Seniorat bis zum Jahre 1194, (2) das geschwächte Prinzipat bis zum Jahre 1227, (3) die Phase der Abwesenheit jeder, selbst nominellen Oberherrschaft und der Vertiefung zumindest in Schlesien, Kujawien und Masowien - der politischen Zersplitterung, (4) frühe Versuche der Überwindung dieses Zustandes und der Entstehung von überregionalen (die Monarchie Heinrichs I. und Heinrichs II. in Schlesien) und gesamtpolnischen politischen Bildungen, wenn auch mit unterschiedlichen territorialen Erfolgen: das Königtum Przemysłs I. von Großpolen (1295-1296), das Wenzels (II. und III.) von Böhmen (1300-1306) und von da bis zur ,definitiven' Krönung Władysławs Lokietek (Ellenlang) im Jahre 1320. Es muß jedoch bemerkt werden, daß das wiederentstandene Königreich Polen Lokieteks am Anfang nur Großund Kleinpolen umfaßte, immerhin zwei der wichtigsten historischen Gebiete Polens. (West-) Pommern fiel schon in der zweiten Hälfte des 12. Jahrhunderts ab, Pommerellen (Ostpommern), erst unlängst (1294) mit (Groß-)Polen verbunden, wurde 1308 durch den Deutschen Orden erobert (zu Polen kam es wieder im 1466), das Lebuser Land fiel in der Mitte des 13. Jahrhunderts zugunsten Brandenburgs ab, im Grenzgebiet zwischen Großpolen und Pommern entstand die brandenburgische Neumark, die schlesischen Fürstentumer wandten sich entschieden der Böhmischen Krone zu, Masowien und ein Teil Kujawiens blieben außerhalb des Königreichs Polen, meistens nur durch den Lehnsbund verbunden (nach dem Tode Kasimirs des Großen 1370 waren die masowischen Piasten eine Zeitlang sogar ganz unabhängig von der 
polnischen Krone). Kasimir, der letzte aus der Piastendynastie auf dem polnischen Thron (1334-1370), konnte nur einen Teil der verlorenen Gebiete zurückgewinnen, er begann gleichzeitig mit der polnischen Expansion in die südöstliche Richtung.

Unter solchen Umständen wird es verständlich, daß wir die Entwicklung des politischen Selbstbewußtseins in Pommern und in Schlesien ${ }^{15}$ ausklammern; infolge des unzureichenden Forschungsstandes bleibt auch Masowien außerhalb der weiteren Erörterungen. ${ }^{16}$

Von erstrangiger Bedeutung fur die Entwicklung und Verstärkung des Gefuhls der gesamtpolnischen Einheit ${ }^{17}$ war, außer der Tatsache, daß ein einziges Piasten-Haus ${ }^{18}$ in der Zersplitterungszeit in allen Teilfürstentümern ungehindert herrschte, die Tätigkeit und die Politik einzelner Herrscher und der Zentralverwaltung. Dieses Thema ist jedoch zu umfangreich, um hier gründlicher behandelt zu werden. Eine besonders wichtige Rolle wird gewöhnlich dem Gesamtherrschertum in den fruhesten Phasen der Staatsentwicklung beigemessen. Sie bestand in der Überwindung älterer Stammesstrukturen, in neuen administrativen Maßnahmen, in der Schaffung neuer Machtzentren, in der Bekămpfung heidnischer Kulte, die mit den partikularen Gentilstrukturen untrennbar verbunden waren, in der Unterstützung der neuen christlichen Religion und der Kirche, in der Organisierung der überregionalen militärischen Unternehmungen, in deren Verlauf die aus verschiedenen Teilen des Staates stammenden Teilnehmer sich gegenseitig besser kennenlernen konnten, indem sie gemeinsam handeln und gesamtpolitische Ziele verfolgen mußten; schließlich in der zielbewußten Siedlungspolitik, die fremdstämmige Enklaven zu bilden suchte, mit der klar erkennbaren Absicht, die traditionellen territorialen Strukturen zu sprengen oder zumindest zu schwächen. Vor allem aber konkretisierte sich die aktive, tatkräftige Rolle der Zentralgewalt in der täglichen Tătigkeit des zwar noch immer primitiven, aber zahlenmäßig und funktional wachsenden Staatsapparates, in der möglichst regelmäßigen Präsenz des Herrschers, in den Tendenzen, die Verwaltung, das Schatzwesen und die Gerichtsbarkeit zu vereinheitlichen.

Die Dezentralisierung des Staates, beginnend mit der Mitte des 12. Jahrhunderts, bedeutete einerseits den Sieg der zentrifugalen Tendenzen, andererseits aber förderte sie - langfristig die Erscheinung neuer unizifierender Kräfte und der an der Überwindung der politischen Zersplitterung interessierten sozialen Gruppen. Die Zeit der Teilfurstentümer wurde nämlich die Periode des gewaltigen - besonders sichtbar im 13. Jahrhundert - zivilisatorischen Fortschritts

15 Vgl. Janusz Maltek, Powstanie poczucia krajowej odrę̧ności w Prusach i jej rozwój w XV i XVI wieku, in: Państwo, naród i stany w świadomości wieków średnich. Pamięci Benedykta Zientary 1929-1983. Red. Aleksander Gieysztor/Sławomir Gawlas. Warszawa 1990, 244-252; Halina Manikowska, Świadomość regionalna na Śląsku w późnym średniowieczu, in: ebd. 253-267.

16 Vgl. Henryk Samsonowicz, Piastowskie Mazowsze a Królestwo Polskie w XIII-XV w., in: Piastowie w dziejach Polski. Zbiór artykułów z okazji trzechsetnej rocznicy wygaśnięcia dynastii Piastów. Red. Roman Heck. Wrocław etc. 1975, 115-134.

17 Vgl. den ausgezeichneten Forschungsbericht von Stawomir Gawlas, Stan badań nad polską świadomościa narodową w średniowieczu, in: Państwo, naród i stany (wie Anm. 15), 149-194.

18 Der Name „Piasten“ (als Nachkommen des legendăren Ahnherren Piast) tauchte allerdings erst in der frühen Neuzeit auf, und zwar bezeichnenderweise zuerst in Schlesien. Vgl. Jerzy Strzelczyk, Die Piasten Tradition und Mythos in Polen, in: Mythen in Geschichte und Geschichtsschreibung aus polnischer und deutscher Sicht. Hrsg. v. Adelheid von Saldern. (Politik und Geschichte, Bd. 1.) Münster 1996, 113-131. 
der Mehrheit der polnischen Gebiete, was mit dem paneuropäischen Landnahme- und Kolonisierungsprozeß aufs engste verbunden und mit der merklichen, obwohl relativen Distanzverminderung zwischen Polen und anderen, zumindest ihm im Westen benachbarten, Ländern identisch war. Die Multiplizierung der Zahl der Teilfurstentumer auf einigen Gebieten Polens trug zur Vermehrung der polnischen ,politischen Nation“ bei, gleichzeitig wurde hier und da sozusagen der kritische Punkt überschritten, was zum Nachlassen der Selbstidentifizienung der Gesellschaft mit dem eigenen Zwergfürstentum und zu einer allmählichen Ausrichtung auf breitere staatliche Strukturen führen konnte. Den neuen Unifizierungstendenzen wurde im Laufe des 13. Jahrhunderts zunehmend auch die katholische Kirche geneigt, besonders der Episkopat, der sich in seinem Besitzstand nicht ganz grundlos gefăhrdet fuhlte, vor allem in den Gebieten, die von Polen getrennt waren, wie auch seitens der expansiven Orden (wie Zisterzienser und Franziskaner), die exemt waren und gelegentlich versuchten, sich aus dem bisherigen kirchenorganisatorischen Rahmen zu lösen. Das Gefuhl der Bedrohung der polnischen territorialen Substanz im Laufe des 13. Jahrhunderts, der die Teilfursten nur sehr begrenzt gewachsen sein konnten, die Konfrontation der öffentlichen Meinung in Polen mit dem fremdstämmigen Element, besonders mit den Deutschen und den Juden, die sich sowohl in Städten wie auch auf dem Lande niederließen und sich meistens eines im Vergleich zu den Eingesessenen gehobenen Rechts- und Sozialstatus erfreuten, die Bevorzugung der Deutschen an manchen Höfen, das Sicherheitsdefizit im Lande und auf den Wegen, schließlich die ganz normalen Schwierigkeiten im Bereich des Handels und des Binnenverkehrs und die wachsende Rolle des Bürgertums alles das forderte eindeutig die zentralistischen Tendenzen, und zwar in immer breiteren Schichten der Bevölkerung.

\section{Historiographie im Dienste der Nationsbildung}

Eine bedeutsame Manifestation solcher Bestrebungen war die Nostalgie nach der verlorenen Größe Polens in der Zeit der ersten Piasten, oder in der sagenumwobenen Urzeit. Es entstanden, wie anderswo in Europa, neue Konzeptionen, die nicht ohne Geschick, wenn auch mühsam, konstruiert wurden. Das Bedürnis, dem polnischen Volke eine möglicherweise glorreiche, d. h. vor allem eine alte Genealogie anzubieten, war offenbar am Anfang des 12. Jahrhunderts noch nicht so empfunden worden, als Gallus Anonymus seine Chronik schrieb ${ }^{19}$; ihr Programm kann am ehesten als eine „restauratio Poloniae“ in der Zeit Bolesławs Krzywousty bezeichnet werden. ${ }^{20}$ Der Zeithorizont der Chronik reicht lediglich und auf wenig konkrete Weise bis in die (legendäre) vierte Generation vor Mieszko I. zurück, und die ganze der Herrschaft dieses Fürsten vorangehende Erzăhlung schwebt irgendwo zwischen Geschichte und

19 Galli Anonymi cronicae et gesta ducum sive principum Polonorum. Ed. Carolus Maleczyński. (MPH NS., Bd. 2.) Cracoviae 1952; Polens Anfänge. Gallus Anonymus: Chronik und Taten der Herzöge und Fürsten von Polen. Übersetzt, eingeleitet und erklärt von Josef Bujnoch. (Slavische Geschichtsschreiber, Bd. 10.) Graz/Wien/Köln 1978.

20 Vgl. Roman Michalowski, „Restauratio Poloniae“ w ideologii dynastycznej Galla Anonima, in: Przeglą Historyczny 76, 1985, 3, 457-480; Czestiaw Deptuła, Galla Anonima mit genezy Polski. Studium z historiozofii i hermeneutyki symboli dziejopisarstwa średniowiecznego. Lublin 1990. 
Sage, weist auch noch auf keine Verbindungen mit der allgemeinen Geschichte hin. Das Werk des Anonymus ist eine Apologie, es entstand in der Stunde der akuten Bedrohung der Herrschaft Bolesławs Krzywousty, die durch die Reaktion eines Teiles der polnischen Gesellschaft nach der drastischen Eliminierung von Bolesławs älterem Bruder Zbigniew verursacht worden war. Die Einheit des polnischen Staates als die notwendige, unverzichtbare Voraussetzung von dessen Existenz hervorzuheben, war das wichtigste Ziel der Auftragsarbeit des fremdståmmigen Chronisten.

Für Wincenty Kadłubek, hundert Jahre später, war dagegen die Aufteilung Polens in Teilfurstentümer eine selbstverstăndliche, akzeptierte Tatsache. Gleichzeitig ist in seiner Chronik eine gewaltige Vertiefung der historischen Perspektive in die antike oder pseudo-antike Geschichte hinein bemerkbar. Die Konzeption eines uralten großen Lechitenimperiums wurde geboren, des Imperiums, das den militärischen Absichten Alexanders des Großen, des Crassus und Julius Cäsars siegreich und glorreich widerstand. Die Chronik des Kadłubek, ein ausgezeichnetes Beispiel für die sogenannte „Renaissance des 12. Jahrhunderts“, ist ein ideengeschichtlich mehrschichtiges Werk; die politische und gesellschaftliche Funktion der Konzeption des Lechitenimperiums hatte sicher eine hochaktuelle Aussage, die gegen die imperialen Tendenzen der Staufer-Kaiser gerichtet wurde, die im Laufe des 12. Jahrhunderts zum brennenden politischen Problem fur ein zersplittertes Polen wurden. ${ }^{21}$

Für Jan Długosz (gest. 1480) ${ }^{22}$, dessen umfangreiches und großangelegtes Werk Annales seu cronicae inclyti Regni Poloniae als die reifste Frucht der mittelalterlichen Historiographie Polens zu bezeichnen ist, waren Poloni, gens oder natio Polonica, die Gemeinschaft derjenigen Menschen, die alle im Rahmen des im 14. Jahrhundert wiedervereinigten Regnum Poloniae und in Masowien gewohnt haben. Außerhalb dieses Begriffes blieb die Bevölkerung der annektierten Territorien, wie auch die Litauer und Ruthenen, obwohl sie nach Dhugosz in einem engen Staatsverhältnis zum Regnum Poloniae blieben. Auch wurden die ihm zeitgenössischen Einwohner Schlesiens und Pommerns durch den Chronisten nie Polen genannt, obwohl sie aus der altpolnischen ethnischen, sprachlichen und politischen Gemeinschaft abstammten und obwohl Długosz ausdrücklich der Hoffnung auf die klinftige Rekuperation auch dieser Gebiete Ausdruck gegeben hat. ${ }^{23}$

21 Magistri Vincentii dicti Kadłubek Chronica Polonorum. Ed. Marian Plezia. (MPH NS., Bd. 11.) Kraków 1994. Vgl. Jacek Banaszkiewicz, Polskie dzieje bajeczne mistrza Wincentego Kadłubka. Wrocław 1998; Marek Cetwiński, Imperium Lechitów. Polityczna doktryna czy opowieść ku pokrzepieniu serc?, in: Europa Środkowa i Wschodnia w polityce Piastów. Red. Krystyna Zielińska-Melkowska. Toruń 1997, 243-248; ders., Aleksander Macedoński i Ślask w „Kronice“ Wincentego Kadłubka, in: Tradycje kultury antycznej na Ślasku. Opole 1997, 195-203. Über einen der Fortsetzer der Chronik Kadłubeks, sog. Dzierzwa (Mierzwa) (Anfang des 14. Jh.), der seine eigene hochinteressante Vision der Urgeschichte Polens entwarf, vgl. Jacek Banaszkiewicz, Kronika Dzierzwy. XIV-wieczne kompendium historii ojczystej. Wrocław u. a. 1979. Über die sogenannte Großpolnische Chronik vgl. die in Anm. 12 zitierte Arbeit.

22 Vgl. Brigitte Kürbis, Johannes Długosz als Geschichtsschreiber, in: Geschichtsschreibung und Geschichtsbewußtsein im spăten Mittelalter. Hrsg. v. Hans Patze. (VuF, Bd. 31.) Sigmaringen 1987, 483-496.

23 Joannis Dlugossii seu Longini canonici Cracoviensis Historiae Polonicae libri XII, t. 1-5 (Opera omnia, t. 10-14.) Ed. Ignatius Zegota Pauli/Alexander Przeździecki, Cracoviae 1873-1879, t. 5 (1878), 473 f. 
Einer so verstandenen polnischen natio ist nach Długosz die fulhrende Rolle in der multinationalen Jagiellonenmonarchie zugefallen. Die Begrindung dieser Rolle wurde vor allem in der alten und glorreichen Vergangenheit gesucht. Diesem Zweck dient die in der Tradition von Kadłubek stehende, jedoch stark erweiterte, bisweilen auch rationalisierte Beschreibung der Geschichte der Lechiten-Polen, die unter allen slawischen Völkem bei weitem die mächtigsten waren. Das bei Długosz vorhandene Bewußtsein der allgemeinslawischen Einheit wurde als ein historisches Argument instrumentalisiert im Sinne der Begrundung der polnischen Ansprüche auf Schlesien und Pommern, wie auch auf Ruthenien, dessen Bevölkerung von Rus' abstammte, dem Sohn Lechs, des sagenhaften Eponymen Polens (wăhrend Rus' in der früheren polnischen Überlieferung als Bruder Lechs galt!), und endlich auf Böhmen - stammten doch auch die Tschechen von Čech, einem jüngeren Bruder Lechs, ab und blieben schon unter der Herrschaft von Krak in der staatlichen Bindung mit Polen.

Das nationale Bewußtsein von Długosz beruhrt sich mit seinem Staatsbewußtsein, ist aber mit letzterem nicht identisch. Długosz hatte keine Bedenken, daß in einem Staat und unter der Herrschaft eines Königs verschiedene, nicht nur slawische Völker vereinigt würden und gemeinsam lebten. Dementsprechend hat der Begriff Regnum Poloniae bei Dhugosz verschiedene Inhalte. Mal wird er zur Bezeichnung Polens, des Landes der Polen, deren patria, verwendet, mal in bezug auf das ganze politische System, das verschiedene Völker mit deren patriae umfaßte.

Die politischen Vorstellungen von Długosz sind zweifelsfrei als Gipfel der Entwicklung des nationalen Bewußtseins im mittelalterlichen Polen zu werten. ${ }^{24}$ In der Biographie dieses Historikers verknüpften sich auf eine einmalige Weise das Werk besonders fordernde Züge wie eine überdurchschnittliche, protohumanistische Bildung, die Bekanntschaft mit den antiken Autoren, die aktive Teilnahme des Chronisten am politischen Leben seines Landes und die Breite der von ihm gepflegten persönlichen Kontakte, die sich praktisch auf alle Stände der Gesellschaft ausdehnten, schließlich viele Auslandsreisen und Kontakte mit europäischen Gelehrten und

(a. 1467): Cepit et me scribentem praesentia Annalia, non mediocris super finito bello Pruthenico, et restitutis terris abstractis dudum, Prussia quoque Regno unita, voluptas, utpote, qui molestius tuleram, Polonicum Regnum a variis nationibus et populis laceratum in dies iri, fortunatum me et caeteros coaetaneos meos ratus, quibus reintegrationem ipsam post tot saecula videre contigit: crediturus fortunatiorem, si Slesiae, Lubuczensem et Stolpensem oras, in quibus tres episcopatus a Boleslao magno, Polonorum primo Rege, et patre suo Myeczslavo fundati, Wratislaviensis videlicet, Lubuczensis et Kamyenensis consistunt, reddi quoque et reuniri Regno Poloniae per clementiam divinam, me inspectante, contingeret: laetior enim exhinc discederem, et in somno meo suavius, molliusque quiescendo accumberem.

24 Vgl. Jadwiga Krzyzaniakowa, Pojęcie narodu w „Rocznikach“ Jana Długosza, in: Sztuka i ideologia XV wieku. Red. Piotr Skubiszewski. Warszawa 1978, 135-153; Slawomir Gawlas, Świadomość narodowa Jana Długosza, in: Studia Źródłoznawcze 27, 1983, 3-66; Urszula Borkowska, Treści ideowe w dziełach Jana Długosza. Kościół i świat poza Kościołem. Lublin 1983. Zu der schon bei Długosz auftauchenden Antemurale-Idee vgl. Urszula Borkowska, The Ideology of Antemurale in the Sphere of Slavic Culture 13th-17th century, in: The Common Christian Roots of the European Nations. An International Colloquium in the Vatican. Florence 1983, 1206-1221; Jadwiga Krzyzaniakowa, Poland as antemurale Christianitatis. The Political and Ideological Foundations of the Idea, in: Polish Western Affairs 33, 1992/2, 3-25 (dt.: Polen als antemurale Christianitatis. Zur Vorgeschichte eines Mythos, in: Mythen [wie Anm. 18], 132-146). 
Diplomaten. Jan Długosz gehörte nicht nur den politischen und Vermögenseliten des damaligen Polen an, sondern auch der intellektuellen Führungsschicht. Das mahnt entschieden zur Vorsicht, seine Ideen und Anschauungen zu verallgemeinern und fur die Abbildung der öffentlichen Meinung auch nur der fuhrenden sozialen Gruppen zu halten. Dieses Problem der Repräsentativität der mittelalterlichen Historiographie bezilglich der Mentalităt breiterer Kreise der damaligen Gesellschaft ist jedoch bekanntlich das Problem nicht nur Polens und muß hier unberücksichtigt bleiben. 



\title{
Der Vergleich in der Erforschung des europäischen Mittelalters
}

\author{
Versuch eines Resümees
}

Von

Frank Rexroth

Wer Wissenschaft betreibt, vergleicht unweigerlich - im großen oder im kleinen. ${ }^{1}$ Es ist eine elementare gedankliche Operation, zwei oder mehr Gegenstände aneinander zu messen, und in allen Wissenschaften macht man insofern ständig Gebrauch von ihr. Dennoch tut man nicht gut daran, jedes Vorgehen, in dem zwei oder mehr Dinge miteinander verglichen werden, als ein „komparatistisches“ zu etikettieren, denn in einer Schublade, in der alles zugleich Platz findet, herrscht bekanntlich Unordnung. Auch in den Kulturwissenschaften besteht daher Einigkeit darüber, daß man von ,Komparatistik ${ }^{‘}$ nur dann sprechen sollte, wenn ein anspruchsvolleres heuristisches Prinzip benannt wird.

Wie dieses Prinzip im einzelnen beschaffen sein soll, mag umstritten sein. Es ist jedoch mit Sicherheit kein Zufall, daß die Entwicklung vergleichender wissenschaftlicher Operationen eng verknüpft ist mit der Neufassung von Wissenschaft als ,Forschung in der Moderne. Vergleichende Erforschung indoeuropäischer Grammatiken oder „archaischer“ religiöser Systeme, auf Vergleichsoperationen beruhende Textkritik, Vergleiche in Kulturgeographie und Völkerkunde waren Hervorbringungen ,modernisierter' Wissenschaft seit der Aufklärung und dem 19. Jahrhundert. So fremd uns heute die erkenntnisleitenden Interessen ihrer Betreiber geworden sein mögen (der Stammbaum der „Kulturnationen“, die Zuordnung von Völkern zu „Kulturstufen“, die Suche nach dem „echten“, „unverfälschten“ Text) - im Hinblick auf unser Methodenarsenal stehen wir in der Tradition jener Ansätze. ${ }^{2}$

1 Der folgende Text beruht auf der mündlichen Zusammenfassung, wie sie am 25. September 1999 in der Berliner Humboldt-Universităt vorgetragen wurde. Die Anmerkungen sind auf wenige Literaturverweise beschränkt, auf Querverweise zu den Beiträgen oben wurde verzichtet.

2 Jürgen Osterhammel, Transkulturell vergleichende Geschichtswissenschaft, in: Geschichte und Vergleich. Ansătze und Ergebnisse international vergleichender Geschichtsschreibung. Hrsg. v. HeinzGerhard Haupt/Jürgen Kocka. Frankfurt a. M.New York 1996, 271-313, v. a. 278; Rudolf Vierhaus, Traditionen vergleichender historischer Kulturwissenschaft in Deutschland. Bemerkungen und Fragen, 
Insofern zielen Verständigungen über die Voraussetzungen und die Heuristik von Vergleichen stets auf einen zentralen Punkt unserer Vorstellungen davon, wie Wissenschaftlichkeit überhaupt zu erzielen ist. Wo es in der Vergangenheit darum ging, disziplinäre Neuanfänge mit den höheren Weihen jener Wissenschaftlichkeit zu versehen, kehrte man Komparatistik bisweilen als eine Grundbedingung zeitgemäßen Forschens so weit heraus, daß sie zum Synonym fur das Zeitgemäße, Richtungweisende werden konnte. Vergleichende Soziologie, so Emile Durkheim 1895, sei keineswegs nur ein besonderer Zweig der Soziologie - „sie ist soweit die Soziologie selbst, als sie aufhört, rein deskriptiv zu sein und danach strebt, sich uber die Tatsachen Rechenschaft zu geben". 3

Nur auf den ersten Blick überraschend ist dabei, daß sich gerade die in diesem disziplinären Ensemble normsetzende Wissenschaft von der Geschichte schwer tat, Verfahren des Vergleichs als legitime Strategien anzuerkennen. Schließlich gehörte es lange Zeit zum Komment der Historiker, Experten furr das zeitbedingt ,Besondere' (Louis Halphen), Fachleute für die Verknüpfung von ,Einzelfällen' (Charles Seignobos) zu sein. ${ }^{4}$ Der Komparatistik unterstellte man dagegen, fur das Individuelle blind und statt dessen erpicht auf das Verbindende, Allgemeine zu sein - ja womöglich der Subsumtion des ersteren unter das vermeintlich universell Gültige entgegenzuarbeiten. ${ }^{5}$ Auch heute noch werden die Begriffe ,miteinander vergleichen' und ,einander gleichsetzen' bisweilen wie Synonyme verwendet, mithin als Ausdrücke für ahistorische Verfahren gebrandmarkt. Man hätte es besser wissen können, da doch schon John Stuart Mill 1881 das Nebeneinander einer method of agreement und einer method of difference postuliert, da Max Weber doch schon als Inhalt der „kritische(n) Vergleichung“ nicht die Jagd ,nach ,Analogien“ und ,Parallelen“ (...), sondern (...) die Herausarbeitung der Eigenart" von Untersuchungsgegenständen benannt hatte. ${ }^{6}$ Insofern erinnerte Otto Hintze seine Zeitgenossen 1929 auch eigentlich nur an Selbstverständlichkeiten, als er den Vergleich als ein probates Mittel empfahl, Allgemeines zu finden, zugleich aber eben auch Individuelles schärfer zu erfassen. ${ }^{7}$

in: Saeculum 40, 1989, 132-135; Horst Fuhrmann, Die Sorge um den rechten Text, in: Geschichte heute. Positionen, Tendenzen und Probleme. Hrsg. v. Gerhard Schulz. Göttingen 1973, 9-23.

3 Emile Durkheim, Die Regeln der soziologischen Methode. Hrsg. v. René König. Frankfurt a. M. 1984 (frz. 1895), 216.

4 Dazu André Burguière, Der Begriff der „Mentalităten“ bei Marc Bloch und Lucien Febvre: zwei Auffassungen, zwei Wege, in: Mentalităten-Geschichte. Zur historischen Rekonstruktion geistiger Prozesse. Hrsg. v. Ulrich Raulff. Berlin 1987, 33-49.

5 Dies macht die frühe franzősische Soziologie zum Ausgangspunkt ihrer Kritik an der zeitgenőssischen Geschichtswissenschaft. ,(...) l'histoire ne peut être une science que dans la mesure où elle explique, et l'on ne peut expliquer qu'en comparant“, schreibt Durkheim 1896/97; „or, dès qu'elle compare, l'histoire devient indistincte de la sociologie." Emile Durkheim, Préface, in: L'année sociologique 1, 1896/97, II f.

6 Heinz-Gerhard Haupt/Jürgen Kocka, Historischer Vergleich: Methoden, Aufgaben, Probleme. Eine Einleitung, in: Geschichte und Vergleich (wie Anm. 2), 9-45, hier 11; Max Weber, Die Stadt. Hrsg. v. Wilfried Nippel. (Max Weber Gesamtausgabe. Abt. I, Bd. 22/5.) Tübingen 1999, 7, vgl. 45.

7 Otto Hintze, Soziologische und geschichtliche Staatsauffassung. Zu Franz Oppenheimers System der Soziologie, in: Soziologie und Geschichte. Gesammelte Abhandlungen. Hrsg. v. Gerhard Oestreich/Otto Hintze. Bd. 2. Göttingen 1964, 239-305, hier 251. 
Für die Neuzeithistorie wurden in den vergangenen Jahren Arbeiten mit programmatischer Absicht zum Druck gebracht, in denen die Chancen historischer Komparatistik und die schon vorzuweisenden Erfolge erörtert wurden. ${ }^{8}$ Herausgeber und Autoren sind sich dort zwar nicht einig daruber, ob historische Komparatistik heute den ihr gebührenden Stellenwert im Ensemble der Methoden einnimmt - Heinz Gerhard Haupt und Jürgen Kocka beklagen Defizite, Hartmut Kaelble ist da zuversichtlicher. Doch schätzen die Vertreter der historischen Sozialwissenschaften das Geschäft des Vergleichens in der Regel sehr hoch ein, sie halten es für methodisch abgesichert und kühl-empirisch. Manchmal propagiert man Komparatistik dort, wo man sich von den konkurrierenden Angeboten derjenigen Ansätze und Richtungen in der Geschichtswissenschaft absetzen will, die man gemeinhin mit der Selbstbesinnung der Geschichtswissenschaft als einer historischen Kulturwissenschaft verbindet, also der Historischen Anthropologie, dem Interesse für Deutungsschemata und Mentalităten, auch der Alltagsgeschichte. Wer vergleiche, so könnte man diesen Gedanken auf den Punkt bringen, der nehme sich sozusagen selbst an die Leine, denn er verpflichte sich zu beständiger Rechenschaft über sein Vorgehen, das heißt vor allem über seine Interpretationsleistungen. ${ }^{9}$ Der Vergleich ist ein analytisches Verfahren, und so erwartet man von ihm, daß er die Narrativität des Historikers in Schach zu halten vermag. ${ }^{10}$ Interessanterweise werden in solchen Stellungnahmen gerade Schlüsselfiguren der historischen Kulturwissenschaften wie Kronzeugen angefuhrt, wenn es um die theoretische Fundierung des historischen Vergleichs als eines Forschungsparadigmas geht - eben Otto Hintze, aber an erster Stelle und immer wieder Marc Bloch wegen seines berühmten, 1927 auf dem Internationalen Historikerkongreß in Oslo vorgetragenen Plädoyers „Für eine vergleichende Geschichtsbetrachtung der europäischen Gesellschaften"."

Allerdings ist auch deutlich geworden, daß Komparatistik keineswegs auf rein empirische Verfahren beschränkt bleibt, ja ganz im Gegenteil: daß gerade dort, wo menschliche Deutungsleistungen und Deutungsschemata, soziale Praktiken und kulturelle Hervorbringungen jeglicher Art zu untersuchen sind, Vergleichsoperationen gute Dienste leisten. Ein prominentes Beispiel mag genügen: Jan Assmann beschließt seine Arbeit über das „kulturelle Gedächtnis“, eine Kulturtheorie von hoher Attraktivităt nicht nur für Ägyptologen, nicht von ungefahr mit einem Vergleich dreier antiker Erinnerungskulturen, die zu jeweils distinkten

8 Geschichte und Vergleich (wie Anm. 2); Hartmut Kaelble, Der historische Vergleich. Eine Einführung zum 19. und 20. Jahrhundert, Frankfurt a. M.NNew York 1999.

9 Jürgen Kocka, Historische Komparatistik in Deutschland, in: Geschichte und Vergleich (wie Anm. 2), 47-60, hier 49: „Vergleichen heißt abstrahieren [hier: von Kontextbezogenheit, F. R.]. So ist verständlich, daß sowohl die herkömmliche Geschichtswissenschaft wie auch die neuere Alltags-, Erfahrungsund Kulturgeschichte, soweit sie auf die Rekonstruktion kleiner Totalităten zielt, die großen Begriffe skeptisch meidet und ,thick description" statt distanzierender Analyse will, mit komparativen Forschungsstrategien wenig anzufiangen weiß.“

10 Kocka, Historische Komparatistik (wie Anm. 9), 47: „Narrativităt und Komparatistik standen - und stehen - in Spannung zueinander".

11 Marc Bloch, Für eine vergleichende Geschichtsbetrachtung der europäischen Gesellschaften, in: Alles Gewordene hat Geschichte. Die Schule der „Annales“ in ihren Texten 1929-1992. Hrsg. v. Matthias Middell/Steffen Sammler. Leipzig 1994, 121-167. 
Formen des Schriftgebrauchs, zu einer spezifischen Kanonisierung von ,Wissen', mithin zu verschiedenen Mustern kollektiver Identität führen. ${ }^{12}$ Und daß der von Pierre Nora angeregten Erforschung der französischen „lieux de mémoire“ nun ăhnliche Projekte in anderen Ländern folgen, wird die vergleichende Betrachtung des kollektiven Erinnerns in der Moderne sicher stimulieren. ${ }^{13}$

Die Mittelalterforschung ist von dieser Hinwendung zum Vergleich nicht ganz unberuhrt geblieben, wenngleich bis heute auffallend wenige entschieden komparatistische Studien von monographischem Zuschnitt vorliegen. Vor allem transnationale oder transkulturelle Studien sind selten. Auf dem Weg des Vergleichs gewonnene Theorien wie die von Richard Kaeuper über die Ursprunge des englischen ,Konstitutionalismus' und des französischen ,Absolutismus' im Hundertjährigen Krieg sind auch im internationalen Maßstab die Ausnahme geblieben, und selbst dort, wo Werke wie František Graus' Studie der französischen, deutschen und böhmischen Geschichtstraditionen gelobt wurden, blieb ihnen eine nachhaltig steuernde Wirkung doch versagt. ${ }^{14}$ Eher noch denken die Mediävisten dann über Vergleiche nach, wenn sie in Kooperation mit Fachkollegen im In- und Ausland größere Projekte planen und exekutieren - vorausgesetzt, sie versprechen sich von internationaler Zusammenarbeit mehr als nur einen Austausch fertiger Ergebnisse.

Es war daher ein Glücksfall sowohl fur die komparatistisch vorgehende Mediävistik als auch für die Möglichkeiten zu internationaler Kooperation, daß das „Institut für vergleichende Geschichte Europas im Mittelalter", das Michael Borgolte 1998 etabliert hat, seine internationalen Kontakte mit einer Arbeitstagung zur vergleichenden Erforschung Europas im Mittelalter initialisierte. Programm und Zuschnitt des Instituts, das an der Berliner Humboldt-Universität beheimatet ist, lassen hoffen, daß die Basis fur internationalen Austausch (und damit unweigerlich für die ,Europäisierung' der Mediävistik) in Deutschland mit seiner Hilfe erneut verbreitert wird. Wer die Arbeit der historischen Auslandsinstitute kennt, wer ab und zu die Gästeliste des Göttinger Max-Planck-Instituts für Geschichte studiert, der ahnt, wie wichtig die Existenz solcher Zentren fur Austausch und Forschungsprogrammatik ist.

Die Berliner Tagung, der der vorliegende Konferenzband geschuldet ist, war daher einer doppelten Zielsetzung verpflichtet: der internationalen Verständigung über „Europa im Mittelalter" als einer Herausforderung fur die künftige Mediävistik und den Vergleichsverfahren, die bei der Erforschung Europas eine Rolle spielen könnten. Nicht thematisch konzentriert war die Arbeitstagung angelegt, sondern im Gegenteil in der Themenwahl absichtsvoll offen und damit attraktiv fur alle Kollegen, die über den Horizont ihrer jeweils spezifischen Fragen hinaus Anregungen und Austausch suchten - Inspiration im Gespräch mit dem Nach-

12 Jan Assmann, Das kulturelle Gedächtnis. Schrift, Erinnerung und politische Identităt in frühen Hochkulturen. München 1992.

13 Pierre Nora (Dir.), Les lieux de mémoire. 3 vol. Paris 1984; Etienne François/Hagen Schulze (Hrsg.), Deutsche Erinnerungsorte. Bd. 1. München 2001; ebd. 16 über die Projekte in anderen europăischen Lăndern.

14 Richard W. Kaeuper, War, Justice, and Public Order. England and France in the Later Middle Ages. Oxford 1988; František Graus, Lebendige Vergangenheit. Überlieferung im Mittelalter und in den Vorstellungen vom Mittelalter. Köln/Wien 1975. 
barn jenseits des Zauns ihrer Provinzen, der Adels-, der Historiographie- oder nationesForschung, der Erforschung der Agrar- und der Synodalgeschichte. Das Band, das die Tagungsteilnehmer einte, war ein methodisches Prinzip und seine Umsetzung in der Praxis. Hierbei spielte auch die Reflexion über die Möglichkeiten und den Zuschnitt einer künftigen „europäischen Geschichte des Mittelalters“ eine Rolle, einer Geschichtsschreibung, die mehr sein sollte als die Buchbindersynthese aus verkürzenden Nationalgeschichten.

Einige Autoren präsentieren ihre Arbeiten bereits als Produkte vergangener, momentan bestehender oder doch zumindest geplanter Forschungsprogramme und des internationalen Dialogs. François Menant kann sich fur die Toskana auf die Arbeit italienischer und englischer Kollegen berufen. Patrick Geary referiert über ein Projekt, das man als transkulturelle Komparatistik reinsten Wassers bezeichnen muß: nämlich die parallele Erforschung von Hofkulturen in Japan, China und Westeuropa nach einer Reihe von vereinbarten Themenschwerpunkten. Es ist sicher kein Zufall, daß es sich bei diesen Themenschwerpunkten sozusagen um Klassiker der anglo-amerikanischen Kulturwissenschaften handelt: ,Public ritual', ,gender', ,the invention of tradition', ,the social construction of knowledge'. Die Überführung allgemein verpflichtender Fragestellungen einer nationalen Wissenschaftstradition in das Stadium des Vergleichs also - das ist eine Konstellation, wie man sie in Deutschland vor allem am Beispiel der Sonderwegsdebatte erleben konnte. ${ }^{15}$ Mögen Skeptiker wie die von Geary eingangs zitierten also ruhig mißtrauisch bleiben - es gibt auch eine Eigendynamik von Forschungsprozessen, die etwas mit Vernunft zu tun hat!

Internationale Projekte der beschriebenen Art fuhren unweigerlich dazu, in einem weiteren als dem gewohnten ,nationalen' Horizont zu denken. So ist es kein Wunder, daß Europa als historische Bezugsgröße in ihnen eine wichtige Rolle spielt - ganz gleich, ob man diesen Horizont sozusagen wie eine Grenze zu fassen versucht oder gerade seine Unschärfe für die eigenen Strategien fruchtbar macht. Erinnert sei nur an die Ambiguităten des Europabegriffs, die Borgolte vor Augen führt. „Europa“ ist einmal ein Quellenbegriff, der oszilliert zwischen der Anwendung auf den Einflußbereich der Westkirche und auf ein größeres, wie auch immer zugeschnittenes Ganzes, das auf jeden Fall Teile der Sclavinia und mitunter auch den griechischen Osten umfassen konnte. Zum anderen eignet diesem Begriff eine ausgeprägte Varianz: Er bezeichnet ein historiographisches Konzept, das um 1700 geschaffen und seither chronologisch ganz unterschiedlich angesetzt wurde, irgendwo zwischen dem Ende der antiken Kaiserherrschaft im Westen und dem Hochmittelalter. Für das 16. Jahrhundert schließlich müßte mit dem Konzept ,kontinentales Staatensystem' eben auch die Bezugsgröße geändert werden, denn nun wäre europäische Politik für den begreifbar, der die Trias Habsburg - Frankreich - Osmanisches Reich einbezieht. So bequem die Gleichsetzung von ,Europa' mit dem Einflußbereich der Westkirche auch sein mag: Wer sich ihr anvertraut, wird leicht zum Geschichtsschreiber eines vornehmlich an Westeuropa orientierten ,mainstream', der das nur vermeintlich Normensetzende herausstreicht. Die Erfahrungen von Differenz und Offenheit, die man macht, wenn man die russische Geschichte, Judentum und

15 Hartmut Kaelble, Vergleichende Sozialgeschichte des 19. und 20. Jahrhunderts: Forschungen europăischer Historiker, in: Geschichte und Vergleich (wie Anm. 2), 91-130, hier 107 ff. 
Islam, den Austausch mit dem vorderen Orient als Bestandteil der europäischen Geschichte begreift (und nicht nur als Zuständigkeitsbereiche von auxiliaren Nischenfächern in der Nachbarschaft), sind die Mühe wert, den Rahmen des Gewohnten zu überschreiten. Weder der Nachweis von Einheit noch der von Säkulartrends sollte Ziel der Arbeit sein. Die Dauerhaftigkeit der Alteritäten, der Gegensätzlichkeiten und Widersprüche zwischen verschiedenen europäischen Kulturen sollte man gerade als Grundbedingung des mittelalterlichen Europa akzeptieren, wie Otto Gerhard Oexle unter Hinweis auf Edgar Morins Versuch von 1987 zeigt, Europa zu „denken“. Konkurrierende Deutungsmuster wie die von der Gesellschaft einerseits als einer differenzierten, hierarchisch nach Ständen geordneten Ganzheit, andererseits als dem genossenschaftlich organisierten Gruppengefuge der mittelalterlichen Stadt prägten eben in ihrer gleichzeitigen und durchaus widersprüchlichen Existenz mittelalterliche Mentalitäten. Dies wäre eine jener „Dialogiken“, die für Morin Europa ausmachen.

Es gibt freilich auch simple forschungsstrategische Vorteile, die sich aus der Weitung des Blicks auf ungewohnte Regionen und das scheinbar Unvereinbare ergeben. Das wird mit Sverre Bagges Beitrag deutlich. Zwar sind die verschiedenen „lateineuropäischen“ Historiographien immer wieder und mit den weithin bekannten Ergebnissen miteinander konfrontiert worden, doch die ostfränkisch-deutsche Chronistik mit der byzantinischen, also dem Werk Anna Komnenas, zu vergleichen - dies ist ein interessanter Anlauf zu neuen Deutungen. Sichtbar wird eine recht unterschiedlich ausgeprägte Befähigung von Geschichtsschreibern des ,Ostens' und des ,Westens', in Kategorien von transpersonaler Staatlichkeit zu denken. Die Entwicklungsgeschichte hin zur Konzeptualisierung von Transpersonalität im Westen wird durch interkulturelle Vergleiche dieser Art gestützt und vielleicht sogar differenziert.

Beim Stichwort ,Interkulturalität' wäre schließlich auch an die Studie von Gadi Algazi zu erinnern. Er zeigt, mit welchem Raffinement man am Hof der Abbasiden bei der Aneignung kultureller Codes vorgehen mußte, wenn die eigene Vergangenheit nicht die erwünschten Muster fur die Reproduktion einer Hofgesellschaft bereitstellte. Am Hof von Bagdad wurde in einer relativ kurzen Zeitspanne von einem Dreivierteljahrhundert die Liebe neu ,modelliert" - und zwar in dem Sinn, daß der langgezogene Prozeß des Werbens um eine launenhafte, anspruchsvolle und überdies sozial tieferstehende Frau den Höflingen die Möglichkeit bot, einen machtrelevanten Habitus zu erlernen und zu verinnerlichen. Der Ideentransfer in das Forschungsprojekt hinein, wie er von den Arbeiten zum französischen amour courtois ausgegangen ist, wird dabei ebenso deutlich wie der von Algazi und seiner Kollegin Rina Drory erreichte Erkenntnis-Überschuß; er sollte seinerseits künftig auf die Erforschung von Troubador-Lyrik und Minnesang zurückwirken. Könnte es nicht sein, so fragt der Verfasser, daß auch in Westeuropa höfische Liebe dem Zweck dienen könnte, machtrelevante Fertigkeiten und Verhaltensweisen zu erlernen, an deren Erwerb den Mächtigen viel gelegen sein mußte? Eine Parallele zu den burgundischen und wittelsbachischen Hochzeiten, die KarlHeinz Spieß vorgestellt hat, ist wohl darin zu sehen, daß es beide Male die Inszenierung von Geschlechterdifferenz war, die für Rituale der Repräsentation und Reproduktion von Macht von zentraler Bedeutung war. Was transdisziplinäres Arbeiten zu bieten hat, wird an Algazis Studie besonders deutlich: Es geht eben nicht nur darum, daß sich die Vertreter der Disziplinen gegenseitig Einblicke in ihre Faktenarsenale gewähren, sondern noch mehr darum, spannende Konzeptualisierungsleistungen, die anderswo näher gelegen haben, auf ihre Übertragbarkeit hin zu überprüfen. Das klassische mediävistische Marschgepäck muß man ja dabei nicht am Wegesrand stehenlassen. 
Und wenn sich ein solcher Transfer von Konzepten an den Begrenztheiten der eigenen Quellenlage stoßen würde? Professor Barrow liefert ein besonders eindringliches Beispiel dafür, wie gerade die überaus problematische Quellenlage, die doch für erhebliche Bereiche mediävistischen Forschens typisch ist, geradezu den idealen Boden für vergleichendes Arbeiten bieten kann. Die Siedlungsgeschichte der Angelsachsen, so kann er zeigen, läßt sich durch das Studium der Schriftquellen, durch Namenkunde und ein bißchen archäologischen Input gerade einmal datieren (zugegebenermaßen für den Nicht-Fachmann erstaunlich genau). Welches aber das Konstitutivum der politischen Gliederung war, das wird erst sichtbar, wenn man schottische Begebenheiten an den englischen mißt. Und man erkennt: Die Gliederung Englands ist den Däneneinfallen und den Versuchen zu ihrer Abwehr geschuldet, diejenige Schottlands folgt dagegen einem Primat der topographischen Grundgegebenheiten. Auch François Menant wird bewegt von der Frage, ob sich die Beobachtungen, die er für die Geschichte des Kreditwesens und der Seigneurien in der Lombardei treffen konnte, aus lokalen Gegebenheiten heraus erklären lassen. Typologische Nähe, ja geradezu die Analogie der Phänomene in der Toskana verbürgte hier den Erfolg des Verfahrens. Um so ernster nehmen muß man Befunde wie den, daß die Kommunebildung auf dem Land, also die Entstehung ländlicher Gemeinden, in Konkurrenz mit der Grundherrschaft gänzlich verschiedene Kreise zu ziehen vermag.

Wenn es tatsächlich gelingt, andere auf einen gemeinsamen Problemhorizont zu verpflichten, wenn man Zeit und Bereitschaft aufbringt, die vertrackten terminologischen Differenzen verschiedener Wissenschaftssprachen bloßzulegen, dann kann man zuversichtlich sein, die Begrenzungen der Forschungsansätze zu überwinden, in denen man sich zwar gleichsam wie von selbst bewegt, die aber nicht weiter tragen. János Baks Bericht uber die Schwierigkeiten bei der Neufassung von Adelsforschung in Ostmitteleuropa notiert insofern präzise, was das vergleichende Verfahren behindert: Wer sich mit den alten Fragen zufriedengibt (auf die er die Antworten in Wirklichkeit natürlich längst parat hält), wer nicht bereit ist, die lange gehandhabten Konzeptbegriffe einmal in produktiver Absicht zu vergessen, muß sich auf Enttäuschungen gefaßt machen. Hans-Werner Goetz vermag eben dies mit seinen Bemerkungen zur internationalen Erforschung fruhmittelalterlicher Grundherrschaft zu zeigen. Die Erforschung der Bewirtschaftungsformen, die man in Deutschland gemeinhin als die Grundherrschaft bezeichnet, steckt in mehreren Schwierigkeiten zugleich: Sie arbeitet mit Typen, die über keine ausreichende Allgemeingültigkeit verfügen, und sie bedient sich dazu einer Begrifflichkeit, die im europäischen Maßstab weniger zur Verständigung als der wechselseitigen Verunsicherung dient. Leichter tut man sich da, wo man Projekte ganz neu plant und von Anfang an vergleichende, möglicherweise quantifizierende Feststellungen über die europaweite Verteilung seiner Befunde zum Ausgangspunkt für das Weiterforschen wăhlt. Johannes Helmrath demonstriert dies, indem er das Quantifizieren von Synoden und Synodalstatuten im europäischen Maßstab als einen ersten möglichen Schritt hin zur weiteren Klärung von Gemeinsamkeiten und Unterschieden präsentiert hat. Es kommt also für solcherlei Verfahren tatsächlich einerseits darauf an, daß man quantifizierende Aussagen treffen kann, andererseits darauf, daß man die Ergebnisse anschließend in Erklärungszusammenhänge einordnet.

Die Primärerfahrung, von der der Tagungsband wohl am häufigsten Zeugnis ablegt, ist diejenige, daß der Vergleich ein probates Mittel ist, das Betriebsblindheiten beseitigt - das auf die Erklärungsbedürftigkeit von Phänomenen aufmerksam macht, die man zuvor unhinterfragt hingenommen hat. David d'Avray illustriert dies gleich dreimal: Mit einem inter- 
kulturellen Vergleich, der die Besonderheiten der okzidentalen Kanonistik klären soll, mit synchronen Vergleichen des Eherechts, die überhaupt erst die Unterschiede in der englischen und norditalienischen Heiratspraxis sichtbar machen, und schließlich mit einem diachronen Vergleich, der ein thematisches Defizit der französischen Predigten über die Ehe aus dem 13. Jahrhundert bloßlegt. Vergleichen heißt also: Differenzen auch dort sehen zu lernen, wo man zuvor geglaubt hatte, über alles im Bilde zu sein. Die Frage, wie man diese Differenzen erklären soll (etwa die Betonung der Ehe als Gnadenmittel in den Predigten des 17. Jahrhunderts) - darüber nachzudenken wäre der jeweils nächste Schritt.

Im folgenden sei auf einige Strategien des Vergleichs genauer eingegangen. Nachzudenken bleibt zunächst über die Relation von Beziehungsgeschichte und Komparatistik, das heißt über die Frage, ob die Phänomene und Praktiken der Vergangenheit, die aneinander gemessen werden, auf gemeinsame Ursachen zurückzufuhren sind, ja ob ihre Akteure etwa im direkten Austausch miteinander standen. Das Thema klingt bei Karl-Heinz Spieß an: Verschiedene Elemente der europäischen Festkultur im 15. Jahrhundert miteinander zu konfrontieren, heißt, zwei Typen von Hochzeitsfeiern auszumachen, die man vielleicht als den ,Huldigungstyp، und den ,fürstlich-exklusiven Typ ' bezeichnen könnte - im Kern also eine herrschaftlich determinierte Form in Burgund und eine, die von der genossenschaftlichen Bindung der anwesenden Fürsten getragen war. Noch spannender wird diese Typologisierung jedoch, wo Spieß sie mit der Frage nach dem Wissensfundus konfrontiert, aus dem die Ausrichter der Feste schöpften. Die Inventare aus dem Lager der anderen waren offenbar bekannt, und kultureller Transfer von Burgund nach Wittelsbach (und später von Italien nach Deutschland) wăre zu erwarten gewesen, fand aber erst auffallend spät statt. Wieso? Man mag funktionalistisch argumentieren und auf den spezifischen Zweck der exklusiv fürstlichen ,deutschen' Treffen verweisen, man mag aber auch danach fragen, ob die blendende burgundische Feier in Bayern anders gesehen und beurteilt wurde als in ihrem Ursprungsland, ob sie mithin ganz bewußt und als Folge spezifischer Werthaltungen nicht übernommen wurde. Hier hat man es also mit einem Fall zu tun, in dem Komparatistik und das noch nicht lange entwickelte Konzept der kulturellen Transferforschung miteinander zu verschränken wären, wollte man mit der Interpretation der Differenzen weiter voranschreiten. ${ }^{16}$ In anderen Fällen mögen Vergleiche freilich dadurch an Reiz gewinnen, daß ihre Gegenstände gänzlich unverbunden und unbeeinflußt voneinander dastehen, so wie Marina Paramonova dies anhand zweier Legendentraditionen, einer altslawischen und einer lateinischen, demonstriert. Sogar die narrativen Konzepte sind hier gänzlich verschieden, werden die Erzăhlungen vom heiligen Wenzel doch einmal am Topos ,Familienfeindschaft', das andere Mal an dem der religiösen Auserwähltheit orientiert.

So wie die Relation zur Beziehungsgeschichte sollte künftig auch die Frage nach der Wirksamkeit historischer ,Kontinuitäten' reflektiert werden - dies vor allem dann, wenn man zum diachronen Vergleich ansetzt. So sind Tore Nybergs Gedanken getragen von einer gewissen Skepsis gegenüber jener Annahme von Kontinuitäten. Diese kann grundlegende

16 Johannes Paulmann, Internationaler Vergleich und interkultureller Transfer. Zwei Forschungsansätze zur europäischen Geschichte des 18. bis 20. Jahrhunderts, in: HZ 267, 1998, 649-685. 
Sachverhalte verschleiern: Die Tatsache etwa, daß sich das Ensemble königlicher Zwangsmittel - und mithin sein Rückgriff auf kirchliche Organe - vor allem während der größeren Präsenz des Papsttums von Avignon in Skandinavien so grundlegend gewandelt hat, daß wir für das Verständnis des Königtums den Entwicklungsgedanken einmal in produktiver Weise fallenlassen sollten. Jan Piskorski äußert sich für sein Thema ähnlich: Siedlungsrechte habe es seit der römischen Antike und gleichsam bis zu Old Shatterhand gegeben, sie seien eben durch die besondere Lebenswirklichkeit von ,border societies' bedingt, und in diesem Sinn gebe es eine Kontinuităt des Phänomens in einem weiten Sinn. Doch dies bedeute noch nicht, daß etwa die karolingerzeitlichen Siedlerrechte aus den limitalen Rechten der Antike ableitbar seien.

Nyberg demonstriert darüber hinaus, daß wir die vorliegenden Forschungsergebnisse gerade aus dem 19. Jahrhundert nicht ohne Ansehen ihrer konstitutiven Wertmaßstäbe übernehmen dürfen. Sein Untersuchungsgegenstand wäre schlechterdings nicht zu behandeln, vergegenwärtigte man sich nicht die Geringschätzung der schwachen mittelalterlichen Königreiche im Zeitalter der konstitutionellen Monarchien, die Verachtung der Papstkirche im lutherischen Skandinavien, die Vergottung der Reformation im protestantischen Milieu. Daniela Rando macht solche Bedingtheiten sogar zum eigentlichen Anliegen ihres Beitrags. Sie unterzieht sich der spannenden Aufgabe, von den Werken der europäischen VenedigForschung seit dem frühen 19. Jahrhundert ausgehend den Weg zurück zu den institutionellen Bedingungen und den ideengeschichtlichen Hintergründen ihres Zustandekommens zu suchen. Man denke nur an Georg Martin Thomas, dem Venedig wie ein Schnittpunkt aus klassisch-griechischer und klassisch-römischer Tradition erschien, oder an Willy Andreas, der in die fin-de-siècle-Gedanken seiner Zeit verstrickt war, ohne daß er dies expliziert hätte. Auch politische Verstrickungen spielten eine Rolle, zum Beispiel in den Einigungsprozeß des italienischen Königreiches. Sie konnten eine monumentale Urkundenedition zum Politikum werden lassen, weil sie in der Habsburgermonarchie vorgenommen worden war. Rando deckt überdies die Folgen der Zeitgebundenheit gerade von Praktiken des Vergleichs auf. Dazu gehört die Kontrastierung von ,Venedig' und ,Florenz' als zwei „Memorienzentren“ Europas; sie war diktiert vom zeitgenössischen Unbehagen an der Moderne, von der Sehnsucht nach dem ,neuen Mittelalter', und sie war verstrickt in Vorannahmen von unaufhebbaren Differenzen, der „Welt des Nordens und des Ostens einerseits, [der] Welt des Westens und des Südens andererseits“. Man kann mit den verschiedenen Anläufen, der Geschichte Venedigs im 19. und 20. Jahrhundert im Medium der Historiographie einen auf die Gegenwart bezogenen „Sinn“ zu verleihen, die „Sinngebung“ der ungarischen Geschichte durch die Konstruktion jeweils passender Mittelalterbilder an die Seite stellen. Daß sich Bak mit Mediävisten aus anderen Staaten Ostmitteleuropas zu vergleichender Adelsforschung zusammentat, sollte man als Versuch verstehen, Komparatistik als Korrektiv gegen solche ideologischen Vereinnahmungen einzusetzen. Beide Studien, die von Rando und die von Bak, verwiesen damit auf ein Postulat, das Otto Gerhard Oexle formuliert hat: Mit der Komparatistik der Phänomene habe eine Komparatistik der Konzepte und Entwurfe Schritt zu halten. Daß Sławomir Gawlas die Rezeption von Lehnswesen und Lehnrecht in Ostmitteleuropa untersuchen kann, hat zur Voraussetzung, daß die unterschiedlichen und miteinander konkurrierenden Konzepte von „Feudalismus“ auf der Forschungsebene erörtert und in ihren theoretischen Prämissen und ihrer empirischen Basis aneinander gemessen werden.

Gerade unter diesem Blickwinkel aber muß die Historisierung der Vergleichsverfahren keineswegs auf die Moderne beschränkt bleiben. Bernd Schneidmüller kann mit zahlreichen 
Belegen dafür aufwarten, daß sich Deutsche und Franzosen schon so lange aneinander maßen, wie ,Frankreich' und ,Deutschland' gedacht werden konnten. Hinter diesen Selbstund Fremdwahrnehmungen standen Reflexionen über die Besonderheit der eigenen Monarchie, die schließlich gerade im Vergleich der auf Wahl begründeten Thronfolgen der Deutschen mit dem französischen Gedanken der ,Erbmonarchie‘ an Profil gewann. Vorstellungen von möglichen Thronfolgepraktiken und Ideen von der Eigenart der französischen Monarchie dank königlicher Langlebigkeit wurden aneinander entwickelt und hatten für lange Zeit Bestand. Mittelalterliche kollektive Identitäten, so kann man auch dem Beitrag von Jerzy Strzelczyk entnehmen, verdankten den Vorstellungen vom ,Anderen' ebenso wichtige Impulse wie dem Wissen von der ,eigenen' Art. Heterostereotype fuhren aber nicht nur dazu, daß eine Gruppe sich ihrer selbst vergewissert, sie sind ihrerseits schon das Resultat von Selbstreflexion: Svetlana Luchitskaja führt die Berichte über eine angebliche Statue Mohammeds, die die Kreuzfahrer im Juli 1099 in der Jerusalemer Al-Aqsa-Moschee vorgefunden haben, auf das ungeklärte Verhältnis der Christen selbst zum Bild zurück: Wo genau verlief die Grenze zwischen dem legitimen Bild im sakralen Raum und dem ,Idol'? Man wußte es offenbar nicht, das Problem wurde mental ,ausgelagert': Das Fremdstereotyp der Muslime wurde um die Komponente des Götzenanbeters bereichert.

Letztlich: Wie bringt man Aspekte des Mentalen, der Deutungsleistungen in die Praxis einer vergleichend arbeitenden Erforschung Europas ein? Es scheint wichtig, daß es Wahrnehmungsphänomene und Transferleistungen waren, die in mehreren der Fallstudien die Vergleichsgrößen erst hervorbrachten, die Historiker Jahrhunderte später untersuchen wollen: die deutsche Festkultur etwa, die durchaus in Kenntnis der gänzlich anderen burgundischen entstand; ,Deutschland' und ,Frankreich', deren Entstehung aus den karolingischen Reichsteilen heraus einem geschaffenen Bewußtsein vom Anderssein geschuldet war; eine Hofkultur in Bagdad, die wußte, daß sie ganz anders sein wollte als die vergangene nomadische Kultur. Es wird sich ganz sicher bewahrheiten, daß Komparatistik die konstitutive Bedeutung des Gedachten, des Wissens und der Deutungsmuster in sich aufnehmen muß: Fragen nach einschlägigen Wertmaßstäben, nach wechselseitiger Wahrnehmung, nach Ideen vom Selbst und Vorstellungen vom Fremden, Untersuchungen der politisch relevanten Denkformen, des spezifischen Zuschnitts politischer Identität und Alterităt. Mag Komparatistik als Komponente der Kulturwissenschaften auch ein Kind der frühen Moderne sein: Sie besitzt sehr wohl eine Zukunftsdimension, deren Erschließung gerade erst begonnen hat. Wieder einmal wird die ,Wissenschaftlichkeit' unserer Disziplinen danach bemessen werden, wie erfolgreich wir komparatistisch arbeiten. 


\section{Abstracts}

\section{Michael Borgolte, Perspectives of European History of the Middle Ages on the Threshold of the twenty-first Century}

In this opening lecture of the colloquium in September 1999 „Europe in the Middle Ages. Theory, methods and practice of comparison in the European sciences of history of the Middle Ages" the tasks of the new "Institute for Comparative History of Europe in the Middle Ages" are outlined and theses for a European science of history in the Middle Ages are presented. The IVGEM being located at the Humboldt-Universität at an interface between Western and Eastern Europe shall thus bring together medievalists of different disciplines and countries to colloquia about supraregional problems in European history and make a contribution to encourage common comparative research. It especially invites foreign scholars to work in Berlin on monographs about subjects of comparative research of the Middle Ages.

A European science of history of the Middle Ages cannot refer to a perception of medieval Europe of itself but it reacts to the change of contemporary Europe concepts. The process of European unification gives history the responsibility to realize unities and differences by means of relationship analyses and comparisons in the history of the pre-modern age in order to make problems and chances of actual developments easier to comprehend. By including the Byzantine and Slav East, the Judaism and the Islamic peripheral areas of Europe, the traditional notion of medieval studies confined to the Latin Europe is challenged. On the other hand a comparative history of Europe in the Middle Ages continues to depend on the preparatory work and assistance of the national sciences of history and the associated special disciplines, not replacing but complementing them. Medieval studies acting Europe-wide and culture-wide will play their part in the formation of contemporary Europe, without allowing themselves to be influenced in any way ideologically or politically.

\section{Patrick J. Geary, Comparative History and Social Science Theory}

Comparative methodology is one of the basic strategies of social scientists whose goal is to elucidate not the particular but the general and are thus prepared to sacrifice accuracy in favor of generality. Critiques of comparative argue that comparison denies the uniqueness of historical phenomena and the importance of individual responsibility. This paper explores other models of historical comparison that can contribute to a better understanding of accuracy and particularity. These include the comparison advocated by Marc Bloch of societies 
that are at once neighboring and contemporary, exercising a constant mutual influence. However, this paper also argues for a place in historical research for the kind of cross-cultural comparative study that juxtaposes unrelated historical phenomena. The goals and methodologies of such a comparison are of a quite different order from either the Blochian comparison of similar, related phenomena, or the social scientist's search for a „scientific methodology". Instead, such comparisons make scholars more aware than before of the contingent nature of cultural production within their specific cultural system. The paper illustrates both kinds of analysis in the study of court cultures; in one analysis those of the later Carolingian courts; in the other, the comparison of Asian and European court cultures.

\section{Otto Gerhard Oexle, Orders and Groups. About the European in the European History}

The special features of the European culture and history do not only exist in the variety of its key ideas but decisively in the dialogues between these principles causing the historical change. This basic idea of Edgar Morin is discussed with regard to its relevance for comparative questions with two essential phenomena of European history: with orders and social groups.

A characteristic feature of the occidental culture proved to be the strained Dialogik between ,order ${ }^{6}$ and the elements ,labour ${ }^{6}$ and ,poverty' which are valued in Judaism and Christianity; the dynamic force of this constellation forming orders should be compared with the ,thought' estate orders of other cultures. Moreover the occidental society obtained its enormous variety of value-worlds decisively from the existence of numerous and very different social groups. Dialogiken resulted from the competition among these group-cultures, but also from the challenge of the ,estate society' by the Schwureinungen opposing group specific, particular values and demands to the ständisches Ganzheitsdenken. In this Dialogik about social basic values there is a cultural difference to antiquity the reasons of which are not least to be sought in the ,group friendliness' of Christianity.

\section{János M. Bak, Problems concerning a comparative Study of Medieval Élites in Eastern Central Europe}

Beginning with a sketchy overview of the functions and prejudices of both true and pretended comparative studies in Hungarian historiography of the last hundred years, the paper reports on the problems of a research project on noble societies (above all, the lesser nobility) in the medieval kingdoms of Hungary-Croatia, Bohemia, Poland-Lithuania, and adjacent territories. While in the late nineteenth and early twentieth century, comparisons were used to demonstrate the unique character of Hungarian statehood (mainly in a polemic against the nationalities and the neighbouring countries of the Dual Monarchy), more systematic comparative approaches were applied in the last 60-70 years. Although the „priority“ (e.g. of settlement in disputed areas) remained a predilection of even serious historians, many scholars turned to comparison in order to understand better the problems of their country's history (even if some of them did so in the framework of a priori Marxist-Leninist catgories). The famous Three Historical Regions by Jenö Szücs (1980) opened an entirely new chapter of comparative studies, aimed at a deeper understanding of the region's („Central Europe's") development and difficulties. The aim of participating in international scho- 
larly discussions has then - especially after the fall of the Soviet régimes - informed the most recent studies, and the research project at the Central European University, Budapest, on „Nobility in Medieval Central Europe“ was launched in this spirit. The five years' project offered a number of lessons, first of all that a systematic study of terminology has to be done, before any reasonable comparison can be made. The difficulties of such a "glossary“ has been demonstrated on the example of the term generatio ("kindred") that meant many different things in the course of centuries and in the countries of the region. Moreover, it became clear that it may not be the best procedure to follow ,Western' models and Fragestellungen, just for the sake of ,participation'. Rather, the region's special conditions (above all, the character and extent of surviving sources) has to be considered when outlining research problems. None the less, both coordinated parallel and joint-cooperative efforts, if clearly focussed on well-defined problems proved to yield results that promise to overcome narrow-minded national images of the past and help to understand certain similarities and differences both within the region and between it and its European surroundings, east and west.

\section{Hans-Werner Goetz, Research on Grundherrschaften of the early Middle Ages - a European Comparison}

It is true that the Grundherrschaft of the Middle Ages is correctly considered a widespread phenomenon determining the Occident. This means that it is suitable for comparison. Yet there exist considerable problems - and these will be the point of this lecture - which are founded in the phenomenon of the Grundherrschaft itself, as well as in the state of research, which in spite of intensive international research during the last few decades, finally concentrates on certain regions where good documentary evidence by Urbare is available. So far, there is no comparison of Grundherrschaften or of research projects. Already a comparison of the - best investigated - West Frankish, Lotharingian and East Rhenish Grundherrschaften reveals at first sight characteristic common interests and differences. However the most important common interest, the Villikationsverfassung, was only one of many operating systems in the East. We still know very little about how they spread. They really co-existed („mixed constitution“) and from my point of view, in research, these are considered too much to be opposites or stages of development. For all the characteristics, which are to a large extent thought to be typical of the East Rhenish Grundherrschaft (small farms, many farm dependants, three-days-statute labour of the subjected Hufner), one can find examples to prove the opposite. On the contrary - everywhere - a variety also within the individual Grundherrschaft seems to be characteristic. This makes comparison difficult. Even the much-discussed theses of grave differences within the South French-Catalan and South Italian regions, which were not penetrated by the Villikationssystem, are based on insufficient empirical studies and on completely different sources. Discussions such as these, being in contrast to recent highly empirical research, are once more very theoretical (including even „feudal revolution of the turn of the millennium"). A hardened, and in the end narrow understanding of ,Grundherrschaft ${ }^{\prime}$ as a concept and system determines the internationally linked research currently taking place - besides trends towards an intensive Urbarforschung, disregard of manorial and preference of economic aspects - more than the different national traditions which nevertheless have to be taken into account as well as a varying understanding of concepts (,Grundherrschaft $t^{6}$,Seigneurie ${ }^{6}$, ,Signoria ${ }^{6}$ ). To achieve an effective 
comparison here - on all sides - primarily the awareness for more openness and variety as to the features of seignorial relations would have to be developed.

\section{François Menant, A few Possibilities of Comparison in rural History from the twelth and thirteenth Centuries by means of Langobardic Examples}

This article proposes as the object of comparison a few social and economic situations which have been studied within the scope of Langobardic campaigns of the high Middle Ages. One wonders to what extent they are to be found again - in comparable surroundings and endowed with a similar documentation - in Occidental Mediterranean or in other regions of the medieval Occident. It mainly deals with the structure of rural society (ruling power, communities), with the complexity of this society, especially with the presence of intermediary rural élites between rulers and peasants, and finally with the variform influence of the town and its inhabitants. The credit, and as a result, the appropriation of land is a preferred measure of this municipal influence using also economic, political or cultural channels.

\section{Sławomir Gawlas, Feudal Law and Feudalism from Polish Perspective}

The diversity of approach to the problems of understanding of the term ,feudalism": legal (as a system of customs and norms of feudal law), sociopolitical (as a type and characteristics of society in which this law was established and maintained) socioeconomic (an agrarian system preceding capitalism and opposed to it, were the great estates were predominant) has historically established, constant basis deeply rooted in the scientific output and theoretical reflections. Simultaneously, a considerable disparity between the conceptualisations of this subject matter leads to a certain closure of national historiography of the different countries within the confines of their own terminological and theme traditions, which in turn confuses and complicates a comparative study. With reference to the Middle Ages the most important is research into societies organised by feudal ties. In the recent phase of discussion the French and Anglo-Saxon historians tend to date the fundamental transformation of social order to around $\mathrm{AD} 1000$. The concept of ,mutation féodale or feudal revolution', however, in spite of the justified critique against it, aptly reflects and illustrates the origins of a feudal state. This diffusion is a clear indication that its model is deeply rooted in the contemporary consciousness and emphasises usefulness of its institutions as a political and social force. This is often more distinct when seen not from a perspective of the centres where they had been established and generally recognised but the retarded peripheries, where the principles of feudal law were applied in sharper contrast to the local relations. An attempt at explaining the fundamental nature of feudal society needs, therefore, to take account of the societies belonging to the same sphere of Western Christendom but distinct in certain aspects. In case of Poland is seems important to thoroughly analyse the underlying reasons for which feudal institutions had not been widely applied, which can shed light on the mechanisms of the reception of its institutions.

From a perspective of Central Europe of fundamental importance was the development of relations in the Holy Roman empire, where the Carolingian principles of the state structures were still vital and the feudal bonds did not form basic joints of the realm. The ministeriales who as a stratum emerged in the eleventh century from the unfree servants was a functional counterpart of liege-homage. The territorialisation of state in the twelth century was accom- 
panied both by feudal modification of internal relations and the development of territorial lordship. Also the status of the ministeriales gradually simulated the feudal institutions. Peripheral location of Poland and the other countries of Central and Eastern Europe caused a certain shift in time of the development phases and a delay in transference of the feudal law. The ministerial stratum provided an attractive pattern that was adapted to the local requirements. The Polish princes defending the monopoly of sovereign power of the Piast dynasty were able in the twelth and thirteenth centuries, by means of reception of German territorial lordship pattern based on the concept of the regalities, to prevent a rise of independent dominions of their people. The rulers maintained the direct dependence of the nobility and interfered with a transformation of the secular and ecclesiastical barons' clientage into feudal vassals. It conduced, however, to the early organisation of the nobility under the leadership of the barons in order to preserve their legal privileges and prevented the princes from applying the feudal patterns in the subsequent stage of the relationship to their people. The lack of conditions for the adaptation, both upwards and downwards, of feudal institutions brought about the development of the heraldic knight clans, based on kinship or family bonds. This ,holding of arm in common' became a main principle on which the closing estate of the nobility was established. It filled a gap in the political sphere made by the lack of the feudal pyramid. These heraldic clans were still of certain significance even in the first quarter of the fifteenth century, which delayed the ultimate development of the noble landed corporations and their representation in form of the dietine.

The example of Poland illustrates that the feudal institutions had a profound influence on the development of European social and political structures. Its reception was closely tied with the development of territorial lordship. On one hand it provided the ruler with the instruments of political authority, on the other it conduced to the development of the great landed estates. Connected with it a constant political game between the authorities and society as a whole made difficult the domination of one of the sides. While the success of the Polish princes who prevented the development of the territorial lordship of their subjects interfered with the wide application of feudal law, at the subsequent stage - through the mechanisms of the noble estate system - turned against their sovereign power.

\section{Jan M. Piskorski, The „Königsfreien“ and the Medieval Colonization}

Not only in the antiquity and the modern age one can speak of ,colonies' and ,colonization' but also in the Middle Ages. There were colonization processes by means of extension of land, occupation and settlement of foreign territories. Good examples are to be found in Spain, the British Isles and some territories of the so-called ,German East colonization'. The gap between the antique, the medieval and the modern colonization phenomena appears here not to be so big as is often assumed.

In the second part of this contribution the question of the so-called ,Königsfreientheorie is discussed. It emerged in the thirties of the twentieth century and was recognized as a valid theory until recently. In conformity with later research this theory has been contradicted. Following this the origin of the „right of colonization“ is discussed. It can be encountered in quite different periods and regions. 


\section{Johannes Helmrath, Particular Synods and Synodal Statutes of the later Middle Ages in European Comparison. Preliminary Reflections on a Project}

Synods firmly belong to the ecclesiastical ,encadrement' of Europe in the Middle Ages and in modern times. They and their production of statutes are, by tradition, objects of canonical and historical science. However, an extensive comparative investigation of the provincial and diocesan synods in European countries is missing. The study wants to open ways to do this. It offers an interim balance of the current research situation and some of its basic problems. Possibilities of a systematic comparison are, on the one hand, investigated by the synods-frequency-model and on the other hand, by the model of the matters of their statutes. As an example of a comparative matter analysis, this contribution finally presents the topic „education of priests and lay catechesis“.

\section{Daniela Rando, Medieval Venice-Research 1850-1950. A first Survey about Subjects and Problems}

The subject „Venice in the Middle Ages“ is treated by comparison of methods and findings of different European historiographies from the period of 1850 until 1950, i.e. this was the century in which the Venice-research developed an organized international character.

During this period research no longer dealt with the medieval Venice on the basis of local historical origins but became more intensive - which was above all due to the availability of new sources and an attempt to create Venice-specific research facilities. This new intensity, however, did not yet mean the foundation of a special "Venezianistik", on the contrary: fragmentation and incoherence towards the object as well as problems of communication and prior understanding of the persons in charge, continued to exist. These difficulties are discussed using the reception of Heinrich Kretschmayr's Geschichte von Venedig (GothaStuttgart 1905-1934) in an exemplary manner.

By the statements of the Venice-historians ,the impression of political life interests, ways of reception and standards of the value of their national, cultural and social origin" (K. Erdmann) are carried into present times. In this way more examples from special research fields (Byzantinistik and Renaissance-research) are stated as well as types and interpretation patterns by which some paradigma changes in conception of history can be recognized. For this reason Venice becomes the classic example of modern history research - also thanks to its unique place in the history of culture.

\section{Gadi Algazi, Court Cultures compared: ,Love' in the early Abbasid Court}

In the Abbasid court, ,love' became the name of the game. The paper seeks to reconstruct the particular features of this cultural model in terms of its status, structure and functions within court society. With the vocabulary of motives adopted in the Abbasid court, ,love' was configured as the motive force for acquiring $a d a b$, refined culture. Through a comparison with north European models of love articulated in the thirteenth-century Roman de la Rose, the paper argues that in both cases, the rise of the courtly code of love was related to specific structures of power. Adab provided the elite with social cohesion through adherence to a common code. The game of love required suspending power differentials between par- 
ticipants. This entailed endowing women - in the Abbasid case, women slaves - with recognized agency. Finally, the paper argues that more than codified cultural competence was at stake. Through participating in the controlled and formalized game of love, courtiers could acquire the less visible, but no less important constituents of court culture - specific strategies for effective action in court. Love thus served to cultivate a specific social competence.

\section{Tore Nyberg, Scandinavian high and late Middle Ages - can they be meaningfully compared?}

Scandinavian historians have long since treated the first centuries of European Christian civilization in Scandinavia (the eleventh to thirteenth centuries) according to other value scales and preferences than the two following centuries which were overshadowed by the Reformation. A comparison between the two epochs of the same cultural area requires some common characteristics, for example the papacy, which is also a distinguishing mark for both epochs of Scandinavia's later history. Scandinavia's high Middle Ages can be shown to be different from its late Middle Ages, as exemplified for example in kingship - personal and sacred as against constitutional forms of government - or in the position of the church in relation to the king - the regional church as a servant and supporter of the king's glory and authority, compared with late medieval Scandinavian sovereigns' use and misuse of ecclesiastical structures for political purposes, while at the same time high prelates enjoyed a prominent position in the King's Council and thereby were made politically responsible for the well-being of the realm. A systematic study of semantics will uncover problems when notions such as regnum and ius regale are being used in Scandinavian sources of the twelfth century as against those of the fifteenth century. Other areas of comparison could be related to the community feeling of ordinary people in Scandinavia in the high and late Middle Ages. Where farmers first found common values of social and religious quality in the community of the village or the small town, where very often the most prominent among them built the church, they later found expression for their community experiences in groups such as guilds and other associations of a looser character. In such a system the function of the parish, in which everybody grew up, was quite another one to the one it had been in missionary times when the parochial system was new.

\section{David L. d'Avray, Comparative History of the Medieval Church's Marriage System}

Three types of comparative history are attempted. Firstly, there is a synchronic comparison between England and Italy in the thirteenth century. In England an ecclesiastical marriage ceremony was required by Church law, even though clandestine marriages were deemed valid; in parts of Italy, at least, there is no evidence that a Church marriage was even required. Again, in the thirteenth century large family clans were important in Italy, while in England they were not. Thus the Church's consanguinity prohibition, legitimated in terms of the need to create bonds between clans, would have seemed more rational in England than in Italy. Secondly, a diachronic comparison between marriage sermons in France in the thirteenth and the seventeenth century reveals the significant absence of the idea of vocation in the earlier period. Finally, the question of western medieval canon law's uniqueness in world history was addressed through a comparison with the sacred laws of Hinduism and Islam. All three sacred laws have a whole series of features in common, but canon law has a high 
degree of formal rationality in the Weberian sense - more like a modern secular judicial system. It also evolved a method possibly unique in world history of administering centralised rational justice at a distance. It also forced secular rulers to submit their marital lives to the rules of a bureaucratic law outside their control - situation unparalleled in the Hindu and Moslem worlds. These differences were elucidated through a detailed analysis of a massive papal bull annulling the marriage of Henry III of England and Joan of Ponthieu.

\section{Sverre Bagge, Medieval Societies and Historiography}

The article compares four historiographical traditions: (1) Byzantium, (2) feudal Europe, represented by Germany, (3) the northern periphery, represented by Norway and Iceland, and (4) Italy in the later Middle Ages and the Renaissance. Its focus is on ,making sense of history', in particular the importance for historical narrative of the presence or absence of an idea of a transpersonal structure or institution that serves to give meaning to the events.

Byzantine historiography had a tradition of ,stateness' and bureaucracy going back to late Antiquity, a tradition which, however, did not prevent politics from also being fairly personal and clientelistic. Anna Komnene's Alexiad offers an example of how the two different approaches meet in a historical account. By contrast, the ,individualistic ${ }^{6}$ and clientelistic approach to politics dominates both in the early German tradition, represented by Thietmar of Merseburg in the early eleventh century, and in the Old Norse sagas of the thirteenth century, as represented by Snorri Sturluson's Heimskringla.

The emergence of larger and more impersonal political structures even in Western Europe leads to a development in the direction of transpersonality. Eleventh and twelfth century Germany forms an early example, particularly the period from the Investiture Contest (1075-1122) onwards. The hierarchy of society, which was implicit in the earlier period, was now made explicit, and the struggles were not - or not only - regarded as conflicts between individuals but as conflicts concerning the right order of the world. It seems likely that we can trace a similar development in other European countries with the emergence of a more organised monarchy. Thirteenth century Norway forms just one example. Still, some kind of intermediate level between this lofty concept and the individual seems to be lacking, i.e. the particular state or nation.

For the emergence of this entity, we have to turn to another region and another period, i.e. Italy and the Renaissance. Already around 1300, Florentine urban chronicles express a strong patriotism and show tendencies towards the understanding of the city as a transpersonal entity. Apparently, however, we have to wait until the first half of the fifteenth century for a consistent account of the city of Florence as an ,impersonal protagonist', i.e. in Leonardo Bruni's Historia Florentini populi.

Finally, the article discusses the importance of ancient historiography and contemporary society and problems for the development of the four historiographical traditions discussed above.

\section{Marina Paramonova, The Family Conflict and the Fratricide in the Lifes of Wenceslas: The two Models of Ruler's Martyrdom}

The violent murder of ruler intended by his relatives or the members of his kin was an ordinary event in the political history of the Early Medieval Europe. Some situations of that kind 
gave rise to the cult of the murdered rulers represented as saints and martyrs. The hagiographic texts narrating about those events could be investigated as an experience of the reconsideration of the conflicts in the ruling dynasties in the terms of the christian religious and moral discourse. The image of reality differs according to rhetorical and ideological schemes invented by the authors representing the literary élites of Christian societies. The functions of these narratives were wider than simply to mirror the real ,events', they created the models for moral rationalization and evaluation of the social reality. The hagiographic works dedicated to one of the first dukes of Bohemia, Wenceslas, who was murdered in 929 (935/936) by his brother Boleslaus, is a good example for comparative study of the different models of the representation of the same situation in the terms of religious thought. The legends written during the last decades of the tenth and the first half of the eleventh century include the Latin as well as Church Slavonic works. However the ideological and discursive differences of the texts are lying beyond the linguistic borders. Generally we can present two models of duke murders. The first one is externalized in the First Church Slavonic Life. This text represents the murder as a result of hostility and destruction of the loyalties inside the ,natural' community (relatives and the surrounding of the ruler). The author accepts this type of relationship as evidence and basic value, which is not articulated in the system of formal norms and principles. His moral reflection on events uses the religious terms of Good and Evil trying to define the quasi-ethical principles preventing the feud. The logical and conceptual network of the Latin lifes is quite different. One can speak about the same type of reflection both in Latin and Slavonic works being based on them despite the individual differences of the singular texts. Representing the saint's conflict with his relatives and ,nobles the authors use the religious and moral terms to formalize the ,natural' relationship and reconsider their foundations in the general religious schemes and moral oppositions. The study of the ideological structure of the early Wencelas lifes could be useful to clarify the terms of the influence of the Bohemian cult on the Old Russian hagiographic and literary tradition of the representation of the family conflicts as well as the limits of that transcultural interchange.

\section{Svetlana Luchitskaja, Muslim ,Idols': Image and Reality}

The problem of the European identity, its originality in contrast with the Muslim East has become the subject of reflection in the Western historiography since the Middle Ages. Chroniclers and travellers related phantastic tales about customs and traditions of the Muslims ascribing to them polytheism and idolatry. And still this distorted image of islam was the major characteristic of the European self-consciousness.

The article deals with one of the aspects of the false image of islam - the representation of the Muslims as pagan idolators. Historians tried to interpret chronicler's strange stories on the golden statues of Mohammad in the mosques from the point of view of the common sense, trying to separate „res factae“ and „res fictae" and to draw a distinct line between the accounts of the eye-witnesses and the second-hand information. The author of this article proceeds from the other theoretical premises trying to investigate the influence of different cultural traditions be it ecclesiastical, literary or biblical. The author shows that the chroniclers projected in a negative manner their own notions and views on the alien culture. As a result we read improbable stories on the religion and cult of the Muslims. 


\section{Geoffrey W. S. Barrow, Divisions of Territory in the early Middle Ages. England and Scotland compared}

From the twelfth to the twentieth century the pattern of territorial divisions in England has been determined by a division into ,counties' (often called ,shires'). Three of these counties (Kent, Sussex, Essex) were tribal kingdoms formed by German colonists in the fifth and sixth centuries, and other early kingdoms, e.g. East Anglia, Lindsey and Deira, underlie later counties (Norfiolk, Suffolk, Lincolnshire, Yorkshire). The tribal pattern was related to the location of tribes within Britain - hence South Saxons (Sussex), East Saxons (Essex), East Angles (East Anglia) etc. The overall pattern does not seem to be closely related to the tribes of Roman Britain or the divisions imposed by Roman governors. From the earlier tenth century to $c$. 1200 England was drastically re-organized, mainly under West Saxon, Norman and Angevin kings, into counties/shires, each under a sheriff and governed from a chief borough (=,fortified town'). This county pattern did not completely obliterate the memory of older tribal kingdoms, e. g. Kent, Sussex, Essex became counties and the names Wessex and East Anglia were not forgotten.

In Scotland the lack of early sources makes it difficult to discern any dominant pattern of territorial divisions before $c$. 1100. Nevertheless, the divisions for which we have firm evidence - Lothian, Cumbria, Galloway, Alba and Argyll - seem to be markedly those of physical geography, not indications of areas claimed by or apportioned to particular tribes or kin-groups. Even Cumbria, ,land of the Cymry', and Argyll, ,shore of the Gael', offer somewhat generalised ethnic references. North of the Clyde-Forth isthmus the country was divided among ,mormaerdoms' (= ,earldoms'), dating from the Pictish period, the substantial majority of which had territorial or descriptive, not tribal, names - Ross, Moray, Buchan, Mar, Atholl, Strathearn, Fife, Menteith (and Lennox). This emphasis on territories points to stability of population over a long period.

\section{Bernd Schneidmüller, Außenblicke für das eigene Herz. Comparative Perception of political Order in the late Middle Ages of Germany and France}

Historical comparison has a long history. From the Middle Ages onwards until the twentieth century it was mostly carried out with clear intentions. Every new comparative approach should consider methods, forms, functions and intentions of former historiographers and younger expert colleagues.

Modern historical science in the twentieth century has frequently used comparisons between Germany and France as a message for the own we-group in order to illustrate either the merits or the backwardness of their own national development by using the neighbour as an example. German medieval studies have been especially interested in the formation of monarchic supremacy in the high and late Middle Ages of France or in the French formation of a nation as a European model, whereas national comparisons clearly played a much less important role in the more modern French research of the Middle Ages. The reasons for such different strategies of argumentation from the respective „national Middle Ages“ originate in different courses of French and German history: Here the Middle Ages became the preferred starting point for a backward, delayed nation, whereas the French identity was formed by very many, only partly medieval roots. 
Prerequisites for such differences of opinion can already be found in medieval historiography using its varying intensive look at the respective neighbour, either as justification or as motivation for the we-group. After having had Frankish interests in common for a long time, i.e. until the eleventh/twelth century, the awareness for rank in history was heightened by the actual separation. If during the Empire it had been founded on the imperial tradition of authority, in France one could be sure of continuous roots from Frankish times. By the very different proximity to the reform church in the eleventh/twelth century, various ideas emerged about the mission within history of salvation. In historical comparison in the high Middle Ages the own people appeared the nobler. Nowadays modern comparative studies have a different approach. Considering the historical examples, however, they should allow themselves to be impressed by the reflecting function of comparisons and to be tempted to exert self-irony.

\section{Karl-Heinz Spieß, Court Festivities in Europe in the fifteenth Century}

Since the fifteenth century, detailed reports have given a vivid impression of the magnificent arrangements of court festivities at the royal courts of Europe. This contribution deals with the question as to whether the prestige competition of European princes ended in relative homogeneity of the festivity culture or whether structural differences within Europe are ascertainable. Among the court festivities as a whole, royal weddings have been exemplarily investigated. On the basis of the wedding of Bruges in 1468 between Charles the Bold of Burgundy and Margaret of York, and the wedding of Landshut in 1475 between Duke George of Bavaria-Landshut and Hedwig of Poland, two festivity types could be established. The model ,Bruges' was also common in Italy, Portugal and England and showed as characteristic elements the inclusion of the town's inhabitants during the bride's entry, the mythical and allegorical raising of the ruler and of his bride, the use of intermedia at the banquet and participants mainly coming from the own court; whereas the ,Landshut' model was more exclusively directed towards the aristocracy. It presented itself as a ,get-together of the royal class and refrained from theatrical effects and image cultivation of the host. These differences have their roots in a varying understanding of principality and still continued to exist until around 1500 . Only in the sixteenth century did the festivity culture of the Renaissance gain the upper hand in Germany.

\section{Jerzy Strzelczyk, In Search of national Identity in the Middle Ages. The Case of Poland.}

It is attempted to carry out an analysis of the development of the feeling of national identity in medieval Poland. In this connection, the basic decisive events in the thirteenth century (political splitting up of Poland, German East settlement) and around the mid-fourteenth century (integration of Rotreußen, soon also the Polish-Lithuanian Union) are considered as well as obstructive and promoting exterior and interior factors. Due to the lack of source material the reflections focus on narration sources. 


\section{Frank Rexroth, Comparative Methods in Research on Medieval Europe. A summarizing Essay}

This essay is an attempt to sum up the contributions by asking which questions of historical research led the authors to applying comparative strategies. It places the discussion of these questions and strategies in a wider historiographical framework: From the late enlightenment onwards, comparative studies have often been considered a precondition when research on cultural phenomena has been evaluated for its Wissenschaftlichkeit. Even today and in the field of cultural studies, the acceptance of historical research is dependent on comparative methods which enable us to investigate not only ,hard' social facts but also mental phenomena: knowledge, patterns of thought and of pre-conscious acting. 


\section{$\mathrm{Zu}$ den Autorinnen und Autoren}

Gadi Algazi, Studium der Geschichte, Arabistik, Literaturwissenschaft und Romanischen Philologie in Tel Aviv und Göttingen; Senior Lecturer am Seminar für Geschichte der Universität Tel Aviv; Herausgeber der Zeitschrift History and Memory; aktuelles Forschungsprojekt: Geschichte des Gelehrtenhabitus 1400-1700.

Jüngste Veröffentlichungen: Kulturkult und die Rekonstruktion von Handlungsrepertoires, in: L'homme 11 (2000); (zusammen mit Rina Drory) L'amour à la cour des 'abbasides: Un code de compétence sociale, in: Annales 55 (2000). Im Erscheinen: Feigned Reciprocities: Lords, Peasants, and the Afterlife of Medieval Social Strategies, in: Negotiating the Gift. Ed. Gadi Algazi/Valentin Groebner/Bernhard Jussen (2001); Scholars in Households: Refiguring the Leamed Habitus, 1400-1600, in: The Scientific Persona. Ed. Lorraine Daston/Otto Sibum (Sondernummer von „Science in Context"); Gelehrte Zerstreutheit und gelernte Vergesslichkeit: Bemerkungen zu ihrer Rolle in der Formierung des Gelehrtenhabitus, in: Le faux pas. Hrsg. v. Peter von Moos (2001).

Sverre Bagge, geb. 1942; Professor für Mittelalterliche Geschichte an der Universität Bergen.

Veröffentlichungen u. a.: The Political Thought of The King's Mirror (1987); Society and Politics in Snorri Sturluson's Heimskringla (1991); From Gang Leader to the Lord's Anointed. Kingship in Sverris Saga and Hákonar Saga (1996); Kings, Politics, and the Right Order of the World in German Historiography c. 950-1150 (im Druck).

János M. Bak, Studium in Ungarm und Deutschland; Promotion in Göttingen 1960; Professor furr mittelalterliche Geschichte an der University of British Columbia von 1968 bis zur Emeritierung 1993; Professor für Mediävistik an der Central European University, Budapest. Seine Interessengebiete erstrecken sich von Fragen der Herrschaft bis zur Sozial- und Rechtsgeschichte insbesondere des Adels.

Veröffentlichungen u. a.: Königtum und Stände in Ungam im 14.-16. Jahrhundert (1973); (Hrsg.) Coronations (1990); (Hrsg.) Nobilities in Central and Eastern Europe (1994); (Hrsg.) Decreta regni mediaevalis Hungariae, 3 vols. (1989-1996). 
Geoffrey W. S. Barrow, geb. 1924; Studium in St Andrews 1941-1943, 1946-1948; Pembroke College Oxford 1948-1950 (B. Litt. 1950); Lecturer am University College London 1950-1961; Professor fur Mittelalterliche Geschichte an der University of Newcastle upon Tyne 1961-1974; Professor fur Schottische Geschichte an der University of St Andrews 1974-1979; Sir William Fraser Professor fur Schottische Geschichte und Palăographie an der University of Edinburgh 1979-1992; Fellow der British Academy 1976 und der Royal Society of Edinburgh 1977; Ehrenpromotionen der University of Glasgow und der University of Newcastle upon Tyne; Vizepräsident der Commission Internationale de Diplomatique.

Veroffentlichungen u. a.: Feudal Britain: the completion of the medieval kingdoms (1956); Regesta Regum Scottorum I, II; Robert Bruce and the community of the realm of Scotland ( $\left.{ }^{3} 1988\right)$; The kingdom of the Scots (1973); The charters of King David I (1124-1153) (1999).

Michael Borgolte, geb. 1948; Professor für Geschichte des Mittelalters an der HumboldtUniversităt zu Berlin; seit 1998 ebd. Leiter des „Instituts für vergleichende Geschichte Europas im Mittelalter“.

Veröffentlichungen u. a.: Der Gesandtenaustausch der Karolinger mit den Abbasiden und mit den Patriarchen von Jerusalem (1976); Geschichte der Grafschaften Alemanniens in fränkischer Zeit (1984); Petrusnachfolge und Kaiserimitation. Die Grablegen der Päpste, ihre Genese und Traditionsbildung (1989, $\left.{ }^{2} 1995\right)$; Die mittelalterliche Kirche (1992); Sozialgeschichte des Mittelalters. Eine Forschungsbilanz nach der deutschen Einheit (1996); (Hrsg.) Mittelalterforschung nach der Wende 1989 (1995); (Hrsg.) Europa im Mittelalter. Abhandlungen und Beitrăge zur historischen Komparatistik, Bde. 1 ff. (1999 ff.); (Hrsg.), Stiftungsgeschichten, Bde. 1 ff. (2000 ff.).

David L. d'Avray, geb. 1952; Studium in Cambridge, Oxford (Promotion), Paris und München; seit 1977 am University College London als Lecturer, Reader (1993) und Professor (1996) tătig; Alexander von Humboldtstipendiat 1983/84; Directeur d'Etudes invité an der Ecole des Hautes Etudes en Sciences Sociales 1997.

Veröffentlichungen u. a.: The Preaching of the Friars. Sermons diffused from Paris before 1300 (1985); Death and the Prince. Memorial Preaching before 1350 (1994); Medieval Marriage Sermons. Mass Communication in a Culture without Print (2001).

Stawomir Gawlas, geb. 1949; Promotion 1979 in Warschau; Habilitation 1996 in Warschau; seit 1998 Professor fur Geschichte des Mittelalters an der Universităt Warschau.

Veröffentlichungen u. a.: O kształt zjednoczonego Królestwa: niemieckie władztwo terytorialne a geneza społecznoustrojowej odrębności Polski (1996, $\left.{ }^{2} 2000\right)$; Mittelalterliche Nationenbildung am Beispiel Polens, in: Mittelalterliche Nationes - neuzeitliche Nationen. Hrsg. v. Almut Bues/Rex Rexheuser (1995); Die Territorialisierung des Deutschen Reichs 
und die teilfurrstliche Zersplitterung Polens zur Zeit des hohen Mittelalters, in: Quaestiones Medii Aevi Novae 1 (1996).

Patrick J. Geary, geb. 1948; Professor fur Mittelalterliche Geschichte an der University of California, Los Angeles.

Veröffentlichungen u. a.: Furta Sacra: Thefts of Relics in the Central Middle Ages (1978, rev. ed. 1991); Aristocracy in Provence: The Rhone Basin at the Dawn of the Carolingian Age (1985); Die Merowinger (1996; engl. 1988); Living with the Dead in the Middle Ages (1994); Phantoms of Remembrance: Memory and Oblivion at the end of the first Millenium (1994).

Hans-Werner Goetz, geb. 1947; Studium der Geschichte und Anglistik an der Ruhr-Universität Bochum 1969-1974; Promotion 1976; Habilitation 1981; seit 1990 Professor für Mittelalterliche Geschichte an der Universität Hamburg; Forschungsschwerpunkte: Geschichtsschreibung, Geschichtsdenken und Geschichtsbewußtsein; Vorstellungswelten und Mentalităten, Verfassung und Gesellschaft des frühen und hohen Mittelalters.

Veröffentlichungen u. a.: „Dux“ und „Ducatus“ (1977); Die Geschichtstheologie des Orosius (1980); Strukturen der spätkarolingischen Epoche (1981); Das Geschichtsbild Ottos von Freising (1984); Leben im Mittelalter (1986); Proseminar Geschichte (1993); Frauen im frühen Mittelalter (1995); (zusammen mit Gerd Althoff und Ernst Schubert) Menschen im Schatten der Kathedrale (1998); Geschichtsschreibung und Geschichtsbewußtsein (1999); Moderne Mediävistik (1999).

Johannes Helmrath, geb. 1953; Studium der Geschichte, Philosophie und Lateinischen Philologie in Aachen, Köln, Bonn, Toulouse und Paris; Promotion 1984; 1981-1988 Wiss. Assistent in Aachen und Köln; 1988-1997 Mitarbeiter der Forschungsstelle ,Deutsche Reichstagsakten' in Köln; seit 1997 Professor für Geschichte des Mittelalters an der Humboldt-Universität zu Berlin.

Veröffentlichungen u. a.: Das Basler Konzil 1431-1449 (1987); Reichstag und Rhetorik. Die Reichstagsreden des Enea Silvio Piccolomini (Habil.schrift Köln 1994; im Druck); (Hrsg.) Studien zum 15. Jahrhundert. Fschr. fur Erich Meuthen zum 65. Geburtstag (1994); (Hrsg.) Quellen zur Geschichte der Stadt Köln, Bd. 2 (1996).

Svetlana Luchitskaja, Promotion 1989 mit einer Arbeit über „Das Rittertum im lateinischen Königtum von Jerusalem“; Mitarbeit an der „Enzyklopädie der mittelalterlichen Kultur“ (Prof. Aaron J. Gurjewitsch); wissenschaftliche Mitarbeiterin am Institut für Allgemeine Geschichte der Russischen Akademie der Wissenschaften; gegenwärtige Forschungsfelder: „Das Bild des Anderen im Mittelalter", mittelalterliche Ikonographie. 
Veröffentlichungen u. a.: L'image de l'arabe dans les chroniques des croisades, in: MA 105 (1999), 717-737; Barbarae nationes: les peuples musulmans dans les chroniques de la Première croisade, in: Autour de la Première croisade. Actes du colloque réunis par Michel Balard (1996), 99-107; La conversion réelle ou imaginaire? Les musulmans vus par les Chroniqueurs de la Première croisade, in: Le Partage du Monde. Colloque du G. D. R. 927 (1998), 193-202; The image of Muhammad in the Latin chronography, in: JMedH 26 (2000), 115-126; Muslims in Christian Imagery of the $13^{\text {th }}$ century: The Visual Code of the Otherness, in: Al-Masaq. Islam and the Medieval Mediterranean, vol. 12 (2000), 37-67. Obraz drugogo: musul'mane v chronikach krestovich pochodov [Das Bild des Anderen: Die Muslime in den Kreuzzugschroniken] (2001).

François Menant, geb. 1948; Studium in Paris (Ecole Normale Supérieure und Sorbonne) und Rom (Ecole française de Rome); Professor fur Mittelalterliche Geschichte an der Ecole Normale Supérieure, Paris; Co-dirige actuellement un programme de recherche international du Centre National de la Recherche Scientifique: „Mécanismes économiques et fonctions sociales de la circulation des biens dans l'Occident médiéval (XI-XV'me siècles): prélèvement seigneurial, marché foncier, crédit“".

Veröffentlichungen u. a.: Lombardia feudale. Studi sull'aristocrazia padana dei secoli XXIII (1992); Campagnes lombardes du Moyen Age (Thèse d'Etat, 1993); (dir.) Les Capétiens, histoire et dictionnaire (1999); (dir. en collaboration) L'anthroponymie, document de l'histoire sociale des mondes médiévaux méditerranéens (1997).

Tore Nyberg, geb. 1931; nach Studienjahren in Uppsala, Lund und München und zahlreichen Forschungsreisen seit 1969 in Dänemark; dort seit 1970 in Odense im Bereich von Forschung und Lehre in mittelalterlicher Geschichte tătig.

Veröffentlichungen u. a.: Birgittinische Klostergrundungen des Mittelalter (1965); Dokumente und Untersuchungen zur inneren Geschichte der drei Birgittenklöster Bayerns 1420-1570, 2 Bde. (1972-1974); Skt. Peters efterfølgere i brydningstider. Omkring pavedømmets historie, Rom og Nordeuropa 750-1200 [Die Nachfolger Petri in Zeiten des Umbruchs. Über Papsttum, Rom und Nordeuropa 750-1200] (1979); Die Kirche in Skandinavien. Mitteleuropäischer und englischer Einfluss im 11. und 12. Jahrhundert (1986). Birgittinsk festgåva [Birgittinische Festgabe], hrsg. von C. F. Hallencreutz und A. Härdelin (1991) [gesammelte Aufsătze in schwedischer Sprache zur Hl. Birgitta von Schweden und den Birgittenorden]; Monasticism in NorthWestern Europe, c. 800-1200 (2000).

Otto Gerhard Oexle, geb. 1939, Direktor am Max-Planck-Institut furr Geschichte in Göttingen und Honorarprofessor fur Mittlere und Neuere Geschichte an der Georg-August-Universität Göttingen.

Veröffentlichungen u. a.: (Hrsg.) Memoria als Kultur (1995); Geschichtswissenschaft im Zeichen des Historismus (1996); (Hrsg.) Stand und Perspektiven der Mittelalterforschung am Ende des 20. Jahrhunderts (1996); (Hrsg., mit Andrea von Hülsen-Esch) Die Repräsen- 
tation der Gruppen. Texte - Bilder - Objekte (1998); (Hrsg.) Naturwissenschaft, Geisteswissenschaft, Kulturwissenschaft (1998); (Hrsg., mit Winfried Schulze) Deutsche Historiker im Nationalsozialismus (1999); Kulturelles Gedächtnis in der Renaissance. Die Fuggerkapelle bei St. Anna in Augsburg (2000); (Hrsg.) Das Problem der Problemgeschichte 1880-1932 (2001).

Marina Paramonova, geb. 1963; Studium der Geschichte an der Moskauer LomonossowStaatsuniversität 1980-1985; Promotion 1990; wissenschaftliche Mitarbeiterin am Institut für Slawenkunde und Balkanistik der Russischen Akademie der Wissenschaften 1989-1995; seit 1996 wissenschaftliche Mitarbeiterin am Institut für Allgemeine Geschichte der Russischen Akademie der Wissenschaften; seit 1999 Mitarbeit am Forschungsprojekt „Die vergleichende Geschichte der lateinischen und altrussischen Kulturen“"

Veröffentlichungen u. a.: Kul'ty svjatych korolej v Zapadnoj i Central'noj Evrope, in: Drugie srednie veka. K 75-letiju A. Ja. Gurevič [Kulte der heiligen Könige in West- und Zentraleuropa, in: Das andere Mittelalter. Festschrift zum 75. Geburtstag von A. J. Gurewitsch] (2000); Politiko-ideologiðeskie idei pervych svjatovaclavskich žitij, in: Slavjano-germanskie issledovanija. Čast' 1 [Politisch-theologische Ideen der ersten Wenzelslegenden" in: Slawisch-deutsche Studien. Teil 1] (2000); Slavjanskij Vostok v Chronike Titmara Merzeburgskogo. Obraz „inogo“ na peresecenii ideologii i ritoriki [Der slawische Osten in der Chronik von Thietmar. Das Bild des "anderen" im Kreuzpunkt von Ideologie und Rhetorik], in: Odissej (1998/1999); Heiligkeit und Verwandtschaft: die dynastischen Motive in den lateinischen Wenzelslegenden und den Legenden des Boris und Gleb, in: Fonctions sociales et politiques du culte des saints dans les sociétés de rite grec et latin au Moyen Âge et au début de l'époque moderne. Approche comparative (1999); Kul'ty svjatych pravitelej v Latinskoj Evrope i Kievskoj Rusi: sravnitel'nyj analiz svjatovaclavskogo i borisoglebskogo kul'tov [Kulte der heiligen Herrscher in Lateineuropa und in der Kiewer Rus': vergleichende Analyse der Wenzel- und Boris-Gleb-Kulte] (2001, im Druck).

Jan Maria Piskorski, geb. 1956; Studium der Archivistik, Geschichte, Latein und altslavischer Sprachen in Posen und Göttingen; Professor für Alte und Mittlere Geschichte an der Universität Szczecin und Leiter des Verlags des Poznańskie Towarzystwo Przyjaciół Nauk (The Poznań Society for the Advancement of the Arts and Sciences); Gastprofessor an den Universitäten Mainz (1997) und Halle/S. (1998).

Jüngere Veröffentlichungen u. a.: Die mittelalterliche Ostsiedlung - ein alter Streit und neue Ergebnisse, in: Transit Brugge-Nowgorod. Eine Straße durch die europäische Geschichte. Hrsg. v. Ferdinand Seibt u. a. (1997); „Das Kreuzritter-Reptil wird niemand zähmen“. Adam Micklewicz über den Deutschen Orden und die Deutschen, in: GWU 48, 1997; Breslau, in: Die Hanse. Lebenswirklichkeit und Mythos. Hrsg. v. Jörgen Bracker u. a. ( $\left.{ }^{3} 1999\right)$; (Hrsg. und Mitverfasser) Stettin. Kurze Stadtgeschichte ( $\left.{ }^{2} 1998\right)$. 
Daniela Rando, geb. 1959; Studium in Padua und Venedig; Promotion 1987; Ricercatrice in Storia medievale an der Universität Trient; Alexander von Humboldt-Stipendiatin 1993/94; Gastwissenschaftlerin am Institut fur Vergleichende Geschichte Europas im Mittelalter der Humboldt-Universität 1999/2000.

Veröffentlichungen u. a.: Una Chiesa di frontiera. Le istituzioni ecclesiastiche veneziane nei secoli VI-XII (1994); Religione e politica nella Marca. Studi su Treviso e sul suo territorio nei secoli XI-XV (1996); (zusammen mit M. Motter) Il „quaternus rogacionum“ del notaio Bongiovanni di Bonandrea (1308-1320) (1997).

Frank Rexroth, geb. 1960; Studium der Geschichte und Germanistik in Freiburg i. Br.; Promotion 1988; Mitarbeiter am Deutschen Historischen Institut London 1989-1992; Postdoc-Stipendiat am Max-Planck-Institut fur Geschichte in Göttingen 1991-1992; Assistent und Privatdozent an der Humboldt-Universităt zu Berlin 1992-1999 (Habilitation 1998); Professor für Geschichte des späten Mittelalters und der Frühen Neuzeit an der Universităt Bielefeld 1999; seit 2000 Professor fur Mittlere und Neuere Geschichte an der Universität Göttingen.

Veröffentlichungen u. a.: Deutsche Universitätsstiftungen von Prag bis Köln (1992); Das Milieu der Nacht. Obrigkeit und Randgruppen im spätmittelalterlichen London (1999).

Bernd Schneidmüller, geb. 1954; Studium in Zürich und Frankfurt/Main; Promotion 1977; Habilitation 1985; Professor an den Universitäten Oldenburg (1987-1990), Braunschweig (1990-1994) und Bamberg (seit 1994).

Veröffentlichungen $u$. a.: Karolingische Tradition und frühes französisches Königtum (1979); Nomen patriae. Die Entstehung Frankreichs in der politisch-geographischen Terminologie (1987); Die Welfen (2000); Herausgeber mehrerer Sammelbände, zuletzt: Ottonische Neuanfänge (2001).

Karl-Heinz Spieß, geb. 1948; Studium der Anglistik und Geschichte in Mainz und Aberdeen; Promotion 1977; Habilitation 1992; Lehrstuhlvertretung in Kassel 1993/94; seit 1994 Inhaber des Lehrstuhls fur Allgemeine Geschichte des Mittelalters und Historische Hilfswissenschaften an der Universität Greifswald; Sprecher des Mittelalterzentrums Greifswald 1995-2001.

Veröffentlichungen u. a.: Lehnsrecht, Lehnspolitik und Lehnsverwaltung der Pfalzgrafen bei Rhein im Spätmittelalter (1978); Das älteste Lehnsbuch der Pfalzgrafen bei Rhein vom Jahr 1401 (1981); Familie und Verwandtschaft im deutschen Hochadel des Spätmittelalters (13. bis Anfang des 16. Jahrhunderts) (1993); (Mithrsg.) Landesgeschichte und Reichsgeschichte. Fschr. fur Alois Gerlich zum 70. Geburtstag (1995); (Mithrsg.) Fremdheit und Reisen im Mittelalter (1997); (Mithrsg.) Prozesse der Normbildung und Normveränderung im mittelalterlichen Europa (2000). 
Jerzy Strzelczyk, geb. 1941; Inhaber des Lehrstuhls furr mittelalterliche Geschichte an der Adam-Mickiewicz-Universität zu Poznań; Alexander von Humboldt-Stipendiat. Korrespondierendes Mitglied der Polnischen Akademie der Wissenschaften (Polska Akademia Umiejetności) in Kraków und der Historischen Kommission zu Berlin; Mitglied der Posener Gesellschaft der Freunde der Wissenschaften (Poznańskie Towarzystwo Przyjaciół Nauk). Forschungsschwerpunkte: ethnische, politische und kulturelle Aspekte der europäischen Geschichte des frühen und hohen Mittelalters; Geschichte Deutschlands und der (west-) slawischen Welt im Mittelalter; Entwicklung des geographischen Wissens und der geographischen Gelehrsamkeit in Altertum und Mittelalter.

Veröffentlichungen u. a. (deutsche Titel): Die Entdeckung Europas (1970, ${ }^{2} 2000$ ); Gervasius von Tilbury. Aus der Geschichte der geographischen Gelehrsamkeit im Mittelalter (1970); Slawen und Germanen in Mitteldeutschland im früheren Mittelalter (1976); Die Goten Geschichte und Legende (1984); Die Iren in der Kultur des mittelalterlichen Europa (1987); Die Wandalen und ihr afrikanischer Staat (1992); Mieszko der Erste (1992; $\left.{ }^{2} 1999\right)$; Die Apostel Europas (1997); Mythen, Legenden und Traditionen der alten Slawen (1998); Bolesław Chrobry (2000); Otto III. (2000). Mehrere Quelleneditionen (Helmold von Bosau; Navigatio s. Brendani; Johannes de Piano Carpini; Kolumban von Luxeuil) und Sammelbände. 



\section{Abkürzungs- und Siglenverzeichnis}

\begin{tabular}{|c|c|c|c|}
\hline Abh. & Abhandlung(en) & Chron. & Chronica \\
\hline Abt. & Abteilung & COD & Conciliorum Oecumenicorum \\
\hline Ačad. Sc. Hung. & $\begin{array}{l}\text { Academicate Scientiarum Hun- } \\
\text { garicae }\end{array}$ & $\operatorname{col}(\mathbf{s})$ & $\begin{array}{l}\text { Decreta } \\
\text { column(s), colonne }\end{array}$ \\
\hline A. D. & Anno Domini & Ciolo. & Colorado \\
\hline AtD & Archiv für Diplomatik & cur. & curavit/-verunt \\
\hline $\mathrm{AHC}$ & $\begin{array}{l}\text { Annuarium Histöriae Cónçi- } \\
\text { liorum }\end{array}$ & d. & died \\
\hline AHR & American Historical Review & D.A & $\begin{array}{l}\text { Deutsches Archiv für Erfor- } \\
\text { schung des Mittelalters }\end{array}$ \\
\hline $\mathrm{AHVN}$ & $\begin{array}{l}\text { Annalen des Historischen } \\
\text { Vereins für den Niederrhein }\end{array}$ & DHEE & $\begin{array}{l}\text { Diccionário de Historia eccle- } \\
\text { siástica de España }\end{array}$ \\
\hline Akād. & Akâdemie & $\mathrm{DHI}$ & Deutsches Historisches Institut \\
\hline AKG & Archiv fur Kulturgéschichte & dir. & directeur(s), diritto (u. ă..) \\
\hline Annales & $\begin{array}{l}\text { Annales. Économies, Sociétés, } \\
\text { Civilisations bzw. Annales. } \\
\text { Histoire, Scieñces Sociales }\end{array}$ & $\begin{array}{l}\text { DS } \\
\text { Ebf. }\end{array}$ & $\begin{array}{l}\text { Diözesansynode(n) } \\
\text { Erzbischof }\end{array}$ \\
\hline ArchHPont & Archivum histōriae pontificiae & EdG & Enzyklopädie deutscher \\
\hline Basler Z & $\begin{array}{l}\text { Basler Zeitschrift für Ge- } \\
\text { schichte und Altertumskunde }\end{array}$ & e.g. & $\begin{array}{l}\text { Geschichte } \\
\text { exempli gratia }\end{array}$ \\
\hline B. C. & Before Christ & EHR & English Historical Review \\
\hline Bd./Bde. & Band/Bände & erw. & erweitert(e) \\
\hline betarib. & bearbeitet & esp. & especially \\
\hline BECh & $\begin{array}{l}\text { Bibliothèque de l'École des } \\
\text { Chartes }\end{array}$ & $\begin{array}{l}\text { Fasc. } \\
\text { fl. }\end{array}$ & $\begin{array}{l}\text { Fascicule } \\
\text { florenus/-i }\end{array}$ \\
\hline Beih. & Beiheft(e) & FMSt & Frühmittelaitterliche Studien \\
\hline Bf. & Bischof & Forsch. & Forschungen \\
\hline BlldtLG & $\begin{array}{l}\text { Blätter für deutsche Landes- } \\
\text { geschichte }\end{array}$ & FRB & Fontes Rerum Bohemicarum \\
\hline c. & canon, capitulum, causa, circa & Fs. Fsn. & Fürst-in \\
\hline cap. & capitulum & Fschr. & Festschrift \\
\hline CCM & $\begin{array}{l}\text { Cahiers de civilisation } \\
\text { médiévale }\end{array}$ & FSGA & $\begin{array}{l}\text { Ausgewählte Queillen zur } \\
\text { deutschen Geschichte des } \\
\text { Mittelalters. Freiherr vom }\end{array}$ \\
\hline cf. & confer & & Stein-Gedächtnisausgabe \\
\hline ch. & chapter & Gesch. & Geschichte \\
\hline
\end{tabular}




\begin{tabular}{|c|c|c|c|}
\hline $\begin{array}{l}\text { gest. } \\
\text { Gf.. }\end{array}$ & $\begin{array}{l}\text { gestorben } \\
\text { Graf }\end{array}$ & NdsJb & $\begin{array}{l}\text { Niedersächsisches Jahrbuch für } \\
\text { Landesgeschichte }\end{array}$ \\
\hline Gft. & Grafschaft & NF. & Neue Folge \\
\hline GG & Geschichte und Gesellschaft & NS. & Nova Series \\
\hline GWU & Geschichte in Wissenschaft und & phil. & philosophisch(e) \\
\hline H. & $\begin{array}{l}\text { Unterricht } \\
\text { Heft }\end{array}$ & PG & $\begin{array}{l}\text { J. P. Migne. Patrologiae com- } \\
\text { pletus cursus. Series Graeca }\end{array}$ \\
\hline Habil. & Habilitationsschrift & PL & $\begin{array}{l}\text { J. P. Migne. Patrologiae com- } \\
\text { pletus cursus. Series Latina }\end{array}$ \\
\hline HessJbLG & $\begin{array}{l}\text { Hessisches Jahrbuch für } \\
\text { Landesgeschichte }\end{array}$ & P \& P & Past and Present \\
\hline Hg./Hgn. & Herzog/-in & PR & Pipe Roll(s) \\
\hline HJb & Historisches Jahrbuch & Praef. & Praefatio \\
\hline HRG & $\begin{array}{l}\text { Handwörterbuch zur deutschen } \\
\text { Rechtsgeschichte }\end{array}$ & $\begin{array}{l}\text { PS } \\
\text { o. J. }\end{array}$ & $\begin{array}{l}\text { Provinzialsynode(n) } \\
\text { ohne Jahr }\end{array}$ \\
\hline $\mathrm{HZ}$ & Historische Zeitschrift & q. & quaestio \\
\hline $\begin{array}{l}\mathrm{Jb}(\mathrm{b}) \\
\mathrm{JbGMOD}\end{array}$ & $\begin{array}{l}\text { Jahrbuch(-bücher) } \\
\text { Jahrbuch für die Geschichte }\end{array}$ & RBPH & $\begin{array}{l}\text { Revue Belge de philologie et } \\
\text { d'histoire }\end{array}$ \\
\hline & Mittel- und Ostdeutschlands & Red. & Redaktion \\
\hline JbWG & Jahrbuch für Wirtschafts- & ref. & reference \\
\hline & geschichte & Reg. & Register \\
\hline JMedH & Journal of Medieval History & repr. & reproduction, reprint \\
\hline K1. & Klasse, Kloster & rev. & revidiert, revised, revisé(e) \\
\hline lib. & liber & RH & Revue historique \\
\hline LMA & Lexikon des Mittelalters & Rh. & Reihe \\
\hline LThK & $\begin{array}{l}\text { Lexikon für Theologie und } \\
\text { Kirche }\end{array}$ & $\begin{array}{l}\text { RhVjbll } \\
\text { ROA }\end{array}$ & Rheinische Vierteljahrsblätter \\
\hline MA & $\begin{array}{l}\text { Le moyen âge. Revue d'histoire } \\
\text { et de philologie }\end{array}$ & RQA & $\begin{array}{l}\text { Römische Quartalschrift für } \\
\text { christliche Altertumskunde und } \\
\text { Kirchengeschichte }\end{array}$ \\
\hline masch. & maschinenschriftlich & s. & siehe, siècle(s), sanctus (u. ă.) \\
\hline Mass. & Massachusetts & sc. & scilicet \\
\hline $\begin{array}{l}\text { Mgf./Mgfn. } \\
\text { MGH }\end{array}$ & $\begin{array}{l}\text { Markgraf/-grăfin } \\
\text { Monumenta Germaniae }\end{array}$ & ScanJH & $\begin{array}{l}\text { Scandinavian Journal of } \\
\text { History }\end{array}$ \\
\hline & Historica & sec. & secolo/-i \\
\hline LL & Leges & Ser. & Serie/-a \\
\hline Schr. & Schriften & Sp. & Spalte \\
\hline SS rer. Germ. & $\begin{array}{l}\text { Scriptores rerum Germani- } \\
\text { carum in usum scholarum } \\
\text { separatim editi }\end{array}$ & SSCI & $\begin{array}{l}\text { Settimane di studio del Centro } \\
\text { Italiano di studi sull'Alto } \\
\text { Medioevo }\end{array}$ \\
\hline MIC & Monumenta Iuris canonici & StorStor & Storia della Storiografia \\
\hline MIÖG & $\begin{array}{l}\text { Mitteilungen des Instituts für } \\
\text { Österreichische Geschichts- } \\
\text { forschung }\end{array}$ & $\begin{array}{l}\text { s.v. } \\
\text { t./T. }\end{array}$ & $\begin{array}{l}\text { sub voce } \\
\text { tomus/Teil(e) }\end{array}$ \\
\hline $\mathrm{PH}$ & $\begin{array}{l}\text { Monumenta Poloniae Historica } \\
\text { Nachdruck, Neudruck }\end{array}$ & $\begin{array}{l}\text { trad. } \\
\text { transl. }\end{array}$ & $\begin{array}{l}\text { traduction } \\
\text { translated }\end{array}$ \\
\hline
\end{tabular}




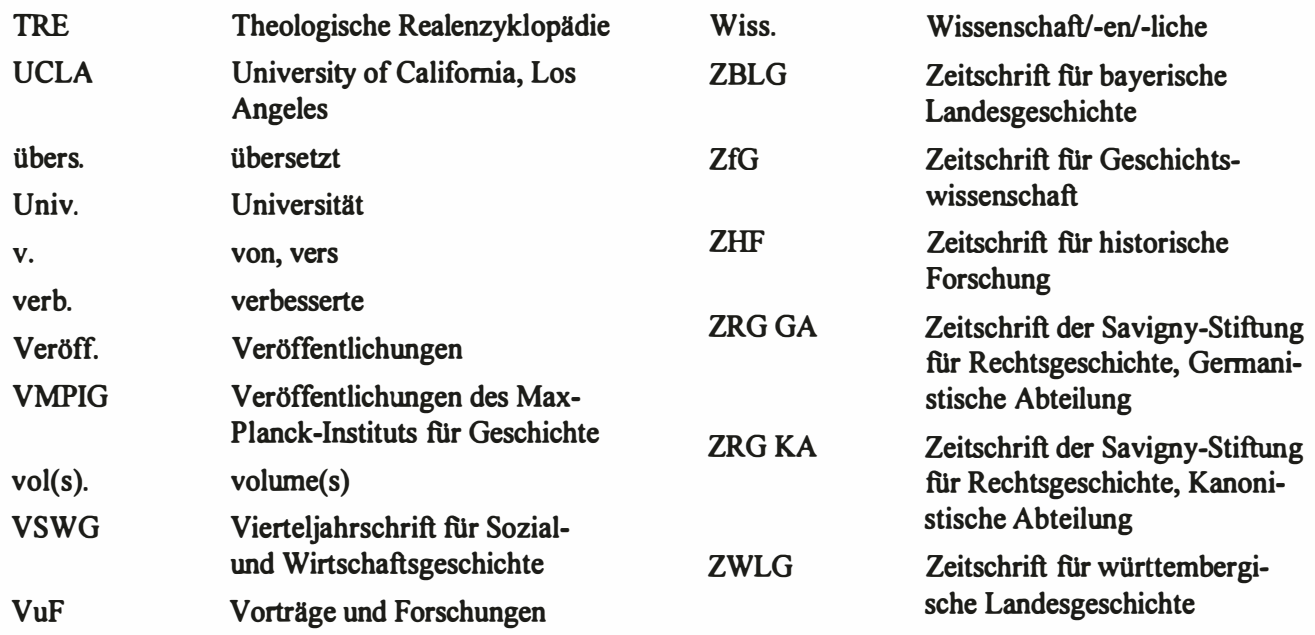





\section{Indices}

Die kursivierten Seitenangaben verweisen auf den Anmerkungsapparat. Moderne Wissenschaftler wurden nur aufgenommen, wenn sie im Text erwăhnt werden. Auf eine Aufnahme von ,Europa', ,Vergleich' und deren Ableitungen wurde verzichtet; ebenfalls unberücksichtigt blieben die in den Beilagen auf S. 336-338 erwähnten Personen.

\section{Personen}

'Abd Allah ibn Tâhir, Statthalter v. Bagdad 193

Acciaiuoli, Donato 243

Adalbert

-, Ebf. v. Hamburg-Bremen 154

-, Bf.. v. Prag 252

Adam v. Bremen 15, 16

Adamnán 308

Ademar v. Chabannes 325

Adso Derviensis 289

Aelfric of Eynsham 125

Aeneas 356

Æthelflaed, Tochter Alfreds de Großen 307

Æthelstan, engl. Kg. 307

Ajax 349

al-Afdal, Wesir 292

Albert, Vogt 120

Albertus Benvenuti Aripandi de Rossis 94

Albrecht

- II., dt. Kg. 353

- Achilles, Mgf. v. Brandenburg 346, 348, 352,354

Alexander

- der Große 367

- IV., Papst 161

- v. Roes 334

Alexios I. Komnenos, byz. Ks. 225-229, 234, $235,245,287$
Al-Fadl ibn Sahl, Wesir 192

Alfons

- II., Kg. v. Neapel 348

- V., Kg. v. Portugal 349

-, Sohn Kg. Johanns II. v. Portugal 349

Alfred der Große, Kg. der Westsachsen 307, 308

Algazi, Gadi 376

al-Mahdî, Kalif v. Bagdad 188

al-Ma'mûn, Kalif v. Bagdad 188, 192

Alvarus v. Cordoba 288

al-Washshâ' 195

al-Zubayr ibn Bakkâr 193

Ammianus Marcellinus 313

Andersen, Per Sveaas 201

Andrássy, Julius Gf.., Jr. 50

Andreas

- II., Kg. v. Ungarn 50

- III., Kg. v. Ungarn 57

- v. Marchiennes 325, 328

Andreas, Willy 179-183, 379

Andrew, Bf. v. Caithness 313

Anna

- (Anne de Bretagne), Kgn. v. Frankreich 180

- Komnene 225-229, 234, 235, 245, 246, 376

Antoine de Bourgogne, Hg. v. Brabant 351

Antoninus, Ebf. v. Florenz 153

Antoninus Pius, Ks. 309

Apollin 291, 292

Apollo 283, 292, 294 
Apponyi, Albert Gf. 50

Arbman, Holger 199

Aristides 176

Aristōteles 43, 212

Amulf v. Kämten, Ks. 326

Artonne, André 152

Assmann, Jan 373

Athelstan s. Athelstan

Auerbach, Erich 224, 225

Augustinus 42, 211, 215

Avril, Joseph 144, 146, 147

Aymon de Grandson, Bf. v. Genf 157

Bach, Johann Sebastian 42

Bàder, Kärl Siegfried 132

Bagge, Sverre 376

Bahrâm Gû̀, persischer Kg. 192, 193, 196

Bak, Jánōs M. 377, 379

Baligant 291

Barnim I., Hg. v. Pommern 112

Baron, Hāns 246

Barraclough, Geoffrey 16

Barrow, Geoffrey W. S. 377

Barthélemy, Dominique 84, 106

Bartlett, Robert 18, 34

Beatrix v. Neapel/Aragón, Kg. v. Ungarn 352,353

Beck, Hans-Georg 174

Beda Venerabilis 305, 306, 308, 309

Bentivoglio, Annibale 3.50

Bernard d'Angers (Bernardus Andegavensis) 295

Bichler, Reinhold 30

Binz, Louis 139

Birger Gunnerseñ, Ebtet. v. Lund 203

Birgitta v. Schweden (Birgirsdotter) 203

Bisson, Thomas N. 78, 105

Bleiber, Waltraut 80

Bloch, Marc 33, 37, 38, 76, 93, 102, 104, 317,373

Buhemund I. v. Tarent, Fs. v. Antiochia 229

Bois, Guy 84

Boleslav I., Fs. v. Böhmen 250, 254, 257-263, $264,275-279$

Bolesław

- I. Chrobry, Kg. v. Polen 364

- III. Krzywousty, Fs. v. Polen 117, 364, 366, 367

Buna v. Savoyen, Hgn v. Mailand 348,354
Bonifaz VIII., Papst 240

Bonnassie, Pierre 78, 83, 84

Borgia, Lucrezia 355

Borgolte, Michael 65, 374, 375

Borilos 225, 226

Boris, hl. 259, 281

Bơ̌ivoj I., Fs. v. Böhmen 272, 273

Borromeo, Carlo 153

Bossuet, Jacques Bénigne 180

Bournazel, Éric 84, 104, 105

Branda, Kardinal 160

Brandt, William 223-225

Braudel, Fernand 2.2

Breengaard, Carsten 201

Brown, Elisabeth A. R. 101

Brühl, Carlrichard 317

Brundage, James A. 210

Bruni, Leonardo 224, 239-246

Brunner, Otto 2.2, 75, 87

Bruno v. Schauenburg, Bf. v. Olmütz 113

Burckhardt, Jacob 177, 178, 180, 182, 343

Camille, Michael 295, 296

Caro, Georg 184

Carocci, Sandro 91

Cech 368

Cheney, Christopher R. 145

Christian

- 267, 268, 270, 271, 273, 274, 275, 276 . 277,279

- I., Kg. v. Dănemark, Norwegen und Schweden 203, 208

Christoph, Hg. v. Bayem 352

Cicero 43, 284

Coleti, Niccold 143

Columban, hll. 312

Compagni, Dino 241, 242, 244, 245

Condorcet, Jean A. N. C de 18

Crabbe, Petrus 143

Criassius 367

Crouzet-Pavan, Elisabeth 182

Danieils, Emil 172, 173

Dannenbauer, Heinnrich 129, 131

Dante Allighieri 15

Dauvillier, Jean 210

David 23I

Davidsohn, Robert 184

Davies, Norman 25, 26

D'Avray, David L. 377 
Dawson, Christopher 18

Delanuelle, Étienne 165

Dette, Christoph 79

Devroey, Jean-Pierre 78-80

Dilcher, Gerhard 46

Dollinger, Philippe 73

Dopsch, Alfons 75

Drahomir (Drahomíra), Fsn. in Böhmen 255, 256, 259, 260, 261-263, 264, 276-278

Drar, Kristin 201

Drory, Rina 187, 376

Duarte s. Eduard

Duby, Georges 58, 63, 76, 77, 83, 84, 191, 194

Duranti, Guillelmus, Bf. v. Mende 160

Durkheim, Emile 25, 52, 372

Durliat, Jean 80, 83

Dygo, Marian 114

Dzierzwa/Mierzwa 367

Eadred, Kg. v. England 307

Eberhard V. im Bart, Gf./Hg. v. Württemberg 353

Edmund, Kg. v. England 307

Eduard

- der Ältere, Kg. v. Wessex 307

- ,der Märtyrer', hl., Kg. v. England 259

-IV., Kg. v. England 356

-, Kg. v. Portugal 349

Egbert, Kg. v. Wessex 303

Eike v. Repchow 115

Ekkehard I., Mgf. v. Meißen 230

Eleonore

- v. Portugal, Ksn. 348, 349

-, Kgn. v. Frankreich, Kgn. v. England 216, 218

- (Leonore) v. Aragón 349

- v. Aragón 348

Elisabeth

- v. Görlitz, Hgn. v. Görlitz und Luxemburg 351

- v. Monfeltro 351

Elmshăuser, Konrad 80, 81

Enea Silvio Piccolomini s. Pius II.

Engel, Pál 56

Enke, Kurt 342

Ericus Olai 205

Erik

- IX. der HI., Kg. v. Schweden 202

- Valkendorf, Ebf. v. Drontheim 203
Este

-, Alfonso I. d', Hg. v. Ferrara 355

-, Ercole I. d', Hg. v. Ferrara 348, 356

-, Isabella d' 350

-, Lucrezia d' 350

Esther 345

Ethelred, Kg. v. Wessex 231

Eulogios v. Cordoba, hl. 288

Euthymios Zigabenos 287

Fallmerayer, Jakob Philipp 174

Fasoli, Gina 173

Ferro, Marc 125, 126

Fichtenau, Heinrich 34

Flodoard v. Reims 324

Folda, Jaroslav 286

Folz, Robert 57

Fossier, Robert 65, 77, 82

Friedrich

- I., Ks. 109, 238, 331, 333

- II., Ks. 332

- III., Ks. 343, 346, 347, 349

- I., Pfalzgf. bei Rhein 353

- v. Flersheim 353

Fritz, Birgitta 204

Fügedi, Erik 56, 60-63

Fulcher v. Chartres 284, 285, 296

Gadamer, Hans-Georg 172

Gallus Anonymus 105, 116, 366, 367

Ganshof, François 99

García y García, Antonio 145

Gaudemet, Jean 210

Gawlas, Sławomir 379

Genicot, Léopold 58, 63

Georg

-, hl. 294

- der Reiche, Hg. v. Bayern-Landshut 346, 347

George Neville, Ebf. v. York 167

Geraldus v. Aurillac, hl. 295

Gerbert v. Aurillac 324

Gereon, hl. 164

Gerics, József 57

Germanos 225

Gibbon, Edward 18

Gianfigliazzi, Rainaldo 243, 244

Giano della Bella 240, 241

Giovanni Tavelli, Bf.. v. Ferrara 153

Giraldus Cambrensis 125

Gisela, Ksn. 327, 328 
Gleb, hl. 259, 281

Goetz, Hans-Werner 78, 377

Goffart, Walter 77

Goliath 231

Gonzaga

-, Barbara 353

-, Elisabetta 350

-, Gian Francesco 350

-, Rudolfo 347

Gonzalo Vargas, Bf. v. Tarragona 151

Goody, Jack 40

Gratian 211, 215

Graus, František 57, 362, 374

Gregor v. Tours, hl. 224, 225, 233, 242

Gregorovius, Ferdinand 184

Guicciardini, Francesco 224

Guido de Monte Roterio s. Guillaume de Montrocher

Guillelmus Durandus v. Mende s. Duranti, Guillelmus

Guillaume de Lorris 191

Guillaume de Montrocher 168

Guizard, Louis 152

Guizot, François 25, 26

Gumpold, Bf. v. Mantua 251-254, 265, 267, 268-271, 274, 275, 279

Györffy, György 56

Hăgermann, Dieter 77, 79, 82, 86

Hajnal, István 53, 59, 64

Håkon

- IV. Håkonsson, Kg. v. Norwegen 238, 239

-, Jarl 231

Halecki, Oskar 18

Halphen, Louis 372

Hardouin, Jean 143

Harrison, Dick 201

Hartmann, Ludo Moritz 173

Hartzheim, Joseph 143

Harûn al-Rashîd, Kalif v. Bagdad 189

Hauck, Albert 138

Haupt, Heinz-Gerhard 373

Heccard, Gf. 81

Hector 349

Hedwig, Andreas 80, 81

Heermann, Johann 42

Heers, Jacques 211

Hefele, Karl Joseph 138
Heinrich

- I., Kg. des ostfrk.-dt. Reiches 229, 233, 234, 326, 327

- II., hl., Ks. 229, 230, 232, 235, 236, 331

- III., Ks. 328

-IV., Ks. 237, 333

- V., Ks. 321, 322, 329

- VI., Ks. 332

-III., Kg. v. England 216-219

- VI., Kg. v. England 348

- VII., Kg. v. England 351, 356

- VIII., Kg. v. England 351

- I., Hg. v. Schlesien 364

- II., Hg. v. Schlesien 364

Helle, Knut 201

Hellström, Jan Arvid 206

Helmholz, Richard H. 210

Helmold v. Bosau 125

Helmrath, Johannes 377

Henricus de Segusio 210

Herkules 286, 346

Hermann II., Hg. v. Schwaben 229, 230

Herre, Paul 173, 179

Hessel, Alfred 184

Hill, Rosalind 285

Himilco der Karthager 309

Hinschius, Paul 138, 156

Hintze, Otto 40, 102, 372, 373

Hitler, Adolf 184

Hobbes, Thomas 226, 236

Hodgkin, Robert H. 302

Hodgson, Francis C. 172

Hoffmann, Erich 201

Hostiensis s. Henricus de Segusio

Hugo

- Capet, Kg. v. Frankreich 84

- v. Fleury 323-325

Huizinga, Johan 343

Hyenstrand, Ake 201

Ibn-al-Athîr 296

Inger, Göran 155

Innozenz IV., Papst 216-219

Irene

-, byz. Ksn. 333

- Dukaina 227

Isaak I. Komnenos, byz. Ks. 225-228 
Isabella

-, Infiantin v. Kastilien 349

- v. Portugal, Hgn. v. Burgund 344, 351

Jaeger, Charles Stephen 194

James s. Jakob

Jakob

- (James) II., Kg. v. England 309

- Ulvsson, Ebf. v. Uppsala 203

Jan Długosz 367-369

Jason 345

Jean s. Johann/Johannes

Jens Grand, Ebf. v. Lund 202

João s. Johann

Jöns Bengtsson Oxenstierna, Ebf. v. Uppsala 203

Johanek, Peter 162, 164

Johann

- (João) I., Kg. v. Portugal 349

- Ohnefurcht, Hg. v. Burgund 350

-, Mgf. v. Brandenburg 352

-, Leopold Albert, Hg. v. Sachsen-Coburg und Gotha

- (John) ,the Scot', Bf. v. Dunkeld 313

Johanna

- I., Kgn. v. Kastilien 345

- v. Ponthieu 216-219

Johannes

- der Täufer 220

- II. Komnenos, byz. Ks. 229

- Andreae 211

- v. Auerbach 168

- Capelli 216, 218

- Damaskenos 287

Jókai, Maurus 51

Jones, Philip 93

Jordan v. Osnabrück 334

Joyce, George H. 210

Juan de Villacreces, Bf. v. Tarragona 151

Judas Ischarioth 260,321

Julius Cäsar 303, 333, 367

Jupiter 285, 286, 292, 294

Kaelble, Hartmut 373

Kaeuper, Richard 374

Kant, Immanuel 20

Karl

- Martell, frk. Hausmeier 327

- (I.) der Große, Ks. 15, 21, 35, 36, 68, 108, $286,292,324,327,328,331,333,335$
- (II.) der Kahle, Ks. 35, 36, 68, 323-326

- (III.) der Dicke, Ks. 319

- (III.) ,der Einfältige', westfrk. Kg. 327

- IV., Ks. 121

- V., Ks. 355

- VIII., Kg. v. Frankreich 180

- I., Kg. v. England 309

- (III.) Knutsson, Kg. v. Schweden 203

- der Kühne, Hg. v. Burgund 343-346, 356

- II. v. Innerösterreich 356

Kasimir

-III. der Große, Kg. v. Polen 121, 122, 364, 365

Katharina, hl. (v. Alexandrien) 294

Kehrberger, Otto 162

Keller, Hagen 93

Kellerman, Gösta 204

Kenneth Mac Alpin 314

Kentigern s. Mungo

Kienast, Walter 316, 317

Kipling, Gordon 342, 343

Kirn, Paul 318

Klaniczay, Gabor 57

Klaniczay, Tibor 57

Knut der Große, Kg. v. England 231

Kocka, Jürgen 373

Kötzschke, Rudolf 87

Konrad

- II., Ks. 237, 327, 328

- III., dt. Kg. 329

Konstantin

- VII. Porphyrogennetos, byz. Ks. 174

-, Sohn v. Ks. Michael VII. Dukas 228

Koselleck, Reinhart 23

Krak 368

Kretschmayr, Heinrich 172, 173, 183, 184

Krumbacher, Karl 174

Kubinyi, András 57

Kuchenbuch, Ludolf $66,68,69,77-82,86$

Kula, Witold 99

Kundera, Milan 55

Lambert v. Saint-Omer 16

Lampert v. Hersfeld 237, 238, 245, 246

Lamprecht, Karl 173

Laurentius v. Amalfi 251, 252, 265-267, 269-271, 274, 275, 276, 277, 279

LeBras, Gabriel 162

Lech 362,368 
Leclercq, Henri 138

Le Goff, Jacques 17

Leo VIII., Papst 326

Leonardo da Vinci 351

Leopold, Sohn v. Queen Victoria 309

Lethen, Helmut 182

Lindkvist, Thomas 201

Livius 245, 246

Ljungfors, Åke 202

Lothar

-I., Ks. 35, 36, 326

- III., Ks. 109, 329, 330

Lucan 322

Luchitskaja, Svetlana 380

Ludmila, hl. 252, 255, 272, 273, 276-278

Ludovico Barbo, Bf. v. Treviso 153

Ludwig

- (I.) der Fromme, Ks. 35, 36

- II. der Deutsche, ostfrk. Kg. 35, 36, 326

- VI., Kg. v. Frankreich 322

- VII., Kg. v. Frankreich 329

- VIII., Kg. v. Frankreich 328, 332

- DX. der Hl., Kg. v. Frankreich 219, 331, 332,356

- II., Kg. v. Bayern 176

- IX. der Reiche, Hg. v. Bayern-Landshut 346

-, Gf. v. Isenburg-Büdingen 352

Ludwig, Gustav 179

Lütge, Friedrich $69,74,75,87$

Lund, Niels 203

Luther, Martin 212, 213

Machiavelli, Niccolò 180, 224, 244, 245

Magnou-Nortier, Elisabeth 76

Magnus

- Birgersson Ladulås, Kg. v. Schweden 202

- Eriksson, Kg. v. Schweden 203

Makkai, László 54

Malatesta

-, Roberto 351

-, Sigismondo 348

Mann, Thomas 181

Mansi, Giovanni Domenico 137, 143

Manteuffiel, Tadeusz 102

Marco Polo 127

Margarete

-I., Kgn. v. Norwegen 205, 208

Margarethe

- v. Anjou, Kgn. v. England 348
- v. York, Hgn. v. Burgund 343-346

Margot 291, 292

Maria

-, hl. 296

- Dukaina, byz. Ksn. 228

-, Hgn. v. Burgund 344

- v. Bayern 356

Mars 283, 292

Marx, Karl 54, 98

Mathilde v. Tuszien, Mgfn. 322

Matthaeus Parisiensis 332

Matthias

-I. Corvinus, Kg. v. Ungarn 52, 352, 353

Maurer, Georg Ludwig v. 75

Maximilian

-I., Ks. 346, 353, 355

- II., Kg. v. Bayern 174, 175

Mayer, Theodor 129, 130

McCormick, Michael 34

Mechthild v. Österreich 347

Medici, Lorenzo ,il Magnifico' de' 348, 356

Meier, Ulrich 45

Melissenos s. Nikephoros Melissenos

Menant, François 77, 78

Menzel, Josef Joachim 129, 130

Merkur 294

Merowech, frk. Kg. 327

Metz, Wolfigang 78

Meuthen, Erich 143

Michael

- I., byz. Ks. 333

- VII. Dukas, byz. Ks. 225, 228

- Psellos s. Psellos, Michael

Miele, Michele 153

Mierzwa s. Dzierzwa

Mieszko

- I., Fs. v. Polen 364, 366

- III. Stary, Fs. v. Polen 117

Mill, John Stuart 372

Mitteis, Heinrich 99

Mohammed 20, 283, 284, 286, 288, 290-292, 295, 296, 298

Monneret de Villard, Ugo 285

Montef eltro

-, Elisabetta v. 351

-, Guidobaldo v. 350

Morimoto, Yoshiki 66, 78

Morin, Edgar 40, 376 
Mossoul Karbouka, Emir 292

Münkler, Herfried 355

Münster, Sebastian 16

Mungo (Kentigern), hl. 310

Munro, Dana C. 285

Muratova, Xenia 285

Myres, John N. L. 302

Nero, Ks. 292

Niederhauser, Emil 57

Nikephoros

- III. Botaneiates, byz. Ks. 225-228

- Bryennios 229

- Melissenos 227

Niketas Byzantios 287

Nikolaus

- v. Myra, hl. 29

-v. Kues 142,168

- Lanckmann v. Falkenstein 349

Nossini 356

Nora, Pierre 374

Nyberg, Tore 378, 379

Nynia, hl. 310

Odin 201, 231

Odo v. Sully s. Sully, Odo v.

Öberg, Jan 202

Oexle, Otto Gerhard 182, 376, 379

Ogier 291

Olav

- Haraldsson der HI., Kg. v. Norwegen 229233, 235, 236

- Engilbriksson, Ebf. v. Drontheim 203

Olesen, Jens E. 204

Olivier 291

- de la Marche 344, 350, 353

Opicino de Canistris 16

Orlando di Lasso 356

Orsini, Chiara 348

Otto

-I., der Große, Ks. 232, 234, 320, 326, 327,333

- II., Ks. 230, 251, 252

- III., Ks. 229, 230, 235, 252, 324, 331

- v. Freising 238, 240, 324-328, 331

Paasche, Fredrik 198

Pach, Zsigmond Pál 54

Palazzini, Pietro 149, 150

Palme, Sven Ulric 204

Pamernecki, Stanislovas 27
Paramonova, Marina 378

Paravicini, Werner 343

Paulus, Apostel 44

Papinianus della Rovere, Bf. v. Novara 160

Percival, John 77

Perikles 176

Perrin, Charles-Edmond 77, 78

Peter v. Aigueblanche, Bf. v. Hereford 216-218

Petit, Louis 143

Petrus

-, Apostel 321

- Alfonsi 288

- Tudebodus 284, 291, 292

- Venerabilis, Abt v. Cluny 288, 289

Pharamund 333

Philipp

- II. Augustus, Kg. v. Frankreich 90, 316, 330,332

- II. der Kühne, Hg. v. Burgund 351

- III. der Gute, Hg. v. Burgund 351

Philippa v. Lancaster 349

Phillips, Mark 224, 241

Piast 365

Pierre de Sampson 160

Pietro Barozzi, Bf. v. Padua 153

Pippin I., Kg. v. Aquitanien 36

Pirenne, Henri 131

Piskorski, Jan 379

Pius II., Papst 15, 153

Plato 42,43

Plautus 355

Plesner, Johann 94

Plutarch 245

Pluto 284

Poly, Jean-Pierre 84, 104, 105

Polybios 245

Pontal, Odette 145, 152, 162

Pontius Pilatus 260

Powicke, Frederik M. 145

Priamos 349

Przemysł I., Kg. v. Polen 364

Przeworski, Adam 31

Psellos, Michael 228

Ptolemăus 309, 311

Putsch, Johannes 16

Radulf v. Caen 283, 285, 290, 294, 295, 297

Raimund v. Aguilers 284 
Rando, Daniela 27, 379

Regino, Abt v. Prüm 319

Remigius, hl., Bf. v. Reims 327

René v. Anjou, Kg. v. Neapel 348, 351

Reynolds, Susan 100, 101, 205

Richer v. Reims 324

Robert

- Guiscard, Hg. v. Apulien und Kalabrien 225, 229

-, Bf.. v. St. Andrews 313

Rösener, Werner 66, 69, 72, 73, 77, 82, 86

Roland 291

Rousset, Paul 293

Rudolf v. Rheinfelden, dt. Gegenkg. 237

Rus' 368

Ruskin, John 171

Russocki, Stanisław 103

Rutkowski, Jan 99

Rymer, Thomas 218

Saint-Simon, Henri de 98

Salomon 284

Sánchez Herrero, José 150

Sanudo (Sanuto), Marino 179, 355

Sawicki, Jakub Th. 138, 147

Sawyer, Birgit 201

Sawyer, Thomas 201

Saxo Grammaticus 197, 198

Schannat, Franziskus 143

Schlesinger, Walter 130, 131

Schmid, Karl 105

Schneidmüller, Bernd 379

Schopenhauer, Arthur 181

Schück, Herman 203

Scott, Walter 312

Seeliger, Gerhard 75

Seggern, Harm v. 344,352

Seignobos, Charles 372

Sforza

-, Galeazzo Maria, Hg. v. Mailand 348, 351, 354, 356

-, Ippolita Maria 348

-, Ludovico 351, 356

-, Polissena 348

Shakespeare, William 226

Sieciech, Palatin 116

Siemomysł, Fs. v. Kujawien 119

Siemowit IV., Fs. v. Masowien-Płock 122

Sigebert v. Gembloux 325
Sigurd Syr 231

Simmel, Georg 181-183

Simon v. Kéza 50

Sjöstrand, Per Olof 201

Skocpol, Theda 32, 33

Skyum-Nielsen, Niels 203

Smolinsky, Heribert 168

Snorri Sturluson 229-236

Sombart, Werner 184

Somers, Margaret 33

Spengler, Oswald 52

Spieß, Karl-Heinz 59, 376, 378

Staab, Franz 79

Staël, Madame de 315

Stenton, Frank M. 302

Stephan v. Gallardon 332

Stone, Lawrence 58

Strzelczyk, Jerzy 380

Suger, Abt v. Saint-Denis 321, 322, 330

Sully, Odo v. (Eudes de), Bf. v. Paris 155, 159

Surius, Laurentius 143

Svatopluk, Fs. des Großmähr. Reiches 363

Svein Alfivason, Jarl 231

Sverre Sigurdarsson, Kg. v. Norwegen 202, 238

Svjatopolk Vladimirovix Okajannyj, Fs. v. Kiev 259,281

Szücs, Jenö 54, 55, 58

Tabacco, Giovanni 132

Tacitus 312,315

Tafel, Gottlieb Lukas 174, 175, 177, 182-184

Tankred v. Tarent, Fs. 283, 284, 296, 297

Tellenbach, Gerd 237

Tervagant 291, 292

Teune, Henry 31

Thiersch, Friedrich 174

Thietmar v. Merseburg 224, 229-236, 245

Thomas

-, Mönch im Kl. Haute-Combe 217

- v. Aquin 168

Thomas, Georg Martin 174-177, 182-184, 379

Thukydides 245

Tiers, Adolphe 179

Timon, Ákos 50

Toubert, Pierre 77, 78

Ulsig, Erik 200

Ursula, hl. 164 
Vauchez, André 57

Venus 287, 288

Verhulst, Adriaan 66, 67, 69-71, 82

Victoria, Kgn. v. England 309

Villani, Giovanni 241, 242, 244, 245

Violante, Cinzio 76

Vincentius (Wincety) Kadłubek, Bf. v. Krakau $363,364,367,368$

Visconti, Giangaleazzo, Hg. v. Mailand 242

Vladimir I. Svjatoslavið der Hl., Fs. v. Kiev 281

Vollrath, Hanna 78

Vratislav I., Fs. v. Böhmen 255, 277

Waldemar IV., Kg. v. Dănemark 203

Wartisław

- III., Hg. v. Pommern 112

Watson, William 314

Weber, Max 20, 40, 52, 209, 213, 215, 221, 234, 372

Weibull, Curt 198

Weibull, Lauritz 198

Weidinger, Ulrich 70,71

Weinberger, Stephen 78

Welf V., Hg. v. Bayern 321, 322

Wenzel

- I. der Hl., Fs. v. Böhmen 249-281, 378

- II., Kg. v. Böhmen 364

- III., Kg. v. Böhmen 364

Werdenberg, Gf. v. 347

Westman, Knut B. 198

Whitelock, Dorothy 145

Wickham, Chris 91

Widukind v. Corvey 232, 234, 236, 245

Wiegand, Peter 139, 145, 154

Wilcox, Donald 224

Wilhelm v. Modena, Kardinalbf. v. Sabina 155

Wilkins, David 145

Winckelmann, Johann Joachim 174

Wipo 236, 237, 240, 327

Władysław

- I. Lokietek, Kg. v. Polen 364

- II. Jagiełło, Kg. v. Polen 122

-, Hg. v. Oppeln 122

Wolfram

- v. Eschenbach 211

-, Bf. v. Würzburg 158

Xuanzong, chin. Ks. 38

Zaborov, Michail 286
Zbigniew, Fs. v. Polen 367

Zrínyi, Nicholas 50

2. Orte

Aachen 35, 326

-, Dt. Historikertag (2000) 13

Abendland s. Okzident

Aberdeen 312

Aberdeenshire 312

Ägypten 219

Ärmelkanal 303

Afrika 15, 16

Agram, Btm. s. Zagreb

Alamannien 68

Alba Regia s. Székeszfehérvár

Albany 309

Alclud 310

Alpen 95

Altmark 112

Amberg 347, 348, 352, 354

Amerika 131; s. a. USA

Angeln 305

Angers, Btm. 153

Angus 312,313

Annandale 311

Antrim 312

Apulien 24

Aquileia 57

Aragón 50, 109, 150-152, 159

Arezzo 239

Argyll 312, 314

Arles, Ebtm. 160, 163

Arras 351

Asien 15, 16, 105, 127

Asturien-Leon 166

Athen 176

Atholl 312,313

Attigny 36

Auch, Ebtm. 152, 167

Augsburg, Btm. 71

Auvergne 295

Auxerre, Btm. 140, 141

Avignon 203, 208, 379

-, Btm./Ebtm. 153, 158, 160, 161, 163

Avon 305, 309

Ayrshire 311

Baden 346 
Bagdad 187, 376, 380

Baltikum 20

Bamberg, Btm. 160

Bari 29

Bamim 112

Basel

-, Btm. 152, 164

-, Univ. 177

Baskenland 118

Bath 301

Bayern $35,65,68,71,73,82,319,326$, 346,378

Bedford 308

Belgien 65, 66, 83, 86

Benevent, Ebtm. 153

Bergen (Norwegen) 204

Berkshire 307, 308

Berlin 27

-, Humboldt-Univ. 374

Bernicia 305, 306, 309, 310

Besançon, Ebtm. 152

Beverly 216

Bober 361

Böhmen 15, 60, 63, 115, 118, 151, 251-253, $268,269,272,280,281,342,361,362$, 364,368

Bologna 184, 242, 243, 350

- , Btm. 153

Bordeaux, Ebtm. 152, 164

Bourges, Ebtm. 152

Brabant 342

Brandenburg 111-114, 121, 346, 364

-, Btm. 154, 168

-, Mark 348

Bremen, Ebtm. 139, 153, 154

Breslau 353

-, Btm. 118, 160

Bretagne 73

-, Htm. 351

Brügge $343-346,348,350-355$

Brüssel 345

Buchan 312, 313

Buckingham 308

Buda, Btm. 161

Budapest 56

-, Central European Univ. 59

Bukarest 56
Burgos, Btm. 151, 159

Burgund 73, 77, 341, 342, 343-345, 351, 353, $354,356,376,378,380$

Byzanz 15-19, 21, 43, 46, 58, 127-129, 131, $223,225-228,234-236,245,376$

-, Hagia Sophia 226

Cadiz 286

Cahors, Btm. 161

Caithness 312, 313

Caledonia 311

Cambrai, Btm. 153, 350

Cambridge 308

Canterbury, Ebtm. 155, 163, 218

Carpentras, Btm. 142

Châlons-en-Champagne 321

Champagne 38

Chester/Cheshire 307, 313

China 32, 37, 38, 105, 127, 375

Chichester, Btm. 218

Clackmannan 312

Clyde 310

Cockburnspath 310

Coimbra 349

Compiègne 36

Copeland 302

Cornwall 303, 308

Costa Cartuta 132

County Durham s. Durham

Cumberland 302, 306, 308, 310, 311

Cumbria 306, 310, 311

Cunningham 311

Czerwieńsk 364

Dănemark 197, 198, 201-205, 301

Dálriata 312,314

Damme 345

DDR 71, 76, 97

Dee 304

Deira 303, 305, 306

Derby 307

Deutsch Kroner Land 121

Deutschland 16, 20, 22, 26, 35, 43, 59, 65, 66, $67,75,77,82,84,86,92,97,102,105$, $128,129,133,138,142,143,144,151$, $152,153,158,168,172,174,179,183$, $223,232,236-238,246,247,315,317-$ $324,333,334,342,343,352,354-357$, $375,378,380$ 
-, (röm.-)dt. Reich 49, 109, 110, 114-116, $119,130,150,160,316,325,328,330$, $343,344,346$

-, Süddeutschland 162

Devon 303, 304, 308

Ditmarschen 118

Dnjepr 55

Donau 63

Dorset 306, 308

Douglasdale 311

Dresden 356

Drontheim, Btm./Ebtm. 150, 164

Dumbarton 310

Dumfries 311

Dundee 312

Dunkeld 312

Durham

-, County 302, 309

-, Pfalzgft. 308

Earn 313

Easter Ross 312

Edinburgh 309, 310

Eger, Btm. s. Erlau

Eichstätt, Btm. 168

Elbe $55,130,333$

Elbslawien 361

England 26, 49, 50, 53, 56, 59, 63, 66, 73, 74, $83,90,97,101,104,109,126,145,148$, $150,151,155,166,167,172,205,209-$ $212,219,231,301-311,314,330,343$, $350,356,377,378$

-, East-Anglia 302, 304-306, 314

-, Middle-Anglia 303, 305, 307

Erlau/Eger, Btm. 155

Esk 306

Eskdale 311

Essex 304, 305, 307, 308

Esztergom s. Gran

Exeter 304

Ferrara 348, 350, 351, 355

-, Btm. 153, 163

Fife $312-314$

Finnland 24, 197, 203

Firth of Clyde 309, 311, 312

Firth of Forth 309, 311, 312

Flandern 331

Florenz 94, 177, 178, 181, 182, 184, 239-246, 348,379
-, Btm./Ebtm. 153, 158, 164

-, Dt. Kunsthist. Institut 179

Forchheim 237

Forth Hills 310

Fothrif 313,314

Frankfurt a.M. 35, 331

-, Reichstag v. 145415

Frankfurt a.d. Oder 20

Frankenreich 107, 128, 129, 131, 132, 319, 325-328

-, Ostfrankenreich $66,68,73,74,82,319$, $320,326,327,333$

-, Westfrankenreich 66, 73, 319, 320, 326, 327,333

Frankreich 16, 22, 32, 35, 43, 49, 53, 59, 64 $66,67,75,77,80,82,83,86,87,90,97$, $102-105,130,131,145,148,150-152$, $165,166,179,183,191,212,213,219$, $231,301,315-325,328,330,331,333$, $334,348,353,375,380$

-, Nordfrankreich 68, 77, 78, 80, 85, 87, 107

-, Südfrankreich 73-75, 78, 85, 109, 158, 160, 164,165

Fraustädter Land 121

Friesland 326

Fulda, Kl. 70-72

Gallien 128, 326, 327

Galloway 308, 311

Genf, Btm. 152, 153, 169

Genua 184

Germanien 15, 326

Gerona, Btm. 150, 151

Giecz 363

Glasgow, Btm. 310

Gloucester 308

Gloucestershire 306

Gnesen 363, 364

-, Ebtm. 150, 155

Göttingen 66, 73

-, Max-Planck-Institut für Geschichte 374

Gowrie 313

Gran/Esztergom, Ebtm. 150, 155, 160

Granada 135

Griechenland 15, 17, 20, 125, 174, 176

Halberstadt, Btm. 154

Halic-Volhynien 122

Hallamshire 307

Hamburg(-Bremen), Ebtm. 154 
Hampshire 303

Haute-Combe, Kl. 217

Havelberg, Btm. 154, 168

Havelland 112

Hebriden 309

Heidelberg 353

Hereford 307

Herefordshire 305

Hertford 308

Hildesheim, Btm. 139, 157

Holland (Lincolnshire) 304, 307

Holstein 111, 113

Hoy 311

Humber 304, 305

Huntingdon 308

Île-de-France 93, 333

Imperium Romanum 17, 18, 34, 125, 127-131, 325, 328-330, 333; s. a. Kaisertum

Irland $26,126,150,314$; s. a. Ulster

Island $197,223,230,232,319$

Israel 13

Italien $16,19,27,35,57,59,65,66,69,70$, $73,76,84,87,89-93,95,96,106,128$, $132,147,148,150,151,153,160,167$, $172,173,175,178,209-212,219,223$, 238, 245, 252, 334, 343, 344, 347-349, $350,351,353,354,356,378$

-, Mittelitalien 333

-, Norditalien $67,68,69,73,78,109,128$, $132,166,378$

-, Süditalien 69, 109

Japan 32, 37, 105, 375

Jerusalem 230, 283, 285, 286, 289

-, Al-Aqsa-Moschee 283-285, 290, 296, 380

-, Tempelberg 289, 296, 298

,- Kgr. 109

Jumne s. Wollin

Kalmar, Union v. 203

Kammin, Btm. 145, 161, 164, 168, 169

Karpaten 131, 361, 363

Kastilien 64, 150-152

Katalonien 74, 78, 105, 109

Kent 301, 303, 304, 306, 307, 308

Kępno, Vertrag v. (1282) 120

Kevesten 307

Kiev 15, 24

Kilpatrick (Alt-) 309

Kinneil 309
Kinross 312

Kintyre 311

Köln, Ebtm. 153, 160, 161, 164, 166, 167

Königgrătz 176

Konstantinopel s. Byzanz

Kopenhagen 200, 204

Korinth 44

Krain 60

Krakau 120, 363, 364

-, Btm. 118, 160

Kroatien 17

Kujawien 119, 364

Kulm

-, Handfeste 114

Lake District 310

Lambeth 163

Lammermuir Hills 310

Lanark 311

Lancashire, 302, 307, 308

Landshut 344, 346-348, 350, 352, 354

Langobardenreich 128, 129, 131, 327

Latium 77, 78, 85, 92

Lausanne, Btm. 152

Lausitz 112, 364

Lavaur, Btm. 167

Lebuser Land 364

Leeds 306

-, Mediăvistenkongreß 59, 339

Leicester 307

Liddesdale 311

Lille $342,343,351$

Lincoln 304, 307

Lincolnshire 304

Lindsey 304,307

Linköping 137

Linlithgow 310

Lissabon $137,348,349,353$

Litauen 27, 62, 135, 361, 363

Little Ouse 305

Livland 126

Loch Lomond 310

Loire 68, 69, 86, 324

Lombardei 77, 89-94, 96, 242, 377

London 301, 351

Lorsch, Kl. 67, 72, 79

Lothian 310,311

Lothringen $68,77,78,326$

Lournand 84, 104 
Lübeck, Btm. 154

Lüttich, Btm. 144

Lund, Ebtm. 150

Lyon, Ebtm. 152

Maas 324

Mâconnais 63

Mähren 272, 273

-, Großmähr. Reich 363

-, Nordmähren 113, 364

Magdeburg, Ebtm. 114, 139, 140, 153, 154, 158,160

Mailand 94, 243, 244, 348, 350, 351

Mainz, Ebtm. 158, 160, 161, 163, 168

Malmö 204

Mantua 350

-, Btm. 153

-, Mgft. 351

Mar 312, 313

Marbach, Kl. 332

Marseille, K1. St. Ruf 160

Masowien 62, 122, 362, 364, 365, 367

Mearns 312, 313

Mecklenburg 111, 125

Meißen 112

-, Btm. 154

Mekka 287

-, Kaaba 287

Mende, Btm. 153

Menteith 312, 313

Mercia 303, 305, 307

Merse 311

Merseburg, Btm. 154, 230

Metz, Btm. 350

Middlesex 305, 307, 308

Milzenerland 364

Mittelmeerraum, westl. 89, 93, 96

Monte Cassino, Kl. 251, 252, 269

Montier-en-Der, K1. 70

Moray 312,313

Moray Firth 307

Morigny, Kl. 324, 330

Moorfoot Hills 310

München 174, 342, 356

-, Bayer. Akad. der Wiss. 174, 175

-, Univ. 174, 175

Namurois 63

Nancy 348

Nantes, Btm. 153, 164
Narbonne, Ebtm. 167

Narbonnensis 85

Naumburg, Btm. 154

Neapel 348

- , Kgr. 351

Nesjar 231

Neumark 364

Neumarkt 112

Neustrien 35, 68

Niederlande 130, 131

Nîmes, Btm. 160, 165

Nithsdale 311

Nordsee 303, 304

Norfolk 305, 306, 308

Northampton 307

Northern Isles 309, 311

Northumberland 302, 308

Northumbria 305

Norwegen 21, 164, 197, 198, 201-204, 206, 223, 231-233, 236, 239

Nottingham 307

Novara, Btm. 158, 160, 161

Novgorod 15

Noyon, Btm. 164

Oder 333, 361

Österreich 111, 175, 346

-, Habsburgerreich 50, 52, 174, 375, 379

Okzident 16-20, 23, 39, 43-46, 48, 89, 93, 95, 96, 171, 172, 293

Orient 19, 171, 176, 292, 376

Orkney 311,312

Oslo 204

-, Historikerkongreß v. 1927373

Osmanisches Reich 375

Osteuropa 18, 19

Ostrów Lednicki 363

Oxford 308

Palästina 285

Paris $36,55,72,333$

-, Btm. 152, 155, 159

- Frieden v. 1920 51, 53

Pennine 304

Pentland Hills 310

Perthshire 312

Peterborough, Soke of 307

Pfalz (Kur-) 346

Pisa 239

Pîtres 36 
Poebene 95

Polen 15, 20, 26, 51, 58, 62, 63, 97, 99, 102 , $105-107,115-123,147,150,155,346$, $348,359-369$

-, Großpolen 112, 362-364

-, Kleinpolen 362-364

-, Südpolen 364

Pommerellen 120, 364

Pommern 62, 112, 113, 364, 365, 367, 368

Portugal 20, 150, 167, 348, 349

Posen 363

-, Btm. 155

Porto 349

Prag 56, 251, 264

-, Btm. 252

-, Veitsdom 262

Preußen 114, 123

Prüm, Kl. 67, 77, 78

Ratzeburg, Btm. 154

Regensburg 35, 251

Reims, Ebtm. 137, 152, 160, 164

Rhein 65

Rheinland 38

-, Ostrheinland 67, 70, 71

- , Westrheinland 67, 70

Rhône 35

Ribble 302

Riga, Btm. 150

Rimini 348, 351

Rodez, Btm. 158, 161, 165

Römisches Reich s. Imperium Romanum

Rom 176, 179, 184, 246, 271, 276, 326

Ross 313

Rotreußen 113

Rouen, Ebtm. 152, 161

Rus' 363

Rußland 15, 17, 20, 32, 53, 55, 281, 375

Ruthenien 361, 368

Saint-Bertin, K1. 67

Saint-Denis, K1. 217, 321, 331

Saint-Germain-des-Prés, Kl. 67, 72, 80, 81

St. Louis 50

Saint-Remi, Kl. 79

Saint-Trophime 163

St. Gallen, Kl. 68, 70, 75, 82

Sachsen 113, 237, 246, 305, 326, 346

Salerno, Ebtm. 153

Salisbury, Btm. 345
Salzburg, Ebtm. 158, 160, 163

Sandomierz/Sandomir 10, 363, 364

Sassari, Ebtm. 153

Savoyen, Htm. 351

Sazava, Kl. 251

Schiehallion 312

Schlesien $62,112,115,119-121,361,363-$ $365,367,368$

Schleswig 305

Schottland 63, 118, 126, 135, 150, 151, 154, $155,308-314,377$

Schwaben 77, 326

Schweden 21, 135, 141, 147, 150, 155, 159, 197, 198, 201-205

Schwerin, Btm. 154

Sclavinia 375

Seine 65,68

Sens 217,218

-, Ebtm. 152

Servais 36

Severn 304, 305

Sevilla 349

Sheffield 307

Shetland 314

Shrewsbury/Shropshire 307

Sizilien 24, 56

Slawenland 15, 16, 111

Slawonien 63

Slowakei 20, 60, 364

Skänninge 155

Skandinavien 16, 17, 21, 147, 150, 155, 197201, 204-208, 379

Skara, Btm. 155

Sluis 344,345

Sorbengebiete 361

Solway 306

Somerset 301, 308

Southampton 308

Spalding 305

Spanien $16,19,21,26,49,75,90,126,131$, $135,137,145,150,151,157,160,166$, $167,219,286,288$

-, Nordspanien 74, 85

Speyer, Btm. 157

Spiš, Btm. s. Zips

Spoleto 67

Staffelsee 67,71

Stafford 307 
Steiermark 111

Stiklestad 233

Stockholm 200, 202, 204

-, Franziskanerkirche 202

Straßburg, Btm. 153

Strathclyde 306,310

Strathearn 312, 313

Sudetenland 361

Suffiolk 305, 306, 308

Surrey 308

Sussex 303-305, 308

Sutherland 313

Székeszfehérvár (Stuhlweißenburg) 56

Tarragona, Ebtm. 141, 151, 152, 157

Tay 312

Tees 302, 306, 309

Teith 314

Tel Aviv, Univ. 187

Teltow 112

Teviotdale 311

Themse 302, 304, 306

Thüringen 112, 326

Tønsberg 203

Toledo, Ebtm. 152

Torgau 355

Toskana 89, 91, 94, 95, 242, 301, 375, 377

Tottenhamshire 307

Toulouse, Ebtm. 167

Toumai, Btm. 350

Tours, Ebtm. 147, 152, 153, 164

Tréguier, Btm. 153, 157

Trianon, Frieden v. 51, 52

Trient, Btm. 132

Trier 343

-, Ebtm. 160

Trøndelag 231

Troja 333, 345, 349

Tschechien 20

Tübingen, Univ. 174

Türkei 20

Tulle, Btm. 161

Turin, Btm. 153

Tweed 310

Tweeddale 311

Ulster 312

Ungarn $20,49-57,60,62,63,116,135,147$, $150,155,157,238,363$

Uppsala, Btm./Ebtm. 150, 155, 159
Urach $344,347,348,353$

Urbino 350

- , Htm. 351

USA $13,26,65,66,77,83$

Utrecht, Btm. 350

Valencia

- , Btm. 151

-, Kgr. 89

Valladolid 166

Venedig 171-184, 379

-, Deputazione veneta 175

-, Ebtm. 153

Vereinigte Staaten v. Amerika s. USA

Veszprém, Btm. 155

Vienne, Ebtm. 152

Vincennes 219

Vineta s. Wollin

Walachei 131

Wales 63, 126, 302, 304

Warwick 307

Wash 304

Waveney 305

Wear 306, 309

Weichsel 363

Weißenburg, Kl. 67, 71, 72, 73, 79

Werden, Kl. 69, 71

Wessex 303, 305, 307, 308, 314

Western Isles 311

Westmorland 302, 308

Whithorn 310

Wieliczka 120

Wien 356

-, Ksl. Akad. der Wiss. 175

-, Btm. 161, 163

-, Konkordat v. 1448204

Wight 304

Wiltshire 308

Winchester 296, 304

Wisbech 305

Wittelsbach 378

Wollin 15

Worcester 307

Worms, Konkordat v. 1122109

Wroxeter 305

Württemberg 346

Würzburg, Btm. 153, 158, 164, 168

Wychwood 305

Wylye 308 
York 304, 308

-, Ebtm. 154, 155, 167, 216, 217

Yorkshire 301, 302, 306-308

Zagreb/Agram, Btm. 155

Zips/Spiš, Btm. 155

Zypern 15

\section{Sachen}

Adel 58-64, 91, 93, 200, 204, 339

Anthropologie 33, 182

Antike 19, 21, 34, 43, 44, 174, 176

Arbeit 43, 44

Architektur 177, 181

Armut 43

Aufklärung 25

Bibel 294, 296

Byzantinistik 174

Christentum 15-19, 43, 44, 47, 48

Conjuratio 45-47

country 301

county 301, 306

Familie s. Verwandtschaft

Feudalismus 32, 58, 60, 97-103, 107, 111, 379

-, „feudale Revolution“ 83-87, 104-107

-, Heerschildordnung 111

-, Inwärtseigen 113

-, Lehnrecht 99, 102, 107-110, 112-115, 117$119,121-123$

-, Libri Feudorum 109

-, Ligesse 109, 110

-, Vasallităt 100

Frau 194, 195

Fürstenherrschaft 255; s. a. Herrscherideal

Grundherrschaft $65-87,97,377$; s. a. Feudalismus

-, Abgabengrundherrschaft 69, 73

-, Geldwirtschaft 81

-, Gutswirtschaft 69, 70, 73

-, Handel 80

-, Hebeamtsverfassung 70

-, klösterliche 67, 70, 77

-, königliche 67, 68

-, Markt 80

-, métayage/mezzadria 95

- , private 70,81

-, Rentengrundherrschaft 68

-, seigneurie $75,76,82,83,85,87,91,92,96$
-,-, masnadieri 92

- , seigneurie foncière 76,87

-, signoria 77

-, signoria rurale 76

-, signoria territoriale 76,77

-, Urbar 65, 78-81, 82, 83

-, Villikation $67,68,70-73,77$

Gruppe, soziale $45-48$

-, Haus 45

Hagiographie 29, 57, 249-281, 294

Heiligkeit 264-272

Herrscherideal/-tugend 256, 257, 265, 268 276, 280

Hinduismus 209, 213-215, 219

Historikerstreit 30

Historiographie

-, antike 223, 224, 245, 246

-, mittelalterliche 15, 50, 223-247, 283-298, 366-369, 376

- der Renaissance 224, 239-246

Hof

- der Abbasiden 188-196, 376

-, byzantinischer 227,228

-, höfische Feste 340, 341, 343, 356, 357

,-- , entremet $345,346,352,354$

-, Fürstenhochzeit 340-356, 378

-, Hofkultur 37, 38, 188, 190, 194-196, 380

-, Königshof 35, 36

Idolatrie 283-292, 294-298

Islam 19, 43, 48, 188, 193, 209, 213-215, 219 , 283-298, 376

Judentum 19, 43, 48, 375

Kaisertum 320, 323, 324, 326, 334; s. a. Imperium Romanum

Kanzleiwesen 202, 203

Kartographie 16

Kirche, griechisch-orthodoxe 287

-, Kirchenvăter 287

Kirche, römisch(-katholisch)e $22,40,199$, 201-205, 267, 287, 288, 366, 375

-, Bistumsorganisation 205, 206

-, kanonisches Recht 209, 214, 215, 218-221, 378

-,-, Eherecht 209-211, 213, 215-220, 378

-, Katechese 165-168

-, -, Ehepredigt 212, 378

-, Ketzer 361

-, Kirchenreform 149, 151, 156, 165, 168, 169 
-, Kirchenväter 287, 294

-, Klerus 42, 267

-,-, Klerusbildung $165,166,168,169$

-, Konzil 148, 159

-, - v. Basel 140, 141, 142, 156, 160

-, -, Lateranum (IV.) 135, 140-142, 149, 154, $156,165,168,210$

,-- v. Nicăa 136,140

,$--v$. Toledo (XVI.) 141

-,-v. Trient 140, 147, 152, 166, 210, 213

-, - v. Vienne 142, 160, 208

-, Mönchsorden 136

-, Papsttum 17, 22, 39, 200, 202, 203, 207. 208, 220, 379

-, Pfarrgemeinde 47, 48, 205, 206

-, Synoden 23, 135-169, 377

-,-, Synodalstatuten $136,137,142-147,152$, $153,155,157-169$

-, -, Synodalstatutenrezeption 159-163

-, Visitation 148, 155

Kirchen, lutherische 199, 220

Klientelismus 229, 234

Königreich/-tum s. Monarchie

Kolonisation 120, 125-133, 379

-, aprisionarii 128, 129, 132

-, Arimannen 128, 129, 132

-, Centene 130, 132

-, „Königsfreie“ 129, 130, 132, 133

-, (dt.) Ostkolonisation 112, 114, 125, 130

Kommune 46, 47, 377

-, Landgemeinde 91, 93, 96

-, podestà 96

Kredit 89, 90, 94, 96

Kreuzzug, erster 283-285, 289, 292, 297

Kultur 188; s. a. Hof

-, Kulturtransfer 378

Landesherrschaft 111, 112, 114, 118, 123

lathe 307

Leibeigenschaft 60

Lehnswesen s. Feudalismus

Liebe 188-196, 376
Literatur 293, 295

-, chansons de geste 290-293

Macht 191-195

Malerei 177

Ministerialităt 92, 110-113, 116

Moderne 21, 23, 42, 173, 182, 184, 371, 379, 380

Monarchie 17, 18, 22, 36, 151, 152, 200-204, $207,232,233,235-238,303,379,380$; s. a. Herrscherideal, Hof

Namengebung 91, 93, 94

Nationalbewußtsein 317, 318, 360-362, 365-368

Orden, Dt. 114, 123, 361, 364

Papsttum s. Kirche

Reformation 26

Renaissance 19, 26, 177, 178, 183, 241, 242

Republik 240, 241, 243-245

Ritual 36

Rittertum 108, 112-114, 116-122

Sachsenspiegel 115

seigneurie s. Grundherrschaft

Seniorat 117,364

shire 306-308

Siedlungsgeschichte $302-305,308,314,377$; s. a. Kolonisation

signoria s. Grundherrschaft

soke 307

Sprachengruppe, ostlechitische 362

Staat 236, 237, 247

-, Staatsbildung 365

Stammesstruktur 363

Stand, Stände 41-44, 47

-, Stăndeversammlung 148

Steuerwesen 202, 203

Synoden s. Kirche

Terminologie 59-64, 104, 205, 377

Thing 206

Tyrannis 243

Verfassung 50

Verwaltung 90

Verwandtschaft $211,212,227,255-257,262-$ 264, 276-281, 378 



Marc Blochs Plädoyer von 1927 für eine vergleichende Geschichte des europäischen Mittelalters war zwar unter seinen Schülern und Enkelschülern nie ganz in Vergessenheit geraten. Doch offenkundig mußte erst die westöstliche Spaltung des Kontinents im Kalten Krieg überwunden werden, damit neue, konzentrierte Anläufe zur Realisierung des umstürzenden Geschichtskonzepts möglich wurden.

Der Aufgabe, die interdisziplinäre, transkulturelle und internationale Erforschung der mittelalterlichen Geschichte voranzutreiben, hat sich das neugegründete „Institut für vergleichende Geschichte Europas im Mittelalter" (IVGEM) an der Humboldt- Universität zu Berlin verschrieben. Zum Einstieg in seine langfristig angelegte Arbeit diente eine Tagung in Berlin im September 1999, auf der Mediävistinnen und Mediävisten aus alien Teilen Europas, aber auch aus Israel und den USA, über Theorie, Methoden und Praxis des Vergleichs Erfahrungen, Erkenntnisse und Perspektiven austauschten. Der Sammelbancl bietet die Vorträge sowie ergänzende Beiträge russischer und polnischer Autorinnen und Autoren.

Mit Beiträgen von Gadi Algazi, David L. d'Avray, Sverre Bagge, János M. Bak, Geoffrey W. S. Barrow, Michael Borgolte, Slawomir Gawlas, Patrick J. Geary, Hans-Werner Goetz, Johannes Helmrath, Svetlana Loutchitskaja, François Menant Tore Nyberg, Otto Gerhard Oexle, Marina Paramonova, Jan M. Piskorski, Daniela Rando, Frank Rexroth, Bernd Schneidmüller, Karl-Heinz Spieß, Jerzy Strzelczyk.
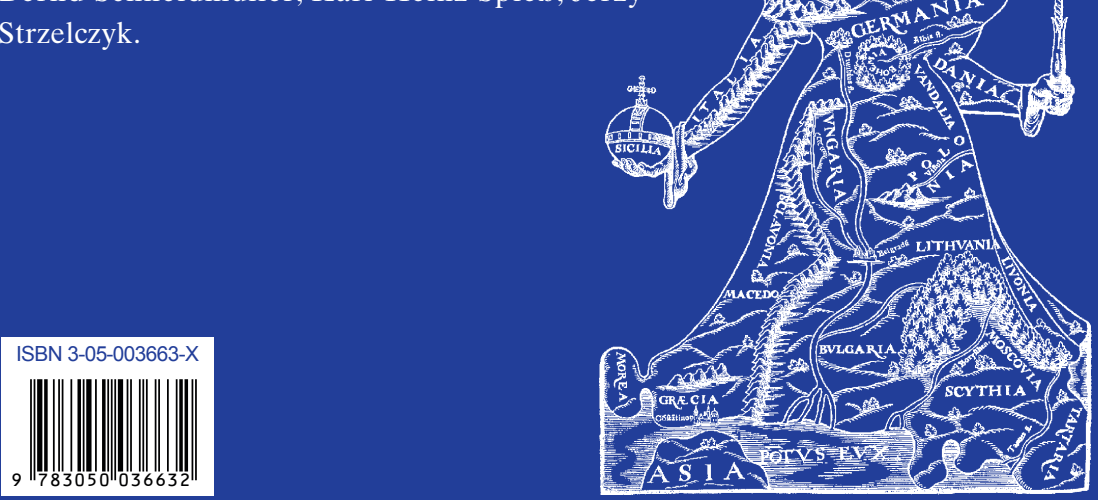